ORNL/TM--11647

DE93 007789

\title{
HIGH FLUX ISOTOPE REACTOR SYSTEM RELAPS INPUT MODEL
}

\author{
D. G. Morris \\ Engineering Technology Division \\ M. W. Wendel \\ Computing Applications Division
}

Date Published: January 1993

Prepared by the

OAK RIDGE NATIONAL LABORATORY

Oak Ridge, TN 37831-6285

managed by

MARTIN MARIETTA ENERGY SYSTEMS, INC.

for the

U.S. DEPARTMENT OF ENERGY

under contract DE-AC05-840R21400 


\section{CONTENTS}

Page

LIST OF FIGURES $\ldots \ldots \ldots \ldots \ldots \ldots \ldots \ldots \ldots \ldots \ldots \ldots \ldots \ldots \ldots \ldots \ldots$, vii

LIST OF TABLES $\ldots \ldots \ldots \ldots \ldots \ldots \ldots \ldots \ldots \ldots \ldots \ldots \ldots \ldots \ldots \ldots \ldots \ldots \ldots \ldots \ldots$

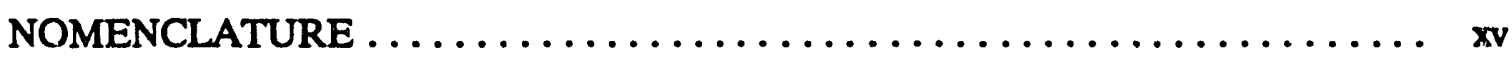

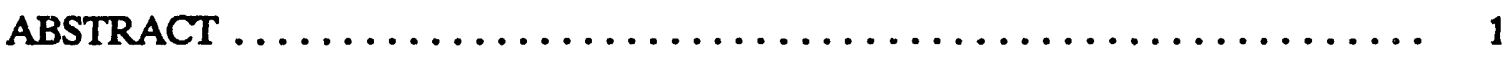

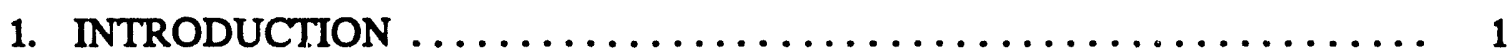

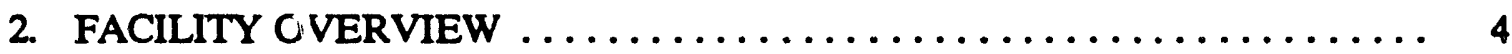

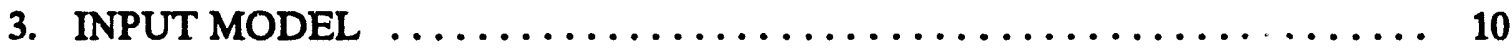

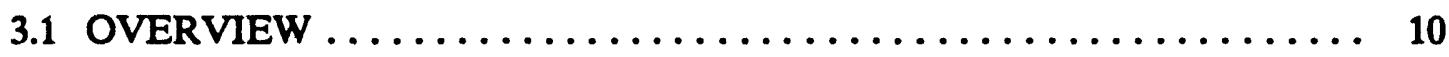

3.2 VESSEL/CORE COMPONENT DESCRIPTIONS $\ldots \ldots \ldots \ldots \ldots \ldots, 15$

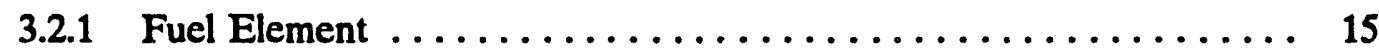

3.2.2 Fuel Labyrinth $\ldots \ldots \ldots \ldots \ldots \ldots \ldots \ldots \ldots \ldots \ldots \ldots \ldots, 30$

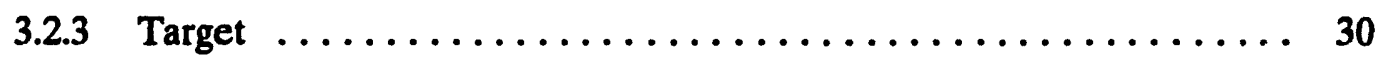

3.2.4 Control Cylinders $\ldots \ldots \ldots \ldots \ldots \ldots \ldots \ldots \ldots \ldots \ldots \ldots .44$

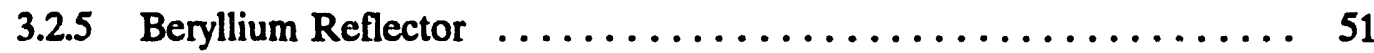

3.2.5.1 Hot removable reflector $\ldots \ldots \ldots \ldots \ldots \ldots \ldots \ldots \ldots, 51$

3.2.5.2 Removable/semipermanent reflector $\ldots \ldots \ldots \ldots \ldots \ldots$. 55

3.2.5.3 Permanent reflector $\ldots \ldots \ldots \ldots \ldots \ldots \ldots \ldots \ldots \ldots, 57$

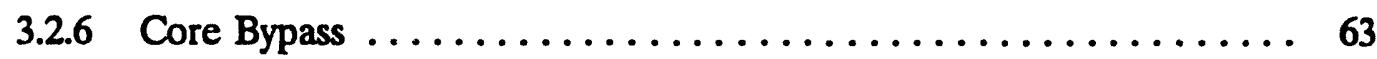

3.2.7 Vessel/Pool Check Valve $\ldots \ldots \ldots \ldots \ldots \ldots \ldots \ldots \ldots \ldots, 65$

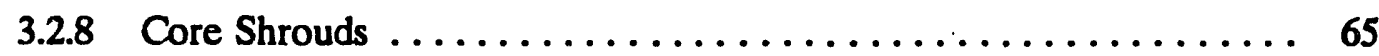

3.2.9 Target Tower $\ldots \ldots \ldots \ldots \ldots \ldots \ldots \ldots \ldots \ldots \ldots \ldots \ldots, 69 \ldots$

3.2.10 Upper Plenum .......................... 69

3.2.11 Lower Plenum $\ldots \ldots \ldots \ldots \ldots \ldots \ldots \ldots \ldots \ldots \ldots \ldots \ldots \ldots$

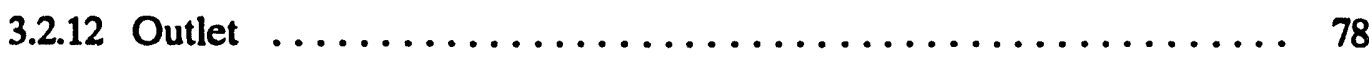

3.3 EXTRA-VESSEL COMPONENT DESCRIPTIONS ............. 79

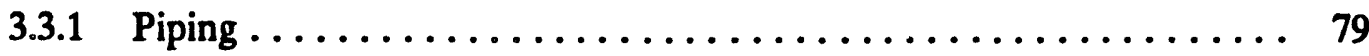

3.3.2 Heat Exchangers $\ldots \ldots \ldots \ldots \ldots \ldots \ldots \ldots \ldots \ldots \ldots, 83$

3.3.3 Primary Coolant Pumps $\ldots \ldots \ldots \ldots \ldots \ldots \ldots \ldots \ldots \ldots, 88$ 
3.3.4 Main and Standby Pressurizer Pumps $\ldots \ldots \ldots \ldots \ldots \ldots$

3.3.5 Auxiliary Pressurizer Pump ................... 96

3.3.6 Letdown and Radiation Block Valves ................ 96

3.3.7 Primary Coolant Head Tank ................... 98

3.3.8 Secondary Coolant System $\ldots \ldots \ldots \ldots \ldots \ldots \ldots \ldots \ldots \ldots$

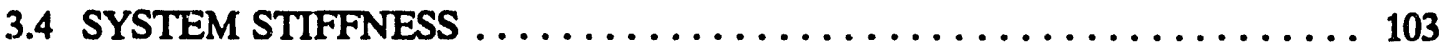

3.4.1 Mathematical Framework ................... 103

3.4.2 Discussion of Terms ........................ 104

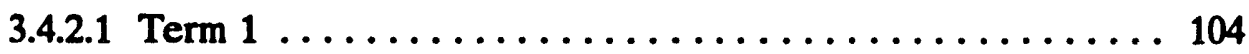

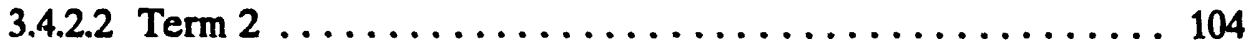

3.4.2.3 Term $3 \ldots \ldots \ldots \ldots \ldots \ldots \ldots \ldots \ldots \ldots \ldots \ldots \ldots \ldots$

3.4.2.4 Term $4 \ldots \ldots \ldots \ldots \ldots \ldots \ldots \ldots \ldots \ldots \ldots \ldots \ldots \ldots$

3.4.3 Combination of Terms $\ldots \ldots \ldots \ldots \ldots \ldots \ldots \ldots \ldots \ldots \ldots$

3.4.4 Inclusion in the Model $\ldots \ldots \ldots \ldots \ldots \ldots \ldots \ldots \ldots \ldots$

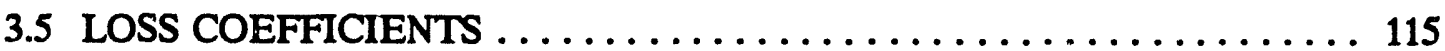

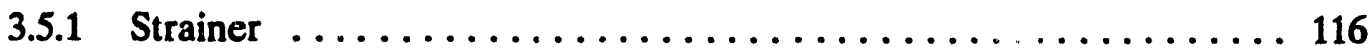

3.5.2 Heat Exchanger Inlet and Outlet $\ldots \ldots \ldots \ldots \ldots \ldots \ldots$

3.5.3 Bends and Elbows $\ldots \ldots \ldots \ldots \ldots \ldots \ldots \ldots \ldots \ldots \ldots$

3.5 .4 Wyes $\ldots \ldots \ldots \ldots \ldots \ldots \ldots \ldots \ldots \ldots \ldots \ldots \ldots \ldots \ldots \ldots \ldots \ldots$

3.5.5 Check Valves and Block Valves $\ldots \ldots \ldots \ldots \ldots \ldots \ldots \ldots \ldots$

3.5.6 Pressurizer Pump Discharge Line . . . . . . . . . . . . . . 121

3.5.7 Pressurizer Pump Suction Line .................. 121

3.6 TRIPS $\ldots \ldots \ldots \ldots \ldots \ldots \ldots \ldots \ldots \ldots \ldots \ldots \ldots \ldots \ldots \ldots \ldots \ldots \ldots$

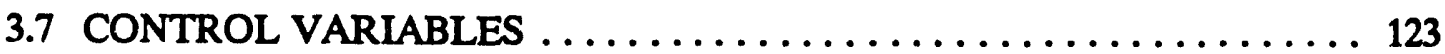

3.7.1 Primary Coolant Head Tank Level .................. 123

3.7.2 Main Circulation Pumps . ................... 126

3.7.3 Main and Standby Pressurizer Pumps ............... 138

3.7.4 Auxiliary Pressurizer Pump . . . . . . . . . . . . . . 138

3.7.5 Letdown Control and Radiation Block Valves ............... 138 
3.7.6 Secondary Coolant Flow $\ldots \ldots \ldots \ldots \ldots \ldots \ldots \ldots \ldots \ldots \ldots \ldots \ldots$

3.7.7 Secondary Coolant Pumps $\ldots \ldots \ldots \ldots \ldots \ldots \ldots \ldots \ldots \ldots \ldots$

3.7 .8 Reactor Trip ......................... 138

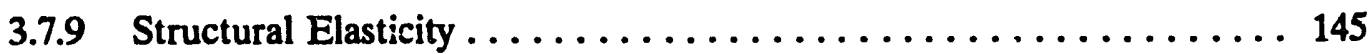

3.7.10 Emergency Depressurization . . . . . . . . . . . . . . 145

3.7.11 Cooling Tower Bypass $\ldots \ldots \ldots \ldots \ldots \ldots \ldots \ldots \ldots \ldots \ldots \ldots \ldots$

3.7.12 Leakage from the Primary Coolant System ............. 145

3.7.13 Cooling Tower Heat Removal ................... 148

3.7.14 Reactor Vessel Check Valve Flow ................. 148

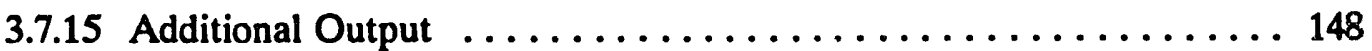

4. PREPROCESSING AND POSTPROCESSING . . . . . . . . . . . . . 149

5. MODEL APPLICATION $\ldots \ldots \ldots \ldots \ldots \ldots \ldots \ldots \ldots \ldots \ldots \ldots$

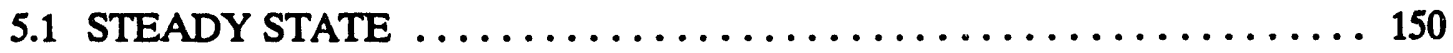

5.2 COSTS AND RUN TIMES $\ldots \ldots \ldots \ldots \ldots \ldots \ldots \ldots \ldots \ldots \ldots \ldots$

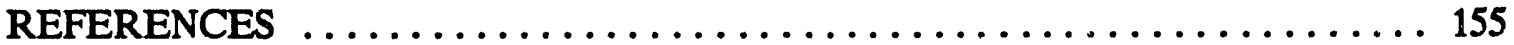

APPENDIX A. INPUT LISTING $\ldots \ldots \ldots \ldots \ldots \ldots \ldots \ldots \ldots \ldots \ldots \ldots$

APPENDIX B. MODELING CAVITATION OF THE HFIR PRIMARY

COOLANT PUMPS $\ldots \ldots \ldots \ldots \ldots \ldots \ldots \ldots \ldots \ldots \ldots \ldots \ldots \ldots \ldots \ldots \ldots$

B.1. SUMMARY $\ldots \ldots \ldots \ldots \ldots \ldots \ldots \ldots \ldots \ldots \ldots \ldots \ldots \ldots \ldots \ldots \ldots \ldots \ldots \ldots \ldots \ldots$

B.2. PUMP CAVITATION MODEL $\ldots \ldots \ldots \ldots \ldots \ldots \ldots \ldots \ldots \ldots \ldots \ldots \ldots \ldots$

B.3. CALCULATION RESULTS $\ldots \ldots \ldots \ldots \ldots \ldots \ldots \ldots \ldots \ldots . \ldots \ldots$

B.4. DAMAGE TO THE PUMP $\ldots \ldots \ldots \ldots \ldots \ldots \ldots \ldots \ldots \ldots \ldots \ldots \ldots$

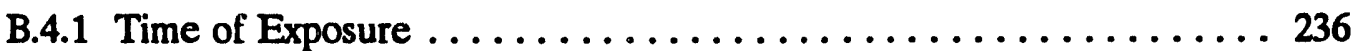

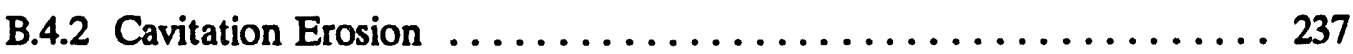

B.4.3 Bearing Damage ........................ 240

B.4.4 Recommendation ......................... 240

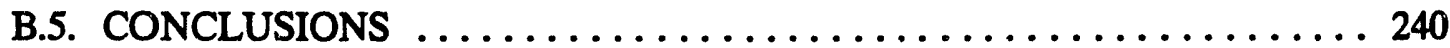

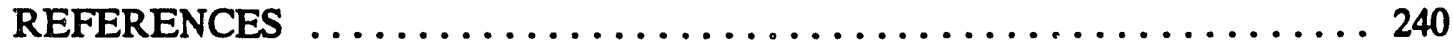

APPENDIX C. PREPROCESSING PROGRAM $\ldots \ldots \ldots \ldots \ldots \ldots \ldots \ldots 243$ 
APPENDIX D. POSTPROCESSING PROGRAM ............... 257

APPENDIX E. ABBREVIATED MODEL FOR OPERATIONAL

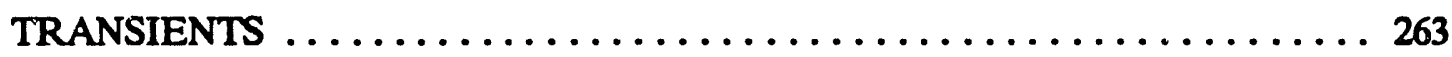

E.1. COARSENING OF NODALIZATION $\ldots \ldots \ldots \ldots \ldots \ldots \ldots \ldots \ldots 263$

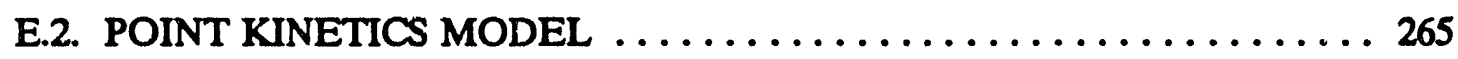

E.2.1 Moderator Temperature Effects $\ldots \ldots \ldots \ldots \ldots \ldots \ldots \ldots \ldots 265$

E.2.2 Thermal Expansion Effects .................... 270

E.2.3 Moderator Density Change in Control Region and Reflector . . . . 270

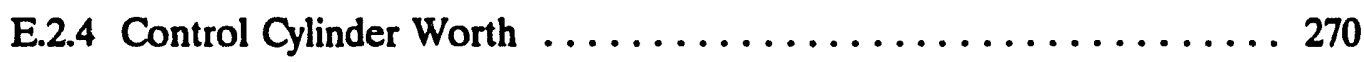

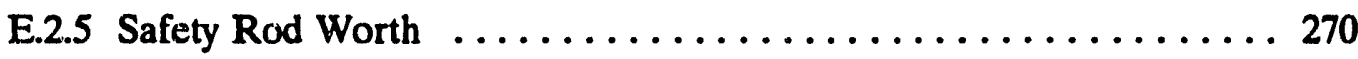

E.2.6 Target Region Void Feedback .................. 272

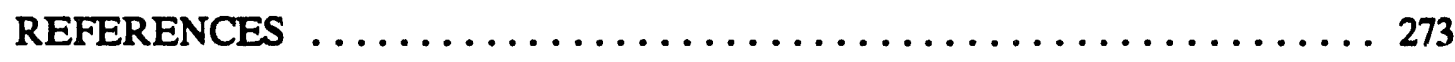

APPENDIX F. INPUT LISTING FOR ABBREVIATED MODEL $\ldots \ldots \ldots \ldots 275$ 


\section{LIST OF FIGURES}

$\begin{array}{lll}\text { Figure } & \text { Page }\end{array}$

1 Core $\ldots \ldots \ldots \ldots \ldots \ldots \ldots \ldots \ldots \ldots \ldots \ldots \ldots \ldots \ldots \ldots \ldots \ldots$

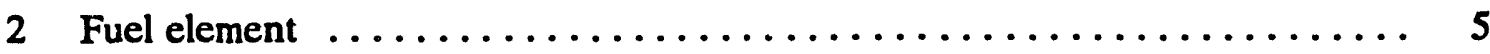

3 Vessel/core cross section $\ldots \ldots \ldots \ldots \ldots \ldots \ldots \ldots \ldots \ldots \ldots \ldots \ldots \ldots$

4 Reactor vessel and pools $\ldots \ldots \ldots \ldots \ldots \ldots \ldots \ldots \ldots \ldots \ldots \ldots \ldots$

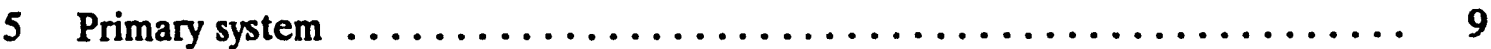

6 Schematic of the HFIR RELAP5 system model $\ldots \ldots \ldots \ldots \ldots \ldots \ldots \ldots$

7 Schematic of the HFIR RELAP5 vessel/core model .............. 12

8 Reactor vessel coolant flow distribution $\ldots \ldots \ldots \ldots \ldots \ldots \ldots \ldots \ldots$

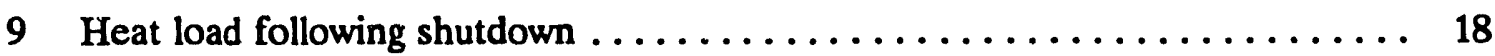

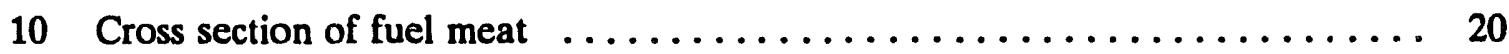

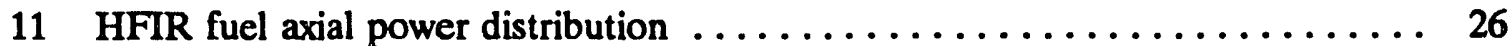

12. Peaking factor as function of film coefficient with fuel meat thickness as parameter ................................. 29

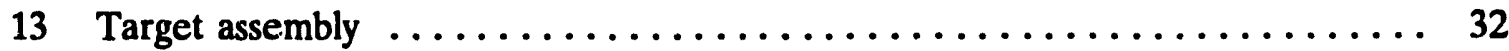

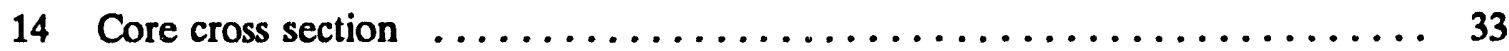

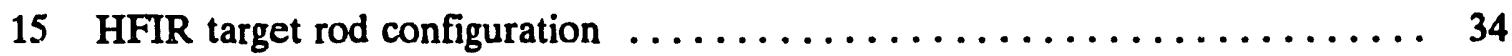

16 Schematic representation of control cylinders within HFIR core $\ldots \ldots \ldots \ldots 45$

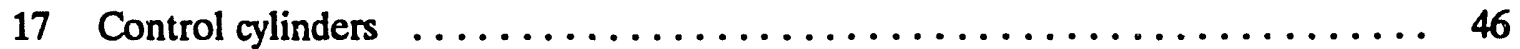

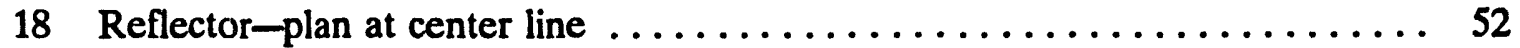

19 Cross section through core and shrouds $\ldots \ldots \ldots \ldots \ldots \ldots \ldots \ldots \ldots \ldots \ldots$

20 Vertical section of HFIR lower plenum $\ldots \ldots \ldots \ldots \ldots \ldots \ldots \ldots$

21 Plan section of core support upper flange $\ldots \ldots \ldots \ldots \ldots \ldots \ldots \ldots \ldots$

22 Heat exchanger cells and pool structures $\ldots \ldots \ldots \ldots \ldots \ldots$

23 Primary coolant clean-up system $\ldots \ldots \ldots \ldots \ldots \ldots \ldots \ldots \ldots \ldots \ldots \ldots$

24 Heat exchanger flow path $\ldots \ldots \ldots \ldots \ldots \ldots \ldots \ldots \ldots \ldots \ldots \ldots \ldots$

25 Schematic of HFIR RELAP5 secondary system model $\ldots \ldots \ldots \ldots \ldots$

26 Heat exchanger discretization sensitivity $\ldots \ldots \ldots \ldots \ldots \ldots \ldots \ldots \ldots$

27 Homologous head curves for main circulation pumps $\ldots \ldots \ldots \ldots \ldots \ldots \ldots$

28 Homologous torque curves for main circulation pumps $\ldots \ldots \ldots \ldots \ldots$ 
29 Comparison of RELAP5 simulated main circulating pump coastdown with

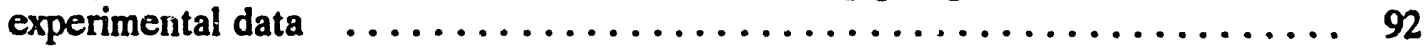

30 Comparison of RELAP5 simulated pressurizer pump coastdown with

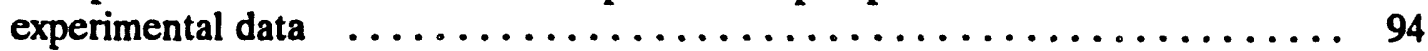

31 Homologous head curves for main pressurizer pumps ............ 95

32 Homologous torque curves for main pressurizer pumps $\ldots \ldots \ldots \ldots \ldots \ldots$

33 Relationship between PC head tank level and pressurizer pump suction pressure and percentage of tank volume containing water $\ldots \ldots \ldots \ldots \ldots 99$

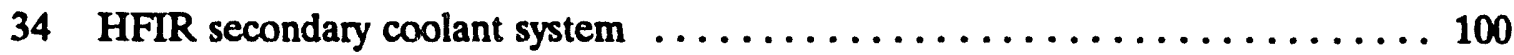

35 Coastdown rate of secondary coolant pumps $\ldots \ldots \ldots \ldots \ldots \ldots \ldots$

36 Exaggerated deformation of pressurized HFIR reactor vessel without

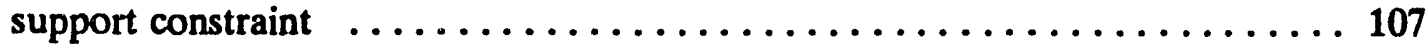

37 Elasticity of HFIR reactor vessel without support constraint $\ldots \ldots \ldots \ldots$. . 108

38 Exaggerated deformation of pressurized HFIR reactor vessel with

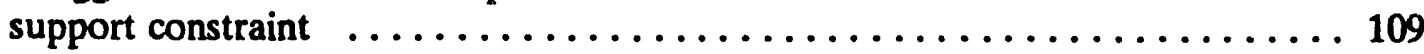

39 Elasticity of HFIR reactor vessel with support constraint $\ldots \ldots \ldots \ldots \ldots \ldots 110$

40 Extraction of structural elasticity from experiments performed by Dixon . . . . 110

41 Water density dependence upon temperature according to RELAP5 water

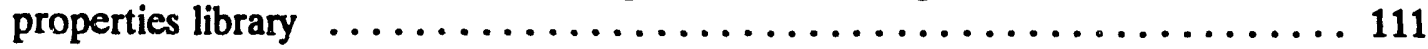

42 Water density dependence upon pressure according to the RELAP5 water properties library ............................. 112

43 Comparison of RELAP5 water density with ASME Steam Table values . . . . 113

44 Upper plenum pressure history during depressurization of system with and without elasticity model $\ldots \ldots \ldots \ldots \ldots \ldots \ldots \ldots \ldots \ldots \ldots \ldots \ldots$

45 Upper plenum history of change in pressure with respect to change in system volume during depressurization of system with and without the

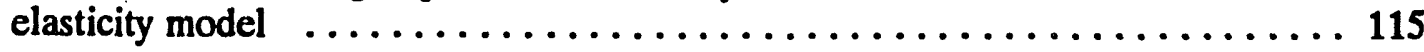

46 Measurements recorded for PdT103 from HFIR hourly checksheets . . . . 118

47 Loss coefficient configurations at wye junctions $\ldots \ldots \ldots \ldots \ldots \ldots \ldots \ldots$

48 Schematic of pressurizer pump suction line $\ldots \ldots \ldots \ldots \ldots \ldots \ldots \ldots \ldots$

49 Primary coolant head tank level control logic $\ldots \ldots \ldots \ldots \ldots \ldots \ldots \ldots$

50 Calculation of actual MCP speed during a pump coastdown $\ldots \ldots \ldots \ldots \ldots$

51 Calculation of head degradation factor for MCP cavitation $\ldots \ldots \ldots \ldots \ldots$ 
52 Calculation of degraded pump speed for MCP cavitation $\ldots \ldots \ldots \ldots \ldots \ldots$

53 Main circulation pump control logic $\ldots \ldots \ldots \ldots \ldots \ldots \ldots \ldots \ldots \ldots \ldots$

54 Main and standby pressurizer pump control logic $\ldots \ldots \ldots \ldots \ldots \ldots \ldots \ldots$

55 Auxiliary pressurizer pump control logic $\ldots \ldots \ldots \ldots \ldots \ldots \ldots \ldots \ldots \ldots$

56 Letdown and radiation block valve control logic . . . . . . . . . . 142

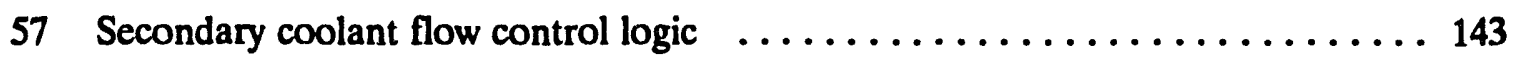

58 Secondary coolant pump control logic $\ldots \ldots \ldots \ldots \ldots \ldots \ldots \ldots \ldots \ldots$

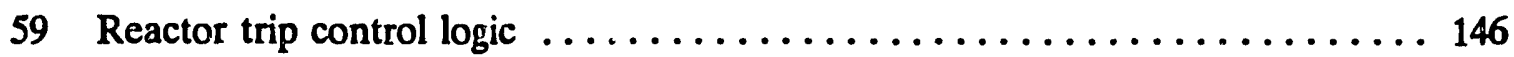

60 Structural elasticity mass injection control logic $\ldots \ldots \ldots \ldots \ldots \ldots \ldots \ldots$

61 Pressures at steady state in RELAP5 model $\ldots \ldots \ldots \ldots \ldots \ldots \ldots \ldots \ldots$

62 Measurements recorded for PdT106 from HFIR hourly readings . . . . . . 153

B.1 Manufacturer's data for required suction head for HFIR primary

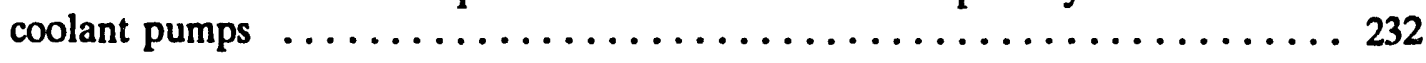

B.2 Nondimensionalized data for required suction head as function of pump flow $\ldots \ldots \ldots \ldots \ldots \ldots \ldots \ldots \ldots \ldots \ldots \ldots \ldots \ldots \ldots \ldots \ldots \ldots$

B.3 Normalized degraded pump head vs available suction head $\ldots \ldots \ldots \ldots 234$

B.4 Control of HFIR primary coolant pump speed $\ldots \ldots \ldots \ldots \ldots \ldots \ldots$

B.5 Flow delivered to reactor vessel during 2 -in. break $\ldots \ldots \ldots \ldots \ldots \ldots$

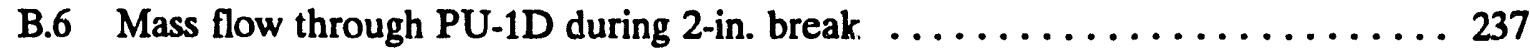

B.7 Closeup of mass flow through PU-1D during 2 -in. break . . . . . . . . . 238

B.8 Nondimensional suction head vs nondimensional flow rate during

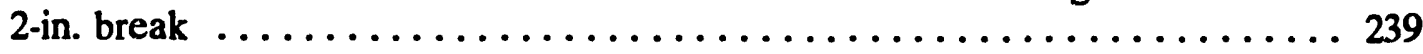

E.1 Abbreviated model primary system nodal diagram $\ldots \ldots \ldots \ldots \ldots \ldots$

E.2 Abbreviated model core nodal diagram $\ldots \ldots \ldots \ldots \ldots \ldots$

E.3 Moderator temperature change contribution to reactivity change control logic $\ldots \ldots \ldots \ldots \ldots \ldots \ldots \ldots \ldots \ldots \ldots \ldots \ldots \ldots \ldots \ldots \ldots$

E.4 Inner fuel thermal expansion contribution to reactivity change control logic . . 272

E.5 Control logic for safety rod insertion after scram is initiated . . . . . . . . 272 


\section{LIST OF TABLES}

Table

Page

1 HFIR core heat loads at nominal 85-MW power level ............. 15

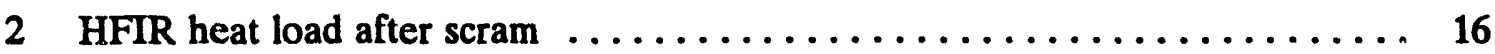

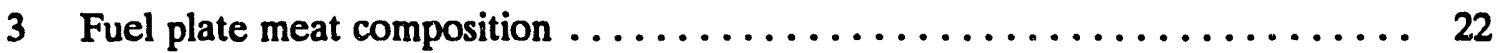

4 Fuel meat specific heat and volumetric heat capacity .............. 23

5 Fuel meat thermal conductivity ....................... 24

6 Clad specific heats and volumetric heat capacity $\ldots \ldots \ldots \ldots \ldots \ldots \ldots$

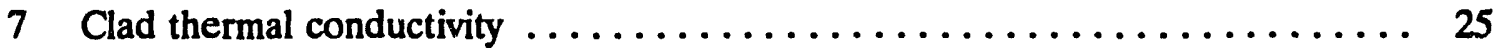

8 Oxide (boehmite) specific heat and volumetric heat capacity ........... 25

9 Normalized HFIR fuel axial power peaking factors . . . . . . . . . . 27

10 Hot channel and local power peaking factors $\ldots \ldots \ldots \ldots \ldots \ldots \ldots \ldots$

11 Fuel internal source multipliers for HFIR RELAP5 model $\ldots \ldots \ldots \ldots \ldots \ldots 31$.

12 Target pellet core composition per $\operatorname{rod} \ldots \ldots \ldots \ldots \ldots \ldots \ldots \ldots \ldots \ldots$

13 Pellet core specific heat and volumetric heat capacity $\ldots \ldots \ldots \ldots \ldots \ldots \ldots$

14 Pellet aluminum jacket specific heat and volumetric heat capacity . . . . . . 38

15 Target pellet containment tube specific heat and volumetric heat capacity . . . 42

16 Target pellet containment tube thermal conductivity . . . . . . . . . . 43

17 Target axial power peaking factors and RELAP5 internal source multipliers ... 44

18 Radial boundaries of regions comprising the control cylinders . . . . . . . . 48

19 Control cylinder core specific heat and volumetric heat capacity . . . . . . . 49

20 Control cylinder clad volumetric heat capacity . . . . . . . . . . . . . . 49

21 Control cylinder clad thermal conductivity . . . . . . . . . . . . . . . 49

22 Control cylinder axial power peaking factors and RELAP5 internal source

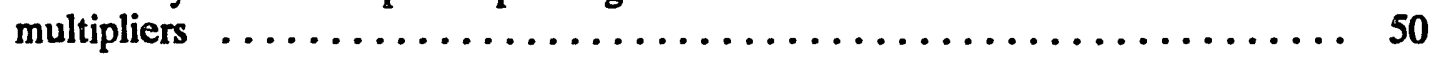

23 Radial boundaries of regions comprising the hot removable reflector cylinders $\ldots \ldots \ldots \ldots \ldots \ldots \ldots \ldots \ldots \ldots \ldots \ldots \ldots \ldots \ldots \ldots \ldots$

24 Beryllium specific heat and volumetric heat capacity . . . . . . . . . . . 54

25 Beryllium thermal conductivity $\ldots \ldots \ldots \ldots \ldots \ldots \ldots \ldots \ldots \ldots \ldots$

26 Hot removable beryllium reflector axial power peaking factors and RELAP5 internal source multipliers $\ldots \ldots \ldots \ldots \ldots \ldots \ldots \ldots \ldots \ldots \ldots \ldots$ 
Table

27 Removable/semipermanent beryllium reflector axial power peaking factors and RELAP5 internal source multipliers $\ldots \ldots \ldots \ldots \ldots \ldots \ldots \ldots \ldots \ldots, 57$

28 Effective natural convection heat transfer coefficients at the beryllium

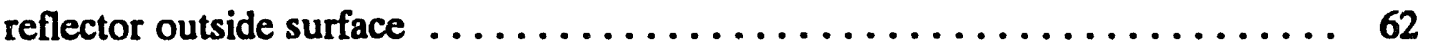

29 Permanent beryllium reflector axial power peaking factors and RELAP5

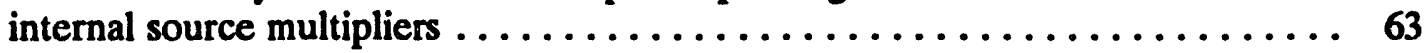

30 Natural convection heat transfer coefficients at the outer shroud surface $\ldots . .68$

31 Carbon steel specific heat and volumetric heat capacity ............. 70

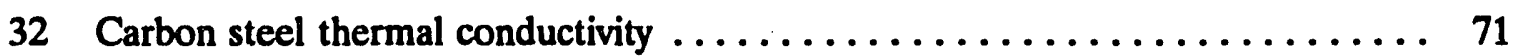

33 304L stainless steel specific heat and volumetric heat capacity $\ldots \ldots \ldots \ldots \ldots 71$

$34304 \mathrm{~L}$ stainless steel thermal conductivity $\ldots \ldots \ldots \ldots \ldots \ldots \ldots \ldots \ldots 71$

35347 stainless steel specific heat and volumetric heat capacity $\ldots \ldots \ldots \ldots \ldots 72$

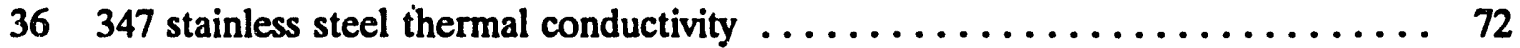

37 Natural convection heat transfer coefficients at the upper vessel sidewall and top head outside surfaces $\ldots \ldots \ldots \ldots \ldots \ldots \ldots \ldots \ldots \ldots \ldots, 74$

38 Radial boundaries of the oxide regions and aluminum comprising the reflector container and pedestal assembly $\ldots \ldots \ldots \ldots \ldots \ldots \ldots \ldots \ldots \ldots \ldots, 78$

39 Dimensiont of steel pipe $\ldots \ldots \ldots \ldots \ldots \ldots \ldots \ldots \ldots \ldots \ldots \ldots \ldots$

40 Selected elerations in the primary coolant system $\ldots \ldots \ldots \ldots \ldots \ldots \ldots, 83$

41 Measurements of secondary side pressure drop $\ldots \ldots \ldots \ldots \ldots \ldots \ldots .88$

42 Moments of inertia for the primary coolant pump and pump motors ....... 88

43 Primary coolant pump performance data at $77^{\circ} \mathrm{F}$ taken from Byron Jackson report $\ldots \ldots \ldots \ldots \ldots \ldots \ldots \ldots \ldots \ldots \ldots \ldots \ldots \ldots . . .6 \%$

44 Pony motor torque supplied to the pump shaft $\ldots \ldots \ldots \ldots \ldots \ldots \ldots \ldots 9$

45 Pump characteristic data for the nain and standby pressurizer pumps at

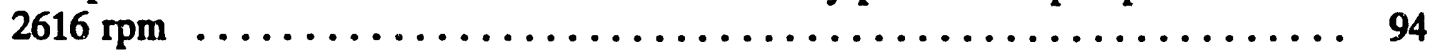

46 Auxiliary pressurizer flow rate as a function of pump head $\ldots \ldots \ldots \ldots \ldots 96$

47 Elasticity in the HFIR primary coolant containment $\ldots \ldots \ldots \ldots \ldots \ldots . \ldots 106$

48 HFIR hourly checksheet data for strainer pressure drop (PdT103) $\ldots \ldots \ldots 117$

49 Loss coefficients for bends and elbows $\ldots \ldots \ldots \ldots \ldots \ldots \ldots \ldots \ldots \ldots$

50 Loss coefficients for diverging wye junctions $\ldots \ldots \ldots \ldots \ldots \ldots \ldots \ldots \ldots$

51 Loss coefficients for converging wye junctions $\ldots \ldots \ldots \ldots \ldots \ldots \ldots \ldots 120$ 
52 Loss coefficients for the block and check valves $\ldots \ldots \ldots \ldots \ldots \ldots \ldots \ldots$

53 Fittings in the pressurizer pump discharge line $\ldots \ldots \ldots \ldots \ldots \ldots \ldots \ldots \ldots$

54 Trips as defined in the RELAP5 system model of the HFIR primary

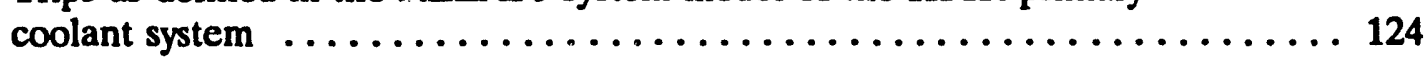

55 Control variables used in the model $\ldots \ldots \ldots \ldots \ldots \ldots \ldots \ldots \ldots \ldots$

56 HFIR hourly checksheet data for vessel pressure drop (PdT106) . . . . . . 152

B.1 CPU times required for $5.08-\mathrm{cm}(2-i n$.$) break simulations \ldots \ldots \ldots \ldots \ldots$

E.1 Control variables used for specifying changes in HFIR fuel reactivity $\ldots \ldots \ldots 267$

E.2 Moderator temperature coefficients in fuel and flux trap regions . . . . . . . 269

E.3 HFIR control plate worth . . . . . . . . . . . . . . . . . . . 269

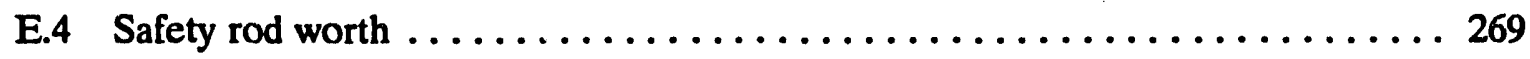

E.5 HFIR target region reactivity as a function of coolant void fraction . . . . . . 270 
NOMENCLATURE

Symbol

$A$
$b$
$c_{1}$
$C$
$C_{p}$
$C_{v}$
$d$
$D_{h}$
$g$
$G$
$h$
$h$
$h$
$H$
$k$
$K$
$K_{f}$
$L$
$n$
$\mathrm{Nu}$
$P$
$r$
$\mathrm{Ra}$
$t$
$T$
$v$
$V$
$w$
$y$

Greek

$\alpha$
$\beta$
$\lambda$
$\mu$
$v$
$\rho$
Definition

area

torque ratio

integration constant

circumference

volumetric heat capacity

valve friction loss coefficient

diameter

hydraulic diameter

flow ratio or acceleration of gravity

volumetric flow rate

head ratio

head loss

pump head

thermal conductivity

loss coefficier t

spring con t. Ant

length

pump speed

Nusselt number

perimeter or pressure

radius

Rayleigh number

thickness

temperature

velocity or pump flow ratio

volume

width

relative valve stem position
Units

$\mathrm{m}^{2}$

m

$\mathrm{m}$

$\mathrm{J} / \mathrm{m}^{3}-^{\circ} \mathrm{C}$

$\mathrm{gal} / \mathrm{min} / \mathrm{psi}^{0.5}$

m

m

- or $\mathrm{m} / \mathrm{s}^{2}$

$\mathrm{m}^{3} / \mathrm{s}$

m

m

$\mathrm{W} / \mathrm{m}-{ }^{\circ} \mathrm{C}$

$\mathrm{MPa} / \mathrm{m}^{3}$

m

$1 / \mathrm{s}$

$\mathrm{m}$ or $\mathrm{MPa}$

m

m

${ }^{\circ} \mathrm{C}$

$\mathrm{m} / \mathrm{s}$ or -

$\mathrm{m}^{3}$

m thermal diffusivity or pump speed ratio coefficient of thermal expansion thermal coefficient of linear expansion Poisson's ratio kinematic viscosity density $\mathrm{m}^{2} / \mathrm{s}$ or $1 /{ }^{\circ} \mathrm{C}$

$1 /{ }^{\circ} \mathrm{C}$

$\mathrm{m}^{2} / \mathrm{s}$

$\mathrm{kg} / \mathrm{m}^{3}$ 


\title{
HIGH FLUX ISOTOPE REACTOR SYSTEM RELAP5 INPUT MODEIS
}

\author{
D. G. Morris \\ M. W. Wendel
}

\begin{abstract}
A thermal-hydraulic computational model of the High Flux Isotope Reactor (HFIR) has been developed using the RELAP5 program. The purpose of the model is to provide a state-of-the art thermal-hydraulic simulation tool for analyzing selected hypothetical accident scenarios for a revised HFIR Safety Analysis Report (SAR). The model includes (1) a detailed representation of the reactor core and other vessel components, (2) three heat exchanger/pump cells, (3) pressurizing pumps and letdown valves, and (4) secondary coolant system (with less detail than the primary system). Data from HFIR operation, component tests, tests in facility mockups and the HFIR, HFIR specific experiments, and other pertinent experiments performed independent of HFIR were used to construct the model and validate it to the extent permitted by the data.

The detailed version of the model has been used to simulate loss-of-coolant accidents (LOCAs), while the abbreviated version has been developed for the operational transients that allow use of a less detailed nodalization. Analysis of station blackout with core long-term decay heat removal via natural convection has been performed using the core and vessel portions of the detailed model.
\end{abstract}

\section{INTRODUCTION}

The High Flux Isotope Reactor (HFIR) is a beryllium-reflected, light-water-cooled and -moderated, aluminum-clad fuel plate, flux-trap-type reactor that utilizes highly enriched ${ }^{235} \mathrm{U}$. The HFIR is designed to produce a very high thermal neutron flux of about $5 \times 10^{15}$ neutrons $/ \mathrm{cm}^{2}-s$ for the production of transuranium isotopes and the performance of various irradiation experiments. The HFIR is a member of a family of "high-performance" research reactors employing plate-type fuel including, for example, the Advanced Test Reactor (ATR) at Idaho National Engineering Laboratory (INEL) and the High Flux Beam Reactor (HFBR) at Brookhaven National Laboratory (BNL). In addition, there are foreign reactors with characteristics similar to the HFIR.

The HFIR was operated for -20 years before its shutdown in November 1986 due to vessel embrittlement concerns. These concerns have been resolved through a fracture mechanics analysis coupled with an annual hydrotest. In support of the restart effort, a number of other safety studies have been completec, and others are still in progress. One of the ongoing studies, which is the subject of this report, involves upgrading the a.nalytical thermal-hydraulic capabilities for the HFIR. In particular, the objective is to provide a stateof-the-art analytical capability for simulating the thermal-hydraulic response of the system to small- and large-break loss-of-coolant accidents (SBLOCAs and LBLOCAs), station blackout 
(necessitating long-term decay heat removal), and a variety of operational transients. To this end, a model has been constructed of the HFIR primary coolant system and pertinent secondary system components and control systems using the RELAP5/MOD2.5 computer code. ${ }^{1}$ This mor'el provides a tool that meets current standards for performing required thermal-hydraulic analyses necessary to develop a revised Safety Analysis Report (SAR) for the HFIR.

RELAP5 is a one-dimensional (1-D), transient, two-phase flow code developed at INEL for the analysis of pressurized-water reactors in support of the United States Nuclear Regulatory Commission (NRC). The code is based on a nonhomogeneous and nonequilibrium model of two-phase flow. The development of RELAP5 has spanned $\sim 10$ years and has benefitted from extensive application and comparison to data in light-water systems.

RELAP5 was selected for use over other candidate codes including TRAC, 2 COBRATRAC, ${ }^{3}$ and RETRAN. ${ }^{4}$ TRAC and COBRATRAC, like RELAP5, were developed through the sponsorship of the NRC. RETRAN is an extension of RELAP4, a predecessor to RELAP5, which contains enhancements sponsored by the Electric Power Research Institute. RELAP5, as well as the other codes, offers an impressive tech-ology base of light-water reactor thermal-hydraulic analysis capability that, although not is eloped for the analysis of plate-fueled reactor systems, can be refined for these systems. Efforts are in progress to refine and benchmark RELAP5 for plate-fueled reactor systems. 5 -7 INEL has developed "updates" to RELAP5 for low-pressure conditions that have been incorporated in version $3 T$ of RELAP5/MOD2.5, which is used for HFIR analysis. Two other changes were made to the code for HFIR analysis, the first of which entailed the implementation of a model for the onset of flow excursion. Over selected parameter ranges the model replaces the standard RELAP5/MOD'i.5 high-flow, critical heat flux (CHF) correlation. The implementation and performance of this model are discussed elsewhere. The second change corrects the inability of the code to accurately simulate fast reacti ity transients typical of the HFIR.9 In addition to code changes, other unique features of HFIR requiring extension of the basic RELAP5 capability were accommodated through the HFIR input model using control variables. An assessment of the applicability of the resulting code/input model for analysis of HFIR postulated accident scenarios for the SAR has been performed, and they were determined to be adequate.

The major difference between the codes is the dimensionality of the thermal-hydraulic equations used in each. While RELAP5 and RETRAN are primarily 1-D codes, TRAC and COBRAVTRAC provide three-dimensional (3-D) capability (although based on a number of significant simplifying assumptions) with COBRAVTRC providing the more detailed treatment of the continuity, momentum, and energy equations. The selection of RELAP5 over the other codes was made for a number of reasons. Foremost, it is anticipated that for most HFIR accidert! sequences to be investigated, multidimensional flow phenomena can be reasonably accornmodated with RELAP5 using approximations (e.g., RELAP5 cross-flow junction and user-specified natural convection coefficients) and/or conservative assumptions. For most sequences, forced flow will be maintained throughout the event, thus providing a primarily 1-D flow.

In general, neglecting multidimensional effects should lead to conservative results (i.e., higher predicted fuel temperatures). For example, fluid mixing, generally a multidimensional phenomenon, results in cooling hot fluid and/or its transport to a cooler region. In the core, conduction along the spanwise dimension of the fuel involute to the cooler side plates mitigates the peak fuel temperature. However, this effect is offset to an extent, depending 
upon the nonuniformity of the flow field (e.g., temperature, velocity, and void fraction) along the span of the involute. If important multidimensional phenomena cannot be adequately accommodated with RELAP5 for a particular accident sequence, then supplemental analysis will be performed. In previous studies ${ }^{10}$ examining HFIR core natural convection decay heat removal, RELAP5 analysis was supplemented with 3-D, single-phase flow analysis using the TEMPEST ${ }^{11}$ computer code.

Among the other factors that led to the selection of RELAP5 was the authors' familiarity with RELAP4 and RELAP5 gained in previous projects. In addition, it is well known that model input requirements and computer run times are significantly greater for multidimensicinal models. Thus, it was felt that the additional cost and time required for a HFIR mufuidi mensional system thermal-hydraulic model was not warranted.

Previcissly developed thermal-hydraulic computer models of HFIR were used in the design of the core and, more recently, to study the response of the system to LBLOCAs and SBLOCAs. For the design of the core, a steady-state, integral thermal-hydraulics model ${ }^{12}$ was developed that simultaneously accounts for nuclear, hydraulic, heat transfer, mechanical, and corrosion factors. Scoping analyses of LBLOCAs have been conducted ${ }^{13,14}$ using a simplified HFIR primary system model developed with MELCOR, ${ }^{15}$ a severe accident analysis code that has the apability to simulate two-phase flow, along with a more detailed core model developed with RELAP5. "Global system" results obtained with MELCOR were used to define thermal-hydraulic boundary conditions for the RELAP5 core model, which included core inlet and outlet conditions (e.g., flows, temperatures, and pressures) throughout the transient. More recently, MELCOR has been used in a stand-alone mode to evaluate the consequences of LBLOCAs, which, by definition, are those LOCAs that result in core damage. Reference 16 provides a representative analysis. Scoping analysis of SBLOCAs was performed with HFIRSYS, ${ }^{17}$ a transient system, thermal-hydraulic model using the Modular Modeling System. ${ }^{18}$ Because HFIRSYS was not designed to simulate two-phase flow, the code cannot predict the response of the system following incipience of boiling. However, it provides a lower bound on the break size that could result in core damage. Analysis with RELAP5 will permit an extension of the HFIRSYS analysis with consideration of the departure from nucleate boiling and flow instability.

In general, a best-estimate HFIR input model was developed for RELAP5, consistent with the intent of the code. However, in instances where a best-estimate approach was not suitable, conservative modeling assumptions were made. Such an approach was taken in situations where uncertainties in a best-estimate model would be large or where a best-estimate model was impractical to implement. The key parameters that have significant uncertainties and were accounted for in the model are fuel plate and element manufacturing variability (defects), power distribution, and preaccident operating conditions (reactor power level, core inlet temperature, core flow, and system pressure). Uncertainties were taken at "worst" case values and then assumed to occur simultaneously. This obviously leads to very conservative results.

The HFIR RELAP5 input model was configured in British units, consistent with the original design calculations and drawings for the system. At a later time, the model can be translated into SI units.

This report describes the development of the HFIR system thermal-hydraulic RELAP5 model. The following chapters include a brief description of the HFIR; a detailed account of the development of the model, containing results of some validation studies; and summary information regarding the application of the model. The appendixes contain a list of the input model, a description of the pump cavitation modeling scheme, pre- and postprocessing programs written for use with the model, and a discussion about an abbreviated version of the model developed for simulating operational transients. 


\section{FACILTYY OVERVIEW}

This section provides a brief description of the HFIR facility. A detailed description of the facility can be found elsewhere. ${ }^{19,20}$ Much of the following discussion has been adapted from Ref 19.

The reactor core, illustrated in Fig. 1, consists of a series of concentric annular regions, each $\sim 2 \mathrm{ft}(0.61 \mathrm{~m})$ high. The target, containing ${ }^{242} \mathrm{Pu}$ and other transuranium isotopes, is positioned on the reactor vertical axis within a 5 -in.-diam $(12.7-\mathrm{cm})$ hole. The fuel region is composed of two concentric fuel elements as shown in Fig. 2. The inner element, which

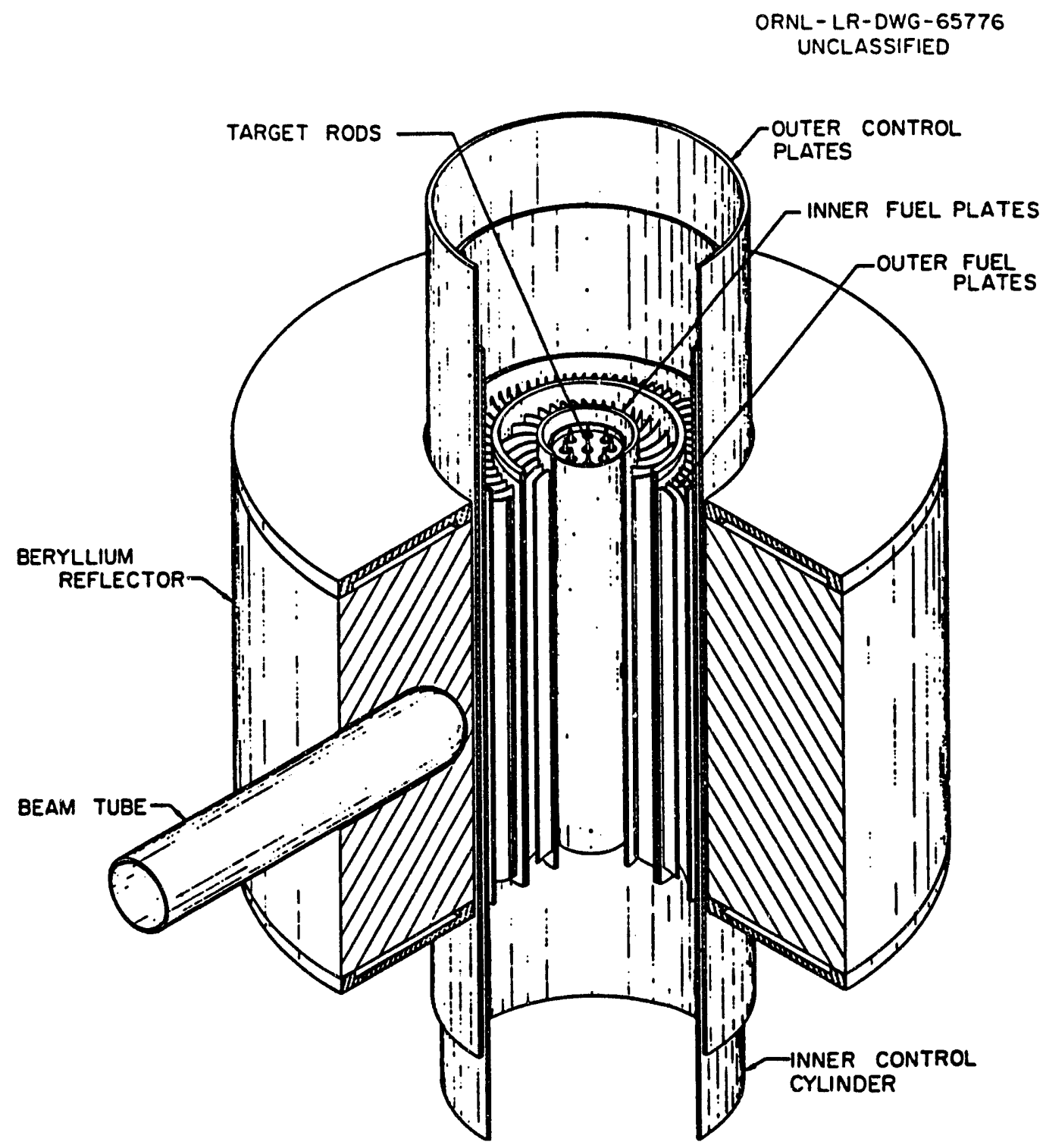

Fig. 1. Core. 


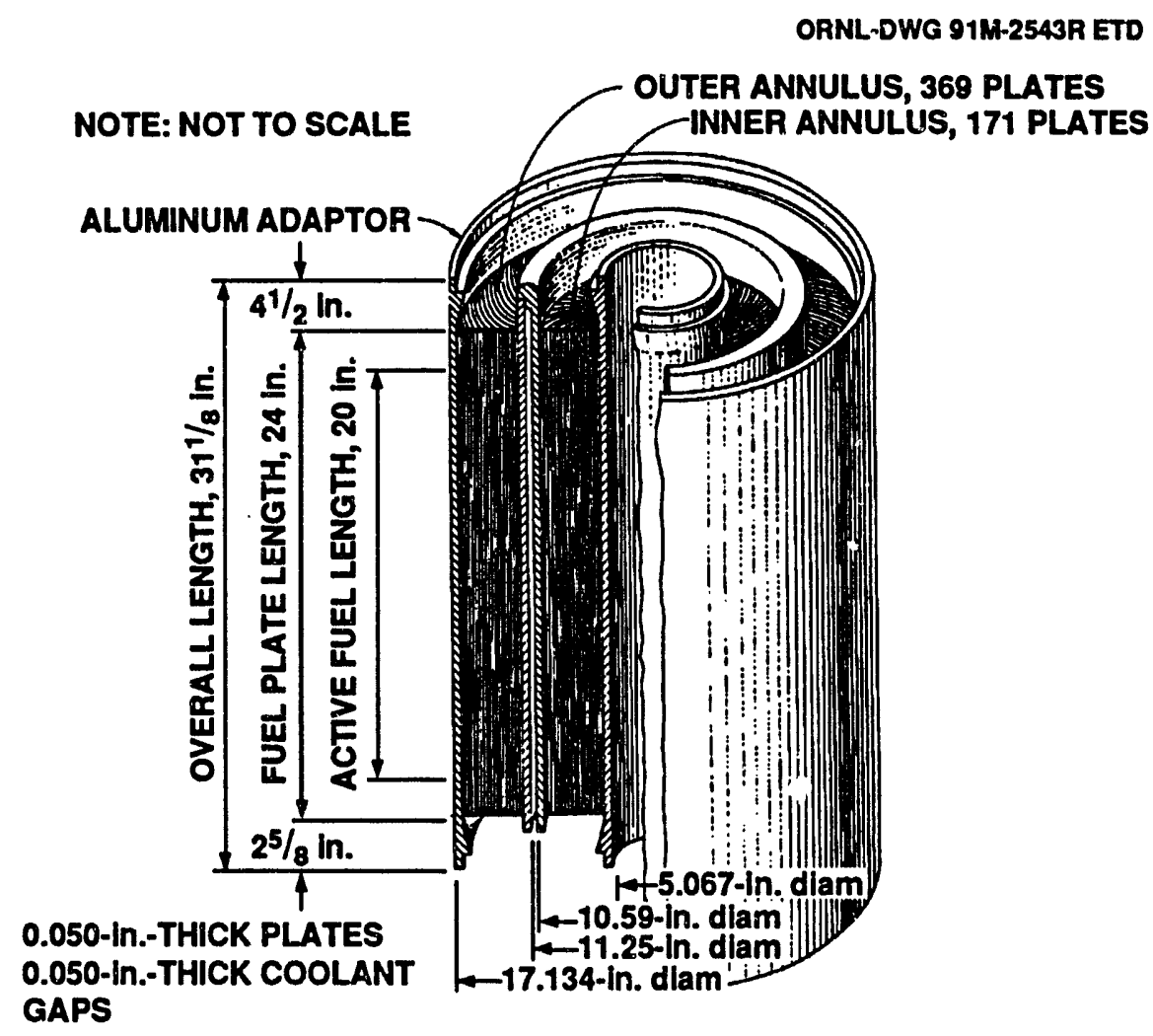

Fig. 2. Fuel element.

contains 171 curved fuel plates, $\mathrm{h}$. an inside diameter of $5.067 \mathrm{in.}(12.87 \mathrm{~cm})$ and an outside diameter of $10.59 \mathrm{in}$. (26.90 cm, . wuter fuel element contains 369 curved fuel plates and has inner and outer diameters of 11.25 and 17.134 in. $(28.58$ and $43.52 \mathrm{~cm})$, respectively. The fuel plates are 0.050 in. $(0.127 \mathrm{~cm})$ thick and are curved in the shape of an involute, thus providing a constant coolant channel width. The coolant channels are also 0.050 in. $(0.127 \mathrm{~cm})$ wide. The plates are of complex, sandwich-type construction composed of a $\mathrm{U}_{3} \mathrm{O}_{8}$-Al cermet clad with type 6061 aluminum. To minimize the radial peak-to-average power density ratio, the fuel is nonuniformly loaded along the arc of the involute. A burnable poison is included in the inner fuel element to further flatten the neutron flux distribution and to reduce the negative reactivity requirements of the control plates. A typical core loading includes $\sim 9.4 \mathrm{~kg}$ of ${ }^{235} \mathrm{U}$ and $2.8 \mathrm{~g}$ of ${ }^{10} \mathrm{~B}$. This provides a maximum of $11 \%$ available reactivity and an average core lifetime of about 23 days.

The control plates, in the form of two thin, poison-bearing, concentric cylinders, are located in an annular region between the outer fuel element and the beryllium reflector. The inner control cylinder has its poison arranged so that reactivity is increased by downward motion. This cylinder is used for shimming and regulation; it has no fast safety function. The outer control cylinder consists of four separate quadrants, each having an independent drive and safety release mechanism. Reactivity is increased as the outer plates are raised. All control plates have three regions of different poison content designed to minimize the axial peak-to-average power density ratio throughout the core lifetime. 
The beryllium reflector is composed of a series of concentric cylinders with a total thickness of $\sim 1 \mathrm{ft}(0.305 \mathrm{~m})$. This, in turn, is bounded by a water reflector of effectively infinite thickness. In the axial direction the reactor is reflected by water.

The reactor core assembly is contained in an 8-ft-diam (2.44-m) pressure vessel, which is located in an 18-ft-diam (5.49-m) cylindrical pool of water. A section through the vessel/core and pool assembly is shown in Fig. 3. The top of the pressure vessel is $17 \mathrm{ft}$ $(5.18 \mathrm{~m})$ below the pool water level, with the reactor centerline $27.5 \mathrm{ft}(8.38 \mathrm{~m})$ below the pool level. Adjacent to, and connected with, the reactor pool is the clean pool where spent elements are stored, which is $20 \mathrm{ft}(6.10 \mathrm{~m})$ deep, $18 \mathrm{ft}(5.49 \mathrm{~m})$ wide, and $41.5 \mathrm{ft}(12.6 \mathrm{~m})$ long, as shown in Fig. 4. Underwater access is also provided to a small [8-ft-diam (2.44-m)] critical facility pool.

The primary coolant enters the pressure vessel through two 16-in.-diam $(40.6-\mathrm{cm})$ pipes above the core, passes downward through the core, and exits through an 18-in.-diam (45.7-cm) pipe beneath the core. For simplicity, only one of the inlet lines is shown in Fig. 3. The design total flow rate is $-16,000 \mathrm{gal} / \mathrm{min}\left(1.01 \mathrm{~m}^{3} / \mathrm{s}\right)$, of which $-13,000 \mathrm{gal} / \mathrm{min}\left(0.82 \mathrm{~m}^{3} / \mathrm{s}\right)$ flows through the fuel region and the remainder through the target, reflector, and control regions. ${ }^{19}$ The system is designed to operate at $100 \mathrm{MW}$ with an inlet pressure up to $1000 \mathrm{psi}$ $(6.88 \mathrm{MPa})$. However, concerns about radiation-induced embrittlement of the pressure vessel prompted a decision to limit operation to $85 \mathrm{MW}$ with an inlet pressure of only $482.7 \mathrm{psi}$ (3.33 $\mathrm{MPa})$. Under these conditions the inlet temperature is $120^{\circ} \mathrm{F}\left(48.9^{\circ} \mathrm{C}\right)$, the corresponding exit temperature is $157^{\circ} \mathrm{F}\left(69.4^{\circ} \mathrm{C}\right)$, and the pressure drop through the core is -105 psi $(0.724 \mathrm{MPa})$.

From the reactor, the coolant flow is distributed to three of four identical heat-exchanger circulation-pump combinations, each located in a separate cell adjacent to the reactor and storage pools. Each cell also contains a letdown control valve, which controls the primary system pressure by extracting flow from the heat exchanger; two block valves for cell isolation; and a check valve to prevent any backflow through the pump. A secondary coolant system removes heat from the primary system and transfers it to the atmosphere by passing water over a four-cell induced-draft cooling tower. Figure 5 shows the arrangement of the reactor vessel, inlet and outlet piping, and one of the four heat exchangers cells; also shown is the injection point in the inlet coolant piping of the low-flow, high-head pressurizer pump that pressurizes the system.

After the reactor is shut down, the main coolant pumps can be operated at reduced flow, driven by small dc "pony" motors located directly above the main ac motors (Fig. 5). Any one of the three operating pony motors can supply sufficient forced convection cooling to remove decay heat from the core.21 The total primary system flow is $2500 \mathrm{gal} / \mathrm{min}\left(0.158 \mathrm{~m}^{3} / \mathrm{s}\right)$ with three pony motors, $2100 \mathrm{gal} / \mathrm{min}\left(0.132 \mathrm{~m}^{3} / \mathrm{s}\right)$ with two pony motors, or $1300 \mathrm{gal} / \mathrm{min}$ $\left(0.082 \mathrm{~m}^{3} / \mathrm{s}\right)$ with only one pony motor operating. Each pony motor is powered by either one of two off-site ac power sources, either one of two on-site emergency diesel generators, or by its own bank of batteries. There are four banks of batteries, one for each pony motor. Each bank has an 8-h lifetime at rated conditions. ${ }^{2}$ Thus, the HFIR has four redundant pony motors, each of which has multiple redundant power sources. In addition, two small, seismically qualified, mobile diesel generators were recently obtained to allow pony motor operation for very long durations. 


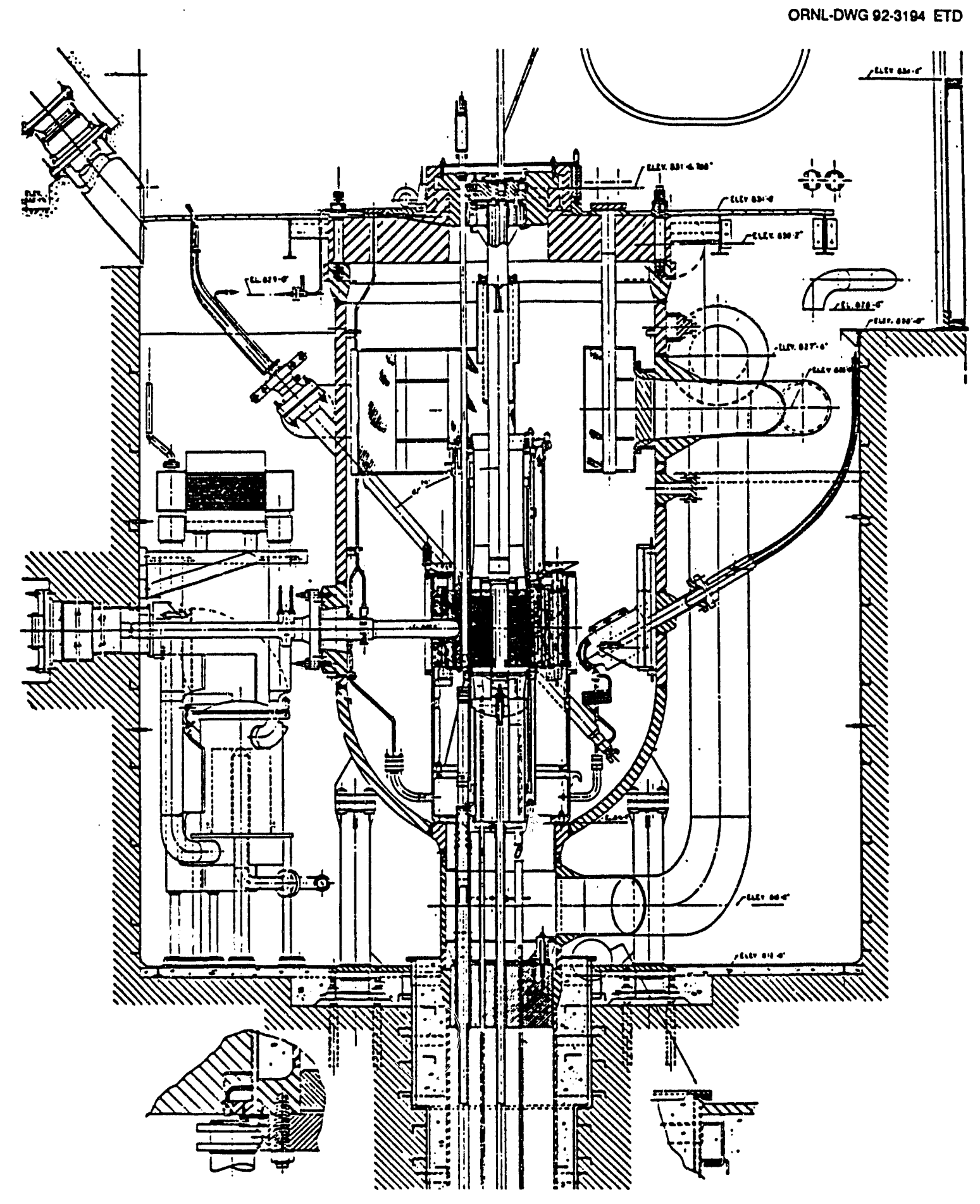

Fig. 3. Vessel/core cross section. 


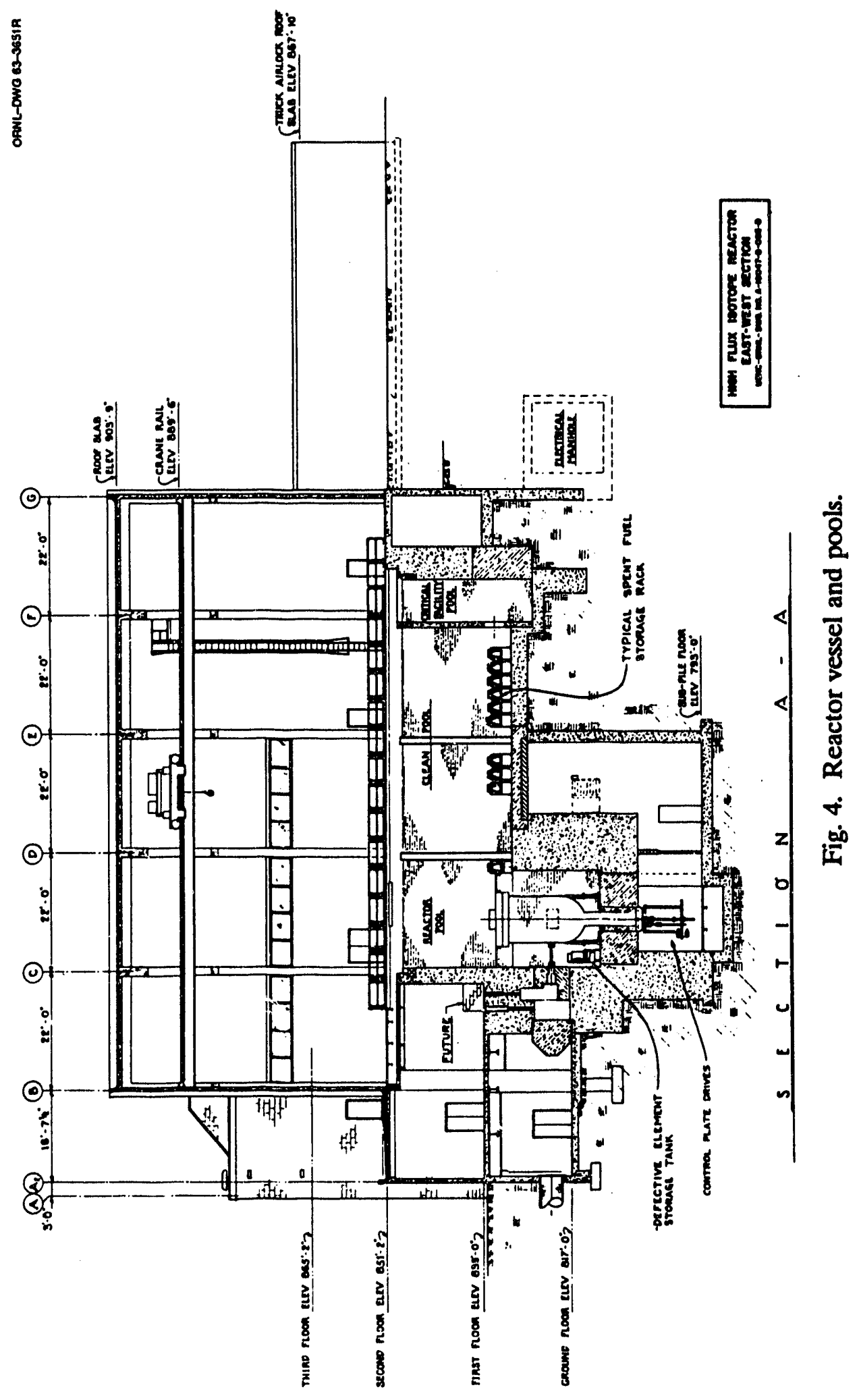




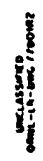

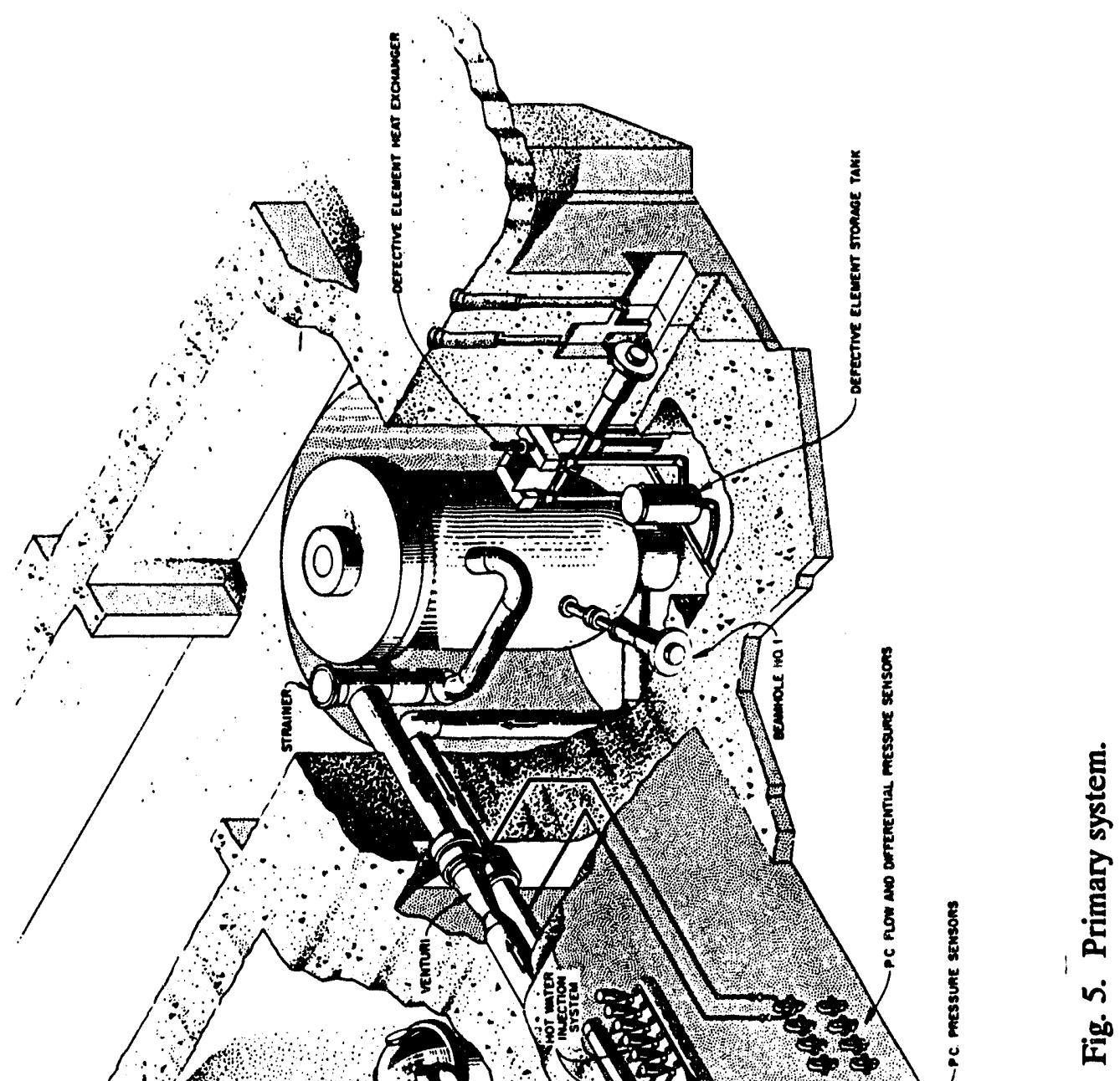




\section{INPUT MODEL}

\subsection{OVERVIEW}

The RELAP5 nodal diagram of the HFIR primary coolant system model is shown in Fig. 6, and a listing of the input is given in Appendix A. The heat exchanger and vessel/core details are not shown in Fig. 6 but will be presented later. Each rectangular box and pump symbol in the nodal diagram represents a single control volume (node) in the RELAP5 model. The lines that link the boxes indicate only the connectivity of the model. Elbows, bends, wyes, expansions, and reductions occur at junctions between the volumes, as indicated in the figure. Three heat exchanger cells have been represented: cells 110, 111, and 113 containing heat exchangers $\mathrm{D}, \mathrm{C}$, and $\mathrm{A}$. Also the piping that leads to and from heat exchanger cell 112 (containing heat exchanger $B$ ) has been included.

Except for the heat exchangers and vessel/core, the high-pressure side of the system was discretized as coarsely as possible while including all of the friction losses (i.e., elbows, wyes, expansions, and reductions) in the piping at the correct locations. A finer discretization was selected in the heat exchangers because the heat exchanger performance was found to be a strong function of the number of volumes used.

The dashed arrow in Fig. 6 between the time-dependent volumes (TDVs) 65 and 68 indicates that, although in reality the flow continues from the letdown valves to the pressurizing pumps, this is not a continuous flow path in the RELAP5 model. Rather, the level in the primary coolant (PC) head tank is monitored using the control systems capability of RELAP5, and the suction pressure (assigned to volume 68) is calculated based on that level.

RELAP5's explicit models for valves and pumps were used where convenient. Friction losses at junctions between volumes were specified through loss coefficients supplied to RELAP5 in addition to the RELAP5 calculated straight-pipe friction losses. Six break locations have been included in the model as shown in Fig. 6.

Although not indicated in Fig. 6, heat structures were attached to all volumes representing the primary coolant piping. This was done to account for the heat capacity of the pipes and, in some cases, to facilitate heat transfer to the reactor pool. Heat loss from piping to surrounding air is small and was neglected.

A schematic diagram of the HFIR vessel/core RELAP5 model is presented in Fig. 7. As shown, the model contains two target channels representing an unheated bypass region and a heated region containing the target rods (see Fig. 1). With reference to Fig. 2, the inner and outer fuel elements are each modeled in two lumped "average" regions and a single "hot" region. As described subsequently, the average regions in each element model are distinguished from each other by power density, one slightly above average and the other slightly below. The region between the fuel elements, the fuel assembly labyrinth, is modeled as an unheated flow channel. The model contains three annular flow passages providing cooling for two sets of heat structures representing the control cylinders and four radial subregions representing the beryllium reflector (see Figs. 1 and 3 ).

The lower end of the target, fuel, and labyrinth channels connects to a common cylindrical region. Similarly, the control cylinder and beryllium reflector regions connect to an annular region. Flow passages exist between these regions beneath the core, so in the model they are connected to each other. The target channels connect to a channel representing the portion of the target tower water contained within the inner shroud above the core (see Fig. 3). Similarly, the fuel channels connect to an annular region within the inner 


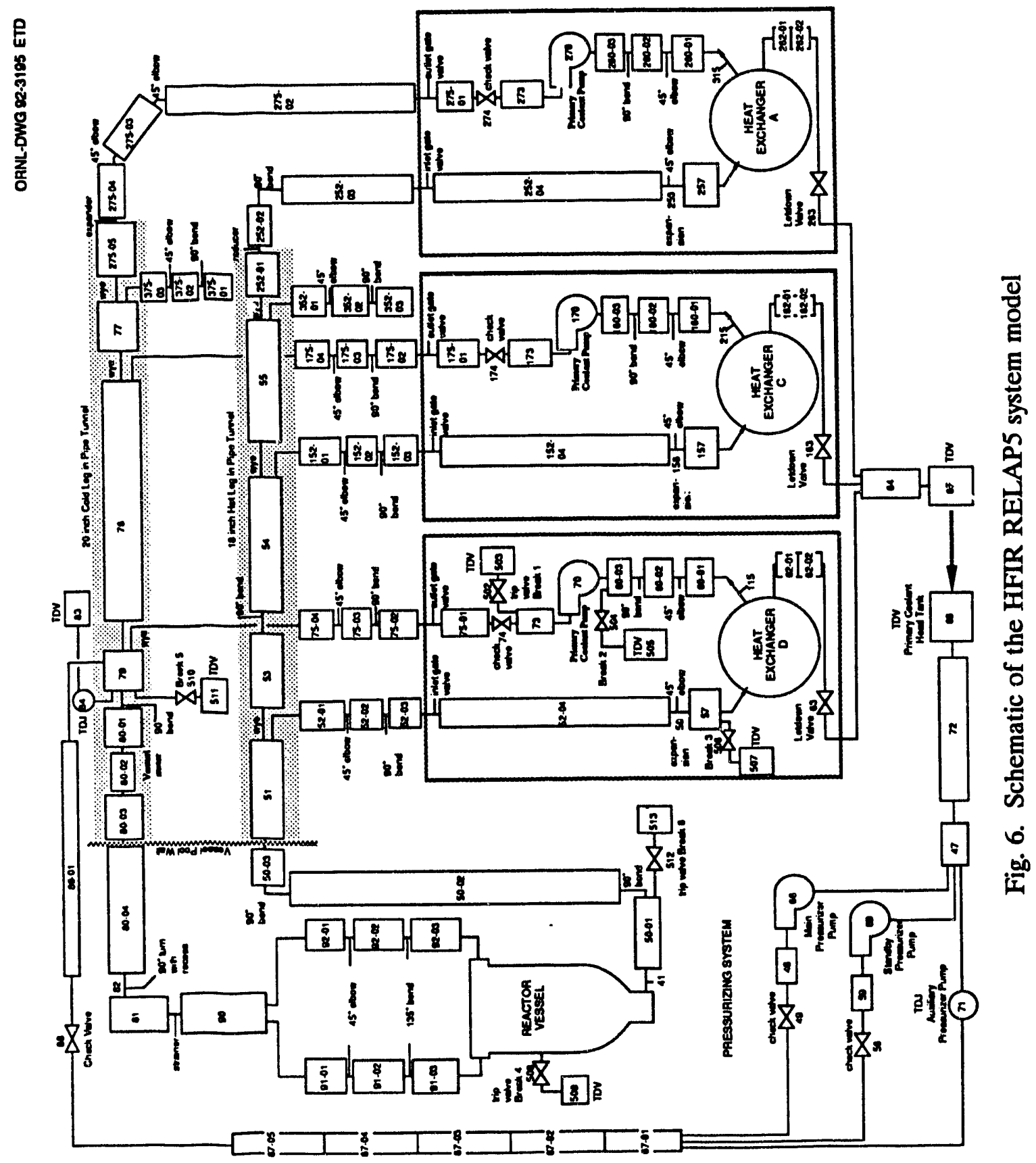




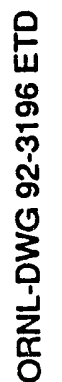

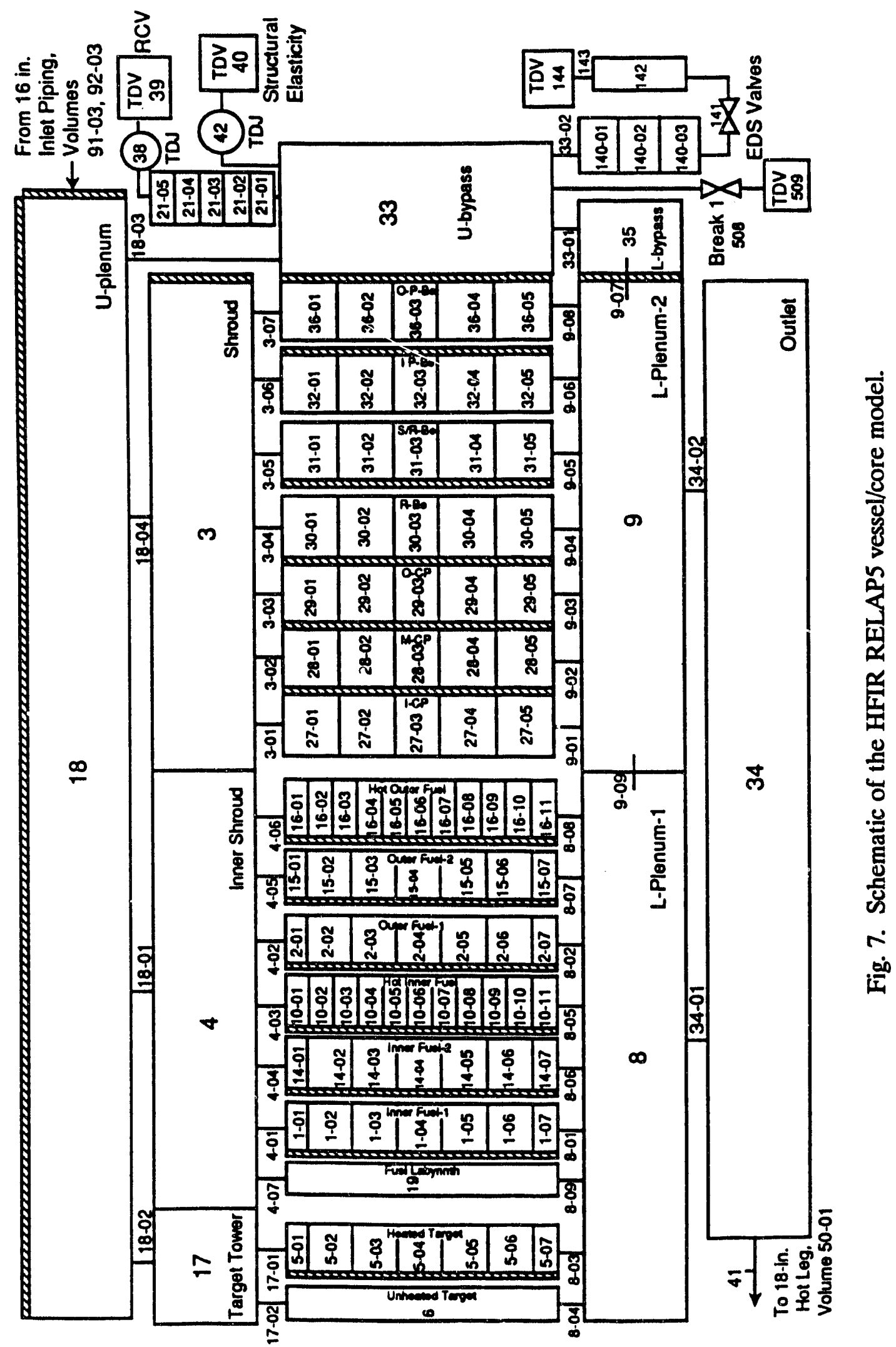


shroud. The control cylinder and beryllium reflector regions connect to an annular region formed by the inner and outer shrouds.

With reference to Fig. 3, the water outside of the core within the vessel is divided into three regions as indicated in Fig. 7. The region denoted as "U-bypass" is connected to components representing a check valve controlling flow from the reactor pool into the vessel. It also connects to components used to simulate the effect of the elasticity of the primary system pressure boundary (e.g., pipe and reactor vessel walls) on system depressurization, and to components representing the emergency depressurization system (EDS). As described in Sect. 3.4, accounting for the effect of structural elasticity is necessary because HFIR normally operates under single-phase, liquid conditions. The upper plenum region connects to heat structures representing the vessel sidewalls and lid, which in turn connect to a component representing the pool conditions. The upper plenum and outlet regions connect to the inlet and outlet piping, respectively.

Based on a review of the HFIR design information, ${ }^{15,20,23-25}$ operating data, ${ }^{26}$ and discussions with HFIR staff, normal flow rates through the various regions of the core are presented in Fig. 8. HFIR design information suggests a total flow rate of $16,156 \mathrm{gal} / \mathrm{min}$ $\left(1.02 \mathrm{~m}^{3} / \mathrm{s}\right)$ (at core inlet). During the operating history of HFIR, flow rates have been observed to vary over the range $-16,500$ to $17,500 \mathrm{gal} / \mathrm{min}\left(1.04\right.$ to $\left.1.10 \mathrm{~m}^{3} / \mathrm{s}\right)$, depending upon the system configuration. Based on typical measured pressure drops through the core (upon which fuel element flow-rate estimates can be made) and discussions with HFIR staff, a normal (steady-state) flow rate of $16,500 \mathrm{gal} / \mathrm{min}\left(1.04 \mathrm{~m}^{3} / \mathrm{s}\right)$ was selected for initializing the vessel/core portion of the model. The design data were normalized to this value, thus preserving the designed flow distribution. As indicated in Fig. 8, the bulk of the flow is through the fuel region, resulting in an average inlet flow velocity of $-52 \mathrm{ft} / \mathrm{s}(1.58 \mathrm{~m} / \mathrm{s})$.

The heat loads in the various regions of the core are provided in Table 1 for the nominal HFIR power level of $85 \mathrm{MW} .^{27}$ As indicated in Table 1, the total is $-1 \mathrm{MW}$ above the nominal 85-MW power level. This results due to extra heat added to the target and control plate regions to account for limitations and uncertainties in calculated heat loads in these regions. The core heat load and its distribution were developed to be applicable throughout the fuel cycle and, as a result, tend to be conservative. The heat load following shutdown was assumed to be the maximum of the beginning-of-cycle (BOC) and end-of-cycle (EOC) values through time. Differences were accounted for between fission and decay heat loads in terms of their contribution to the total load after shutdown through time and distribution in the core. Heat deposited above and below the core and within its radial extent was assumed to be deposited in the core itself in the same relative portions as that calculated to be actually deposited. On the same relative basis, heat deposited outside the radial extent of the core was assumed to be deposited in the extra-fuel element regions of the core.

The total core post-shutdown heat load is shown in Table 2 and Fig. 9.27 Time in both is the time after initiation of insertion of safety plates. The calculated heat loads are based on an assumed safety plate insertion time of $250 \mathrm{~ms}$ (Ref. 28). The HFIR technical specifications $^{29}$ indicate that the time-of-flight for the safety plate (measured from the initiation of the scram signal until the plate is seated) cannot exceed $450 \mathrm{~ms}$. The time before the plates begin to move has been measured to be $<24 \mathrm{~ms}$ (Ref. 30). This dead time consists of the magnet release time (cannot exceed $12 \mathrm{~ms}$ ) and the mechanical response time, which is administratively controlled. In this model, the time-of-flight was assumed to be 450 ms, consisting of 200 -ms dead time plus 250 -ms insertion time (Fig. 9 and Table 2). This is conservative because it is known that the plates begin to move $176 \mathrm{~ms}$ sooner than has been assumed. 


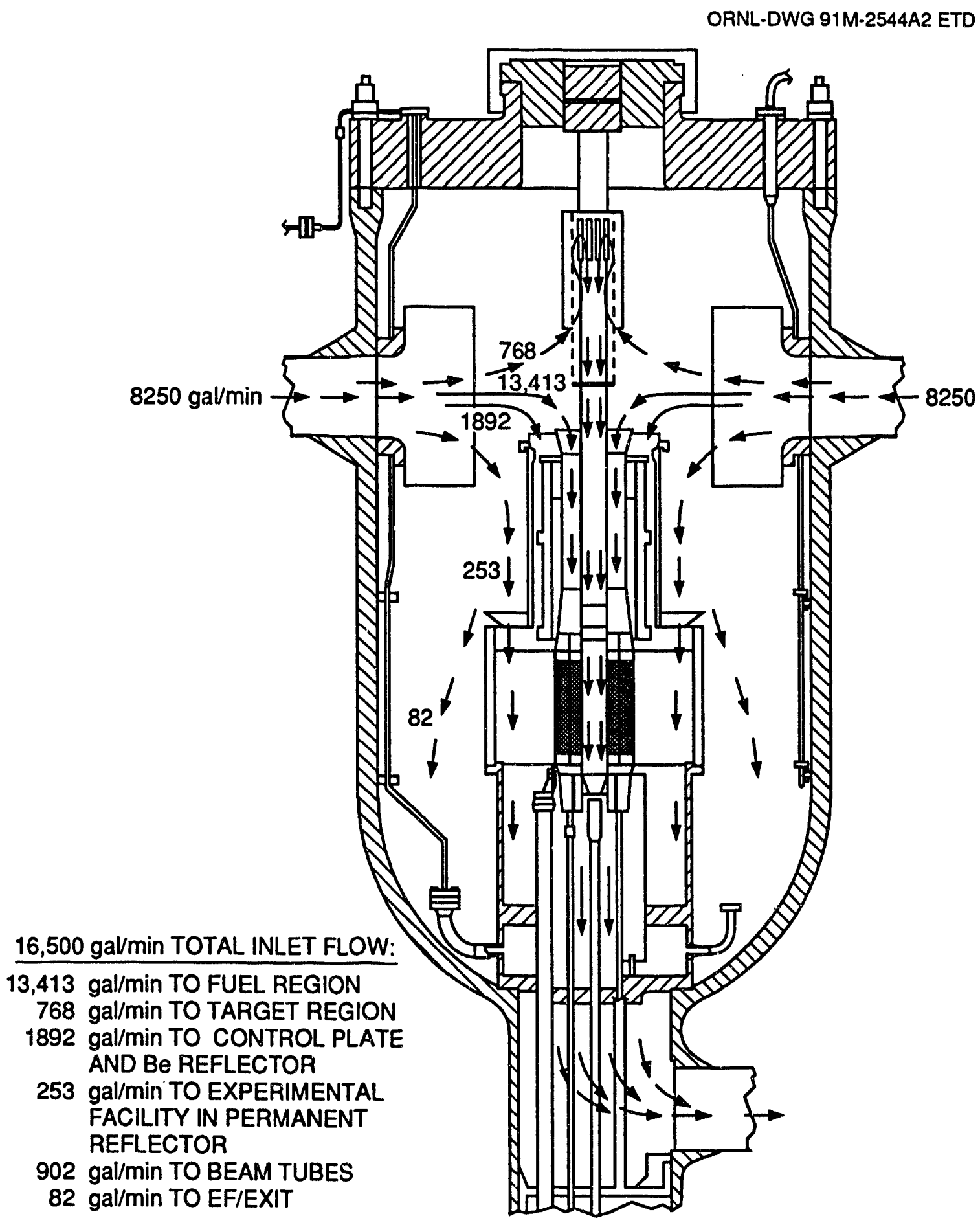

Fig. 8. Reactor vessel coolant flow distribution. 
The increase (rather than the expected decrease) in the extra-fuel element heat load that occurs from 1680 to $1920 \mathrm{~s}$ (Table 2) is due to a redistribution of the decay heat load from that obtained in the base heat loads calculation through the first $1800 \mathrm{~s}$ following shutdown. During this time a greater percentage of the load remains in the fuel element than calculated. ${ }^{27}$ There is a corresponding decrease in the extra-fuel element regions because the total deposited in the core is unchanged.

Table 1. HFIR core heat loads at nominal 85-MW power level

\begin{tabular}{lc}
\hline \multicolumn{1}{c}{ Region } & $\begin{array}{c}\text { Heat load } \\
\text { (MW) }\end{array}$ \\
\hline Fuel" & 80.7 \\
Target & 0.888 \\
Control cylinders & 1.71 \\
Removable beryllium reflector & 0.327 \\
Semipermanent beryllium reflector & 1.21 \\
Permanent beryllium reflector & 1.08 \\
Total & $\mathbf{8 5 . 9}$ \\
\hline
\end{tabular}

\footnotetext{
Includes fuel plates, side plates, and water in fuel chanrels.

'Includes permanent beryllium reflector, vertical experimental facilities, and horizontal beam tube aluminum liners.
}

\subsection{VESSEI CORE COMPONENT DESCRIPTIONS}

The components that comprise the HFIR vessel/core RELAP5 input model are described in detail in this section. For each component a description is presented that includes the relevant assumptions, geometry, thermophysical properties, heat transfer characteristics, and nominal flow rates and power.

\section{Fuel Element}

As shown in Fig. 7 and described previously, the fuel element is divided into six regions. The two average inner fuel element lumps are each composed of 85 fuel plates and flow channels (Inner Fuel-1 and -2). The remaining fuel plate and flow channel, of the total 171 inner fuel element plates and channels, represent a hot fuel region (Hot Inner Fuel). Similarly, the two average outer fuel element lumps are each composed of 184 fuel plates and flow channels (Outer Fuel-1 and -2). The remaining fuel plate and flow channel, of the total 369 outer fuel element plates and channels, represent a hot fuel region (Hot Outer Fuel). 
Table 2. HFIR heat load after scram

\begin{tabular}{|c|c|c|c|}
\hline \multirow[b]{2}{*}{$\begin{array}{l}\text { Time } \\
(\mathrm{s})\end{array}$} & \multicolumn{3}{|c|}{$\begin{array}{l}\text { Heat loads } \\
\text { (MW) }\end{array}$} \\
\hline & $\begin{array}{l}\text { Fuel } \\
\text { element }\end{array}$ & $\begin{array}{l}\text { Extra-fuel } \\
\text { element }\end{array}$ & Total \\
\hline 0.00 & 80.720 & 5.2173 & 85.9373 \\
\hline 0.01 & 80.370 & 5.1954 & 85.5654 \\
\hline 0.05 & 58.370 & 4.0134 & 62.3834 \\
\hline 0.10 & 21.190 & 2.0232 & 23.2132 \\
\hline 0.15 & 11.580 & 1.5092 & 13.0892 \\
\hline 0.20 & 9.940 & 1.4115 & 11.3515 \\
\hline 0.25 & 9.840 & 1.4078 & 11.2478 \\
\hline 0.30 & 9.740 & 1.3932 & 11.1332 \\
\hline 0.35 & 9.650 & 1.3895 & 11.0395 \\
\hline 0.40 & 9.560 & 1.3846 & 10.9446 \\
\hline 0.45 & 9.470 & 1.3700 & 10.8400 \\
\hline 0.50 & 9.400 & 1.3663 & 10.7663 \\
\hline 0.55 & 9.320 & 1.3639 & 10.6839 \\
\hline 0.60 & 9.230 & 1.3504 & 10.5804 \\
\hline 0.65 & 9.170 & 1.3468 & 10.5168 \\
\hline 0.70 & 9.100 & 1.3443 & 10.4443 \\
\hline 0.75 & 9.020 & 1.3297 & 10.3497 \\
\hline 0.80 & 8.960 & 1.3272 & 10.2872 \\
\hline 0.85 & 8.900 & 1.3248 & 10.2248 \\
\hline 0.90 & 8.830 & 1.3126 & 10.1426 \\
\hline 1.00 & 8.250 & 1.1880 & 9.4380 \\
\hline 3.00 & 6.720 & 1.0464 & 7.7664 \\
\hline 5.00 & 5.860 & 0.9634 & 6.8234 \\
\hline 9.00 & 4.890 & 0.8645 & 5.7545 \\
\hline 20.00 & 3.770 & 0.7350 & 4.5050 \\
\hline 40.00 & 2.950 & 0.6264 & 3.5764 \\
\hline 60.00 & 2.530 & 0.5678 & 3.0978 \\
\hline 80.00 & 2.280 & 0.5275 & 2.8075 \\
\hline 100.00 & 2.100 & 0.4982 & 2.5982 \\
\hline 120.00 & 1.970 & 0.4750 & 2.4450 \\
\hline 140.00 & 1.890 & 0.4567 & 2.3467 \\
\hline 160.00 & 1.810 & 0.4444 & 2.2544 \\
\hline 180.00 & 1.750 & 0.4298 & 2.1798 \\
\hline 200.00 & 1.700 & 0.4200 & 2.1200 \\
\hline 220.00 & 1.670 & 0.4127 & 2.0827 \\
\hline 240.00 & 1.620 & 0.4017 & 2.0217 \\
\hline 360.00 & 1.470 & 0.3675 & 1.8375 \\
\hline 480.00 & 1.370 & 0.3419 & 1.7119 \\
\hline 600.00 & 1.310 & 0.3260 & 1.6360 \\
\hline 720.00 & 1.250 & 0.3101 & 1.5601 \\
\hline
\end{tabular}


Table 2 (continued)

\begin{tabular}{|c|c|c|c|}
\hline \multirow[b]{2}{*}{$\begin{array}{l}\text { Time } \\
\text { (s) }\end{array}$} & \multicolumn{3}{|c|}{$\begin{array}{l}\text { Heat loads } \\
\text { (MW) }\end{array}$} \\
\hline & $\begin{array}{l}\text { Fuel } \\
\text { element }\end{array}$ & $\begin{array}{l}\text { Extra-fuel } \\
\text { element }\end{array}$ & Total \\
\hline 840.00 & 1.190 & 0.2967 & 1.4867 \\
\hline 960.00 & 1.150 & 0.2869 & 1.4369 \\
\hline $1,080.00$ & 1.120 & 0.2796 & 1.3996 \\
\hline $1,200.00$ & 1.090 & 0.2723 & 1.3623 \\
\hline $1,320.00$ & 1.060 & 0.2637 & 1.3237 \\
\hline $1,440.00$ & 1.030 & 0.2564 & 1.2864 \\
\hline $1,560.00$ & 1.000 & 0.2503 & 1.2503 \\
\hline $1,680.00$ & 0.980 & 0.2442 & 1.2242 \\
\hline $1,920.00$ & 0.905 & 0.2747 & 1.1797 \\
\hline $2,040.00$ & 0.886 & 0.2698 & 1.1558 \\
\hline $2,160.00$ & 0.870 & 0.2650 & 1.1350 \\
\hline $2,400.00$ & 0.838 & 0.2552 & 1.0932 \\
\hline $2,640.00$ & 0.810 & 0.2466 & 1.0566 \\
\hline $2,880.00$ & 0.786 & 0.2393 & 1.0253 \\
\hline $3,120.00$ & 0.763 & 0.2320 & 0.9950 \\
\hline $3,600.00$ & 0.724 & 0.2198 & 0.9438 \\
\hline $7,200.00$ & 0.553 & 0.1685 & 0.7215 \\
\hline $10,800.00$ & 0.469 & 0.1429 & 0.6119 \\
\hline $14,400.00$ & 0.416 & 0.1270 & 0.5430 \\
\hline $18,000.00$ & 0.379 & 0.1153 & 0.4943 \\
\hline $21,600.00$ & 0.352 & 0.1071 & 0.4591 \\
\hline $25,200.00$ & 0.330 & 0.1004 & 0.4304 \\
\hline $28,800.00$ & 0.312 & 0.0949 & 0.4069 \\
\hline $32,400.00$ & 0.297 & 0.0904 & 0.3874 \\
\hline $36,000.00$ & 0.283 & 0.0861 & 0.3691 \\
\hline $39,600.00$ & 0.272 & 0.0828 & 0.3548 \\
\hline $43,200.00$ & 0.262 & 0.0797 & 0.3417 \\
\hline $46,800.00$ & 0.252 & 0.0767 & 0.3287 \\
\hline $50,400.00$ & 0.244 & 0.0742 & 0.3182 \\
\hline $54,000.00$ & 0.237 & 0.0720 & 0.3090 \\
\hline $57,600.00$ & 0.230 & 0.0700 & 0.3000 \\
\hline $61,200.00$ & 0.223 & 0.0678 & 0.2908 \\
\hline $64,800.00$ & 0.218 & 0.0663 & 0.2843 \\
\hline $68,400.00$ & 0.212 & 0.0645 & 0.2765 \\
\hline $72,000.00$ & 0.207 & 0.0630 & 0.2700 \\
\hline $75,600.00$ & 0.202 & 0.0614 & 0.2634 \\
\hline
\end{tabular}


ORNL-DWG 92-3197 ETD

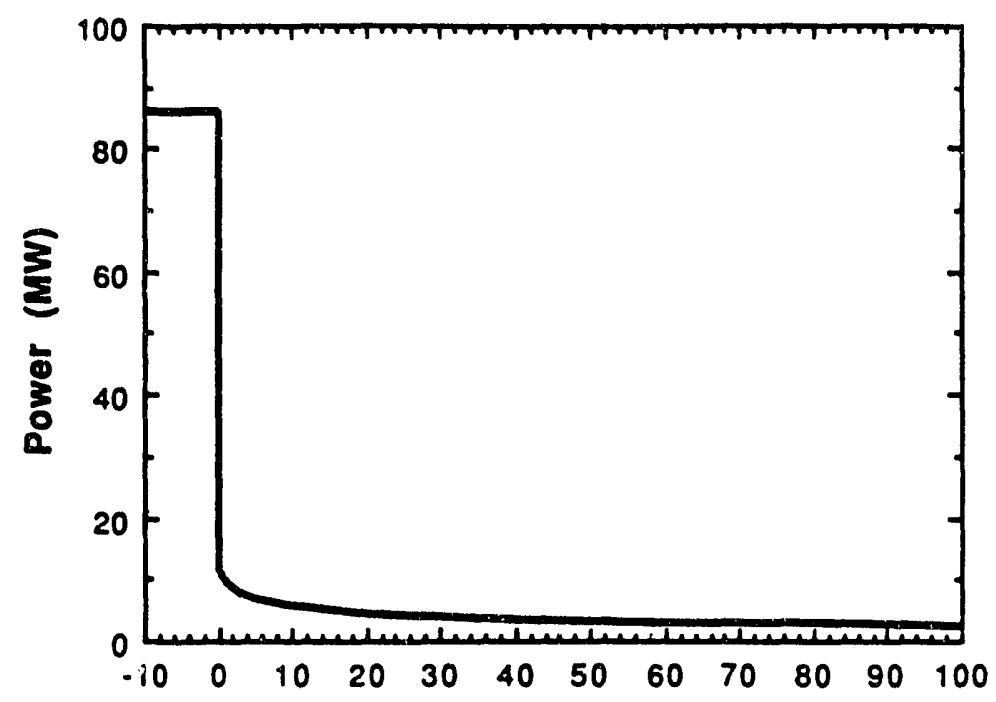

Time (s)

Fig. 9. Heat load following shutdown.

The average fuel element channels are assumed to have the nominal design gap width of 50 mils $(1.27 \mathrm{~mm}$ ) adjusted for the presence of the oxide film (boehmite). The oxide thickness is conservatively taken to be the EOC value, 0.689 mils $(0.0175 \mathrm{~mm}){ }^{31}$ The hot fuel channels have a gap width of 35 mils $(0.889 \mathrm{~mm})$ based on analysis of steady-state operation, which accounts for fuel element manufacturing tolerances; fuel plate deflections; thermal expansion; and oxide buildup. ${ }^{31}$ This value is slightly less than that calculated at the location of the "limiting" incipient boiling heat flux at EOC during steady-state operation. Because channel gap width is narrowest at EOC, the value chosen is conservative. For the hot region fuel, an EOC oxide thickness of 1.21 mils $(0.031 \mathrm{~mm})$ was selected that conservatively reflects the effects of the narrow channel and higher than average power density on oxide buildup. ${ }^{31}$ The radial boundaries of the inner, $r_{i}$ and $r_{0}$, and outer, $r_{i}$ and $r_{0}$, fuel element involutes are ${ }^{32,33}$

$$
\begin{aligned}
& r_{i}^{j}=0.2268 \mathrm{ft}(0.06913 \mathrm{~m}) \\
& r_{0}=0.4198 \mathrm{ft}(0.1280 \mathrm{~m}) \\
& r_{i}=0.4894 \mathrm{ft}(0.1492 \mathrm{~m}) \\
& r_{0}=0.6926 \mathrm{ft}(0.2111 \mathrm{~m})
\end{aligned}
$$

Because the fuel element flow area and plate cross-sectional area are equal, the nominal flow areas per plate for the inner, $A_{f, n m}^{i}$, and outer, $A_{f, n m}^{o}$, fuel element regions are

$$
\begin{aligned}
& A_{f, n m}^{i}=0.00115 \mathrm{ft}^{2}\left(1.07 \times 10^{-4} \mathrm{~m}^{2}\right), \\
& A_{f, n m}^{o}=0.00102 \mathrm{ft}^{2}\left(9.48 \times 10^{-5} \mathrm{~m}^{2}\right) .
\end{aligned}
$$


With the nominal plate thickness [50 mils $(1.27 \mathrm{~mm})$ ], the width of the flow channel and fuel plate in the spanwise direction can be calculated for the inner, $w_{s}^{i}$, and outer, $w_{s}^{o}$, fuel element regions:

$$
\begin{aligned}
& w_{s}^{i}=0.276 \mathrm{ft}(0.0841 \mathrm{~m}), \\
& w_{s}^{0}=0.245 \mathrm{ft}(0.0747 \mathrm{~m}) .
\end{aligned}
$$

The corresponding widths of the fuel bearing regions, $w_{f}^{j}$ and $w_{f}^{0}$, are

$$
\begin{aligned}
& w_{f}^{j}=0.256 \mathrm{ft}(0.0780 \mathrm{~m}), \\
& w_{f}^{0}=0.230 \mathrm{ft}(0.0701 \mathrm{~m}) .
\end{aligned}
$$

The "true" fuel element channel flow area and hydraulic diameter can be determined after accounting for the fuel oxide film thickness. Formation of the oxide results in the consumption of aluminum producing a film $25.4 \%$ thicker than the thickness of metal consumed. ${ }^{35}$ Thus, the fuel plate thickness in the average fuel element lumps, $t_{p, a v}$ is

$$
\begin{aligned}
t_{p, a v} & =50+2 \text { (oxide thickness }- \text { Al consumed) mils, } \\
& =50+2(0.689-0.689 / 1.254) \text { mils, } \\
t_{p, a v} & =50.3 \text { mils }(1.28 \mathrm{~mm})
\end{aligned}
$$

The flow area per plate, $A_{f, a v}^{i}$ and $A_{f, a v}^{o}$ and channel gap width, $t_{c, a v}\left(t_{c, a v}^{j}=t_{c, a v}\right)$, in the inner and outer average fuel element regions are reduced proportionally with the increase in plate thickness:

$$
\begin{aligned}
t_{c, a v} & =49.7 \text { mils }(1.26 \mathrm{~mm}), \\
A_{f, a v}^{i} & =0.00114 \mathrm{ft}^{2}\left(1.06 \times 10^{-4} \mathrm{~m}^{2}\right), \\
A_{f, a v}^{o} & =0.00101 \mathrm{ft}^{2}\left(9.38 \times 10^{-5} \mathrm{~m}^{2}\right) .
\end{aligned}
$$

The hydraulic diameters of the inner, $D_{h y, a v}^{i}$, and outer, $D_{h y, a v}^{o}$, average fuel element regions are

$$
\begin{aligned}
D_{h y} & =4 A_{f} \text { /wetted perimeter, } \\
D_{h y, a v}^{i} & =8.14 \times 10^{-3} \mathrm{ft}\left(2.48 \times 10^{-3} \mathrm{~m}\right), \\
D_{h y, a v}^{\circ} & =8.11 \times 10^{-3} \mathrm{ft}\left(2.47 \times 10^{-3} \mathrm{~m}\right) .
\end{aligned}
$$

Fuel element plates consist of three regions: fuel ("meat"), clad, and oxide. A cross section of the fuel meat is shown in Fig. 10. In the model, the fuel meat is homogenized over the $30-\mathrm{mil}(0.76-\mathrm{mm})$ thickness. With reference to the axial plane (curved) of symmetry through a plate, the outer boundaries of the three regions of an average plate are

$$
\begin{aligned}
& \text { oxide, } x_{o, a v} \\
& x_{o, a v}=\frac{t_{p, a v}}{2}=2.09496 \times 10^{-3} \mathrm{ft}\left(6.38538 \times 10^{-4} \mathrm{~m}\right) ;
\end{aligned}
$$


N
0
0
1
0
0
0
$\vdots$
$\vdots$
2
0
0
0

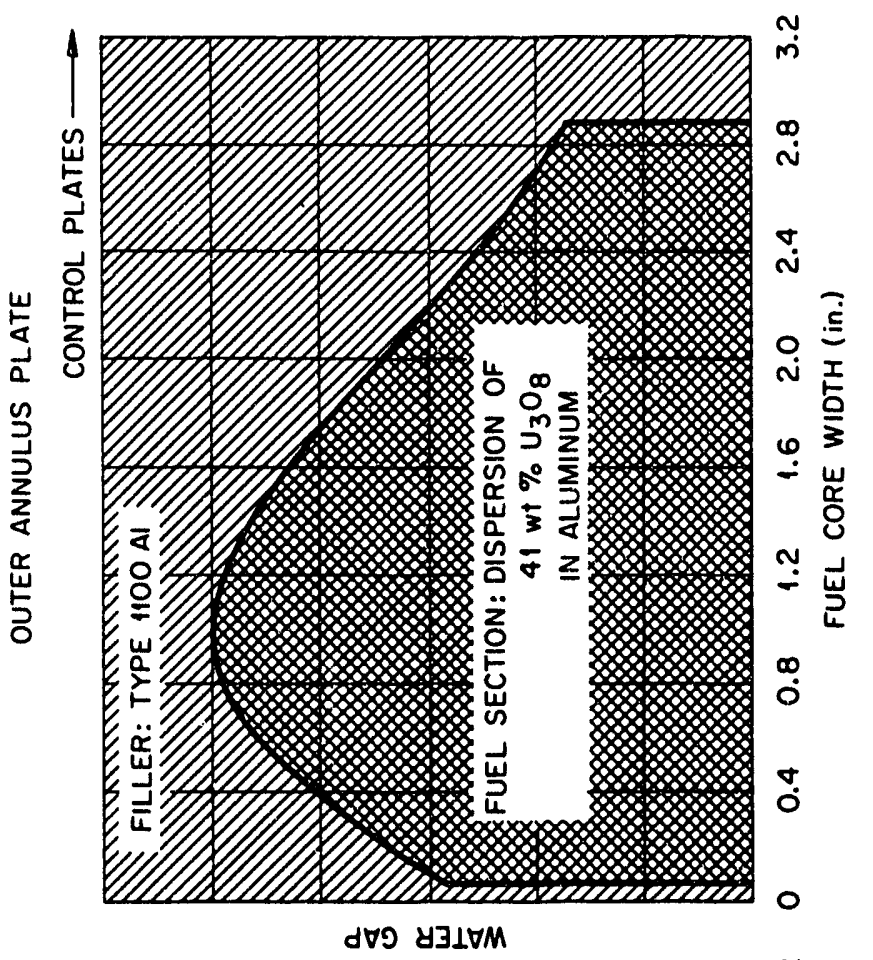

ฮี

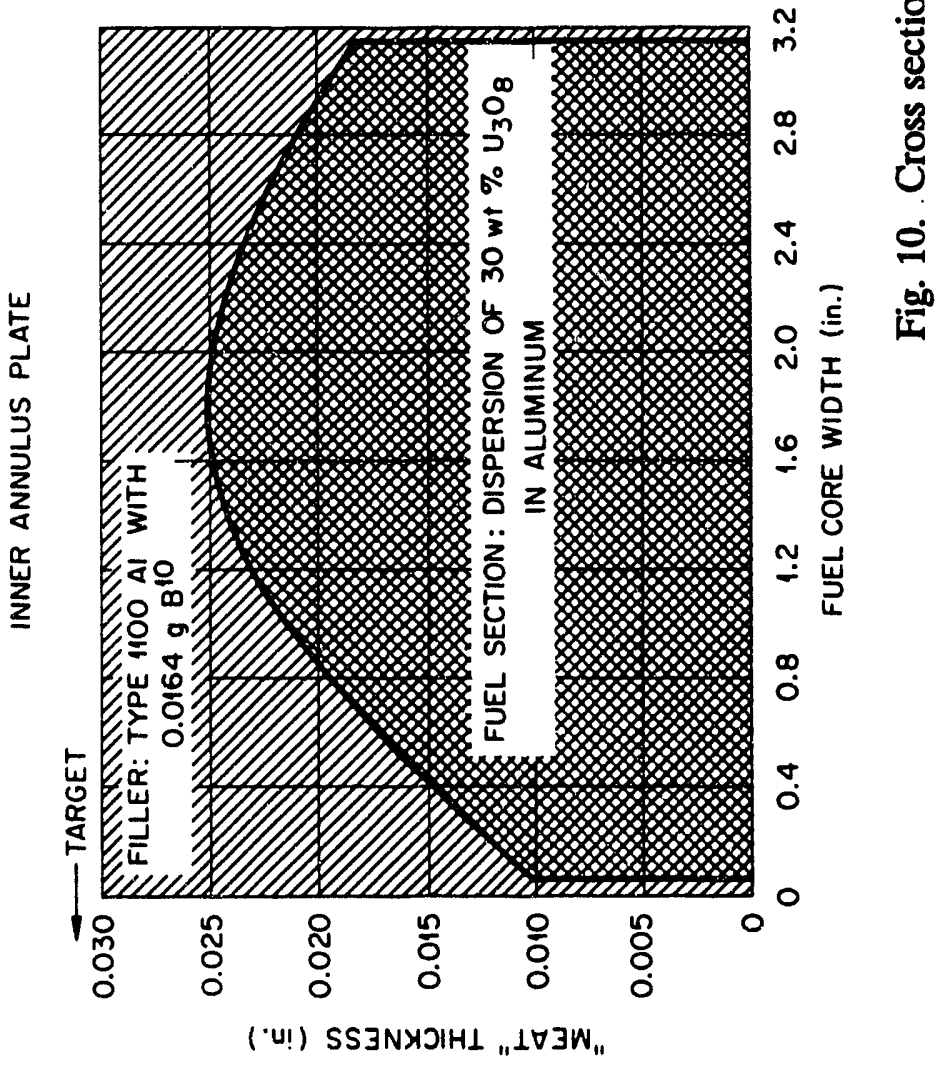




$$
\begin{aligned}
& \text { clad, } x_{c, a v} \\
& \begin{aligned}
x_{c, a v} & =x_{o, a v}-\text { oxide thickness, } \\
& =2.09496 \times 10^{-3}-0.689 /(12 \times 1000) \mathrm{ft}, \\
x_{c, a v} & =2.03754 \times 10^{-3} \mathrm{ft}\left(6.21042 \times 10^{-4} \mathrm{~m}\right) ;
\end{aligned} \\
& \text { fuel, } x_{f, a v} \\
& x_{f, a v}=15 \mathrm{mils}=1.25 \times 10^{-3} \mathrm{ft}\left(3.81 \times 10^{-4} \mathrm{~m}\right) .
\end{aligned}
$$

The hot channel fuel element flow areas, $A_{f, h t}^{i}$ and $A_{f, h t}^{o}$, and hydraulic diameters, $D_{h y, h t}^{i}$ and $D_{h y, h s,}^{o}$ are

$$
\begin{aligned}
A_{f} & =t_{c} w_{s}, \\
A_{f, h t}^{i} & =(0.035 / 12)(0.276) \mathrm{ft}^{2}, \\
A_{f, h t}^{i} & =8.05 \times 10^{-4} \mathrm{ft}^{2}\left(7.48 \times 10^{-5} \mathrm{~m}^{2}\right), \\
A_{f, h t}^{o} & =(0.035 / 12)(0.245) \mathrm{ft}^{2}, \\
A_{f, h s}^{o} & =7.14 \times 10^{-4} \mathrm{ft}^{2}\left(6.63 \times 10^{-5} \mathrm{~m}^{2}\right), \\
D_{h y, h s}^{i} & =5.77 \times 10^{-3} \mathrm{ft}\left(1.76 \times 10^{-3} \mathrm{~m}\right), \\
D_{h y, h s}^{o} & =5.76 \times 10^{-3} \mathrm{ft}\left(1.76 \times 10^{-3} \mathrm{~m}\right) .
\end{aligned}
$$

The thickness of the hot fuel plates $t_{p, h s}$ is based on the nominal value

$$
\begin{aligned}
& t_{p, h t}=50+2(1.21-1.21 / 1.254) \mathrm{mils}, \\
& t_{p, h t}=50.5 \text { mils }(1.28 \mathrm{~mm}) .
\end{aligned}
$$

Because fuel plate manufacturing specifications allow plates to be $50 \pm 1$ mils $(1.27 \pm 0.0254$ $\mathrm{mm}$ ) thick, ${ }^{36}$ the modeled fuel plate heat-conduction resistance and heat capacity are slightly lower than actual. The heat-conduction resistance of the oxide film (a minimum thickness of $0.689 \mathrm{mil}$ is used in the model) is at least 2 times that of the rest of the fuel plate. Thus, the error incurred in the total conduction resistance is $<1 \%$. The use of a slightly low heat capacity is conservative (i.e., results in a higher fuel plate heat-up rate). The hot channel gap width used in the model does account for channel narrowing caused by a plate with the maximum thickness permitted in the specifications. The outer boundaries of the three regions comprising the hot fuel plates are

$$
\begin{aligned}
& \text { oxide, } x_{o, h t} \\
& x_{o, h t}=\frac{x_{p h t}}{2}=2.10376 \times 10^{-3} \mathrm{ft}\left(6.41226 \times 10^{-4} \mathrm{~m}\right) ;
\end{aligned}
$$




$$
\begin{aligned}
& \text { clad, } x_{c, h t} \\
& \begin{aligned}
x_{c, h t} & =x_{o, h t}-\text { oxide thickness, } \\
& =2.10376 \times 10^{-3}-1.21 /(12 \times 1000) \mathrm{ft}, \\
x_{c, h t} & =2.00293 \times 10^{-3} \mathrm{ft}\left(6.10493 \times 10^{-4} \mathrm{~m}\right) ;
\end{aligned} \\
& \text { fuel, } x_{f, h t} \\
& x_{f, h t}=15 \text { mils }=1.25 \times 10^{-3} \mathrm{ft}\left(3.81 \times 10^{-4} \mathrm{~m}\right) .
\end{aligned}
$$

The nominal length of the "active" (fueled) portion of the fuel plates is $20 \mathrm{in} .(50.8 \mathrm{~cm})$. There are 2-in. $(5.08-\mathrm{cm})$ extensions above and below the fueled portion that are "inactive." That is, nominally no fuel is present in these extensions, but manufacturing specifications allow fuel to extend slightly into them. As explained subsequently, this can result in very high, local heat flux peaking and is therefore modeled. The total active fuel heat transfer area is $428.8 \mathrm{ft}^{2}\left(39.84 \mathrm{~m}^{2}\right){ }^{25}$ This area only encompasses the active length of the element and, in the spanwise dimension, the fuel bearing width. The active heat transfer areas of the inner, $A_{s}^{i}$ and outer $A_{s}^{o}$ fuel plates are

$$
\begin{aligned}
& A_{s}^{i}=0.853 \mathrm{ft}^{2}\left(0.0792 \mathrm{~m}^{2}\right) \\
& A_{s}^{o}=0.767 \mathrm{ft}^{2}\left(0.0712 \mathrm{~m}^{2}\right)
\end{aligned}
$$

Conservatively, these areas are used in the model. In addition, the side plates are not modeled; thus heat transfer to them is neglected.

The composition of the meat region in the active portion of the fuel plates is provided in Table 3 on a per plate basis. The mass of the aluminum filler in the inner fuel element fuel plate was assumed to be the difference between the total mass and the mass of the other components. The former was determined by dividing the $\mathrm{U}_{3} \mathrm{O}_{8}$ mass by its mass fraction (i.e., $19.28 \mathrm{~g} / 0.226=85.3 \mathrm{~g}){ }^{34}$ Referring to Fig. 10 , the meat exists in the center 30 -mil $(0.76-\mathrm{mm})$

Table 3. Fuel plate meat composition ${ }^{34}$

\begin{tabular}{lcc}
\hline & \multicolumn{2}{c}{$\begin{array}{c}\text { Mass } \\
\text { Material }\end{array}$} \\
\cline { 2 - 3 } & $\begin{array}{c}\text { Inner } \\
\text { element }\end{array}$ & $\begin{array}{c}\text { Outer } \\
\text { element }\end{array}$ \\
\hline $\mathrm{U}_{3} \mathrm{O}_{8}$ & 19.28 & 23.42 \\
$\mathrm{Al}^{a}$ & 44.59 & 35.00 \\
$\mathrm{~B}_{4} \mathrm{C}$ (filler) & 0.1188 & \\
$\mathrm{Al}^{a}$ (filler) & $\underline{21.3}$ & $\underline{22.64}$ \\
\multicolumn{1}{c}{ Total } & 85.3 & 81.06 \\
\hline
\end{tabular}

${ }^{a}$ Type 1100 aluminum. 
width of the plate. The density of the meat can be calculated based on its volume. Consistent with the fuel plate heat transfer area and volume assumed in the model, the meat volume is calculated using the width of the fuel bearing region. The volumes of the meat in each plate in the inner $V_{m}^{i}$ and outer $V_{m}^{o}$ fuel element regions are

$$
\begin{aligned}
& V_{m}^{i}=1.07 \times 10^{-3} \mathrm{ft}^{3}\left(3.03 \times 10^{-5} \mathrm{~m}^{3}\right) \\
& V_{m}^{o}=9.58 \times 10^{-4} \mathrm{ft}^{3}\left(2.71 \times 10^{-5} \mathrm{~m}^{3}\right)
\end{aligned}
$$

Thus, the densities of the meat in the inner $\rho_{m}^{i}$ and outer $\rho_{m}^{o}$ fuel element plates are

$$
\begin{aligned}
& \rho_{m}^{i}=176.1 \mathrm{lb} / \mathrm{ft}^{3}\left(2821 \mathrm{~kg} / \mathrm{m}^{3}\right), \\
& \rho_{m}^{o}=186.3 \mathrm{lb} \mathrm{m}_{\mathrm{m}} / \mathrm{ft}^{3}\left(2984 \mathrm{~kg} / \mathrm{m}^{3}\right) .
\end{aligned}
$$

The temperature-dependent specific heat of the fuel meat region was calculated as a mass weighted average of those of aluminum and $\mathrm{U}_{3} \mathrm{O}_{8}$. The effect of $\mathrm{B}_{4} \mathrm{C}$ on specific heat in the inner fuel element meat is ignored because its mass fraction is small. Temperaturedependent thermophysical properties of the aluminum in the fuel meat, 1100 aluminum, could not be found. Because 1100 aluminum is $+99 \%$ aluminum, ${ }^{37}$ values for pure aluminum were used. Table 4 presents temperature-dependent specific heats for aluminum and $\mathrm{U}_{3} \mathrm{O}_{8}$, the average fuel meat values for the inner and outer elements, and the volumetric heat

\begin{tabular}{|c|c|c|c|c|c|c|}
\hline \multirow[b]{2}{*}{$\begin{array}{c}\text { Temperature } \\
\left({ }^{\circ} \mathrm{F}\right)\end{array}$} & \multicolumn{4}{|c|}{$\begin{array}{l}\text { Specific heat } \\
\left(\mathrm{Btu} / \mathrm{b}_{\mathrm{m}}-^{\circ} \mathrm{F}\right)\end{array}$} & \multicolumn{2}{|c|}{$\begin{array}{c}\text { Voimetric heat } \\
\text { capacity } \\
\left(\mathrm{Btu} / \mathrm{ft}^{3}-^{\circ} \mathrm{F}\right)\end{array}$} \\
\hline & $\mathrm{Al}$ & $\mathrm{U}_{3} \mathrm{O}_{8}$ & $\begin{array}{l}\text { Inner } \\
\text { element }\end{array}$ & $\begin{array}{c}\text { Outer } \\
\text { element }\end{array}$ & $\begin{array}{c}\text { Inner } \\
\text { element }\end{array}$ & $\begin{array}{c}\text { Outer } \\
\text { element }\end{array}$ \\
\hline 80 & 0.21 .5 & 0.068 & 0.182 & 0.173 & 32.1 & 32.2 \\
\hline 440 & 0.238 & 0.079 & 0.202 & 0.192 & 35.6 & 35.8 \\
\hline 980 & 0.274 & 0.081 & 0.230 & 0.218 & 40.5 & 40.6 \\
\hline 1205 & 0.305 & 0.079 & 0.254 & 0.240 & 44.7 & 44.7 \\
\hline
\end{tabular}
capacity (product of specific heat and density) for the elements, which is the quantity needed for input to RELAP5.

Table 4. Fuel meat specific heat and volumetric heat capacity ${ }^{38,39}$

The thermal conductivity of the "fuel section" in the fuel meat of both the inner and outer fuel element plates has been measured (see Fig. 10). ${ }^{40}$ Data were collected using samples of hi-fired $\mathrm{U}_{3} \mathrm{O}_{8}$ - $\mathrm{Al}$ cermet, which contained 12.45 and $18.05 \% \quad \mathrm{U}_{3} \mathrm{O}_{8}$ by volume (30 and $40 \%$ by weight) for the inner and outer fuel element regions, respectively. Conservatively, these values are used for the entire fuel meat regions in the model. Thus, the thermal conductivity of the fuel meat in the inner and outer fuel element plates is provided in Table 5. Data at lower temperatures were used to develop linear models (of thermal conductivity as a function of temperature) using regression analyses that were in turn used 
Table 5. Fuel meat thermal conductivity

\begin{tabular}{ccc}
\hline \multirow{2}{*}{$\begin{array}{c}\text { Temperature } \\
\left({ }^{\circ} \mathrm{F}\right)\end{array}$} & \multicolumn{2}{c}{$\begin{array}{c}\text { Thermal conductivity } \\
\left.\text { (Btu/s-ft- }{ }^{\circ} \mathrm{F}\right)\end{array}$} \\
\cline { 2 - 3 } & Inner element & Outer element \\
\hline 80.3 & 0.02844 & 0.02553 \\
260.3 & 0.02819 & 0.02539 \\
900 & $0.02792^{a}$ & $0.02540^{\circ}$ \\
1204 & $0.02773^{a}$ & $0.02535^{a}$ \\
\hline
\end{tabular}

${ }^{a}$ Extrapolated.

to extrapolate values at higher temperatures. The fuel meat thermal conductivity does not appear to be very temperature sensitive.

Based on a description of the HFIR fuel plate fabrication procedures, ${ }^{41}$ the center 30 mils $(0.76 \mathrm{~mm}$ ) of the inactive portion of the fuel plates (described below) consists of 1100 and 6061-0 aluminum. The composition and thermophysical properties are assumed to be the same as those of the clad material.

The fuel plate cladding consists of 1 -mil-thick $(0.0254-\mathrm{mm}) 1100$ aluminum adjacent to the fuel meat and 9-mil-thick $(0.229-\mathrm{mm}) 6061-0$ aluminum. ${ }^{34,42}$ As for 1100 aluminum, temperature-dependent specific heat data could not be located for 6061-0 aluminum, so values for 6061-T6 were used. Due to the similarity of the thermal properties of 1100 and 6061-0 aluminum and the thinness of the 1100 aluminum portion, a single set of compositionaveraged properties was calculated for the clad. The density of 6061 aluminum at room temperature (RT) is $169 \mathrm{lb} / \mathrm{ft}^{3}\left(2710 \mathrm{~kg} / \mathrm{m}^{3}\right)$ (Ref. 43$)$, the same as that for 1100 aluminum. ${ }^{37}$ Clad specific heats and volumetric heat capacity are given in Table 6, where averaged values are mass (thickness) weighted.

Similarly, the clad thermal conductivity was composition averaged (values of pure aluminum used for 1100 aluminum). Thermal conductivities are presented in Table 7. The value for $6061-0$ aluminum at $1204^{\circ} \mathrm{F}\left(651^{\circ} \mathrm{C}\right)$ was extrapolated based on a second-degree polynomial curve fit to data.

The oxide that forms on the fuel plates has been determined to be boehmite, which is the monohydrate of aluminum oxide $\left(\alpha \mathrm{Al}_{2} \mathrm{O}_{3} \cdot \mathrm{H}_{2} \mathrm{O}\right){ }^{35,44}$ The specific heat of boehmite could not be found; therefore values of aluminum oxide $\left(\mathrm{Al}_{2} \mathrm{O}_{3}\right)$ were used. ${ }^{45}$ The density

Table 6. Clad specific heats and volumetric heat capacity ${ }^{38,46}$

\begin{tabular}{|c|c|c|c|c|}
\hline \multirow{2}{*}{$\begin{array}{c}\text { Temperature } \\
\left({ }^{\circ} \mathrm{F}\right)\end{array}$} & \multicolumn{3}{|c|}{$\begin{array}{l}\text { Specific heat } \\
\left(\text { Btu/bb } \mathrm{b}^{\circ}{ }^{\circ} \mathrm{F}\right)\end{array}$} & \multirow{2}{*}{$\begin{array}{l}\text { Volumetric hea } \\
\text { capacity } \\
\left(\mathrm{Btu} / \mathrm{ft}^{3}-^{\circ} \mathrm{F}\right)\end{array}$} \\
\hline & Al & 6061-T6 Al & $<$ Clad $>$ & \\
\hline 80 & 0.215 & 0.215 & 0.215 & 36.3 \\
\hline 440 & 0.238 & 0.236 & 0.236 & 39.9 \\
\hline 980 & 0.274 & 0.269 & 0.270 & 45.6 \\
\hline 1160 & 0.297 & 0.280 & 0.282 & 47.7 \\
\hline
\end{tabular}


Table 7. Clad thermal conductivity ${ }^{47,48}$

\begin{tabular}{cccc}
\hline \multirow{2}{*}{$\begin{array}{c}\text { Temperature } \\
\left({ }^{\circ} \mathrm{F}\right)\end{array}$} & \multicolumn{3}{c}{$\begin{array}{c}\text { Thermal conductivity } \\
\left(\mathrm{Btu} / \mathrm{s}-\mathrm{ft}-{ }^{\circ} \mathrm{F}\right)\end{array}$} \\
\cline { 2 - 4 } & $\mathrm{Al}$ & $6061-0 \mathrm{Al}$ & $<$ Clad $>$ \\
\hline 82.4 & 0.0381 & 0.0281 & 0.0291 \\
442.4 & 0.0381 & 0.0314 & 0.0321 \\
802.4 & 0.0363 & 0.0311 & 0.0316 \\
1204 & 0.0339 & $0.0269^{\circ}$ & $0.0276^{a}$
\end{tabular}

${ }^{a}$ Extrapolated.

of boehmite at RT has been reported to be $189 \mathrm{lb} / \mathrm{mt}^{3}\left(3.02 \mathrm{~g} / \mathrm{cm}^{3}\right) .^{35}$ Specific heat and volumetric heat capacity of boehmite are presented in Table 8 , based on property assumptions above. The thermal conductivity of boehmite has been reported to be $1.3 \mathrm{Btu} / \mathrm{h}-\mathrm{ft}-{ }^{\circ} \mathrm{F}$ $\left(3.61 \times 10^{-4} \mathrm{Btu} / \mathrm{s}-\mathrm{ft}-{ }^{\circ} \mathrm{F}\right.$ or $\left.2.25 \mathrm{~W} / \mathrm{m}-\mathrm{K}\right) .^{35,44}$

Table 8. Oxide (boehmite) specific heat and volumetric heat capacity

\begin{tabular}{ccc}
\hline $\begin{array}{c}\text { Temperature } \\
\left({ }^{\circ} \mathrm{F}\right)\end{array}$ & $\begin{array}{c}\text { Specific } \\
\text { heat }^{\mathrm{a}} \\
\left(\mathrm{Btu}^{\mathrm{B}} \mathrm{b}_{\mathrm{m}} \mathrm{-}^{\circ} \mathrm{F}\right)\end{array}$ & $\begin{array}{c}\text { Volumetric } \\
\text { heat } \\
\text { capacity } \\
\left(\mathrm{Btu}^{\mathrm{ft}} \mathrm{f}^{\circ}{ }^{\circ} \mathrm{F}\right)\end{array}$ \\
\hline 80 & 0.19 & 35.9 \\
440 & 0.25 & 47.3 \\
980 & 0.28 & 52.9 \\
1205 & 0.29 & 54.8 \\
\hline
\end{tabular}

${ }^{a}$ Values of $\mathrm{Al}_{2} \mathrm{O}_{3}$ used for boehmite.

During HFIR normal operation the flow rate through the fuel element is estimated to be $13,277 \mathrm{gal} / \mathrm{min}\left(0.838 \mathrm{~m}^{3} / \mathrm{s}\right)$ or $1828 \mathrm{lb}_{\mathrm{m}} / \mathrm{s}(829.2 \mathrm{~kg} / \mathrm{s})$. The roughness of aluminum oxidized under conditions representative of those in HFIR has been meas' red and found to range from 20 to $60 \mu$ in. $^{49}$ To provide a pressure drop through the fuel element that is representative ( $-100 \mathrm{psi}$ or $0.689 \mathrm{MPa})$, a fuel roughness value of $20 \mu \mathrm{in}$. was used in the model. Because the fuel plates are "rounded" at the top, the smooth area change option in RELAP5 was used at the entrance to the fuel element (junction 4-01 through 4-06). The fuel plates are not "rounded" at the bottom, so the abrupt area change option was used at the exit (junctions 8-01, 8-02, and 8-05 through 8-08).

As shown previously in Table 1, the power absorbed in the fuel region is $80.7 \mathrm{MW}$ during normal steady-state operation. In the RELAP5 model, all of this power is conservatively assumed to be absorbed in the fuel bearing region of the fuel plates. Because the power 
densiiy varies spatially within the fuel (among other reasons), the fuel element is modeled with average and hot fuel regions that are divided axially into subregions.

The average fuel regions are broken axially into seven subregions as shown in Fig. 7. The top and bottom subregions are 2 in. $(5.08 \mathrm{~cm})$ long and contain the inactive portions (extensions) of the fuel plates. The remaining five subregions, each 4 in. $(10.16 \mathrm{~cm})$ long, contain the active portion of the fuel plates. In each of the pairs of average fuel regions in the inner and outer fuel element model, one region has a power density $1 \%$ above average and the other $1 \%$ below. This variation is representative of total plate loading tolerances. ${ }^{50}$ In addition, the multiple average regions give the model more "flexibility" to accommodate spatial variations in flow through the fuel element. The average axial power distributions in the inner and outer fuel elements are presented graphically in Fig. 11(a) and in tabular form in Table 9. ${ }^{27}$ These are based on EOC decay heat load distributions that were chosen because they best represent averages spatially and temporally.
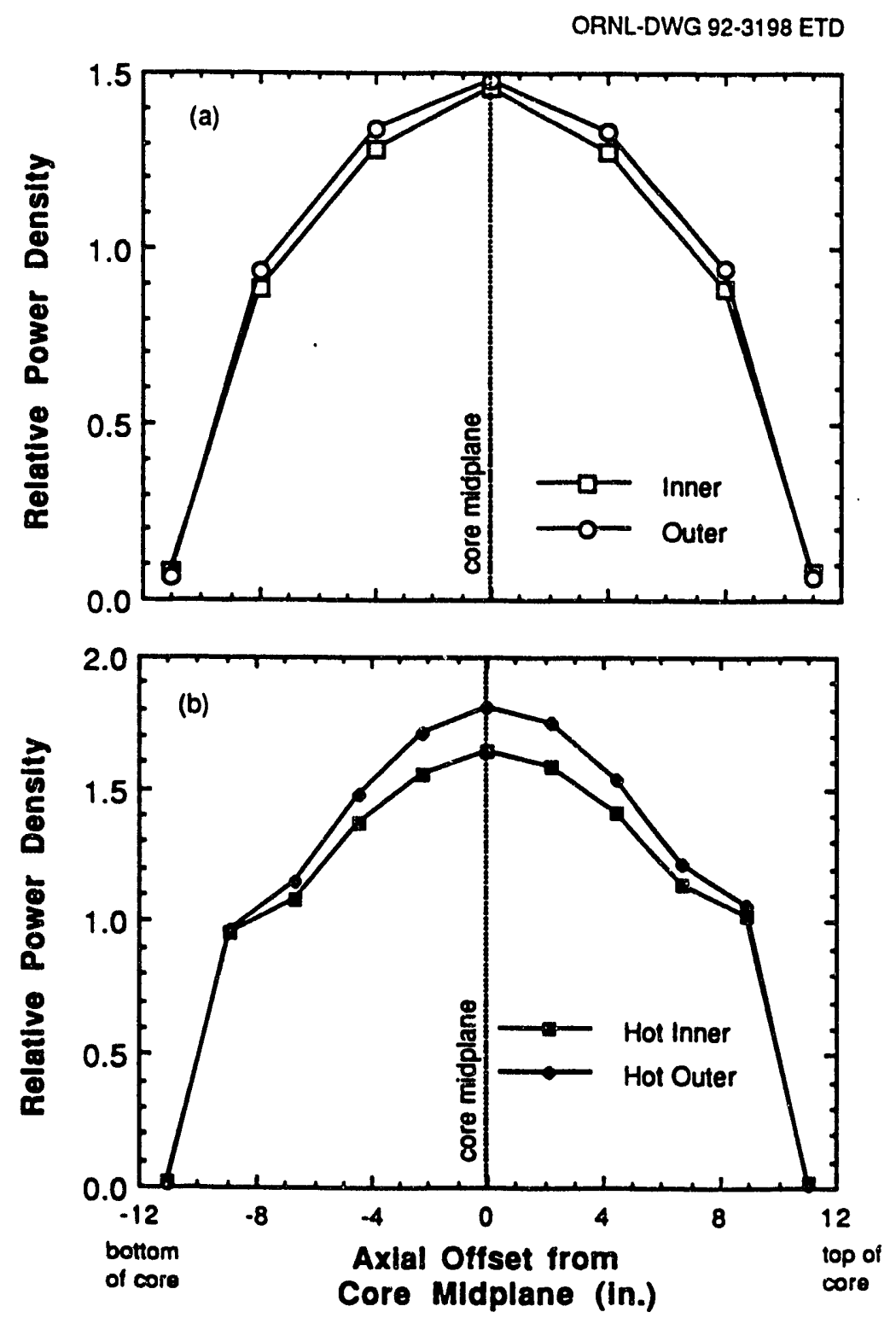

Fig. 11. HFIR fuel axial power distribution. 
Table 9. Normalized HFIR fuel axial power peaking factors

\begin{tabular}{|c|c|c|c|c|}
\hline \multirow{3}{*}{ Axial location } & \multicolumn{4}{|c|}{ Peaking factors } \\
\hline & \multicolumn{2}{|c|}{ Inner element } & \multicolumn{2}{|c|}{ Outer element } \\
\hline & $\begin{array}{l}\text { Average } \\
\text { fuel }\end{array}$ & $\begin{array}{l}\text { Hot } \\
\text { fuel }\end{array}$ & $\begin{array}{l}\text { Average } \\
\text { fuel }\end{array}$ & $\begin{array}{l}\text { Hot } \\
\text { fuel }\end{array}$ \\
\hline \multicolumn{5}{|l|}{ Top-to-bottom } \\
\hline 1 & 0.0809 & 0.0163 & 0.0643 & 0.0144 \\
\hline 2 & 0.8871 & 1.02 & 0.939 & 1.06 \\
\hline 3 & 1.275 & 1.14 & 1.33 & 1.22 \\
\hline 4 & 1.453 & 1.41 & 1.48 & 1.54 \\
\hline 5 & 1.285 & 1.58 & 1.34 & 1.75 \\
\hline 6 & 0.8871 & 1.64 & 0.935 & 1.81 \\
\hline 7 & 0.0809 & 1.56 & 0.0624 & 1.71 \\
\hline 8 & & 1.37 & & 1.48 \\
\hline 9 & & 1.08 & & 1.15 \\
\hline 10 & & 0.953 & & 0.970 \\
\hline 11 & & 0.0149 & & 0.0133 \\
\hline Element entrance (local) & & 1.515 & & 1.580 \\
\hline Element exit (local) & & 1.342 & & 1.342 \\
\hline
\end{tabular}

The hot fuel regions, each representing a single fuel plate and flow channel (one pair from the inner fuel element and one pair from the outer), simulate fuel plates with the highest power density and the narrowest channel gap. As shown in Fig. 7, these two regions have a finer axial discretization than the average regions. This allows a better representation of the axial power distribution and flow field. As in the average regions, the hot region top and bottom subregions are 2 in. $(5.08 \mathrm{~cm})$ long and contain the nominally inactive portions of the fuel plate. The remaining nine subregions, each $2.22 \mathrm{in}$. (5.64 cm) long, contain the active portion of the fuel plate. The axial power distributions in the two hot fuel regions are taken to be those at the radial position during the fuel cycle where the respective inner and outer fuel element plates are closest to their thermal limit during normal, steady-state operation. ${ }^{51}$ This occurs at BOC at radial positions referenced to the core centerline of 3.94 in. $(10.0 \mathrm{~cm})$ and $5.96 \mathrm{in} .(15.15 \mathrm{~cm})$ for the inner and outer fuel element plates, respectively. ${ }^{51,52}$ The axial power distributions in the hot fuel regions are presented in Fig. 11(b) and Table 9.27 These are fission heat load distributions that are, as expected, more peaked than EOC decay heat load distributions at the same locations. "Localized" axial distribution power factors at the very entrance and exit of the hot regions at the same radial positions as above are also presented in Table 9.52 As explained subsequently, these distribution factors are used in the modeling of fuel plate heat flux peaking due to fuel extending beyond the nominal axial boundary of the active portion of the fuel plates. The power density in the hot channels is increased further above average due to uncertainty in the calculated power distribution (10\%) plus an allowance for power tilt associated with experiments $(9 \%) ;{ }^{53}$ the possible existence of a "hot streak" within the channel; ${ }^{54}$ and, as 
just mentioned, the possibility that fuel could extend beyond the nominal axial boundary of the fuel..$^{55}$

Conservatively, these effects are assumed to occur simultaneously within the hot fuel regions along the entire fuel plate. Table 10 lists the values of the hot fuel regions peaking factors. The hot fuel regions also include local hot spots that represent the effect of fuel plate nonbonds and fuel segregation. ${ }^{56}$ The heat flux peaking effect of a fuel plate nonbond in the presence of a "worst-case" (i.e., at fuel manufacturing specification limits) fuel segregation defect depends upon the thickness of the fuel meat. A correlation was previously developed to describe nonbond (with fuel segregation) flux peaking in terms of the location of the defect along the span of the fuel plate for both inner and outer fuel element plates. The nonbond peaking factors, $U_{20}^{i}$ and $U_{20}^{o}$, for the inner and outer fuel plates are ${ }^{56}$

$$
U_{20}^{i}=1.33687-0.35423 s+0.14503 s^{2}-0.01669 s^{3},
$$

and

$$
U_{20}^{\rho}=1.180171-0.278079 s+0.151756 s^{2}-0.014261 s^{3},
$$

where $s$ is the distance (inches) along the span of the fuel plate. Evaluating these equations at the limiting radial (span) positions ${ }^{57}$ [inner fuel element plate radial and span positions

\begin{tabular}{|c|c|c|c|c|}
\hline \multicolumn{5}{|l|}{ Peaking factors } \\
\hline \multicolumn{5}{|c|}{ Hot fuel } \\
\hline \multicolumn{2}{|c|}{$\begin{array}{l}\text { Power distribution uncertainty } \\
\text { Hot streak } \\
\text { Fuel plate heated length uncertainty }\end{array}$} & $\begin{array}{l}1.199 \\
1.10 \\
1.025\end{array}$ & & \\
\hline \multirow[t]{4}{*}{ Total $^{a}$} & \multicolumn{4}{|c|}{1.35} \\
\hline & \multicolumn{4}{|c|}{ Local } \\
\hline & \multicolumn{2}{|c|}{ Active } & \multicolumn{2}{|c|}{ Entrance and exit } \\
\hline & $\begin{array}{l}\text { Inner } \\
\text { element }\end{array}$ & $\begin{array}{l}\text { Outer } \\
\text { element }\end{array}$ & $\begin{array}{l}\text { Inner } \\
\text { element }\end{array}$ & $\begin{array}{l}\text { Outer } \\
\text { element }\end{array}$ \\
\hline Power distribution uncertainty & 1.199 & 1.199 & 1.199 & 1.199 \\
\hline Nonbond & 1.08 & 1.16 & 1.08 & 1.16 \\
\hline Fuel segregation & 1.3 & 1.3 & 1.3 & \\
\hline Fuel beyond axial boundary & & & 1.44 & 1.23 \\
\hline Total $^{a}$ & 1.68 & 1.81 & 2.42 & 2.22 \\
\hline
\end{tabular}

Table 10. Hot fuel regions and lccal power peaking factors

${ }^{a}$ Multiplicative. 
are $3.94 \mathrm{in}$. (10.0 cm) and 1.487 in. $(3.78 \mathrm{~cm})$, respectively], outer element plate radial and span positions are 5.96 in. $(15.15 \mathrm{~cm})$ and 0.0923 in. $(0.234 \mathrm{~cm})$, respectively. Note: the 0.0739-in. value given for " $\Delta r_{2}$ " for the outer fuel element plates is incorrect in Ref. 57; it should be 0.09157 in., that is, the radial difference between the first mesh point in the outer fuel element plates $(15.15 \mathrm{~cm} \text { or } 5.9646 \mathrm{in} \text {. })^{52}$ and the outside radius of the inner side plate of the outer fuel element give $U_{20}$ and $U_{20}$ as 1.08 and 1.16 , respectively. The heat flux peaking caused $2 y$ combined nonbond and fuel segregation defects is also affected by the heat transfer coefficient. Values reported in Table 10 are based on a heat transfer coefficient of $15,000 \mathrm{Btu} / \mathrm{h}-\mathrm{ft}^{2}-\mathrm{e}^{-}\left(85 \mathrm{~kW} / \mathrm{m}^{2}-\mathrm{K}\right)$, which is representative during LOCA. The variation in the peaking factor with the heat transfer coefficient for several fuel meat thicknesses is shown in Fig. $12^{\text {s }}$

Representation of the local hot spot is accomplished in the model with an additional heat structure with an area much smaller ( -0.01 times) than the normal hot channel heat structure. This allows simulation of a local, high fuel plate heat flux coupled with fluid conditions dictated by the heat structures representing the "global" hot fuel plate characteristics. In the present RELAF'5 model, there is a local hot spot in each axial segment of the hot fuel plates, including the nominally inactive portions (extensions). The latter segments (denoted "entrance and exit" in Table 10) represent hot spots in fuel extending beuond the nominal axial boundary of the active portion of the fuel plates." The exit hot spots are the locations in the fuel elements at which the hot inner and outer fuel element plates are closest to th. air thermal limit during normal, steady-state operation. ${ }^{51}$ Table 10 lists the values of the local hot fuel regions power peaking factors, which, like the hot fuel region factors, are assumsd to occur simultaneously.

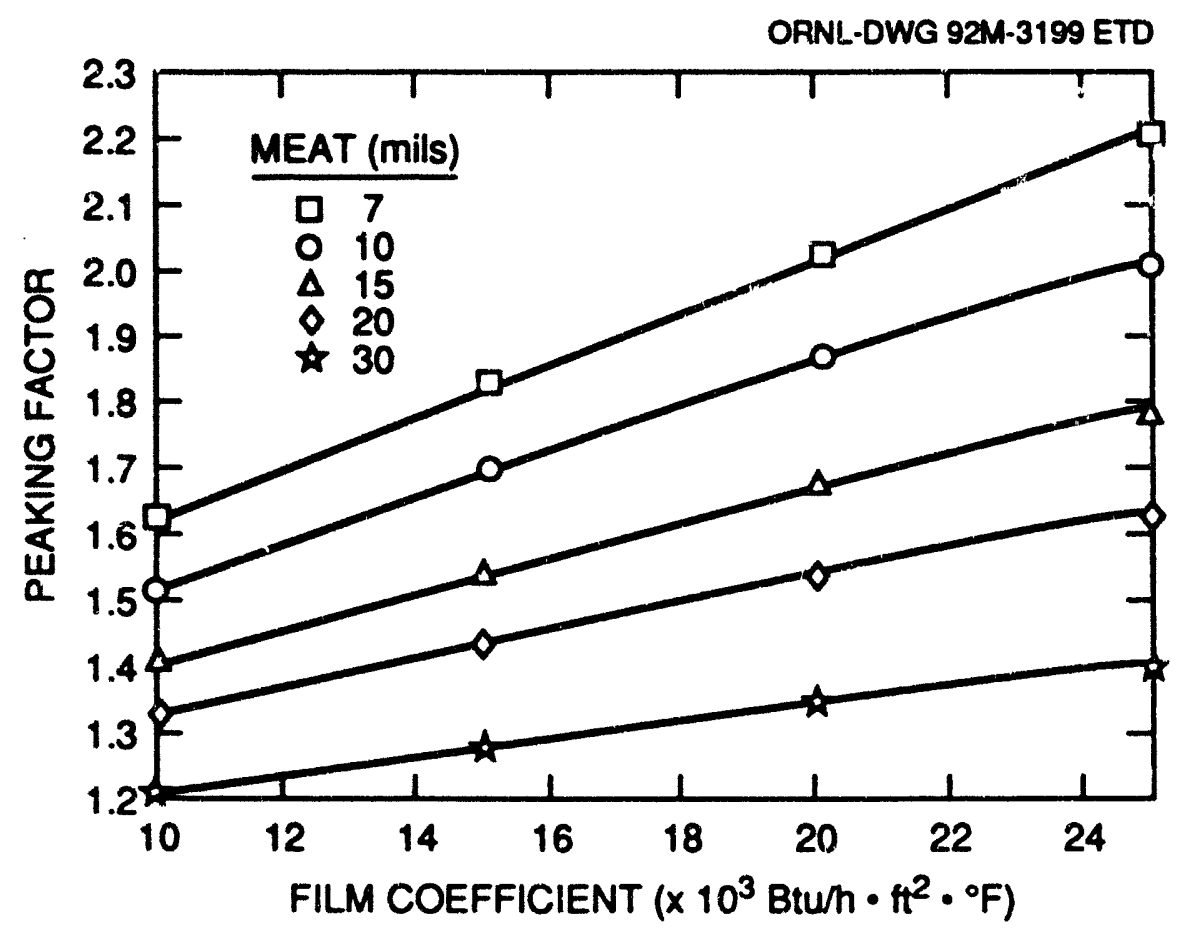

Fig. 12. Peaking factor as function of film coefficient with fuel meat thickness as parameter. 
RELAP5 heat structure internal source multipliers were calculated by distributing the total fuel element power to each heat structure according to surface area. Then, axial power factors presented in Table 9 were used, along with appropriate power peaking factors, to represent the spatial core power distribution. Table 11 presents the fuel internal source multipliers calculated and used in the RELAPS model (these multipliers are referenced to the fuel element power). ${ }^{n}$

\subsection{Fuel Labyrinth}

The fuel labyrinth, the flow passage between the inser and outer fuel elements, is modeled as a single volume (Fig. 7). The volume is not thermally connected to the fuel heat structures and therefore provides them no cooling. The flow passage is an annulus with the following dimensions: ${ }^{25}$

$$
\begin{aligned}
& \text { inside diameter }=10.590 \text { in. }(26.899 \mathrm{~cm}) \text {, } \\
& \text { outside diameter }=11.250 \mathrm{in} .(28.575 \mathrm{~cm}) \text {. }
\end{aligned}
$$

Thus, the flow area $A_{f}$ and hydraulic diameter $D_{h y}$ of the channel are

$$
\begin{aligned}
& A_{f}=0.0786 \mathrm{ft}^{2}\left(7.30 \times 10^{-3} \mathrm{~m}^{2}\right), \\
& D_{h y}=0.0550 \mathrm{ft}\left(1.68 \times 10^{-2} \mathrm{~m}\right) .
\end{aligned}
$$

With reference to Fig. 2, the length of the fuel labyrinth is assumed to be 24 in. $(61 \mathrm{~cm})$, the same as the fuel.

The top portion of the labyrinth provides a large flow resistance, which only allows a flow rate of $\sim 136 \mathrm{gal} / \mathrm{min}\left(8.58 \times 10^{-3} \mathrm{~m}^{3} / \mathrm{s}\right)$ or $18.7 \mathrm{lb} / \mathrm{s}(8.48 \mathrm{~kg} / \mathrm{s})$ during HFIR normal steadystate operation. This flow resistance is represented in RELAP5 using the abrupt area change model (at junction 4-07) with an orifice possessing an area -21 times smaller $\left(0.0037 \mathrm{ft}^{2}\right.$ or $3.4 \times 10^{-4} \mathrm{~m}^{2}$ ) than the labyrinth flow area. The annulus was assumed to have the same ch`nnel surface roughness as the fuel, $20 \mu \mathrm{min}$. $\left(5.08 \times 10^{-4} \mathrm{~mm}\right)$. The abrupt area change model was alse ised at the outlet (at junction 8-09).

\subsection{Target}

As indicated previously, the target assembly is located inside the 5-in.-diam (12.7-cm) hole within the inner fuel element. Figure 13 provides a view of the details of the target assembly in a typical configuration, while Fig. 14 shows its position within the core. The configuration of the target assembly varies depending upon the needs of experimenters. ${ }^{60}$ In Fig. 13, the assembly contains 30 target rods containing curium oxide-aluminum pellets and a hydraulic tube in the central target region, occupying the position otherwise filled by the central target rod. The hydraulic tube can contain up to nine 0.5-in.-diam (1.27-cm), 2 9/16-in.-long $(6.51-\mathrm{cm})$ capsules. For the development of the target assembly model for RELAP5 it was assumed for simplicity that the target region contained 31 target rods, inciuding one rod replacing the hydraulic tube. The design of the target rods is presented in Fig. 15.

With reference to Fig. 15, water flows in the annulus formed by the tube containing the heavy metal pellets and the outer target rod tube. In Fig. 7, hydrodynamic volumes 5-01 through 5-07 are used to model this "heated" target flow path. A second flow path exists 


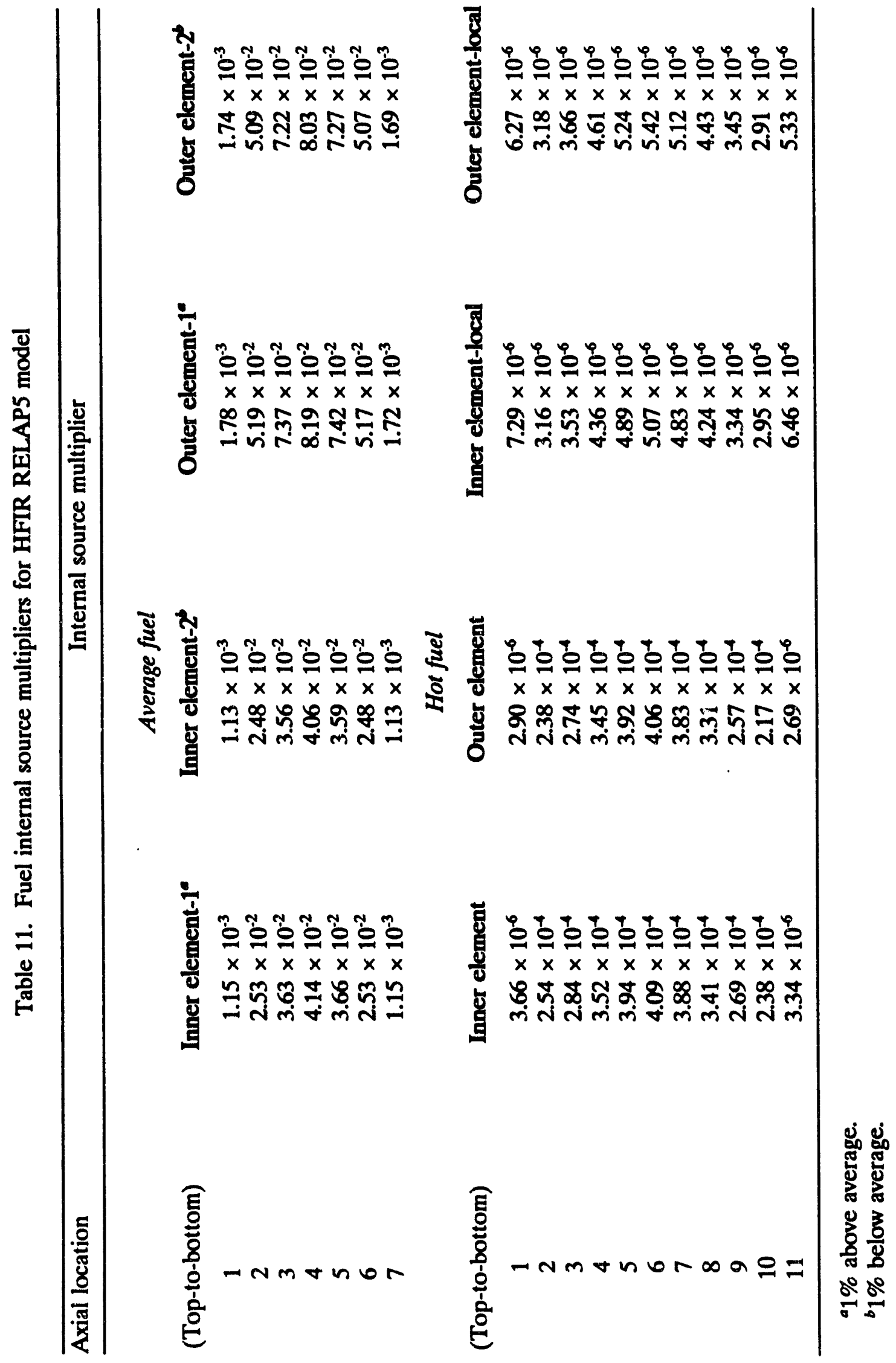




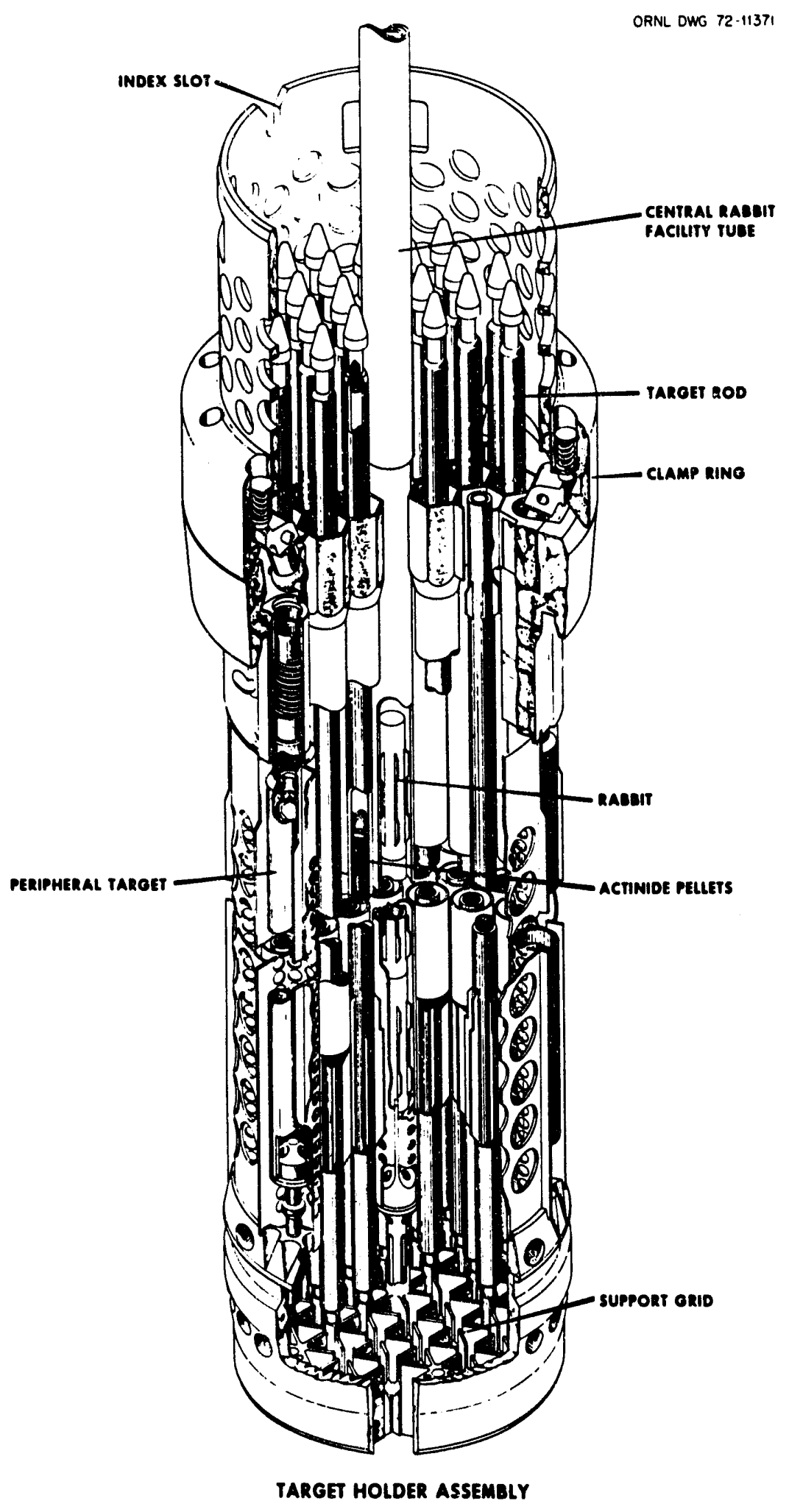

Fig. 13. Target assembly. 

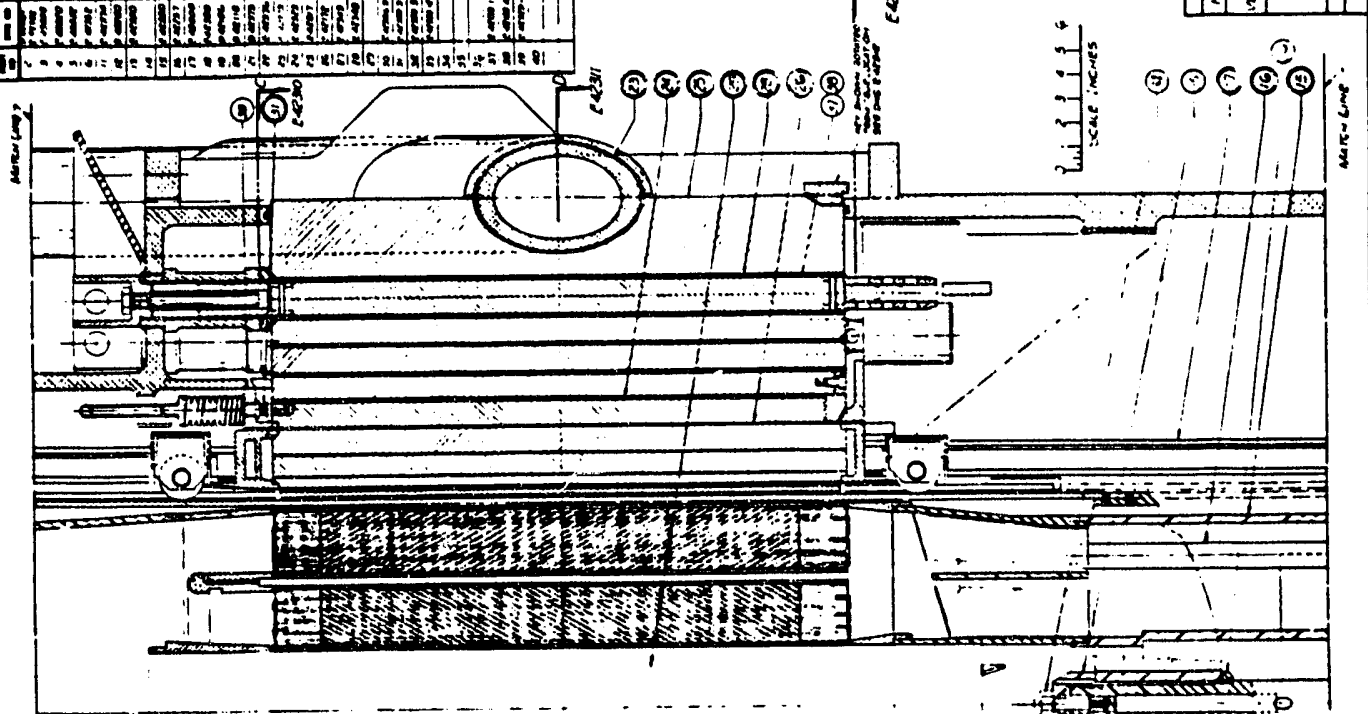

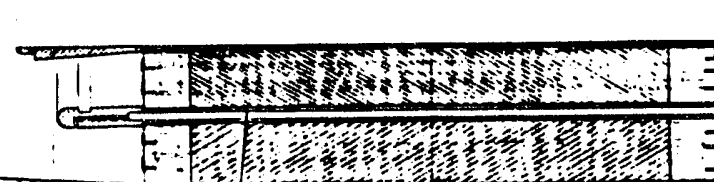

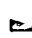
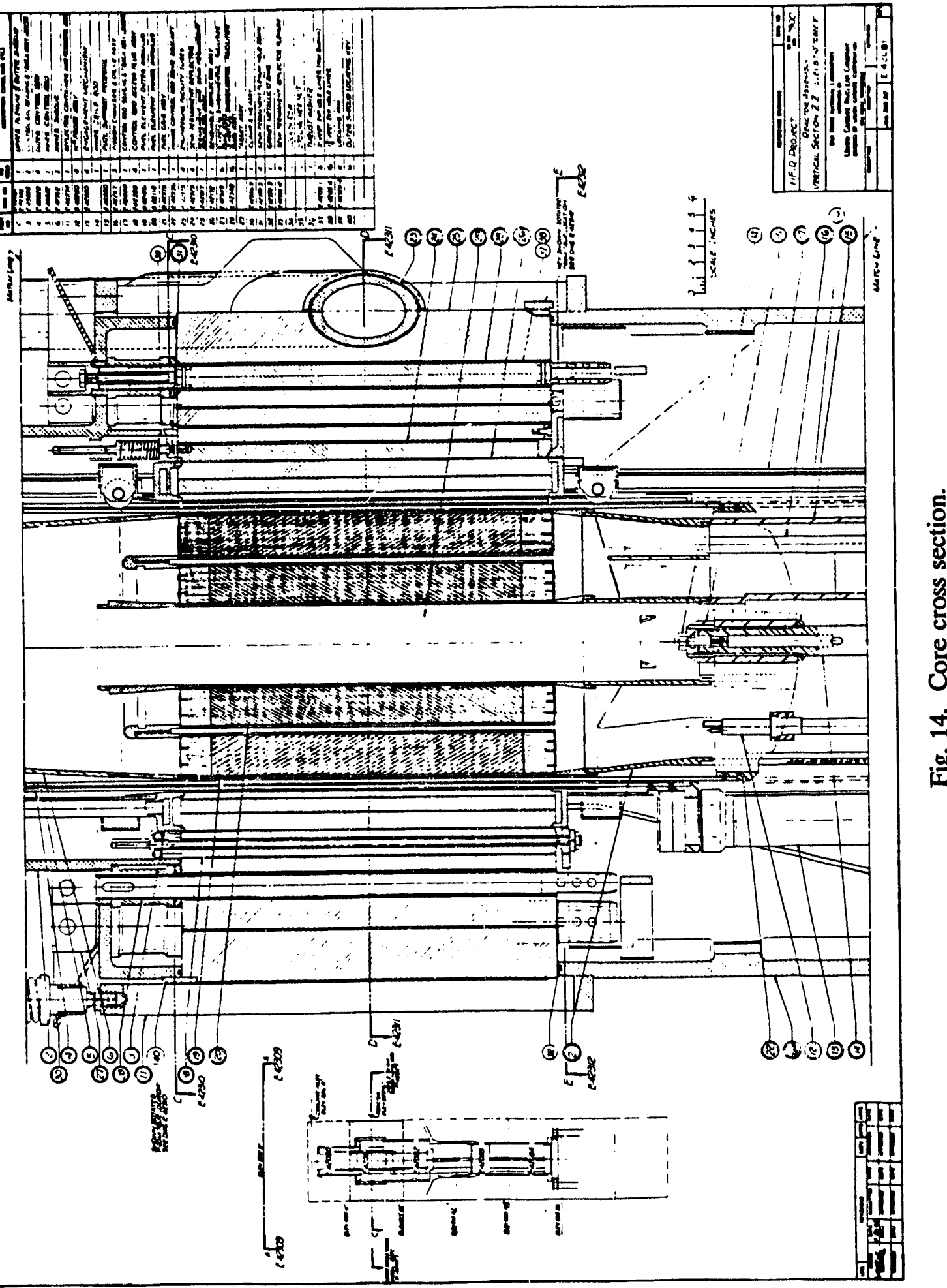

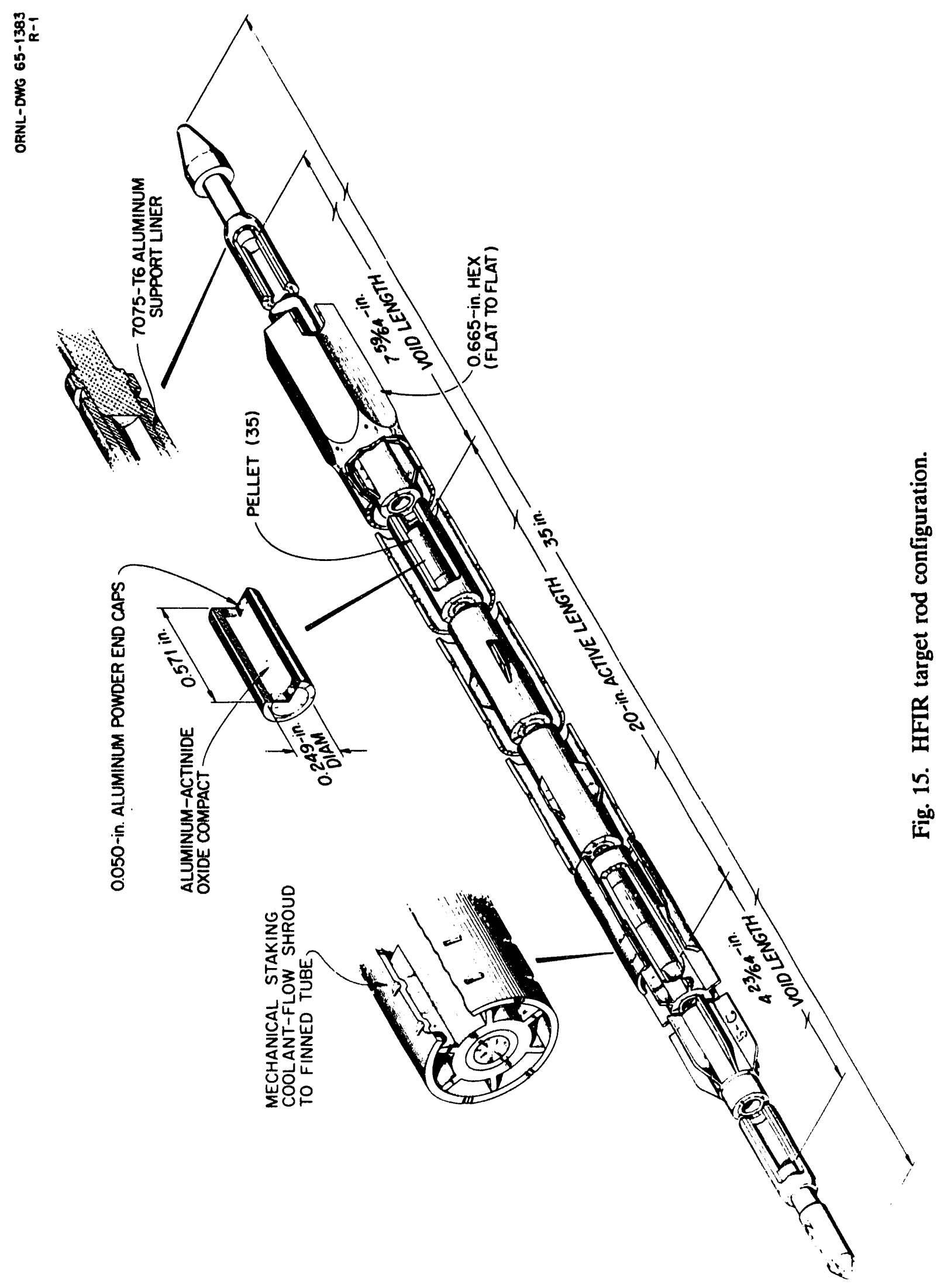
through the target assembly around the target rods. This "unheated" region is modeled with hydrodynamic volume 6 in Fig. 7.

As in the fuel region, oxide is assumed to form on aluminum components in the target region, and its effect on conduction heat transfer is modeled. However, for the purposes of calculating the flow areas and hydraulic diameters in this region, the effect of the oxide is small and ignored. The inside and outside diameters of the target rod (heated) annular flow path formed by the pellet containment tube and the target rod shroud are ${ }^{61}$

inside diameter $=0.369$ in. $(0.937 \mathrm{~cm})$,

outside diameter $=0.594 \mathrm{in} .(1.51 \mathrm{~cm})$.

Thus, the total target heated flow area $A_{f}^{h}$ is

$$
\begin{aligned}
& A_{f}^{h}=31 \pi\left(0.594^{2}-0.369^{2}\right) /(2 \times 12)^{2} \mathrm{ft}^{2}, \\
& A_{f}^{h}=3.66 \times 10^{-2} \mathrm{ft}^{2}\left(5.70 \times 10^{-3} \mathrm{~m}^{2}\right) .
\end{aligned}
$$

The heated target region hydraulic diameter $D_{h y}^{h}$ is

$$
\begin{aligned}
D_{h y}^{u} & =\frac{4 \cdot 6.72 \times 10^{-2}}{(5.33+1.33)} \mathrm{ft}, \\
D_{h y}^{h} & =1.87 \times 10^{-2} \mathrm{ft}\left(5.70 \times 10^{-3} \mathrm{~m}\right) .
\end{aligned}
$$

The flow area of the unheated target region is taken to be the area of the hole within the inner fuel element less the area occupied by the target rods. The diameter of the hole $D_{h}$ and the outside diameter of the target rod shrouds $O D_{1}$ are $^{62}$

$$
\begin{aligned}
& D_{h}=5.067 \text { in. }(12.9 \mathrm{~cm}) \\
& O D_{t}=21 / 32 \text { in. }=0.0547 \mathrm{ft}(0.0167 \mathrm{~m}) .
\end{aligned}
$$

The unheated target region flow area $A_{f}^{u}$ is then calculated as

$$
\begin{aligned}
& A_{f}^{u}=\pi[5.067 /(12 \times 2)]^{2}-31 \pi(0.0547 / 2)^{2} \mathrm{ft}^{2}, \\
& A_{f}^{u}=6.72 \times 10^{-2} \mathrm{ft}^{2}\left(6.24 \times 10^{-3} \mathrm{~m}^{2}\right) .
\end{aligned}
$$

The hydraulic diameter of the unheated region $D_{h y}^{u}$ is calculated based on $A_{f}^{u}$ and the wetted perimeter of the outside surface of the target rods $P_{r}$ and the hole containing the target assembly $P_{h}$

$$
D_{h y}^{u}=4 A_{f}^{u} f\left(P_{r}+P_{h}\right) \text {, }
$$

where

$$
\begin{aligned}
& P_{r}=31 \pi \times 0.0547 \mathrm{ft}, \\
& P_{h}=\pi \times 5.067 / 12 \mathrm{ft} .
\end{aligned}
$$


Thus,

$$
\begin{aligned}
& D_{h y}^{u}=\frac{4 \cdot 6.72 \times 10^{-2}}{(5.33+1.33)} \mathrm{ft}, \\
& D_{h y}^{\mu}=4.04 \times 10^{-2} \mathrm{ft}\left(1.23 \times 10^{-2} \mathrm{~m}\right) .
\end{aligned}
$$

As indicated in Fig. 15, the diameter of the target pellets is $0.249 \mathrm{in} .(0.632 \mathrm{~cm})$. Curium oxide, in a matrix of aluminum, is contained within the $0.195-\mathrm{in} .(0.495-\mathrm{cm})$ region. ${ }^{61}$ The curium oxide-aluminum core is jacketed in 0.027 -in.-thick $(0.0686-\mathrm{cm}) 1100$ aluminum around the circumference and 0.050 -in.-thick $(0.127-\mathrm{cm})$ pure aluminum powder compacted at the ends. The pellets are contained in a 59 -mil-thick $(1.50-\mathrm{mm}) 8001$ aluminum tube [outer radius $r_{\text {rod }}$ of 0.1845 in. $\left.(0.4686 \mathrm{~cm})\right]$ with discontinuous fins that position it inside the outer target rod tube also constructed of 8001 aluminum. ${ }^{61}$ As will be described subsequently, a small gas gap [ 0.5 mils $(0.13 \mathrm{~mm})]$ exists at RT between the pellets and containment tube and becomes even smaller at HFIR normal operating conditions. ${ }^{63}$ As will be described subsequently, the gas gap is taken to be $0.1 \mathrm{mil}\left(2.54 \times 10^{-3} \mathrm{~mm}\right)$ in the model. Oxide is assumed to form on the aluminum tube containing the pellets. The thickness of the oxide is taken to be the same as that used for the average fuel plate, $0.689 \mathrm{mil}(0.0175 \mathrm{~mm})$. Thus, the outer radial boundaries of the regions comprising the pellet and containment tube are

$$
\begin{aligned}
& \text { oxide, } r_{\text {o }} \\
& r_{0}=r_{\text {rod }}+\text { (oxide thickness - Al consumed), } \\
& =0.015375+(0.689-0.689 / 1.254) /(1000 \times 12) \mathrm{ft} \text {, } \\
& r_{o}=0.0153866 \mathrm{ft}\left(4.68984 \times 10^{-3} \mathrm{~m}\right) \text {; } \\
& \text { containment tube, } r_{c} \\
& r_{c}=r_{o} \text { - oxide thickness, } \\
& =0.0153866-0.689 /(1000 \times 12) \mathrm{ft} \text {, } \\
& r_{c}=0.0153292 \mathrm{ft}\left(4.67234 \times 10^{-3} \mathrm{~m}\right) \text {; } \\
& r_{g}=0.01038333 \mathrm{ft}\left(3.16484 \times 10^{-3} \mathrm{~m}\right) ; \\
& r_{j}=0.010375 \mathrm{ft}\left(3.16230 \times 10^{-3} \mathrm{~m}\right) ; \\
& r_{p}=8.125 \times 10^{-3} \mathrm{ft}\left(2.477 \times 10^{-3} \mathrm{~m}\right) .
\end{aligned}
$$

With reference to Figs. 14 and 15, the length of the target region is taken to be 24 in. $(61.0 \mathrm{~cm})$, the same as the fuel element. The active length of the target rods is taken to be 20 in. $(50.8 \mathrm{~cm})$, the nominal value, with the remaining length containing an aluminum support liner and a void space for fission gas release instead of the curium oxide pellets as shown in Fig. 15. The total surface area of the target tubes containing the pellets $A_{s}^{h}$ is 


$$
\begin{aligned}
& A_{s}^{h}=31 \pi \times 2 \times 0.0153866 \times 20 / 12 \mathrm{ft}^{2}, \\
& A_{s}^{h}=4.99 \mathrm{ft}^{2}\left(0.464 \mathrm{~m}^{2}\right) .
\end{aligned}
$$

Similarly, the total surface area of the unheated portion of the tubes $A_{s}^{u}$ is

$$
\begin{aligned}
& A_{s}^{u}=31 \pi \times 2 \times 0.0153866 \times 4 / 12 \mathrm{ft}^{2} \\
& A_{s}^{u}=0.999 \mathrm{ft}^{2}\left(0.0928 \mathrm{~m}^{2}\right) .
\end{aligned}
$$

The curium oxide-aluminum pellet core is composed of $11.2 \mathrm{~g}$ of curium oxide as $\mathrm{CmO}_{1.73}$, per rod, $20 \%$ "void," and the balance 1100 aluminum. ${ }^{64}$ For modeling purposes, the 1100 aluminum jacket at the ends of each pellet within the core radius is taken to be part of the core. Table 12 presents the mass and volume of each component in the pellet region assumed to comprise the core. Calculations used the density of pure aluminum, $169 \mathrm{lb}_{\mathrm{m}} / \mathrm{ft}^{3}\left(2710 \mathrm{~kg} / \mathrm{m}^{3}\right)\left(\right.$ Ref. 37), and a $\mathrm{CmO}_{2}$ density of $227 \mathrm{lb}_{\mathrm{m}} / \mathrm{ft}^{3}\left(3640 \mathrm{~kg} / \mathrm{m}^{3}\right)$ (Ref. 65) for $\mathrm{CmO}_{1.73}$.

Table 12. Target pellet core composition per rod

\begin{tabular}{lcc}
\hline Component & $\begin{array}{c}\text { Volume } \\
\text { fraction } \\
(\%)\end{array}$ & $\begin{array}{c}\text { Mass } \\
\left(\mathrm{lb}_{\mathrm{m}}\right)\end{array}$ \\
\hline $\mathrm{CmO}_{1.73}$ & 30 & 0.0247 \\
$1100 \mathrm{Al}$ & 50 & 0.0308 \\
Void & 20 & - \\
Total & & 0.0555 \\
\hline
\end{tabular}

${ }^{a}$ Total volume of $3.64 \times 10^{-4} \mathrm{ft}^{3}$.

The temperature-dependent specific heat of the pellet core was calculated as a mass weighted average of those of pure aluminum and $\mathrm{CmO}_{1.73}$. The specific heat of $\mathrm{CmO}_{1.73}$ could not be found, so values of $\mathrm{Cm}_{2} \mathrm{O}_{3}$ are used that are expected to be representative of $\mathrm{CmO}_{1.73}$ (Refs. 66 and 67). Table 13 presents the specific heats of aluminum and $\mathrm{CmO}_{1.73}$ along with the mass weighted core average value and the volumetric heat capacity.

The thermal conductivity of the pellet core was taken to be a constant, due to the lack of temperature-dependent property data. However, based on the weak temperature dependence of the fuel meat thermal conductivity and the similarity of these materials, available data should be adequate. The thermal conductivity value selected for the pellet core is based on measurements of aluminum $-\mathrm{U}_{3} \mathrm{O}_{8}$ void material. ${ }^{68}$ The data indicate that voids and $\mathrm{U}_{3} \mathrm{O}_{8}$ particles reduce the thermal conductivity of the cermet by roughly the same amount. Thus, for the pellet core composition of 30 and $20 \%$ by volume $\mathrm{CmO}_{1.73}$ (assumed 
to affect cermet thermal conductivity like $\mathrm{U}_{3} \mathrm{O}_{8}$ ) and void, respectively, the thermal conductivity of the core $k_{c}$ is taken to be $\mathrm{e}^{68}$

$$
k_{c}=13.9 \mathrm{Btu} / \mathrm{h}-\mathrm{ft}-{ }^{\circ} \mathrm{F}=0.00386 \mathrm{Btu} / \mathrm{s}-\mathrm{ft}-{ }^{\circ} \mathrm{F}(24.0 \mathrm{~W} / \mathrm{m}-\mathrm{K}) \text {. }
$$

Table 13. Pellet core specific heat and volumetric heat capacity

\begin{tabular}{|c|c|c|c|c|}
\hline \multirow{2}{*}{$\begin{array}{l}\text { Temperature } \\
\left({ }^{\circ} \mathrm{F}\right)\end{array}$} & \multicolumn{3}{|c|}{$\begin{array}{l}\text { Specific heat } \\
\left(B t u / b_{m^{-}}{ }^{\circ} F\right)\end{array}$} & \multirow{2}{*}{$\begin{array}{c}\begin{array}{c}\text { Volumetric } \\
\text { heat capacity } \\
\left(\mathrm{Btu} / \mathrm{ft}^{3}-{ }^{\circ} \mathrm{F}\right)\end{array} \\
\text { Core }^{b}\end{array}$} \\
\hline & $\overline{\mathrm{Al}}$ & $\mathrm{CmO}_{1.73}$ & Core $^{a}$ & \\
\hline 80 & 0.215 & $0.0627^{c}$ & $0.148^{c}$ & $22.5^{c}$ \\
\hline 440 & 0.238 & 0.0688 & 0.164 & 24.9 \\
\hline 980 & 0.274 & 0.0751 & 0.186 & 28.3 \\
\hline 1205 & 0.305 & 0.0769 & 0.205 & 31.2 \\
\hline
\end{tabular}

The volumetric heat capacity and thermal conductivity of the pellet aluminum jacket is taken to be that of pure aluminum. The former property values (presented in Table 14) are derived from specific heat values (also provided) and an aluminum density of $169 \mathrm{lb}_{\mathrm{m}} / \mathrm{ft}^{3}(2710$ $\left.\mathrm{kg} / \mathrm{m}^{3}\right) .^{37}$ The latter property values were previously presented for the fuel plate cladding (Table 6).

Table 14. Pellet aluminum jacket specific heat and volumetric heat capacity ${ }^{38}$

\begin{tabular}{ccc}
\hline $\begin{array}{c}\text { Temperature } \\
\left({ }^{\circ} \mathrm{F}\right)\end{array}$ & $\begin{array}{c}\text { Specific heat } \\
\left(\mathrm{Btu} / \mathrm{/b} \mathrm{b}_{\mathrm{m}}{ }^{\circ} \mathrm{F}\right)\end{array}$ & $\begin{array}{c}\text { Volumetric heat } \\
\text { capacity } \\
\left(\mathrm{Btu} / \mathrm{ft}^{3}-{ }^{\circ} \mathrm{F}\right)\end{array}$ \\
\hline 80 & 0.215 & 36.3 \\
440 & 0.238 & 40.2 \\
980 & 0.274 & 46.3 \\
1205 & 0.305 & 51.5 \\
\hline
\end{tabular}

The target containment tube, containing helium at $\sim 0.5$ atm of pressure, ${ }^{64}$ is collapsed on the pellets hydrostatically. Destructive tests indicate that the maximum initial RT clearance between the pellet and tube is $0.5 \mathrm{mil}(0.0127 \mathrm{~mm}) .{ }^{69}$ During irradiation in the 
HFIR, temperature differences between the pellet and tube will cause the gap to close further. Based on the thermal expansion of the pellet/tube and fission gas release, an estimate of the gap resistance can be made. It is noted that due to the importance of pelletto-tube contact in determining the gap resistance, the RELAP5 gap conductance model, which ignores this mechanism, could not be used.

The target tube gap resistance has been investigated in a previous study. ${ }^{63}$ The analysis presented here is similar. Gap resistances have been calculated for aluminum in contact with uranium metal with 1 lium in the gap and with a $50 \%$ helium plus $50 \%$ xenon and krypton mixture by volume. ${ }^{70}$ At a mean contact pressure of $200 \mathrm{psi}(1.38 \mathrm{MPa})$ and a temperature of $752^{\circ} \mathrm{F}\left(400^{\circ} \mathrm{C}\right)$, the gap thermal conductance coefficient $h_{c}$ was calculated to be $-40,000 \mathrm{Btu} / \mathrm{h}-\mathrm{ft}^{2}{ }^{\circ} \mathrm{F}\left(0.227 \mathrm{MW} / \mathrm{m}^{2}-\mathrm{K}\right)$ for the case with helium in the gap and $-30,000 \mathrm{Btu} / \mathrm{h}-\mathrm{ft}^{2}-{ }^{\circ} \mathrm{F}\left(0.170 \mathrm{MW} / \mathrm{m}^{2}-\mathrm{K}\right)$ with the helium, xenon, and $\mathrm{krypton}$ gas mixture in the gap. In a second study, ${ }^{71}$ gap resistances were measured between several metals, including aluminum. For rough aluminum surfaces [50 to $100 \mu \mathrm{in}$. $\left(1.27 \times 10^{-3}\right.$ to $2.54 \times 10^{-3}$ $\mathrm{mm})]$ in contact with each other, $h_{c}$ was found to be -2000 to $3500 \mathrm{Btu} / \mathrm{h}-\mathrm{ft}^{2}{ }^{\circ} \mathrm{F}(11,357$ to $\left.19,874 \mathrm{~W} / \mathrm{m}^{2}-\mathrm{K}\right)$ with a contact pressure of $200 \mathrm{psi}(1.38 \mathrm{MPa})$, temperature of $500^{\circ} \mathrm{F}$ $\left(260^{\circ} \mathrm{C}\right)$, and air in the gap. With a temperature of $300^{\circ} \mathrm{F}\left(149^{\circ} \mathrm{C}\right), h_{c}$ "decreased" to $\sim 1400$ to $4000 \mathrm{Btu} / \mathrm{h}-\mathrm{ft}^{2}{ }^{\circ} \mathrm{F}\left(7949\right.$ to $\left.22,713 \mathrm{~W} / \mathrm{m}^{2}-\mathrm{K}\right)$. Increasing the contact pressure to $500 \mathrm{psi}$ (3.45 $\mathrm{MPa})$ resulted in $h_{c}$ increasing dramatically at a temperature of $300^{\circ} \mathrm{F}\left(148.9^{\circ} \mathrm{C}\right)$ $\left(h_{c}-3000\right.$ to $8500 \mathrm{Btu} / \mathrm{h}-\mathrm{ft}^{2}{ }^{\circ} \mathrm{F}$ or 17,035 to $\left.48,265 \mathrm{~W} / \mathrm{m}^{2}-\mathrm{K}\right)$ and even more so at $500^{\circ} \mathrm{F}$ $\left(260^{\circ} \mathrm{C}\right)\left(h-5500\right.$ to $11,000 \mathrm{Btu} / \mathrm{h}-\mathrm{ft}^{2}-{ }^{\circ} \mathrm{F}$ or 31,230 to $\left.62,461 \mathrm{~W} / \mathrm{m}^{2}-\mathrm{K}\right)$. Similarly, in the former study, ${ }^{70}$ the thermal conductance coefficient was calculated to increase significantly with increasing contact pressure.

The composition of the gas in the target rods can be estimated based on the initial pressure of the helium fill gas and the fission gas released during irradiation. It has been estimated that $215 \mathrm{~cm}^{3}$ (Ref. 62) of gas at STP will be produced during irradiation, of which $5 \%\left(10.75 \mathrm{~cm}^{3}\right)$ or less will escape the pellets and enter the target tube plenum and gap. $^{72}$ The gases released during irradiation and their volume fractions are xenon (91.6\%), helium (6\%), and krypton $(2.4 \%)$. Based on the above information and the void volume in each target rod $\left(6.5 \mathrm{~cm}^{3}\right){ }^{62}$ the composition of the gas occupying the gap was determined to be $70 \%$ xenon, $28 \%$ helium, and $2 \%$ krypton. At $500^{\circ} \mathrm{F}\left(260^{\circ} \mathrm{C}\right)$, the thermal conductivity of the target gas mixture $\left(-0.020 \mathrm{Btu} / \mathrm{h}-\mathrm{ft}-{ }^{\circ} \mathrm{F} \text { or } 0.035 \mathrm{~W} / \mathrm{m}-\mathrm{K}\right)^{73}$ is similar to that of air $\left(\sim 0.025 \mathrm{Btu} / \mathrm{h}-\mathrm{ft}-{ }^{\circ} \mathrm{F}\right.$ or $\left.0.043 \mathrm{~W} / \mathrm{m}-\mathrm{K}\right) .^{74}$ Thus, the thermal conductance coefficient data described above are representative of those for the target gap.

Based on the above discussion, to achieve a reasonably high gap thermal conductance coefficient between the target pellet and tube, a contact pressure on the order of 200 psi $(1.38 \mathrm{MPa})$ or higher is needed. Given a desired contact pressure (e.g., 500 psi or $3.45 \mathrm{MPa}$ ), the required temperature drop through the gap can be determined to provide the necessary pressure supporting thermal expansion. Based on analysis elsewhere, ${ }^{75}$

$$
t=C-\left(T_{1}-T_{2}\right) \lambda R,
$$

where

$$
\boldsymbol{t}=\text { clearance (gap) at operating conditions, mils; }
$$

$T_{2}=$ average target tube temperature, ${ }^{\circ} \mathrm{F}$;

$T_{1}=$ average pellet temperature, ${ }^{\circ} \mathrm{F}$;

$\lambda=$ aluminum linear thermal expansion coefficient, $14.2 \times 10^{-6} /{ }^{\circ} \mathrm{F}\left(2.56 \times 10^{-5} /{ }^{\circ} \mathrm{C}\right) ;^{37}$ 


$$
\begin{aligned}
& R=\text { pellet radius, } 124.5 \mathrm{mils}(3.162 \mathrm{~mm}) \\
& C=\text { initial clearance, } 0.5 \text { mils }(0.013 \mathrm{~mm})
\end{aligned}
$$

A second equation, which relates the contact pressure $P$ to the interference $I$ (the difference in diameters between the pellet and tube at temperature in an unconstrained state) is ${ }^{76}$

$$
I=\frac{4 b^{3} P\left(c^{2}-a^{2}\right)}{E\left(c^{2}-b^{2}\right)\left(b^{2}-a^{2}\right)},
$$

where

$$
\begin{aligned}
a & =\text { pellet inside radius }=0, \\
b & =\text { pellet (including jacket) outside radius }=0.010375 \mathrm{ft}(0.31623 \mathrm{~cm}), \\
c & =\text { tube outside radius }=0.0153292 \mathrm{ft}(0.467234 \mathrm{~cm}), \\
E & =\text { aluminum modulus of elasticity, } 1 \times 10^{7} \mathrm{psi}(68,948 \mathrm{MPa}){ }^{37}
\end{aligned}
$$

With $P=500 \mathrm{psi}$, the interference is found to be

$$
\begin{aligned}
& I=\frac{4 \cdot(0.010375)^{3} \cdot 500 \cdot(0.0153292)^{2} \cdot 12 \cdot 1000}{1 \times 10^{7} \cdot\left[(0.015392)^{2}-(0.010375)^{2}\right] \cdot(0.010375)^{2}} \text { mils } . \\
& I=0.046 \text { mils }\left(1.17 \times 10^{-3} \mathrm{~mm}\right) .
\end{aligned}
$$

By letting $t=-I=-0.046$ mils $\left(-1.17 \times 10^{-3} \mathrm{~mm}\right)$, the temperature difference between the pellet and tube, $T_{1}-T_{2}$, can be calculated with Eq. (1):

$$
\begin{aligned}
& T_{1}-T_{2}=(0.5+0.046) /\left(14.2 \times 10^{-6} \times 124.5\right)^{\circ} \mathrm{F}, \\
& T_{1}-T_{2}=309^{\circ} \mathrm{F}-310^{\circ} \mathrm{F}\left(172^{\circ} \mathrm{C}\right) .
\end{aligned}
$$

Because $T_{1}-T_{2}$ will be greater than the gap temperature drop, a gap drop of $310^{\circ} \mathrm{F}\left(172^{\circ} \mathrm{C}\right)$ will conservatively result in a contact pressure of $500 \mathrm{psi}(3.45 \mathrm{MPa})$.

The analysis above neglects the effect of the difference between the gas pressure within the tube and the external tube pressure. The gas pressure $P_{g}$ inside the tube can be estimated using the ideal gas law given the preoperation (cold) and operation (hot) gas volumes and temperatures, and preoperation pressure, that is,

$$
P_{g}=P_{i} V_{r} T_{r},
$$

where

$$
\begin{aligned}
& P_{i}=\text { preoperation pressure } \\
& V_{r}=\text { hot-to-cold volume ratio at STP } \\
& T_{r}=\text { hot-to-cold absolute temperature ratio. }
\end{aligned}
$$


As indicated previously, the preoperation gas volume at STP is $3.25 \mathrm{~cm}^{3}$, while the corresponding operation value is $14 \mathrm{~cm}^{3}$. Thus, $V_{r}=4.31$. Assuming preoperation and operation gas temperatures of $80^{\circ} \mathrm{F}(300 \mathrm{~K})$ and $600^{\circ} \mathrm{F}(589 \mathrm{~K})$, respectively, gives $T_{r}=1.96$. Thus, with a $P_{i}$ of $0.5 \mathrm{~atm}(7.35 \mathrm{psi}$ or $0.051 \mathrm{MPa})$,

$$
\begin{aligned}
& P_{g}=7.35 \times 4.31 \times 1.96 \mathrm{psi}, \\
& P_{g}=02 \mathrm{psi}(0.43 \mathrm{MPa}) .
\end{aligned}
$$

Obviously, under normal operation the external tube pressure will be much higher than $P_{\xi}$; however, under accident conditions the external pressure could drop to atmospheric pressure or lower (for a very brief duration). Assuming an external pressure of $14.7 \mathrm{psi}(0.10 \mathrm{MPa})$ the difference is $-50 \mathrm{psi}(0.35 \mathrm{MPa})$. The effect of this difference is very small because small variations $-310^{\circ} \mathrm{F}\left(172^{\circ} \mathrm{C}\right)$ produce large variations in the contact pressure.

During HFIR normal steady-state operation, the target heat load is $\sim 0.888 \mathrm{MW}$ (see Table 1). Applying this load to the total target rod surface area at the pellet-tube interface $\left[A_{s}^{p-t}=A_{s}^{h} \times r_{j} / r_{o}=4.99 \mathrm{ft}^{2} \times 0.010375 / 0.0153866=3.36 \mathrm{ft}^{2}\left(0.312 \mathrm{~m}^{2}\right)\right]$, the peak heat flux $q_{p}^{\prime \prime}$ is found to be $1.09 \times 10^{6} \mathrm{Btu} / \mathrm{h}-\mathrm{ft}^{2}\left(3.44 \times 10^{6} \mathrm{~W} / \mathrm{m}^{2}\right)$. An "implied" thermal conductance coefficient $h_{c}^{i}$ can be calculated based on the gap temperature drop $\Delta T_{g}$ necessary to produce a 500-psi (3.45-MPa) contact pressure and the peak heat flux at the pellet/tube interface. That is,

$$
\begin{aligned}
h_{c}^{i} & =q_{p}^{\prime} / \Delta T_{g} \\
& =1.09 \times 10^{6} / 310 \mathrm{Btu} / \mathrm{h}-\mathrm{ft}^{2}-{ }^{\circ} \mathrm{F}, \\
h_{c}^{i} & =3516 \mathrm{Btu} / \mathrm{h}-\mathrm{ft}^{2}-{ }^{\circ} \mathrm{F}\left(14,323 \mathrm{~W} / \mathrm{m}^{2}-\mathrm{K}\right) .
\end{aligned}
$$

The value of $h_{c}^{i}$ is at the low end of the range of measured values of $h_{c}$ described previously at a contact pressure of $500 \mathrm{psi}(3.45 \mathrm{MPa})$ and temperatures of 300 and $500^{\circ} \mathrm{F}(148.9$ and $\left.260^{\circ} \mathrm{C}\right) .{ }^{71}$ Conservatively, the value of $h_{c}$ selected for use in the RELAP5 model is

$$
h_{c}=3500 \mathrm{Btu} / \mathrm{h}-\mathrm{ft}^{2}-^{\circ} \mathrm{F}\left(19,873 \mathrm{~W} / \mathrm{m}^{2}-\mathrm{K}\right) \text {. }
$$

Importantly, use of this value of $h_{c}$ will lead to a conservative calculation of the gap temperature drop at the target hot spot (i.e., core axial centerline) and a representative value at other locations only when the heat flux is not too much below $q_{p}^{\prime \prime}$. As the heat flux decreases further, this value becomes optimistic. In these cases, the analyst should simply add an additional temperature margin to the code predicted values to determine the pellet temperatures. A conservative temperature margin can be calculated as the difference between the code calculated gap temperature drop and that needed to provide a $h_{c}=3500$ $\mathrm{Btu} / \mathrm{h}-\mathrm{ft}^{2}-^{\circ} \mathrm{F}\left(19,873 \mathrm{~W} / \mathrm{m}^{2}-\mathrm{K}\right)\left[\Delta T_{8}-310^{\circ} \mathrm{F}\left(172^{\circ} \mathrm{C}\right)\right]$.

With the $0.1-$ mil $\left(2.54 \times 10^{-3}-\mathrm{mm}\right)$ gap assumed for the RELAP5 model, the effective thermal conductivity $k_{\text {eff }}$ of the gap is

$$
\begin{aligned}
& k_{\text {eff }}=h_{c} \times 0.1 \mathrm{mil} \text {, } \\
& =3500 \mathrm{Btu} / \mathrm{h}-\mathrm{ft}^{2}-{ }^{\circ} \mathrm{F} \times 0.1 \mathrm{mil} \text {, } \\
& k_{\text {eff }}=8.11 \times 10^{-6} \mathrm{Btu} / \mathrm{s}-\mathrm{ft}-{ }^{\circ} \mathrm{F}\left(5.06 \times 10^{-3} \mathrm{~W} / \mathrm{m}-\mathrm{K}\right) \text {. }
\end{aligned}
$$


As mentioned previously, the portion of the target tube without pellets contains a void space for fission gas release and an aluminum support liner. Because the thermal contact between the target tube and support liner may or may not be good, the liner is not included in the heat structure model of this portion of the target rod. Thus, the model includes only the tube and oxide, with outer radial boundaries as given previously for the region with pellets.

Thermophysical properties could not be found for the 8001 aluminum ${ }^{62}$ target pellet containment tube. The composition of the alloy, in percent, is 0.17 silicon, $0.45-0.7$ iron, 0.15 copper $9.9-1.3$ nickel, 0.05 zinc, and the balance essentially aluminum. ${ }^{7}$

The specific heat of 8001 aluminum was taken to be the mass weighted average of the values of its major constituents, aluminum (98.5\%), nickel (1\%), and iron (0.5\%). The specific heats of the components are presented in Table 15 along with the composition average specific heat and volumetric heat capacity. The calculation of the latter assumed a material density of pure aluminum, $169 \mathrm{lb} / \mathrm{mt}^{3}\left(2710 \mathrm{~kg} / \mathrm{m}^{3}\right) .^{37}$

The thermal conductivity of the 8001 aluminum containment tube was taken to be that of an alloy with a composition as close as possible to 8001 cluminum. The composition of the alloy selected, in percent, is 0.43 iron, 0.10 silicon, 0.32 magnesium, and the balance aluminum. The thermal conductivity of this alloy is presented in Table $16^{78}$

The flow rate through the target region during HFIR normal operation varies from about 710 to $770 \mathrm{gal} / \mathrm{min}\left(0.045\right.$ to $\left.0.049 \mathrm{~m}^{3} / \mathrm{s}\right)$, depending upon the target configuration as well as that of the remainder of the system..$^{60}$ When the target is configured with 30 target rods and the hydraulic tube, design information indicates that the flow rate is $752 \mathrm{gal} / \mathrm{min}\left(0.047 \mathrm{~m}^{3} / \mathrm{s}\right)$ with $649 \mathrm{gal} / \mathrm{min}\left(0.041 \mathrm{~m}^{3} / \mathrm{s}\right)$ through the heated flow path and $103 \mathrm{gal} / \mathrm{min}\left(6.5 \times 10^{-3}\right.$ $\mathrm{m}^{3} / \mathrm{s}$ ) through unheated flow paths. Following normalization of these flows based on operation data, the flows through the target region are 663 and $105 \mathrm{gal} / \mathrm{min}\left(4.1 \times 10^{-2}\right.$ and $6.62 \times 10^{-3} \mathrm{~m}^{3} / \mathrm{s}$ ) for the heated and unheated regions, respectively.

Table 15. Target pellet containment tube specific heat and volumetric heat capacity

\begin{tabular}{|c|c|c|c|c|c|}
\hline \multirow{2}{*}{$\begin{array}{c}\text { Temperature } \\
\left({ }^{\circ} \mathrm{F}\right)\end{array}$} & \multicolumn{4}{|c|}{ 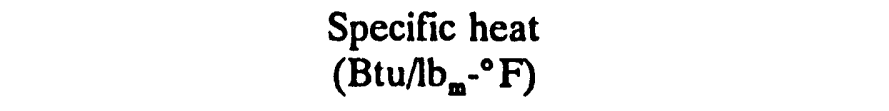 } & \multirow{2}{*}{$\begin{array}{c}\text { Volumetric } \\
\text { heat } \\
\text { capacity } \\
\left(\mathrm{Btu} / \mathrm{ft}^{3}-^{\circ} \mathrm{F}\right)\end{array}$} \\
\hline & Aluminum ${ }^{a}$ & Iron $^{b}$ & Nickel $^{c}$ & Tube $^{d}$ & \\
\hline 80 & 0.215 & 0.104 & 0.107 & 0.213 & 36.0 \\
\hline 440 & 0.238 & 0.128 & 0.125 & 0.236 & 39.9 \\
\hline 674 & 0.252 & 0.141 & 0.160 & 0.251 & 42.4 \\
\hline 710 & 0.255 & 0.142 & 0.130 & 0.253 & 42.8 \\
\hline 980 & 0.274 & 0.161 & 0.126 & 0.272 & 46.0 \\
\hline 1205 & 0.305 & 0.190 & 0.131 & 0.303 & 51.2 \\
\hline
\end{tabular}

\footnotetext{
${ }^{a}$ Reference 38 .

${ }^{b}$ Reference 79.

'Reference 80.

${ }^{d}<C_{p}($ tube $)>=0.985 C_{p}(\mathrm{Al})+0.005 C_{p}(\mathrm{Fe})+0.01 C_{p}(\mathrm{Ni})$.
} 
Table 16. Target pellet containment tube thermal conductivity

\begin{tabular}{cc}
\hline $\begin{array}{c}\text { Temperature } \\
\left({ }^{\circ} \mathrm{F}\right)\end{array}$ & $\begin{array}{c}\text { Thermal } \\
\text { conductivity } \\
\left(\mathrm{Btu} / \mathrm{s}-\mathrm{ft}-{ }^{\circ} \mathrm{F}\right)\end{array}$ \\
\hline 80 & $0.0336^{\circ}$ \\
122 & 0.0336 \\
302 & 0.0347 \\
572 & 0.0356 \\
1200 & $0.0383^{\circ}$ \\
\hline \multicolumn{2}{c}{ 'Values extrapolated based on linear } \\
equation fit to data.
\end{tabular}

The roughness of the surfaces of the target region structures was assumed to be $20 \mu$ in. $\left(5.08 \times 10^{-4} \mathrm{~mm}\right)$, the same as that used for the fuel. Calibration of the model to obtain the desired flows through the heated and unheated regions was achieved using the abrupt area change model at the channel entrances (junctions 17-01 and 17-02) and exits (junctions 8-03 and 8-04). At the channel exits, the model simulates the target grid orifices, which are positioned beneath the target assembly. The area used to model the orifices is approximately 3 times smaller than the heated channel flow area. An area approximately 19 times smaller $\left(0.004789 \mathrm{ft}^{2}\right.$ or $\left.4.45 \times 10^{-4} \mathrm{~m}^{2}\right)$ than the unheated channel area is used at the channel exit and was found to provide the same pressure drop that exists at the heated channel exit (i.e., the pressure drop simulating that over the target grid orifices). In addition, an area approximately 14 times smaller $\left(0.00349 \mathrm{ft}^{2}\right.$ or $\left.3.24 \times 10^{-4} \mathrm{~m}^{2}\right)$ than the unheated channel flow area was used at the channel entrance. This simulates pressure drops through various orifices controlling flow through the target "bypass" (unheated) region.

The power liberated in the target region during HFIR normal operation at $85 \mathrm{MW}$ is 888 $\mathrm{kW}$, as presented previously in Table 1. In the RELAP5 model, this power is assumed to be absorbed within the pellet core. Because the radial peak-to-average thermal neutron flux ratio in the target is small, $\leq 1.04$, radial power variations within this region are neglected. ${ }^{81}$ The average of the target BOC fission and EOC decay heat axial distributions was used in the model. The two distributions are similar. The average distribution over the active length derived from the base heat load calculations was scaled upward to account for the difference between the target configuration used in the calculations and that producing the highest heat loads. In addition, it was scaled upward to account for uncertainties in the calculations. A multiplicative factor of $\mathbf{2 . 2 2}$ was used that includes a $\mathbf{1 5 \%}$ margin for uncertainty. The effect of this factor is to increase the target loads to 2.1 times that obtained in the base heat load calculations (i.e., $417 \mathrm{~kW}$ at $85 \mathrm{MW}$ total core power). ${ }^{27}$

As indicated in Fig. 7 , the heated target region is broken axially into seven subregions. The top and bottom subregions are 2 in. $(5.08 \mathrm{~cm})$ long and contain the portions of the rod without pellets. The remaining five subregions, each 4 in. $(10.2 \mathrm{~cm})$ long, contain the pellets. Target rod RELAP5 internal source multipliers were calculated by distributing the total target region power to each heat structure according to surface area. Then, the axial power factors were used to scale the multipliers to represent the axial power variation. The target region 
multipliers are referenced to the extra-fuel element power. Table 17 presents the target region axial power peaking factors and internal source multipliers.

Table 17. Target axial power peaking factors and

RELAP5 internal source multipliers

\begin{tabular}{ccc}
\hline $\begin{array}{c}\text { Axial } \\
\text { location } \\
\text { (top-to-bottom) }\end{array}$ & $\begin{array}{c}\text { Axial power } \\
\text { peaking } \\
\text { factor }\end{array}$ & $\begin{array}{c}\text { Internal } \\
\text { source } \\
\text { multiplier }\end{array}$ \\
\hline 1 & 0.458 & $3.72 \times 10^{-3}$ \\
2 & 1.87 & $3.04 \times 10^{-2}$ \\
3 & 2.77 & $4.48 \times 10^{-2}$ \\
4 & 3.10 & $5.02 \times 10^{-2}$ \\
5 & 2.75 & $4.45 \times 10^{-2}$ \\
6 & 1.84 & $2.98 \times 10^{-2}$ \\
7 & 0.444 & $3.60 \times 10^{-3}$ \\
\hline
\end{tabular}

\subsubsection{Control cylinders}

As shown in Fig. 7, the control cylinders and associated flow channels are modeled with two sets of heat structures (28-01 through 28-05 and 29-01 through 29-05) and three flow channels (hydrodynamic volumes 27,28 , and 29). The location of the control cylinders and annular cooling passages within the HFIR core are indicated in Fig. 16. As shown, the control cylinders are contained in an annular region between the outer fuel element and the beryllium reflector. With reference to Fig. 7 , the outermost control region flow channel is connected to heat structures representing the innermost portion of the removable beryllium reflector (to be described in the following section).

The inner control cylinder, which is a single piece, performs shim and regulating functions. The outer cylinder is divided into quadrants, each performing shim and safety functions. The control cylinders are divided into three longitudinal sections, each of which has different neutron absorbing characteristics. The "black" region is the most absorbing followed in turn by the "gray" and "white" regions. The composition and location of these regions are provided in Fig. 17.

As assumed in calculating flow areas and hydraulic diameters for the target region, the presence of the oxide on aluminum structures in the control region is neglected due to its small effect on these parameters. However, also consistent with previous treatment, the effect of the oxide on control cylinder heat transfer is modeled.

The inside and outside radii of the annular region containing the control cylinders are ${ }^{25}$

inside radius $=8.567$ in. $(21.76 \mathrm{~cm})$,

outside radius $=9.436 \mathrm{in} .(23.97 \mathrm{~cm})$. 


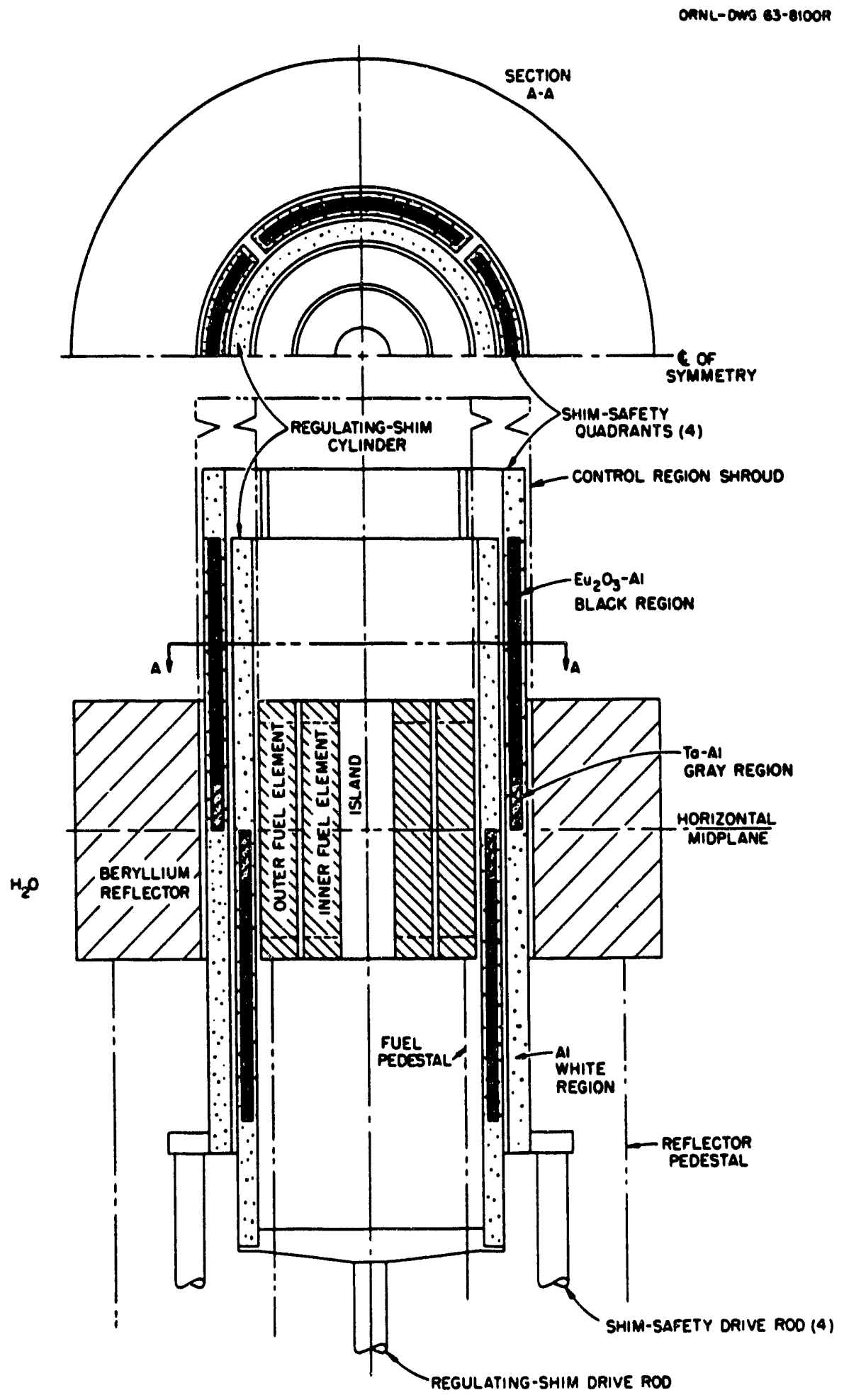

Fig. 16. Schematic representation of control cylinders within HFIR core. 


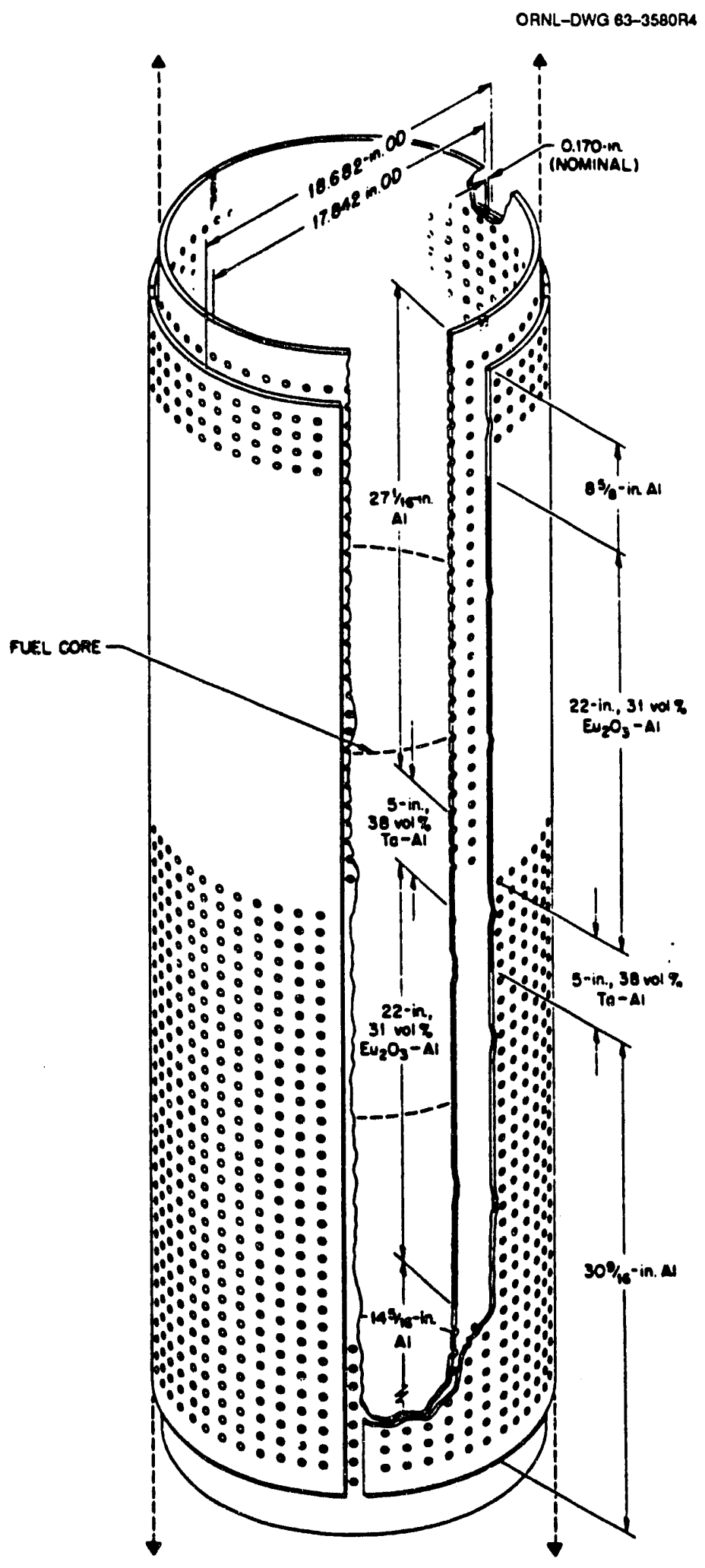

Fig. 17. Control cylinders. 
The inside $r_{i}^{j}$ and outside $r_{o}^{j}$ radii of the inner control cylinder and those of the outer control cylinder $p_{i}$ and $p_{o}$ are

$$
\begin{aligned}
& r_{i}^{r}=8.671 \text { in. }(22.02 \mathrm{~cm}), \\
& r_{0}=8.921 \text { in. }(22.66 \mathrm{~cm}), \\
& r_{i}=9.091 \text { in. }(23.09 \mathrm{~cm}), \\
& r_{0}=9.341 \text { in. }(23.73 \mathrm{~cm}) .
\end{aligned}
$$

For each outer control cylinder quadrant, $P_{i}$ and $p_{o}$ include a radial offset of 0.041 in. (0.104 $\mathrm{cm}$ ) in the quadrant median axial centerline from the core centerline. ${ }^{82}$ The thickness of the inner, $\Delta r_{i}$, middle, $\Delta r_{m}$, and outer, $\Delta r_{o}$, annular flow passages are therefore

$$
\begin{aligned}
\Delta r_{i} & =0.104 \text { in. }(0.264 \mathrm{~cm}), \\
\Delta r_{m} & =0.170 \text { in. }(0.432 \mathrm{~cm}), \\
\Delta r_{o} & =0.095 \text { in. }(0.241 \mathrm{~cm}) .
\end{aligned}
$$

The flow area $A_{f}^{i}$ and hydraulic diameter $D_{k y}^{i}$ of the inner annular region are calculated as follows:

$$
\begin{aligned}
A_{f}^{i} & =\pi\left(8.671^{2}-8.567^{2}\right) / 144 \mathrm{ft}^{2}, \\
A_{f}^{i} & =0.0391 \mathrm{ft}^{2}\left(3.63 \times 10^{-3} \mathrm{~m}^{2}\right), \\
D_{h y}^{i} & =4 A_{f}^{i} / \text { wetted perimeter, } \\
& =4 \times 0.0391 /[2 \pi(8.567+8.671) / 12] \mathrm{ft}, \\
D_{h y}^{i} & =0.0173 \mathrm{ft}\left(5.27 \times 10^{-3} \mathrm{~m}\right) .
\end{aligned}
$$

Similarly, the flow areas $A_{f}^{m}$ and $A_{f}^{o}$ and hydraulic diameters $D_{k y}^{m}$ and $D_{k y}^{o}$, of the middle and outer annular regions, respectively, were calculated to be

$$
\begin{aligned}
A_{f}^{m} & =0.0668 \mathrm{ft}^{2}\left(6.21 \times 10^{-3} \mathrm{~m}^{2}\right), \\
D_{h y}^{m} & =0.0283 \mathrm{ft}\left(8.63 \times 10^{-3} \mathrm{~m}\right), \\
A_{f}^{o} & =0.0389 \mathrm{ft}^{2}\left(3.61 \times 10^{-3} \mathrm{~m}^{2}\right), \\
D_{h y}^{o} & =0.0158 \mathrm{ft}\left(4.82 \times 10^{-3} \mathrm{~m}\right) .
\end{aligned}
$$

Because the reactor will generally be shut down following the initiation of accidents of interest, the RELAP5 input model is configured with the black region within the vertical boundaries of the core. In addition, it is assumed for simplicity that the black region extends the full 24-in. $(61.0-\mathrm{cm})$ height of the core, when in fact the length of the black region is 22 in. $(55.9 \mathrm{~cm})^{82}$

As indicated in Fig. 17, the black region contains a europium oxide $\left(\mathrm{Eu}_{2} \mathrm{O}_{3}\right)$-aluminum "core" clad in 6061-F aluminum. The core and clad thicknesses are 0.2 and 0.025 in. (0.508 and $0.064 \mathrm{~cm}$ ), respectively. ${ }^{81}$ An oxide film is assumed to form on the control cylinder surfaces with a thickness of $0.689 \mathrm{mil}(0.0175 \mathrm{~mm})$, the same as that used for the average fuel 
plates. The radial boundaries of the regions comprising the conirol cylinders are presented in Table 18.

Table 18. Radial boundaries of regions comprising the control cylinders

\begin{tabular}{lcclcc}
\hline & \multicolumn{2}{c}{$\begin{array}{c}\text { Inner control cylinder radius } \\
\text { (ft) }\end{array}$} & & \multicolumn{2}{c}{$\begin{array}{c}\text { Outer control cylinder } \\
\text { (ft) }\end{array}$} \\
\cline { 2 - 3 } \cline { 5 - 6 } Region & Inside & Outside & & Inside & Outside \\
\cline { 2 - 3 } & & & & & \\
Oxide & 0.722571 & 0.722628 & & 0.754155 & 0.754212 \\
Clad & 0.722628 & 0.724667 & & 0.754212 & 0.756250 \\
Core & 0.724667 & 0.741333 & & 0.756250 & 0.772917 \\
Clad & 0.741333 & 0.743371 & & 0.772917 & 0.774955 \\
Oxide & 0.743371 & 0.743428 & & 0.774955 & 0.775012 \\
\hline
\end{tabular}

${ }^{a}$ Based on outer control cylinder inside and outside radii of curvature of 9.050 and 9.300 in., respectively. ${ }^{82}$

The inside $A_{s, i}^{i}$ and outside $A_{s, o}^{i}$ surface areas of the inner control cylinder and those of the outer cylinder, $A_{s, i}^{o}$ and $A_{s, o}^{o}$, are

$$
\begin{aligned}
A_{s, i}^{i} & =2 \pi r_{i}^{i} L \\
& =2 \pi \times 0.722571 \times 2 \mathrm{ft}^{2}, \\
A_{s, i}^{i} & =9.08 \mathrm{ft}^{2}\left(0.844 \mathrm{~m}^{2}\right), \\
A_{s, o}^{i} & =9.34 \mathrm{ft}^{2}\left(0.868 \mathrm{~m}^{2}\right), \\
A_{s, i}^{o} & =9.48 \mathrm{ft}^{2}\left(0.881 \mathrm{~m}^{2}\right), \\
A_{s, 0}^{o} & =9.74 \mathrm{ft}^{2}\left(0.905 \mathrm{~m}^{2}\right) .
\end{aligned}
$$

The core region of the control cylinders contains $59.14 \mathrm{wt} \% \mathrm{Eu}_{2} \mathrm{O}_{3}$ and the balance 1100 aluminum. ${ }^{82}$ The density of the core region at RT is reported to be $4.25 \mathrm{~g} / \mathrm{cm}^{3}$ $\left(265.3 \mathrm{lb}_{\mathrm{m}} / \mathrm{ft}^{3}\right){ }^{82}$ The temperature-dependent specific heat of the control cylinder core was calculated as a mass weighted average of those of pure aluminum and $\mathrm{Eu}_{2} \mathrm{O}_{3}$ (cubic crystal structure) ${ }^{83}$ Table 19 presents the specific heats of aluminum and $\mathrm{Eu}_{2} \mathrm{O}_{3}$ along with the core average values and the core volumetric heat capacity. The core region thermal conductivity is reported to be $39 \mathrm{Btu} / \mathrm{h}-\mathrm{ft}-{ }^{\circ} \mathrm{F}\left(0.0108 \mathrm{Btu} / \mathrm{s}-\mathrm{ft}-{ }^{\circ} \mathrm{F}\right.$ or $\left.67.5 \mathrm{~W} / \mathrm{m}-\mathrm{K}\right)$, presumably at $\mathrm{RT}^{82}$ no temperature-dependent data could be located.

Thermophysical properties of the 6061-F aluminum control cylinder cladding could not be found. Therefore, properties of 6061-T6 aluminum were used. The specific heat of 6061T6 aluminum was presented previously in Table 6 and was used, along with its density, 169 $\mathrm{lb}_{\mathrm{m}} / \mathrm{ft}^{3}\left(2710 \mathrm{~kg} / \mathrm{m}^{3}\right)$, to calculate the clad volumetric heat capacities presented in Table 20 . The clad thermal conductivity is presented in Table 21 . 
Table 19. Control cylinder core specific heat and volumetric heat capacity

\begin{tabular}{|c|c|c|c|c|}
\hline \multirow{2}{*}{$\begin{array}{c}\text { Temperature } \\
\left({ }^{\circ} \mathrm{F}\right)\end{array}$} & \multicolumn{2}{|c|}{$\begin{array}{l}\text { Specific heat } \\
\left(B t u / b_{m}-{ }^{\circ} F\right)\end{array}$} & \multirow[b]{2}{*}{ Core } & \multirow{2}{*}{$\begin{array}{l}\text { Volumetric } \\
\text { heat capacity } \\
\left(\mathrm{Btu} / \mathrm{ft}^{3}-^{\circ} \mathrm{F}\right)\end{array}$} \\
\hline & $\mathrm{Al}^{a}$ & $\mathrm{Eu}_{2} \mathrm{O}_{3}^{b}$ & & \\
\hline 80 & 0.215 & 0.085 & 0.138 & 36.6 \\
\hline 440 & 0.238 & 0.093 & 0.152 & 40.3 \\
\hline 980 & 0.274 & 0.099 & 0.171 & 45.4 \\
\hline 1205 & 0.305 & 0.101 & 0.184 & 48.8 \\
\hline
\end{tabular}

${ }^{a}$ Reference 38.

${ }^{b}$ Reference 84.

Table 20. Control cylinder clad volumetric heat capacity

\begin{tabular}{cc}
\hline $\begin{array}{c}\text { Temperature } \\
\left({ }^{\circ} \mathrm{F}\right)\end{array}$ & $\begin{array}{c}\text { Volumetric heat } \\
\text { capacity } \\
\left(\mathrm{Btu}^{\left.\mathrm{ft} \mathrm{ft}^{\circ}-\mathrm{F}\right)^{\mathrm{a}}}\right.\end{array}$ \\
\hline 80 & 36.3 \\
440 & 39.9 \\
980 & 45.5 \\
1160 & 47.3 \\
\hline
\end{tabular}

${ }^{a} 6061-$ T6 aluminum values used.

Table 21. Control cylinder clad thermal conductivity ${ }^{48}$

\begin{tabular}{cc}
$\begin{array}{c}\text { Temperature } \\
\left({ }^{\circ} \mathrm{F}\right)\end{array}$ & $\begin{array}{c}\text { Thermal conductivity } \\
(\text { Btu/s-ft- }\end{array}$ \\
\hline 82.4 & 0.0255 \\
442.4 & 0.0299 \\
802.4 & 0.0310 \\
1204 & $0.0276^{b}$ \\
\hline
\end{tabular}

${ }^{a}$ 6061-T6 aluminum values used.

${ }^{b}$ Extrapolated. 
Based on design information, ${ }^{82}$ the flow rate through the control region during HFIR normal operation is $1080 \mathrm{gal} / \mathrm{min}\left(0.06814 \mathrm{~m}^{3} / \mathrm{s}\right)$. A flow rate of $1103 \mathrm{gal} / \mathrm{min}$ $\left(0.06959 \mathrm{~m}^{3} / \mathrm{s}\right)$ or $151.9 \mathrm{lb}_{\mathrm{m}} / \mathrm{s}(68.90 \mathrm{~kg} / \mathrm{s})$ was calculated for the control region following normalization with operation data.

As shown in Fig. 17, the control cylinders possess numerous holes that make the calculation of flow/pressure drop difficult. Thus, an "effective" roughness of the control region surfaces was selected that provided the desired flow and pressure drop. On this basis, a surface roughness of $6.5 \times 10^{-4} \mathrm{ft}\left(1.98 \times 10^{-4} \mathrm{~m}\right)$ is used in the model. Consistent with the flow geometry, the abrupt area change model was used at the entrances and exits to the control region.

The power liberated in the control cylinders during HFIR normal operation at $85 \mathrm{MW}$ is estimated to be $1.71 \mathrm{MW}$, as presented previously in Table 1. In the RELAP5 model, the total heat load is assumed to be absorbed within the core of the control cylinders and along the modeled $2-\mathrm{ft}(0.610-\mathrm{m})$ length, rather than their full length. With reference to Fig. 7 , the control region is divided axially into five subregions. The center region is 4 in. $(10.2 \mathrm{~cm})$ long, and each of the remaining four subregions are $5 \mathrm{in} .(12.7 \mathrm{~cm})$ long. The axial power distribution in the control cylinders is based on the decay heat load distribution with an adjustment. This was done because control cylinder heating due to fission heat loads was calculated under normal operating conditions with the cylinders far from their shutdown position. Thus, the fission axial heat load distribution is not representative after shutdown. However, the extra fission heat absorbed in the black regions of the control cylinders compared to the white regions is not included in the decay heat axial distribution. Thus, based on a comparison of fission heat loads in these regions, the decay heat axial distribution was adjusted upward by $38 \%$ to account for this effect. ${ }^{27}$ The resulting axial power factors are presented in Table 22. Also presented in Table 22 are the RELAP5 heat structure multipliers for the control cylinders. The multipliers were calculated by distributing the 1.71-MW control region heat load based on relative heat structure surface area and axial power factor. The control region multipliers are referenced to the extra-fuel element power.

Table 22. Control cylinder axial power peaking factors and RELAP5 internal source multipliers

\begin{tabular}{|c|c|c|c|c|}
\hline \multirow{2}{*}{$\begin{array}{l}\text { Axial location } \\
\text { (top-to-bottom) }\end{array}$} & \multicolumn{2}{|c|}{$\begin{array}{l}\text { Axial power } \\
\text { peaking factor }\end{array}$} & \multicolumn{2}{|c|}{$\begin{array}{c}\text { Internal } \\
\text { source multiplier }\end{array}$} \\
\hline & Inner & $\overline{\text { Outer }}$ & Inner & Outer \\
\hline 1 & 1.03 & 0.829 & $3.17 \times 10^{-2}$ & $2.47 \times 10^{-2}$ \\
\hline 2 & 1.63 & 1.63 & $5.02 \times 10^{-2}$ & $4.86 \times 10^{-2}$ \\
\hline 3 & 1.88 & 1.88 & $4.64 \times 10^{-2}$ & $4.47 \times 10^{-2}$ \\
\hline 4 & 1.63 & 1.63 & $5.02 \times 10^{-2}$ & $4.86 \times 10^{-2}$ \\
\hline 5 & 0.842 & 1.03 & $2.60 \times 10^{-2}$ & $3.07 \times 10^{-2}$ \\
\hline
\end{tabular}




\subsubsection{Beryllium Reflector}

The beryllium reflector is shown in vertical cross section in Fig. 14 and in horizontal cross section at the core midplane in Fig. 18. It is evident in Fig. 18 that the reflector is composed of five concentric cylinders that are cooled by many small coolant passages (the small circles within and at interfaces between cylinders). The inner three reflector cylinders comprise the "removable" beryllium reflector. The fourth cylinder is referred to as the "semipermaneni" reflector while the outermost and largest cylinder is the "permanent" reflector. Also noteworthy in Fig. 18 are the experimental facilities located in, or terminating in, the reflector. These include three horizontal beam tubes, four slant access tubes called engineering facilities, and 42 vertical holes. The latter are denoted by "VXF" and "RB" along with the facility number (Fig. 18 does not contain the recent modifications to the RB facilities). ${ }^{24}$

As shown in Fig. 7, the beryllium reflector is divided into four subregions in the RELAP5 input model. With the exception of the engineering facilities, the experimental facilities are "homogenized" within these subregions. Because the engineering facilities are on the periphery of the reflector, flow through them is assumed to occur through the modeled bypass regions (U-bypass and L-bypass in Fig. 7). The innermost subregion ( $\mathrm{R}-\mathrm{Be}$ ) consists of the inner beryllium cylinder in the removable reflector. This small region was created to simulate the portion of the reflector with the highest heat load per unit volume. The subregion adjacent to this region ( $\mathrm{S} / \mathrm{R}-\mathrm{Be}$ ) is composed of the remaining two removable reflector cylinders along with the semipermanent reflector cylinder. The last two subregions model the permanent reflector. This portion of the reflector was divided into two pieces to better represent the cooling characteristics of each. The inner region (I-P-Be) includes the portion up to and including half of the outermost ring of small holes. The outer region (O-P-Be) consists of the remaining portion and is cooled by water in the vessel adjacent to it in addition to the small coolant holes.

A detailed description of the four reflector subregions comprising the model is presented in the following three subsections. In the first, the innermost ("hot") removable reflector subregion is described. In the following two subsections, descriptions are provided of the subregion composed of the rest of the removable reflector and semipermanent reflector and the two subregions comprising the permanent reflector.

\subsubsection{Hot removable reflector}

The hot removable reflector subregion contains a beryllium cylinder with inner and outer radii of 9.498 and $9.889 \mathrm{in}$. (24.12 and $25.12 \mathrm{~cm}$ ), respectively. ${ }^{25}$ The inside surface of the cylinder is lined with 62 -mil-thick $(1.57-\mathrm{mm})$ aluminum. Cooling of this portion of the reflector is provided on the inside surface of the aluminum by water flowing between it and the outermost control cylinder (see Sect. 3.2.4). On the outside surface of the beryllium cylinder, cooling is provided by water flowing through 144 grooves [ $0.125 \mathrm{in}$. $(0.318 \mathrm{~cm})$ in diameter] on the surfaces comprising the interface between the two innermost reflector cylinders. $^{85}$ Consistent with the treatment of oxide in other regions, oxide is assumed to form on the inside surface of the aluminum liner, and its effect on conduction heat transfer is modeled.

Based on previous analysis, ${ }^{85}$ the grooves are assumed to be 0.125 -in.-diam $(0.318-\mathrm{cm})$ holes. Thus, the flow area per hole $A_{f}^{h}$ and the hydraulic diameter $D_{h y}$ are

$$
\begin{aligned}
& A_{f}^{h}=8.52 \times 10^{-5} \mathrm{ft}^{2}\left(7.92 \times 10^{-6} \mathrm{~m}^{2}\right), \\
& D_{h y}=1.04 \times 10^{-2} \mathrm{ft}\left(3.17 \times 10^{-3} \mathrm{~m}\right) .
\end{aligned}
$$




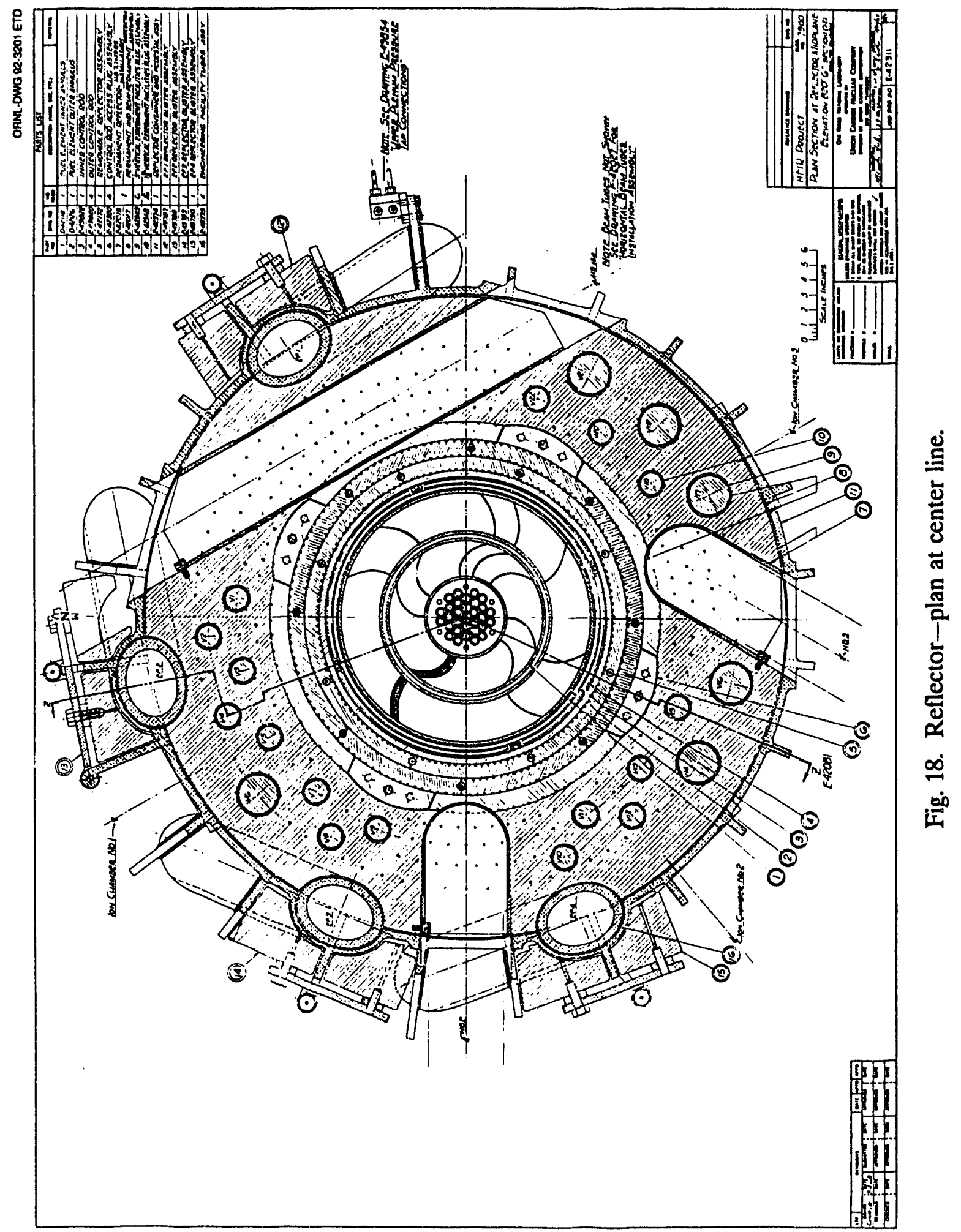


It was assumed that the flow through half of the holes between the two innermost reflector cylinders effectively cools each cylinder. Therefore, with 72 holes associated with the hot removable reflector region, the total flow area $A_{f}^{\prime}$ is

$$
A_{f}^{f}=6.13 \times 10^{-3} \mathrm{ft}^{2}\left(5.69 \times 10^{-4} \mathrm{~m}^{2}\right) \text {. }
$$

The thickness of the oxide on the inner surface of the aluminum liner is assumed to be $0.689 \mathrm{mil}(0.0175 \mathrm{~mm})$ (the same as that in the target and control regions). Accounting for the presence of the oxide, the radial boundaries of the regions comprising the hot removable reflector cylinders are presented in Table 23.

Table 23. Radial boundaries of regions

comprising the hot removable reflector cylinders

\begin{tabular}{lll}
\hline & \multicolumn{2}{c}{$\begin{array}{c}\text { Radii } \\
(\mathrm{ft})\end{array}$} \\
\cline { 2 - 3 } & \multicolumn{1}{c}{ Inside } & \multicolumn{1}{c}{ Outside } \\
\hline Oxide & 0.786322 & 0.786379 \\
Aluminum & 0.786379 & 0.7915 \\
Beryllium & 0.7915 & 0.8241 \\
\hline
\end{tabular}

The heat transfer surface area $A_{s}^{h}$ of half the holes along the 2-ft $(0.610-\mathrm{m})$ length $L$ of the reflector is

$$
\begin{aligned}
& A_{s}^{h}=72 \times 2 \pi r L, \\
& A_{s}^{h}=4.71 \mathrm{ft}^{2}\left(0.438 \mathrm{~m}^{2}\right) .
\end{aligned}
$$

The total outside surface area $A_{s}^{c}$ of the innermost reflector cylinder is

$$
\begin{aligned}
& A_{s}^{c}=2 \pi r L \\
& A_{s}^{c}=10.36 \mathrm{ft}^{2}\left(0.9624 \mathrm{~m}^{2}\right) .
\end{aligned}
$$

In modeling the heat transfer from the outside cylinder surface to the fluid, the surface area is conservatively taken to be the smaller of the two areas above. Thus, in using the RELAP5 1-D conduction model in cylindrical geometry the "effective" height of the reflector cylinder, $h_{\text {eff }}$ is

$$
\begin{aligned}
& h_{\text {eff }}=2 \times 4.71 / 10.36 \mathrm{ft}, \\
& h_{\text {eff }}=0.909 \mathrm{ft}(0.277 \mathrm{~m}) .
\end{aligned}
$$

The reduction of the effective cylinder height results in a similar reduction in the area of the inside surface of the aluminum liner. In addition, the volume and mass of the cylinder are 
effectively reduced by $55 \%$ as is the total heat capacity. On the other hand, the volumetric heat generation rate is increased by $55 \%$. The mass and total heat capacity was not "corrected" in the model by using higher "effective" densities because the region comprises a small portion of the reflector, and thus it would not be expected to effect the rest of the system significantly. In light of the other effects of using a reduced cylinder effective height, the model should be conservative overall.

The reflector liner is constructed of 6061-T6 aluminum. ${ }^{85}$ Thermophysical properties of this alloy have been previously presented in Tables 19 and 20. Similarly, properties of the oxide film were presented in Sect. 3.2.1. The density of beryllium at RT is reported to be 116 $\mathrm{lb}_{\mathrm{m}} / \mathrm{ft}^{3}\left(1858 \mathrm{~kg} / \mathrm{m}^{3}\right){ }^{86}$ The specific heat and volumetric heat capacity of beryllium are presented in Table $24,{ }^{87}$ and its thermal conductivity is provided in Table $25^{88}$

Table 24. Beryllium specific heat and volumetric heat capacity

\begin{tabular}{ccc}
\hline $\begin{array}{c}\text { Temperature } \\
\left({ }^{\circ} \mathrm{F}\right)\end{array}$ & $\begin{array}{c}\text { Specific heat } \\
\left(\mathrm{Btu}^{\prime} / \mathrm{b}_{\mathrm{m}}{ }^{\circ} \mathrm{F}\right)\end{array}$ & $\begin{array}{c}\text { Volumetri? heat } \\
\text { capa ity } \\
\left(\mathrm{Btu}^{\mathrm{f}} / \mathrm{ft}^{3}{ }^{\circ} \mathrm{F}\right)\end{array}$ \\
\hline 80 & 0.432 & 50.1 \\
392 & 0.540 & 62.6 \\
752 & 0.615 & 71.3 \\
1292 & 0.692 & 80.3 \\
\hline
\end{tabular}

Table 25. Beryllium thermal conductivity

\begin{tabular}{cc}
$\begin{array}{c}\text { Temperature } \\
\left({ }^{\circ} \mathrm{F}\right)\end{array}$ & $\begin{array}{c}\text { Thermal conductivity } \\
\left(\mathrm{Btu} / \mathrm{s}-\mathrm{ft}-{ }^{\circ} \mathrm{F}\right)\end{array}$ \\
\hline 80 & 0.0322 \\
260 & 0.0258 \\
620 & 0.0202 \\
1160 & 0.0156 \\
\hline
\end{tabular}

Based on previous design data and calculations, the total flow rate through the removable reflector was determined to be $-132 \mathrm{gal} / \mathrm{min}\left(8.33 \times 10^{-3} \mathrm{~m}^{3} / \mathrm{s}\right)$ during HFIR normal operation. $^{85}$ These calculations indicated that the fluid velocity was $12.5 \mathrm{ft} / \mathrm{s}(3.81 \mathrm{~m} / \mathrm{s})$ through the total 272 removable reflector holes. The flow rate through the 72 holes associated with the hot removable reflector region can be calculated by scaling the total flow with the relative number of holes. Thus, the subregion flow rate $G$ is

$$
\begin{aligned}
& G=132 \times 72 / 272 \mathrm{gal} / \mathrm{min}, \\
& G=34.9 \mathrm{gal} / \mathrm{min}\left(2.20 \times 10^{-3} \mathrm{~m}^{3} / \mathrm{s}\right) .
\end{aligned}
$$


After normalizing this value with operation data, the flow becomes $35.6 \mathrm{gal} / \mathrm{min}$ $\left(2.25 \times 10^{-3} \mathrm{~m}^{3} / \mathrm{s}\right)$ or $4.91 \mathrm{lb} / \mathrm{m}(2.23 \mathrm{~kg} / \mathrm{s})$. To provide the desired flow rate at the measured pressure drop through the reflector $[-10 \mathrm{psi}(0.0689 \mathrm{MPa})$ in normal operation], the roughness of the channel surfaces was selected to be $2.1 \times 10^{-4} \mathrm{ft}\left(6.40 \times 10^{-5} \mathrm{~m}\right)$. The effect of this "calibration" is to distribute the small pressure drop [ 1 psi $\left.\left(6.89 \times 10^{-3} \mathrm{MPa}\right)\right]$ caused by orifices at the top of the removable reflector over the total length of the channel. The approach simplified the calibration with little loss of accuracy. The abrupt area change model is used at the entrance and exit to the hot removable reflector region based on the nominal channel area.

As indicated in Table 1, the power liberated in the hot removable reflector during HFIR normal operation at $85 \mathrm{MW}$ is estimated to be $327 \mathrm{~kW}$. The average of the region's BOC fission and EOC decay heat axial distributions was used in the model. The two distributions are similar. ${ }^{27}$ In the radial direction, the heat is assumed to be absorbed uniformly. With reference to Fig. 7 , the hot reflector region and the other reflector regions are divided into five subregions, with a discretization matching that of the control region. The center region is 4 in. $(10.16 \mathrm{~cm})$ long, with each of the remaining subregions 5 in. $(12.7 \mathrm{~cm})$ long. As described previously, the effective (modeled) heights of the reflector cylinder heat structures are $\sim 55 \%$ shorter than actual. Based on the relative heat structure surface areas, the axial power factors, and the total $327-\mathrm{kW}$ heat load, RELAP5 internal source multipliers were calculated. Multipliers are referenced to the extra-fuel element power and are presented in Table 26 along with the axial power factors.

Table 26. Hot removable beryllium reflector axial power peaking factors and RELAP5 internal source multipliers

\begin{tabular}{ccc}
\hline $\begin{array}{c}\text { Axial location } \\
\text { (top-to-bottom) }\end{array}$ & $\begin{array}{c}\text { Axial power } \\
\text { peaking factor }\end{array}$ & $\begin{array}{c}\text { Internal } \\
\text { source } \\
\text { multiplier }\end{array}$ \\
\hline 1 & 0.709 & $1.13 \times 10^{-2}$ \\
2 & 1.21 & $1.92 \times 10^{-2}$ \\
3 & 1.35 & $1.73 \times 10^{-2}$ \\
4 & 1.16 & $1.84 \times 10^{-2}$ \\
5 & 0.654 & $1.04 \times 10^{-2}$ \\
\hline
\end{tabular}

\subsubsection{Removable/semipermanent reflector}

The "removable/semipermanent" beryllium reflector subregion is 3.236 in. $(8.219 \mathrm{~cm})$ thick with inner and outer radial boundaries of 9.889 and $13.125 \mathrm{in}$ ( 25.12 and $33.338 \mathrm{~cm}$ ), respectively. With reference to Fig. 18, cooling of this region of the reflector is provided by small coolant passages. Some of these passages are 0.125 -in.-diam $(0.318-\mathrm{cm})$ grooves, while others are narrow slots of differing dimensions. ${ }^{85}$ For simplicity, it is assumed that all the flow is through 0.125 -in.-diam $(0.318-\mathrm{cm})$ holes. Thus, the region hydraulic diameter is $0.0104 \mathrm{ft}$ $\left(3.175 \times 10^{-3} \mathrm{~m}\right)$. The total "effective" number of holes in this region was calculated based on a reported flow velocity of $\sim 13 \mathrm{ft} / \mathrm{s}(3.96 \mathrm{~m} / \mathrm{s})$ and total flow rate of $\sim 600 \mathrm{gal} / \mathrm{min}(\sim 1.34$ 
$\mathrm{ft}^{3} / \mathrm{s}$ or $0.038 \mathrm{~m}^{3} / \mathrm{s}$ ) during normal HFIR operation..$^{85}$ It was assumed that half of the flow at the interface between the semipermanent and permanent reflector $\left[28 \mathrm{gal} / \mathrm{min}\left(1.77 \times 10^{-3}\right.\right.$ $\mathrm{m}^{3} / \mathrm{s}$ ) total] contributes to the total region flow. The total number of 0.125 -in.-diam $(0.318-\mathrm{cm})$ holes $N_{h}$ is calculated to be

$$
\begin{aligned}
N_{h} & \left.=\text { flow/(velocity } A_{f}^{h}\right), \\
& =1.34 /\left(13 \times 8.52 \times 10^{-5}\right), \\
N_{h} & =1.21 \times 10^{3} .
\end{aligned}
$$

The total flow area is $0.103 \mathrm{ft}^{2}\left(9.57 \times 10^{-3} \mathrm{~m}^{2}\right)$, and the total surface area $A_{f}^{h}$ implied by $N_{h}$ holes is

$$
\begin{aligned}
A_{s}^{h} & =\pi D L N_{h}, \\
& =\pi \times 0.0104 \times 2 \times 1.21 \times 10^{3} \mathrm{ft}^{2}, \\
A_{s}^{h} & =79.1 \mathrm{ft}^{2}\left(7.35 \mathrm{~m}^{2}\right) .
\end{aligned}
$$

Due to the numerous cooling passages between the three beryllium cylinders, they are "decoupled" from a thermal-conduction standpoint. Conservatively, "slab" geometry was used to model the cylinders where the slab thickness was taken to be half that of the semipermanent reflector cylinder (the thickest region between coolant passages, 1.183 in.). ${ }^{25}$ The half-thickness was used because one side of the slab is adiabatic, representing a plane of symmetry through its center (horizontally) and along its length. The area of the adiabatic slab surface was selected after considering the total volume of the beryllium cylinders within the region and the total surface area of the holes $A_{s}^{h}$. The total volume $V$ of this region is

$$
\begin{aligned}
& V=\pi\left[(13.125 / 12)^{2}-(9.889 / 12)^{2}\right] \times 2 \mathrm{ft}^{3}, \\
& V=3.25 \mathrm{ft}^{3}\left(0.0920 \mathrm{~m}^{3}\right) .
\end{aligned}
$$

The total surface area $A_{s}^{v}$ of the slab, which is consistent with this volume, is

$$
\begin{aligned}
A_{s}^{v} & =2 \text { V/slab thickness, } \\
& =2 \times 3.25 / 1.183 \times 12 \mathrm{ft}^{2}, \\
A_{s}^{v} & =65.9 \mathrm{ft}^{2}\left(6.12 \mathrm{~m}^{2}\right) .
\end{aligned}
$$

Because $A_{s}^{v}<A_{s}^{h}$, a surface area of $65.9 \mathrm{ft}^{2}\left(6.12 \mathrm{~m}^{2}\right)$ for the model was selected that is slightly conservative and provides the correct region volume.

As mentioned previously, during HFIR normal operation the flow rate through this region was found to be $-600 \mathrm{gal} / \mathrm{min}\left(0.038 \mathrm{~m}^{3} / \mathrm{s}\right)$. Following normalization with operation data, the flow becomes $613 \mathrm{gal} / \mathrm{min}\left(0.039 \mathrm{~m}^{3} / \mathrm{s}\right)$ or $84.4 \mathrm{lb}_{\mathrm{m}} / \mathrm{s}(38.28 \mathrm{~kg} / \mathrm{s})$. The roughness of channel surfaces in this region is the same as that used in the hot removable reflector region, $2.1 \times 10^{-4} \mathrm{ft}\left(6.4 \times 10^{-5} \mathrm{~m}\right)$. This value provides the desired region flow rate and pressure drop. The abrupt area change model is used at the entrance and exit to the region.

As indicated in Table 1, the power liberated in this region during HFIR normal operation at $85 \mathrm{MW}$ is estimated to be $1.21 \mathrm{MW}$. The average of the region's BOC fission and EOC decay heat axial distributions was used in the model. The two distributions are similar. ${ }^{27}$ The 
region heat generation is assumed to be uniform in the radial direction. With reference to Fig. 7, the region is divided into five subregions with a discretization matching that of the control region and other reflector regions. RELAP5 internal source multipliers for this region were calculated based on relative heat structure surface areas, the axial power factors, and the total 1.21-MW heat load. The multipliers are referenced to the extra-fuel element power along with the axial power factors and are presented in Table 27.

Table 27. Removable/semipermanent beryllium reflector axial power peaking factors and RELAPS internal source multipliers

\begin{tabular}{ccc}
\hline $\begin{array}{c}\text { Axial location } \\
\text { (top-to-bottom) }\end{array}$ & $\begin{array}{c}\text { Axial power } \\
\text { peaking factor }\end{array}$ & $\begin{array}{c}\text { Internal } \\
\text { source } \\
\text { multiplier }\end{array}$ \\
\hline 1 & 0.715 & $4.22 \times 10^{-2}$ \\
2 & 1.19 & $7.02 \times 10^{-2}$ \\
3 & 1.34 & $6.32 \times 10^{-2}$ \\
4 & 1.16 & $6.84 \times 10^{-2}$ \\
5 & 0.675 & $3.98 \times 10^{-2}$ \\
\hline
\end{tabular}

\subsubsection{Permanent reflector}

As indicated previously, this region is broken into two parts to more adequately represent their cooling characteristics, which are a little different. The total thickness of the permanent reflector cylinder is 8.375 in. (21.3 cm) with inner and outer radia boundaries $r_{i}$ and $r_{o}$ of 13.125 and 21.5 in. ( 33.3 and $54.6 \mathrm{~cm}$ ), respectively. With reference to Fig. 18, the region is cooled by five concentric rings of 80 coolant holes [0.125-in.-diam $(0.318-\mathrm{cm})]$ uniformly spaced within each ring except where altered by experimental facilities. ${ }^{25}$ Additional cooling is provided in experimental facilities through narrow slots, beam tubes, and by portions of the coolant passages through the semipermanent/permanent reflector interface and control cylinder access plugs. ${ }^{85}$ The inner permanent reflector region is bounded radially by the innermost and outermost [18.219-in. (46.276-cm)] rings of holes. It is assumed that the flow associated with these rings is split equally between the removable/semipernanent reflector and outer permanent reflector regions, respectively (i.e., the number of holes at each interface is split equally tetween adjacent regions). As mentioned previously, the outer permanent reflector revion is also cooled by water outside of the reflector within the vessel.

As in the removable/semipermanent reflector region, it is assumed that all the flow through the permanent reflector is through 0.125 -in.-diam $(0.318-\mathrm{cm})$ holes. As before, the region hydraulic diameter is $0.0104 \mathrm{ft}\left(3.17 \times 10^{-3} \mathrm{~m}\right)$. The split of the total permanent reflector flow between the inner and outer regions was based simply on the ratio of the nominal number of cooling holes associated with each region (as per the above assumption regarding the "splitting" of holes between regions, theic are 40 nominal holes associated with the outer region and 320 with the inner). The total "effective" number of holes in each subregion was "back-calculated" based on a reported flow velocity of $\sim 15 \mathrm{ft} / \mathrm{s}(4.57 \mathrm{~m} / \mathrm{s})$ and 
total flows of $423 \mathrm{gal} / \mathrm{min}\left(0.942 \mathrm{ft}^{3} / \mathrm{s}, 59.1 \mathrm{lb}_{\mathrm{m}} / \mathrm{s}, 0.027 \mathrm{~m}^{3} / \mathrm{s}\right)$ and $53 \mathrm{gal} / \mathrm{min}\left(0.12 \mathrm{ft}^{3} / \mathrm{s}\right.$, $7.4 \mathrm{lb}_{\mathrm{m}} / \mathrm{s}, 3.34 \times 10^{-3} \mathrm{~m}^{3} / \mathrm{s}$ ) for the inner and outer subregions, respectively. ${ }^{85}$ The total effective number of 0.125 -in.-diam $(0.318-\mathrm{cm})$ holes, $N_{h}^{i}$ and $N_{h}^{o}$, in the inner and outer subregions, respectively, are

$$
\begin{aligned}
& N_{h}^{i}=0.942 /\left(15 \times 8.52 \times 10^{.5}\right), \\
& N_{h}^{i}=737, \\
& N_{h}^{s^{i}}=0.12 /\left(15 \times 8.52 \times 10^{-5}\right), \\
& N_{h}^{s^{o}}=94 .
\end{aligned}
$$

The corresponding flow areas $A_{f}^{i}$ and $A_{f}^{\circ}$ are

$$
\begin{aligned}
& A_{f}^{i}=6.28 \times 10^{-2} \mathrm{ft}^{2}\left(5.83 \times 10^{-3} \mathrm{~m}^{2}\right), \\
& A_{f}^{0}=8.01 \times 10^{-3} \mathrm{ft}^{2}\left(7.44 \times 10^{-4} \mathrm{~m}^{2}\right) .
\end{aligned}
$$

The heat flow within the permanent reflector is 3-D in character. Simulating the heat flow with RELAP5's 1-D conduction model required simplifying assumptions. In the model, the total permaneat reflector volume is divided into $N_{h}^{i}$ and $N_{h}^{\circ}$ subvolumes ("unit cells") in the inner and outer subregions, respectively. Each subvolume is assumed to be a beryllium cylinder with a 0.125 -in.-diam $(0.318-\mathrm{cm})$ [or $0.00521-\mathrm{ft}$-radius $(0.159-\mathrm{cm})$ ] coolant hole in the center. For the subvolumes in the inner reflector subregion, the outside surface is assumed to be adiabatic. In the outer subregion, the outside surface of the cylinder is cooled by water in the vessel. The total volumes of the inner $V_{i}$ and outer $V_{o}$ reflector subregions are

$$
\begin{aligned}
& V_{i}=\pi\left[(18.219 / 12)^{2}-(13.125 / 12)^{2}\right] \times 2 \mathrm{ft}^{3}, \\
& V_{i}=6.97 \mathrm{ft}^{3}\left(0.197 \mathrm{~m}^{3}\right), \\
& V_{0}=\pi\left[(21.5 / 12)^{2}-(18.219 / 12)^{2}\right] \times 2 \mathrm{ft}^{3}, \\
& V_{0}=5.69 \mathrm{ft}^{3}\left(0.161 \mathrm{~m}^{3}\right) .
\end{aligned}
$$

The corresponding horizontal cross-sectional areas $A_{c}^{i}$ and $A_{c}^{o}$ of the subvolumes in the inner and outer subregions, respectively, are

$$
\begin{aligned}
A_{c}^{i} & =V_{i} /\left(2 N_{h}^{i}\right) \mathrm{ft}^{2}, \\
& =6.97 /(2 \times 737) \mathrm{ft}^{2}, \\
A_{c}^{i} & =4.73 \times 10^{-3} \mathrm{ft}^{2}\left(4.39 \times 10^{-4} \mathrm{~m}^{2}\right) \\
A_{c}^{o} & =5.69 /(2 \times 94) \mathrm{ft}^{2}, \\
A_{c}^{o} & =3.03 \times 10^{-2} \mathrm{ft}^{2}\left(2.81 \times 10^{-3} \mathrm{~m}^{2}\right) .
\end{aligned}
$$

After accounting for the area of the 0.125 -in.-diam $(0.318-\mathrm{cm})$ hole, the horizontal crosssectional areas $A_{c, b}^{i}$ and $A_{c, b}^{o}$ of the beryllium in the subvolumes in the inner and outer subregions, respectively, are 


$$
\begin{aligned}
A_{c, b}^{i} & =A_{c}^{i}-A_{f}^{h}, \\
& =4.73 \times 10^{-3}-8.52 \times 10^{-5} \mathrm{ft}^{2}, \\
A_{c, b}^{i} & =4.64 \times 10^{-3} \mathrm{ft}^{2}\left(4.31 \times 10^{-4} \mathrm{~m}^{2}\right), \\
A_{c, b}^{o} & =3.03 \times 10^{-2}-8.52 \times 10^{-5} \mathrm{ft}^{2}, \\
A_{c, b}^{o} & =3.02 \times 10^{-2} \mathrm{ft}^{2}\left(2.81 \times 10^{-3} \mathrm{~m}^{2}\right) .
\end{aligned}
$$

The total volumes of beryllium $V_{b}^{i}$ and $V_{b}^{0}$ in the inner and outer reflector subregions, respectively, are

$$
\begin{aligned}
V_{b}^{i} & =A_{c, b}^{i} N_{h}^{i} L, \\
& =4.64 \times 10^{-3} \times 737 \times 2 \mathrm{ft}^{3}, \\
V_{b}^{i} & =6.84 \mathrm{ft}^{3}\left(0.194 \mathrm{~m}^{3}\right), \\
V_{b}^{\circ} & =3.02 \times 10^{-2} \times 94 \times 2 \mathrm{ft}^{3}, \\
V_{b}^{0} & =5.68 \mathrm{ft}^{3}\left(0.135 \mathrm{~m}^{3}\right) .
\end{aligned}
$$

The sum lengths $L_{s}^{i}$ and $L_{s}^{o}$ of the cylinders in the inner and outer subregions, respectively, are

$$
\begin{aligned}
L_{s}^{i} & =L N_{h}^{i}, \\
& =2 \times 737 \mathrm{ft}, \\
L_{s}^{i} & =1474 \mathrm{ft}(449 \mathrm{~m}), \\
L_{s}^{o} & =2 \times 94 \mathrm{ft}, \\
L_{s}^{o} & =188 \mathrm{ft}(57.3 \mathrm{~m}) .
\end{aligned}
$$

The outside radii $r_{c}^{j}$ and $r_{c}^{\circ}$ of the cylinders in the inner and outer subregions, respectively, are

$$
\begin{aligned}
r_{c}^{j} & =\left(A_{c}^{i} / \pi\right)^{k /}, \\
& =\left(4.73 \times 10^{-3} / \pi\right)^{1 / 4} \mathrm{ft}, \\
r_{c}^{i} & =0.0388 \mathrm{ft}(0.0118 \mathrm{~m}), \\
r_{c} & =\left(3.03 \times 10^{-2} / \pi\right)^{k /} \mathrm{ft}, \\
r_{c} & =0.0982 \mathrm{ft}(0.0299 \mathrm{~m}) .
\end{aligned}
$$

As mentioned previously, heat transfer from the outside surfaces of the cylinders in the outer reflector subregion to the vessel water is modeled. The actual heat transfer surface area $A_{s}^{a}$ is

$$
\begin{aligned}
A_{s}^{a} & =2 \pi r_{0} L, \\
& =2 \pi \times 21.5 / 12 \times 2 \mathrm{ft}^{2}, \\
A_{s}^{a} & =22.5 \mathrm{ft}^{2}\left(2.09 \mathrm{~m}^{2}\right) .
\end{aligned}
$$


However, the "implied" heat transfer surface area $A_{s}^{i}$ in the model is

$$
A_{s}^{i}=2 \pi r_{c}^{j} L N_{h}^{o}
$$

Thus,

$$
\begin{aligned}
& A_{s}^{i}=2 \pi \times(0.0982) \times 2 \times 94 \mathrm{ft}^{2}, \\
& A_{s}^{i}=116 \mathrm{ft}^{2}\left(10.78 \mathrm{~m}^{2}\right) .
\end{aligned}
$$

To properly calculate the heat transfer from the outside surfaces of the outer region reflector cylinder subvolumes, the heat transfer coefficient applied at the outside surfaces is reduced by the ratio of the actual to implied area,

$$
\begin{aligned}
& A_{s}^{a} / A_{s}^{i}=22.5 / 116 \\
& A_{s}^{a} / A_{s}^{i}=0.195 .
\end{aligned}
$$

The heat transfer coefficient applied to the outside surfaces was input directly to RELAP5. Since the cross-sectional flow area $\left[-42 \mathrm{ft}^{2}\left(3.9 \mathrm{~m}^{2}\right)\right]$ of the upper bypass region is large relative to the total flow through the region $\left[-82 \mathrm{gal} / \mathrm{min}\left(5.17 \times 10^{-3} \mathrm{~m}^{3} / \mathrm{s}\right)\right.$ during normal operation], the average velocity is very low $\left[-0.004 \mathrm{ft} / \mathrm{s}\left(1.22 \times 10^{-3} \mathrm{~m} / \mathrm{s}\right)\right]($ see Figs. 3 , 6 , and 7). Thus natural convection will dictate flow and heat transfer in this region. Because the natural convective heat transfer coefficient is a nonlinear function of the temperature difference between the reflector surface and water, it could not be accommodated using a RELAP5 "general" table. Thus, the following approximate approach was taken.

The Rayleigh number $R a_{L_{c}}$ is given by ${ }^{89}$

$$
R a_{L_{c}}=\frac{g L_{c}^{3} \beta \Delta T}{v \alpha}=\frac{g \beta}{v^{2}} \operatorname{Pr} L_{c}^{3} \Delta T,
$$

where

$$
\begin{aligned}
g & =\text { acceleration due to gravity, } \\
L_{c} & =\text { characteristic dimension, } \\
\beta & =\text { coefficient of thermal expansion, } \\
\Delta T & =\text { wall-to-fluid temperature difference, } \\
v & =\text { kinematic viscosity, } \\
\alpha & =\text { thermal diffusivity, } \\
\operatorname{Pr} & =\text { Prandtl number. }
\end{aligned}
$$

For the purposes of calculating water properties, a film temperature of $140^{\circ} \mathrm{F}\left(60^{\circ} \mathrm{C}\right)$ was selected. As will be shown in Sect. 5.1, this is lower than the value that exists during HFIR normal, steady-state operation at $85 \mathrm{MW}$. Because natural convection heat transfer increases due to property changes with increasing film temperature, the value chosen is conservative 
in this case. During simulated accident sequences, the value will obviously change, and it may be necessary to revise property values (and heat transfer coefficients). Based on a film temperature of $140^{\circ} \mathrm{F}\left(60^{\circ} \mathrm{C}\right)$, the property values are $e^{74,90}$

$$
\begin{aligned}
& v=5.14 \times 10^{-6} \mathrm{ft}^{2} / \mathrm{s}\left(4.78 \times 10^{-7} \mathrm{~m}^{2} / \mathrm{s}\right), \\
& \alpha=1.67 \times 10^{-6} \mathrm{ft}^{2} / \mathrm{s}\left(1.55 \times 10^{-7} \mathrm{~m}^{2} / \mathrm{s}\right), \\
& \beta=0.28 \times 10^{-3} /{ }^{\circ} \mathrm{F}\left(5.04 \times 10^{-4} /{ }^{\circ} \mathrm{C}\right) .
\end{aligned}
$$

With $L_{c}=2 \mathrm{ft}$, the height of the reflector, the Rayleigh number is calculated to be

$$
\begin{aligned}
R a_{L_{c}} & =\frac{\left(32 \mathrm{ft} / \mathrm{s}^{2}\right)(2 \mathrm{ft})^{3}\left(0.28 \times 10^{-3} /{ }^{\circ} \mathrm{F}\right)}{\left.5.14 \times 10^{-6} \mathrm{ft}^{2} / \mathrm{s}\right)\left(1.67 \times 10^{-6} \mathrm{ft}^{2} / \mathrm{s}\right)} \quad \Delta T, \\
R a_{L_{c}} & =8.34 \times 10^{9} /{ }^{\circ} \mathrm{F} \Delta T .
\end{aligned}
$$

A criterion for determining whether a vertical cylinder can be treated like a vertical flat plate is ${ }^{89}$

$$
D / L_{c} \geq 35 /\left(G r_{L_{c}}\right)^{1 / 4},
$$

where

$$
\begin{aligned}
& D=\text { diameter of the cylinder, } \\
& G r=\text { Grashof number }\left(=R a_{L_{c}} / P r\right), \\
& P r=\text { Prandtl number }\left(=3.02 \text { at } 140^{\circ} \mathrm{F}\right) .^{74}
\end{aligned}
$$

With $D=3.58 \mathrm{ft}(21.5 \times 2 / 12 \mathrm{ft})$ and an assumed $\Delta T \approx 1^{\circ} \mathrm{F}$ (or larger), the criterion is satisfied as shown below:

$$
3.58 / 2 \geq 35 /\left(8.34 \times 10^{9} / 3.02\right)^{4 / 4} \text {, }
$$

$1.79 \geq 0.15$.

A turbulent natural convection flow will exist if $R a_{L_{c}}>10^{9}$, which implies for the case here that

$$
\begin{aligned}
& \Delta T>10^{9} /\left(8.34 \times 10^{9}\right){ }^{\circ} \mathrm{F}, \\
& \Delta T>0.12^{\circ} \mathrm{F}\left(0.067^{\circ} \mathrm{C}\right) .
\end{aligned}
$$

For turbulent flow, the vertical flat-plate average Nusselt number $N u_{a v}$ is given by ${ }^{89}$

$$
N u_{a v}=0.10\left(R a_{L_{c}}\right)^{\mathbf{k}},
$$

where

$$
N u_{a v}=\frac{h L_{c}}{k},
$$




$$
\begin{aligned}
& h=\text { natural convection heat transfer coefficient, } \\
& k=\text { thermal conductivity }\left[=0.376 \mathrm{Btu} / \mathrm{h}-\mathrm{ft}-{ }^{\circ} \mathrm{F} \text { at } 140^{\circ} \mathrm{F}\left(0.651 \mathrm{~W} / \mathrm{m}-\mathrm{K} \text { at } 60^{\circ} \mathrm{C}\right)\right] .^{74}
\end{aligned}
$$

The average heat transfer coefficient is therefore

$$
h=1.06 \times 10^{-2} \Delta T^{* 6} \mathrm{Btu} / \mathrm{s}-\mathrm{ft}^{2}-{ }^{\circ} \mathrm{F} \text {, }
$$

with $\Delta T$ in ${ }^{\circ} \mathrm{F}$. After accounting for the difference between the actual and modeled surface area, the "effective" heat transfer coefficient $h_{\text {eff }}$ is

$$
\begin{aligned}
& h_{\text {dff }}=0.195 \times 1.06 \times 10^{-2} \Delta T^{46} \mathrm{Btu} / \mathrm{s}-\mathrm{ft}^{2}-{ }^{\circ} \mathrm{F}, \\
& h_{\text {eff }}=2.07 \times 10^{-3} \Delta T^{*} \mathrm{Btu} / \mathrm{s}-\mathrm{ft}^{2}-{ }^{\circ} \mathrm{F}
\end{aligned}
$$

Because the volume of water in the upper bypass region is large relative to the amount of heat deposited in it, it is assumed that its temperature is constant at $120^{\circ} \mathrm{F}\left(48.9^{\circ} \mathrm{C}\right)$ for the purposes of evaluating $h_{\text {eff }}$ This simplification is necessary because the RELAP5 general table allows heat transfer coefficients to be input as a function of only one temperature. In the model, the heat transfer coefficient depends only on the temperature of the outer surface of the reflector. Table 28 presents effective coefficients calculated using Eq. (3). When $\Delta T$ is less than zero, indicating heat transfer from the vessel water to the reflector, the absolute value is used.

Table 28. Effective natural convection heat transfer coefficients at the beryllium reflector outside surface

\begin{tabular}{cl}
$\begin{array}{c}\text { Beryllium surface } \\
\text { temperature } \\
\left({ }^{\circ} \mathrm{F}\right)\end{array}$ & $\begin{array}{c}\text { Heat transfer coefficient } \\
\left(\mathrm{Btu} / \mathrm{s}-\mathrm{ft}^{2}{ }^{\circ} \mathrm{F}\right)\end{array}$ \\
\hline 100 & 0.00562 \\
115 & 0.00354 \\
120 & 0.0 \\
125 & 0.00354 \\
140 & 0.00562 \\
165 & 0.00736 \\
200 & 0.00892 \\
240 & 0.0102 \\
280 & 0.0112 \\
320 & 0.0121
\end{tabular}

The normal operation flows through the permanent reflector of 423 and $53 \mathrm{gal} / \mathrm{min}$ $\left(2.67 \times 10^{-2}\right.$ and $\left.3.34 \times 10-3 \mathrm{~m}^{3} / \mathrm{s}\right)$ for the inner and outer subregions, respectively, were normalized with data. The flows were found to be $432 \mathrm{gal} / \mathrm{min}\left(0.027 \mathrm{~m}^{3} / \mathrm{s}\right)$ or $59 \mathrm{lb}_{\mathrm{m}} / \mathrm{s}$ 
$(26.7 \mathrm{~kg} / \mathrm{s})$ and $54 \mathrm{gal} / \mathrm{min}\left(3.41 \times 10^{-4} \mathrm{~m}^{3} / \mathrm{s}\right)$ or $7.4 \mathrm{lb} / \mathrm{m} / \mathrm{s}(3.36 \mathrm{~kg} / \mathrm{s})$. The roughness of channel surfaces was selected to provide the desired flow and pressure drop. A value of $4.1 \times 10^{-5} \mathrm{ft}$ $\left(1.25 \times 10^{-5} \mathrm{~m}\right)$ was chosen. The abrupt area change model was used at the entrance and exit of both subregions.

The total power liberated in the permanent reflector during HFIR normal operation is estimated to be $1.08 \mathrm{MW}$, as indicated in Table 1. This includes heating in the permanent reflector and the experimental facilities and horizontal beam tube liners within it. The loads to the inner and outer subregions are 0.833 and $0.244 \mathrm{MW}$, respectively. ${ }^{27}$ As was the case for the other reflector regions, the respective averages of the subregions' BOC fission and EOC decay heat axial distributions were used in the model. The BOC fission and EOC decay heat load axial distributions within each subregion are similar. ${ }^{27}$ The radial load variation within each subregion was assumed to be uniform. With reference to Fig. 7, the subregions are each divided into five axial segments with discretizations matching that of the control region and other reflector regions. RELAP5 internal source multipliers for the heat structures within each subregion were calculated based on their heat load and their respective heat structure surface areas and axial power factors. The multipliers are referenced to the extra-fuel element power and are presented along with the axial power factors in Table 29.

Table 29. Permanent beryllium reflector axial power peaking factors and RELAP5 internal source multipliers

\begin{tabular}{cccccc}
\hline & \multicolumn{2}{c}{$\begin{array}{c}\text { Axial power } \\
\text { peaking factor }\end{array}$} & & \multicolumn{2}{c}{ Internal source multipliers } \\
\cline { 2 - 3 } \cline { 5 - 6 } $\begin{array}{c}\text { Axial location } \\
\text { (top-to-bottom) }\end{array}$ & $\begin{array}{c}\text { Inner } \\
\text { subregion }\end{array}$ & $\begin{array}{c}\text { Outer } \\
\text { subregion }\end{array}$ & & $\begin{array}{c}\text { Inner } \\
\text { subregion }\end{array}$ & $\begin{array}{c}\text { Outer } \\
\text { subregion }\end{array}$ \\
\hline 1 & 0.765 & 0.807 & & $3.11 \times 10^{-2}$ & $9.60 \times 10^{-3}$ \\
2 & 1.15 & 1.12 & & $4.67 \times 10^{-2}$ & $1.33 \times 10^{-2}$ \\
3 & 1.27 & 1.22 & & $4.13 \times 10^{-2}$ & $1.16 \times 10^{-2}$ \\
4 & 1.13 & 1.11 & & $4.59 \times 10^{-2}$ & $1.32 \times 10^{-2}$ \\
5 & 0.743 & 0.791 & & $3.02 \times 10^{-2}$ & $9.41 \times 10^{-3}$ \\
\hline
\end{tabular}

\subsubsection{Core Bypass}

The water within the vessel surrounding the outer shroud above the core, the core, and the lower plenum beneath the core (see Fig. 3) is represented in the model in two regions, U-bypass and L-bypass (see Fig. 7). The U-bypass region includes the water within vertical boundaries corresponding to the bottom of the core and the top of the outer shroud. The L-bypass region includes the water surrounding the lower plenum. This subdivision permits the representation of thermal stratification within the water that occurs due to heating of the portion adjacent to the outer shroud and core, while the remainder remains relatively cool. As indicated previously for the permanent beryllium reflector, the current model assumes that for the purposes of calculating the natural convection heat transfer coefficients at the outside surfaces of the outer shroud and core, the temperature of the U-bypass water is constant at 
$120^{\circ} \mathrm{F}\left(48.9^{\circ} \mathrm{C}\right)$, the nominal reactor inlet temperature. Although the heat transfer is much less, the same assumption is used in heat transfer coefficient calculations for the outer surfaces of the lower plenum heat structures, which attach to the L-bypass region. Heat transfer from the $\mathrm{U}$ - and L-bypass regions through the vessel walls to the pool is conservatively neglected. Extension of the current model to better represent these aspects can be made when needed.

The height of the U-bypass region is $5.92 \mathrm{ft}(1.8 \mathrm{~m})$, of which $3.92 \mathrm{ft}(1.19 \mathrm{~m})$ is along the vertical extent of the outer shroud and $2 \mathrm{ft}(0.610 \mathrm{~m})$ is along the core. ${ }^{91}$ The inner radii of these subregions are 1.20 and $1.79 \mathrm{ft}(0.366$ and $0.546 \mathrm{~m})$, respectively. ${ }^{91}$ The outer radius $r_{o}$ of both subregions is $3.982 \mathrm{ft}(1.19 \mathrm{~m}){ }^{92}$ With these dimensions, a region volume $V$ and average flow area $\left\langle A_{f}\right\rangle$ was calculated as

$$
\begin{aligned}
V= & \pi\left(3.92^{2}-1.20^{2}\right) 3.92+\pi\left(3.92^{2}-1.79^{2}\right) 2 \mathrm{ft}^{3}, \\
V= & 247.9 \mathrm{ft}^{3}\left(7.02 \mathrm{~m}^{3}\right), \\
<A_{f}> & =V / \text { height}, \\
& =247.9 / 5.92 \mathrm{ft}^{2}, \\
<A_{f}> & =41.88 \mathrm{ft}^{2}\left(3.82 \mathrm{~m}^{2}\right) .
\end{aligned}
$$

The hydraulic diameter $D_{h y}$ of the U-bypass region was calculated using an average value of the region inner radius (based on $\left\langle A_{f}\right\rangle$ and region outer radius, $\left\langle r_{i}\right\rangle=1.43 \mathrm{ft}(0.436 \mathrm{~m})$ :

$$
\begin{aligned}
D_{h y} & =4<A_{f}>/ 2 \pi\left(r_{o}+\left\langle r_{i}>\right),\right. \\
& =4 \times 41.88 / 2 \pi(3.92+1.43) \mathrm{ft}, \\
D_{h y} & =4.98 \mathrm{ft}(1.52 \mathrm{~m}) .
\end{aligned}
$$

The height and inner radius $r_{i}$ of the L-bypass region are 3.74 and $1.76 \mathrm{ft}$ (1.14 and 0.536 $\mathrm{m})$, respectively. Because the region outer radius varies continuously along its height, average flow areas were calculated at five elevations, which along with their respective heights, were used to estimate the total region volume. A value of $98 \mathrm{ft}^{3}\left(2.77 \mathrm{~m}^{3}\right)$ was determined. ${ }^{27}$ As with the U-bypass region, the region average flow area $\left\langle A_{f}\right\rangle$ was calculated as

$$
\begin{aligned}
\left\langle A_{f}\right\rangle & =\text { volume/height, } \\
& =98 . / 3.74 \mathrm{ft}^{2}, \\
\left.<A_{f}\right\rangle & =26.2 \mathrm{ft}^{2}\left(2.43 \mathrm{~m}^{2}\right) .
\end{aligned}
$$

The hydraulic diameter $D_{h y}$ was calculated using an average value of the region outer radius $\left\langle r_{o}\right\rangle=3.38 \mathrm{ft}(1.03 \mathrm{~m})$ :

$$
\begin{aligned}
D_{h y} & =4<A_{f}>/ 2 \pi\left(<r_{o}>+r_{i}\right), \\
& =4 \times 26.2 / 2 \pi(3.38+1.76) \mathrm{ft}, \\
D_{h y} & =3.25 \mathrm{ft}(0.988 \mathrm{~m}) .
\end{aligned}
$$

As mentioned in Sect. 3.2.5, flow through the engineering facilities (denoted EF1-4 in Fig. 18) is assumed to occur through the bypass regions. In the model, flow passes through 
junction 9-07 (see Fig. 7), a cross-flow junction, between the L-bypass and L-plenum-2 (outer lower plenum) regions. The junction area is taken to be the combined area of the four engineering facility cooling lines at their connection to the L-plenum-2 region. The inside diameter of each line at this location is $0.15 \mathrm{ft}$ (Ref. 93), from which the combined area was determined to be $0.071 \mathrm{ft}^{2}\left(6.6 \times 10^{-3} \mathrm{~m}^{2}\right)$. The roughness of the channel surfaces in the bypass region was taken to be $1.5 \times 10^{-4} \mathrm{ft}\left(4.57 \times 10^{-5} \mathrm{~m}\right)$, which corresponds to commercial steel piping. ${ }^{94}$

The total flow rate through the engineering facilities during normal reactor operation is estimated to be $80 \mathrm{gal} / \mathrm{min}\left(5.05 \times 10^{-3} \mathrm{~m}^{3} / \mathrm{s}\right){ }^{95}$ After normalizing this value with operation data, the flow becomes $82 \mathrm{gal} / \mathrm{min}\left(5.17 \times 10^{-3} \mathrm{~m}^{3} / \mathrm{s}\right)$ or $11.2 \mathrm{lb} / \mathrm{s}(5.08 \mathrm{~kg} / \mathrm{s})$. To provide this flow rate through the bypass regions, a forward flow energy loss coefficient of 2700 was selected for junction 9-07 connecting the L-bypass and L-plenum-2 regions along with the junction smooth area change model. An equivalent reverse loss coefficient was also used.

The U-bypass region receives heat from the permanent reflector (O-P-Be in Fig. 7) and from the shroud region. Heat transfer modeling in the former case was described in Sect. 3.2.5.3; a similar discussion for the latter case will be presented in Sect. 3.2.8. Likewise, modeling of heat transfer from the L-plenum-2 region to the L-bypass region will be described in Sect. 3.2.11.

\subsubsection{Vessel/Pool Check Valve}

The vessel contains a check valve, which permits flow from the reactor pool into the vessel if the vessel pressure drops below the pool pressure head. The valve piping is connected at an elevation about $1.5 \mathrm{ft}(0.457 \mathrm{~m})$ below the bottom of the vessel inlet piping penetration $^{96}$ (see Fig. 3). The valve itself is located 10 in. $(25.4 \mathrm{~cm})$ above the top of the vessel lid and is a 2 -in. $(5.08-\mathrm{cm})$ swing check valve. ${ }^{97}$ With the normal reactor pool depth of $36 \mathrm{ft}(11 \mathrm{~m})$, the pool pressure at the valve, which is $19 \mathrm{ft} 10 \mathrm{in}$. $(6.05 \mathrm{~m})$ above the bottom, is 21.7 psia ( $0.150 \mathrm{MPa})$.

With reference to Fig. 7, the check valve is modeled using a time-dependent junction component. A time-dependent volume represents the reactor pool conditions [21.7 psia, $\left.100^{\circ} \mathrm{F}\left(0.150 \mathrm{MPa}, 37.78^{\circ} \mathrm{C}\right)\right]$. Viscous losses in the 2 -in. $(5.08-\mathrm{cm})$ pipe joining the valve to the vessel are also included in the model. Flow through the valve is determined by a control system (see Sect. 3.7.14).

\subsubsection{Core Shrouds}

Two concentric shrouds are located above the core as shown in Fig. 19. They provide proper distribution of coolant flow and furnish support and alignment for various components above the core. The desired flow into the reflector and control regions is achieved with orifices in the shroud flange and between the shroud flange and inner shroud. ${ }^{20}$

The region encompassed by the shrouds are modeled in two subregions as indicated in Fig. 7 (inner shroud and shroud). In addition to heat transport through the vertical flow path, heat transfer from the region between the shrouds (shroud in Fig. 7) to the U-bypass region is modeled. Hot water within the shroud is transferred through the 6061 aluminum outer shroud wall to the cooler water in the vessel bypass region. The roughness of surfaces in the inner shroud and shroud region was taken to be $1.5 \times 10^{-4} \mathrm{ft}\left(4.57 \times 10^{-5} \mathrm{~m}\right) .^{94}$ 


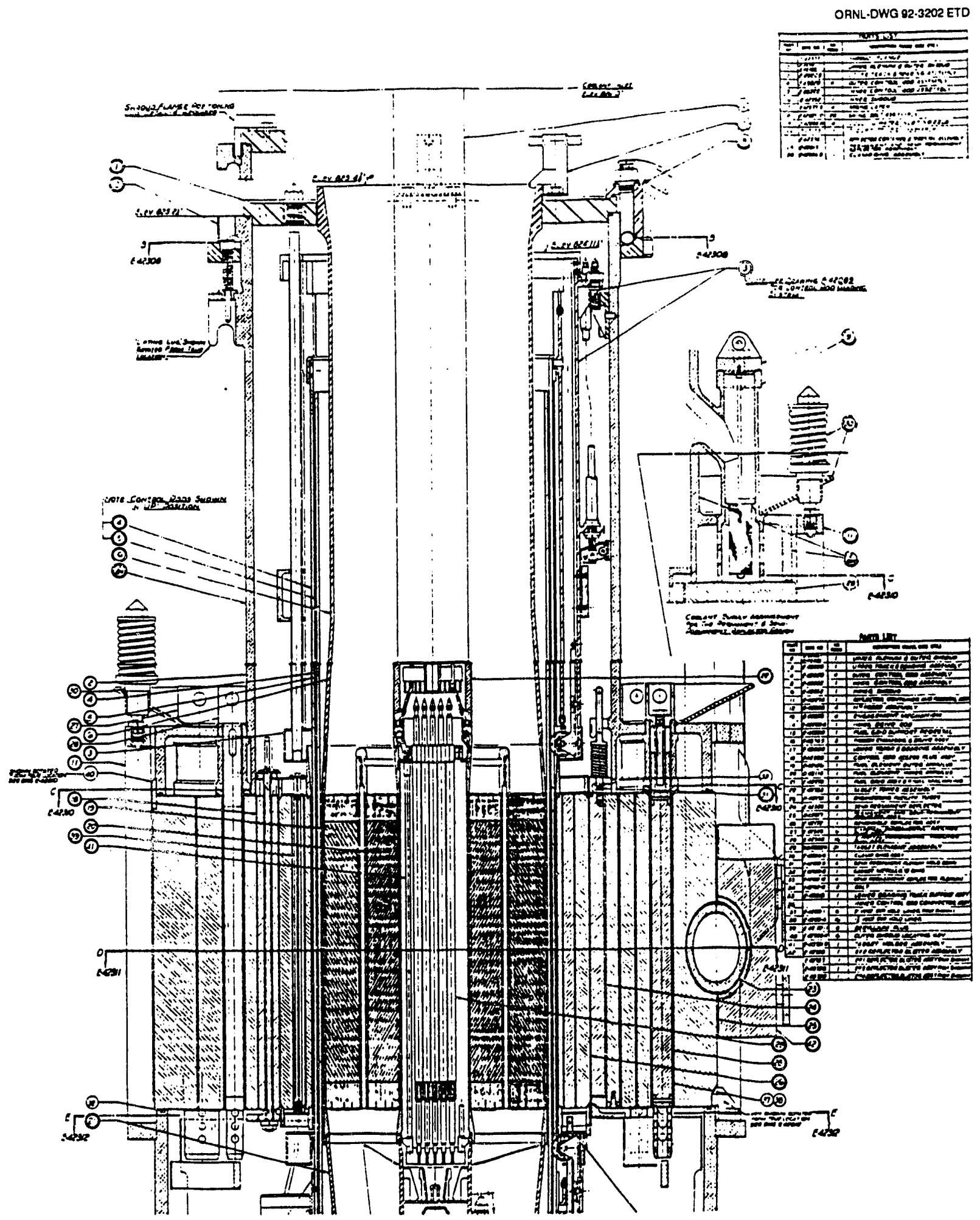

Fig. 19. Cross section through core and shrouds. 
The inner shroud region is an annular region formed by the target tower and inner shroud and extends $3.92 \mathrm{ft}(1.19 \mathrm{~m})$ above the core. ${ }^{91}$ The inner $r_{i}$ and outer $r_{o}$ radii of the annulus are ${ }^{91}$

$$
\begin{aligned}
& r_{i}=0.248 \mathrm{ft}(0.076 \mathrm{~m}), \\
& r_{o}=0.692 \mathrm{ft}(0.211 \mathrm{~m})
\end{aligned}
$$

With these dimensions, the region flow area $A_{f}$ volume $V$, and hydraulic diameter $D_{h y}$ were calculated to be

$$
\begin{aligned}
A_{f} & =1.31 \mathrm{ft}^{2}\left(0.122 \mathrm{~m}^{2}\right), \\
V & =5.1352 \mathrm{ft}^{3}\left(0.145 \mathrm{~m}^{3}\right), \\
D_{h y} & =0.89 \mathrm{ft}(0.271 \mathrm{~m}) .
\end{aligned}
$$

The shroud region is an annular region formed by the inner and outer shrouds. The region also extends $3.92 \mathrm{ft}(1.19 \mathrm{~m}), h$, above the core. ${ }^{91}$ Neglecting the presence of the oxide on the aluminum outer shroud wall (the inner shroud is constructed of stainless steel), the inner and outer radii, $r_{i}$ and $r_{o}$, respectively, of the annular flow passage are ${ }^{91}$

$$
\begin{aligned}
& r_{i}=0.715 \mathrm{ft}(0.218 \mathrm{~m}) \\
& r_{o}=1.14 \mathrm{ft}(0.347 \mathrm{~m})
\end{aligned}
$$

With these dimensions, the regions flow area $A_{f}$ volume $V$, and hydraulic diameter $D_{h y}$ were calculated to be

$$
\begin{aligned}
A_{f} & =2.48 \mathrm{ft}^{2}\left(0.231 \mathrm{~m}^{2}\right), \\
V & =9.7216 \mathrm{ft}^{3}\left(0.275 \mathrm{~m}^{3}\right), \\
D_{h y} & =0.85 \mathrm{ft}(0.259 \mathrm{~m}) .
\end{aligned}
$$

The effect of the oxide on the outer shroud wall was included in the calculation of its inner and outer surface areas and thermal conduction resistance. As with other aluminum core components, the shroud oxide thickness was assumed to be $0.689 \mathrm{mil}(0.0175 \mathrm{~mm})$. The average thickness of the shroud wall was taken to be 0.7 in. $(1.78 \mathrm{~cm}){ }^{91}$ Thus, the inner $r_{i}^{p}$ and the outer $r_{0}^{\circ}$ radii and of the outer shroud wall, accounting for oxide, are

$$
\begin{aligned}
& r_{i}^{o}=1.139988 \mathrm{ft}(0.347468 \mathrm{~m}), \\
& r_{o}^{o}=1.198345 \mathrm{ft}(0.365260 \mathrm{~m}) .
\end{aligned}
$$

The thickness of the aluminum portion is then $0.69891 \mathrm{in} .(1.7752 \mathrm{~cm})$. The inner and outer surface areas $A_{s}^{i}$ and $A_{s}^{o}$ of the outer shroud wall are

$$
\begin{aligned}
A_{s}^{i} & =2 \pi r_{i}^{0} h, \\
A_{s}^{i} & =2 \pi \times 1.139988 \times 3.92 \mathrm{ft}^{2}, \\
A_{s}^{i} & =28.08 \mathrm{ft}^{2}\left(2.51 \mathrm{~m}^{2}\right),
\end{aligned}
$$




$$
\begin{aligned}
& A_{s}^{o}=2 \pi \times 1.198345 \times 3.92 \mathrm{ft}^{2}, \\
& A_{s}^{o}=29.52 \mathrm{ft}^{2}\left(2.74 \mathrm{~m}^{2}\right) .
\end{aligned}
$$

The thermophysical properties for shroud wall modeling have been presented in Tables 20 and 21 for 6061 aluminum and in Table 8 and Sect. 3.2.1 for oxide.

Following the approach taken for modeling beryllium reflector heat transfer to the U-bypass region, natural convection heat transfer was modeled at the interface between the outer shroud and U-bypass region. Heat transfer coefficients were input to RELAP5 as a function of the shroud surface temperature in a general table. Input values are presented in Table 30 and were obtained by dividing those in Table 27 [which are based on Eq. (3)] by

Table 30. Natural convection heat transfer coefficients at the outer shroud surface

\begin{tabular}{cl}
\hline $\begin{array}{c}\text { Shroud surface } \\
\text { temperature } \\
\left({ }^{\circ} \mathrm{F}\right)\end{array}$ & $\begin{array}{c}\text { Heat transfer coefficient } \\
\left(\mathrm{Btu} / \mathrm{s}-\mathrm{ft}^{2}{ }^{\circ} \mathrm{F}\right)\end{array}$ \\
\hline 100 & 0.0287 \\
115 & 0.0181 \\
120 & 0.0 \\
125 & 0.0181 \\
140 & 0.0287 \\
165 & 0.0377 \\
200 & 0.0457 \\
240 & 0.0523 \\
280 & 0.0575 \\
320 & 0.0620 \\
\hline
\end{tabular}

0.195. This adjustment removes the effective area scaling used in modeling heat transfer at the beryllium reflector outside surface, which is not appropriate for modeling heat transfer at the shroud surface. In this case the actual heat transfer area is used in the model. Note that because a turbulent natural convection flow exists, the heat transfer coefficient is not a function of the height of the heat transfer surface. Therefore, Eq. (3), which was derived for the beryllium reflector outside surface (height of $2 \mathrm{ft}$ ), is also valid for the outer shroud surface (height of $3.92 \mathrm{ft}$ ). Thus, the average heat transfer coefficient $h$ is given by [see Eq. (3)]

$$
\begin{aligned}
& h=2.07 \times 10^{-3} \Delta T^{1 / 3} \mathrm{Btu} / \mathrm{s}-\mathrm{ft}^{2}-^{\circ} \mathrm{F} / 0.195, \\
& h=1.06 \times 10^{-2} \Delta T^{1 / 3} \mathrm{Btu} / \mathrm{s}^{-\mathrm{ft}^{2}-{ }^{\circ} \mathrm{F}}
\end{aligned}
$$


Shroud orifices limit flow significantly to the control and reflector regions. The pressure drop through the orifices is on the order of $100 \mathrm{psi}(0.689 \mathrm{MPa}){ }^{24,98}$ This flow resistance is represented in RELAP5 using the abrupt area change model at junction 18-04 with an orifice possessing an area approximately 40 times smaller $\left(0.064 \mathrm{ft}^{2}\right.$ or $\left.0.0059 \mathrm{~m}^{2}\right)$ than the shroud flow area. A match to HFIR design flows was thereby achieved that, following normalization with normal operation data, provided a flow rate of $2238 \mathrm{gal} / \mathrm{min}(308 \mathrm{lb} / \mathrm{s})$. The abrupt area change model was also used at the shroud outlet.

\subsection{Target Tower}

With reference to Figs. 3 and 7, the portion of the target tower contained within the inner core shroud is represented in the RELAP5 model by the "Target Tower" region (singlevolume number 17). Only the flow within the tower is modeled. The height $h$ and radius $r$ of the cylindrical region are ${ }^{91}$

$$
\begin{aligned}
& h=3.92 \mathrm{ft}(1.19 \mathrm{~m}), \\
& r=0.203 \mathrm{ft}(0.062 \mathrm{~m}) .
\end{aligned}
$$

The region flow area $A_{f}$ volume $V$, and hydraulic diameter $D_{h y}$ are

$$
\begin{aligned}
& A_{f}=0.129 \mathrm{ft}^{2}\left(0.012 \mathrm{~m}^{2}\right) \\
& V=0.50568 \mathrm{ft}^{3}\left(0.014 \mathrm{~m}^{3}\right) \\
& D_{h y}=0.405 \mathrm{ft}(0.123 \mathrm{~m})
\end{aligned}
$$

The roughness of the tower channel surface was taken to be $1.5 \times 10^{-4} \mathrm{ft}\left(4.57 \times 10^{-5} \mathrm{~m}\right)$, corresponding to commercial steel piping. ${ }^{94}$ The abrupt area change model was used at the entrance and exit of the channel.

\subsection{Upper Plenum}

The portion of the vessel and water that is above the top of the core shrouds is included in the "U-plenum" region in the model (see Figs. 3 and 7). The height $h$ and radius $r$ of the region is ${ }^{92}$

$$
\begin{aligned}
& h=4.37 \mathrm{ft}(1.33 \mathrm{~m}), \\
& r=3.92 \mathrm{ft}(1.19 \mathrm{~m}) .
\end{aligned}
$$

The region flow area $A_{f}$ volume $V$, and hydraulic diameter $D_{h y}$ are

$$
\begin{aligned}
& A_{f}=48.3 \mathrm{ft}^{2}\left(4.49 \mathrm{~m}^{2}\right), \\
& V=211 \mathrm{ft}^{3}\left(5.98 \mathrm{~m}^{3}\right) \\
& D_{h y}=7.83 \mathrm{ft}(2.39 \mathrm{~m}) .
\end{aligned}
$$

In the model the height of the region was changed so that the elevation change between the inlet and outlet piping could be accurately represented. Inlet and outlet piping connect to 
the vessel with cross-flow junctions that are required to be attached at the vertical center of the connecting volume (i.e., U-plenum and outlet volumes in Fig. 7). To conserve region volume, the flow area was increased proportionally by the decrease in region height. The model height $h^{m}$ and flow area $A_{f}^{m}$ are

$$
\begin{aligned}
& h^{m}=1.99 \mathrm{ft}(0.606 \mathrm{~m}), \\
& A_{f}^{m}=106 \mathrm{ft}^{2}\left(9.85 \mathrm{~m}^{2}\right) .
\end{aligned}
$$

The vessel sidewall is nominally $3.123 \mathrm{in.}(7.94 \mathrm{~cm})$ thick and composed of ASTM A212 grade B plate $[27 / 8$ in. $(7.30 \mathrm{~cm})$ thick] clad on the inside with $304 \mathrm{~L}$ stainless steel plate $[0.125$ in. $(0.318 \mathrm{~cm})$ thick] and on the outside with 347 stainless steel weld overlay [0.125 in. $(0.318$ $\mathrm{cm}$ ) thick]. ${ }^{99,100}$ The thickness of the 347 stainless steel weld overlay is not consistently given in Refs. 98 and 100 [0.125 in. $(0.318 \mathrm{~cm})$ and 0.10 in. $(0.254 \mathrm{~cm})]$; conservatively (i.e., to provide the maximum heat conduction resistance), the larger value was selected for use in the model. The vessel top head is nominally 14.25 in. $(36.2 \mathrm{~cm})$ thick and composed of ASTM A105 grade II forgings [14 in. ( $35.6 \mathrm{~cm})$ thick] clad overall with 347 stainless steel weld overlay [0.125 in. $(0.318 \mathrm{~cm})$ thick $].^{100,101}$ Thermophysical property values of ASTM A212 grade B and A105 grade II carbon steel could not be found, so those of a similar alloy were used. ${ }^{102}$ The density of carbon steel with $\approx 0.5 \%$ carbon was selected whose value at $R T$ is $487 \mathrm{lb}_{\mathrm{m}} / \mathrm{ft}^{3}\left(7801 \mathrm{~kg} / \mathrm{m}^{3}\right)$ (Ref. 74). The specific heat of a carbon steel with $0.77 \%$ carbon $^{103}$ [except for the value at $68^{\circ} \mathrm{F}\left(20^{\circ} \mathrm{C}\right)$, which is of $\approx 0.5 \%$ carbon steel] ${ }^{74}$ was used with the density value above to calculate the volumetric heat capacity of the vessel carbon steel. These values are presented in Table 31 for a range of temperatures. The vessel carbon steel thermal conductivity is taken to be that of carbon steel with $0.31 \%$ carbon; ${ }^{104}$ values are listed in Table 32. The density of the 304L stainless steel vessel sidewall clad at RT is $501.3 \mathrm{lb}_{\mathrm{m}} / \mathrm{ft}^{3}\left(8025 \mathrm{~kg} / \mathrm{m}^{3}\right)$. ${ }^{105}$ The specific heat and volumetric heat capacity of $304 \mathrm{~L}$ stainless steel are presented in Table 33, ${ }^{106}$ while its thermal conductivity is provided in Table 34 (based on that of 304 stainless steel) ${ }^{107}$ The density of the 347 stainless steel vessel clad at $\mathrm{RT}$ is $493.8 \mathrm{lb}_{\mathrm{m}} / \mathrm{ft}^{3}\left(7910 \mathrm{~kg} / \mathrm{m}^{3}\right),{ }^{105}$ and its other relevant thermophysical property data are presented in Tables 35 and 36 .

Table 31. Carbon steel specific heat

\begin{tabular}{|c|c|c|}
\hline $\begin{array}{l}\text { Temperature } \\
\left({ }^{\circ} \mathrm{F}\right)\end{array}$ & $\begin{array}{l}\text { Specific heat } \\
\left(\text { Btu/lb } \mathrm{b}_{\mathrm{m}}{ }^{\circ} \mathrm{F}\right)\end{array}$ & $\begin{array}{l}\text { Volumetric heat } \\
\text { capacity } \\
\left(\text { Btu/ } / \mathrm{ft}^{3}-^{\circ} \mathrm{F}\right)\end{array}$ \\
\hline 68 & 0.111 & 54.3 \\
\hline 176 & 0.120 & 58.7 \\
\hline 428 & 0.132 & 64.5 \\
\hline 986 & 0.163 & 79.7 \\
\hline
\end{tabular}
and volumetric heat capacity 
Table 32. Carbon steel thermal conductivity

\begin{tabular}{cc}
\hline $\begin{array}{c}\text { Temperature } \\
\left({ }^{\circ} \mathrm{F}\right)\end{array}$ & $\begin{array}{c}\text { Thermal conductivity } \\
\left(\text { Jtu/s-ft- }{ }^{\circ} \mathrm{F}\right)\end{array}$ \\
\hline 86 & 0.0112 \\
212 & 0.00919 \\
439 & 0.00658 \\
932 & 0.00339 \\
\hline
\end{tabular}

Table 33. 304L stainless steel specific heat and volumetric heat capacity

\begin{tabular}{ccc}
\hline $\begin{array}{c}\text { Temperature } \\
\left({ }^{\circ} \mathrm{F}\right)\end{array}$ & $\begin{array}{c}\text { Specific heat } \\
\left(\mathrm{Btu} / \mathrm{b}_{\mathrm{m}}{ }^{\circ} \mathrm{F}\right)\end{array}$ & $\begin{array}{c}\text { Volumetric heat } \\
\text { capacity } \\
\left(\mathrm{Btu}^{\circ} \mathrm{ft}^{3}{ }^{\circ} \mathrm{F}\right)\end{array}$ \\
\hline 50 & $0.089^{\circ}$ & $44.6^{a}$ \\
80 & $0.089^{a}$ & $44.6^{a}$ \\
440 & 0.091 & 45.6 \\
620 & 0.092 & 46.1 \\
980 & 0.098 & 49.1 \\
\hline
\end{tabular}

${ }^{a}$ Values extrapolated.

Table 34. 304L stainless steel thermal conductivity

\begin{tabular}{cc}
\hline $\begin{array}{c}\text { Temperature } \\
\left({ }^{\circ} \mathrm{F}\right)\end{array}$ & $\begin{array}{c}\text { Thermal conductivity } \\
\left(\text { Btu/s-ft- }{ }^{\circ} \mathrm{F}\right)\end{array}$ \\
\hline 50 & 0.00239 \\
80 & 0.00244 \\
440 & 0.00294 \\
520 & 0.00317 \\
980 & 0.00361 \\
\hline
\end{tabular}


Table 35. 347 stainless steel specific

heat and volumetric heat capacity (Ref. 106)

\begin{tabular}{ccc}
\hline $\begin{array}{c}\text { Temperature } \\
\left({ }^{\circ} \mathrm{F}\right)\end{array}$ & $\begin{array}{c}\text { Specific heat } \\
\left(\mathrm{Btu}^{\prime} / \mathrm{b}_{\mathrm{m}}{ }^{\circ}{ }^{\circ} \mathrm{F}\right)\end{array}$ & $\begin{array}{c}\text { Volumetric heat } \\
\text { capacity } \\
\left(\mathrm{Btu}^{3} \mathrm{ft}^{3}-{ }^{\circ} \mathrm{F}\right)\end{array}$ \\
\hline 80 & 0.109 & 53.8 \\
440 & 0.120 & 59.3 \\
620 & 0.125 & 61.7 \\
980 & 0.135 & 66.7 \\
\hline
\end{tabular}

Table 36. 347 stainless steel thermal conductivity (Ref. 108)

\begin{tabular}{cc}
\hline $\begin{array}{c}\text { Temperature } \\
\left({ }^{\circ} \mathrm{F}\right)\end{array}$ & $\begin{array}{c}\text { Thermal conductivity } \\
\left(\mathrm{Btu} / \mathrm{s}-\mathrm{ft}-{ }^{\circ} \mathrm{F}\right)\end{array}$ \\
\hline 80 & 0.00238 \\
440 & 0.00286 \\
620 & 0.00308 \\
980 & 0.00353 \\
\hline
\end{tabular}

For the calculation of heat transfer from upper plenum water to the reactor pool, conduction heat transfer through the vessel sidewall is modeled in cylindrical geometry. Conduction through the vessel top head is modeled in "slab" geometry. The inside and outside surface areas of the sidewall, $A_{s}^{i}$ and $A_{s}^{o}$, respectively, and that of the top head $A_{s}^{h}$ $\operatorname{are}^{92}$

$$
\begin{aligned}
& A_{s}^{i}=108 \mathrm{ft}^{2}\left(10.03 \mathrm{~m}^{2}\right) \\
& A_{s}^{0}=115 \mathrm{ft}^{2}\left(10.68 \mathrm{~m}^{2}\right), \\
& A_{s}^{h}=48.3 \mathrm{ft}^{2}\left(4.49 \mathrm{~m}^{2}\right) .
\end{aligned}
$$

The top head surface area only includes the portion bounded by the inside diameter of the vessel.

During normal HFIR operation, heat transfer from the upper plenum to the pool is small relative to thic core power. However, after reactor shutdown or when operating at low power and the forced flow rate is low (i.e., pony motor driven) or there is no forced flow, heat transfer is more significant. In this case, even with pony motor forced flow, natural convection will dictate heat transfer along vessel walls [average forced flow velocity is only $\approx 0.06 \mathrm{ft} / \mathrm{s}(0.018 \mathrm{~m} / \mathrm{s})$ in upper plenum]. Depending upon the simulation, the upper plenum water temperature may increase significantly above normal $\left[\approx 120^{\circ} \mathrm{F}\left(48.9^{\circ} \mathrm{C}\right)\right]$. Because the heat transfer coefficient cannot be input in RELAP5 as a function of the water and vessel 
wall temperatures, both of which may vary with time, a representative coefficient is used. For the sidewall a value of $0.028 \mathrm{Btu} / \mathrm{s}-\mathrm{ft}^{2}-{ }^{\circ} \mathrm{F}\left(568 \mathrm{~W} / \mathrm{m}^{2}-\mathrm{K}\right)$ was selected that corresponds to roughly a $20^{\circ} \mathrm{F}\left(11^{\circ} \mathrm{C}\right)$ water-to-wall temperature difference (see Sect. 3.2.5.3 and Table 30). The same approach is used to calculate natural convection heat transfer to the vessel top head. However, natural convection heat transfer is more effective to a cold horizontal surface facing downward than to a vertical surface. In the former case the average turbulent Nusselt number is given by ${ }^{89}$

$$
N u_{a v}=0.15 R a_{L_{c}}{ }^{k} \text {. }
$$

The leading coefficient $(0.15)$ is 1.5 times that for vertical surfaces (see Sect. 3.2.5.3). Thus, the representative heat transfer coefficient selected for the inside surface of the vessel top head is $0.042 \mathrm{Btu} / \mathrm{s}-\mathrm{ft}^{2}{ }^{\circ} \mathrm{F}$ (150 Btu/h-ft$\left.{ }^{2}{ }^{\circ} \mathrm{F}, 852 \mathrm{~W} / \mathrm{m}^{2}-\mathrm{K}\right)$. Obviously, depending upon the accident simulated, these values may require revision.

Modeling of natural convection heat transfer from the outer surface of the U-plenum region vessel walls to the reactor pool can be accomplished accurately when the pool temperature remains nearly constant through the duration of an accident simulation. Aside from long-duration simulations (or simulations of certain "catastrophic" events), the pool temperature should not vary significantly due to its large thermal capacity. In this case, the natural convection heat transfer coefficient can be input to RELAP5 in a general table as a function of the outer vessel wall temperature. Following the procedure used in Sect. 3.2.5.3 for reflector-to-bypass natural convection heat transfer, and accounting for the difference between horizontal and vertical surface heat transfer, vessel sidewall and top head convection coefficients were calculated. As before, a conservative film temperature was selected, $104^{\circ} \mathrm{F}$ $\left(40^{\circ} \mathrm{C}\right)$ in this case. Corresponding property values are ${ }^{74,90}$

$$
\begin{aligned}
& v=7.08 \times 10^{-6} \mathrm{ft}^{2} / \mathrm{s}\left(6.58 \times 10^{-7} \mathrm{~m}^{2} / \mathrm{s}\right), \\
& \alpha=1.63 \times 10^{-6} \mathrm{ft}^{2} / \mathrm{s}\left(1.51 \times 10^{-7} \mathrm{~m}^{2} / \mathrm{s}\right), \\
& \beta=0.19 \times 10^{-3} /{ }^{\circ} \mathrm{F}\left(3.4 \times 10^{-4} /{ }^{\circ} \mathrm{C}\right) .
\end{aligned}
$$

With $L_{c}=4.39 \mathrm{ft}$, the vessel sidewall height over which heat transfer to the pool is modeled, $R a_{L_{c}}$ is calculated to be

$$
R a_{L_{c}}=4.46 \times 10^{10} \Delta T^{\circ} \mathrm{F} .
$$

Using this and the following $N u_{a v}$ for turbulent flow as before, that is, ${ }^{89}$

$$
N u_{a v}=0.10\left(R a_{L_{c}}\right)^{1 / 3}
$$

where

$$
\begin{aligned}
& N u_{a \nu}=\frac{h L_{c}}{K}, \\
& h=\text { natural convection heat transfer coefficient, } \\
& k=\text { thermal conductivity }\left[=0.363 \mathrm{Btu} / \mathrm{h}-\mathrm{ft}-{ }^{\circ} \mathrm{F} \text { at } 140^{\circ} \mathrm{F}\left(0.628 \mathrm{~W} / \mathrm{m}-\mathrm{k} \text { at } 40^{\circ} \mathrm{C}\right)\right],^{74}
\end{aligned}
$$


the average heat transfer coefficient for the vessel sidewall (outside surface) is

$$
h=8.15 \times 10^{-3} \Delta T^{4 / 6} \mathrm{Btu} / \mathrm{s}-\mathrm{ft}^{2}-{ }^{\circ} \mathrm{F} .
$$

Note that $\Delta T$ is the difference between the sidewall outside surface temperature and the reactor pool temperature. For the vessel lid outside surface the heat transfer coefficient is simply 1.5 times that for the sidewall (for the same temperature difference) as indicated previously. Vessel sidewall and lid (outside surfaces) heat transfer coefficients are presented in Table 37 and are based upon a constant pool temperature of $100^{\circ} \mathrm{F}\left(37.8^{\circ} \mathrm{C}\right)$.

The inside surfaces of the U-plenum region are assumed to have a roughness of $1.5 \times 10^{-4}$ (Ref. 94). The inlet piping connects to the U-plenum region with a cross-flow junction. The abrupt area change model is used at all connections to the U-plenum.

\subsubsection{Lower Plenum}

The region beneath the core that extends to the base of the fuel and reflector support is represented in the model in two regions, L-plenum-1 and L-plenum-2 (see Figs. 3, 7, and 20). The L-plenum-1 region is the cylindrical region bounded radially by the outer wall of the fuel grid support pedestal. L-plenum-2 is an annular region bounded at its inner radius by the fuel grid support pedestal and at its outer radius by the reflector container and pedestal assembly and the fuel and reflector support. L-plenum-1 connects to the fuel and target regions, while L-plenum-2 connects to the control and reflector regions. Two vertical slots in the fuel grid support pedestal permit flow between L-plenum-1 and L-plenum-2.

The height and diameter of the L-plenum-1 region are 3.74 and $1.26 \mathrm{ft}(1.14$ and $0.384 \mathrm{~m}$ ), respectively. ${ }^{91}$ The region flow area $A_{f}^{l}$ and hydraulic diameter $D_{h y}^{l}$ are

$$
\begin{aligned}
& A_{f}^{l}=1.25 \mathrm{ft}^{2}\left(0.116 \mathrm{~m}^{2}\right), \\
& D_{h y}^{l}=1.26 \mathrm{ft}(0.384 \mathrm{~m}) .
\end{aligned}
$$

Table 37. Natural convection heat transfer

\begin{tabular}{|c|c|c|}
\hline \multirow{2}{*}{$\begin{array}{l}\text { Outside vessel surface } \\
\text { temperature } \\
\left({ }^{\circ} \mathrm{F}\right)\end{array}$} & \multicolumn{2}{|c|}{$\begin{array}{l}\text { Heat transfer } \\
\text { coefficient } \\
\left(\mathrm{Btu} / \mathrm{s}-\mathrm{ft}^{2}-^{\circ} \mathrm{F}\right)\end{array}$} \\
\hline & Sidewall & Top head \\
\hline 100 & 0 & 0 \\
\hline 105 & 0.0139 & 0.0209 \\
\hline 120 & 0.0221 & 0.0332 \\
\hline 140 & 0.0278 & 0.0418 \\
\hline 160 & 0.0319 & 0.0479 \\
\hline 180 & 0.0351 & 0.0527 \\
\hline 200 & 0.0378 & 0.0567 \\
\hline 212 & 0.0392 & 0.0588 \\
\hline
\end{tabular}
coefficients at the upper vessel sidewall and top head outside surfaces 


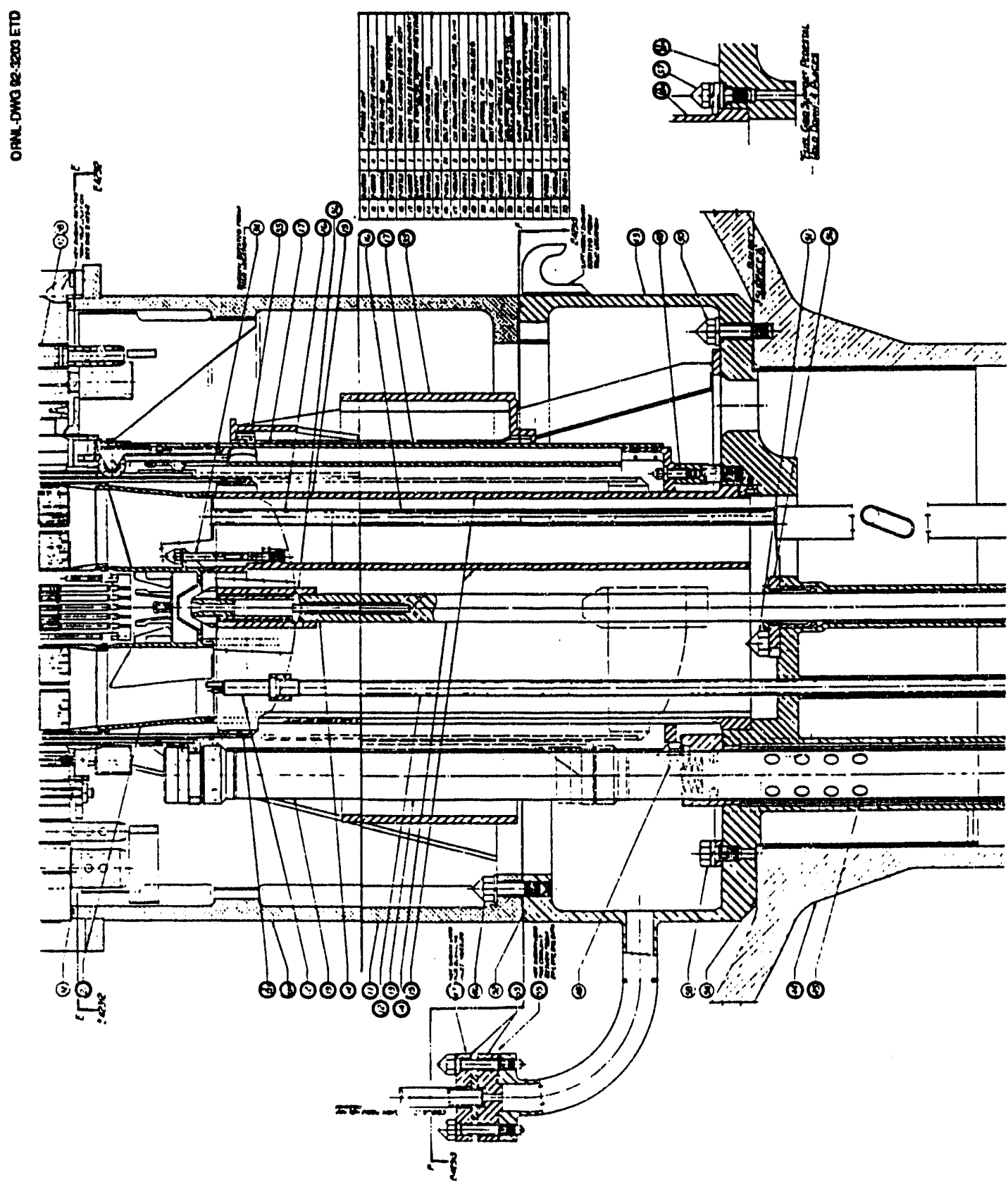

是 
The two fuel grid support pedestal slots are $180^{\circ}$ apart and $0.5 \mathrm{in} .(1.27 \mathrm{~cm})$ wide and 34.4 in. $(87.4 \mathrm{~cm})$ long. ${ }^{109}$ The total slot flow area is then $0.239 \mathrm{ft}^{2}\left(0.0222 \mathrm{~m}^{2}\right)$. This flow path is represented in the model using a cross-flow junction (9-09 in Fig. 7). The flow resistance through the slot is modeled using a smooth area change at the junction along with a form loss coefficient. Conservatively (more loss), the form loss is assumed to consist of a "sudden contraction" (L-Plenum-1 or -2 into the slots) and a "sudden expansion" (slots into L-Plenum1 or -2 ) with area ratios providing the maximum possible loss. That is, for the sudden contraction form loss $K_{c}$, the ratio of the "exit" (slots) to "entrance" (L-Plenum-1 or -2) areas $A_{S} / A_{L}$ is taken to be 0 , which gives for $K_{c}$ (Ref. 110)

$$
K_{c}=a\left[1-\left(A_{s} / A_{L}\right)^{2}\right]
$$

where

$$
\begin{aligned}
a & =0.4 \text { to } 0.5 \text { (conservatively use } 0.5 \text { ), } \\
K_{c} & =0.5 .
\end{aligned}
$$

For the sudden expansion form loss $K_{e}$, the ratio of the entrance (slots) to exit (L-Plenum-1 or -2) areas $A_{S} / A_{L}$ is taken to be 0 , which gives for $K_{e}$ (Ref. 110)

$$
\begin{aligned}
& K_{e}=\left(1-A_{S} / A_{L}\right)^{2}, \\
& K_{e}=1.0 .
\end{aligned}
$$

Thus, the total form loss is 1.5 , which is used as the forward and reverse value in the RELAP5 input model.

The area $A_{f j}^{1}$ of the junction connecting the L-plenum-1 and outlet regions (see Figs. 7 and 21) was estimated by summing the available flow area indicated in the plan section of the core support upper flange. $A_{f j}^{1}$ was determined to be $0.77 \mathrm{ft}^{2}\left(0.072 \mathrm{~m}^{2}\right) .^{27}$

The height and inner and outer radii of the $L$-plenum- 2 region are $3.74,0.671$, and $1.70 \mathrm{ft}(1.14,0.205$, and $0.518 \mathrm{~m})$, respectively. ${ }^{91}$ The region flow area $A_{f}^{2}$ and hydraulic diameter $D_{h y}^{2}$ are

$$
\begin{aligned}
& A_{f}^{2}=7.66 \mathrm{ft}^{2}\left(0.712 \mathrm{~m}^{2}\right), \\
& D_{h y}^{2}=2.06 \mathrm{ft}(0.628 \mathrm{~m}) .
\end{aligned}
$$

The area $A_{f j}^{2}$ of the junction connecting the L-plenum-2 and outlet regions (see Figs. 7 and 21) was found by summing the flow areas of the eight large holes shown in the plan section of the core support flange. $A_{f j}^{2}$ was determined to be $0.543 \mathrm{ft}^{2}\left(0.050 \mathrm{~m}^{2}\right)^{27}$

The roughness of the channel surfaces in L-plenum- 1 and $\mathrm{L}$-plenum-2 regions was taken to be $1.5 \times 10^{-4} \mathrm{ft}\left(4.57 \times 10^{-5} \mathrm{~m}\right)$, which corresponds to commercial steel piping. ${ }^{94}$ The abrupt area change model is used at junctions connecting the L-plenum-1 and L-plenum-2 regions to regions above and below them.

As mentioned previously, heat transfer from the L-plenum-2 region to the L-bypass region is modeled. Heat flows through the reflector container and pedestal assembly and through the fuel and reflector support. The former is constructed of 6061 aluminum. ${ }^{111}$ The cylindrical structure is $2.6 \mathrm{ft}(0.792 \mathrm{~m})$ high with an inside diameter of $3.37 \mathrm{ft}(1.03 \mathrm{~m})$ and a wall thickness of $1 \mathrm{in}$. $(2.54 \mathrm{~cm})$ over most of its height [2.2 ft $(6.71 \mathrm{~m})]{ }^{91}$ Elsewhere, 


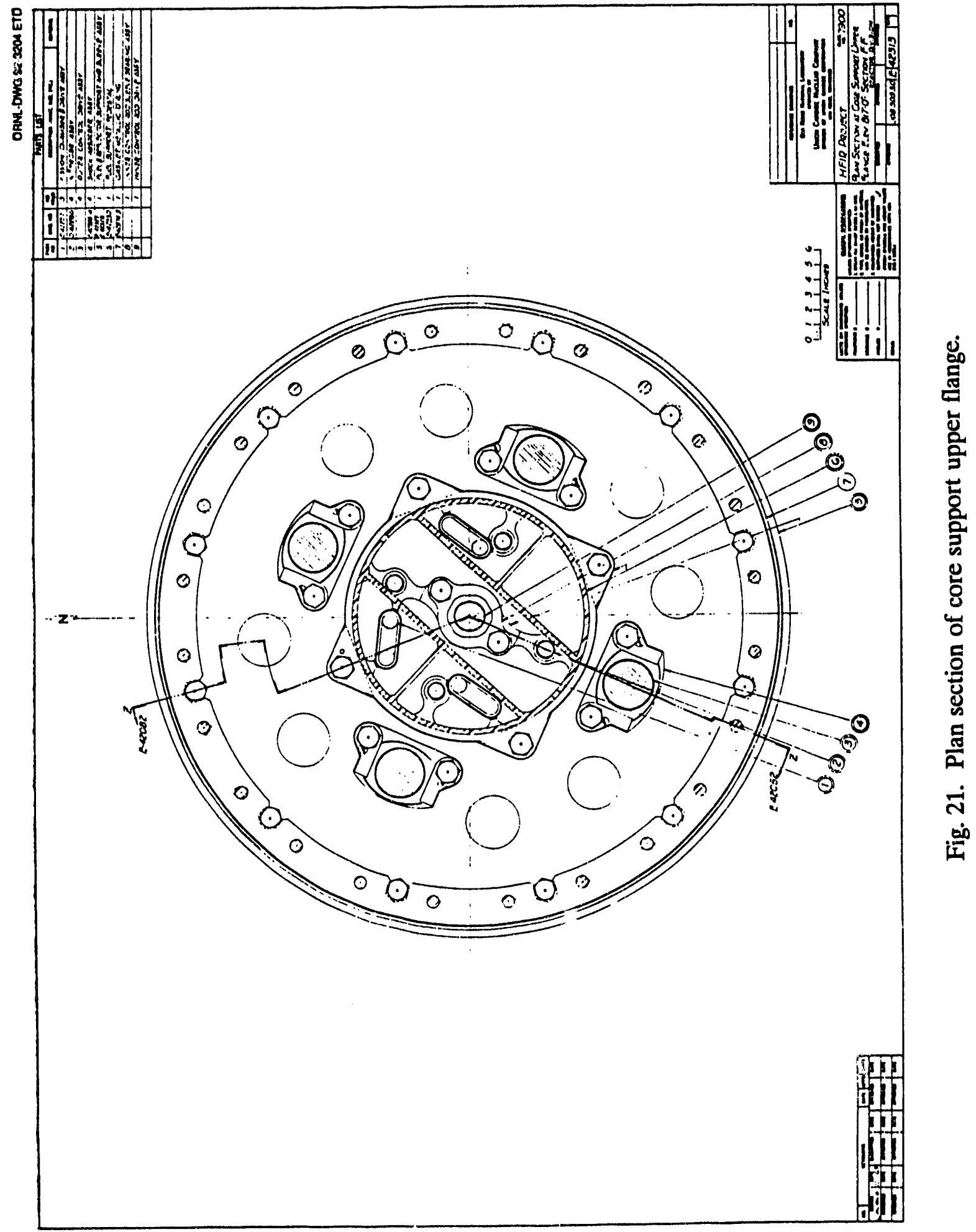


the wall thickness is significantly greater. Conservatively, heat transfer is assumed to occur only over the thinner portion. The thickness of the oxide on the inner and outer surfaces of the structure is assumed to be $0.689 \mathrm{mil}(0.018 \mathrm{~mm})$, as was assumed for the target, control, and reflector regions. Accounting for the presence of the oxide, the radial boundaries of the oxide regions and aluminum are presented in Table 38. The fuel and reflector support is constructed of $304 \mathrm{~L}$ stainless steel. ${ }^{93,112}$ As above, heat transfer through the cylindrical structure was assumed to occur only over the height where the wall thickness was at its minimum nominal value, $0.65 \mathrm{in}$. $(1.65 \mathrm{~cm})$. Thus, the height and inside diameter of the structure are taken to be 0.92 and $3.43 \mathrm{ft}(0.280$ and $1.05 \mathrm{~m})$, respectively. ${ }^{91}$

The thermophysical properties used for reflector container and pedestal assembly modeling have been presented in Tables 20 and 21 for 6061 aluminum and in Table 8 and Sect. 3.2.1 for oxide. Properties of 304L stainless steel for fuel and reflector support modeling have been presented in Tables 32 and 33 and in Sect. 3.2.10.

Natural convection heat transfer was assumed to occur along the outer surfaces of the L-plenum-2 heat structures, as was assumed in modeling the outer core shroud wall transfer to the U-bypass region. The heat transfer coefficients input to RELAP5 as a function of the heat structure outer surface temperature are the same as those used for the core shroud presented previously in Table 30. (Note again that a turbulent natural convection flow exists, making differences in heat transfer surface heights irrelevant.)

Table 38. Radial boundaries of the oxide regions and aluminum comprising the reflector container and pedestal assembly

\begin{tabular}{lcc}
\hline \multirow{2}{*}{\multicolumn{1}{c}{ Region }} & \multicolumn{2}{c}{$\begin{array}{c}\text { Radii } \\
\text { (ft) }\end{array}$} \\
\cline { 2 - 3 } & Inside & Outside \\
\hline Inside-surface oxide & 1.684988 & 1.685045 \\
Aluminum & 1.685045 & 1.768288 \\
Outside-surface oxide & 1.768288 & 1.768345 \\
\hline
\end{tabular}

\subsubsection{Outlet}

With reference to Figs. 3 and 7, the region beneath the lower plenum and connecting to the outlet pipe is represented in the RELAP5 model by the "outlet" region (branch volume No. 34). Only the flow within the region is modeled. The height and diameter are 3.69 and $2.74 \mathrm{ft}(1.12$ and $0.835 \mathrm{~m}),{ }^{91}$ respectively. The region flow area $A_{f}$ and hydraulic diameter $D_{h y}$ are

$$
\begin{aligned}
& A_{f}=5.90 \mathrm{ft}^{2}\left(0.548 \mathrm{~m}^{2}\right), \\
& D_{h y}=2.74 \mathrm{ft}(0.835 \mathrm{~m}) .
\end{aligned}
$$


The roughness of the outlet channel surfaces was taken to be $1.5 \times 10^{-4} \mathrm{ft}(4.57 \times$ $10^{-5} \mathrm{~m}$ ), corresponding to commercial steel piping. ${ }^{94}$ The abrupt area change model was used at the entrance and exit to the region. The exit of the outlet region was connected to the outlet pipe with a cross-flow junction.

\subsection{EXTRA-VESSEL COMPONENT DESCRIPTIONS}

The assumptions and calculations, ${ }^{113}$ which were used to represent each component in the RELAP5 model for the primary coolant system outside of the vessel, are described in this section.

\subsubsection{Piping}

Lengths and elevations of the piping throughout the high pressure side of the primary coolant system were obtained from available drawings. ${ }^{114}$ Pipe diameters and thicknesses ${ }^{119}$ used in the model are given in Table 39.

Table 39. Dimensions of steel pipe

\begin{tabular}{cccc}
\hline Schedule & $\begin{array}{c}\text { Nominal } \\
\text { diameter } \\
\text { (in.) }\end{array}$ & $\begin{array}{c}\text { Indide } \\
\text { diameter } \\
\text { (in.) }\end{array}$ & $\begin{array}{c}\text { Thickness } \\
\text { (in.) }\end{array}$ \\
\hline 40 & 2 & 2.067 & 0.154 \\
40 & 3 & 3.068 & 0.216 \\
40 & 4 & 4.026 & 0.237 \\
40 & 10 & 10.020 & 0.365 \\
40 & 14 & 13.126 & 0.437 \\
40 & 16 & 15.000 & 0.500 \\
40 & 18 & 16.876 & 0.562 \\
40 & 20 & 18.814 & 0.593 \\
80 & 10 & 9.564 & 0.593 \\
& & & \\
\hline
\end{tabular}

The hot leg stretching from the vessel outlet down the pipe tunnel (Figs. 5 and 6) consists of 18-in. (45.7- $\mathrm{cm})$ schedule 40 pipe. The cold leg stretching down the pipe tunnel to the strainer housing (Figs. 5 and 6 ) is 20 -in. (50.8-cm) schedule 40 pipe. Pipes in the pipe tunnel are gently sloped (less than $1^{\circ}$ ) so that the ends nearer the vessel are lowest. The two inlet pipes that join the strainer to the vessel (Figs. 5 and 6 ) are 16-in. $(40.6-\mathrm{cm})$ schedule 40 pipe.

The four heat exchanger cells (Fig. 22) are at the same elevation, and from inlet block valve to outlet block valve (Figs. 5 and 22), the cells are identical. Because only three of the four heat exchanger cells are valved into the system at a time, only three cells were modeled (cells 110,111 , and 113 , or D, C, and A, respectively). The lines leading up to the block valves for cell 112 were also included in the model (pipes 375 and 352 in Fig. 6). 


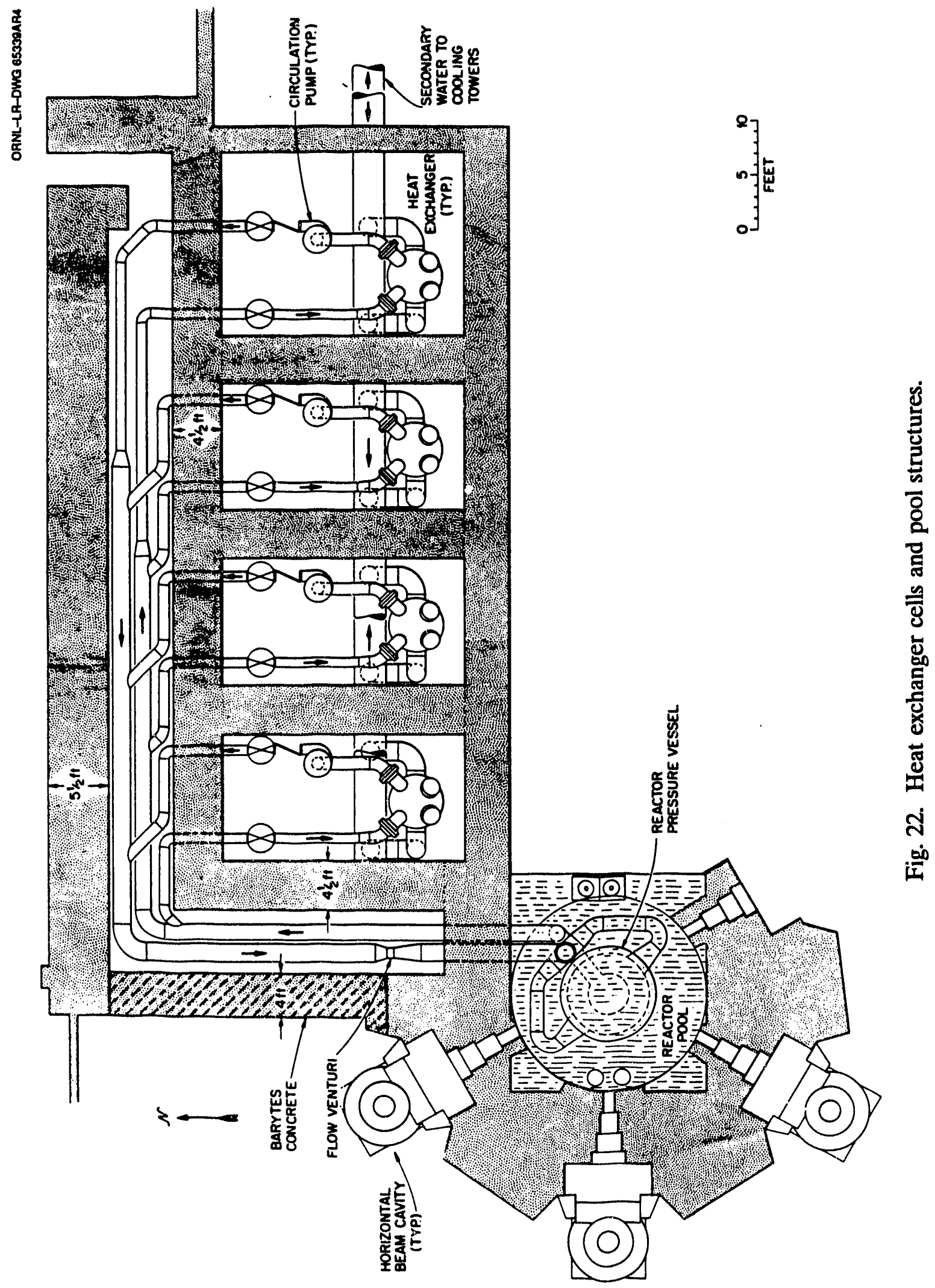


A short segment of 10 -in. $(25.4-\mathrm{cm})$ schedule 80 pipe is used for the branch side of the wyes in the pipe tunnel to and from each heat exchanger cell (Fig. 22 and volumes 52-01, 75-04, 152-01, 175-04, 352-01, and 375-03 in Fig. 6). From the schedule 80 section to the inlet block valve in each heat exchanger cell, the pipe is 10 -in. $(25.4-\mathrm{cm})$ schedule 40 . This same size pipe stretches from the inlet block valve to an expansion fitting just upstream of the heat exchanger inlet (Fig. 22). The piping gently slopes downward in both directions from the isolation block valves: to the heat exchangers in one direction and to the pipe tunnel in the other. Fourteen-inch $(35.6-\mathrm{cm})$ schedule 40 pipe is used in the heat exchanger (Fig. 22 and volumes 57, 157, and 257 in Fig. 6) and between the heat exchanger and the main circulating pump (Fig. 22 and pipes 60, 160, and 260 in Fig. 6). The remainder of the piping in the cell, from the pump discharge to the schedule 80 section near the wye fitting, is 10 -in. (25.4-cm) schedule 40 (Fig. 22).

The line extending from the pressurizer pumps to the pipe tunnel (Fig. 23 and volume 67 in Fig. 6) is 3-in. (7.62-cm) schedule 40 and $148 \mathrm{ft}(45.1 \mathrm{~m})$ long. ${ }^{114,120-122}$ The line from the primary coolant head tank to the pressurizer pumps (Fig. 23 and volume 72 in Fig. 6) is 4-in. (10.2-cm) schedule 40 and is $66.5 \mathrm{ft}(20.3 \mathrm{~m})$ long. The letdown lines extending from the heat exchangers to the letdown valves (Fig. 23) are $2-i n .(5.08-\mathrm{cm}$ ) schedule 40 and are about $30 \mathrm{ft}(9.14 \mathrm{~m})$ long.

Heat structures were included in the model to represent the pipe walls. The material used for the piping heat structures was 304L stainless steel, the properties of which were given in Tables 33 and 34.

Convective heat transfer to air from pipes in the pipe tunnel, heat exchanger cells, and the pressurizer line was neglected (conservative for most transients). Although heat structure models are provided, an insulated boundary condition was chosen. Convective heat transfer from the primary coolant piping to the pool surrounding the reactor vessel was included. A correlation developed by Churchill and $\mathrm{Chu}^{15}$ was used to generate tables for the heat transfer coefficient as a function of temperature for the horizontal 16-in. $(40.6-\mathrm{cm})$ inlet pipes, the portion of the horizontal 20 -in. $(50.8-\mathrm{cm})$ cold leg pipe that is submerged in the pool, and the portion of the 18-in. $(45.7-\mathrm{cm})$ hot leg pipe that is submerged in the pool. A correlation from Kreith ${ }^{16}$ was used to generate tables for the natural convective heat transfer coefficient from the vertical strainer housing and the vertical portion of the 18-in. $(45.7-\mathrm{cm})$ hot leg.

Some of the key elevations are listed in Table 40. The highest elevations in the lines leading toward and away from the heat exchangers are located at the isolation block valves. The highest elevation in the system is at the top of the strainer housing.

Because RELAP5 checks that the net elevation change around a closed loop is exactly zero, very small adjustments [no larger than $10^{-3} \mathrm{ft}\left(3.05 \times 10^{-3} \mathrm{~m}\right)$ ] had to be made to the net elevation change of a few volumes in the system. The surface roughness ${ }^{94}$ was assumed to be $1.5 \times 10^{-4} \mathrm{ft}\left(4.57 \times 10^{-5} \mathrm{~m}\right)$ for each pipe volume in the system except for the heat exchanger tubing where a smoother surface $\left[10^{-6} \mathrm{ft}\left(3.05 \times 10^{-7} \mathrm{~m}\right)\right]$ was assumed. The sensitivity of the flow rate to surface roughness was determined by assuming a surface roughness of $10^{-6} \mathrm{ft}\left(3.05 \times 10^{-7} \mathrm{~m}\right)$ everywhere. This resulted in increasing the primary coolant flow by only $75 \mathrm{gal} / \mathrm{min}\left(4.73 \times 10^{-3} \mathrm{~m}^{3} / \mathrm{s}\right)(<0.5 \%)$. Loss coefficients for the piping that are used to calculate the pressure drop due to friction brought on by changing the flow cross section or direction (e.g., bends, wyes, expansions, and contractions) are discussed in Sect. 3.5. 


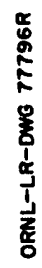

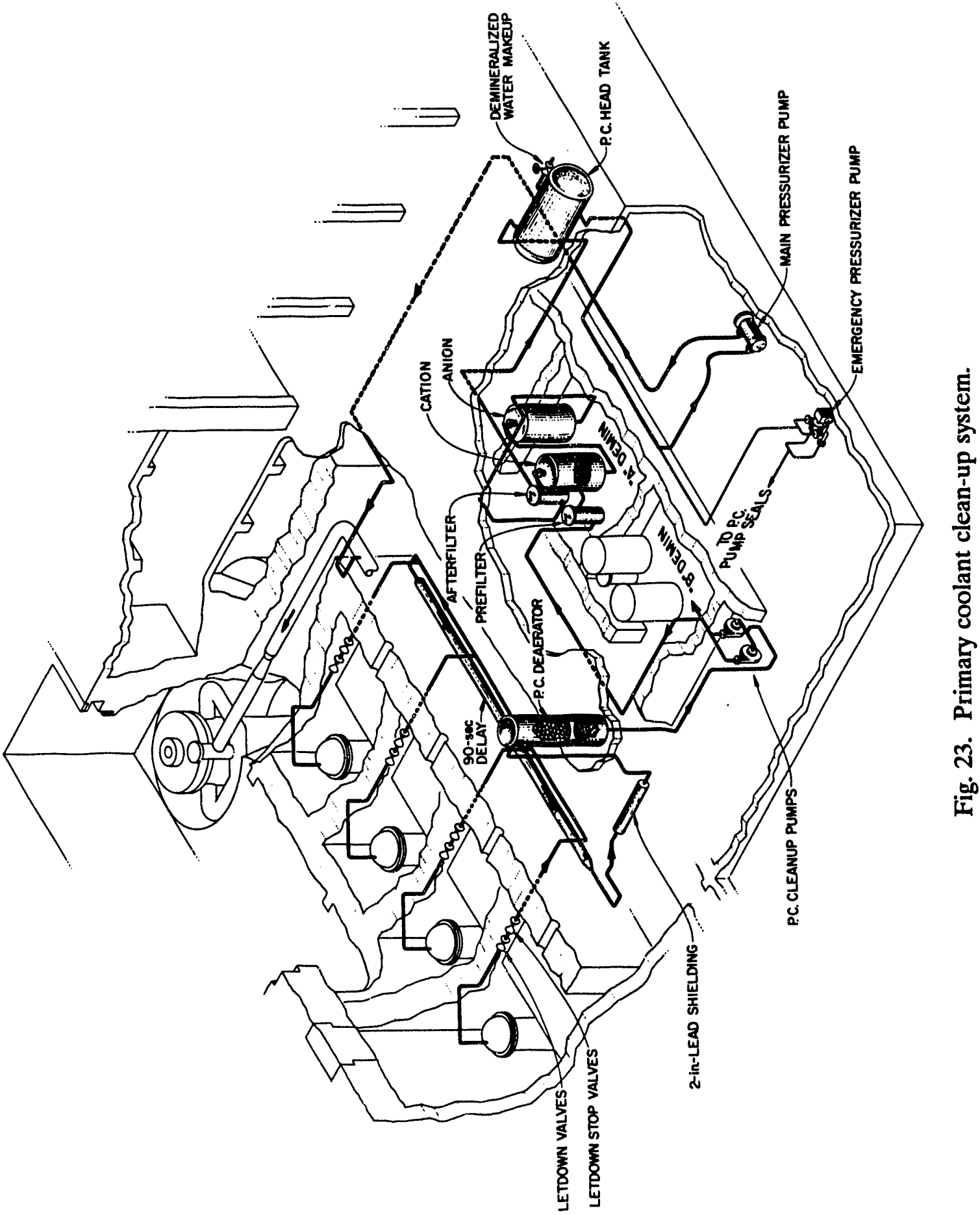


Table 40. Selected elevations in the primary coolant system ${ }^{115,125}$

\begin{tabular}{|c|c|}
\hline Location & Elevation \\
\hline Top of strainer housing ${ }^{118}$ & $832 \mathrm{ft} 77 / 16 \mathrm{in}$. \\
\hline 16-in. inlet pipes & $826 \mathrm{ft}$ \\
\hline 18-in. outlet from vessel & $813 \mathrm{ft} 6$ in. \\
\hline 20-in. line into strainer & $830 \mathrm{ft} 2$ in. \\
\hline $\begin{array}{l}\text { Heat exchanger inlet and } \\
\text { outlet }\end{array}$ & $827 \mathrm{ft} 8$ in. \\
\hline Inlet isolation block valves & $827 \mathrm{ft} 81 / 8$ in. \\
\hline Outlet isolation block valves & $830 \mathrm{ft} 71 / 2 \mathrm{in}$. \\
\hline Bottom of PC head tank ${ }^{126}$ & $835 \mathrm{ft}$ \\
\hline $\begin{array}{l}\text { Suction and discharge of main } \\
\text { and standby pressurizer } \\
\text { pumps }^{116}\end{array}$ & $819 \mathrm{ft} \mathrm{53/4} \mathrm{in.}$ \\
\hline
\end{tabular}

\subsubsection{Heat Exchangers}

The original HFIR heat exchangers were replaced in 1985 by new, more efficient heat exchangers manufactured by Joseph Oat Corporation. This was done because of concern that the old exchangers might experience a multiple tube rupture. The new heat exchangers (Figs. 5 and 22$)$ are $~ 30 \mathrm{ft}(9.14 \mathrm{~m})$ high and $4 \mathrm{ft}(1.22 \mathrm{~m})$ in diameter. The flow paths taken by the secondary and primary water are indicated in Fig. 24. In Fig. 25, the RELAP5 nodal diagram for the three active heat exchangers and the secondary flow system is shown. Each heat exchanger was modeled by combining pipe, single volume, single junction, and heat structure RELAP5 components in such a way that the resulting heat exchanger performance was consistent with the observed performance of the new heat exchangers. Although the original exchangers were designed for inlet conditions of $5000 \mathrm{gal} / \mathrm{min}\left(0.315 \mathrm{~m}^{3} / \mathrm{s}\right), 167^{\circ} \mathrm{F}$ $\left(75^{\circ} \mathrm{C}\right)$ primary flow, and $6667 \mathrm{gal} / \mathrm{min}\left(0.421 \mathrm{~m}^{3} / \mathrm{s}\right), 85^{\circ} \mathrm{F}\left(29.4^{\circ} \mathrm{C}\right)$ secondary flow each, the new exchangers require only about $4000 \mathrm{gal} / \mathrm{min}\left(0.252 \mathrm{~m}^{3} / \mathrm{s}\right)$ of secondary flow each to remove the $85 \mathrm{MW}$ generated at normal operation. See the discussion of the model of the secondary coolant system (Sect. 3.3.8) for the exact value of secondary coolant flow used in the model and an explanation of how it was calculated.

The RELAP5 1-D model is sufficient to accurately model the primary side flow because of the simple U-tube geometry. As shown in Fig. 25, the primary fluid in the tube bundle is represented with 20 volumes linked in series (e.g., pipes 100,101, 104, and 105, each of which contains five volumes). This level of refinement was selected after determining the sensitivity of the exchangers to discretization by making some preliminary RELAP5 runs. Pressure 


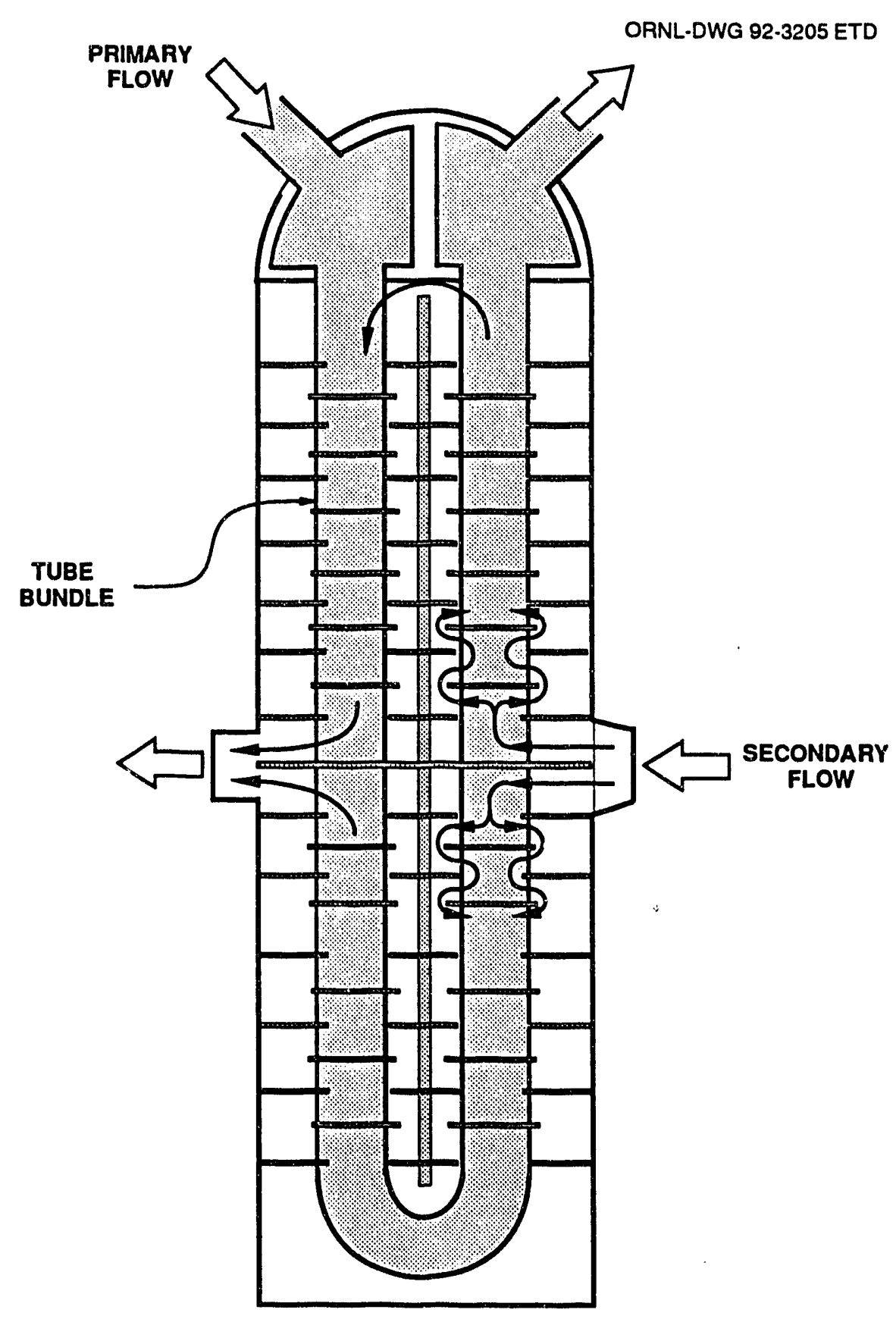

Fig. 24. Heat exchanger flow path.

losses due to the U-tube curvature have been neglected because of the large radius-ofcurvature-to-diameter ratio. According to manufacturer's data, ${ }^{127}$ the tube bundle consists of 1200 stainless steel tubes with an average tube length of 710.52 in. $(18.05 \mathrm{~m})$. Each tube has inner and outer diameters of 0.555 and 0.625 in. (1.41 and $1.59 \mathrm{~cm}$ ), respectively. The heat exchanger is capped with a hemispherical shell. Half of the volume inside this shell lies on either side of the heat exchanger: one-quarter-sphere volume upstream (hot side) and onequarter-sphere volume downstream (cold side). Each of these volumes is charasterized in the 


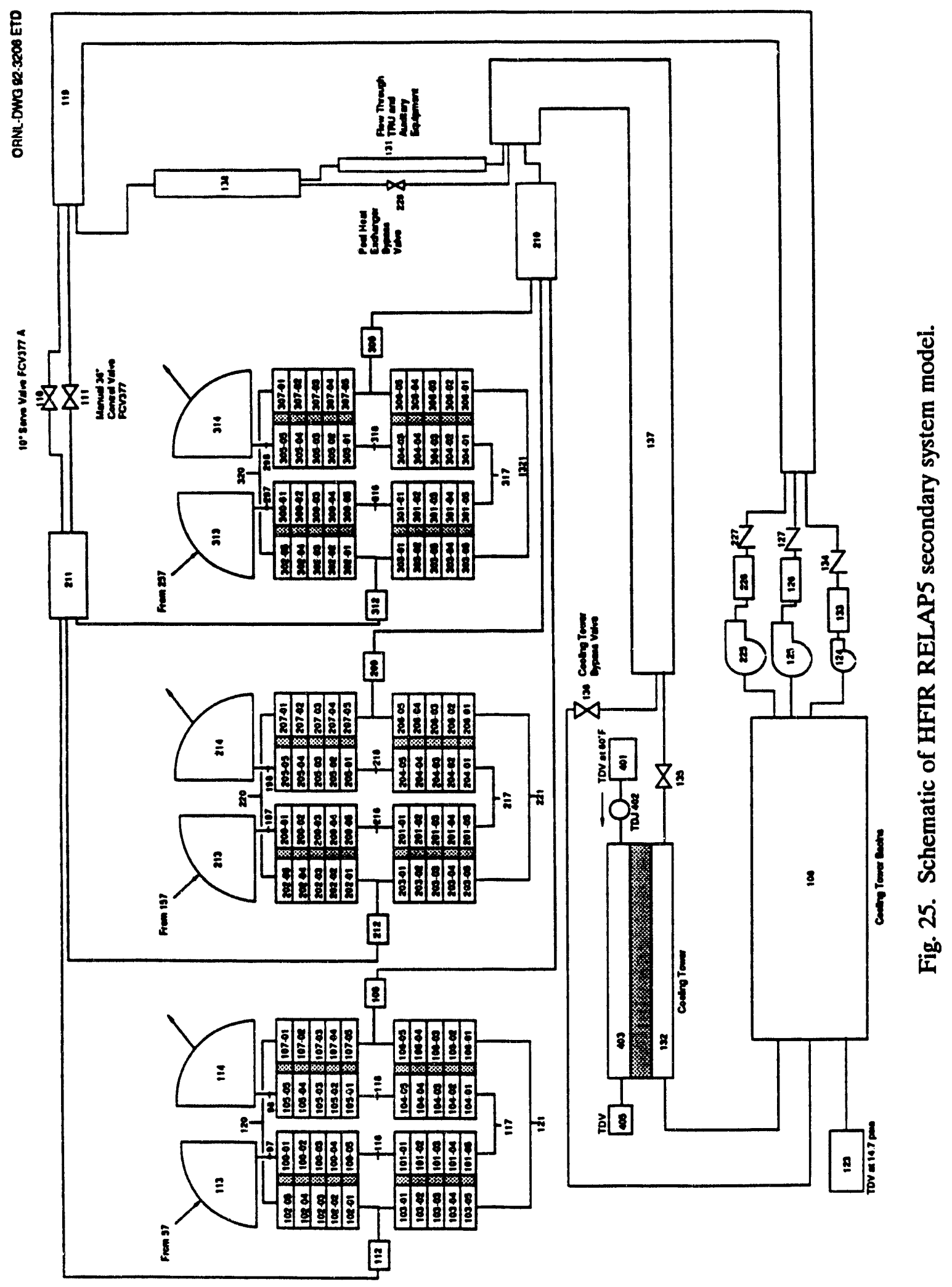


RELAP5 model by a control volume (node) having the actual quarter-sphere volume of $7.8644 \mathrm{ft}^{3}\left(0.223 \mathrm{~m}^{3}\right)$ and a length equal to the spherical radius of $1.9583 \mathrm{ft}(0.597 \mathrm{~m})$. Letdown flow is extracted off of the cold quarter-sphere plenum at the outlet of each heat exchanger.

The secondary side flow pattern is much more complicated. As seen in Fig. 24, the flow enters the heat exchanger about halfway up the primary outlet side. It then splits; some of the flow goes up, and some down. Both streams weave through the baffle configuration and then recombine at the secondary outlet, which is located about halfway up the primary inlet side. Details of the complex flow pattern on the secondary side of the heat exchanger cannot be resolved using the 1-D RELAP5 program. To calculate the heat transfer through the heat exchanger, RELAP5 uses the Dittus-Boelter correlation ${ }^{1,20}$

$$
N u_{D}=0.023 \operatorname{Re}_{D}^{0.8} P^{0.4} \text {, }
$$

where

$$
\begin{aligned}
& N u_{D}=\frac{h D_{h y}}{k}, \\
& R e_{D}=\frac{Q D_{h y}}{v A} .
\end{aligned}
$$

Here $h$ is the local heat transfer coefficient, $D_{h y}$ is the hydraulic diameter, $A$ is the crosssectional flow area, $v$ is the kinematic viscosity, $k$ is the water thermal conductivity, and $Q$ is the volumetric flow rate.

Two problems exist with using this correlation on the secondary side. First, it is based on experiments for fully developed turbulent flow in pipes. However, the actual secondary flow is an extremely complicated 3-D flow with many areas of recirculation. Second, much of the secondary flow is orientated across the U-tubes rather than parallel with them. A correlation for tube bundles in cross-flow given by $\mathrm{Kreith}^{21}$ indicates that $N u_{D}$ is proportional to $\operatorname{Re}_{D}{ }^{0.6}$ and $\mathrm{Pr}^{0.3}$. Despite these two problems, Dittus-Boelter is used to predict the heat transfer to the secondary side. By calibrating the model so that the heat exchanger performs properly at the design conditions, it is assumed that the Dittus-Boelter correlation is adequate for all cases.

The secondary-side Reynolds number depends upon the flow rate, the hydraulic diameter, and the cross-sectional flow area. Although the flow rate for the secondary side is known, the appropriate cross-sectional area and hydraulic diameter are not clear. Once a crosssectional area is selected, the hydraulic diameter can be chosen so that the appropriate amount of heat is transferred from the primary fluid to the secondary fluid. The secondary side cross-sectional flow area was selected to be the average of that within the tube bundle region and that between the bundle and the shell outside wall, or $1.373 \mathrm{ft}^{2}\left(0.1276 \mathrm{~m}^{2}\right)$.

An appropriate hydraulic diameter, which results in matching the current heat exchanger performance, can be determined for any nodalization. Ideally, the discretization should be made fine enough that the calibrated secondary-side hydraulic diameter is unaffected by further refinement in the streamwise direction. If the steady-state results are dependent upon the nodalization, subsequent transient results will be less dependable. The results from the calibration runs for the heat exchanger are shown in Fig. 26. At least 80 volumes per heat 
ORNL-DWG 92-3207 ETD

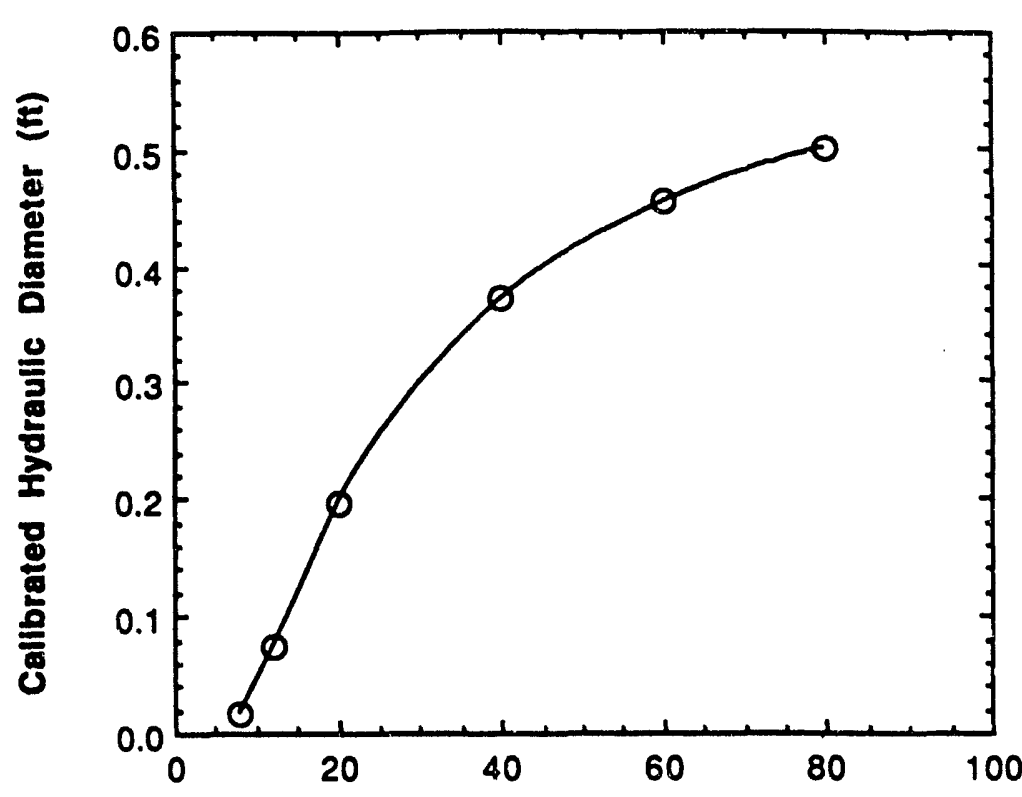

Number of Volumes (Nodes) per Heat Exchanger

Fig. 26. Heat exchanger discretization sensitivity.

exchanger are required for the results to be essentially independent of the node distribution. In the heat exchanger model there is a one-to-one correspondence between the primary side volumes, the heat structures representing the tubing, and the secondary side volumes. Therefore, for a model including 20 primary flow volumes (and heat structures), 10 secondary side volumes are used for both the upper and lower flow paths. For each additional node (volume) used in discretization of the primary side, six additional hydrodynamic volumes and three additional heat structures are required. Also, to keep the discretization symmetric within a heat exchanger, the discretization can only be increased in increments of four primary side volumes.

To maintain higher computational speed, only 20 volumes were used. For 20 volumes, the hydraulic diameter that yielded the measured heat transfer rate (see Ref. 113) was $0.1960 \mathrm{ft}$.

Measurements for the secondary side pressure drop through the heat exchangers were recorded by D. M. McGinty ${ }^{130}$ and are shown in Table 41 . Only one new heat exchanger was installed when these measurements were taken in 1985. For the three lower flow rates only two cells were active (two pumps running). Three cells were active for the three higher flows.

These data are not consistent with current plant data ${ }^{131}$ that indicate a 12-psi (0.0827-MPa) pressure drop at a flow rate of $14,500 \mathrm{gal} / \mathrm{min}\left(0.915 \mathrm{~m}^{3} / \mathrm{s}\right)$. The reason for the inconsistency is unknown; however, the more recent plant data were used to determine an appropriate loss coefficient for the shell side of the heat exchanger. A total loss coefficient of 107.1 was calculated and distributed equally among the nine junctions on the secondary (shell) side flow path. 
Table 41. Measurements of secondary side pressure drop

\begin{tabular}{cccc}
\hline $\begin{array}{c}\text { Total flow } \\
\text { (gal/min) }\end{array}$ & $\begin{array}{c}\text { Cell } 110 \text { (old) } \\
\Delta P \\
(\mathrm{psi})\end{array}$ & $\begin{array}{c}\text { Cell } 111 \text { (new) } \\
\Delta P\end{array}$ & $\begin{array}{c}\text { Cell } 113 \text { (old) } \\
(\mathrm{psi})\end{array}$ \\
\hline 10,000 & 7.62 & $a$ & $(\mathrm{psi})$ \\
11,000 & 9.12 & $a$ & 8.12 \\
12,000 & 10.88 & $a$ & 9.62 \\
15,000 & 7.62 & 8.12 & 11.38 \\
16,500 & 9.00 & 9.50 & 8.25 \\
18,000 & 10.75 & 11.25 & 9.62 \\
& & & 11.38 \\
\hline
\end{tabular}

${ }^{a}$ Heat exchanger isolated when this measurement was taken.

\subsubsection{Primary Coolant Pumps}

The main circulation (or primary coolant) pumps PU-1A, PU-1B, PU-1C, and PU-1D (Fig. 5) were manufactured by the Byron Jackson Division of Borg Warner Corporation. They are constant speed, centrifugal, axial flow pumps. Piping connections to the pump are 14 in. $(35.6 \mathrm{~cm})$ in diameter on the suction side and $10 \mathrm{in} .(25.4 \mathrm{~cm})$ in diameter on the discharge side (Fig. 5). The moments of inertia ${ }^{132}$ for the pump, main motor, and pony motor are listed in Table 42.

Table 42. Moments of inertia for the primary coolant pump and pump motors

\begin{tabular}{lc}
\hline Component & $\begin{array}{c}\text { Moment of inertia } \\
\left(\mathrm{lb}_{\mathrm{m}}-\mathrm{ft}^{2}\right)\end{array}$ \\
\hline Main ac motor & 421.0 \\
Pony motor & 9.5 \\
Pump impeller & $\underline{37.5}$ \\
Total & 468.0 \\
\hline
\end{tabular}

The performance of the main circulation pumps is described in a Byron Jackson manufacturer's report. ${ }^{133}$ Some of these data (for operation with the main ac motor) are given in Table 43.

Normally the main circulation pumps are driven by an $1800-\mathrm{rpm}$ ac motor. If the ac motor fails or is tripped, back-up dc 270-rpm pony motors (see Sect. 2) should continue to drive the pumps. The main ac motors will be tripped if low system pressure ( $<264.7$ psia) is detected or if a loss-of-offsite-power (LOOP) occurs. They may also be shut down because 
Table 43. Primary coolant pump performance data at $77^{\circ} \mathrm{F}$ taken from Byron Jackson report

\begin{tabular}{lcccc}
\hline $\begin{array}{c}\text { Speed } \\
(\mathrm{rpm})\end{array}$ & $\begin{array}{c}\text { Flow } \\
\text { (gal/min) }\end{array}$ & $\begin{array}{c}\text { Head } \\
(\mathrm{ft})\end{array}$ & $\begin{array}{c}\text { Power } \\
\text { (bhp) }\end{array}$ & $\begin{array}{c}\text { Efficiency } \\
(\%)\end{array}$ \\
\hline 1780 & 9750 & 206.7 & 675 & 75.4 \\
1780 & 9200 & 239.1 & 664 & 83.2 \\
1780 & 8600 & 263.6 & 658 & 86.8 \\
1780 & 8000 & 281.0 & 646 & 87.8 \\
1782 & 7050 & 312.1 & 623 & 89.1 \\
1784 & 6050 & 340.5 & 579 & 89.8 \\
1786 & 5000 & 366.3 & 529 & 87.5 \\
1786 & 3970 & 379.7 & 481 & 79.0 \\
1788 & 3000 & 393.4 & 426 & 70.0 \\
1790 & 2000 & 398.7 & 358 & 56.1 \\
1792 & 1000 & 410.0 & 288 & 36.0 \\
1793 & 0 & 413.3 & 275 & 0.0 \\
& & & & \\
\hline
\end{tabular}

excessive vibration (possibly caused by two-phase flow) is detected; however, this is not represented in the model.

The RELAP5 pump model consists of a hydrodynamic volume and two junctions. ${ }^{1}$ The developed pump head is added into the momentum equations as a body force. This body force term is calculated based on the pump flow rate at the previous time step. For this reason, the pump head at any time is not necessarily consistent with the pump speed and flow at the same time. This may lead to numerical difficulties if the user is not careful. RELAP5 requires that the head and torque data be input in dimensionless, homologous form. Using the data in Table 43, the necessary homologous curves were generated.

The homologous curves for these data, assuming rated conditions of speed, $1786 \mathrm{rpm}$; flow, $5000 \mathrm{gal} / \mathrm{min}\left(0.315 \mathrm{~m}^{3} / \mathrm{s}\right)$; head, $366.3 \mathrm{ft}(111.6 \mathrm{~m}) \mathrm{H}_{2} \mathrm{O}$; and torque, $1361.2 \mathrm{ft}-\mathrm{lb}_{\mathrm{f}}$ (1845.5 N-m), are plotted in Figs. 27 and 28. Figure 27 indicates that the dimensionless head curve, which was generated from the 1800 -rpm data, is also adequate for 270 -rpm pony motor operation. The dimensionless variables required to define the positive flow, positive speed homologous curves are as follows:

$$
\begin{aligned}
& H A N=h / \alpha^{2}, \\
& H V N=h / v^{2}, \\
& B A N=b / \alpha^{2},
\end{aligned}
$$

where

$$
\begin{aligned}
& h=\text { head } / h_{n} \\
& v=\text { flow } / q_{n} \\
& \alpha=\text { speed } / n_{n} \\
& b=\text { torque } / b_{n}
\end{aligned}
$$




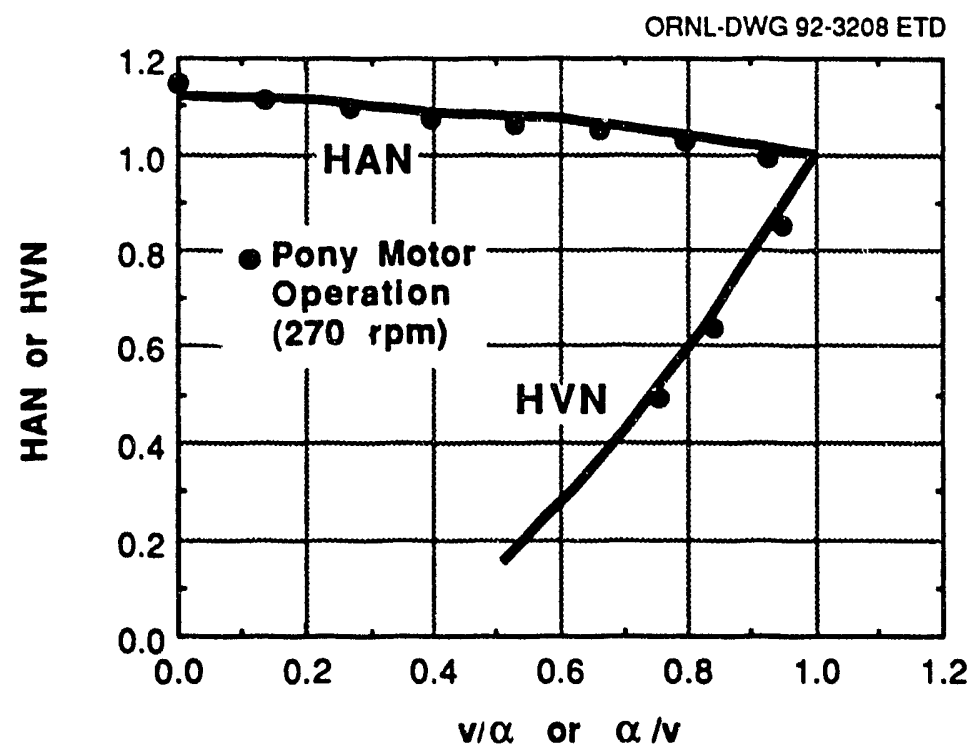

Fig. 27. Homologous head curves for main circulation pumps.

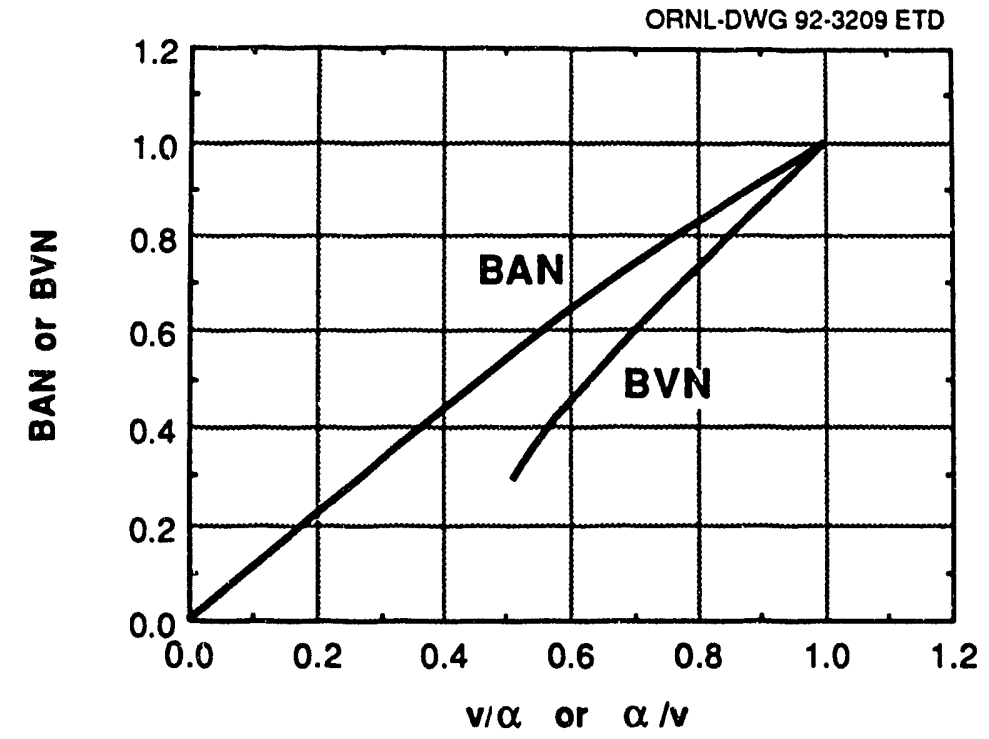

Fig. 28. Homologous torque curves for main circulation pumps.

$$
\begin{aligned}
& h_{r}=\text { rated head, } \\
& q_{r}=\text { rated flow, } \\
& n_{r}=\text { rated speed, } \\
& b_{r}=\text { rated torque }
\end{aligned}
$$

The term torque, as used above, refers to the fluid (hydraulic) torque, which can be calculated by dividing the power supplied to the pump by the pump speed and then multiplying that quotient by the pump efficiency. 
Data for the pumps are available only for conditions of positive flow and speed. Although significant flow in the reverse direction through the pumps is prevented by check valves immediately downstream, for pump performance with negative flow or speed, data built into the RELAP5 program for a Bingham Pump Company pump ${ }^{1}$ with a specific speed of $4200 \mathrm{rpm} \mathrm{gal} / \mathrm{min}^{1 / 2} / \mathrm{ft}^{* / 4}$ were used. Nothing is known about the adequacy of the Bingham model in the HFIR model, so if reverse flow is important for a transient, the analyst should independently ensure that the results are valid, or at least conservative.

For some transients, the pump experiences conditions of two-phase flow. For such transients, RELAP5 requires specification of two parameters termed the head multiplier and head difference. These two parameters relate the single-phase pump performance to the twophase pump performance. No two-phase data are available for the main circulation pumps, so available data for other centrifugal pumps ${ }^{1}$ were used. If significant void exists in one of the pump volumes, it is again necessary that the analyst independently validate the model results. As discussed in detail in Sect. 3.7.2 and Appendix B, should the pump experience cavitation conditions, the pump head is degraded by artificially changing the pump speed.

In the model, the pumps are always controlled by a specified pump speed. When establishing a steady state, the pump speed is adjusted until the desired primary flow is obtained. During most transients the pump is either (1) running at full ac motor speed, (2) coasting down from ac motor speed to pony motor speed, or (3) running at pony motor speed $(270 \mathrm{rpm})$. The actual pump speed is always calculated using RELAP5 control variables (see Sect. 3.7.2). During the pump coastdown, a torque balance is made on the pump shaft to calculate the pump speed according to the relation

$$
\begin{aligned}
& I \frac{d \alpha}{d t}=T_{m}-T_{f}-T_{h}, \\
& I=\text { pump inertia }\left(\mathrm{lb}_{\mathrm{m}}-\mathrm{ft}^{2}\right), \\
& T_{m}=\text { motor torque }\left(\mathrm{ft}-\mathrm{lb}_{\mathrm{f}}\right), \\
& T_{f}=\text { shaft friction torque }\left(\mathrm{ft}-\mathrm{lb}_{\mathrm{f}}\right), \\
& T_{h}=\text { hydraulic torque }\left(\mathrm{ft}-\mathrm{lb}_{\mathrm{f}}\right) .
\end{aligned}
$$

Manufacturer's data ${ }^{132}$ for the torque exerted by the pony motor as a function of shaft speed are given in Table 44.

Table 44. Pony motor torque supplied to the pump shaft ${ }^{134}$

\begin{tabular}{rr}
$\begin{array}{c}\text { Speed } \\
(\mathrm{rpm})\end{array}$ & $\begin{array}{r}\text { Torque } \\
\left(\mathrm{ft}-\mathrm{lb}_{\mathrm{f}}\right)\end{array}$ \\
\hline $0^{\circ}$ & 300.0 \\
145 & 129.0 \\
225 & 77.2 \\
305 & 47.6 \\
425 & 25.4 \\
532 & 15.8 \\
$800^{\circ}$ & 0.0 \\
\hline
\end{tabular}

${ }^{a}$ Extrapolated from data. 
After the pumps were rebuilt, data were taken ${ }^{135}$ for the simultaneous coastdown of three main circulation pumps. The total flow rate through the vessel was measured as the pumps coasted down. The pump shaft friction coefficients were adjusted in the model until the measured coastdown curve was closely matched (Fig. 29). The final expression for pump shaft friction torque $T_{f}$ is

$$
T_{f}=20+50 \alpha+300 \alpha^{2} \mathrm{ft}-1 \mathrm{~b}_{\mathrm{f}} .
$$

The hydraulic torque $T_{h}$ is calculated as

$$
T_{h}=\frac{H G}{n},
$$

where $H$ is the pump pressure head, $G$ is the flow rate, and $n$ is the pump speed.

By balancing the torques applied to the pump shaft, the actual pump speed is determined. However, if pump cavitation occurs, the actual pump speed is not always used for the pump model. Rather, the pump speed is modulated to appropriately degrade the pump head, as would occur when the pump cavitates. The pump cavitation model is discussed further in Sect. 3.7.2 and Appendix B.

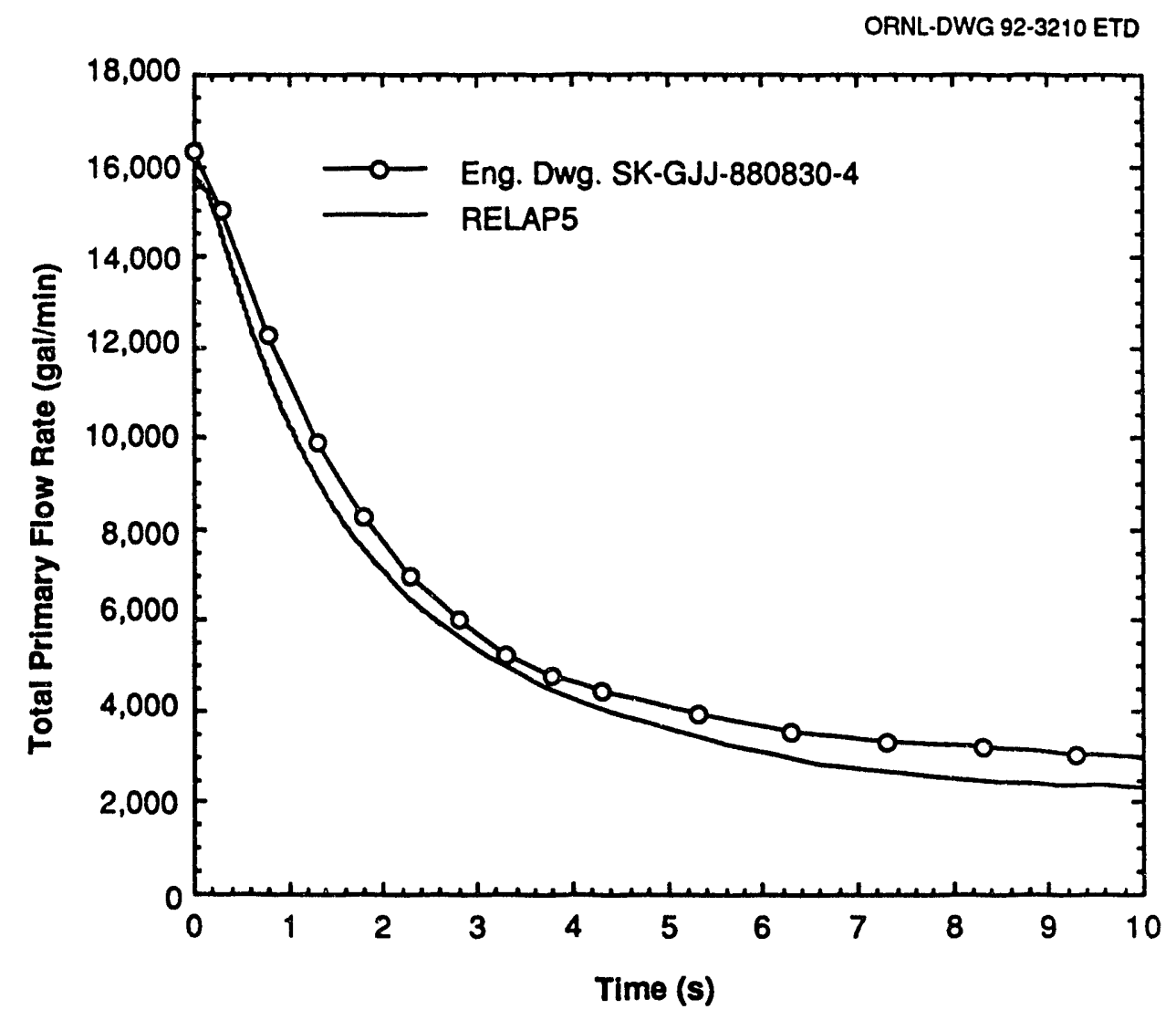

Fig. 29. Comparison of RELAP5 simulated main circulating pump coastdown with experimental data. 


\subsubsection{Main and Standby Pressurizer Pumps}

The main and standby multistage centrifugal pressurizer pumps (PU-4A and PU-4B) were supplied by Allis-Chalmers, along with an Instruction Book, ${ }^{28}$ which contains head, braking horsepower, and efficiency correlations at various pump speeds. The speed of the operating pump is set manually by the operator to achieve the desired 120 -gal/min $\left(7.57 \times 10^{-3} \mathrm{~m}^{3} / \mathrm{s}\right)$ letdown flow. The pump speed can range from 0 to $3600 \mathrm{rpm}$, but for $85-\mathrm{MW}$ reactor operation, it is set between 2200 and $2400 \mathrm{rpm}$. Normally, only one (either PU-4A or PU-4B) pressurizer pump is running. The pump, which is running during normal steady state, will be referred to as the main pressurizer pump. The standby pressurizer pump is interchangeable with the main pressurizer pump and operates with it in a parallel flow arrangement (Fig. 6). The automatic start feature of the standby pump is no longer used; the standby pump will only start on a manual signal. After the standby pressurizer pump start-up signal has been received, a delay of $10 \mathrm{~s}$ occurs before the pump ramps up to speed. ${ }^{29}$ Currently this is modeled in RELAP5 by linearly increasing the speed from zero to the same speed at which the main pressurizer pump is running from 10 to $11 \mathrm{~s}$ after the start-up signal is received.

If any one of the following conditions exist, the main (and possible standby) pressurizer pumps are tripped:

1. the pressurizer pump discharge pressure exceeds 532.7 psia (3.67 $\mathrm{MPa})$,

2. the pressurizer pump suction pressure remains below $15.2 \mathrm{psia}(0.105 \mathrm{MPa})$ for at least $5 \mathrm{~s}$,

3. the emergency depressurization valves are tripped open [based on a low primary coolant temperature $\left(<90^{\circ} \mathrm{F}\right)$ ], or

4. the primary coolant head tank level falls below $25 \% .^{30}$

As with the main circulation pumps, the rate of coastdown of the pressurizer pumps after shutdown depends upon shaft friction and the inertia of the rotating parts attached to the shaft. The pressurizer pump shaft is attached to an electromagnetic clutch with a relatively large moment of inertia. Although the inertia of the clutch and pump combination is not known for certain, an accurate enough value of $120 \mathrm{lb}_{\mathrm{m}}-\mathrm{ft}^{2}\left(5.06 \mathrm{~kg}-\mathrm{m}^{2}\right)$ was calculated by Sozer $^{31}$ based on a comparison with a measured coastdown rate. Sozer also calculated a shaft friction coefficient of $247.66 \mathrm{ft}^{-\mathrm{lb}_{\mathrm{f}}}(335.6 \mathrm{~N}-\mathrm{m})$ (appropriate conversions applied). This coefficient is used by RELAP5 as a multiplier on the square of the pump speed ratio to determine the frictional torque during coastdown. A sample calculation was performed for the coastdown of the pressurizer pump to verify that the inertia and friction coefficient values calculated by Sozer indeed bring about a close fit with the plant data. ${ }^{32}$ Results of this comparison are shown in Fig. 30. An additional coastdown simulation, which was performed for a different initial flow rate and pump head (same initial speed), showed that the fluid inertia was enough lower than the pump inertia that the coastdown was independent of the initial flow rate through the pump.

The performance data for a pump speed of $2616 \mathrm{rpm}$ as extracted from the Instruction Book $^{136}$ are tabulated in Table 45. These data were fitted with polynomials. The rated conditions were then selected such that the homologous curves (see Sect. 3.3.3) pass through the point (1.,1.). Finally the homologous curves, shown in Figs. 31 and 32, were generated. The rated speed is $2616 \mathrm{rpm}$, the rated head selected is $1376.909 \mathrm{ft}(419.682 \mathrm{~m})$, the rated flow selected is $200 \mathrm{gal} / \mathrm{min}\left(0.01262 \mathrm{~m}^{3} / \mathrm{s}\right)$; and the rated torque is $139.75 \mathrm{ft}-1 \mathrm{~b}_{\mathrm{f}}(189.47 \mathrm{~N}-\mathrm{m})$. 


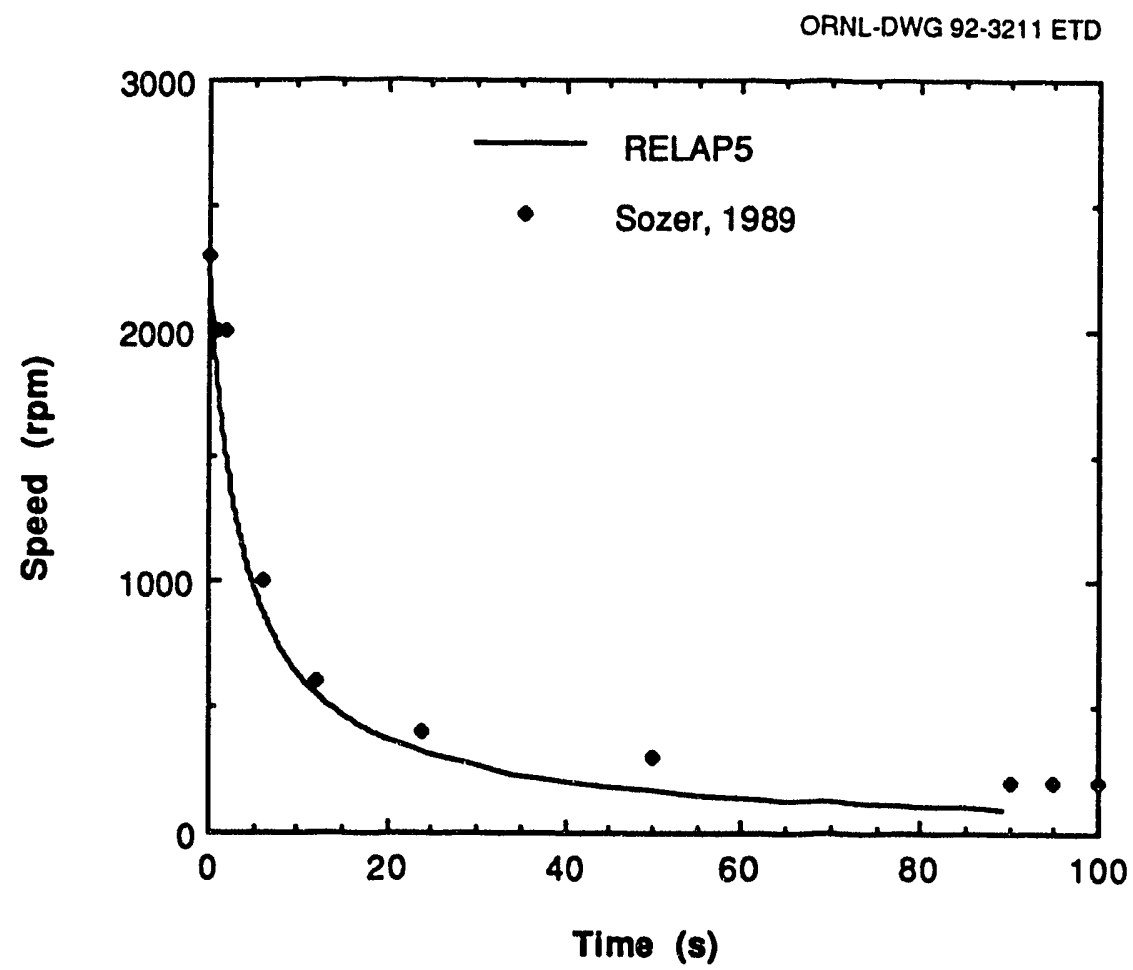

Fig. 30. Conparison of RELAP5 simulated pressurizer pump coastdown with experimental data

Table 45. Pump characteristic data for the main and standby pressurizer pumps at $2616 \mathrm{rpm}$

\begin{tabular}{|c|c|c|c|c|c|c|c|}
\hline \multicolumn{4}{|c|}{ Pump 69037} & \multicolumn{4}{|c|}{ Pump 69038} \\
\hline $\begin{array}{l}\text { Flow } \\
\text { rate } \\
\text { (gal/min) }\end{array}$ & $\begin{array}{c}\text { Head } \\
\text { (ft } \mathrm{H}_{2} \mathrm{O} \text { ) }\end{array}$ & $\begin{array}{r}\text { Power } \\
\text { (bhp) }\end{array}$ & $\begin{array}{c}\text { Efficiency } \\
(\%)\end{array}$ & $\begin{array}{l}\text { Flow } \\
\text { rate } \\
\text { (gal/min) }\end{array}$ & $\begin{array}{c}\text { Head } \\
\left(\text { ft } \mathrm{H}_{2} \mathrm{O}\right)\end{array}$ & $\begin{array}{r}\text { Power } \\
\text { (bhp) }\end{array}$ & $\begin{array}{c}\text { Efficiency } \\
(\%)\end{array}$ \\
\hline 365 & 923.4 & 176 & 48.2 & 368 & 922.6 & 176 & 48.5 \\
\hline 309 & 1085.5 & 171 & 49.5 & 322 & 1085.4 & 172 & 51.3 \\
\hline 261 & 1245.5 & 164 & 49.9 & 273 & 1245 & 165 & 51.9 \\
\hline 202 & 1384.4 & 147 & 48 & 206 & 1380.9 & 150 & 47.7 \\
\hline 122 & 1452.9 & 120 & 37.4 & 145.5 & 1452.5 & 131 & 40.7 \\
\hline 51.4 & 1476.6 & 90 & 21.1 & 44.5 & 1488 & 87 & 19.2 \\
\hline 0 & 1482 & 84 & 0 & 0 & 1495 & 71 & 0 \\
\hline
\end{tabular}


ORNL-DWG 92-3212 ETD

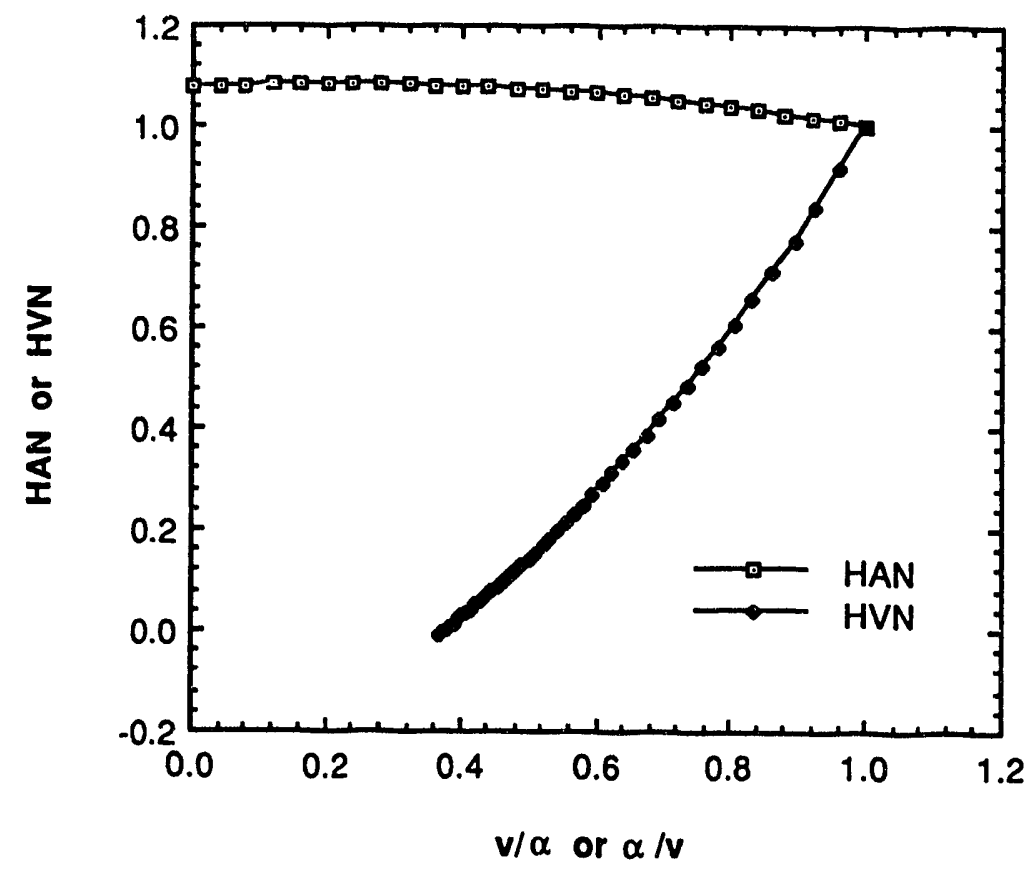

Fig. 31. Homologous head curves for main pressurizer pumps.

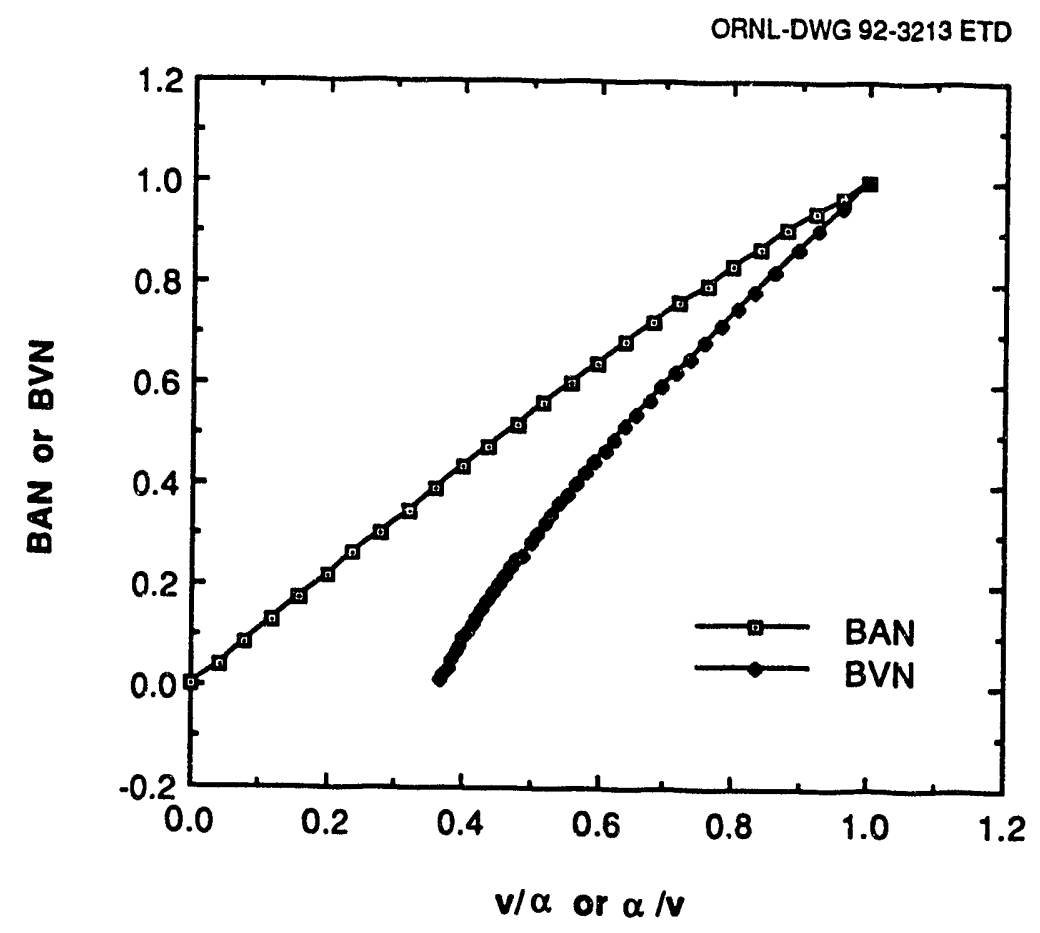

Fig. 32. Homologous torque curves for main pressurizer pumps. 


\subsubsection{Auxiliary Pressurizer Pump}

The auxiliary pressurizer pump (PU-11) was supplied by Sunstrand Fluid Handling along with head, efficiency, and braking horsepower data at $3541 \mathrm{rpm}^{141}$ For pump head $<133.9 \mathrm{psi}(0.923 \mathrm{MPa})$ [153.9 psia (1.06 MPa) system pressure], this pump has a constant flow of $39 \mathrm{gal} / \mathrm{min}\left(2.46 \times 10^{-3} \mathrm{~m}^{3} / \mathrm{s}\right)$. The auxiliary pressurizer pump suction comes from the primary coolant head tank, so the suction pressure is nearly constant at 20 psia $(0.138 \mathrm{MPa})$, varying only slightly as the level in the tank changes. It has been modeled using a timedependent junction (specified flow rate) and is started only after the pressurizer flow into the cold leg drops below $75 \mathrm{gal} / \mathrm{min}\left(4.73 \times 10^{-3} \mathrm{~m}^{3} / \mathrm{s}\right)$. The flow rate is increased linearly from zero flow to the flow indicated by the pump data at $5 \mathrm{~s}$ after trip. The data have been digitized from the curve supplied by Sunstrand, and the flow rate as a function of pump head is shown in Table 46.

Table 46. Auxiliary pressurizer

flow rate as a function of pump head

\begin{tabular}{cc}
\hline $\begin{array}{c}\text { Pump head } \\
\text { (psi) }\end{array}$ & $\begin{array}{c}\text { Flow rate } \\
(\mathrm{lb} / \mathrm{s})\end{array}$ \\
\hline 216.0 & 0.0 \\
214.0 & 2.77 \\
204.0 & 4.16 \\
198.7 & 4.42 \\
185.8 & 4.71 \\
172.8 & 4.92 \\
133.9 & 5.38 \\
0.0 & 5.38 \\
\hline
\end{tabular}

\subsubsection{Letdown and Radiation Block Valves}

The pressure in the primary coolant system is controlled by opening or closing the letdown valves (PCV 127-4, -5, and -7), which are located in the 2-in. (5.08-cm) letdown lines branching off of the cold side of each heat exchanger (Fig. 23). The pressure is monitored upstream of the strainer (PT 127), and a signal is sent to a Foxboro Model 58 pneumatic three-mode proportional/integral/derivative (PID) controller (PRC-127). PID control action is defined as ${ }^{142}$

$$
m(t)=K_{p} e(t)+K_{p} T_{d} \frac{d}{d t}[e(t)]+\frac{K_{p}}{T_{i}} \int_{0}^{t} e(t) d t
$$

where $m(t)$ is the control action (in this case stem position), $e(t)$ is the error signal (in this case difference between pressure and setpoint pressure), $K_{p}$ is the proportional gain, $T_{d}$ is the derivative time, and $T_{i}$ is the integral (or reset) time. 
The letdown valve receives the pressure signal from the controller in the range of 3 to 15 psi, so that for a signal change of 1 psi, the corresponding fractional change in valve stem position is $1 / 12$ of the total valve stroke. The controller settings were read ${ }^{1 / 3}$ on August 9 , 1989, and reported to be

proportional band setting $=100 \%$ (gain $=1.0$ ),

reset setting $=12 \mathrm{~s}$,

derivative setting $=9 \mathrm{~s}$.

These settings were made by trial and error while the system was operating. The gain of 1.0 indicated above is for the controller only. The actual gain is $0.08333 \mathrm{psi}^{-1}$ because of the signal conversion from the controller output to valve stem position at the valve. When these settings were substituted into the RELAP5 control systems, the letdown valve control became unstable. By trial and error, parameters for control of the stem position based on the raw error signal were determined to be $0.0005-\mathrm{psi}^{-1}\left(0.073-\mathrm{MPa}^{-1}\right)$ gain, 0.857-s reset time, 1.15-s derivative constant, and 1-s lag time for the valve actuator. The valve is not allowed to open faster than $0.5848 \mathrm{~s}^{-1}$ or close faster than $0.1163 \mathrm{~s}^{-1}$. These rates are based on the maximum times that have been measured ${ }^{137}$ for fully opening $(17.1 \mathrm{~s})$ or fully closing $(8.6 \mathrm{~s})$ the letdown control valves.

A RELAP5 servo-valve component is used to represent each letdown valve. Using the control systems model, the pressure in the upper plenum of the reactor vessel is monitored, and the letdown valve position is controlled. Equal percentage valve $\operatorname{trim}^{14}$ with a maximum $C_{v}$ of $8.7 \mathrm{gal} / \mathrm{min} / \mathrm{psi}^{0.5}$ is assumed. The maximum $C_{v}$ is the constant that relates flow through the valve $G_{\text {max }}$ to the pressure drop across the valve $\Delta P$ when the valve is fully open by the relation,

$$
G_{\text {max }}=C_{v} \Delta P^{K}
$$

where $G_{\max }$ is in $\mathrm{gal} / \mathrm{min}$ and $\Delta P$ is in psi.

For equal percentage valve trim, equal incremental changes in the stem position produce equal percentage changes in the flow for a constant pressure difference, ${ }^{145}$ or, in equation form,

$$
\frac{1}{G} d G=d y,
$$

where $G$ is the flow at stem position $y$. Integrating gives

$$
y=\ln G+c_{1}
$$

and

$$
g=\exp \frac{y-1}{c_{1}}
$$

where $g$ is the ratio between the flow when the stem is at position $y$ and the flow when the value is completely open $(y=1.0)$. The constant $c_{1}$ for the letdown valves is unknown. For 
a given pressure drop across the valve, $C_{v}$ is proportional to the flow rate, hence the $C_{v}$ dependence upon stem position, which must be supplied to RELAP5, can be calculated from the above equation. Until more information on the valve is obtained, it has been assumed thet $C_{v}$ is proportional to $y^{3}$. This is a good approximation to equal percentage valve trim.

Two radiation block valves are in position immediately downstream of each letdown valve. If the system pressure falls below $407.7 \pm 12$ psia $(2.81 \mathrm{MPa})$, the block valves immediately close. This is modeled as a part of the letdown control system in the RELAP5 input. For LOCA analyses, the HFIR RELAP5 model conservatively closes the letdown valves when the pressure falls below 395.7 psia (2.728 MPa).

\subsubsection{Primary Coolant Head Tank}

The primary coolant (PC) head tank (Fig. 23) has a capacity of 2500 gal $\left(0.46 \mathrm{~m}^{3}\right)$ and is $6 \mathrm{ft} 6 \mathrm{in} .(1.98 \mathrm{~m})$ in diameter and $11 \mathrm{ft} 8 \mathrm{in}$. $(3.55 \mathrm{~m})$ long. ${ }^{146}$ This tank, located on the first floor, serves as the supply [via a $4-\mathrm{in} .(10.16-\mathrm{cm})$ line] to the suction side of the pressurizer pumps (PU- 4A, $-4 \mathrm{~B}$, and -11) on the ground floor. The water that exi he highpressure system through the letdown valves is eventually returned to the $P C$ head ink after passing through the clean-up system. The mass of water passing through the letdown valves at a given time is assumed to te equal to the mass of water passing into the PC head tank from the clean-up system.

The level in the PC head tank must be monitored in the model to determine when the pressurizer pumps should be shut down and when the demineralized make-up flow should be supplied. If the level in the PC head tank drops below $25 \%$, then the pressurizer pumps are shut down. If the level in the PC head tank is detected to be $<70 \%$, then a make-up flow of demineralized water is supplied to it by demineralized water pump PU-18A or PU-18E. During normal operation, this situation will occur due to leakage (S.ct. 3.7.12) at the primary coolant pump seals, and the make-up flow will be more than enough to replenish the tank. In the model, if the level drops below $70 \%$, then an assumed maximum make-up flow of $90 \mathrm{gal} / \mathrm{min}\left(5.68 \times 10^{-3} \mathrm{~m}^{3} / \mathrm{s}\right)$ is supplied. ${ }^{147}$ This is the maximum design flow through the demineralizer system.

There is an additional reason for keeping track of the level in the PC head tank. Once the system has been depressurized, the head across the pressurizer pump(s) is relatively small; thus, a small change in the suction pressure brought about by a change in the head tank level may significantly affect pressurizer pump performance.

The PC head tank is represented with an $80^{\circ} \mathrm{F}\left(26.7^{\circ} \mathrm{C}\right)$ time-dependent volume (volume 68) for which the pressure is calculated using the RELAP5 control systems model (see Sect. 3.7.1). The mass flows in and out of the tank are summed, and that sum is integrated over the time to deternine the mass of water in the tank. The tank level can then be calculated knowing the tank geometry. The dependence of the level and the pressurizer pump suction pressure upon the fraction of the tank volume containing water is shown in Fig. 33. The initial level in the tank is assumed to be $70 \%$ (the lowest level allowed before the make-up flow is added). "The pressure that is assigned to time-dependent volume 68 is equal to the tank overpressure $\left(-50 \text {-in. } \mathrm{H}_{2} \mathrm{O} \text { vacuum }\right)^{148}$ plus the static head $(0-6 \mathrm{ft}$ or $0-1.83 \mathrm{~m})$ of the tank water.

\subsubsection{Secondary Coolant System}

The HFIR secondary coolant system is shown in Fig. 34. Each of the three available main secondary coolant pumps (PU-6A, $-6 \mathrm{~B}$, and $-6 \mathrm{C}$ ) have a capacity of $13,000 \mathrm{gal} / \mathrm{min}$ 
ORNL-DWG 92-3214 ETD

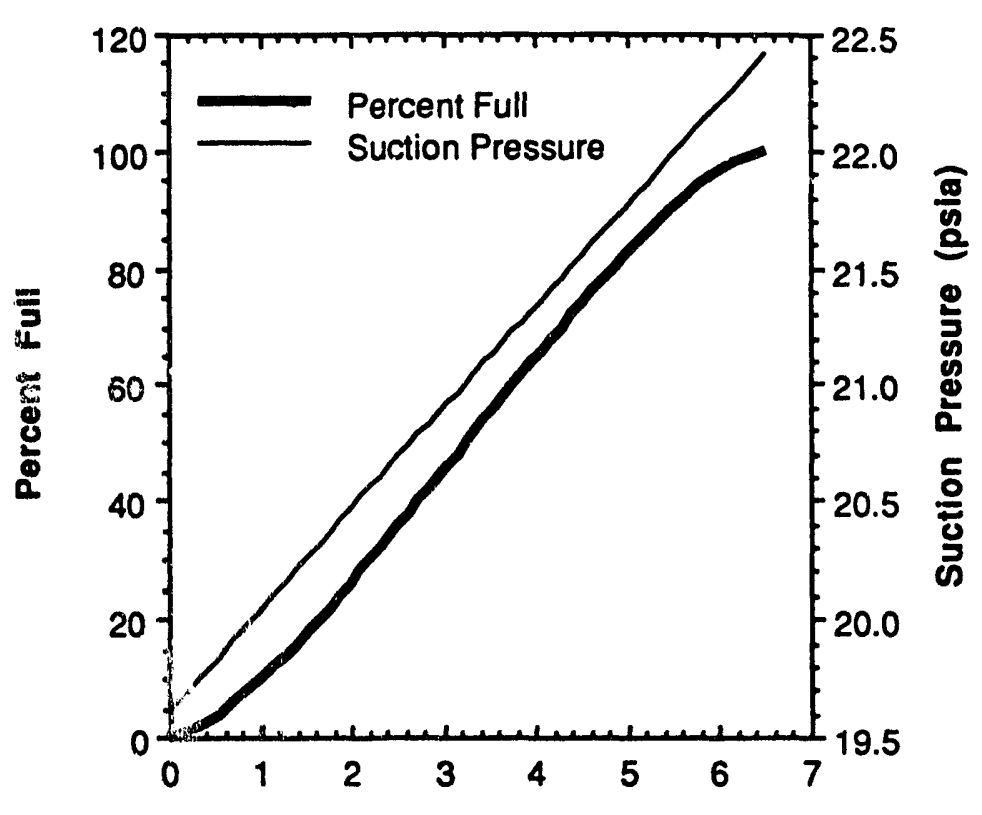

Actual Level (ft)

Fig. 33. Relationship between PC head tank level and pressurizer pump suction pressure and percentage of tank volume containing water.

$\left(0.82 \mathrm{~m}^{3} / \mathrm{s}\right)$ when operated at $1160 \mathrm{rpm}$ and $120 \mathrm{ft}(36.6 \mathrm{~m})$ total developed head. ${ }^{149}$ Only two of the pumps are operated at a given time.

When the reactor is shut down, or an emergency situation occurs, the auxiliary secondary coolant pump $^{150}$ (PU-14) with $6000-\mathrm{gal} / \mathrm{min}\left(0.379-\mathrm{m}^{3} / \mathrm{s}\right)$ capacity at 100 -ft total developed head and $1200 \mathrm{rpm}$ circulates flow through the system. If the line power is lost, the auxiliary secondary pump is powered by diesel generators using a second motor winding (600 rpm) to supply $3000 \mathrm{gal} / \mathrm{min}\left(0.190 \mathrm{~m}^{3} / \mathrm{s}\right)$ of secondary coolant flow.

Before the new heat exchangers were installed, $20,000 \mathrm{gal} / \mathrm{min}\left(1.26 \mathrm{~m}^{3} / \mathrm{s}\right)$ of secondary flow was supplied to the primary coolant heat exchangers, and the remaining $6000 \mathrm{gal} / \mathrm{min}$ $\left(0.379 \mathrm{~m}^{3} / \mathrm{s}\right)$ was diverted to other auxiliary equipment and the Transuranium Processing Facility (TRU). ${ }^{150}$ However, because the new heat exchangers have been installed, between 11,400 and $14,500 \mathrm{gal} / \mathrm{min}\left(0.719 \text { and } 0.915 \mathrm{~m}^{3} / \mathrm{s}\right)^{131,151}$ has been required to remove the heat generated in the reactor. Much of the secondary flow is allowed to bypass the pool heat exchangers through HCV 438 and thus remains at the secondary coolant inlet temperature of $85^{\circ} \mathrm{F}\left(29.4^{\circ} \mathrm{C}\right)$. In this manner, when the flows recombine before entering the cooling tower, the cold bypass water keeps the cooling tower inlet temperature low enough to avoid cooling tower damage.

The cooling tower ${ }^{152}$ has been designed to cool $26,000 \mathrm{gal} / \mathrm{min}\left(1.64 \mathrm{~m}^{3} / \mathrm{s}\right)$ from 115 to $85^{\circ} \mathrm{F}$ (46.1 to $29.4^{\circ} \mathrm{C}$ ) by transferring heat to a $77^{\circ} \mathrm{F}\left(25^{\circ} \mathrm{C}\right)$ wet-bulb-temperature environment. The cooling tower basin contains 400,000 gal $\left(1514 \mathrm{~m}^{3}\right)$ of water divided into four equal compartments.

The secondary coolant flow rate through the heat exchangers is automatically controlled with a Foxboro Model 58 controller by adjusting throttling valve FCV $377 \mathrm{~A}$ in a 10 -in. 


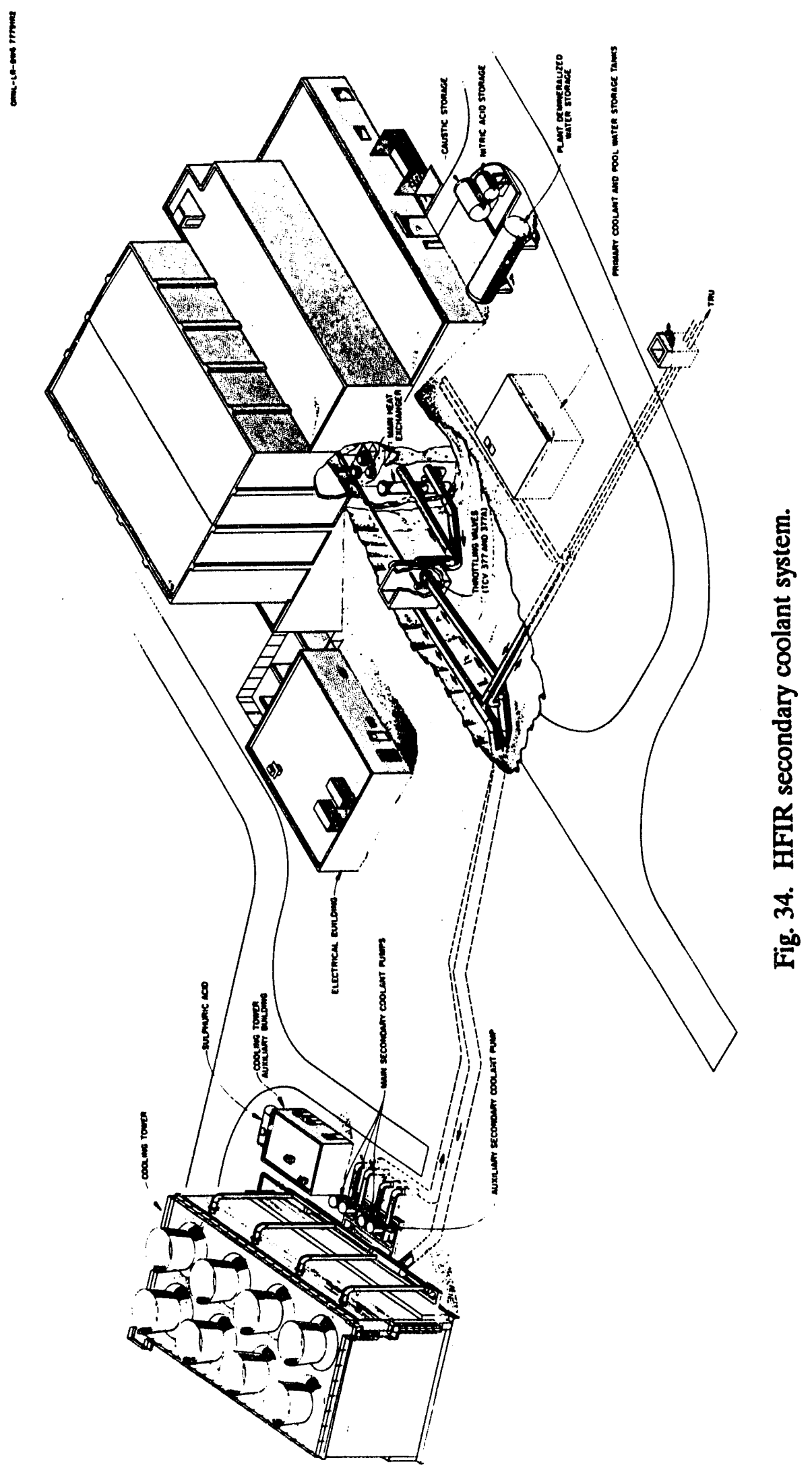


( $0.254-\mathrm{m})$ bypass pipe, which is in parallel with the main $36-$ in. $(0.914-\mathrm{m})$ pipe. Throttling valve FCV 377 located in the 36-in. line is adjusted manually to keep the desired flow rate within the range of the valve in the 10 -in. line. The 10-in. control valve is positioned to maintain the vessel inlet temperature at $120^{\circ} \mathrm{F}\left(48.9^{\circ} \mathrm{C}\right)$ using PID control (see Sect. 3.3.6).

When scram occurs, the two main secondary coolant pumps are tripped, and the cooling tower bypass valve FCV-362A opens (within $87 \mathrm{~s})^{137}$ to prevent overcooling of the primary coolant, and the auxiliary secondary coolant pump is started.

The representation of the secondary side of each heat exchanger has already been discussed (Sect. 3.3.2). The nodal diagram for the secondary coolant system was shown in Fig. 25. Five volumes are included in each of the pipe components numbered 100-107, 200-207, and 300-307.

It was desired to correctly model the heat removal and overall flow rates in the system, but some of the details (such as the distribution of flow through the TRU and auxiliary equipment) are unimportant and would require significant effort to include in the model. For this reason, a simplified representation of the secondary cooling system was used, and then a calibration of some of the pipe lengths was performed ${ }^{113}$ to match available flow rate and pressure data. The available data consist of heat exchanger flow rate, total flow rate (based on pump discharge pressure meașurement and head/flow curve), and heat exchanger pressure drop. The time-dependent volume 123 is used to maintain the secondary coolant pump suction pressure at atmospheric pressure. (The pump suction is near the same level as the surface of the water in the cooling tower basins.) The two operating main secondary coolant pumps are represented with the RELAP5 Bingham pump model, ${ }^{1}$ and the auxiliary secondary coolant pump is included separately. The same moment of inertia and friction coefficients were assumed for the main secondary coolant pumps as for the primary coolant pumps. The coastdown of the main secondary coolant pumps after a reactor trip is illustrated in Fig. 35

ORNL-DWG 92-3215 ETD

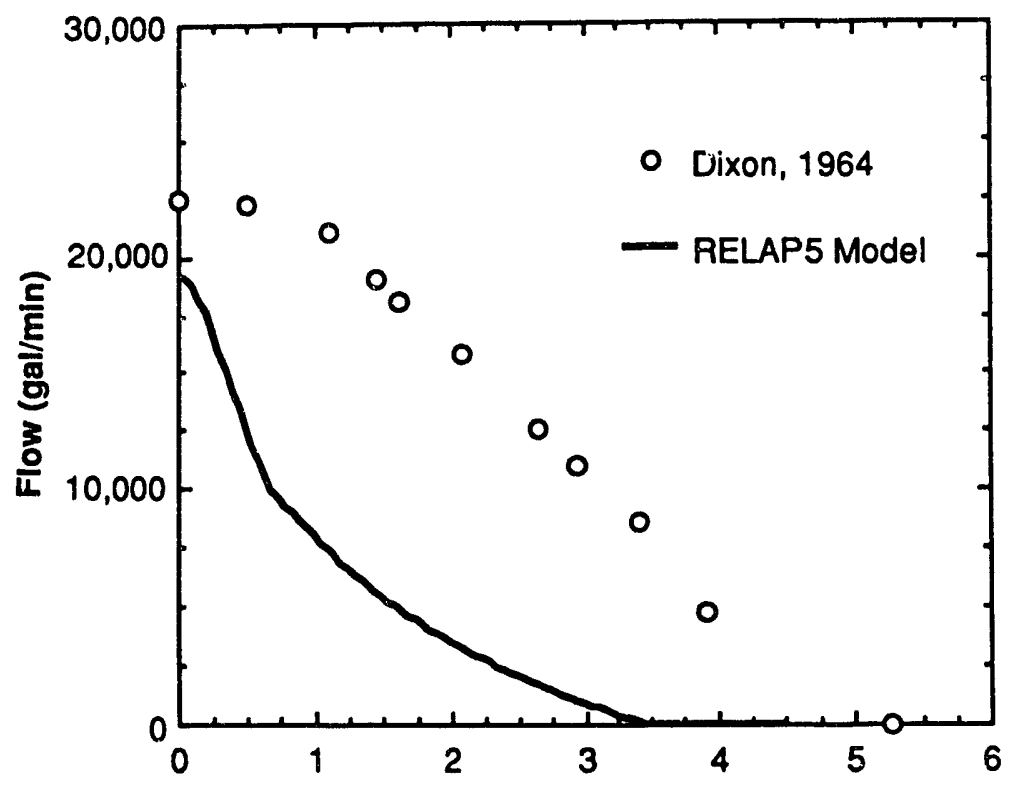

Time (s)

Fig. 35. Coastdown rate of secondary coolant pumps. 
(data taken from Ref. 153). The data were taken with the old heat exchangers in place, and because the RELAP5 model is for the new system, the initial flow rate is lower. For LOCA transients the model of the secondary system is adequate because the critical time period for the fuel is early in the calculation before transient effects in the secondary system affect the primary coolant. If the model is used for a long running transient, with the secondary flows changing, more modeling may be necessary.

In the model, when power is supplied to the main secondary coolant pumps, they are controlled at a specified speed of $1186 \mathrm{rpm}$. A ramp time of $5 \mathrm{~s}$ is assumed for the auxiliary secondary pump to come to full speed, once the reactor is tripped. The auxiliary pump is always controlled by a specified speed, depending on the mode of operation.

Water passing through the cooling tower is represented in the model by pipe component 132 , containing five volumes. Here the heat is removed from the secondary coolant across five heat structures to the cooling tower stream. The cooling tower stream is a separate flow system (Fig. 25) consisting of a $60^{\circ} \mathrm{F}$ mass source (time-dependent volume 401 ), a specified flow rate junction (time-dependent junction 402), a pipe used to remove heat from the secondary system (pipe 403), and a mass sink (time-dependent volume 405). The flow rate is controlled (see Sect. 3.7.13) so that the secondary coolant leaving the cooling tower is at $85^{\circ} \mathrm{F}$.

The cooling tower bypass valve (component 136 in Fig. 25) is normally closed so all of the secondary flow passes through component 132 . An additional valve is included (component 135) so that when the cooling tower bypass valve opens, the flow through the cooling tower is simultaneously stopped.

The secondary flow, which is diverted to the auxiliary equipment and the TRU, is represented by volume 131 . Valve 228 is used to represent the flow bypassing the pool heat exchangers.

As shown in Fig. 25, the 10-in. bypass line containing FCV 377A has been represented in the model with a servo valve RELAP5 component inserted to regulate the flow. A control system has been implemented for controlling the stem position of this valve. The control system receives an error signal based on the inlet vessel water temperature. The 36-in. manual control valve has also been represented with a servo valve component. The value for the area should be set so that the secondary flow rate through the heat exchangers is between 11,400 and $14,500 \mathrm{gal} / \mathrm{min}$. The abrupt area change model is used to characterize the pressure-flow performance of both flow-control valves 377 and 377A. The settings on the F'ID controller on August 9, 1989, were

$$
\text { proportional band setting }=10 \%(\text { gain }=10.0) \text {, }
$$

reset setting $=30 \mathrm{~s}$,

derivative setting $=6 \mathrm{~s}$.

As for the letdown control system, using these settings in the model caused the calculation to enter into oscillation; the current values being used are

$$
\begin{aligned}
& \text { gain }=0.2, \\
& \text { reset time }=20 \mathrm{~s}, \\
& \text { derivative time }=2.5 \mathrm{~s} .
\end{aligned}
$$


Although a substantial discrepancy exists, for LOCAs and most operational transient calculations, accurate modeling of the automatic control of the secondary coolant flow is not critical. For transients where it is important, the analyst should do further work in arriving at conservative settings.

As has been mentioned, the secondary piping components outside of the heat exchangers have been modeled using approximate dimensions. Although the total secondary flow rate is not directly measured, the outlet pressure of the secondary coolant pumps is indicated in the control room. On September 25, 1990, this reading indicated 65 psig. ${ }^{154}$ From the pump curves for the secondary coolant pumps, ${ }^{155}$ this indicates a total flow of about 18,000 $\mathrm{gal} / \mathrm{min}$. It has already been mentioned that the heat exchanger flow is normally somewhere between 11,400 and $14,500 \mathrm{gal} / \mathrm{min}$. Another constraint on the secondary-side hydraulics is that FCV 377A controls only about 7\% of the flow. The dimensions of pipes 137 and 131 (Fig. 25) and the position of manually controlled valve 377 were adjusted in the model until the above constraints were satisfied. The total heat transfer area of the heat exchanger was then calibrated so that during steady-state, $85-\mathrm{MW}$ operations with FCV 377A at a stem position of 0.5 , the primary coolant inlet temperature is $120^{\circ} \mathrm{F}\left(48.9^{\circ} \mathrm{C}\right)$.

\subsection{SYSTEM STIFFNESS}

The HFIR does not have a conventional pressurizer such as that found in other lightwater reactors. Rather, it uses a high-head, low-flow pressurizing pump to pressurize the allliquid system. The stiffness of the system depends upon both the compressibility of the water and the structural elasticity of the piping, vessel, and other components that contain the water. Because RELAP5 does not account for the stretching (or shrinkage) of the piping structures, a control systems model was developed to simulate the effect. The structural elasticity is only important when the system pressure changes drastically (such as the depressurization that immediately follows a significant break in the primary coolant containment). Once vapor is generated in the system, the structural elasticity is no longer important because the vapor is highly compressible.

\subsubsection{Mathematical Framework}

Pressure chariges in the single-phase HFIR primary coolant system can be directly attributed to one $\mathrm{c} i$ thrse causes: changes in the mass inventory of the system, changes in the total volume of the system (structural expansion or contraction), or changes in the temperature of the water. The relationship between the above effects can be expressed mathematically by considering contributions to changes in the total system inventory for a system with uniform temperature and pressure.

$$
\begin{aligned}
& d(\text { mass })=d(\rho V)=\frac{\partial}{\partial T}(\rho V) d T+\frac{\partial}{\partial P}(\rho V) d P \\
& d(\text { mass })=\left(\rho \frac{\partial V}{\partial T}+V \frac{\partial \rho}{\partial T}\right) d T+\left(\rho \frac{\partial V}{\partial P}+V \frac{\partial \rho}{\partial P}\right) d P
\end{aligned}
$$

Considering a finite change in mass $\Delta(\rho V)$ that results in a corresponding change in temperature $\Delta T$ and in pressure $\Delta P$, then rearranging gives 


$$
\begin{aligned}
& \Delta(\rho V)=\rho \frac{\partial V}{\partial T} \Delta T+\rho \frac{\partial V}{\partial P} \Delta P+V \frac{\partial \rho}{\partial T} \Delta T+V \frac{\partial \rho}{\partial P} \Delta P, \\
& \Delta(\rho V)=\text { term } 1+\text { term } 2+\operatorname{term} 3+\operatorname{term} 4
\end{aligned}
$$

where

term $1=$ expansion or contraction of the primary system pressure boundary due to the temperature change,

term 2 = expansion or contraction of the primary system pressure boundary due to the pressure change,

term $3=$ density variation in the water due to the temperature change,

term $4=$ density variation in the water due to the pressure change.

\subsubsection{Discussion of Terms}

\subsubsection{Term 1}

The expansion or contraction of the pressure boundary due to temperature changes in the piping and vessel can be approximated by considering the system to be made up of unconstrained pipes. The linear expansion in the length of metal $L$ with constant thermal expansion coefficient $\lambda$ is given by

$$
\frac{\partial L}{\partial T}=\lambda L
$$

If the length of pipe $L$ and the inner circumference of the pipe $C$ behave according to relation [Eq. (5)], then

$$
\frac{\partial V}{\partial T}=\frac{\partial}{\partial T}\left(\frac{C^{2} l}{4 \pi}\right)=\frac{C l}{2 \pi} \frac{\partial C}{\partial T}+\frac{C^{2} \partial l}{4 \pi \partial T}=\frac{3}{4} \frac{\lambda C^{2} l}{\pi}=3 \lambda V .
$$

Dixon ${ }^{153}$ determined that the high-pressure side of the primary coolant system, with three heat exchanger cells considered and only an orifice in the reactor vessel, contains about $12,500 \mathrm{gal}\left[1671 \mathrm{ft}^{3}\left(47.32 \mathrm{~m}^{3}\right)\right]$. The pipes are stainless steel $\left[\lambda=9.6 \times 10^{-6}{ }^{\circ} \mathrm{F}^{-1}\right.$ $\left.\left(1.728 \times 10^{-5}{ }^{\circ} \mathrm{C}^{-1}\right)\right] .^{156}$ The model, based on the dimensions in the available drawings, includes $11,600 \mathrm{gal}\left(43.91 \mathrm{~m}^{3}\right)$ with the target, core, and reflectors in place. Applying Eq. (6) gives a volume sensitivity with respect to a temperature of $0.04458 \mathrm{ft}^{3} /{ }^{\circ} \mathrm{F}\left(0.00227 \mathrm{~m}^{3} /{ }^{\circ} \mathrm{C}\right)$.

\subsubsection{Term 2}

The structural elasticity of any component is here defined as the quantity

$\frac{1}{V} \frac{\partial V}{\partial P}$

where $V$ is the fluid volume within that component, and $P$ is the fluid (internal) pressure. 
The structural expansion or contraction due to pressure change in the pipes can also be estimated assuming that the system consists of unconstrained pipes. The radial deflection of a thin-walled cylinder pressurized from the inside is ${ }^{157}$

$$
\Delta r=\frac{P^{2}}{E t}
$$

where $P$ is the gage pressure in the pipe, $r$ is the pipe radius, $E$ is the modulus of elasticity $\left(30 \times 10^{6}\right.$ psi for stainless steel), ${ }^{158}$ and $t$ is the wall thickness. The change in length $\Delta l$ is

$$
\Delta=-\frac{\operatorname{Pr} \mu l}{E t}
$$

where $\mu$ is Poisson's ratio ( 0.3 for stainless steel) ${ }^{158}$ Using the above expressions, the structural elasticity for an unconstrained pipe can be determined as follows. The unstressed volume $V_{o}$ contained within a pipe is

$$
V_{0}=l \pi r^{2}
$$

The volume $V$ contained within a pipe with internal gage pressure $P$ is

$$
\begin{aligned}
V & =\pi(l+\Delta l)(r+\Delta r)^{2} \\
& =\pi\left(l-\frac{P r \mu l}{E t}\right)\left(r+\frac{P r^{2}}{E t}\right)^{2} .
\end{aligned}
$$

So the sensitivity of contained volume with respect to pressure can be calculated as

$$
\frac{\partial V}{\partial P}=2 \pi\left(l-\frac{P r \mu l}{E t}\right)\left(r+\frac{P r^{2}}{E t}\right)\left(\frac{r^{2}}{E t}\right)+\pi\left(-\frac{\mu r l}{E t}\right)\left(r+\frac{P r^{2}}{E t}\right)^{2} .
$$

Dividing by the unstressed volume and simplifying gives

$$
\frac{1}{V_{0}} \frac{\partial V}{\partial P}=\frac{r}{E t}\left\{2+\frac{2 P r}{E t}-\mu\left[1+\frac{4 P r}{E t}+3\left(\frac{P r}{E t}\right)^{2}\right]\right\} \text {. }
$$

But $\operatorname{Pr} / E t<<1$ for standard steel pipes with internal pressures $<1000 \mathrm{psi}$, and $V \approx V_{o}$, so,

$$
\frac{1}{V} \frac{\partial V}{\partial P}=\frac{r}{E t}(2-\mu)=\frac{d}{E t}\left(1-\frac{\mu}{2}\right),
$$

where $d=2 r$. The above equation was applied to pipes in the HFIR primary coolant system to estimate the change in volume with respect to pressure. It was also applied to the reactor vessel. Although the vessel is radially constrained at top and bottom, it will be shown that the elasticity predicted by this simple model is accurate enough. Table 47 shows how the 
water volume is distributed throughout the primary system and gives the change in volume with respect to pressure (elasticity) for each part. Volumes listed in Table 47 for which no stiffness numbers are given were assumed to be structurally rigid. The table includes only those volumes in the high-pressure system (upstream of the letdown valves and downstream of the pressurizer pumps).

Table 47. Elasticity in the HFIR primary coolant containment

\begin{tabular}{|c|c|c|c|c|c|}
\hline Component & $\begin{array}{c}\text { Inside } \\
\text { diameter } \\
\text { (in.) }\end{array}$ & $\begin{array}{c}t \\
\text { (in.) }\end{array}$ & $\begin{array}{l}\frac{1}{V} \frac{\partial V}{\partial P} \\
\left(\mathrm{psi}^{-1}\right)\end{array}$ & $\begin{array}{l}\text { Volume } \\
\left(\mathrm{ft}^{3}\right)\end{array}$ & $\begin{array}{c}\frac{\partial V}{\partial P} \\
\left(\mathrm{ft}^{3} / \mathrm{psi}\right)\end{array}$ \\
\hline Reactor vessel & 94.0 & 3.125 & $9.1 \times 10^{-7}$ & 629.54 & $5.73 \times 10^{-4}$ \\
\hline HX tubing & 0.555 & 0.035 & $4.8 \times 10^{-7}$ & 358.73 & $1.72 \times 10^{-4}$ \\
\hline Cold leg (20 in.) & 18.814 & 0.593 & $9.6 \times 10^{-7}$ & 151.94 & $1.46 \times 10^{-4}$ \\
\hline Hot leg (18 in.) & 16.876 & 0.562 & $9.1 \times 10^{-7}$ & 140.63 & $1.28 \times 10^{-4}$ \\
\hline $\begin{array}{l}\text { 10-in. pipes } \\
\text { (sched. 40) }\end{array}$ & 10.02 & 0.365 & $8.3 \times 10^{-7}$ & $\begin{array}{r}111.50 \\
47.19\end{array}$ & $0.93 \times 10^{-4}$ \\
\hline HX plena & & & & 38.13 & $0.35 \times 10^{-4}$ \\
\hline 14-in. pipes & 13.126 & 0.437 & $9.1 \times 10^{-7}$ & 35.19 & $0.32 \times 10^{-4}$ \\
\hline $\begin{array}{l}\text { 16-in. pipes } \\
\text { Strainer housing }\end{array}$ & 15.0 & 0.5 & $9.1 \times 10^{-7}$ & 10.45 & \\
\hline $\begin{array}{l}\text { 10-in. pipes } \\
\text { (sched. 80) }\end{array}$ & 9.564 & 0.593 & $4.6 \times 10^{-7}$ & 8.82 & $0.04 \times 10^{-4}$ \\
\hline Pzr. line & & & & 7.60 & \\
\hline Venturi & & & & 4.59 & \\
\hline PC pumps & & & & 2.82 & \\
\hline Letdown pipes & & & & 0.70 & \\
\hline Total & & & & 1547.83 & $1.183 \times 10^{-3}$ \\
\hline
\end{tabular}

Based on the total fractional volume change of $0.001183 \mathrm{ft}^{3} / \mathrm{psi}\left(0.00486 \mathrm{~m}^{3} \mathrm{MPa}\right)$, the effective structural stiffness of the system is $113 \mathrm{psi} / \mathrm{gal}\left(206 \mathrm{MPa} / \mathrm{m}^{3}\right)$.

It is important to adequately represent the vessel elasticity because the vessel contains about $40 \%$ of the water in the system. The vessel is capped by a 13 -in.-thick $(33.0-\mathrm{cm})$ lid, and necks down from the 94 -in.-diam $(239-\mathrm{cm})$ section through a hemispherical section to a 31-in.-diam (78.7-cm) section. Because the vessel shape (Fig. 3 ) is markedly different from that of an unconstrained pipe, two axisymmetric $\mathrm{ADINA}^{159}$ simulations were run to 
calculate the deformation (and fractional volume change) of the vessel as it is pressurized from atmospheric pressure to $1000 \mathrm{psi}(6.89 \mathrm{MPa})$. ADINA is a finite-element stress analysis code.

The first simulation was run assuming that the vessel was constrained only at the lowermost point in the vertical direction. The exaggerated deformation resulting from this simulation is shown in Fig. 36. The fractional volume change with respect to pressure is essentially constant (Fig. 37). This quantity was calculated by numerically evaluating the volume contained within the vessel, based on the deformed geometry at each loading. For

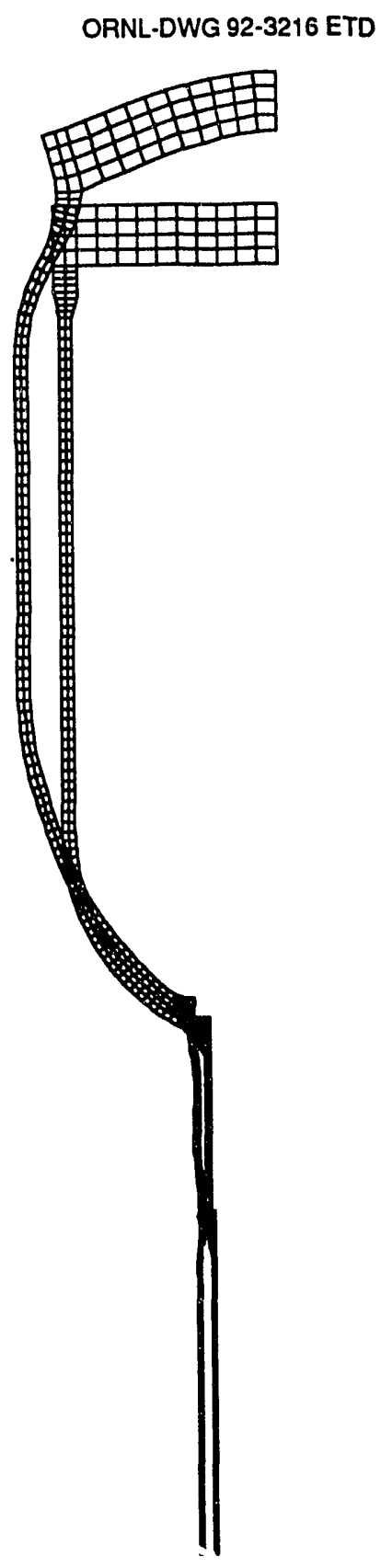

Fig. 36. Exaggerated deformation of pressurized HFIR reactor vessel without support constraint. 


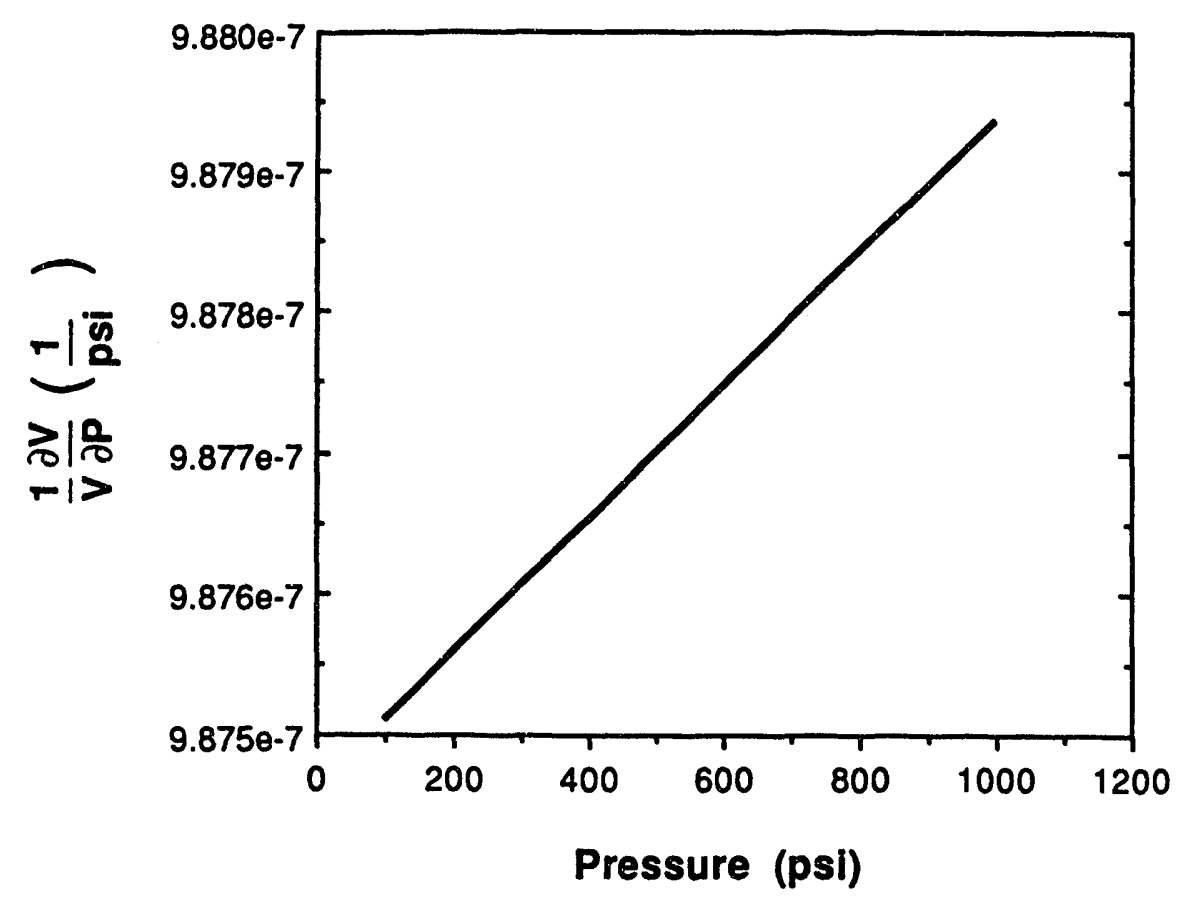

Fig. 37. Elasticity of HFIR reactor vessel without support constraint.

the second simulation, the part of the vessel in contact with the vessel supports was constrained in both the vertical and horizontal directions. The results are shown in Figs. 38 and 39.

The elasticity of the vessel is only slightly greater than the Table 47 estimate. It is not intuitively clear whether the finite-element results should give a larger or smaller value for the vessel elasticity than the unconstrained pipe calculation. Although the additional radial constraints have been imposed with the finite-element model, the lid also allows vertical elongation of the vessel, whereas the unconstrained pipe estimate assumes shrinkage in the vertical direction. It is concluded from these results that the unconstrained pipe estimate for overall structural stiffness [112 psi/gal $\left.\left(204 \mathrm{MPa} / \mathrm{m}^{3}\right)\right]$ is about right with regard to the vessel contribution.

If temperature effects are assumed to be small (as will be shown), then terms 1 and 3 can be neglected and Eq. (4) can be used to calculate the overall structural elasticity:

$$
\frac{1}{V} \frac{\partial V}{\partial P}=\frac{1}{\rho V} \frac{\Delta(\rho V)}{\Delta P}-\frac{1}{\rho} \frac{\partial \rho}{\partial P} .
$$

The measurements of $\Delta P$ (pressure change) and $\Delta(\rho V)$ (change in system inventory), taken by Dixon, ${ }^{153}$ can be directly substituted into the above equation. Because Dixon's measurements were taken with all four heat exchanger cells open, the total volume within the system pressure boundary was larger than that for the normal system configuration during operation. This was accounted for, and Fig. 40 shows that the analytical results are consistent with those measurements taken by Dixon. 


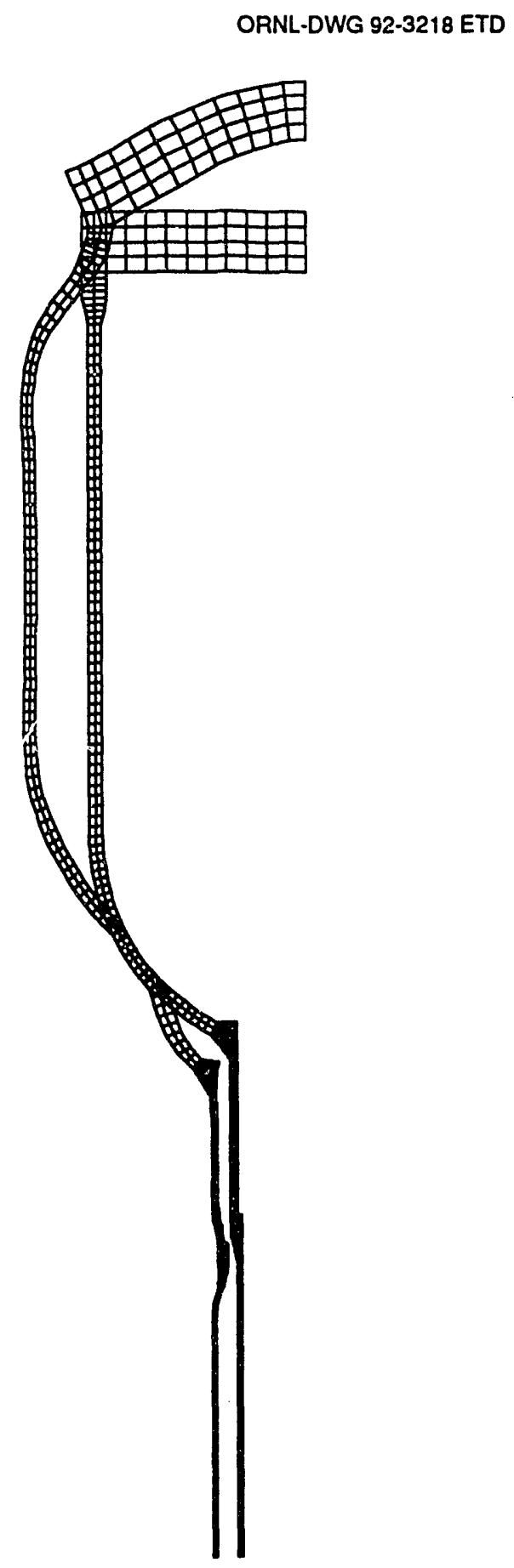

Fig. 38. Exaggerated deformation of pressurized HFIR reactor vessel with support constraint. 


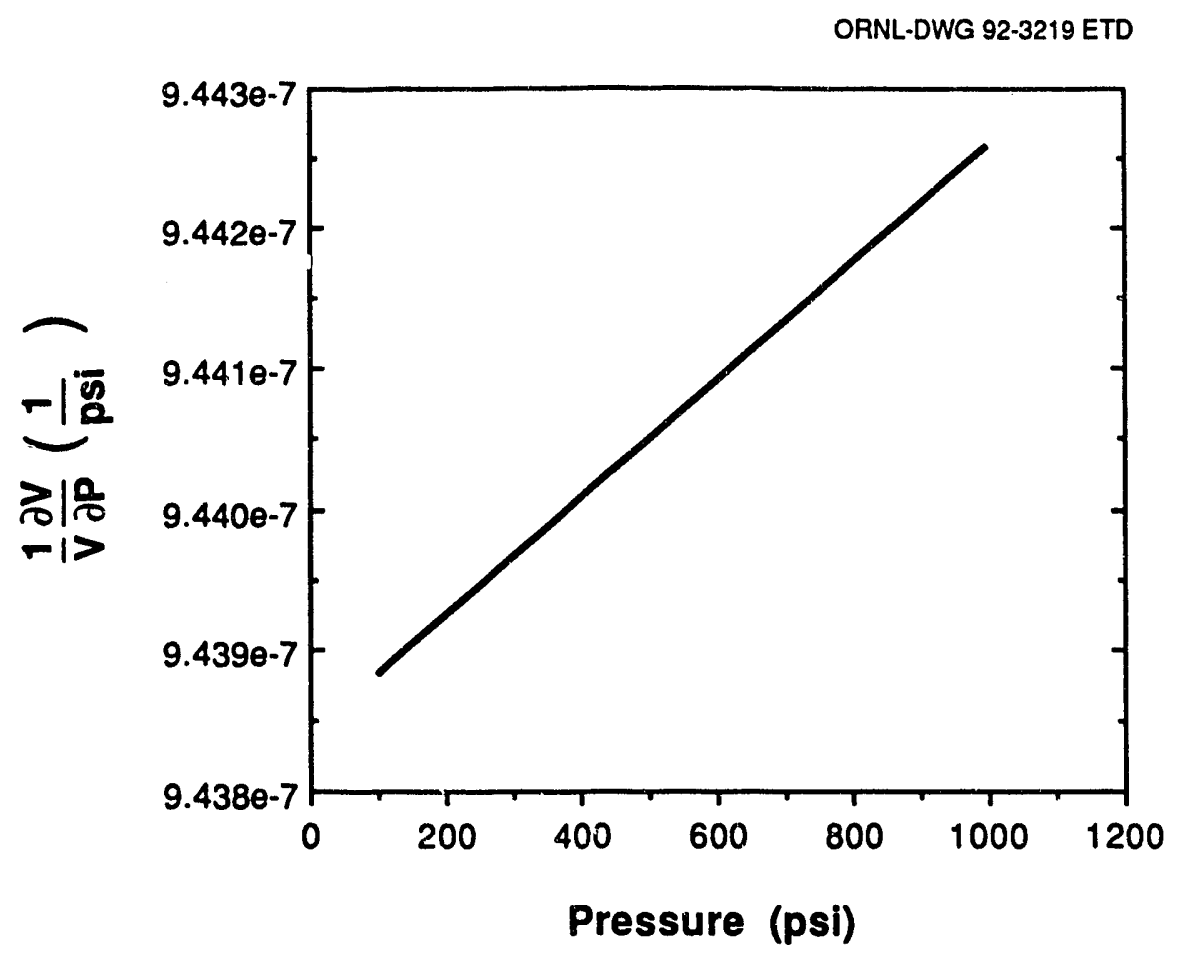

Fig. 39. Elasticity of HFIR reactor vessel with support constraint.

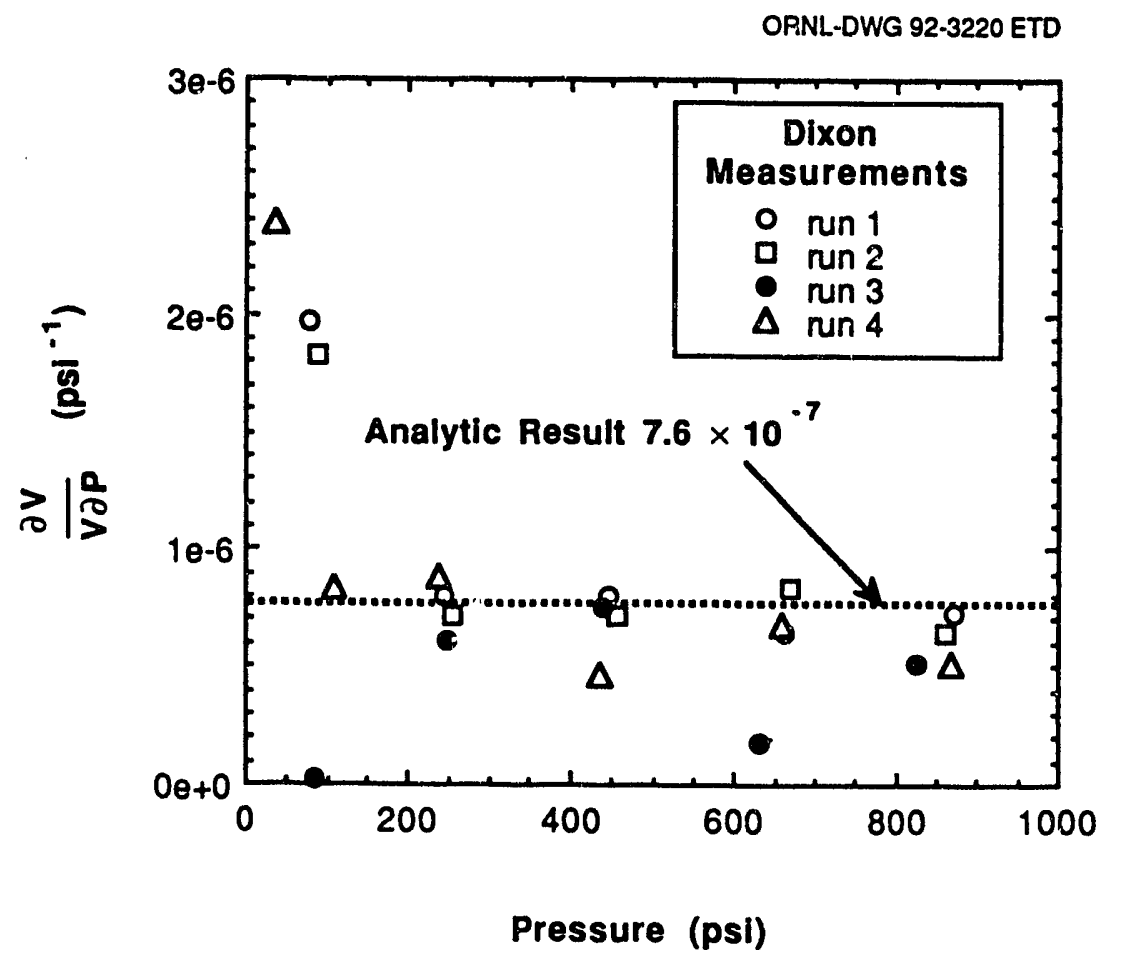

Fig. 40. Extraction of structural elasticity from experiments performed by Dixon. 


\subsubsection{Term 3}

Sample calculations run with the RELAP5 computer program indicate that the total temperature change of the HFIR system during depressurization from 1000 to 25 psi (6.89 to $0.172 \mathrm{MPa})$ is about $-0.3^{\circ} \mathrm{F}\left(-0.167^{\circ} \mathrm{C}\right)$. This result has been independently confirmed by Sozer. ${ }^{160}$ The temperature- and pressure-dependent density was extracted from RELAP5 using sample calculations. The density dependence upon temperature and pressure is fitted with polynomials in Figs. 41 and 42. Using the curve fit shown in Fig. 41, the sensitivity of density with respect to temperature at $100^{\circ} \mathrm{F}$ is about $-0.0132 \mathrm{lb}_{\mathbf{m}} / \mathrm{ft}^{3}-{ }^{\circ} \mathrm{F}$.

\section{$3.424 \operatorname{Term} 4$}

The compressibility of water is easily obtained from Fig. 42 . Here, it can be seen that $\partial \rho / \tilde{a P}$ is about $1.89 \times 10^{4} \mathrm{ib} / \mathrm{ft}^{3}$-psi at $90^{\circ} \mathrm{F}$ over the range of pressure from atmospheric to 1000 psi and $1.88 \times 10^{-4} \mathrm{lb}_{-} / \mathrm{ft}^{3}$-psi at $100^{\circ} \mathrm{F}$ over the same range of pressure. From this number, term 4 can be calculated.

One common way to char-cterize the stiffness of the system is to calculate $K_{f}$ which is a spring constant in psi/gal based solely on fluid compressibility. Using the total volume in the model $\left[1551 \mathrm{ft}^{3}\left(43.9 \mathrm{~m}^{3}\right)\right], K_{f}$ is

$$
K_{f}=\frac{\rho}{V \frac{d \rho}{d P}}=28.4 \mathrm{psi} / \mathrm{gal}\left(51.7 \mathrm{MPa} / \mathrm{m}^{3}\right) \text {. }
$$

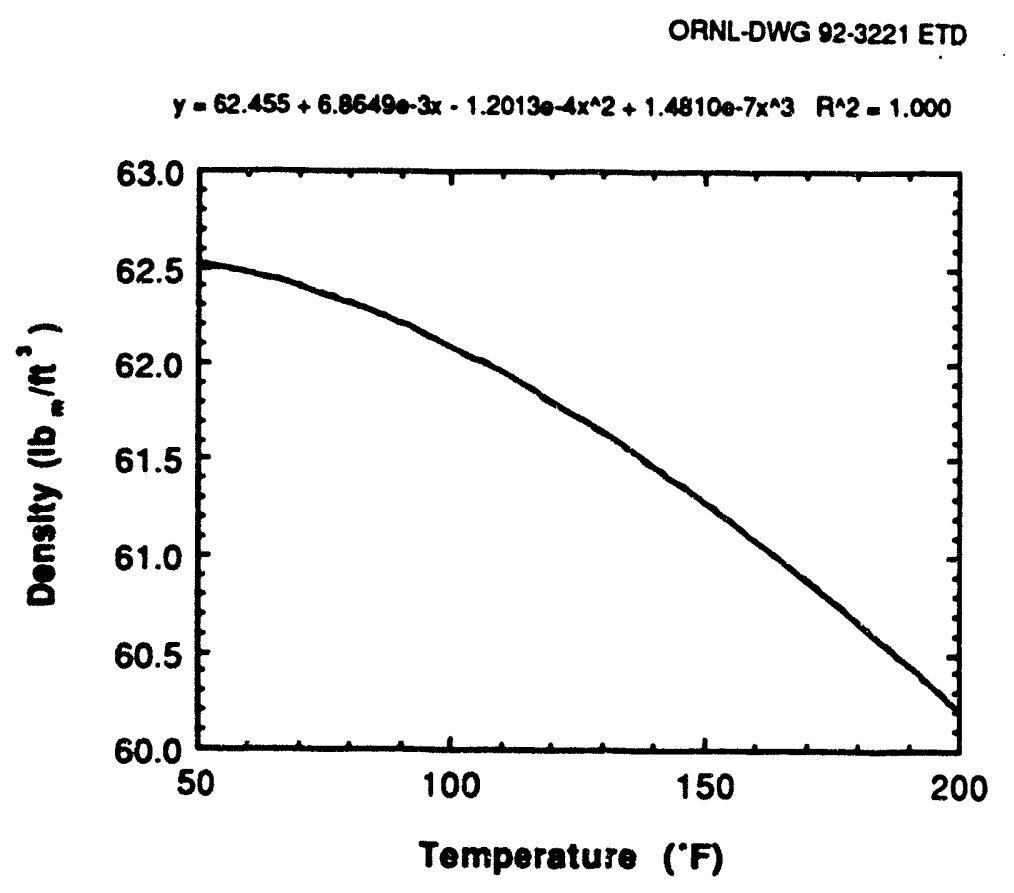

Fig. 41. Water density dependence upon temperature according to RELAP5 water properties library. 


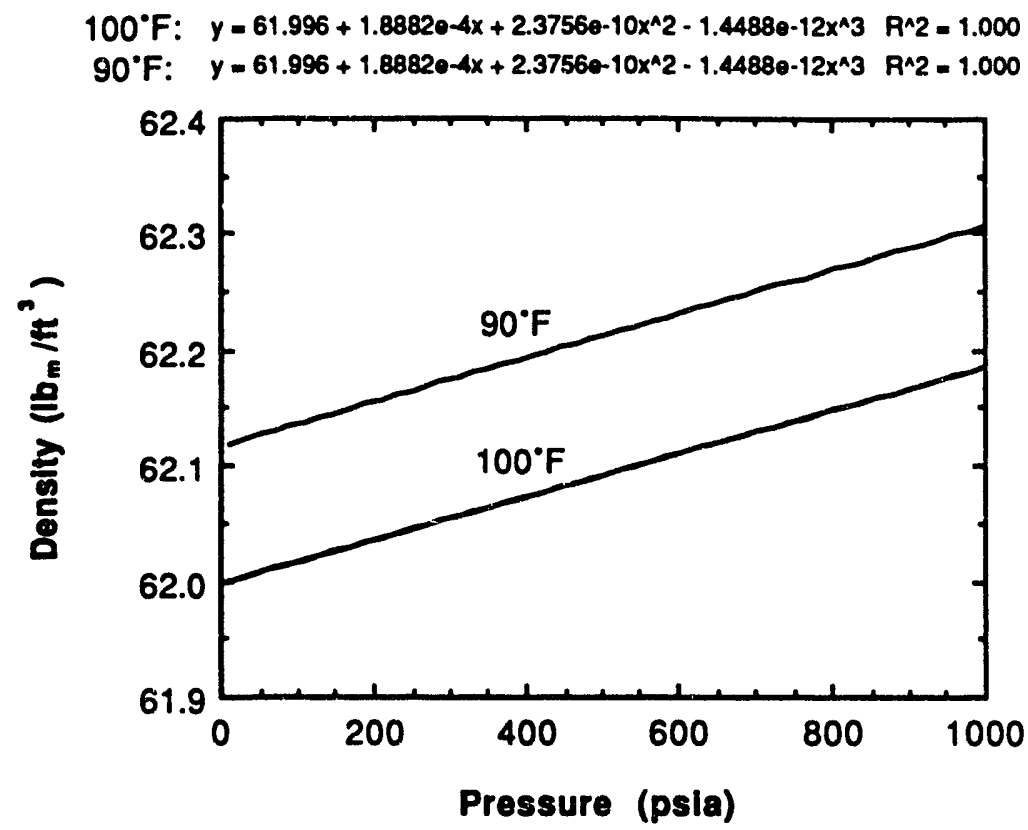

Fig. 42. Water density dependence upon pressure according to the RELAP5 water properties library.

To validate the density information for water that exists in RELAP5, a comparison was made to the ASME steam tables. ${ }^{161}$ Figure 43 shows the density as a function of pressure at $100^{\circ} \mathrm{F}$ as calculated by RELAP5. Data taken from the ASME Steam Tables is plotted on the same graph. The stair-step behavior of the ASME data is due to the limit of significant figures available. Excellent agreement is seen as RELAP5 data split right through the middle of the ASME data.

\subsubsection{Combination of Terms}

Assuming the primary coolant system, initially at 1000 psi and $100^{\circ} \mathrm{F}$, depressurizes to 25 psi during which the adiabatic, uniform temperature change is $-0.3^{\circ} \mathrm{F}$, the terms in Eq. (2) can be calculated as

$$
\begin{aligned}
& \text { term } 1=61.5 \frac{\mathrm{lb}_{\mathrm{m}}}{\mathrm{ft}^{3}} \times 0.0458 \frac{\mathrm{ft}^{3}}{{ }^{\circ} \mathrm{F}} \times-0.3^{\circ} \mathrm{F}=-0.823 \mathrm{lb}_{\mathrm{m}}, \\
& \text { term } 2=61.5 \frac{\mathrm{lb}_{\mathrm{m}}}{\mathrm{ft}^{3}} \times 0.001183 \frac{\mathrm{ft}^{3}}{\mathrm{psi}} \times-975 \mathrm{psi}=-70.94 \mathrm{lb}_{\mathrm{m}},
\end{aligned}
$$

term $3=1548 \mathrm{ft}^{3} \times-0.0132 \frac{\mathrm{lb}_{\mathrm{m}} / \mathrm{ft}^{3}}{{ }^{\circ} \mathrm{F}} \times-0.3^{\circ} \mathrm{F}=6.13 \mathrm{lb}=$,

term $4=1548 \mathrm{ft}^{3} \times 0.000188 \mathrm{lb}_{\mathrm{z}} / \mathrm{ft}^{3} / \mathrm{psi} \times-975 \mathrm{psi}=-283.7 \mathrm{lb}$. 


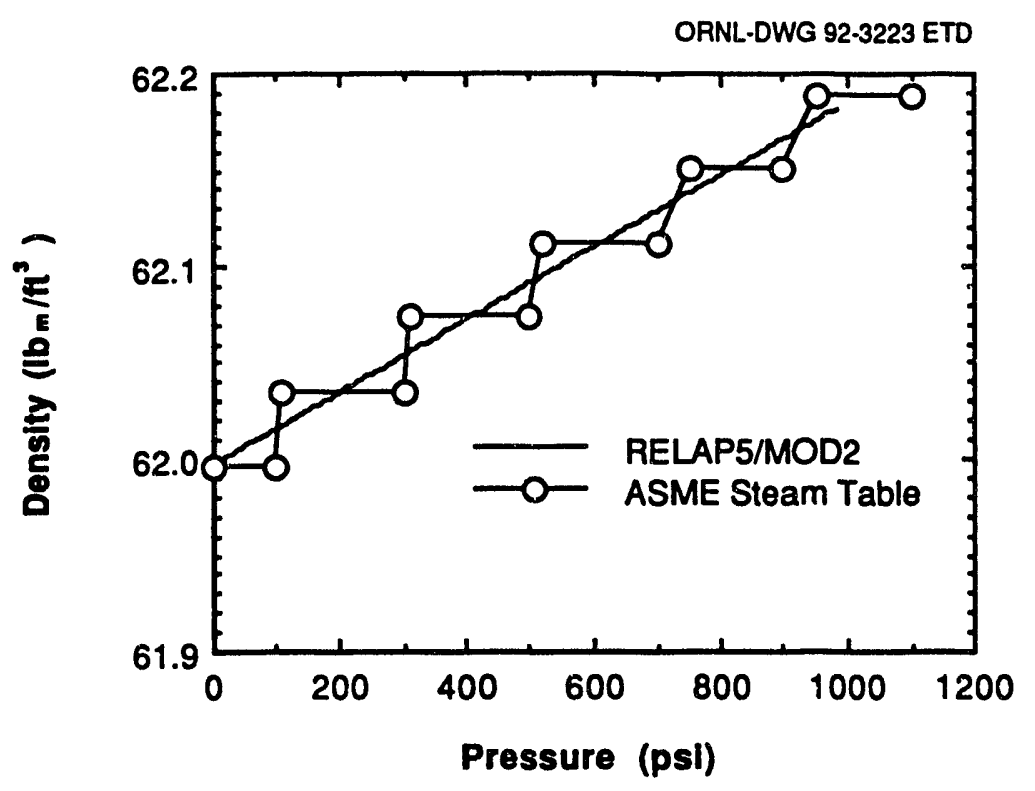

Fig. 43. Comparison of RELAP5 water density with ASME Steam Table values.

Thus, during the depressurization, $349 \mathrm{lb}_{\mathrm{m}}\left(42.1 \mathrm{gal}\right.$ at $\left.100^{\circ} \mathrm{F}\right)$ is lost from the system; $0.2 \%$ is due to thermal contraction of the pipes, $-1.8 \%$ to the water contracting, $20.3 \%$ to structural contraction due to internal pressure change, and $81.3 \%$ to isothermal compressibility of the water.

RELAP5 accounts for the water compressibility (term 4) and temperature change (term 3) in its normal solution process. The thermal expansion of the pipes (term 1) due to an adiabatic depressurization (or repressurization) is neglected. Furthermore, all dimensional changes due to thermal changes of the pipes are neglected for all transients. The structural elasticity of the system is significant and must be accounted for in the model.

\subsubsection{Inclusion in the Model}

RELAP5 does not automatically account for stretching of the system pressure boundary (pipes, vessel, and other components) as quantified in term 2 above. Rather, using the control systems, a method for representing the structural stiffness was devised whereby mass is added to or taken away from the system depending on whether the pressure is decreasing or increasing. Because the structural stiffness (the reciprocal of $d V / d P$ ) has been quantified (113 psi/gal), by monitoring the time rate of change in system pressure $(d P / d t)$, the amount of volume per unit time that should be added to or taken away from the system to account for shrinkage or expansion of the pressure boundary can be calculated as $d P / d t \times d V / d P$.

Because different places in the system experience different pressure changes, it is possible that injecting (or ejecting) all of this mass compensation at a single point based upon the pressure monitored at a single point may not be sufficient to accurately represent the distributed pressure boundary changes. Concentrating the injection of mass might also lead to some instability in the model.

Initial testing of the single-monitor/single-injector model was done for a sudden depressurization from a zero velocity, pressurized state where the rate of mass loss from the 
system was fixed. The pressure in the reactor vessel was monitored and mass added to or taken away from the system depending on the rate of pressure change. The mass injection (or ejection) occurred at the largest volume in the system (volume 33 in Fig. 7).

Depressurization of the system was simulated with and without the effects of structural elasticity by specifying a constant leakage rate. The results indicated that the singlemonitor/single-injector model is adequate to represent the distributed effect of the structural elasticity because the results have the same qualitative behavior.

No instabilities were observed for these initial runs. However, the initial break simulations were run where the mass loss from the system varied with time. Instability was observed, and it was necessary to lag the response of the mass injection/ejection to the pressure change. The response follows the relation,

$$
Q^{\bullet}=\int_{0}^{t} \frac{Q-Q^{*}}{t_{L}} d t,
$$

where at time $t, Q$ is the product $d P / d t \times d V / d P$ (calculated injection/ejection rate), $Q^{\bullet}$ is the adjusted rate of volumetric injection/ejection, and $t_{L}$ is a characteristic lag time. For all of the transients that have been run to date, using $10^{-3} \mathrm{~s}$ for $t_{L}$ has produced the best results.

Figures 44 and 45 show a comparison of depressurization (via a 1.5-in. break without the pumps and reactor operating) results with and without the single-monitor/single-injector structural elasticity model. The vessel upper plenum pressures are compared in Fig. 44, and the stiffness values based on the time rate of pressure change in the upper plenum during the depressurization are compared in Fig. 45. Although for single phase, the same behavior is seen with and without the structural elasticity model, it is expected that when some vapor exists in the system, the signal propagation rate will be greatly reduced. This could result in making the elasticity control system unstable. For SBLOCA transients, two-phase flow generally occurs first (if at all) during the initial depressurization. It is falling pressures (and

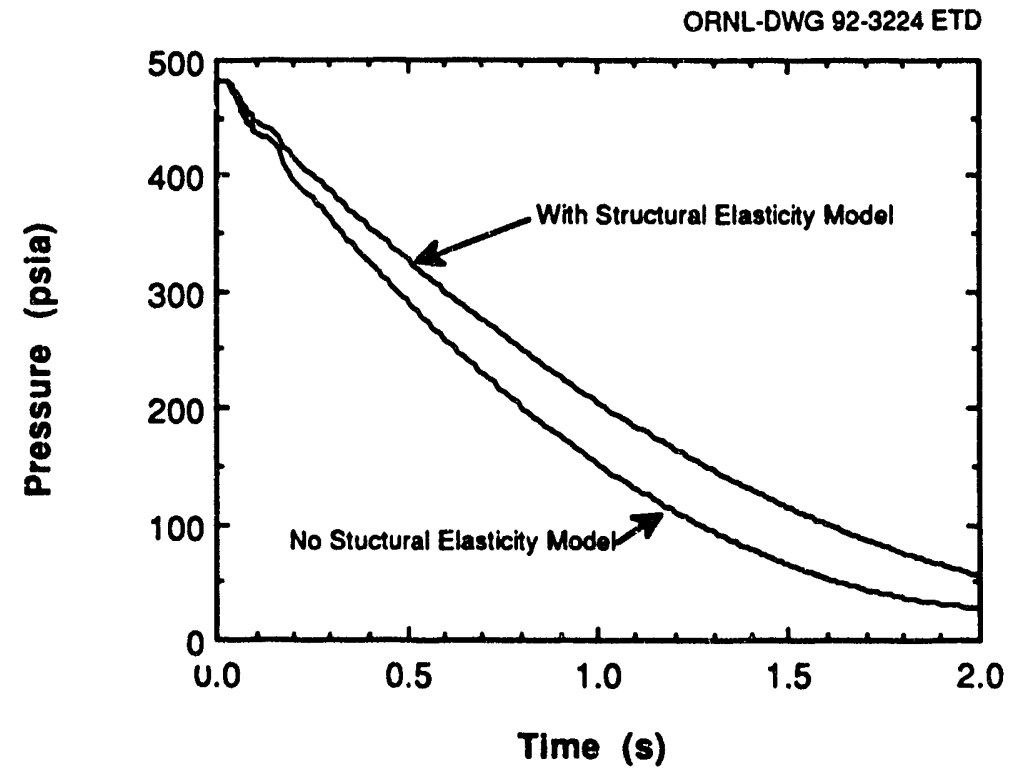

Fig. 44. Upper plenum pressure history during depressurization of system with and without elasticity model. 
ORNL-DWG 92.3225 ETD

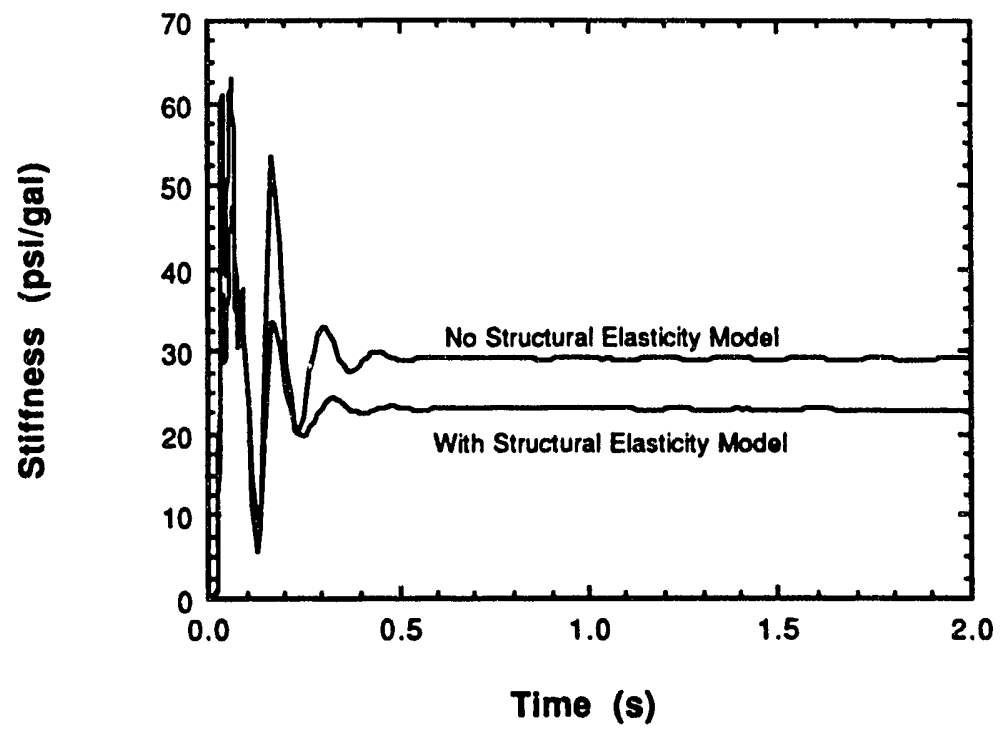

Fig. 45. Upper plenum history of change in pressure with respect to change in system volume during depressurization of system with and without the elasticity model.

not rising temperatures) that will bring about two-phase flow, which occurs first in the hot leg or at the suction to the main circulation pump(s). The elasticity control system must be engaged during the initial depressurization because this is the time when its effect will be significant. However, to disengage the elasticity control system before two-phase flow occurs, a cutoff value was set for the pressure at the suction side of main circulation pump PU-1D (generally the lowest pressure in the system). This cutoff value was chosen to be 20.0 psia, which is greater than the anticipated saturation pressure just after the initial depressurization.

The time-dependent junction 42 is assigned a mass flow rate, via control variables 372-376 (see Sect. 3.7.10), based on the pressure changes at volume 33. Junction 42 (Fig. 7) joins time-dependent volume 40 to volume 33 . Volume 40 serves as the source or sink for mass injected or ejected from the system. The temperature of the water in volume 40 is equal to that in volume 33. Because the mass flow injection rate is specified, the pressure and associated density in volume 40 are unimportant.

\subsection{LOSS COEFFICIENTS}

RELAP5 contains a smooth area change (no irreversible losses unless specified by the code user) model and an abrupt area change model, ${ }^{162}$ which take into account form losses that occur at a transition to larger or smaller pipe size. The smooth area change model was invoked at the Venturi flowmeter (Fig. 5). The sudden change in diameter between the schedule 40 and schedule 8010 -in. pipes in cells 110 and 111 is modeled with the abrupt area change model. The abrupt area change model is also specified at the break junctions.

To include other head losses incurred due to flow through various fittings, including bends (elbows), valves, tees, wyes, and heat exchanger tube entrance and exit, empirical loss coefficients were supplied to the RELAP5 program. The loss coefficient $K$ is the number of 
velocity heads lost at a junction. One velocity head is defined as $v^{2} / 2 g$, so the loss coefficient is

$$
K=\frac{h_{l}}{v^{2} / 2 g},
$$

where $v$ is the average fluid velocity at the junction, $g$ is the acceleration of gravity, and $h_{l}$ is the irreversible head loss. The values selected for junction loss coefficients in the RELAP5 model are discussed in this section. It has been assumed for all of the junctions that the loss coefficient $K$ is independent of Reynolds number.

\subsubsection{Strainer}

The HFIR inlet piping strainer is described by Abbatiello and Fraas. ${ }^{163}$ It consists of two layers: a steel plate with holes and a steel screen. Idel'Chik ${ }^{164}$ gives correlations for the loss coefficients through the plate and the screen. The Idel'Chik correlations were developed for a flat screen and plate; however, it is here applied to the conical screen and plate. Also each correlation is for either a screen or plate by itself, whereas the two are abutted in the HFIR water strainer. The total surface area of the plate neglecting the holes was calculated to be $9.773 \mathrm{ft}^{2}\left(0.908 \mathrm{~m}^{2}\right)$. The fraction of open area to closed area was calculated to be 0.403 in the plate and 0.1902 in the screen. Using the Idel'Chik correlations, this gives a loss coefficient of $\mathbf{2 . 8 0}$ for the plate and $\mathbf{1 9 . 2}$ for the screen. These loss coefficients are based on the average velocity corresponding to the total surface area of the strainer $\left(9.773 \mathrm{ft}^{2}\right)$. The loss coefficient is assumed to be the same for flow in either direction through the strainer. Some selected hourly readings ${ }^{26}$ since 1969 for the pressure drop across the strainer housing (PdT103) range from 11.2 to $13.1 \mathrm{psi}$ (77.2 to $90.3 \mathrm{kPa}$ ). These data are shown in Table 48 and Fig. 46.

The two data points in Fig. 46 that indicate a pressure drop of $<10$ psi were taken in 1969, before the most recent strainer design was adopted (1972). One pressure tap for PdT103 is located $2 \mathrm{ft}(0.61 \mathrm{~m})$ upstream (in the 20 -in. cold leg) of the strainer housing, and the downstream taps are located in a straight portion of the 16-in. inlet lines connecting to the reactor vessel. ${ }^{165}$ The readings from PdT103 include not only the strainer pressure drop but also pressure losses into and out of the strainer housing, several feet of piping friction loss, pressure loss at the $45^{\circ}$ bend in the 16-in. inlet piping, about $5 \mathrm{ft}(1.52 \mathrm{~m})$ of static head pressure recovery, and pressure recovery due to different velocities at the two tap locations. The head loss through the strainer itself was calculated by Abbatiello and Fraas ${ }^{163}$ to be $0.5 \mathrm{psi}$; however, an incorrect amount (635 in. $\left.{ }^{2}\right)$ of open area in the screen was assumed in this calculation. The correct value is about 268 in. ${ }^{2}\left(1729 \mathrm{~cm}^{2}\right)$. This error resulted in underpredicting the velocity and pressure drop.

The pressure drop through the strainer screen and plate can be calculated as

$$
\Delta P=K \frac{\rho G^{2}}{2 g A^{2}},
$$

where $K$ is the total loss coefficient, $\rho$ is the density $\left(61.7 \mathrm{lb}_{\mathrm{m}} / \mathrm{ft}^{3}\right.$ at $\left.120^{\circ} \mathrm{F}\right), G$ is the volumetric flow rate, $g_{c}$ is $32.2 \mathrm{lb}_{\mathrm{m}}-\mathrm{ft} / / \mathrm{b}_{r} \mathrm{~s}^{2}$, and $A$ is the area upon which the loss coefficients were based. This expression gives $\Delta P=1.95$ psi due to the strainer alone, assuming the loss coefficients taken from Idel'Chik, and a flow rate of $16,000 \mathrm{gal} / \mathrm{min}$. 
Table 48. HFIR hourly checksheet data for strainer pressure drop (PdT103)

\begin{tabular}{ccc}
\hline & \multicolumn{2}{c}{ Presure drop } \\
\cline { 2 - 3 } Date & in. $\mathrm{H}_{2} \mathrm{O}$ & \multicolumn{1}{c}{ psi } \\
\hline $09-01-69$ & 270 & 9.653 \\
$09-01-69$ & 270 & 9.653 \\
$12-03-73$ & 325 & 11.620 \\
$04-15-75$ & 325 & 11.620 \\
$04-01-78$ & 348 & 12.442 \\
$09-15-79$ & 351 & 12.549 \\
$09-24-79$ & 351 & 12.549 \\
$07-03-81$ & 353 & 12.621 \\
$07-26-81$ & 355 & 12.692 \\
$11-11-82$ & 315 & 11.262 \\
$11-24-82$ & 313 & 11.190 \\
$11-29-82$ & 313 & 11.190 \\
$05-08-83$ & 323 & 11.548 \\
$05-20-83$ & 318 & 11.369 \\
$07-01-83$ & 328 & 11.727 \\
$09-12-84$ & 332 & 11.870 \\
$09-23-84$ & 328 & 11.727 \\
$03-01-85$ & 348 & 12.442 \\
$03-18-85$ & 350 & 12.513 \\
$09-06-85$ & 350 & 12.513 \\
$09-18-85$ & 349 & 12.478 \\
$11-01-86$ & 365 & 13.050 \\
$11-03-86$ & 365 & 13.050 \\
\hline
\end{tabular}

A cross-flow junction is used in the model to represent the juncture between the 20-in. cold leg (volume 80-04) and the top volume (81) of the strainer housing. At this junction a loss coefficient of 1.44 based on the Idel'Chik correlation ${ }^{166}$ for a sharp elbow with a recess is used. This means the pressure drop at the entrance to the strainer housing is about $3.32 \mathrm{psi}(0.0229 \mathrm{MPa})$. Because the stream is turned $90^{\circ}$ in volume 81 , RELAP5 forces the velocity in volume 81 to be zero so that the pressure is equal to the stagnation pressure. $A$ tee junction exists at the exit of the strainer housing, branching into the 16-in. inlet pipes. From Miller, ${ }^{167}$ the tee loss coefficient based on the 16-in. pipe area is about 1.95. This results in a pressure drop through the tee of $2.74 \mathrm{psi}(0.0189 \mathrm{MPa})$. The pressure difference $\Delta P_{103}$ can be calculated then by adjusting the total heau losses by the elevation and velocity differences,

$$
\begin{aligned}
\Delta \bar{F}_{103} & =1.95+3.32+2.74-\frac{\rho g}{g_{c}}\left(z_{\text {upstream }}-z_{\text {downstream }}\right) \\
& -\frac{\rho}{2 g_{c}}\left(v_{\text {upstream }}^{2}-v_{\text {donnstream }}^{2}\right)+\text { line losses }
\end{aligned}
$$




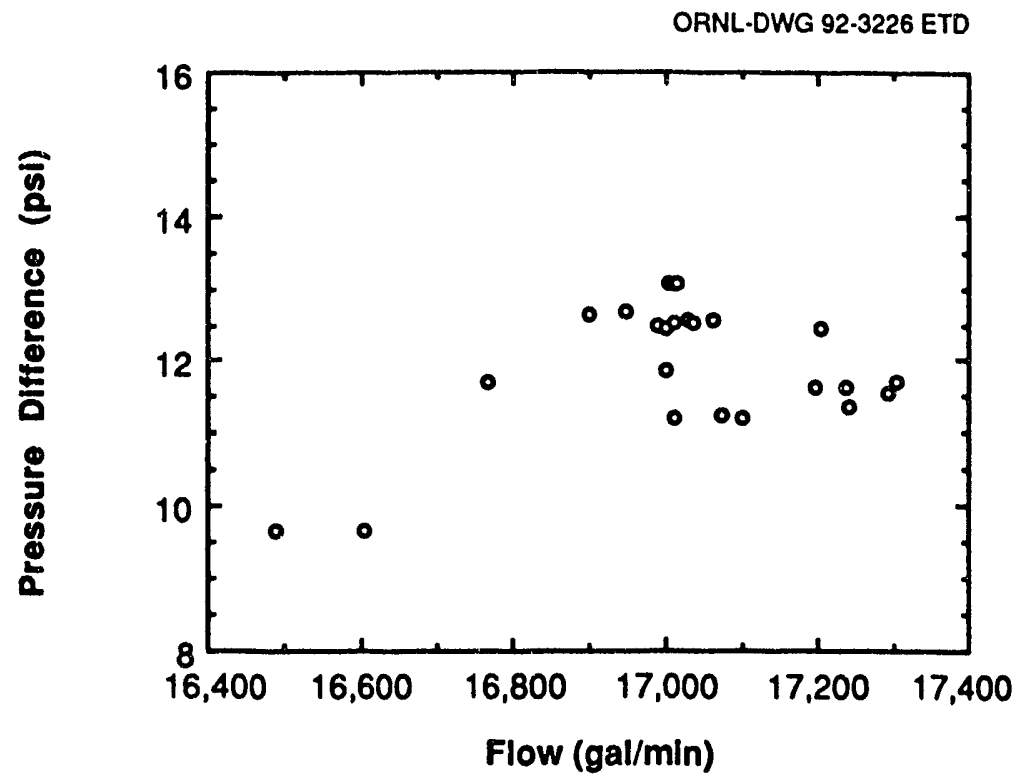

Fig. 46. Measurements recorded for PdT103 from HFIR hourly checksheets.

$$
\begin{aligned}
& =1.95+3.32+2.74-1.79-0.868+\text { line losses } \\
& =5.35 \text { psi }+ \text { line losses }
\end{aligned}
$$

The steady-state value for PdT103 calculated in the model including line losses is $5.58 \mathrm{psi}$ $(0.0385 \mathrm{MPa})$. Although this is about half of what was measured, the flow is also low $(16,171 \mathrm{gal} / \mathrm{min})$. Still, increasing the flow to $17,000 \mathrm{gal} / \mathrm{min}$ would only result in an increase to $6.2 \mathrm{psi}(0.0427 \mathrm{MPa})$ for PdT103. It was assumed that the cause for the discrepancy was that the loss coefficients calculated with the Idel'Chik correlations at the entrance and exit of the strainer housing were not accurate for this application. To be consistent with the measured data, both of these loss coefficients were set at 2.915 , resulting in a pressure drop of 10.67 psi (0.0736 MPa).

\subsubsection{Heat Exchanger Inlet and Outlet}

Loss coefficients at the inlet and outlet of the tube bundle on the primary side of the heat exchanger were calculated based on correlations published in Idel'Chik. ${ }^{168}$ A Reynolds number of 60,000 was calculated for steady-state flow through each tube. For the entrance into a thick-walled orifice, the loss coefficient is 1.455 . For discharge from a conduit (heat exchanger tube), the loss coefficient is 2.0. For reverse flow through the exchanger, the loss coefficient at the inlet is the same as for forward flow at the outlet and vice versa.

\subsubsection{Bends and Elbows}

At many locations throughout the primary cooling system, bends and elbows of $45^{\circ}, 90^{\circ}$, and $135^{\circ}$ exist in the piping. The ratio between the radius of curvature and the nominal pipe diameter is 1.5 for the bends in the pipe, except for in the 16-in. inlet lines where the ratio is 1.0. The loss coefficients for all sizes of bends and elbows are given in Table 49. 
Table 49. Loss coefficients for bends and elbows

\begin{tabular}{ccccc}
\hline $\begin{array}{c}\text { Pipe size } \\
\text { (in.) }\end{array}$ & $\begin{array}{c}\text { Angle } \\
\text { (deg) }\end{array}$ & Crane $^{a}$ & Miller $^{b}$ & Used \\
\hline 10 & 45 & 0.014 & 0.072 & 0.10 \\
10 & 90 & 0.196 & 0.185 & 0.19 \\
14 & 45 & 0.124 & 0.090 & 0.10 \\
16 & 135 & 0.131 & 0.095 & 0.10 \\
16 & 90 & 0.335 & 0.250 & 0.22 \\
18 & 90 & 0.168 & 0.175 & 0.17 \\
20 & 90 & 0.168 & 0.175 & 0.17 \\
\hline
\end{tabular}

${ }^{a}$ Reference 169.

${ }^{b}$ Reference 170.

\subsubsection{Wyes}

As flow diverges from the hot leg to the heat exchangers and converges into the cold leg from the heat exchanger, frictional losses occur at the wye junctions. Works by Idel'Chik ${ }^{171}$ and Miller ${ }^{172}$ both contain information regarding loss coefficients at wyes. The loss coefficients calculated from these two references and the actual values used in the model are tabulated in Tables 50 and 51, with reference to Fig. 47. Values are tabulated for both the 18-in. (45.7-cm) hot leg and the 20 -in. $(50.8-\mathrm{cm})$ cold leg. The $G_{1}, G_{2}$, and $G_{3}$ are the flows at the points 1, 2, and 3 in Fig. 47.

Because the correlations give loss coefficients based on the smaller of the : two areas and, in the model, the main passage area was always used, the resulting coefficienis were adjusted. The values used in the RELAP5 model are the "adjusted" values.

Table 50. Loss coefficients for diverging wye junctions

\begin{tabular}{ccccccl}
\hline $\begin{array}{c}\text { Pipe size } \\
\text { (in.) }\end{array}$ & Configuration & $G_{1} / G_{2}$ & Miller & Idel'Chik $^{b}$ & Assumed & Adjusted \\
\hline 18 & $K_{31}$ & $1 / 3$ & 0.95 & 0.548 & 0.95 & 0.878 \\
18 & $K_{32}$ & $1 / 3$ & -0.025 & 0.044 & 0.0 & 0.0 \\
18 & $K_{31}$ & $1 / 2$ & 1.20 & 1.10 & 1.10 & 1.02 \\
18 & $K_{32}$ & $1 / 2$ & 0.025 & 0.0 & 0.0 & 0.0 \\
18 & $K_{32}$ & 0 & 0.040 & 0.0 & 0.0 & 0.0 \\
20 & $K_{31}$ & $1 / 3$ & 1.10 & 0.756 & 1.0 & 0.6 \\
20 & $K_{32}$ & $1 / 3$ & -0.025 & 0.044 & 0.0 & 0.0 \\
20 & $K_{31}$ & $1 / 2$ & 1.80 & 1.81 & 1.81 & 0.49 \\
20 & $K_{32}$ & $1 / 2$ & 0.025 & 0.10 & 0.0 & 0.0 \\
20 & $K_{32}$ & 0 & 0.040 & 0.0 & 0.0 & 0.0 \\
\hline
\end{tabular}

${ }^{a}$ Reference 172.

${ }^{b}$ Reference 171. 
Table 51. Loss coefficients for converging wye junctions

\begin{tabular}{ccccccl}
\hline $\begin{array}{c}\text { Pipe size } \\
\text { (in.) }\end{array}$ & Configuration & $G_{1} / G_{2}$ & Miller $^{\circ}$ & Idel'Chik $^{b}$ & Assumed & Adjusted \\
\hline 18 & $K_{13}$ & $1 / 3$ & 0.75 & 0.64 & 0.75 & 0.69 \\
18 & $K_{23}$ & $1 / 3$ & 0.07 & 0.086 & 0.086 & 0.086 \\
18 & $K_{13}$ & $1 / 2$ & 1.80 & 1.69 & 1.69 & 0.69 \\
18 & $K_{23}$ & $1 / 2$ & -0.20 & -0.308 & 0.0 & 0.0 \\
18 & $K_{23}$ & 0 & 0.00 & 0.0 & 0.0 & 0.0 \\
20 & $K_{13}$ & $1 / 3$ & 1.20 & 1.17 & 1.2 & 0.72 \\
20 & $K_{23}$ & $1 / 3$ & -0.02 & -0.051 & 0.0 & 0.0 \\
20 & $K_{13}$ & $1 / 2$ & 2.90 & 2.88 & 2.88 & 0.77 \\
20 & $K_{23}$ & $1 / 2$ & -0.40 & -0.614 & 0.0 & 0.0 \\
20 & $K_{23}$ & 0 & 0.0 & 0.0 & 0.0 & 0.0 \\
\hline
\end{tabular}

${ }^{a}$ Reference 172.

${ }^{b}$ Reference 171.

ORNL-DWG 92-3227 ETD

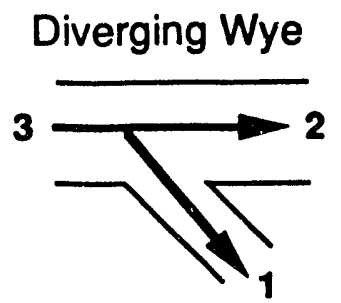

Converging Wye

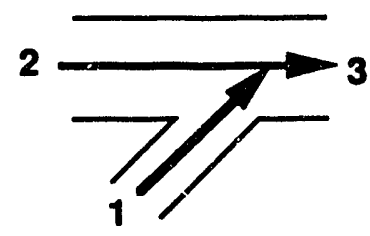

Fig. 47. Loss coefficient configurations at wye junctions.

Some of the coefficients in Tables 50 and 51 are negative because momentum is transferred from one flow path to another; hence, flow along one of the paths actually experiences a head gain rather than a head loss at the wye. Flow along the other flow path, however, more than makes up for this by experiencing a head loss.

\subsubsection{Check Valves and Block Valves}

Loss coefficients for the isolation block valves at the inlet and outlet of each heat exchanger cell and that for the check valve immediately downstream of each main circulating pump (see Fig. 5) were taken from Crane ${ }^{173}$ and Miller. ${ }^{174}$ The loss coefficients are tabulated in Table 52. 
Table 52. Loss coefficients for the block and check. valves

\begin{tabular}{lllc}
\hline Block valve & Crane $^{a}$ & Miller $^{b}$ & $\begin{array}{c}\text { Used in } \\
\text { model }\end{array}$ \\
\hline Block valve & 0.112 & 0.15 & 0.13 \\
Check valve & 0.65 & 0.5 & 0.65 \\
\hline
\end{tabular}

${ }^{a}$ Reference 173.

${ }^{b}$ Reference 174.

\subsubsection{Pressurizer Pump Discharge Line}

The types of form losses in the 3-in. (7.62-cm) pressurizer pump discharge line are due to the fittings ${ }^{114,120-122}$ shown in Table 53. The equivalent $L / d^{\prime} \mathrm{s}^{175}$ and the $K$ values, assuming a friction factor of 0.02 , are also given. Here $L$ is the equivalent length and $d$ is the pipe diameter.

Table 53. Fittings in the pressurizer pump discharge line

\begin{tabular}{clrl}
\hline $\begin{array}{c}\text { Number of } \\
\text { fittings }\end{array}$ & Type of fitting & $L / d$ 's & $K$ \\
\hline 15 & $90^{\circ}$ elbows & 450 & 9.0 \\
3 & $45^{\circ}$ elbows & 36 & 0.72 \\
5 & Tees (flow through) & 100 & 2.0 \\
2 & Swing check valves & 270 & 5.4 \\
1 & Fully open globe valve & 340 & 6.8 \\
1 & Half-open globe valve & 340 & 6.8 \\
1 & Orifice flow meter & 50 & 0.1 \\
\hline
\end{tabular}

The pressure losses in the pressurizer pump discharge line become particularly important when the system has been depressurized and the pressurizer pump flow rate is high. The magnitude of these line losses then determines what the primary coolant system pressure will be and how quickly the PC head tank is emptied.

\subsubsection{Pressurizer Pump Suction Line}

If the suction pressure to the pressurizer pumps falls below 15.2 psia $(0.107 \mathrm{MPa})$ and remains $<16.7$ psia for $5 \mathrm{~s}$, then the pumps will be tripped to avoid cavitation. The losses in the 4-in. (10.2-cm) suction line, which extends $72.21 \mathrm{ft}$ from the primary coolant (PC) head tank to the pumps, are important because they detract from the available suction head. Given the losses and the tank level, the maximum allowable pressurizer flow rate without 
pump trip can be determined. A schematic with the associated measurements ${ }^{116,176-179}$ indicating the location of valves, bends, wyes, and tees is given in Fig. 48. The pressurizer pump suction pressure can be defined as

$$
P_{\text {suction }}=P_{\text {op }}+\frac{\rho g h}{g_{c}}+\frac{\rho g \Delta z}{g_{c}}-\frac{\rho G^{2}}{2 g_{c} A^{2}}\left(1+\frac{f L}{d}\right),
$$

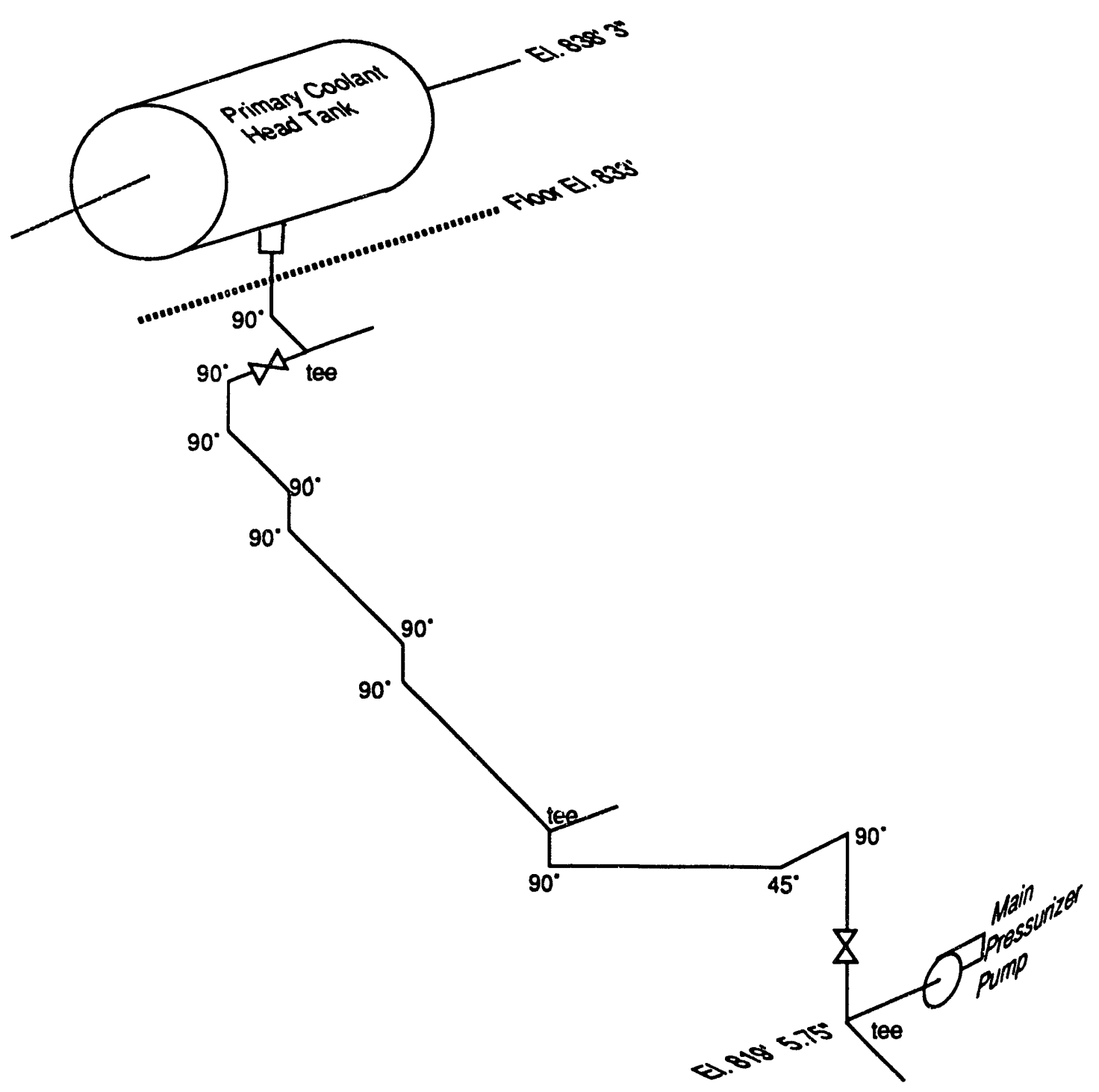

Fig. 48. Schematic of pressurizer pump suction line. 
where $h$ is the height of water in the PC head tank, $P_{o p}$ is the overpressure in the primary coolant head tank, $\Delta z$ is the elevation difference between the bottom of the PC head tank and the suction ports to the pressurizer pumps, $L$ is effective pipe length including form losses, and $G$ is the suction line flow rate. Solving the above equation for $G$ gives

$$
G=\sqrt{\frac{-g_{c} \frac{\left(P_{\text {suction }}-P_{o p}\right)}{\rho}+(h+\Delta z) g}{\frac{8}{\pi^{2} d^{4}}\left(\frac{f L}{d}+1\right)}} .
$$

The following values are assumed: the normal value for $h$ (before pump trip on low PC head tank level) of $4.5 \mathrm{ft}(0.508 \mathrm{~m})$, the minimum allowable suction pressure of 15.2 psia $(0.107 \mathrm{MPa})$, a density of $62 \mathrm{lb}_{\mathrm{m}} / \mathrm{ft}^{3}\left(993 \mathrm{~kg} / \mathrm{m}^{3}\right), \Delta z$ of $15.52 \mathrm{ft}(4.578 \mathrm{~m})$, an inside diameter of $0.336 \mathrm{ft}(0.102 \mathrm{~m})$, and an overpressure in the head tank of 12.9 psia $(0.0889 \mathrm{MPa}){ }^{148}$ Using loss coefficients from Ref. 175, the total loss coefficient through the 4-in. (10.16-cm) suction pipe is 9.6. Assuming a friction coefficient of $0.017, \mathrm{~L} / \mathrm{d}$ is $637 \mathrm{ft}$. Substituting these values into the expression for $G$ gives a maximum allowable pressurizer flow before pump trip of $0.7903 \mathrm{ft}^{3} / \mathrm{s}\left(355 \mathrm{gal} / \mathrm{min}\right.$ or $\left.0.0224 \mathrm{~m}^{3} / \mathrm{s}\right)$.

\subsection{TRIPS}

Trips are set in the model to control the transient by starting and/or stopping various actions of system components. Table 54 lists the trip numbers and the purpose for each trip.

\subsection{CONTROL VARIABLES}

The control variables ${ }^{1}$ are used in determining when and how events should happen during a transient; obtaining additional output from the run; and calculating pressures, flow rates, and valve positions to be supplied to certain preselected system components. Any dependent variable referenced by a control variable is in the SI units system, so when working in English units, conversion factors are included in the input. The control variables used in the HFIR model are described briefly in Table 55. The control variable types are explained in the RELAP5 documentation. ${ }^{180}$

\subsubsection{Primary Coolant Head Tank Level}

Control variables (CVs) 1-7 are used to monitor the level in the primary coolant head tank. This is accomplished by summing the mass flows into the tank (CV 2) at each time step and integrating that sum to get the percentage of the tank volume occupied by water. The level indicator, which ranges from 0 to $6 \mathrm{ft}$, is 2 in. above the bottom of the tank. A logic diagram for this control system is shown in Fig. 49. 
Table 54. Trips as defined in the RELAP5 system model of the HFIR primary coolant system

Trip

No.

Trip is true if:

501

503

505

506

507

508

509

510

511

512

513

514

515

516

518

519

521

The current time is greater than or equal to the final time of the simulation. Transient calculation is to begin (as opposed to establishing a new steady state). Control variable 502 (pressurizer pump suction pressure) is low (less than control variable 692).

Control variable 500 (temperature of volume $80-01$ ) is greater than control variable 674 (maximum allowable primary coolant temperature).

Control variable 206 (reactor temperature-trip indicator) is $>0.5$.

Control variable 501 (pressure in volume 18-01, upper plenum) is less than control variable 675 (reactor trip pressure).

Control variable 204 (flux-to-flow ratio) is greater than control variable 676 (ratio at which reactor is tripped).

Control variable 208 (reactor trip indicator) is $>0.5$.

Control variable 7 (PC head tank level) is less than control variable 677 (demineralizer flow trip level).

Control variable 7 (PC head tank level) is less than control variable 678 (pressurizer pump trip setpoint).

Control variable 502 (pressure in volume 47-01, pressurizer pump suction line) is less than control variable 679 (very low suction pressure). This trip is used by the control system for pressurizer pump trip.

Standby press srizer pump trip on signa! (currently disabled).

Control variable 503 (flow rate at junction 79-04, pressurizing flow) is less than control variable 681 (auxiliary pressurizer pump trip on setpoint).

Control variable 501 (pressure in volume 18-01, upper plenum) is less than control variable 682 (radiation block valve closure setpoint).

Control variable 505 (pressure in volume 48-01, main pressurizer pump discharge) is greater than control variable 684 (maximum pressure allowed before main pressurizer pump trips off).

Control variable 255 (EDS trip) is $>0$.

Control variable 18 (duration in secends of low suction pressure to pressurizer pumps) is 25 (if true, trip pressurizer pumps off). 
Table 54 (continued)

Trip

No.

Trip is true if:

525

The vessure in volume 60-03 (MCP suction) is $<20$ psia (disable structural elasticity control system).

S26 Control variable 500 (temperature in volume 80-01) is less than control variable 685 (minimum aliowable temperature before the emergency depressurization system trip).

528 Control variable 501 is less than control variable 686 (setpoint pressure for reset trip on EDS).

529 Time is greater than -1.0. This trip is always true.

530 Control variable 114 is $<1$ (MCP in cell D has cavitated).

531 Control variable 139 is $<1$ (MCP in cell $C$ has cavitated).

532 Control variable 164 is $<1$ (MCP in cell A has cavitated).

533 Control variable 501 is less than control variable 683 (mininum allowable primary pressure before tripping MCPs).

536 Control variable 117 ( $\nu / \alpha$ ratio for $\mathrm{MCP}$ in cell $\mathrm{D})$ is $>1$.

537 Control variable 142 ( $\nu / \alpha$ ratio for $M C P$ in well $C)$ is $>1$.

538 Control variable 167 ( $v / \alpha$ ratio for $M C P$ in cell $A)$ is $>1$.

551-599 These trips are used for transient definitior.

600 Trip 501 is true (terminate the simulation).

602 Trip 515 and 503 are true (auxiliary pressurizer pump trip on).

603 Trip 526 is truc and trip 528 is false (open EDS valves).

605 Trips 606 and 505 are true (low pressurizer pump suction pressure exists in conjunction with a previous very low pressure indication).

606 Trip 513 or 605 is true (pressurizer pump trip if this trip remains true for $5 \mathrm{~s}$ ).

609 Trip 518 or trip 519 is true (signal to disengage pressurizer pumps based on EDS activation or high primary pressure).

610 Trip 609 or 553 is true (loss of ac power to pressurizer pumps).

611 Trip $\mathbf{5 5 5}$ or $\mathbf{6 1 0}$ is true (trip to check for pressurizer pump failure).

612 Trips 503 and 514 are true (trip to engage standby pressurizer pumps).

613 Trips 512 and 521 are false (trip pressurizer pumps because of low PC head tank level or low suction pressure). 
Table 54 (continued)

\begin{tabular}{|c|c|}
\hline $\begin{array}{l}\text { Trip } \\
\text { No. }\end{array}$ & Trip is true if: \\
\hline 614 & $\begin{array}{l}\text { Trip } 613 \text { is false or trip } 611 \text { is true (if true, begin using torque balance to } \\
\text { determine the main pressurizer pump speed coastdown rate). }\end{array}$ \\
\hline 615 & $\begin{array}{l}\text { Trip } 614 \text { is false (stop using specified pump velocity table for the pressurizer } \\
\text { pump). }\end{array}$ \\
\hline 622 & Trip 579 is false and trip 516 is true (signal to close letdown block valves). \\
\hline 623 & $\begin{array}{l}\text { Trip } 589 \text { is false (auxiliary pressurizer pump is available) and trip } 602 \text { is true } \\
\text { (trip auxiliary pressurizer pump on). }\end{array}$ \\
\hline 643 & Trip 510 or 551 is true (initiate automatic scram). \\
\hline 644 & $\begin{array}{l}\text { Trips } 571 \text { and } 518 \text { are true (trip reactor at pressurizer pump trip for loss of } \\
\text { instrument air case). }\end{array}$ \\
\hline 645 & $\begin{array}{l}\text { Trip } 507 \text { or } 508 \text { is true (temperature or pressure indicates a reactor trip should } \\
\text { occur). }\end{array}$ \\
\hline 646 & $\begin{array}{l}\text { Trip } 644 \text { or } 509 \text { is true (reactor trip based on pressurizer pump trip initiator on } \\
\text { loss of instrument air or FFR initiator). }\end{array}$ \\
\hline 647 & Trip 646 or 645 is true (signal sent to initiate scram). \\
\hline 648 & Trip 643 is true and trip 583 is false (scram initiated). \\
\hline 649 & Trip 648 is true and trip 586 is false (trip off PU-6B). \\
\hline 650 & Trip 649 is false (speed table trip on PU-6B). \\
\hline 651 & Trip 649 or 568 is true (trip off PU-6A). \\
\hline 652 & T.ip 651 is false (speed table trip on PU-6A). \\
\hline 660 & Trip 553 or 533 is true (trip MCPs). \\
\hline
\end{tabular}

\subsubsection{Main Circulation Pumps}

The main circulation pumps are controlled with trips 529-533, 536-538, and CVs 77-193. CVs 77-102 are used to calculate the actual pump speeds during or after coastdown (Fig. 50). CVs 74-76 and 103-180 are used to modulate the pump speed if the pumps are cavitating based on the Byron Jackson pump data (see Appendix B). This is accomplished by first calculating the degraded pump head based on data (Fig. 51) and then determining the degraded (modulated) pump speed (Fig. 52) corresponding to the degraded pump head. If a steady state is being established (trip 503 is false), then CVs 181-193 are used to control the pump speed so that the setpoint primary flow rate is reached. If a transient has begun, then the same set of control variables set the pump speed to (1) the lacest steady-state value if the pump has not been tripped, (2) the actual speed of the pump during or after coastdown 
Table 55. Control variables used in the model

\begin{tabular}{cll}
\hline No. & Type & \\
\hline 1 & TRIPUNIT & Demineralized water flow rate into the PC head tank. \\
2 & SUM & Net rate of mass change in the tank. \\
3 & TRIPUNIT & On/off switch for adjustment of PC head level. \\
4 & MULT & Product of variables 2 and 3. \\
5 & INTEGRAL & Current percentage of tank volume occupied by water. \\
6 & FUNCTION & Actual tank level based on variable 5. \\
7 & SUM & Tank level indicated in control room. \\
8 & TRIPUNIT & On/off switch for standby pressurizer pump. \\
9 & TRIPDLAY & Most recent time standby pressurizer pump start-up signal was received. \\
10 & SUM & Time elapsed since start-up signal was received. \\
11 & MULT & Product of variables 8 and 10. \\
12 & FUNCTION & Speed in rpm of the standby pressurizer pump. \\
15 & TRIPDLAY & Most recent time low-pressurizer pump suction pressure was detected. \\
16 & SUM & Time elapsed since low pressure was detected. \\
17 & TRIPUNIT & On/off switch for low suction pressure. \\
18 & MULT & Product of variables 16 and 17. \\
19 & TRIPUNIT & Flag to disable/enable auxiliary pressurizer pump flow. \\
20 & SUM & Auxiliary pressurizer pump head. \\
21 & FUNCTION & Auxiliary pressurizer pump flow based on the existing pump head. \\
22 & TRIPDLAY & Time that auxiliary pressurizer pump was tripped. \\
23 & SUM & Time elapsed since auxiliary pressurizer pump was tripped. \\
24 & FUNCTION & Start-up factor used to ramp the auxiliary pressurizer pump speed over \\
& & a 5-s interval. \\
25 & MULT & Adjusted auxiliary pressurizer pump speed; product of variables 21 and \\
26 & SUM & Current time step. \\
27 & TRIPUNIT & Loss of instrument air flag (zero if loss of instrument air). \\
28 & TRIPUNIT & Radiation block valve multiplier, set to zero if trip 622 is false. \\
& TRIPDLAY & Last time trip 622 turned true. \\
& SUM & Time elapsed since trip 622 last turned true. \\
& & \\
& &
\end{tabular}


Table 55 (continued)

\begin{tabular}{|c|c|c|}
\hline No. & Type & Description \\
\hline 31 & MULT & Product of CVs 28 and 30. \\
\hline 32 & SUM & Letdown block valve factor to range from 0.0 to 1.0 . \\
\hline 33 & MULT & Product of CVs 27 and 32 (radiation block valve position). \\
\hline 34 & SUM & $\begin{array}{l}\text { LD control system error; system setpoint pressure less the current } \\
\text { pressure at volume } 79-01 \text {. }\end{array}$ \\
\hline 35 & PROP-INT & Proportional/integral LD control signal. \\
\hline 36 & DIFFREND & Derivative LD control signal. \\
\hline 37 & SUM & PID control signal; sum of variables 37 and 38 . \\
\hline 38 & SUM & Unrestricted letdown control valve adjustment. \\
\hline 39 & DIV & Letdown control valve stem speed. \\
\hline 40 & MULT & Restricted letdown control valve adjustment. \\
\hline 41 & SUM & New letdown control valve position. \\
\hline 42 & MULT & Product of adjusted stem position and radiation block valve position. \\
\hline 43 & MULT & Current problem time. \\
\hline 45 & SUM & Gage pressure (psi) in volume 79-01. \\
\hline 46 & POWERR & Exponential term of leakage correlation. \\
\hline 47 & MULT & Product of CV 46 and density in 79-01 (mass flow leakage from system). \\
\hline 52 & SUM & $\begin{array}{l}\text { Secondary flow control system error; current 18-01 temperature less the } \\
\text { setpoint temperature. }\end{array}$ \\
\hline 53 & PROP-INT & Proportional/integral secondary control signal. \\
\hline 54 & DIFFREND & Derivative secondary control signal. \\
\hline 55 & SUM & PID control signal; sum of variables 53 and 54 . \\
\hline 56 & LAG & Time lag to actuate secondary flow control valve based on PID signal. \\
\hline 57 & SUM & Adjusted secondary flow control valve position. \\
\hline 58 & TRIPDLAY & Time that signal was received to start auxiliary secondary coolant pump. \\
\hline 59 & SUM & $\begin{array}{l}\text { Time elapsed since start signal for auxiliary secondary coolant pump was } \\
\text { received. }\end{array}$ \\
\hline 60 & FUNCTION & Factor used for accelerating the auxiliary secondary coolant pump. \\
\hline 61 & TRIPUNIT & On/off switch for starting the auxiliary secondary coolant pump. \\
\hline 62 & TRIPUNIT & $\begin{array}{l}\text { On/off switch for using secondary motor winding on auxiliary secondary } \\
\text { pump. }\end{array}$ \\
\hline
\end{tabular}


Table 55 (continued)

\begin{tabular}{|c|c|c|}
\hline No. & Type & Description \\
\hline 63 & SUM & Adjustment for speed of auxiliary secondary pump. \\
\hline 64 & MULT & Auxiliary secondary coolant pump speed in rpm. \\
\hline 65 & SUM & $\begin{array}{l}\text { Requested valve position for heat exchanger bypass valve less flag for } \\
\text { sudden valve closure. }\end{array}$ \\
\hline 66 & LAG & Five-millisecond lag for closing heat exchanger bypass valve. \\
\hline 67 & TRIPUNIT & Switch for sudden closure of FCV377. \\
\hline 68 & TRIPDLAY & Last time trip 569 (closure of FCV377) turned true. \\
\hline 69 & SUM & Time since trip 569 last turned true. \\
\hline 70 & DIV & Factor for ramping FCV377 closed. \\
\hline 71 & MULT & Adjustment for FCV377 valve position. \\
\hline 72 & TRIPUNIT & Flag to indicate loss of instrument air. \\
\hline 73 & SUM & Valve position for FCV377. \\
\hline 74 & MULT & Velocity head (psi) at PU-1D suction volume. \\
\hline 75 & MULT & Velocity head (psi) at PU-1C suction volume. \\
\hline 76 & MULT & Velocity head (psi) at PU-1A suction volume. \\
\hline 77 & TRIPUNIT & Flag-indicating MCPs have been tripped. \\
\hline 78 & TRIPUNIT & Flag-indicating MCPs have not been tripped. \\
\hline 79 & FUNCTION & Torque on PU-1D due to friction. \\
\hline 80 & FUNCTION & Motor torque applied to PU-1D shaft. \\
\hline 81 & MULT & Hydraulic power developed by PU-1D. \\
\hline 82 & DIV & Hydraulic torque applied to PU-1D shaft. \\
\hline 83 & SUM & Sum of PU-1D torques divided by the pump inertia. \\
\hline 84 & MULT & Adjustment for rate of change of PU-1D pump speed. \\
\hline 85 & INTEGRAL & Adjustment for PU-1D pump speed (rpm). \\
\hline 86 & SUM & Actual speed of PU-1D. \\
\hline $87-94$ & & Same as $79-86$ except applied to PU-1C. \\
\hline 95-102 & & Same as $79-86$ except applied to PU-1A. \\
\hline 103 & SUM & Temperature in ${ }^{\circ} \mathrm{C}$ of volume $60-03$. \\
\hline 104 & SUM & Temperature in ${ }^{\circ} \mathrm{F}$ of volume $60-03$. \\
\hline 105 & FUNCTION & $\begin{array}{l}\text { Saturation pressure at volume } 60-03 \text { based on properties in general } \\
\text { Table } 35 \text {. }\end{array}$ \\
\hline
\end{tabular}


Table 55 (continued)

\begin{tabular}{|c|c|c|}
\hline No. & Type & Description \\
\hline 106 & DIV & Flow rate in $\mathrm{gal} / \mathrm{min}$ through pump PU-1D. \\
\hline 107 & DIV & Nondimensional pump flow coefficient $C_{Q}$ for PU-1D. \\
\hline 108 & FUNCTION & Critical value of nondimensional pump NPSH coefficient $C_{H S}$ for PU-1D. \\
\hline 109 & MULT & Critical value of NPSH (ft) for PU-1D. \\
\hline 110 & MULT & Critical value of NPSH (psi) for PU-1D. \\
\hline 111 & MULT & Suction pressure (psia) to PU-1D. \\
\hline 112 & SUM & Available NPSH to PU-1D (CV $111+$ CV $74-$ CV 105). \\
\hline 113 & DIV & Ratio of available NPSH to critical NPSH. \\
\hline 114 & FUNCTION & Head degradation factor $(<1,>0)$ for PU-1D. \\
\hline 115 & MULT & Flow ratio for PU-1D $(v)$ \\
\hline 116 & MULT & Speed ratio for PU-1D $(\alpha)$ \\
\hline 117 & DIV & Quantity $v / \alpha$ (see Sect. 3.3.3) for PU-1D. \\
\hline 118 & DIV & Quantity $\alpha / \nu$ (see Sect. 3.3.3) for PU-1D. \\
\hline 119 & FUNCTION & Quantity HVN (see Sect. 3.3.3) for PU-1D. \\
\hline 120 & TRIPUNIT & $\begin{array}{l}\text { Flag to indicate if PU-1D is operating in the second portion (HVN) of } \\
\text { the homologous data. }\end{array}$ \\
\hline 121 & TRIPUNIT & $\begin{array}{l}\text { Flag to indicate if PU-1D is operating in the first portion (HAN) of the } \\
\text { homologous data. }\end{array}$ \\
\hline 122 & MULT & $\begin{array}{l}\text { Quantity HVN (see Sect. 3.3.3) for PU-1D after head degradation factor } \\
\text { has been applied (if } v / \alpha<1 \text { ). }\end{array}$ \\
\hline 123 & MULT & Square of degraded pump speed (if $v / \alpha>1$ ) \\
\hline 124 & POWERR & Degraded pump speed (if $v / \alpha>1$ ). \\
\hline 125 & FUNCTION & $\begin{array}{l}\text { Quantity } \alpha / v \text { (see Sect. 3.3.3) for PU-1D based on degraded pump head } \\
\text { (CV 122). }\end{array}$ \\
\hline 126 & MULT & Degraded pump speed (if $v / \alpha<1$ ) \\
\hline 127 & SUM & $\begin{array}{l}\text { Degraded pump speed (less than actual pump speed only if pump is } \\
\text { cavitating) for PU-1D. }\end{array}$ \\
\hline \multicolumn{2}{|c|}{ 128-152 } & Same as $103-127$ except applied to PU-1C. \\
\hline \multicolumn{2}{|c|}{$153-177$} & Same as $103-127$ except applied to PU-1A. \\
\hline 178 & LAG & Degraded pump speed for PU-1D after time lag has been applied. \\
\hline 179 & LAG & Degraded pump speed for PU-1C after time lag has been applied. \\
\hline 180 & LAG & Degraded pump speed for PU-1A after time lag has been applied. \\
\hline
\end{tabular}


Table 55 (continued)

\begin{tabular}{|c|c|c|}
\hline No. & Type & Description \\
\hline 181 & TRIPUNIT & Trip flag if the transient has not begun (establishing steady state). \\
\hline 182 & SUM & Error in primary coolant flow. \\
\hline 183 & MULT & $\begin{array}{l}\text { Error used in adjusting MCP speed (nonzero only if establishing steady } \\
\text { state). }\end{array}$ \\
\hline 184 & PROPINT & Proportional/integral control of MCP speed (for steady state only). \\
\hline 185 & DIFFREND & Differential control of MCP speed (for steady state only). \\
\hline 186 & SUM & $\begin{array}{l}\text { PID control signal for regulating MCP speed to reach a new steady-state } \\
\text { value of primary flow. }\end{array}$ \\
\hline 187 & MULT & Product of CVs 186 and 78 (nonzero only for steady state). \\
\hline 188 & MULT & Product of CVs 178 and 77 (nonzero only for transient). \\
\hline 189 & SUM & Sum of CVs 187 and 188 (speed used in table for PU-1D). \\
\hline 190 & MULT & Product of CVs 179 and 77 (nonzero only for transient). \\
\hline 191 & SUM & Sum of CVs 187 and 190 (speed used in table for PU-1C). \\
\hline 192 & MULT & Product of CVs 180 and 77 (nonzero only for transient). \\
\hline 193 & SUM & Sum of CVs 187 and 192 (speed used in table for PU-1A). \\
\hline 200 & TRIPDLAY & Time since reactor trip was initiated. \\
\hline 201 & FUNCTION & Flux ratio at current time. \\
\hline 202 & DIV & $\begin{array}{l}\text { Total flow in gallons per minute through reactor vessel measured at } \\
\text { Venturi flowmeter. }\end{array}$ \\
\hline 203 & MULT & Flow ratio at current time. \\
\hline 204 & DIV & Flux-to-flow ratio. \\
\hline 205 & TRIPUNIT & Flag for exceeding maximum primary coolant temperature. \\
\hline 206 & DELAY & Time delay of $2 \mathrm{~s}$ for primary coolant temperature sensor to respond. \\
\hline 207 & TRIPUNIT & Scram signal initiated if trip 647 is true. \\
\hline 208 & DELAY & Delay scram by $0.05 \mathrm{~s}$. \\
\hline 252 & TRIPUNIT & $\begin{array}{l}\text { Flag to indicate that the primary coolant temperature has fallen below } \\
\text { the allowable limit. }\end{array}$ \\
\hline 253 & TRIPUNIT & Flag to indicate loss of instrument air (EDS valves fail closed). \\
\hline 254 & MULT & Flag to indicate signaled position of EDS valves. \\
\hline 255 & DELAY & $\begin{array}{l}\text { Time delay of } 2 \mathrm{~s} \text { for primary coolant temperature sensor to respond; } \\
\text { trip indicator for emergency depressurization valves to open. }\end{array}$ \\
\hline 290 & TRIPUNIT & Flag indicating that reactor has tripped. \\
\hline
\end{tabular}


Table 55 (continued)

\begin{tabular}{|c|c|c|}
\hline No. & Type & Description \\
\hline 291 & TRIPDLAY & Time that reactor trip occurred. \\
\hline 292 & SUM & Time since reactor trip occurred. \\
\hline 293 & MULT & $\begin{array}{l}\text { Argument for function indicating cooling tower bypass valve stem } \\
\text { position. }\end{array}$ \\
\hline 294 & FUNCTION & Cooling tower bypass valve stem position. \\
\hline 295 & SUM & One minus CV 294 used for control of cooling tower valve stem position. \\
\hline 300 & SUM & Error in cooling tower outlet temperature. \\
\hline 301 & MULT & Product of CV 181 and CV 300 (nonzero only for steady state). \\
\hline 302 & PROP-INT & $\begin{array}{l}\text { Proportional/integral control signal for maintaining cooling tower outlet } \\
\text { temperature. }\end{array}$ \\
\hline 303 & DIFFREND & $\begin{array}{l}\text { Derivative control signal for maintaining cooling tower outlet } \\
\text { temperature. }\end{array}$ \\
\hline 304 & MULT & Product of CV 181 and CV 303 (nonzero only for steady state). \\
\hline 305 & SUM & $\begin{array}{l}\text { PID control signal for maintaining feedwater (cooling tower outlet) } \\
\text { temperature. }\end{array}$ \\
\hline 319 & SUM & Pressure drop across reactor check valve. \\
\hline 320 & FUNCTION & $\begin{array}{l}\text { Flow through reactor check valve based on pressure/flow characteristic } \\
\text { of the valve. }\end{array}$ \\
\hline 321 & LAG & Flow through reactor check valve after time lag has been applied. \\
\hline 372 & DIFFREND & Time rate of change of pressure in volume $33-01$. \\
\hline 373 & MULT & $\begin{array}{l}\text { Necessary volumetric injection/ejection to accommodate structural } \\
\text { elasticity. }\end{array}$ \\
\hline 374 & LAG & Adjusted injection/ejection mass flow for stability. \\
\hline 375 & TRIPUNIT & $\begin{array}{l}\text { Switch for elasticity system based on whether the MCP suction pressure } \\
\text { (Volume } 60-03 \text { ) is }<20 \text { psia (trip } 525 \text { ). }\end{array}$ \\
\hline 376 & MULT & $\begin{array}{l}\text { Product of elasticity on/off switch (control variable } 375 \text { ) and calculated } \\
\text { elasticity injection/ejection (control variable 374). }\end{array}$ \\
\hline 900 & POWERR & Square root of the velocity through the outer fuel hot channel. \\
\hline 901 & SUM & Subcooled margin at the exit of the outer fuel hot channel. \\
\hline 902 & MULT & Costa flow excursion prediction (heat flux limit for hot channel). \\
\hline 903 & DIV & Ratio of hot-spot heat flux to heat flux limit. \\
\hline 904 & POWERR & Square root of velocity through the outer permanent beryllium reflector. \\
\hline 905 & SUM & Subcooled margin at the exit of the outer permanent beryllium reflector. \\
\hline
\end{tabular}


Table 55 (continued)

\begin{tabular}{|c|c|c|}
\hline No. & Type & Description \\
\hline 906 & MUI.T & Costa flow excursion prediction for beryllium reflector. \\
\hline 907 & DIV & Ratio of beryllium heat flux to heat flux limit. \\
\hline 909 & DIV & Cooling tower flow rate (gal/min). \\
\hline 910 & DIV & Cooling tower bypass flow rate (gal/min). \\
\hline 911 & SUM & Total secondary flow (gal/min). \\
\hline 912 & DIV & Secondary heat exchanger flow (gal/min). \\
\hline 913 & DIV & Cooling tower heat removal flow rate (gal/min). \\
\hline 915 & DIV & Total pressurizing flow (gal/min). \\
\hline 916 & DIV & Reactor check valve flow (gal/min). \\
\hline 917 & DIV & Flow out break number 1 (gal/min). \\
\hline 918 & DIV & Flow out break number 2 (gal/min). \\
\hline 919 & DIV & Flow out break number 3 (gal/min). \\
\hline 920 & DIV & Flow out break number 4 (gal/min). \\
\hline 921 & DIV & Flow out break number 5 (gal/min). \\
\hline 922 & DIV & Flow out break number 6 (gal/min). \\
\hline 923 & DIV & Structural elasticity model flow (gal/min). \\
\hline 924 & DIV & Leakage model flow (gal/min). \\
\hline 925 & SUM & Total letdown mass flow $(\mathrm{kg} / \mathrm{s})$. \\
\hline 926 & DIV & Total letdown volumetric flow (gal/min). \\
\hline 930 & SUM & $T_{\text {sat }}-T_{\text {fuel }}$ at outer fuel hot spot. \\
\hline 931 & SUM & $T_{\text {sat }}-T_{\text {fuel }}$ at inner fuel hot spot. \\
\hline 994 & SUM & PdT103 in psi. \\
\hline 995 & SUM & PdT106 in psi. \\
\hline 996 & SUM & Total heat transferred through heat exchanger in cell 110. \\
\hline 997 & SUM & Total heat transferred through heat exchanger in cell 111. \\
\hline 998 & SUM & Total heat transferred through heat exchanger in cell 113. \\
\hline 999 & SUM & Total heat transferred through the three heat exchangers. \\
\hline
\end{tabular}




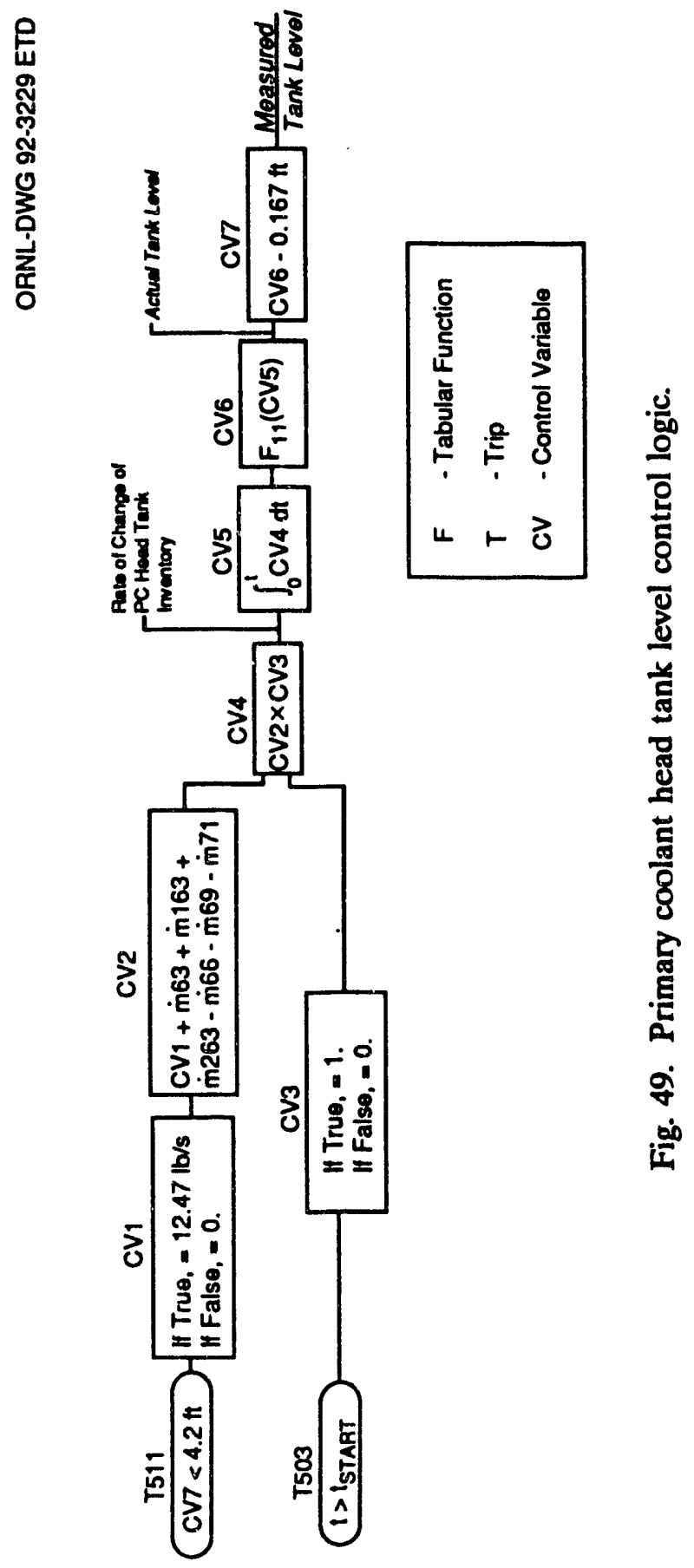




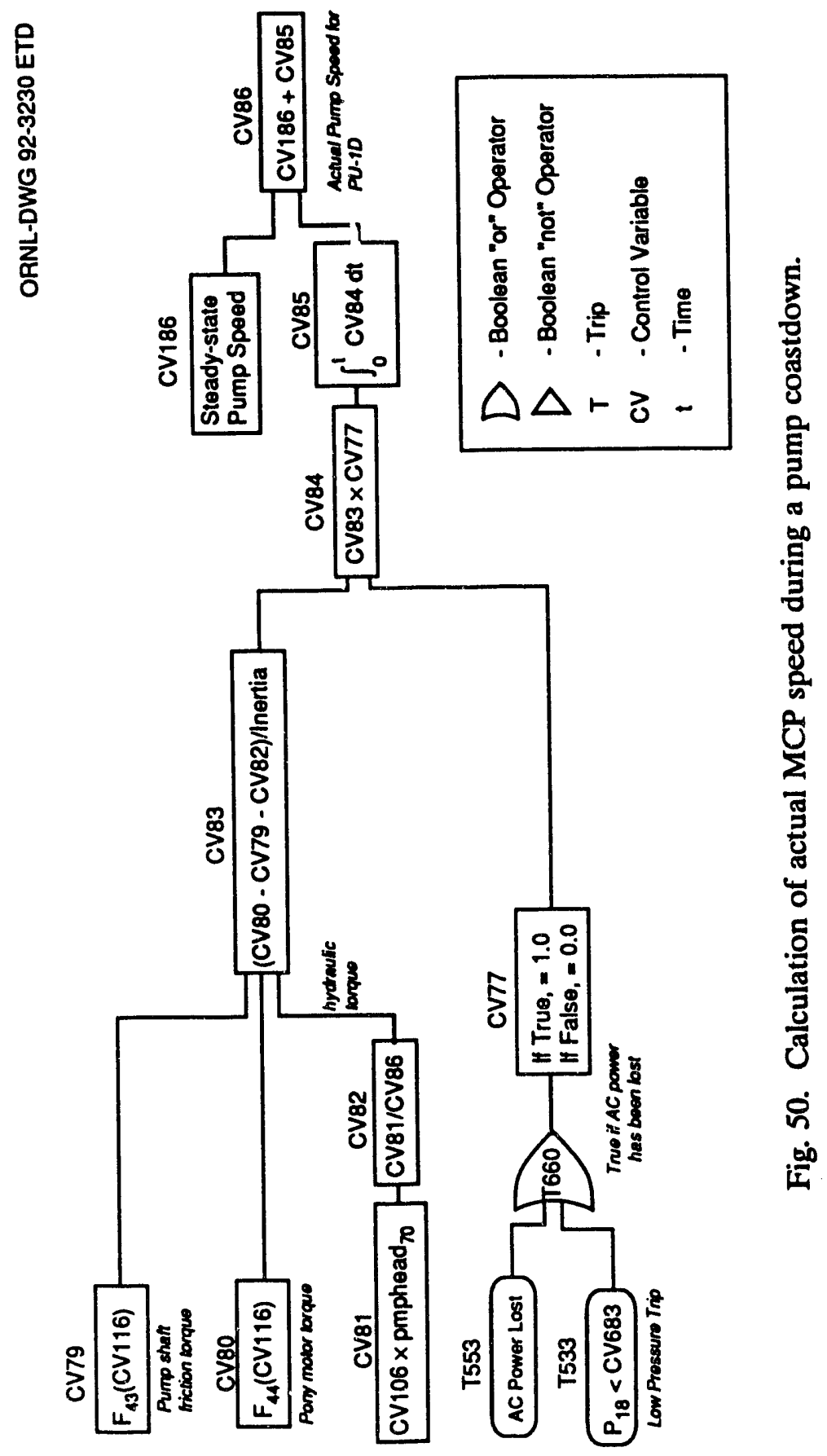



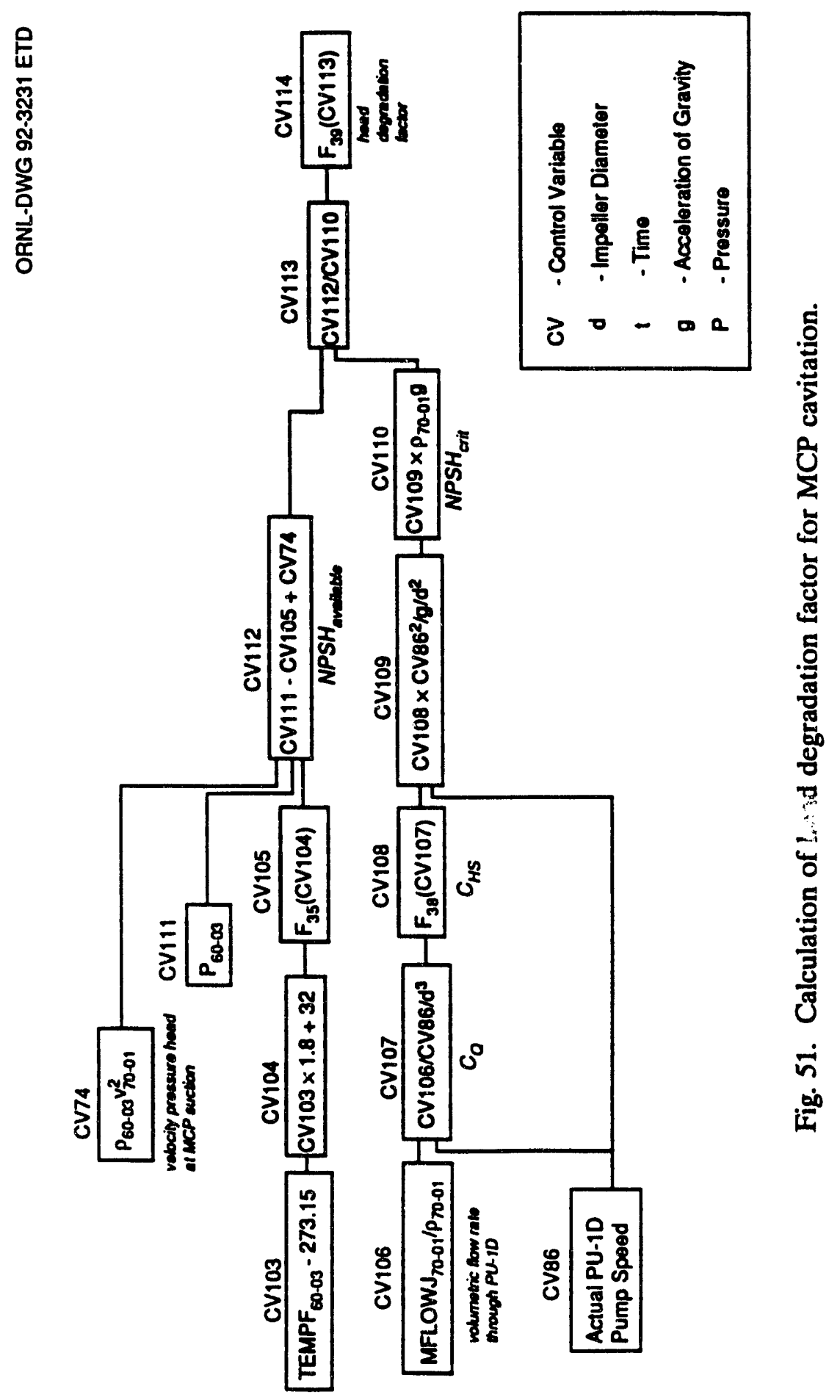


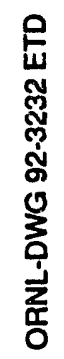
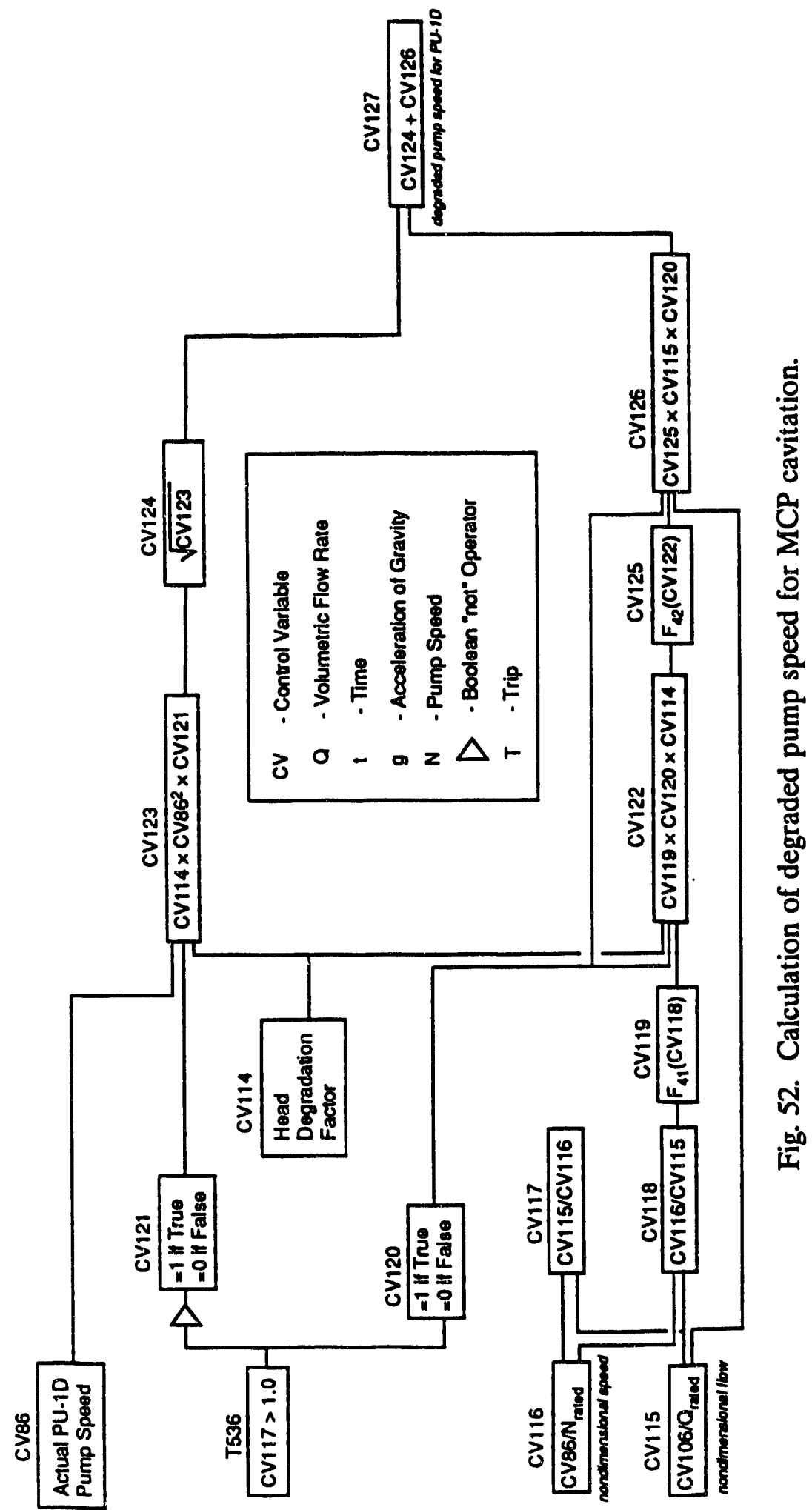
as calculated by CVs $77-102$, or (3) a modulated speed if pump cavitation is occurring (Fig. 53).

\subsection{Main and Standby Pressurizer Pumps}

CVs 8-12 are used to ramp up the standby pressurizer pump speed once the start-up signal has hren received. CVs 15-18 are used to trip both the main and standby pressurizer pumps based on low suction pressure. This occurs if the flow rate gets so high that the static suction pressure falls below 15.2 psia (see Sect. 3.5.7) and remains below 16.7 psia for at least 5 s (Ref. 181). Pressurizer pumps also trip if the head tank level drops below 25\%. A logic diagram for this control system is shown in Fig. 54.

\subsubsection{Auxiliary Pressurizer Pump}

CVs 19-25 are used to specify the auxiliary pressurizer pump flow rate based on its head/flow curve (see Sect. 3.3.5). Five seconds are assumed for the pump reaching full speed. The logic diagram is shown in Fig. 55.

\subsubsection{Letdown Control and Radiation Block Valves}

CVs 26-43 are used to control the operating pressure in the system. The stem position of the letdown valves is adjusted using PID control action to maintain pressure in volume 79-01 to the setpoint pressure (CV 670). The stem position is not allowed to change faster than the measured opening and closing valve speeds (Sect. 3.3.6). Also the valve is closed if the condition for radiation block valve closure is met. The logic diagram is shown in Fig. 56.

\subsubsection{Secondary Coolant Flow}

CVs 52-57 are used to control the secondary coolant flow rate. A PID controller is modeled for control of the normalized flow area of the secondary coolant 10-in. bypass valve (FCV 377A). The control logic diagram is shown in Fig. 57. Manual control of the FCV 377 flow area is accomplished using CVs 67-73.

\subsubsection{Secondary Coolant Pumps}

The main and auxiliary secondary coolant pump control logic is diagrammed in Fig. 58. The main pumps, which use trips and no CVs, are tripped whenever a reactor scram occurs or if the coupling between the motor and pump fails. Control variables 58-64 are used to linearly ramp the auxiliary pump speed starting at zero speed just after the reactor trip and ending at $1200 \mathrm{rpm}$ (or $600 \mathrm{rpm}$ if ac power is lost) $5 \mathrm{~s}$ after the reactor trip.

\subsubsection{Reactor Trip}

An automatic reactor trip will occur when the temperature of water entering the vessel exceeds a setpoint (nominally $130^{\circ} \mathrm{F}$ ), when the primary pressure falls below a setpoint (nominally $370.7 \mathrm{psia}$ ), or when the flux-to-flow ratio exceeds a setpoint (nominally 1.25 ). Control variables 200-208 are used to monitor whether these setpoints have been exceeded 


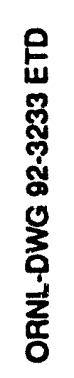

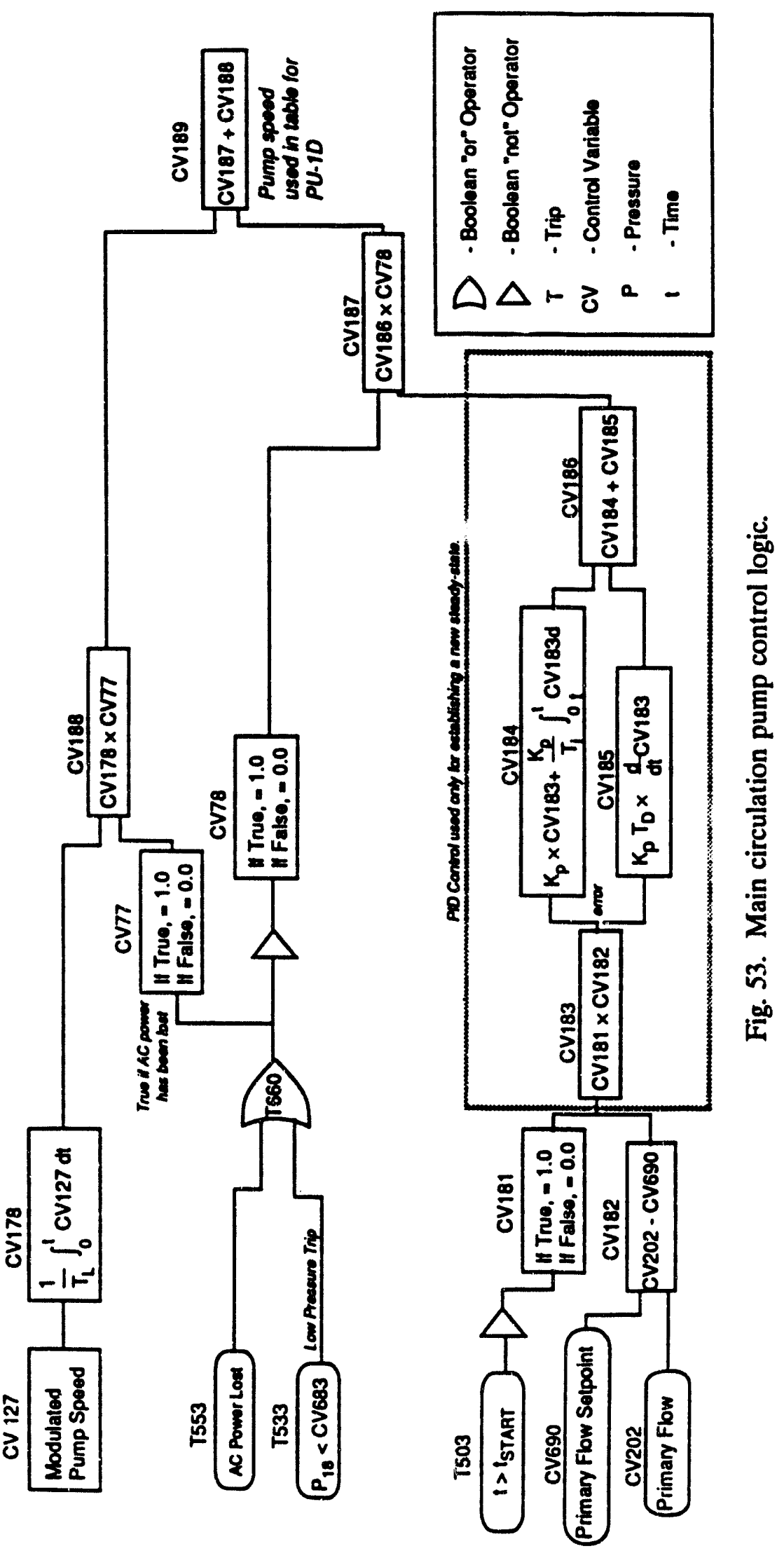




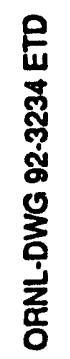

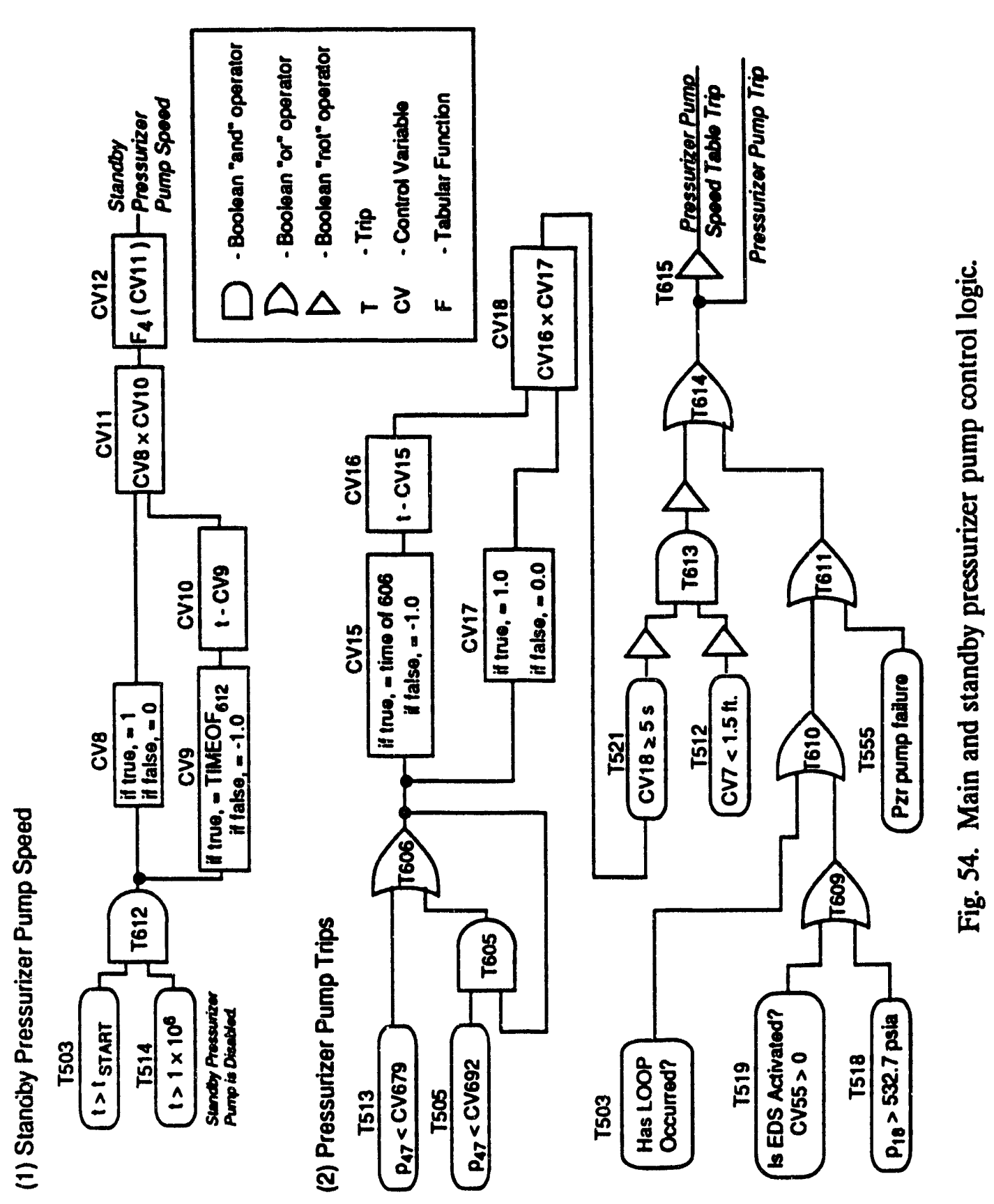




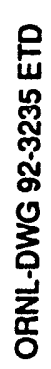

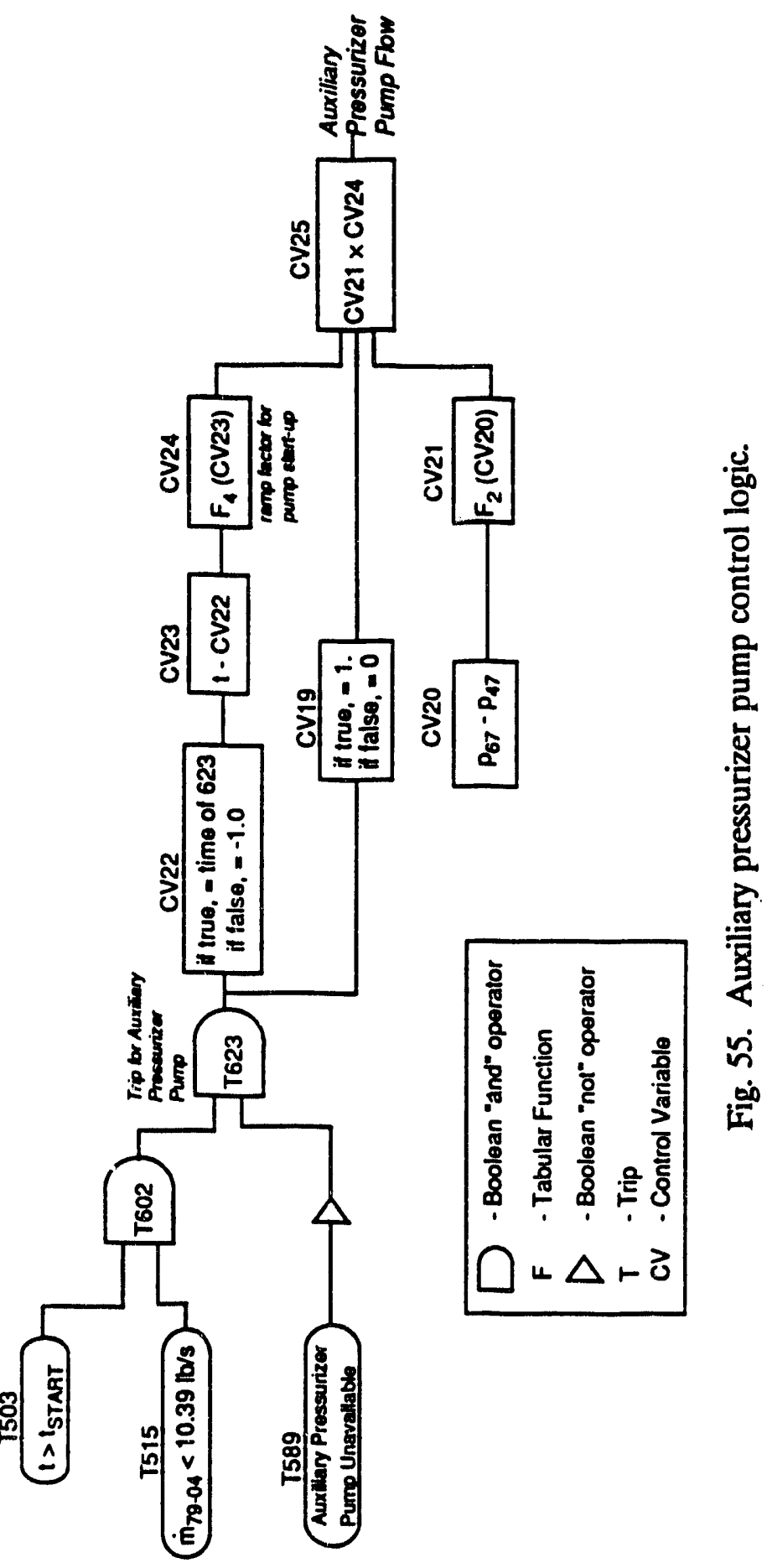




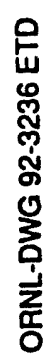

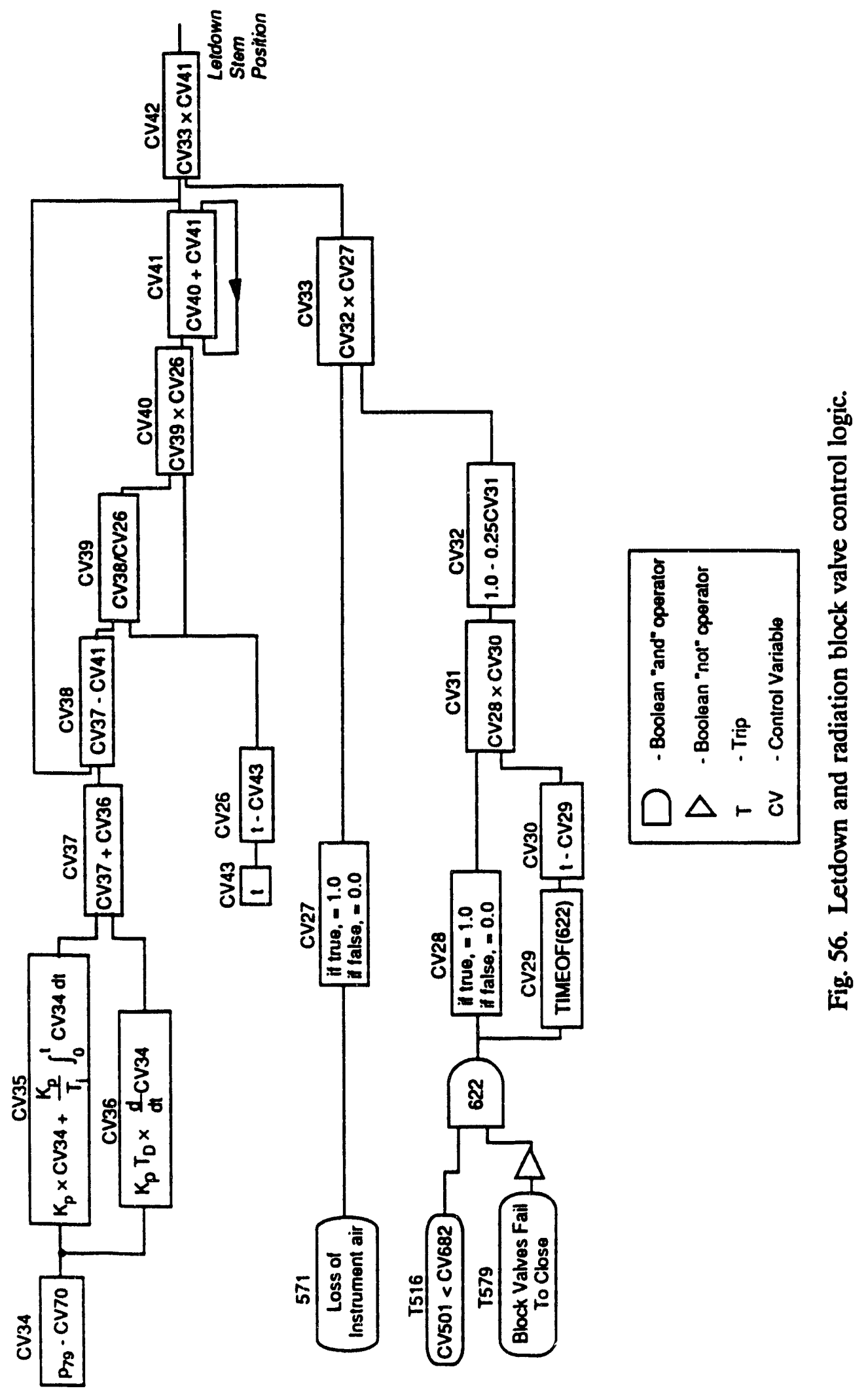




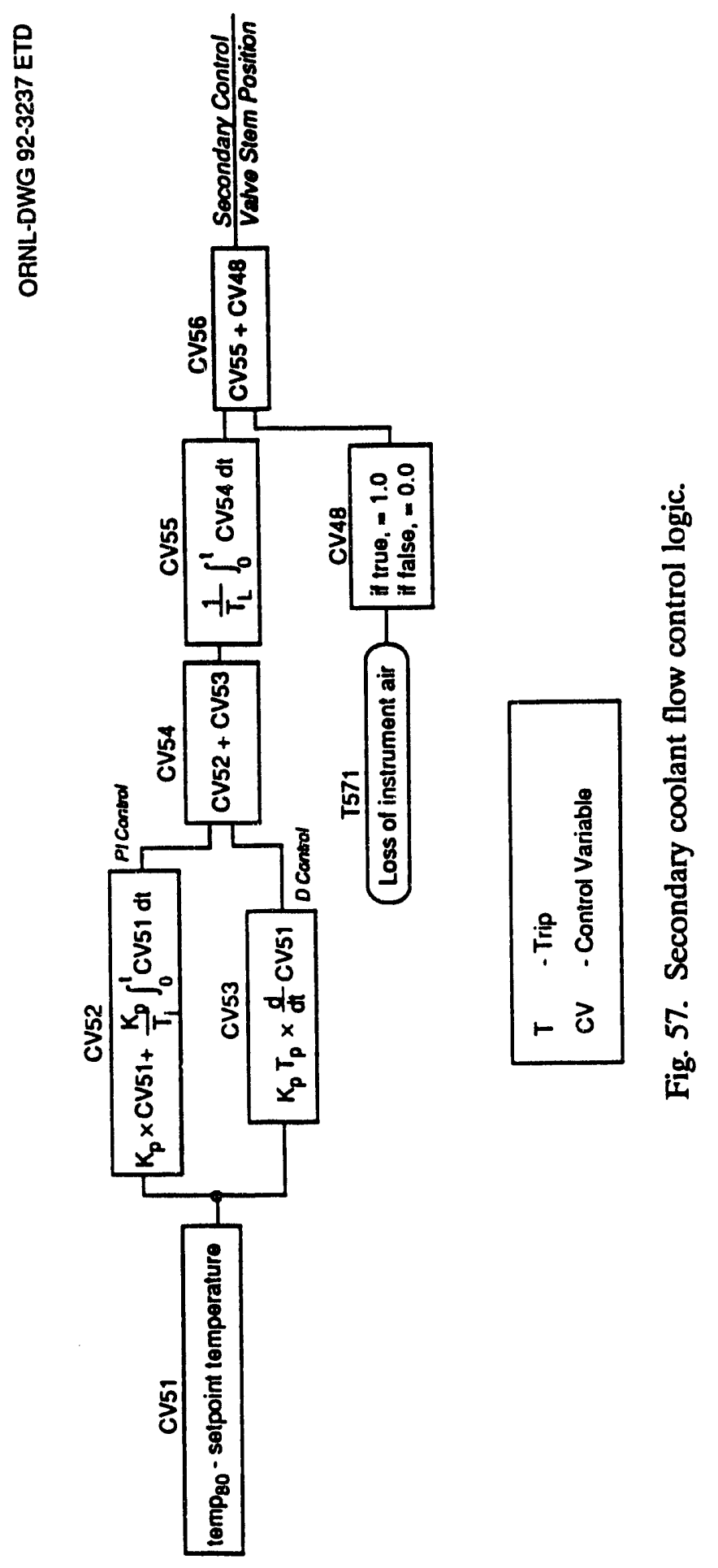




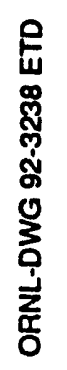

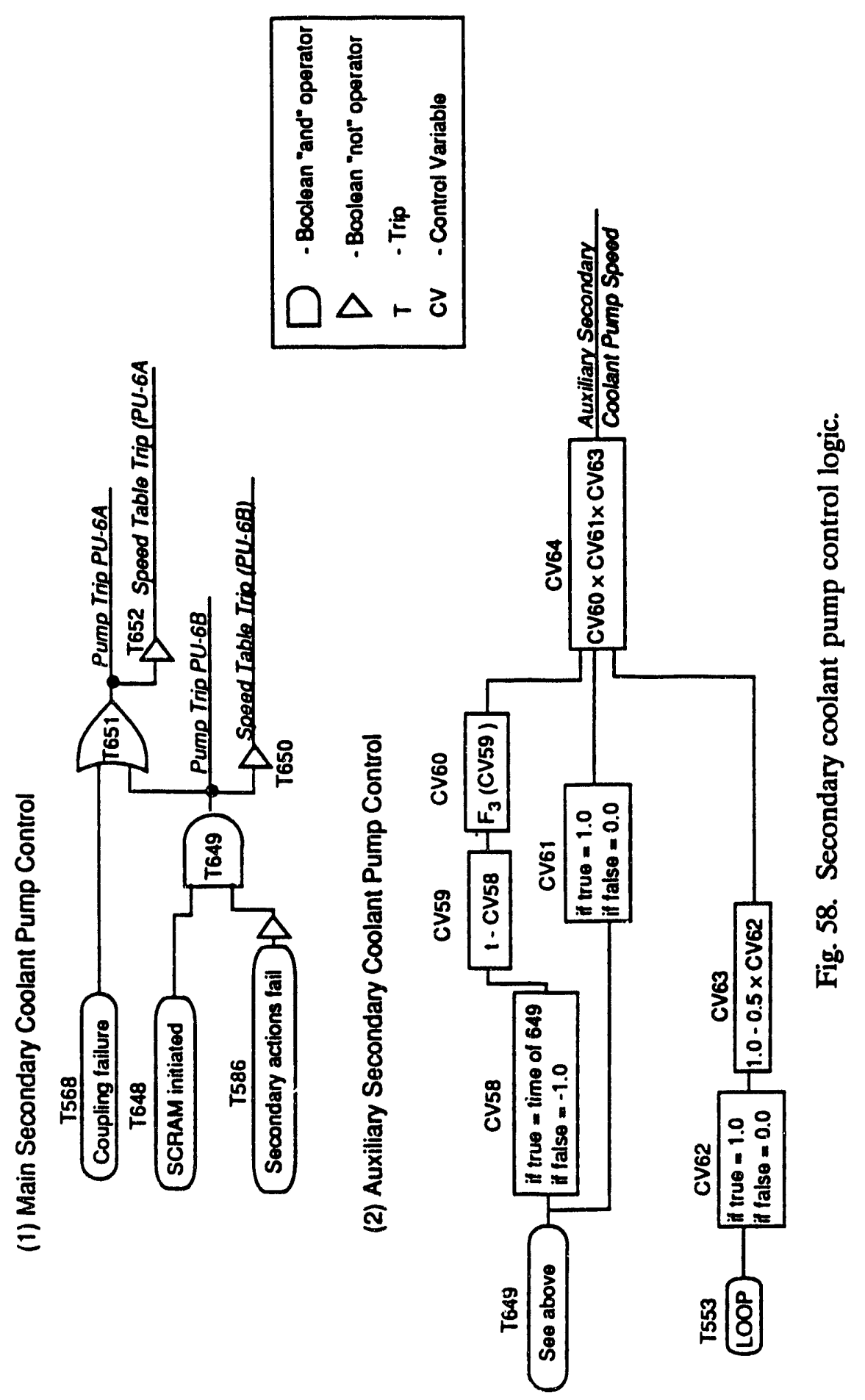


and, if so, to initiate a reactor trip. To account for instrument uncertainties, the pressure trip value was set at 370.7 psia (382.7-12 psia), and the flux-flow ratio trip was set at 1.2875 $(1.25 \times 1.03)$. A 2 -s time delay is applied to the initiation of a reactor trip based on high primary temperature to include the time for the temperature sensor to respond to actual conditions. The pressure sensors are assumed to respond immediately. The control logic diagram is shown in Fig. 59.

\subsubsection{Structural Elasticity}

To represent the structural elasticity, CVs 372-376 are used to either inject or eject mass from the system based on whether the system pressure is decreasing or increasing. No adjustment is made if the elasticity control is disabled (trip 525). Also a time lag is introduced to keep the system stable. The logic diagram is shown in Fig. 60 .

\subsubsection{Emergency Depressurization}

If the primary coolant temperature drops below $90^{\circ} \mathrm{F}$, then the emergency depressurization system (EDS) is activated (trip 526). The EDS valves, which open when the system is activated, reclose if the primary pressure falls below $314.7 \mathrm{psia}$ (2.17 $\mathrm{MPa}$ ). The CVs 252-255 are used to control the EDS valves. The temperature sensor is assumed to lag the primary coolant temperature by $2 \mathrm{~s}$. This is represented with a 2-s delay (CV 255) in the EDS control system. The value of CV 255 indicates the stem position of the EDS control valves (component 141), which are modeled as either fully open or fully closed. As presently installed in the model, the EDS system is based on preliminary design information. For transients where its performance is important, the analyst will have to enhance the model.

\subsubsection{Cooling Tower Bypass}

After the main secondary coolant pumps are tripped, the cooling tower bypass valve is opened to prevent overcooling the primary system. CVs 290-295 are used to represent this action. General Table 38 is used to determine the stem position of the cooling tower bypass valve.

\subsubsection{Leakage from the Primary Coolant System}

Control variables $43-45$ are used to calculate the appropriate leakage rate from the primary coolant system. CV 45 is used by time-dependent junction 84 to drain flow from volume 79. Volume 79 was selected because it is a convenient location on the discharge side of all three pumps (where the actual leakage occurs). This is conservative for all transients except overpressurization transients, where the leakage should either be disabled or attached to the hot leg (pump suction side). W. E. Thomas assembled the following correlation (unpublished) based on some data taken by M. B. Farrar on September 9, 1986, for the leakage rate from the primary system:

$$
G=0.0784 P^{0.4416},
$$

where $G$ is the flow rate in $\mathrm{gal} / \mathrm{min}$ and $P$ is the system gage pressure (psig). Using the system stiffness of $22 \mathrm{psi} / \mathrm{gal}$, this correlation gives a depressurization rate of $26 \mathrm{psi} / \mathrm{min}$ at 
是
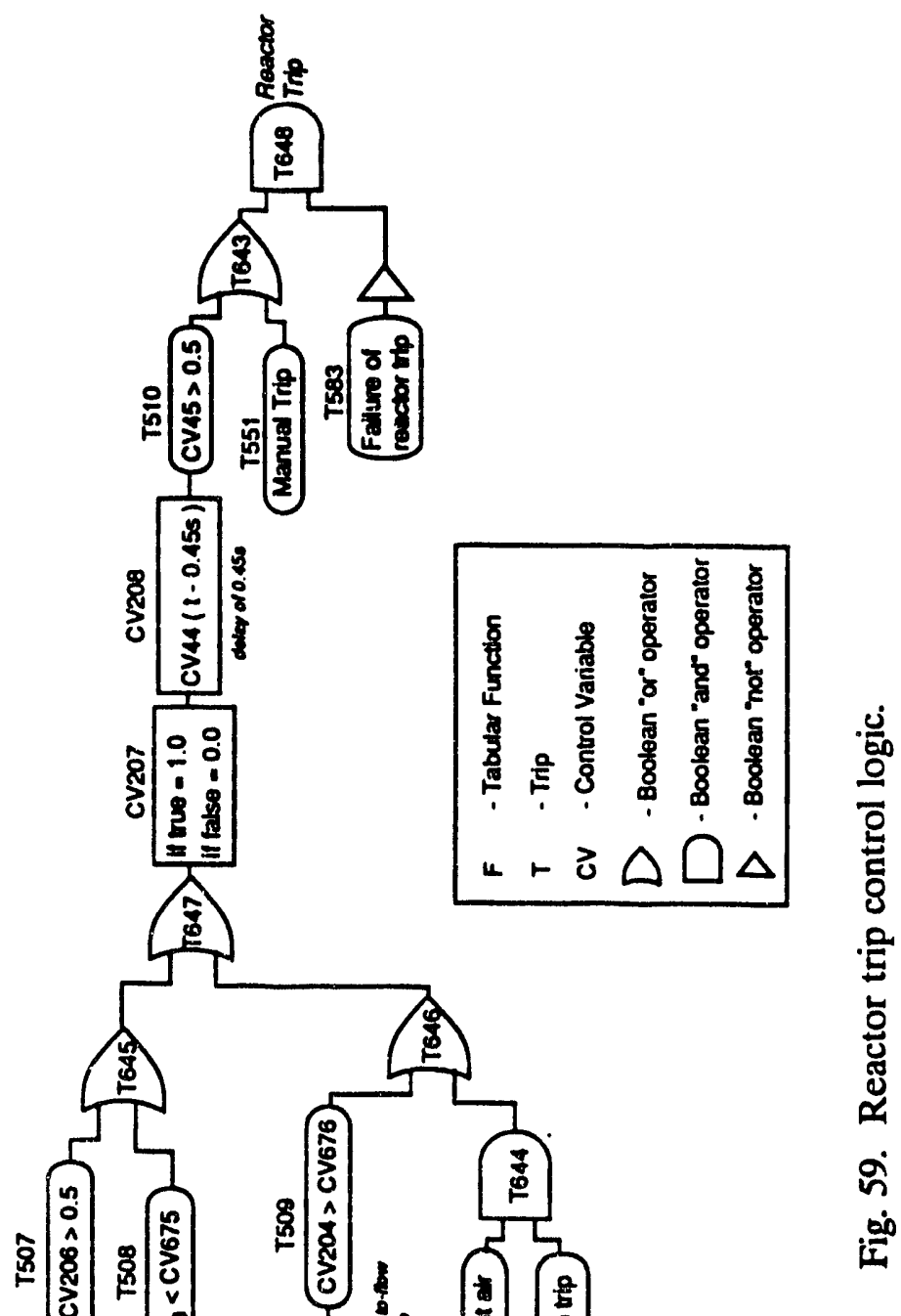


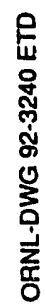

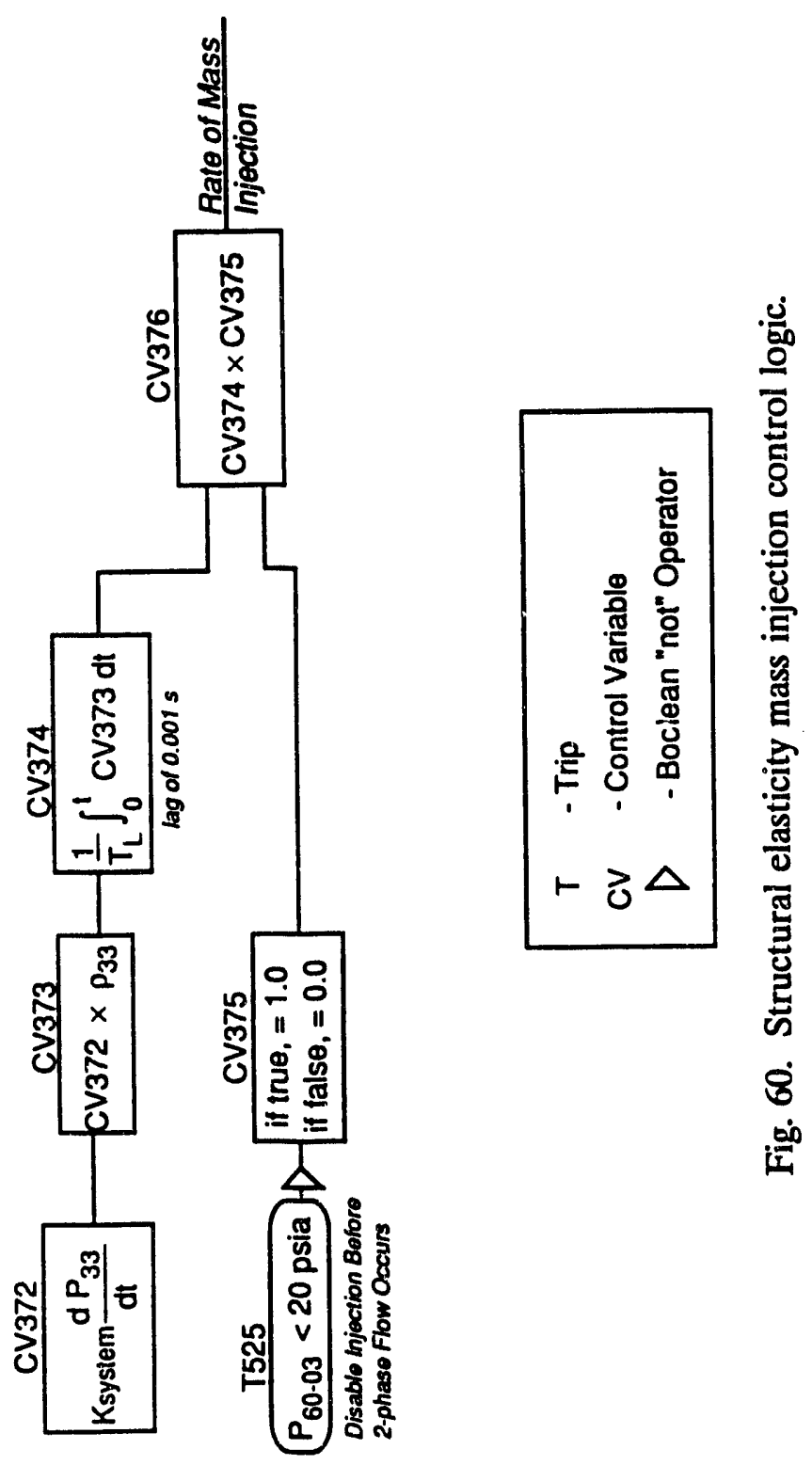




\subsubsection{Cooling Tower Heat Removal}

Although in actuality the secondary heat is lost to the outside environment through a fan-controlled cooling tower, in the model, the secondary heat loss occurs through a heat structure to a cold stream of water by forced convection. The flow rate of this stream is controlled using CVs $300-305$ so that the temperature of the secondary coolant is $85^{\circ} \mathrm{F}$ leaving the cooling tower. This control is accomplished using PID control action as discussed in Sect. 3.3.6.

\subsubsection{Reactor Vessel Check Valve Flow}

CVs 319-321 are used to specify the flow through the reactor check valve, which is a function of the pressure difference between volume 21-05 and the vessel pool. A tabular function is input as a general table that gives the pressure-drop/flow relationship for the valve. Instead of forcing the flow through the valve to instantaneously adjust to the value from the tabular function, a time lag is introduced to avoid "fluttering." Fluttering occurs when the valve opens and closes alternately on each successive time step.

\subsubsection{Additional Output}

CVs 900-904 are used to predict flow excursion (using a correlation developed by Costa) ${ }^{182}$ in the inner fuel hot channel. Secondary flow rates are monitored in units of gallons per minute with CVs 909-913. Primary inventory gains and losses are monitored in units of gallons per minute with CVs 915-926. Margins to boiling $\left({ }^{\circ} \mathrm{F}\right)$ are monitored at the two hot spots (one for each of the fuel elements) with CVs 930-931. The pressure drop across the strainer is calculated with CV 994. The pressure drop in the primary coolant across the reactor vessel, including the strainer pressure drop, is calculated with CV 995 . The primary coolant heat losses in the heat exchangers are calculated with CVs 996-999. 


\section{PREPROCESSING AND POSTPROCESSING}

Two FORTRAN programs were written to aid setting up RELA.P5 input and postprocessing RELAP5 results. The first program, a preprocessor, initializes the input with temperatures, pressures, and mass flows at the initial time. The user may opt to initialize the input at uniform temperature and pressure and zero mass flows; or the temperatures, pressures, and flows from a previous major edit in a normal RELAP5 output file may be read and automatically loaded into the input. The second option allows the user to initialize input at steady state, with the pumps at full speed and reactor at full power. The program does not initialize time-dependent volumes, time-dependent junctions, time-dependent tables, or trips; so it may be necessary for the user to initialize some of these components manually. This program is also useful for converting between MOD2 and MOD3 versions of the input. A listing of this preprocessor and user instructions are given in Appendix C.

The second program, a postprocessor, was written to translate information from a strip file into TECPLOT ${ }^{183}$ readable format. A strip file is the formatted output of selected dependent variables, as a function of time, throughout the entire simulation. RELAP5 always writes this information in the SI units system to the restart/plot file. A strip data file is created on a subsequent RELAP5 run using the "strip" option on card 100. 


\section{MODEL APPLICATION}

The intended use for the detailed model described in this report (input listing shown in Appendix A) is for analysis of SBLOCA transients in the HFIR primary coolant system. ${ }^{184}$ By definition, a small break is one that does not result in fuel damage. Additional modeling capability has been included beyond the bare minimum necessary to simulate SBLOCA transients, and other applications of the model, especially the abbreviated version described in Appendix $\mathrm{E}$ (and listed in Appendix F), are expected. Already, the model has been used to perform unheated LBLOCA analysis for the purpose of benchmarking the MELCOR severe accident model of the HFIR. ${ }^{185}$

When applying this model, either in the detailed or abbreviated form, to any transient other than a SBLOCA, it is very important to consider the adequacy of its capabilities regarding that application. It is likely that additional modeling capability will be necessary to produce meaningful simulations of these transients. For example, very simple representations for the EDS system, secondary coolant system, and low-pressure clean-up system are included in the model. In all probability, simulation of transients during which the performance of one of these systems is critical to the results will require modification of the baseline model.

In this section, the steady-state performance of the model at nominal conditions is described and compared with available plant data. In addition, computational performance statistics are supplied. The input listing in Appendix $\mathrm{A}$ has been initialized at pre-LOCA conditions, that is, those conditions that are considered conservative (e.g., low pressure and high temperature) for a LOCA transient.

\subsection{STEADY STATE}

The steady-state pressures as calculated by RELAP5/MOD2.5 (RELAP5/MOD3 yields almost identical results) for $85-\mathrm{MW}$ operation are shown in Fig. 61 at the nominal primary flow rate of $16,500 \mathrm{gal} / \mathrm{min}$. The calculated primary coolant flow rate using the actual pump speed is $15,850 \mathrm{gal} / \mathrm{min}$. The calculated value for PdT106 (difference in pressure between volumes $80-03$ and 51 ) at $15,850 \mathrm{gal} / \mathrm{min}$ is $142 \mathrm{psi}$. Some checksheet data ${ }^{26}$ are listed in Table 56 and plotted in Fig. 62.

Some uncertainty in the flow rate data may exist because of the placement of the pressure tap in the cold leg. The tap is located in the diffusing portion of the Venturi flowmeter, where a complex flow pattern is likely.

As the resistance to flow through the vessel increases (due to a particular fuel element having slightly smaller flow area or corrosion), it is expected that the pressure drop across the core would increase and the flow through the vessel would decrease, assuming the pump performance and hot and cold leg piping remains unchanged. The calculated steady state does not lie within the spread of the data; however, it is only $4 \%$ less than the nominal flow of $16,500 \mathrm{gal} / \mathrm{min}$. Table 56 shows some data taken from HFIR checksheets.

Some experimentation with the model was done to determine possible reasons for the discrepancy between the calculation and the data. At the time this testing was done, the predicted primary coolant flow rate was $16,124 \mathrm{gal} / \mathrm{min}$, which is lower than the current estimate of $16,171 \mathrm{gal} / \mathrm{min}$. The following reasons were suggested for the discrepancy between the calculated values for total flow rate and vessel pressure drop (PdT106) and those values recorded in the hourly checksheets: 


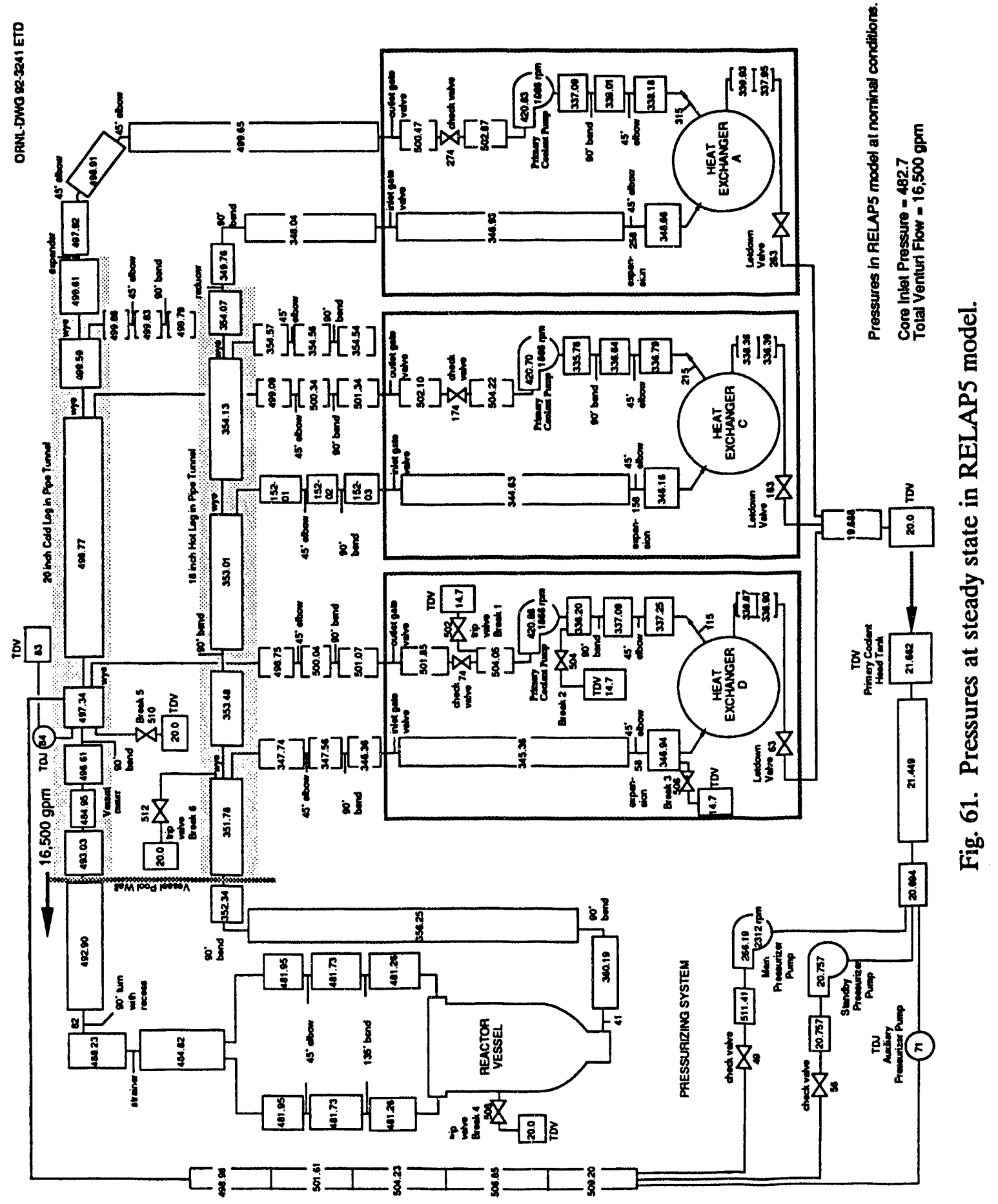


Table 56. HFIR hourly checksheet

data for vessel pressure drop (PdT106)

\begin{tabular}{lll}
\hline Date & $\begin{array}{l}\text { Flow } \\
\text { rate } \\
\text { (gal/min) }\end{array}$ & $\begin{array}{c}\text { Pressure } \\
\text { drop } \\
\text { (psi) }\end{array}$ \\
\hline $09-01-69$ & 16,490 & 138 \\
$09-01-69$ & 16,605 & 138 \\
$12-03-73$ & 17,238 & 136 \\
$04-15-75$ & 17,195 & 136 \\
$04-01-78$ & 17,205 & 141 \\
$09-15-79$ & 17,064 & 140 \\
$09-24-79$ & 17,030 & 140 \\
$07-03-81$ & 16,900 & 135 \\
$07-26-81$ & 16,950 & 135 \\
$11-11-82$ & 17,074 & 134 \\
$11-24-82$ & 17,010 & 135 \\
$11-29-82$ & 17,100 & 134 \\
$05-08-83$ & 17,292 & 135 \\
$05-20-83$ & 17,240 & 134 \\
$07-01-83$ & 17,305 & 132 \\
$09-12-84$ & 17,000 & 133 \\
$09-23-84$ & 16,767 & 133 \\
$03-01-85$ & 16,999 & 135 \\
$03-18-85$ & 17,011 & 135 \\
$09-06-85$ & 17,037 & 132 \\
$09-18-85$ & 16,989 & 131 \\
$11-01-86$ & 17,003 & 126 \\
$11-03-86$ & 17,015 & 126 \\
\hline & &
\end{tabular}

1. The primary coolant pumps actually run at a speed higher than $1800 \mathrm{rpm}$ (used in the model).

2. The pump performance curves, which were based on data taken for only one of the pumps, are not representative for all of the pumps.

3. The friction pressure drop on the pump side of PdT106 is being overestimated because either the surface roughness of $1.5 \times 10^{-4} \mathrm{ft}$ or the form loss coefficients at the junctions are too great.

No data were found for any of the main circulating pumps except the pump with factory No. 37172, impeller R-3341. However, it was found that increasing the pump speed by $50 \mathrm{rpm}$ (to $1850 \mathrm{rpm}$ ), the vessel flow increased from 16,124 to $16,600 \mathrm{gal} / \mathrm{min}$ and the vessel pressure drop increased from 128.4 to 136.1 psi. When all of the form loss coefficients on the pump side of PdT106 were set to zero, the values changed to $16,810 \mathrm{gal} / \mathrm{min}$ and 
ORNL-DWG 92-3242 ETD

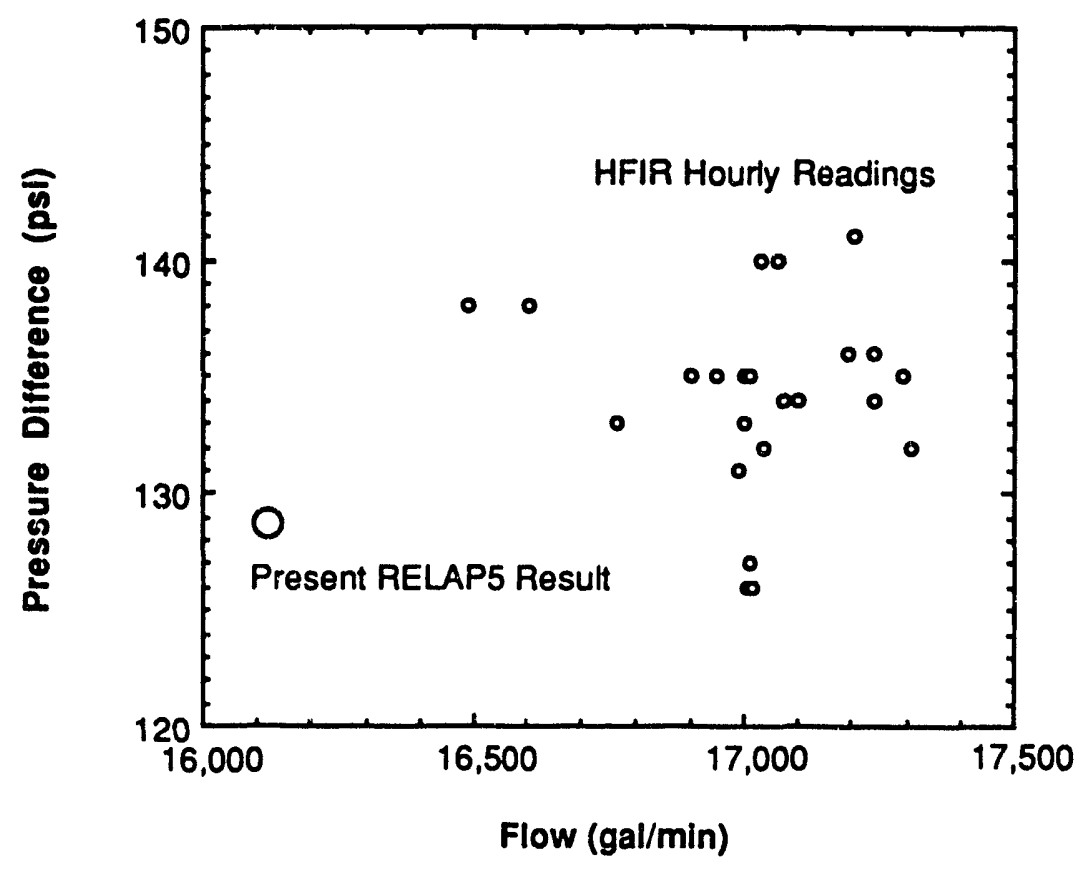

Fig. 62. Measurements recorded for PdT106 from HFIR hourly readings.

139.6 psi. When a smooth pipe assumption was made (roughness of $10^{-6} \mathrm{ft}$ ), the vessel flow increased only slightly, to $16,200 \mathrm{gal} / \mathrm{min}$.

Because changing the form loss coefficients enough to make tne calculated results consistent with the data cannot be justified, and smoothing the pipes did not significantly improve the match, it was assumed that inaccuracy in the pump model was the primary cause of the discrepancy. It is not likely that the pump motors have consistently been running at $1850 \mathrm{rpm}$ rather than $1800 \mathrm{rpm}$ for 20 years, so the discrepancy is probably due to the inappropriateness of the characteristic pump curve to describe all four primary coolant pumps. If the Venturi is consistently indicating a flow rate higher than the true value, this could also explain the discrepancy.

Before the model is used for a specific transient, it is necessary to establish the appropriate steady-state operating condition. This is accomplished by controlling the pump speed until the setpoint for primary coolant flow is reached (see Sect. 3.7.2).

\subsection{COSTS AND RUN TIMES}

A material Courant limit is applied to each hydrodynamic volume in the system to keep the solution stable. This limit is 0.00323 to $0.00328 \mathrm{~s}$ (depending on the selected flow rate) for the detailed RELAP5 model during normal steady-st :e operation. The limiting volume in the system is $1-07$, which is the most downstream volume in one of the average channels of the inner fuel. The limit outside of the vessel is a factor of 5 higher. The model currently runs at a time step of $0.003125 \mathrm{~s}$ at $85-\mathrm{MW}$ steady conditions. Although the input shows a requested time step of $0.1 \mathrm{~s}$, RELAP5 halves this value until a satisfactory time step has been 
reached. To run one simulated second of real time during which the HFIR is running steadily at $85 \mathrm{MW}$, the model requires $175 \mathrm{~s}$ of cpu time on the IBM RS6000/Model 320 (AIX version 3.2, XLF version 2.1) using RELAP5/MOD2.5 version 3T.

During LOCAs for which the system depressurizes and the main circulating pumps are tripped, the Courant limit is relaxed because the coolant velocity decreases significantly. Unless voiding occurs in the coolant, or noncondensible air enters the system, these simulations run much more quickly because of the larger stability limit. 


\section{REFERENCES}

1. V. H. Ransom et al., RELAP5/MOD2 Code Manual, Volume 1: Code Structure, Systems, Models, and Solution Methods, August 1985, and Volume 2: Users Guide and Input Requirements, NUREG/CR-4312 (EGG-2396), EG\&G Idaho, Inc., December 1985.

2. TRAC PF1/MODI: An Advanced Best-Estimate Computer Program for Pressurized Water Reactor Thermal-Hydraulic Analysis, NUREG/CR-3858, Safety Code Development Group, Los Alamos Natl. Lab., July 1986.

3. M. J. Thurgood et al., COBRA/TRAC $\rightarrow A$ Thermal-Hydraulics Code for Transient Analysis of Nuclear Reactor Vessels and Primary Coolant Systems, Equations and Constitutive Models, Vol. 1, NUREG/CR-3046 (PNL-4395), Pacific Northwest Laboratories, March 1983.

4. J. H. McFadden, R. E. Narum, and C. E. Peterson, RETRAN-02-A Program for Transient Thermal-Hydraulic Analysis of Complex Fluid Flow Systems, Volume 1: Theory and Numerics (Rev. 2), EPRI-NP-1850, Electric Power Research Institute, November 1984.

5. A. E. Ruggles, Oak Ridge National Laboratory, letters to C. D. Fletcher, Idaho National Engineering Laboratory, "Review of RELAP5/MOD2 Two-Phase ThermaiHydraulic Models and Identification of Changes Needed for Applicability to Plate Fueled Reactor Cores," January 27, 1989, and March 3, 1989.

6. A. E. Ruggles and D. G. Morris, "Thermal-Hydraulic Simulation of Natural Convection Decay Heat Removal in the High Flux Isotope Reactor Using RELAP5 and TEMPEST, Part 2: Interpretation and Validation of Results, " pp. 3-39-3-45 in Proceedings of the First International RELAP5 User Seminar, College Station, Texas, January 31-February 2, 1989, CONF-890173.

7. A. E. Ruggles and P. T. Williams, "RELAP5/MOD2 Benchmarking Study: Critical Heat Flux Under Low Flow Conditions," p. 204 in Trans. of ANS 1990 Annual Meeting, June 10-14, 1990.

8. H. A. Glovier, Oak Ridge National Laboratory, letter to H. Randall Fair, Department of Energy, "High Flux Isotope Reactor (HFIR) Key Milestone, Complete Thermal Hydraulic Analysis (HFIRMS-010), Action Step 11, Final Verification and Validation (V\&V) Report," February 3, 1992.

9. J. D. Freels, Oak Ridge National Laboratory, letter to D. H. Cook et al., Oak Ridge National Laboratory, "Review Comments and Changes for the HFIR RELAP5 Point Kinetics Input Deck," January 20, 1992.

10. D. G. Morris et al., "Thermal-Hydraulic Simulation of Natural Convection Decay Heat Removal in the High Flux Isotope Reactor Using RELAP5 and TEMPEST, Part 1: Models and Simulation Results, "pp. 3-32-3-38 in Proceedings of the First International 
RELAP5 User Seminar, College Station, Texas, January 31-February 2, 1989, CONF890173.

11. D. S. Trent, L. L. Eyler, and M. J. Budden, A Computer Program for ThreeDimensional Time-Dependent Hydrothermal Analysis, PNL-4348, Vol. 1, Rev. 3, Pacific Northwest Laboratories, April 1991.

12. H. A. McLain, HFIR Fuel Element Steady State Heat Transfer Analysis, ORNL/TM1904, revised version, Union Carbide Corp. Nuclear Div., Oak Ridge Natl. Lab., December 1967.

13. R. P. Taleyarkhan, Oak Ridge National Laboratory, letter to D. G. Morris, Oak Ridge National Laboratory, "Transmittal of Core Boundary Conditions for RELAP5 Evaluations," January 9, 1989.

14. P. T. Williams and D. G. Morris, Martin Marietta Energy Systems, Inc., letter to R. P. Taleyarkhan, Oak Ridge National Laboratory," MELCOR/RELAP5 HFIR Core LBLOCA Study," July 12, 1989.

15. R. M. Summers et. al., MELCOR 1.8.0: A Computer Code for Nuclear Reactor Severe Accident Source Term and Risk Assessment Analyses, NUREG/CR-5531 (SAND9O0364, R3), Sandia Natl. Lab., January 1991.

16. R. H. Morris, "HFIR MELCOR Simulation for a Large Break LOCA in the Pipe Tunnel," HFIR Calculation C-HFIR-91-029, Martin Marietta Energy Systems, Inc., Oak Ridge Natl. Lab., December 1991.

17. T. L. Wilson, HFIR Systems Transient Model, ORNL/RRD/INT-25, Martin Marietta Energy Systems, Inc., Oak Ridge Natl. Lab., October 30, 1987.

18. Modular Modeling System (MMS): A Code for the Dynamic Simulation of Fossil and Nuclear Power Plants, Volumes 1-4, CS/NP-3016-CCM, Electric Power Research Institute, March 1983.

19. The High Flux Isotope Reactor-A Functional Description, Vol. 1A, Text, F. T. Binford, T. E. Cole, and E. N. Cramer, ed., May 1968, and Vol. 1B, Illustrations, F. T. Binford and E. N. Cramer, ed., ORNL-3572 (Rev. 2), Union Carbide Corp. Nuclear Div., Oak Ridge Natl. Lab., June 1968.

20. HFIR Staff, Operating Manual for the High Flux Isotope Reactor, ORNL/TM-1138/R1, Union Carbide Corp. Nuclear Div., Oak Ridge Natl. Lab., September 1982.

21. Ref. 19, Vol. 1A, p. 6-14.

22. W. E. Sallee, Oak Ridge National Laboratory, letter to S. E. Burnette, Oak Ridge National Laboratory, "Engineering Report: Acceptance Test Results for Pony Motor Battery Systems PU-1E, PU-1F, PU-1G, and PU-1H, and Test Evaluations and Comments," February 7, 1990. 
23. C. A. Sweet, HFIR Design Data-No. 1, Oak Ridge Natl. Lab. internal report, August 7, 1970.

24. B. H. Montgomery, K. R. Thoms, and C. D. West, "Appendix A: HFIR Model-E Removable Reflector Hydraulics," Final Report of the HFIR Irradiation Facilities Improvement Project, ORNL/TM-10505, pp. 149-167, Martin Marietta Energy Systems, Inc., Oak Ridge Natl. Lab., September 1987.

25. Summary of HFIR Design Parameters for 85 MW Operation, ORNL/RRD/INT-55, Martin Marietta Energy Systems, Inc., Oak Ridge Natl. Lab., March 1989.

26. HFIR Hourly Readings, Nov. 2, 1986, April 1, 1978, and Sept. 1, 1969.

27. D. G. Morris, Oak Ridge National Laboratory, letter to B. L. Lepard, Oak Ridge National Laboratory, "HFIR Vessel/Core RELAP5 Model Input Calculation Notes," February 28, 1992.

28. T. Sofu, University of Tenessee, letter to B. L. Lepard, Oak Ridge National Laboratory, "HFIR Safety System Response Time as Calculated in REACC," February 19, 1992.

29. Research Reactors Division Staff, High Flux Isotope Reactor Technical Specifications, ORNL/TM-5711/R2, pp. 3-5, Martin Marietta Energy Systems, Inc., Oak Ridge Natl. Lab., rev. September 1990.

30. R. E. Hale, "Validation and Verification Report HFIR Time-of-Flight Measurement System," Research Reactors Division, Martin Marietta Energy Systems, Inc., Oak Ridge Natl. Lab., to be published.

31. Ref. 12 , pp. 77 and 81 .

32. Eng. Dwg. D-42113, Rev. E, ORNL HFIR.

33. Eng. Dwg. D-42121, Rev. F, ORNL HFIR.

34. Ref. 23, pp. 94-121.

35. Ref. 12 , pp. 21-23.

36. G. A. Bowden and R. W. Knight, Specifications for High Flux Isotope Reactor Fuel Elements HFIR-FE-3, ORNL/TM-9220, p. 10, Martin Marietta Energy Systems, Inc., Oak Ridge Natl. Lab., August 1984.

37. Metals Handbook, Vol. 1, Properties and Selection of Metals, 8th ed., American Society for Metals, 1961, p. 936.

38. Thermophysical Properties of High Temperature Solid Materials, Y. S. Touloukian, ed., Purdue University, West Lafayette, Ind., 1967, Vol. 1, pp. 11-12. 
39. Ref. 38, Vol. 4, pp. 499-500.

40. D. L. McElroy, Oak Ridge National Laboratory, letter to R. W. Knight, Oak Ridge National Laboratory, "Physical Properties of Al Cermets," January 5, 1970.

41. R. W. Knight, J. Binns, and G. M. Adamson, Jr., Fabrication Procedures for Manufacturing High Flux Isotope Reactor Fuel Elements, ORNL-4242, pp. 9-13, Union Carbide Corp. Nuclear Div., Oak Ridge Natl. Lab., June 19, 1968.

42. N. Hilvety and T. G. Chapman, HFIR Fuel Element Steady State Heat Transfer Analysis, ORNL-TM-1903, p. 38, Union Carbide Corp. Nuclear Div., Oak Ridge Natl. Lab., December 1967.

43. Aerospace Structural Metals Handbook, Vol. 3, AFML-TR-68-115, Mechanical Properties Data Center, Belfour Stulen, Inc., 1975, code 3206, p. 1.

44. J. C. Griess et al., Effect of Heat Flux on the Corrosion of Aluminum by Water, Part III, Final Report on Tests Relative to the High Flux Isotope Reactor, ORNL-3230, Union Carbide Corp. Nuclear Div., Oak Ridge Natl. Lab., December 5, 1961.

45. Ref. 38, Vol. 4, pp. 8-10.

46. Recommended Values of the Thermophysical Properties of Eight Alloys, Major Constituents and Their Oxides, Y. S. Touloukian, ed., Purdue University, West Lafayette, Ind., February 1966, pp. 326-328.

47. Y. S. Touloukian et al., Thermophysical Properties of Matter, IFT/Plenum, Vol. 1, p. 9, 1970.

48. R. E. Pawel, Oak Ridge National Laboratory, personal communication to D. G. Morris, Oak Ridge National Laboratory, May 1989.

49. J. C. Griess et al., Effect of Heat Flux on the Corrosion of Aluminum by Water, Part 1: Experimental Equipment and Preliminary Test Results, ORNL-2939, p. 25, Union Carbide Corp. Nuclear Div., Oak Ridge Natl. Lab., April 29, 1960.

50. Ref. 12, p. 62.

51. Ref. 12, pp. 72-73.

52. Ref. 12, p. 57.

53. W. E. Thomas, Oak Ridge National Laboratory, letter to R. D. Cheverton, Oak Ridge National Laboratory, "Reevaluation of Uncertainty Factor $\mathrm{U}_{3}$ Based on Actual Scram Setpoint," June 7, 1989.

54. Ref. 12 , p. 16.

55. Eng. Dwgs. D-42114 and D42122, ORNL HFIR. 
56. Ref. 12, pp. 17-18.

57. Ref. 12, p. 64.

58. J. R. Kirkpatrick, Oak Ridge K-25 Site, letter to D. G. Morris, Oak Ridge National Laboratory, "HFIR Hot Side Peaking Factors as Functions of Meat Thickness and Film Coefficient," June 9, 1992.

59. Ref. 12 , p. 63.

60. W. E. Thomas, Oak Ridge National Laboratory, personal communication to D. G. Morris, Oak Ridge National Laboratory, April 1988.

61. J. D. Sease, The Fabrication of Target Elements for the High-Flux Isotope Reactor, ORNL/TM-1712, Appendix A, pp. 29-31, Union Carbide Corp. Nuclear Div., Oak Ridge Natl. Lab., March 1967.

62. Ref. 19, Vol. 1A, pp. 5-2-5-3.

63. T. G. Chapman, HFIR Target Design Study, ORNL/TM-1084, Union Carbide Corp. Nuclear Div., Oak Ridge Natl. Lab., Sept. 3, 1965.

64. J. E. Bigelow, Oak Ridge National Laboratory, personal communication to D. G. Morris, Oak Ridge National Laboratory, May 1989.

65. C. W. Alexander, Oak Ridge National Laboratory, personal communication to D. G. Morris, Oak Ridge National Laboratory, December 1987.

66. R. E. Hale, Oak Ridge National Laboratory, letter to B. L. Lepard, Oak Ridge National Laboratory, "Specific Heat of $\mathrm{CmO}_{1.73}$," April 7, 1991.

67. R. L. Gibby, C. E. McNeilly, and T. D. Chikalla, "The Thermal Diffusivity, Thermal Conductivity, and Transformation Temperatures of Curium Sesquioxide, "J. Nucl. Mat., 34, 299-306 (1970).

68. R. K. Williams and R. S. Graves, Oak Ridge National Laboratory, letter to G. L. Copeland, Oak Ridge National Laboratory, "Thermal Conductivity Measurements on 6061 Al Clad, $\mathrm{U}_{3} \mathrm{O}_{8}$-Al Fuel Plates," January 14, 1980.

69. Ref. 63, p. 10.

70. H. French and W. M. Rohsenow, "Prediction of Thermal Conductance of Metallic Surfaces in Contact," J. Heat Transfer, 15-24 (February 1963).

71. N. D. Weills and E. A Ryder, "Thermal Resistance Measurements of Joints Formed Between Stationary Metal Surfaces," Trans. ASME 71, 259-267 (1949). 
72. A. L. Lotts et al., Analysis of Failure of HFIR Target Elements Irradiated in SRL and in HFIR-An Interim Status Report, ORNL/TM-2236, p. 35, Union Carbide Corp. Nuclear Div., Oak Ridge Natl. Lab., February 1972.

73. M. W. Wendel, Oak Ridge K-25 Site, letter to D. G. Morris, Oak Ridge National Laboratory, "Calculation of Effective Gap Thermal Conductivity with RELAP5," June 5, 1991.

74. B. V. Karlekar and R. M. Desmond, Engineering Heat Transfer, West Publishing Company, 1977, pp. 547-576.

75. Ref. 63, p. 6.

76. A. Higdon et al., Mechanics of Materials, 3rd ed., John Wiley and Sons, New York, 1976, pp. 157-166.

77. Woldman's Engineering Alloys, 6th ed., R. C. Gibbons, ed., American Society for Metals, 1979, p. 1767.

78. Ref. 47, Vol. 1, curve 4, pp. 905-907.

79. Ref. 47, Vol. 4, curve 8, pp. 102-109.

80. Ref. 47, Vol. 4, curves 3 and 10, pp. 146-152.

81. R. D. Cheverton and T. M. Sims, HFIR Core Nuclear Design, ORNL-4621, pp. 22-28, Union Carbide Corp. Nuclear Div., Oak Ridge Natl. Lab., July 1971.

82. Ref. 23, pp. 76-93.

83. G. A. Bowden, G. R. Hicks, and R. W. Knight, Fabrication Procedures for HFIR Control Plates, ORNL/TM-9365, p. 11, Martin Marietta Energy Systems, Inc., Oak Ridge Natl. Lab., October 1984.

84. Ref. 38 , Vol. 4, pp. 170-171.

85. Ref. 23, Vol. 1, pp. 7-75.

86. Ref. 38, Vol. 1, pp. 48-49.

87. Ref. 47, Vol. 4, curve 9, pp. 16-20.

88. Ref. 47, Vol. 1, p. 24.

89. Ref. 74 , pp. $415-462$.

90. C. A. Meyer et al., ASME Steam Tables, 4th ed., American Society of Mechanical Engineers, 1979. 
91. Ref. 19, Vol. IB, p. 55.

92. Eng. Dwg. M-11506-OH-507, ORNL HFIR.

93. Eng. Dwg. E-42328, ORNL HFIR.

94. F. M. White, Fluid Mechanics, McGraw-Hill Book Company, New York, 1979, p. 332.

95. Ref. 23, p. 124.

96. Eng. Dwg. D-49852, ORNL HFIR.

97. Vendor Dwg., William Powell Co., C51089, ORNL HFIR.

98. Ref. 21, pp. 122-123.

99. Ref. 20, pp. 2-25.

100. Ref. 19, Vol. 1A, pp. B-1-B-2.

101. Ref. 19, Vol. 1B, p. 69.

102. Ref. 37, pp. 264 and 586.

103. Ref. 47, Vol. 4, curve 5, pp. 619-622.

104. Ref. 47, Vol. 1, curve 139, pp. 1113-1123.

105. Ref. 38, Vol. 3, pp. 145-146.

106. Ref. 38, Vol. 3, pp. 161-163.

107. Ref. 47, Vol. 1, curve A, pp. 1174-1175.

108. Ref. 47, Vol. 1, curve B, pp. 1174-1175.

109. Eng. Dwg. E-42350, Rev. 1, ORNL HFIR.

110. M. M. El-Wakil, Nuclear Heat Transport, Intext Educational Publishers, New York, 1971, pp. 347-351.

111. Ref. 19, Vol. 1A, p. 5-5.

112. Eng. Dwg. E-42359, Rev. C, ORNL HFIR.

113. M. W. Wendel, Research Reactors Division Calculation, C-HFIR-91-006 (HFIR RELAP5 extra-vessel input calculation papers), Martin Marietta Energy Systems, Inc., Oak Ridge K-25 Site, 1990. 
114. Eng. Dwg. 1546-01-M5506, ORNL HFIR.

115. Eng. Dwg. 1546-01-M5507, ORNL HFIR.

116. Eng. Dwg. 1546-01-M5515, ORNL HFIR.

117. Southwest Fabrication and Welding Co. Dwg. S.O. 9614, Isometric 1, ORNL HFIR.

118. Southwest Fabrication and Welding Co. Dwg. S.O. 9614, Isometric 2, ORNL HFIR.

119. T. Baumeister and L. S. Marks, Standard Handbook for Mechanical Engineers, McGraw-Hill Book Company, New York, 7th ed., 1958, pp. 8-202.

120. Eng. Dwg. 1546-01-5509, ORNL HFIR.

121. Eng. Dwg. E-49866, ORNL HFIR.

122. Eng. Dwg. 1546-01-5512, ORNL HFIR.

123. S. W. Churchill and H. H. S. Chu, "Correlating Equations for Laminar and Turbulent Free Convection from a Horizontal Cylinder," Int. J. Heat Mass Transfer 18, 1049-1053 (1975).

124. F. Kreith, Principles of Heat Transfer, Intext Educational Publishers, New York, 3rd ed., 1973, pp. 395-396.

125. Eng. Dwg. 1546-M-5508, ORNL HFIR.

126. ACME Copper Smithing and Machine Company, Dwg. 5942, ORNL HFIR.

127. Design Report on High Flux Isotope Reactor Primary Heat Exchangers, TM Report 743, Joseph Oat Corporation, June 1985.

128. F. W. Dittus and L. M. K. Boelter, "Heat Transfer in Automobile Radiators of the Tubular Type," University of California Publications, Vol. 2, 1930, pp. 443-461.

129. Ref. 124, p. 481.

130. D. M. McGinty, "Hydraulic Vibration Analysis and Thermal Performance Tests of New Primary Heat Exchanger," Oak Ridge National Laboratory Equipment Maintenance Standards, Reactor Operations Section, High Flux Isotope Reactor, Standard No. 3070, May 1985.

131. Internal correspondence to M. W. Wendel, Oak Ridge K-25 Site, from B. L. Lepard, Jr., Oak Ridge National Laboratory, "High Flux Isotope Reactor Secondary Heat Exchanger Flow Rate and Pressure Drop," May 30, 1991. 
132. Intra-Laboratory Correspondence to T. E. Cole, Oak Ridge National Laboratory, from H. A. McLain, Oak Ridge National Laboratory, Revised Flow Coast-down Times in the HFIR Primary Coolant System Following an Electrical Failure of All Three Pumps Neglecting the Effects of the Pony Motor, September 25, 1962.

133. Report of Test from the Byron Jackson Hydraulic Test Facilities, Byron Jackson Order No. 371720, January 1963.

134. Ideal Electric Co. test data supplied to HFIR with pony motors.

135. Eng. Dwg. SK-GJJ-880830-4, ORNL HFIR.

136. Allis-Chalmers Instruction Book, Allis Chalmers Order No. 1-0832-80435, March 14, 1963.

137. T. D. Radcliff and B. L. Lepard, Jr., Description of Reactor Transients to be Analyzed for the Completion of the Accident Analyses in Chapter 15 of the High Flux Isotope Reactor Safety Analysis Report (SAR), Martin Marietta Energy Systems, Inc., Oak Ridge Natl. Lab., 1991.

138. Ref. 20, pp. 3-112.

139. A. Sozer, Oak Ridge National Laboratory, "Main Pressurizer Pump Coastdown Prediction and Comparison to HFIR Test Data," internal correspondence, March 16, 1989.

140. Letter from A. Sozer, Oak Ridge National Laboratory, to D. H. Cook, Oak Ridge National Laboratory, "HFIR Pump Manufacturer and Coastdown Curves," June 21, 1989.

141. Y. Sunstrand Fluid Handling Certified Test Curve, HFIR files, Reactor Research Division, Martin Marietta Energy Systems, Inc., June 17, 1987.

142. K. Ogata, Modern Control Engineering, Prentice-Hall, Englewood Cliffs, N.J., 1970, p. 158.

143. D. S. Asquith, Oak Ridge National Laboratory, personal communication to M. W. Wendel, Oak Ridge Gaseous Diffusion Plant, August 1989.

144. S. J. Ball, Oak Ridge National Laboratory, Results of Loss of Pressure Accident Study for HFIR, internal memorandum to N. Hilvety, January 12, 1962.

145. J. W. Hutchinson, ed., ISM Handbook of Control Valves, 2nd ed., 1976, p. 9.

146. Ref. 19, Vol. 1A, p. 6-6.

147. Ref. 19, Vol. 1A, pp. 10-7-10-8. 
148. B. L. Lepard, Jr., Oak Ridge National Laboratory, "High Flux Isotope Reactor HotOff-Gas System Pressure," internal memorandum to M. W. Wendel, Oak Ridge K-25 Site, May 30, 1991.

149. Ref. 19, p. B-6.

150. Ref. 19 , p. 6-8.

151. HFIR hourly readings, Dec. $1-4,1990$.

152. Ref. 20 , p. 6-29.

153. G. J. Dixon, Preliminary HFIR Hydraulic Tests, ORNL 64-12-43, Oak Ridge Natl. Lab., 1963.

154. B. L. Corbett, Oak Ridge National Laboratory, personal communication to M. W. Wendel, Oak Ridge Gaseous Diffusion Plant, September 25, 1990.

155. Ref. 20, pp. 6-35.

156. CRC Handbook of Chemistry and Physics, R. C. Weast, ed., 55th ed., CRC Press, Cleveland, Ohio, 1974, p. D-150.

157. R. J. Roark and W. C. Young, Formulas for Stress and Strain, 5th ed., McGraw-Hill, New York, 1975, p. 448.

158. Ref. 156 , pp. 5-6.

159. ADINA." A Finite Element Program for Automatic Dynamic Incremental Noninear Analysis, Report AE-81-1, ADINA Engineering, September 1981.

160. A. Sozer, "Calculation of HFIR System Elasticity Constant and Structural Elasticity Coefficient from HFIR Hydraulic Test Data," Oak Ridge Natl. Lab., internal memorandum, April 11, 1989.

161. C. A. Meyer et al., Thermodynamic and Transport Properties of Steam, The American Society of Mechanical Engineers, New York, 1967.

162. J. A. Trapp and V. H. Ransom, RELAP5 Hydrodynamic Model Progress Summary-Abrupt Area Changes and Parallel Branching, PG-R-77-92, EG\&G Idaho, Inc., November 1977.

163. A. A. Abbatiello and A. P. Fraas, "The HFIR Water Strainer," ORNL TM-3460, Union Carbide Corp. Nuclear Div., Oak Ridge Natl. Lab., March 1972.

164. I. E. Idel'Chik, Handbook of Hydraulic Resistance Coefficients of Local Resistance and of Friction, AEC-TR-6630, published pursuant to an agreement with the U.S. Atomic Energy Commission and the National Science Foundation, Washington, D.C., 1960, 
pp. 326-327. (Distributed by NTIS, Springfield, Va., published by the Israel Program for Scientific Translations, Jerusalem, 1966.)

165. Eng. Dwg. 1546-01-I-4024, Rev. B, ORNL HFIR.

166. Ref. 164, p. 215.

167. D. S. Miller, Internal Flow Systems, BHRA Fluid Engineering, 1978, p. 237.

168. Ref. 164, pp. 144 and 417.

169. Flow of Fluids Through Valves, Fittings, and Pipe, Crane Co., Technical Paper No. 410, Eighteenth Printing, 1979, p. A-29.

170. Ref. 167, p. 141.

171. Ref. 164, pp. 263 and 280.

172. Ref. 167, p. 224.

173. Flow of Fluids Through Valves, Fittings, and Pipe, Crane Co., Technical Paper No. 410, Eighteenth Printing, 1979, p. A-27.

174. Ref. 167, pp. 270-275.

175. S. Levy, Fluid Flow Technology of Nuclear Reactor Safety, Vol. 2. Reactor Materials and Engineering, MIT Press, 1973, p. 283.

176. Eng. Dwg. 1546-M-5512, Rev. A, ORNL HFIR.

177. Eng. Dwg. 1546-M-5513, Rev. C, ORNL HFIR.

178. Eng. Dwg. 1546-M-5516, Rev. B, ORNL HFIR.

179. Eng. Dwg. 1546-M-5534, Rev. B, ORNL HFIR.

180. Ref. 1, Vol. 2, pp. 323-334.

181. Eng. Dwg. 1546-01-E-2119, ORNL HFIR.

182. A. E. Ruggles, Oak Ridge National Laboratory, letter to D. L. Selby, Oak Ridge National Laboratory, "Preferred Correlation for Flow Excursion in the ANSR," July 30, 1990.

183. TECPLOT User's Manual, Ver. 4.0, Amtec Engineering, Inc., Bellevue, Wash., June 1990. 
184. M. W. Wendel and P. T. Williams, Oak Ridge K-25 Site, RRD technical calculations (HFIR small break LOCA analysis), C-HFIR-91-014 thru C-HFIR-91-020, April 4, 1992.

185. M. W. Wendel, Oak Ridge K-25 Site, "RELAP5 Simulation of an Unheated 10-in. Double-Ended Pipe Break at the Discharge of a Main Circulating Pump," C-HFIR91-005, June 6, 1991. 
Appendix A

INPUT LISTING 


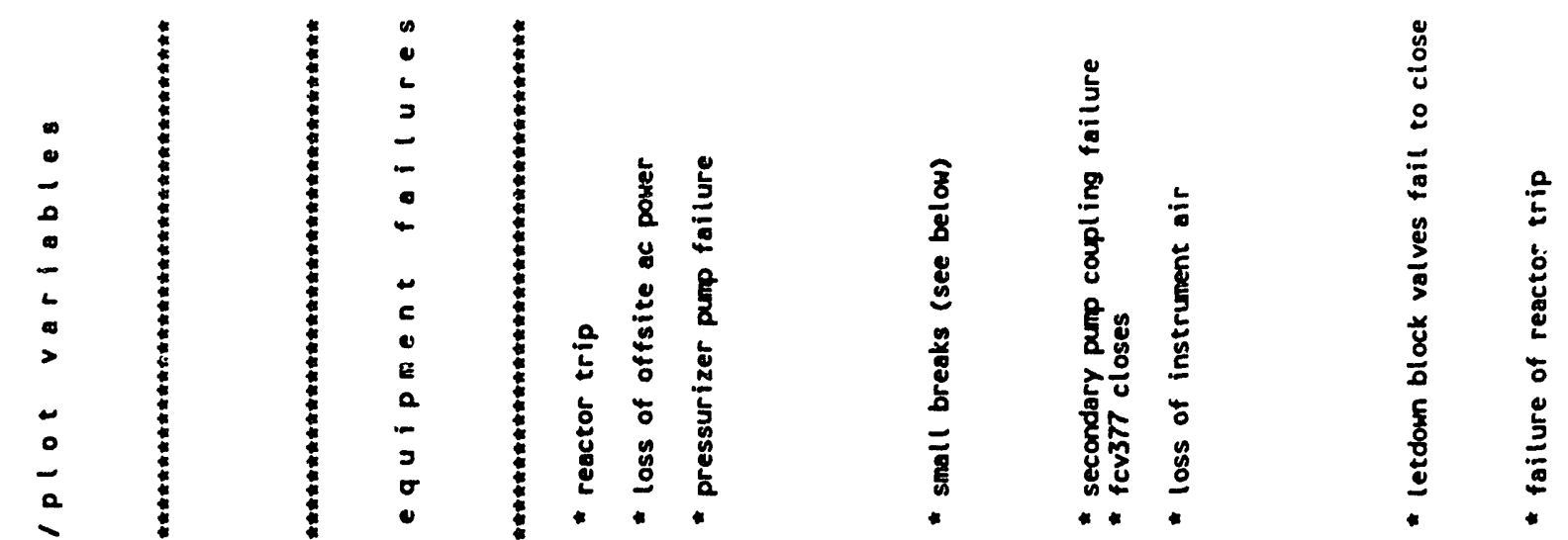

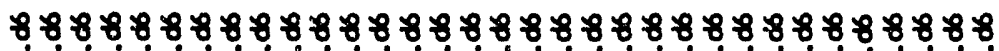

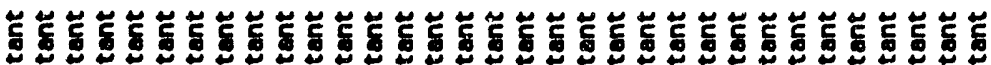

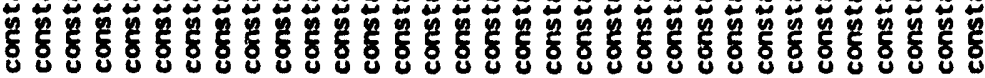

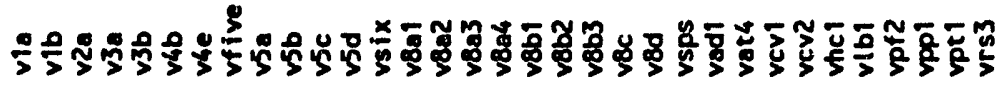

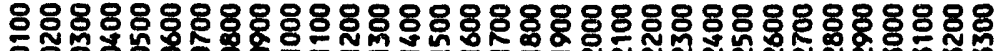

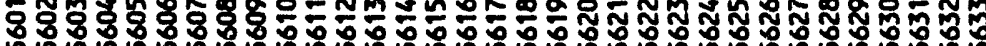
的

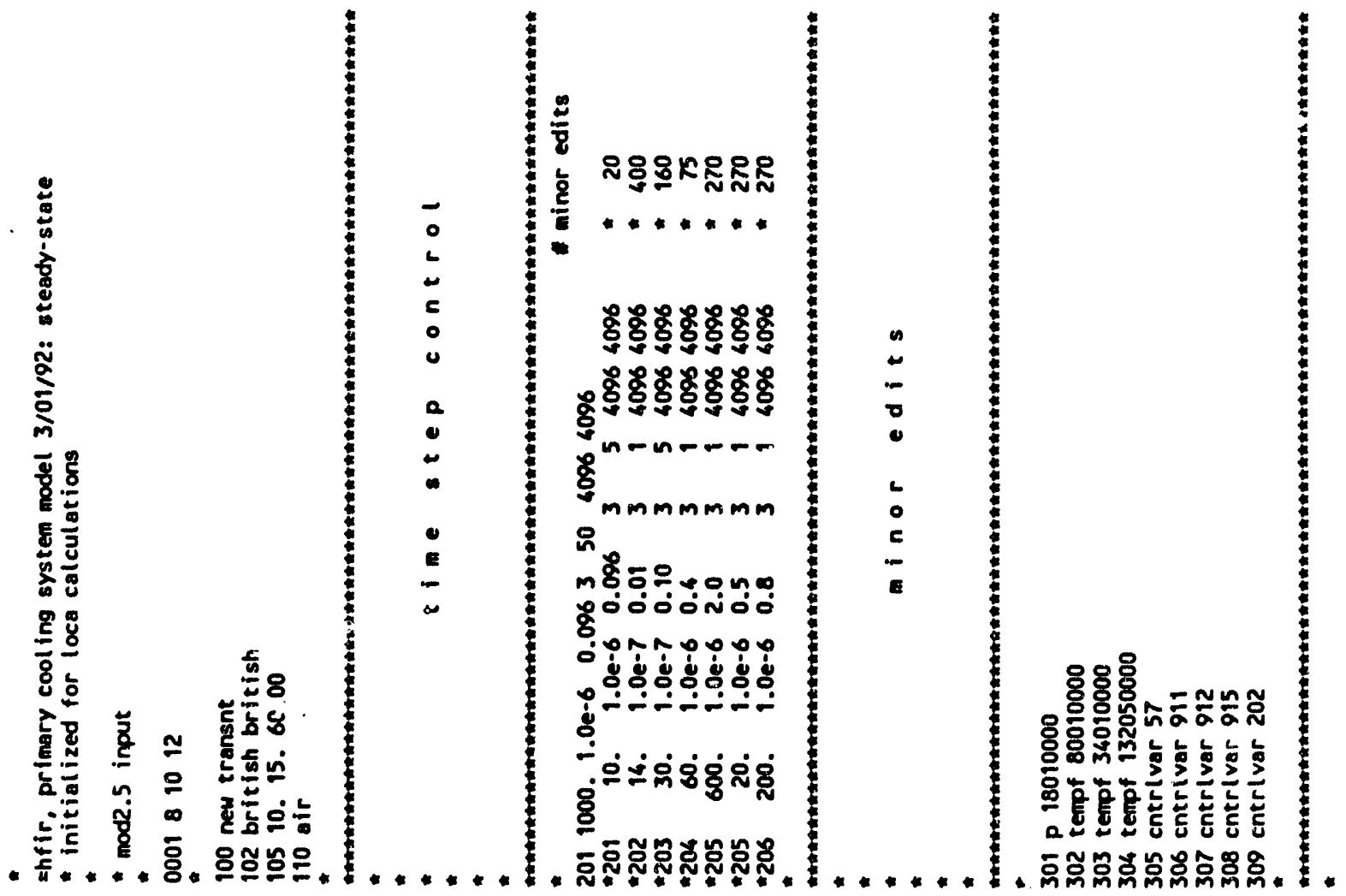



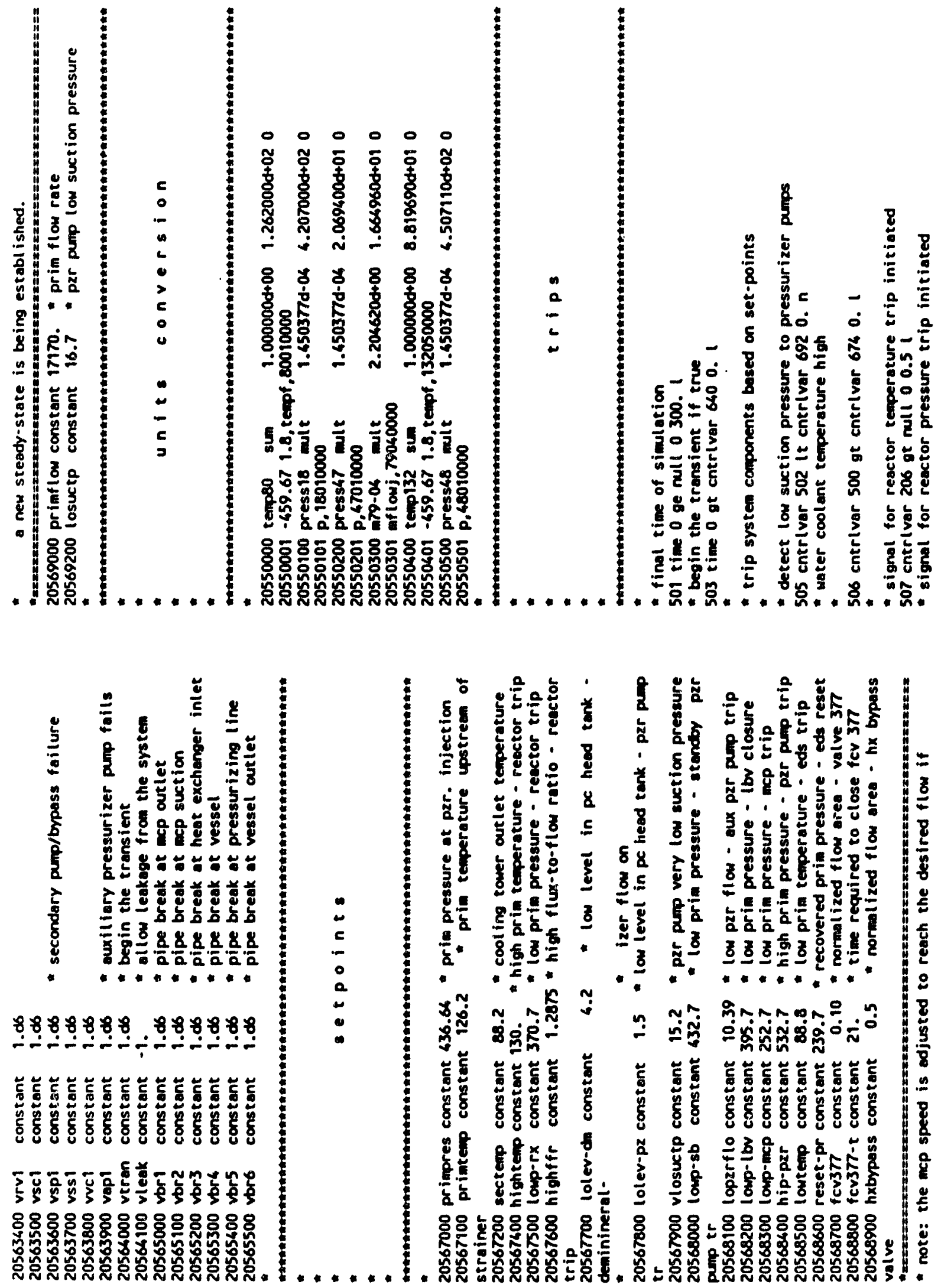


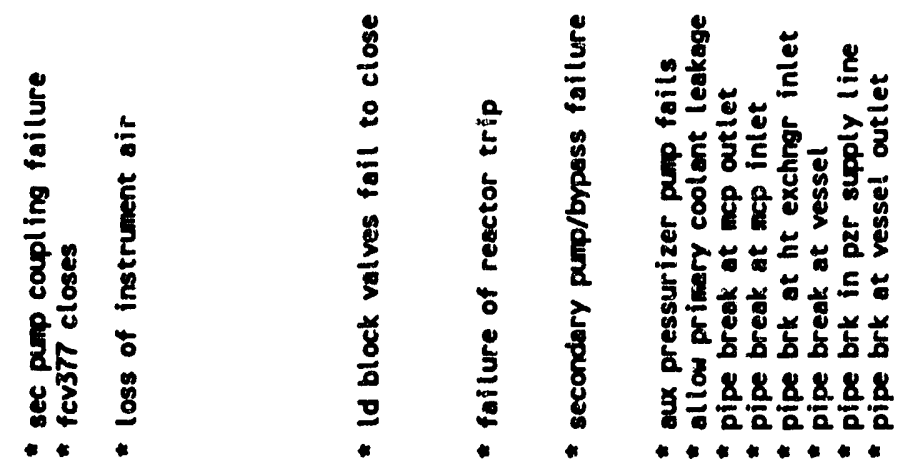

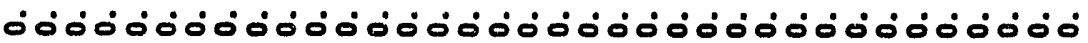

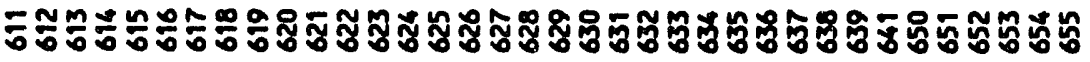

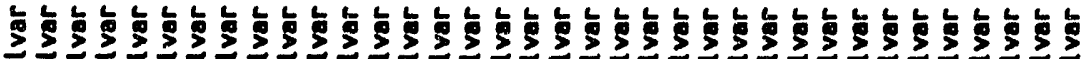

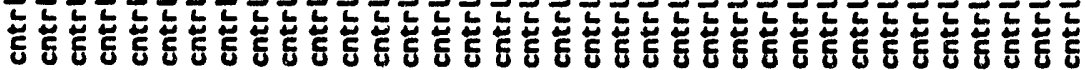

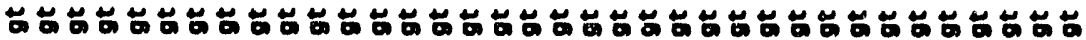
000000000000000000000000000000000000

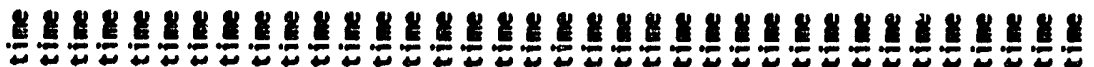

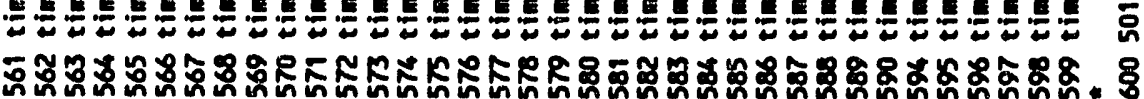
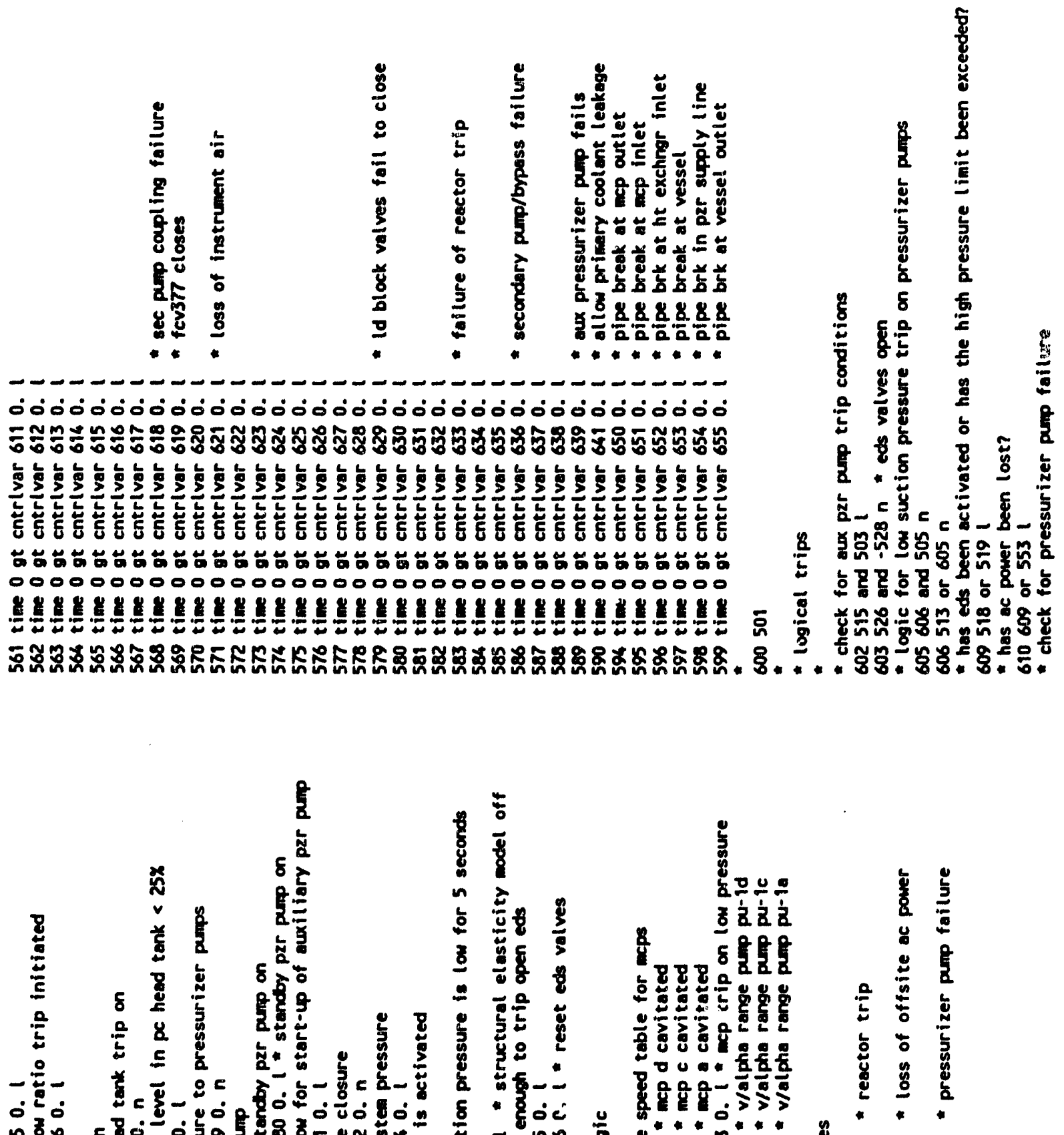

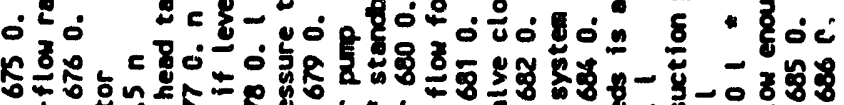

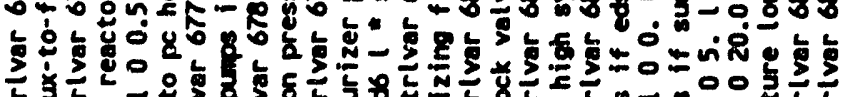

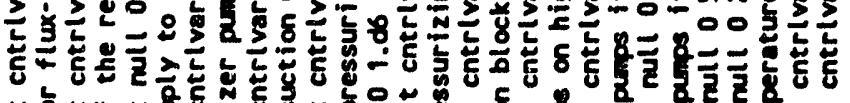

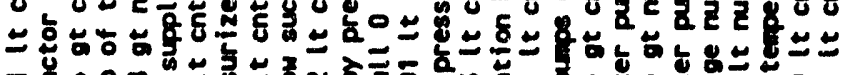

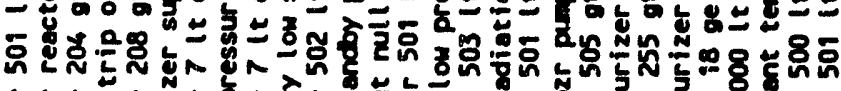

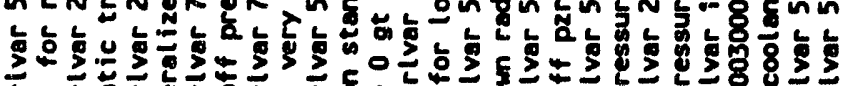

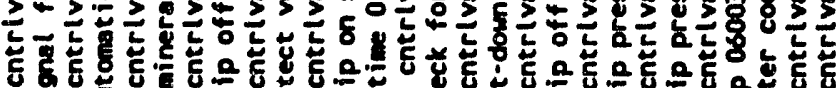

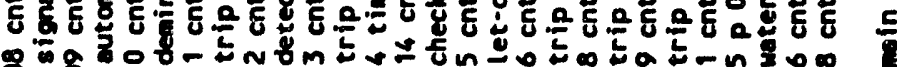

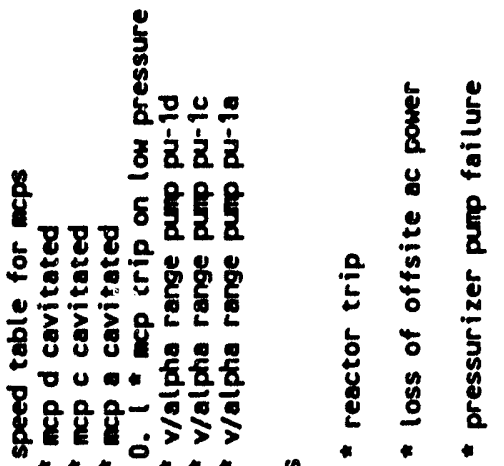

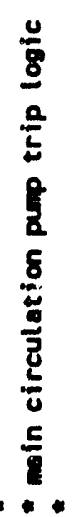

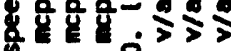

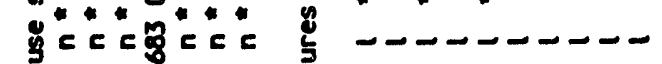

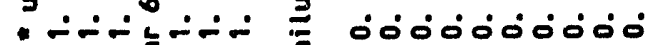

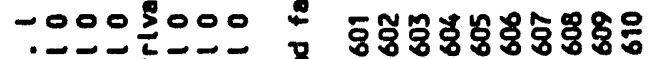

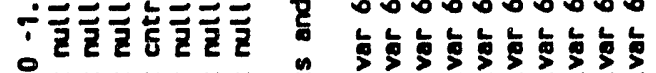
은丶万茫落

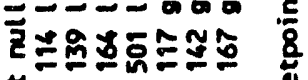

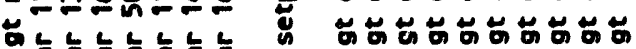

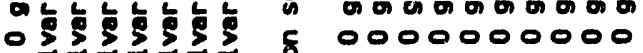

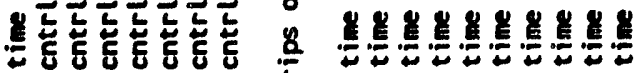

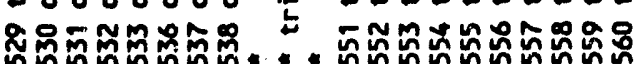



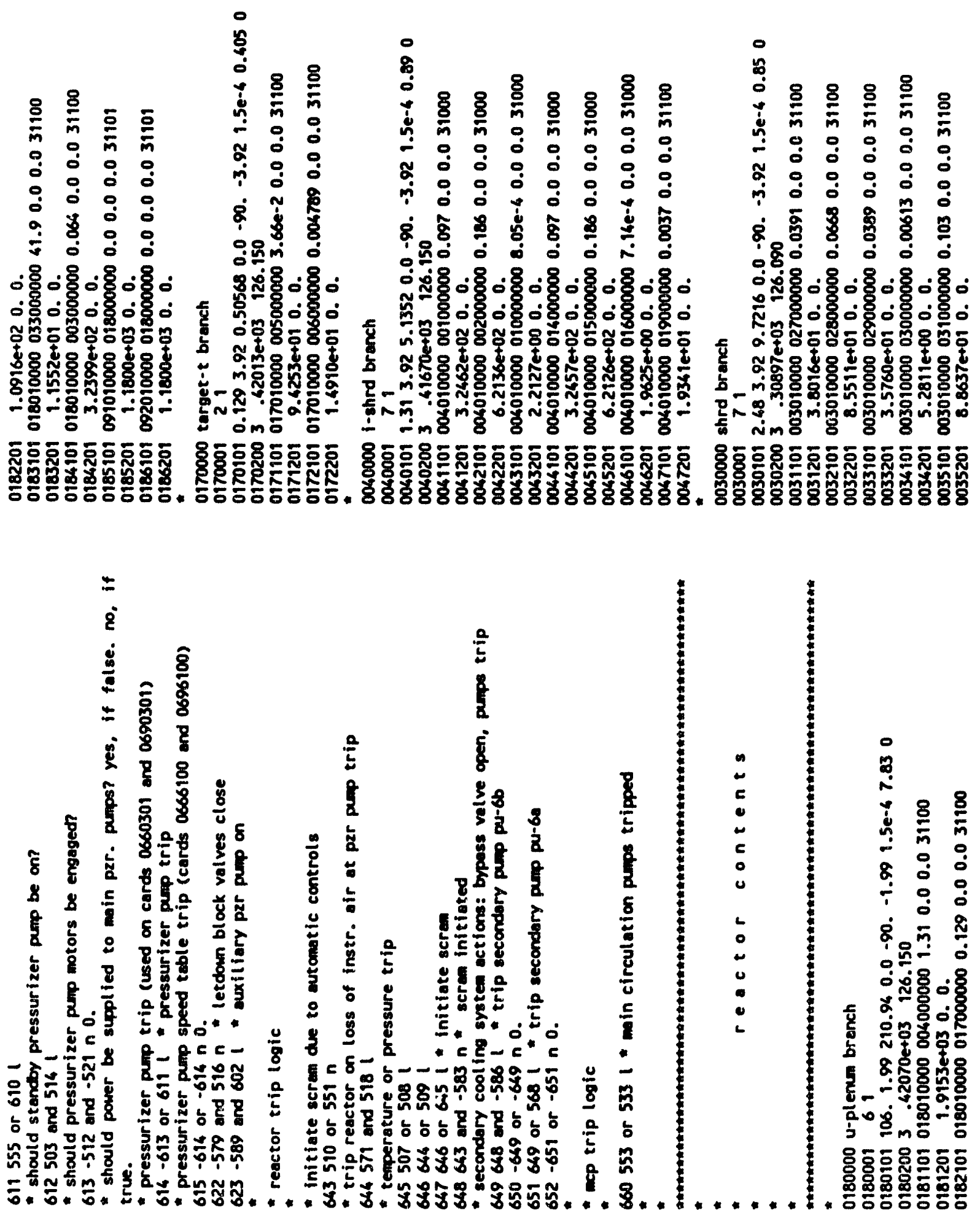

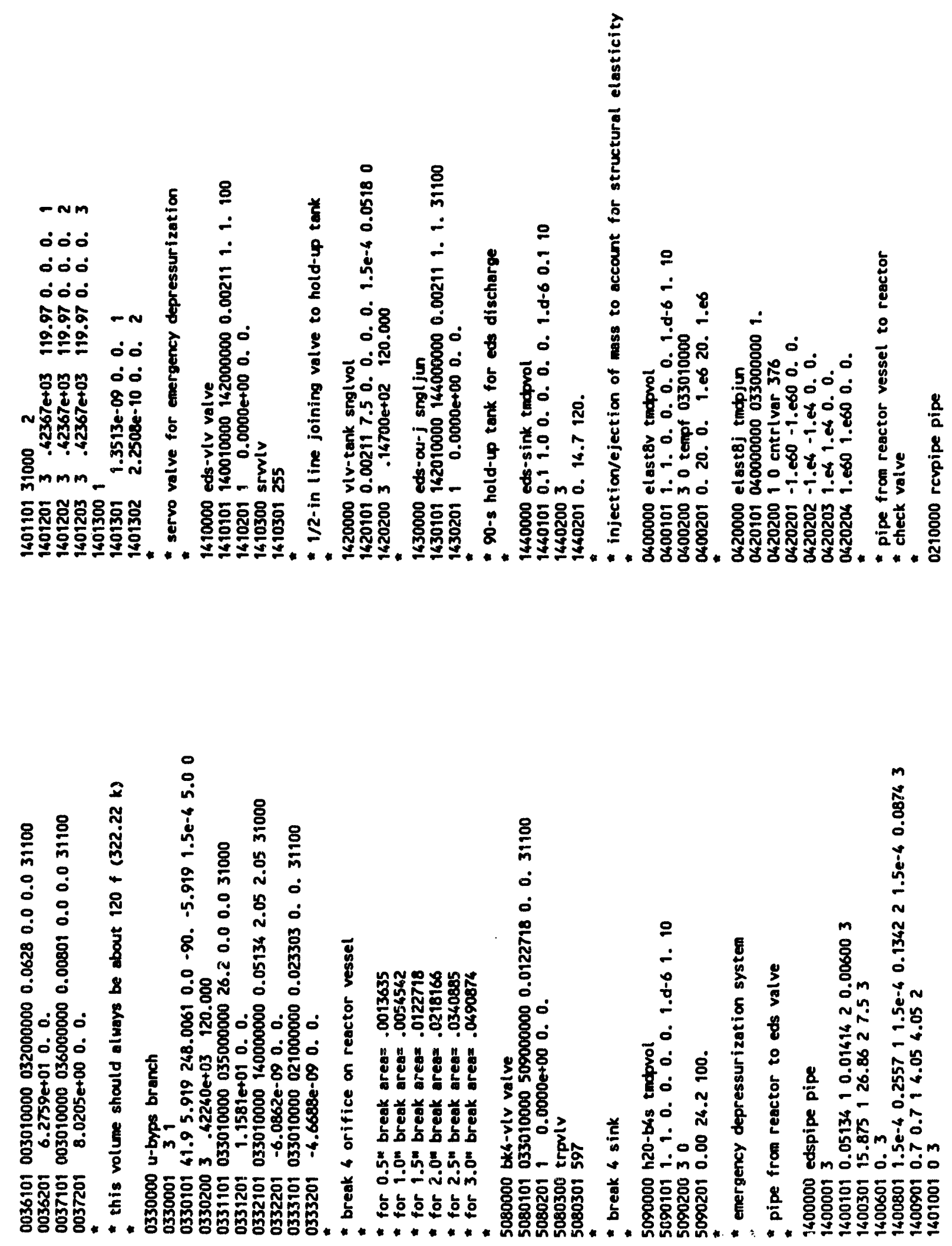

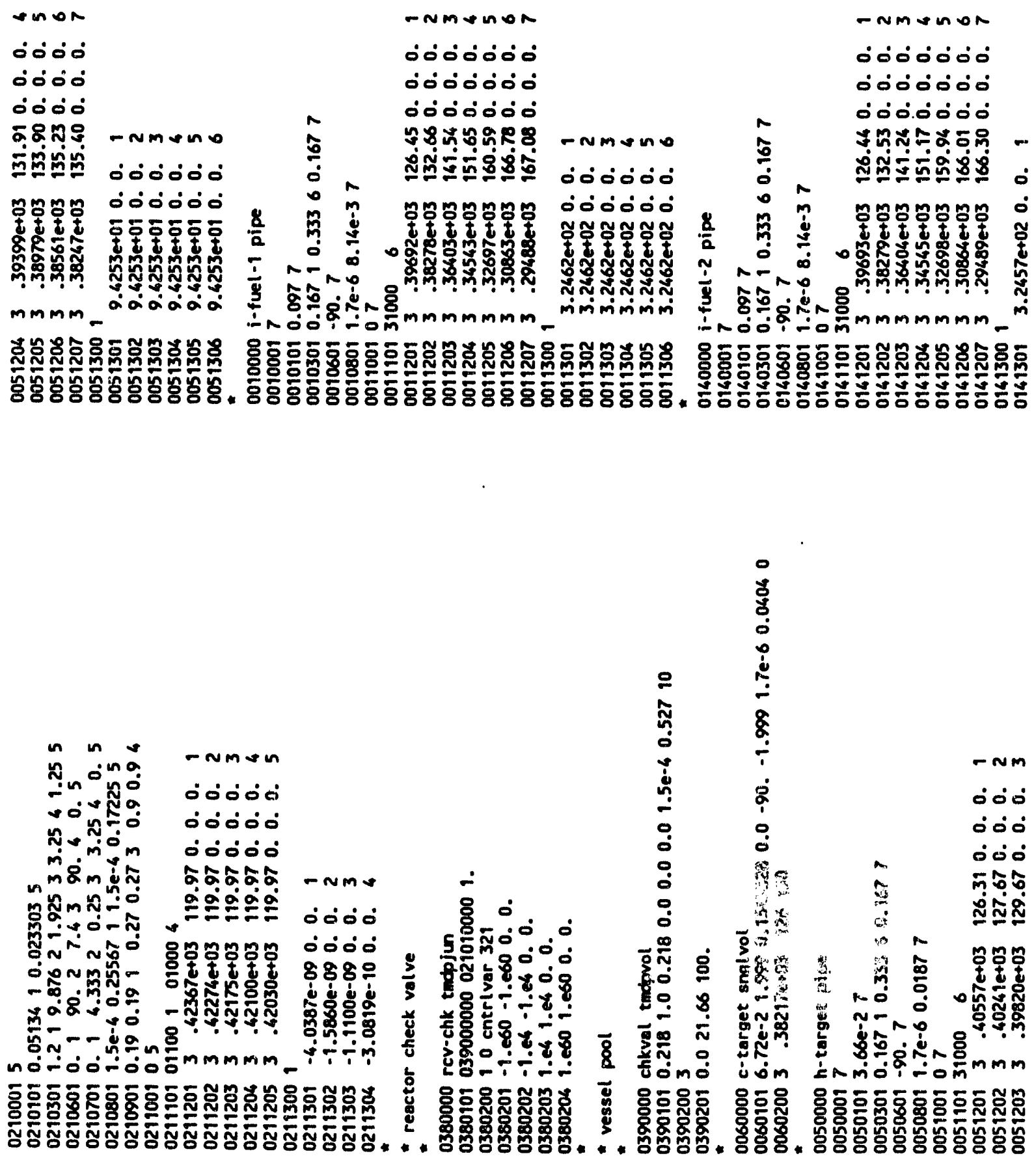

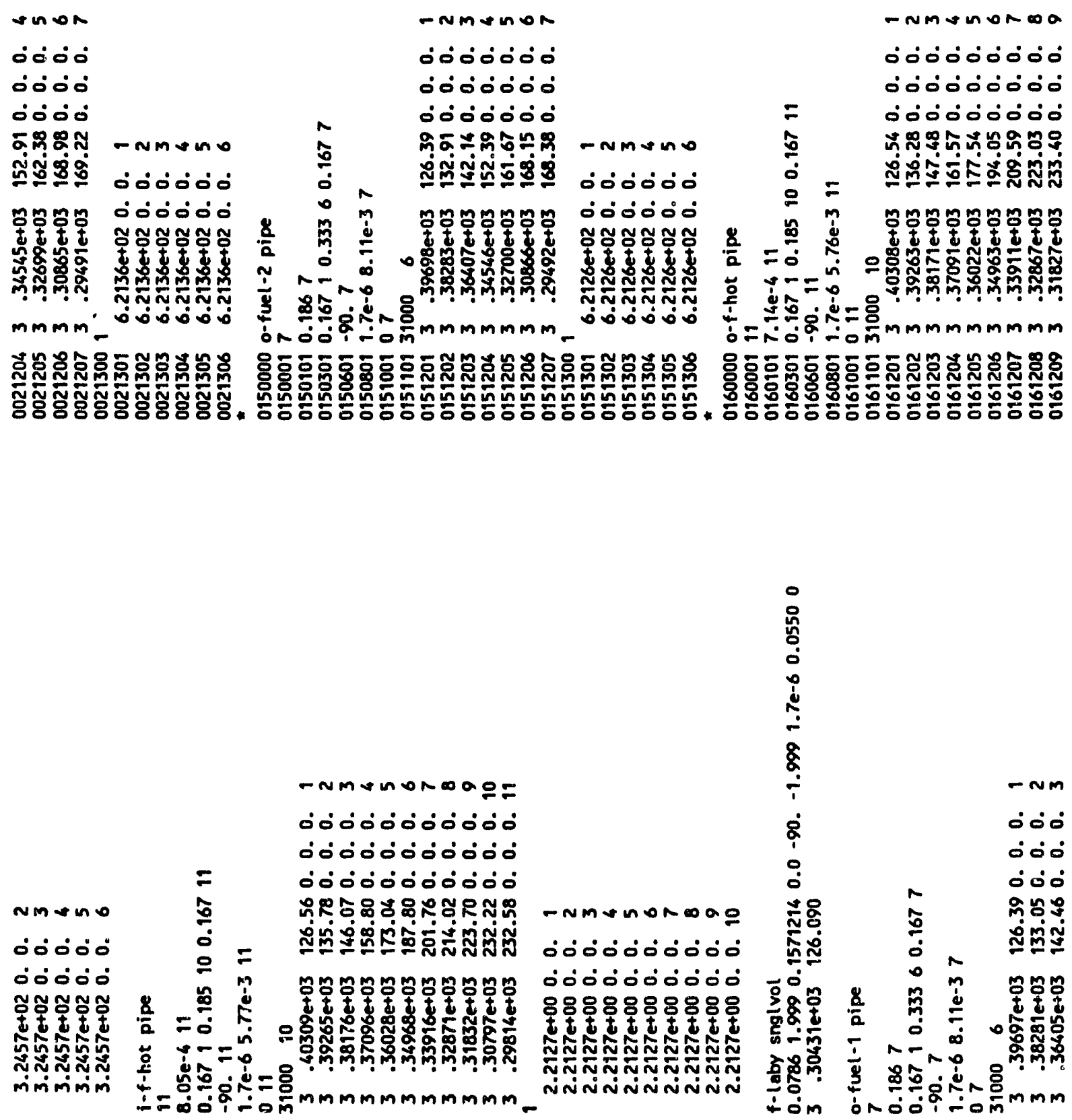

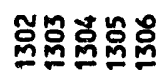

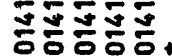

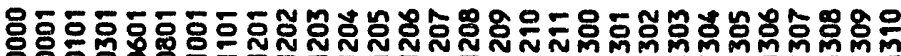

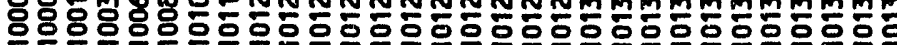

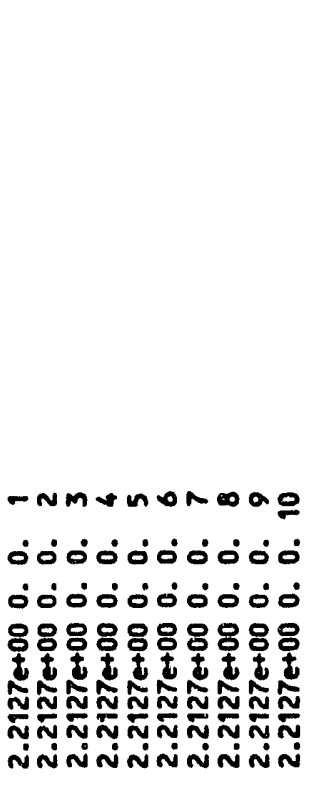

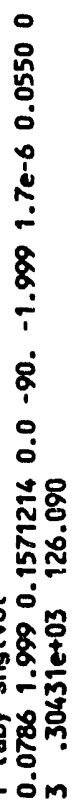

- Nm ¿ं० ¿0ं ம் $\dot{0}$ 옹ํํ 里 $\underset{2}{m}$ moñ

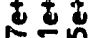
合空 m! IN รั 85

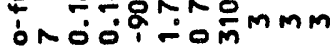

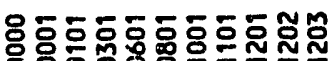

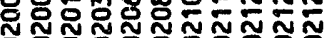



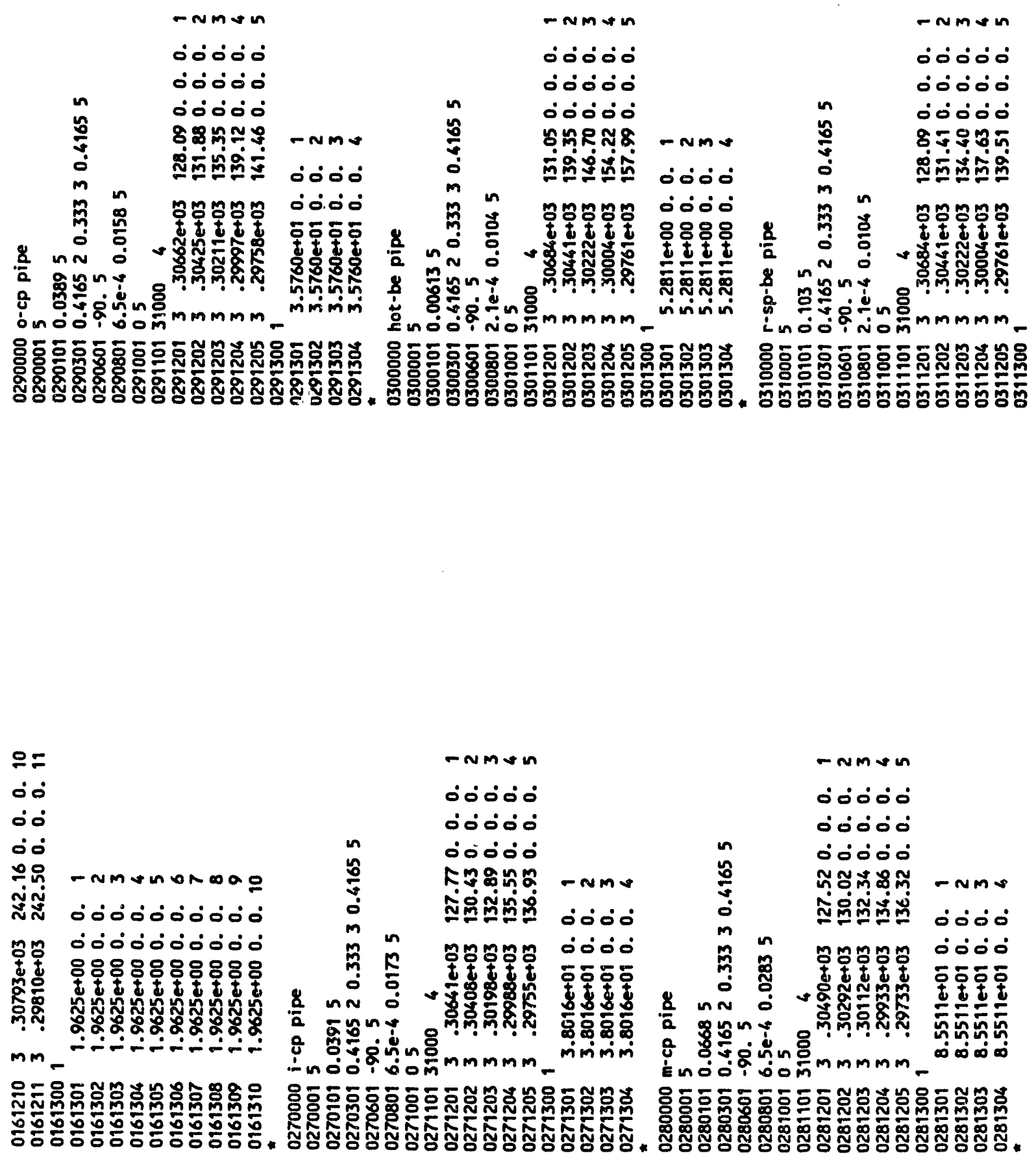

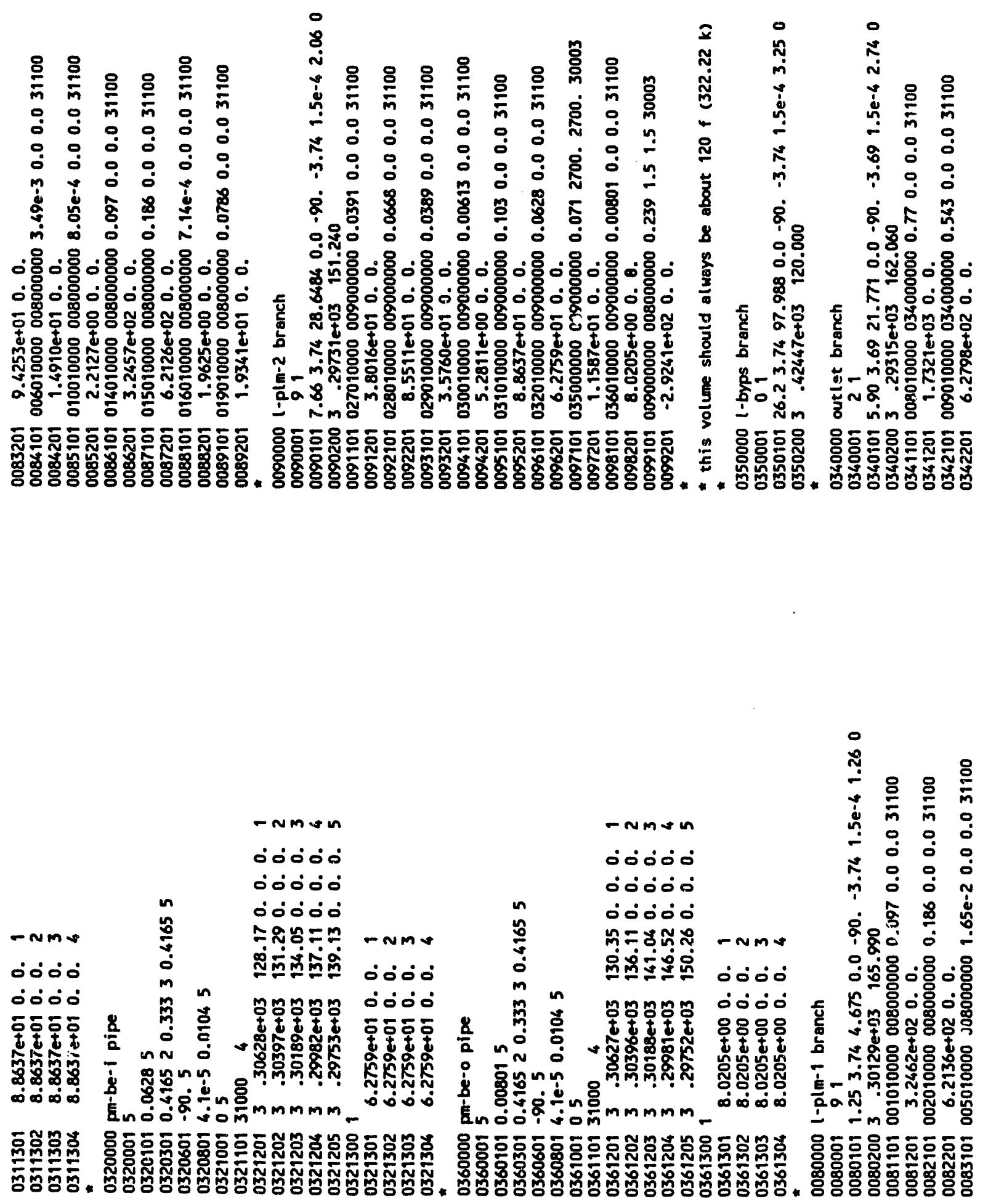

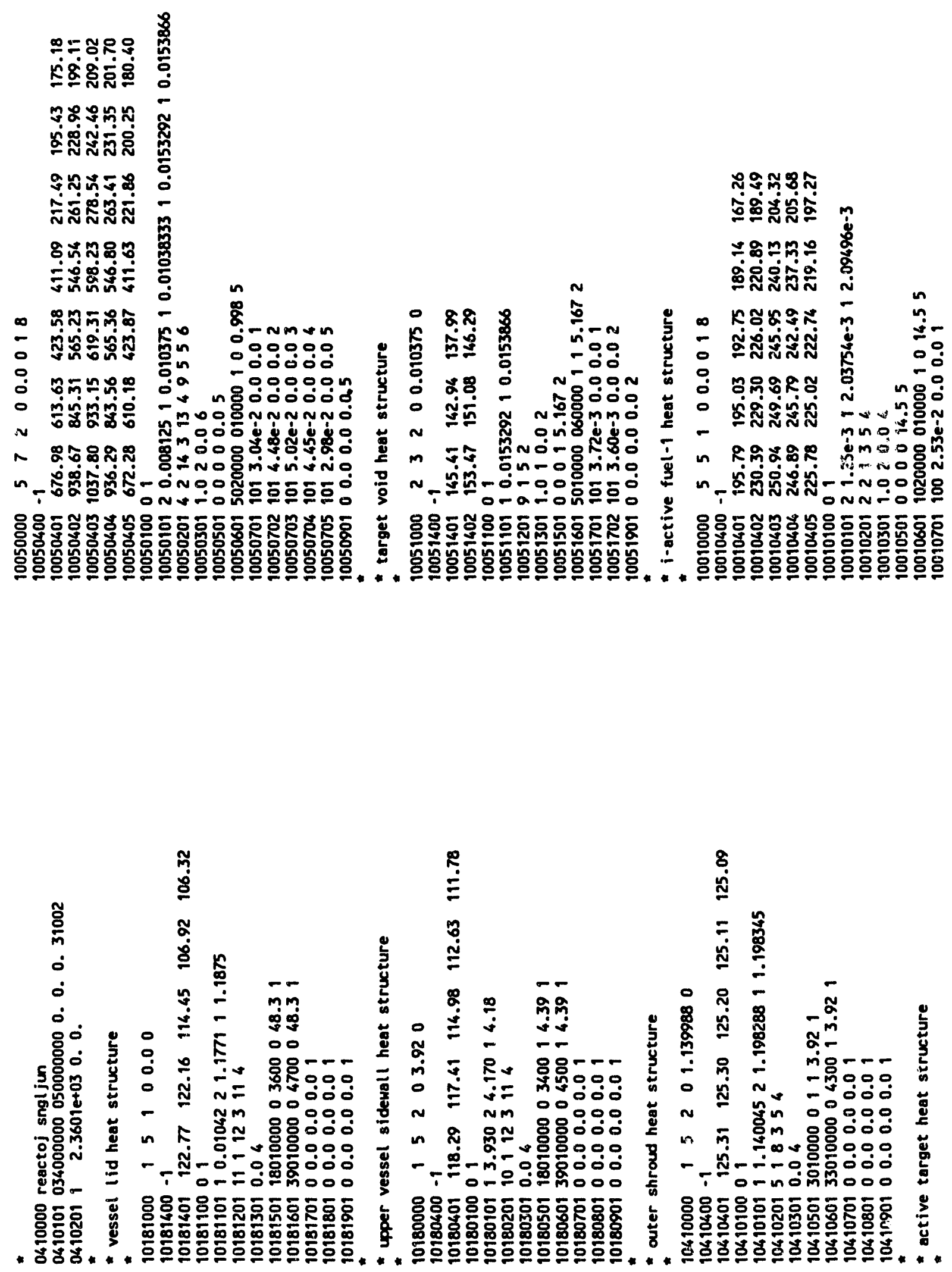

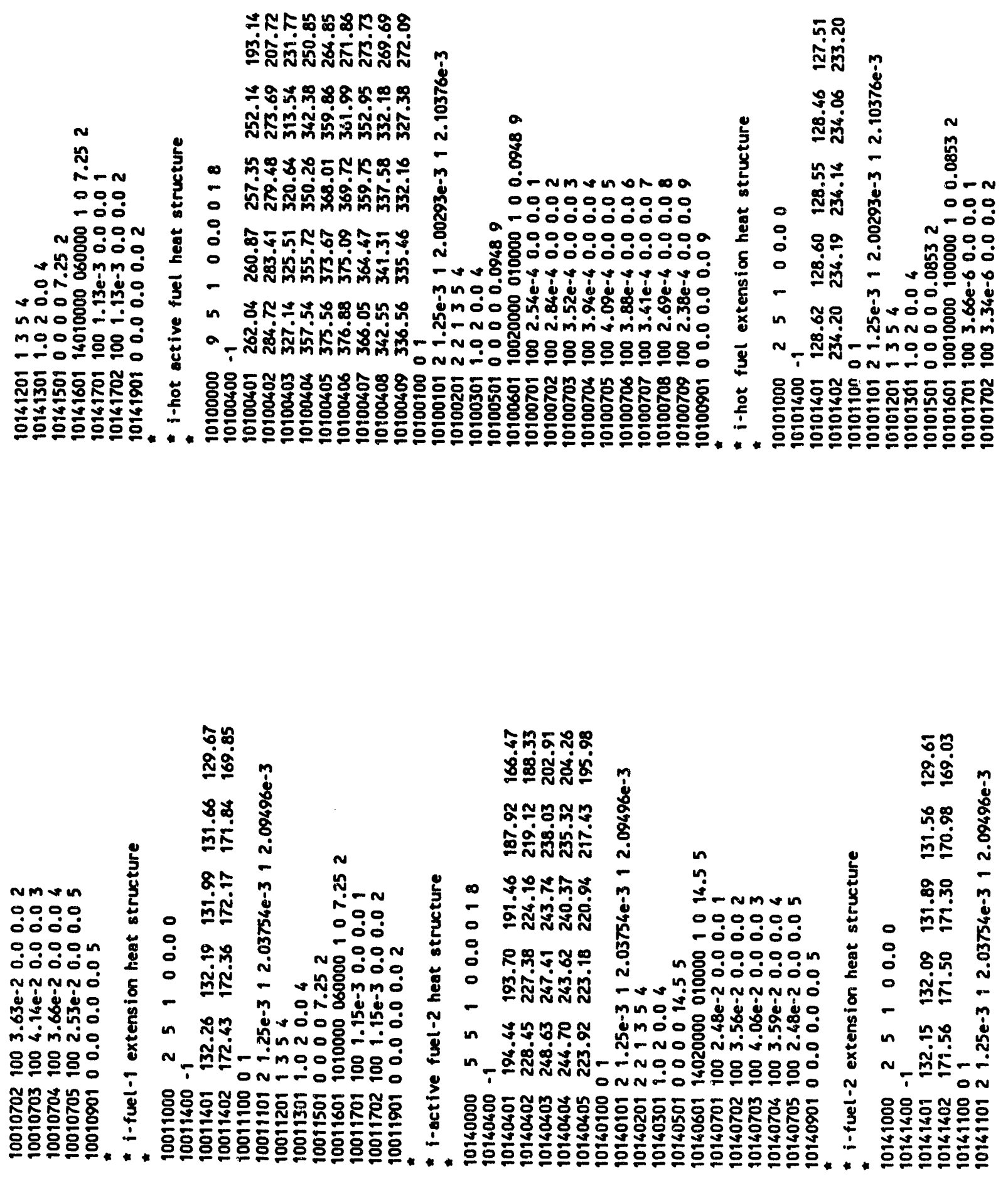

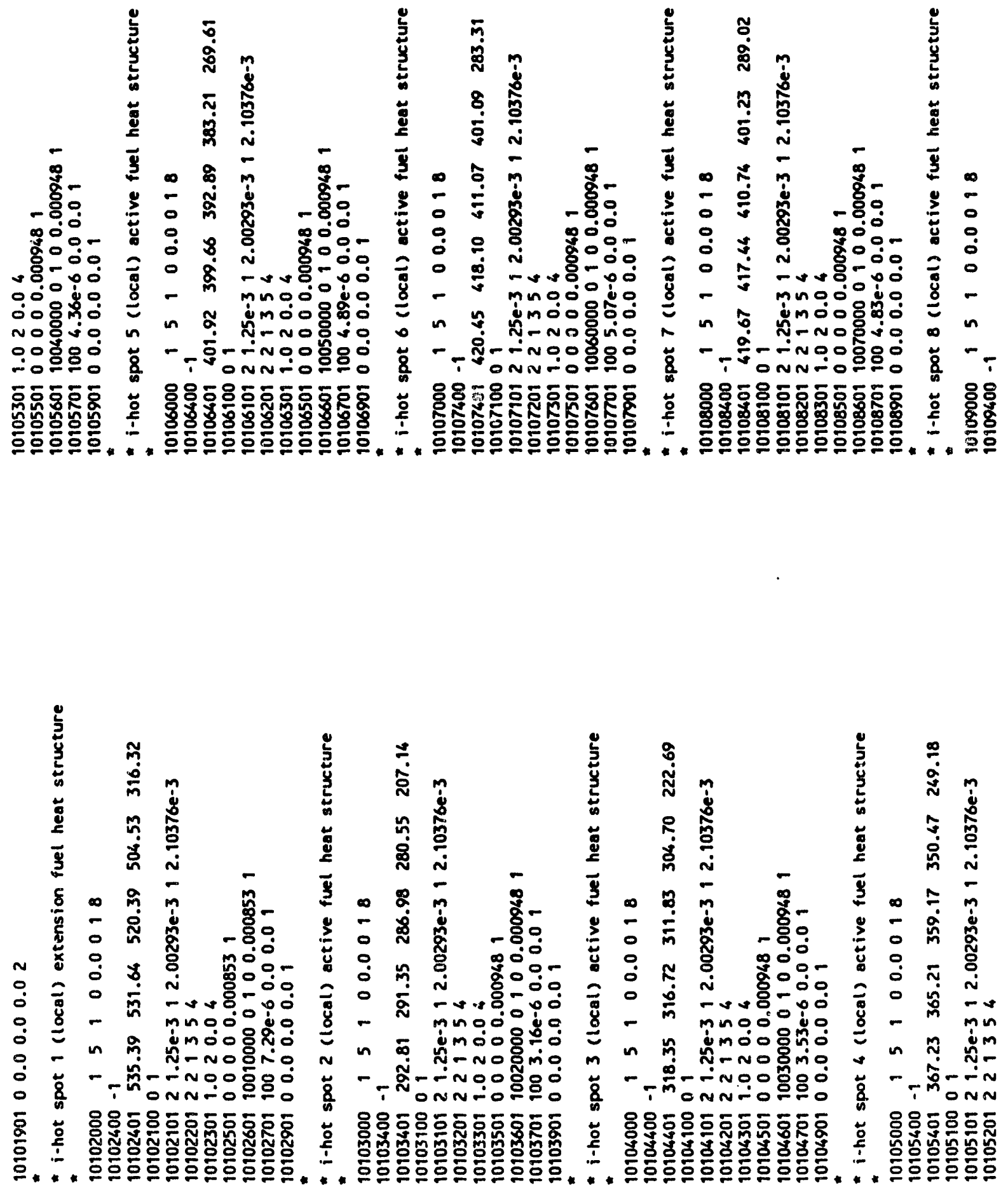

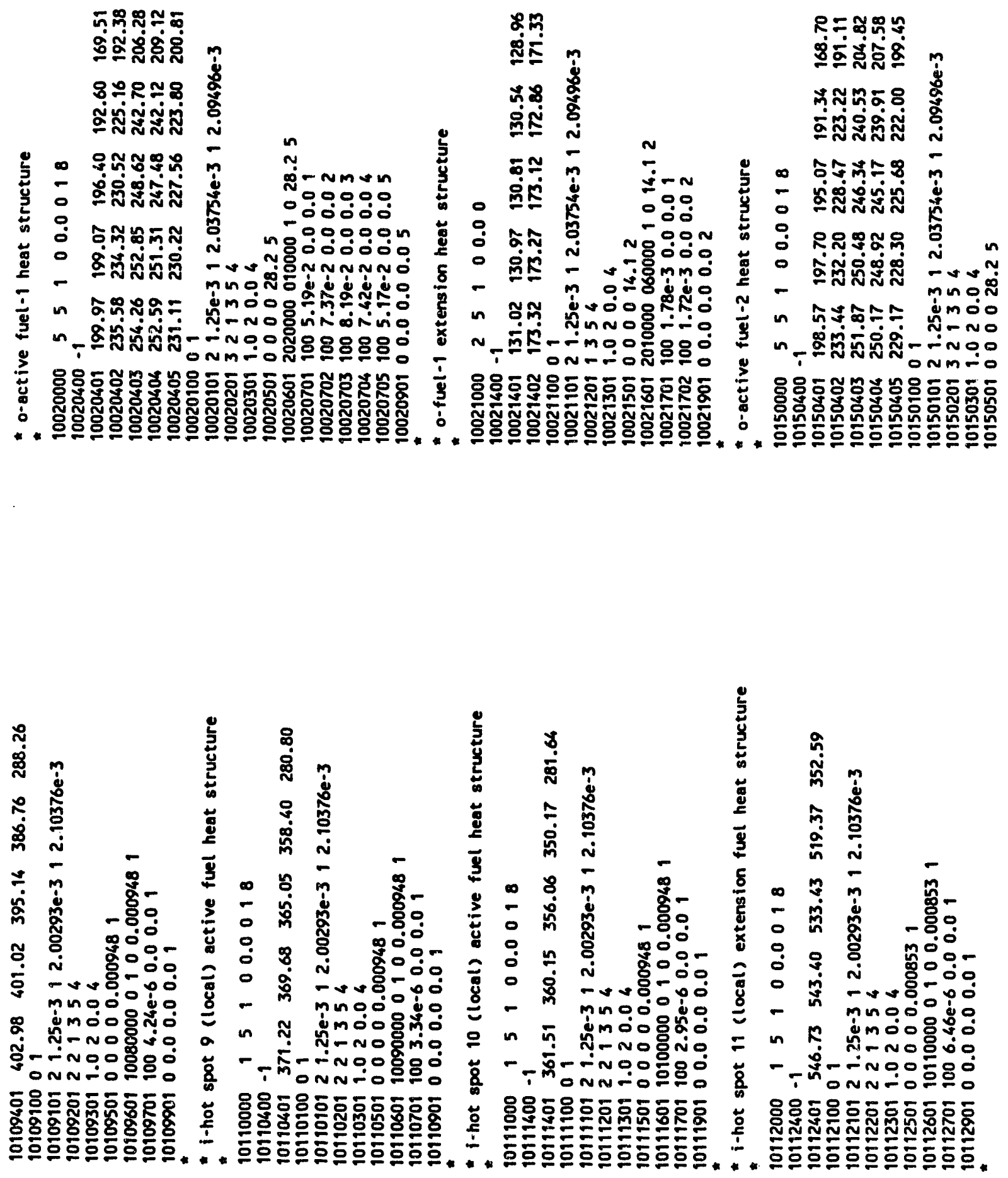

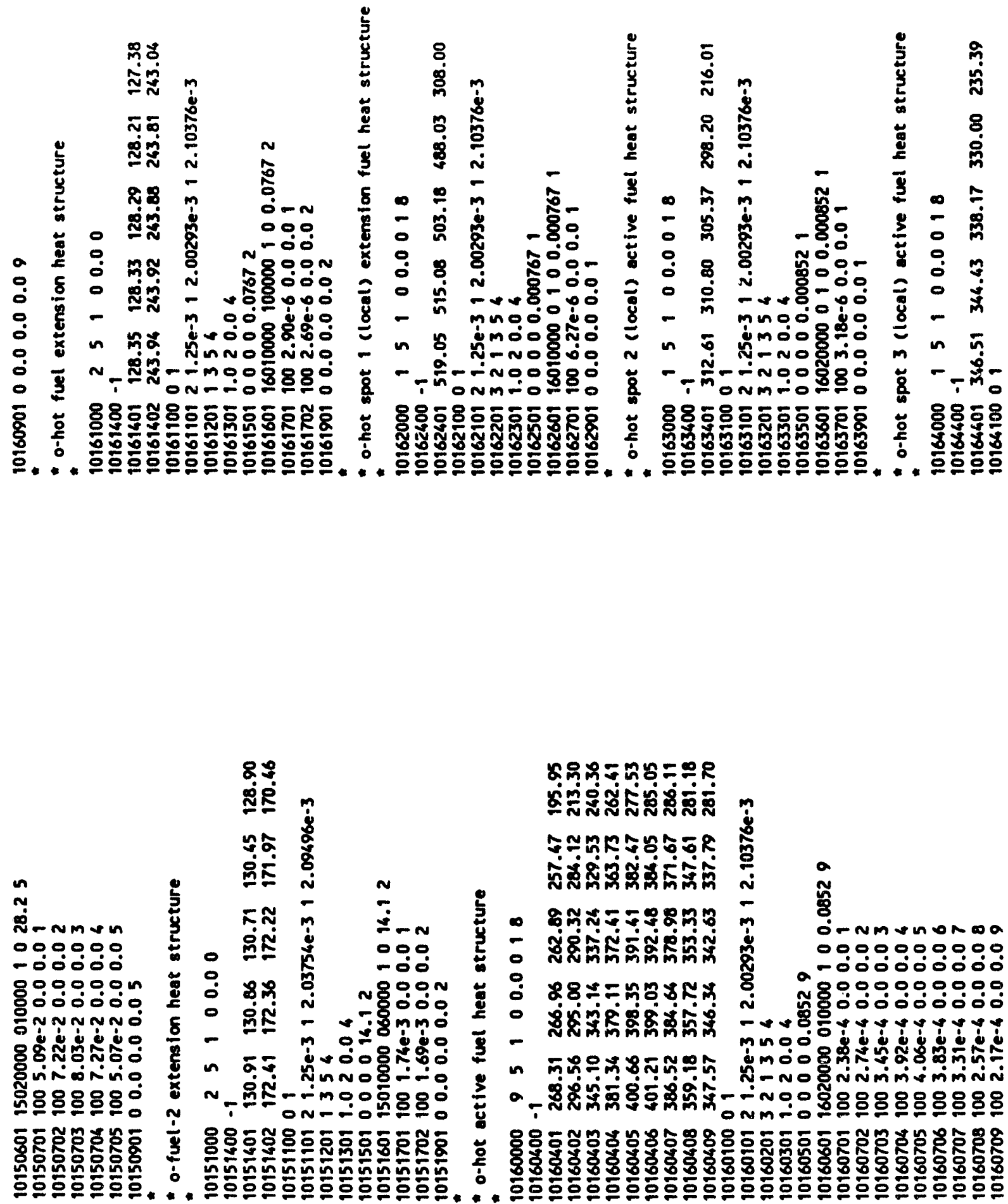

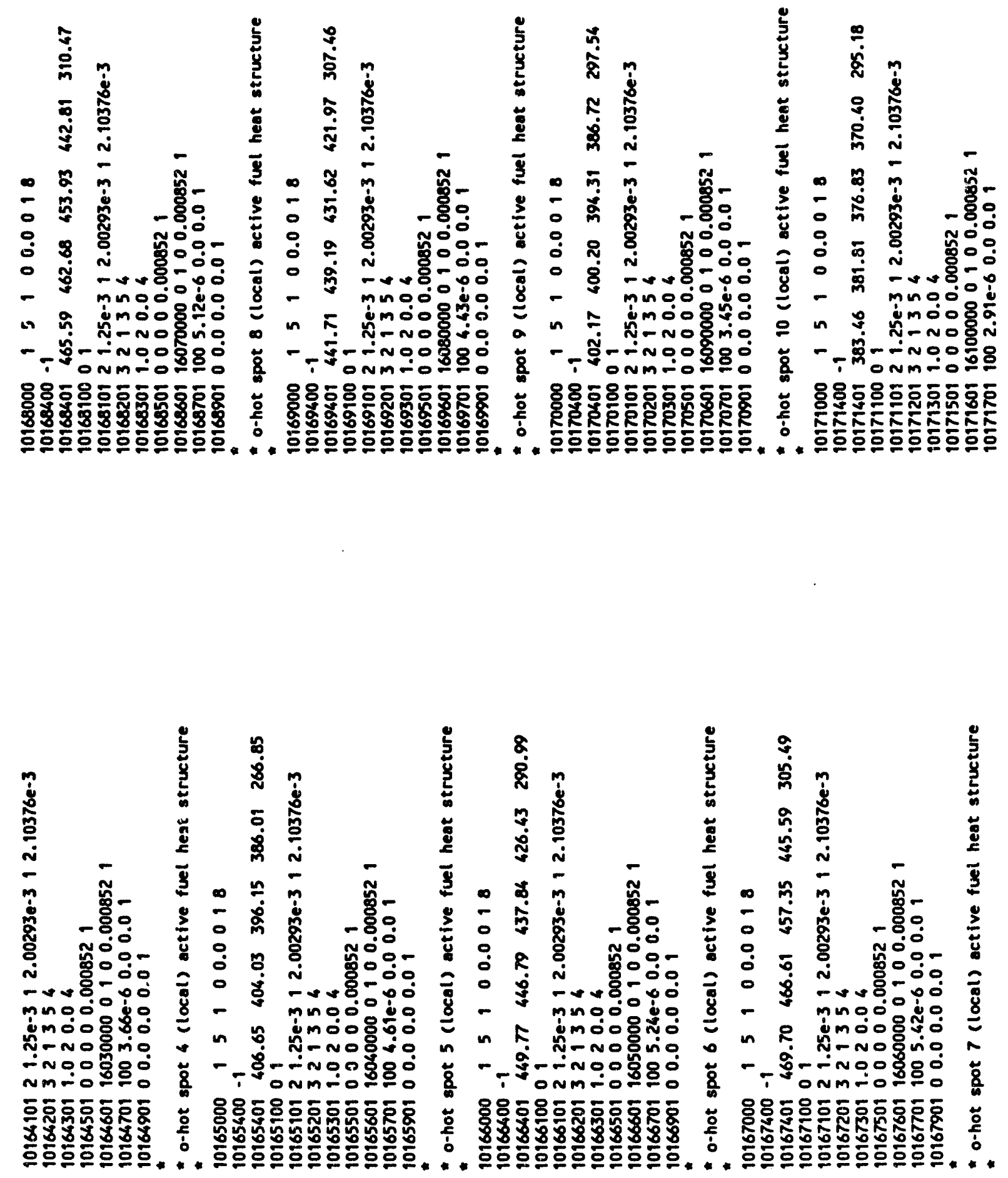

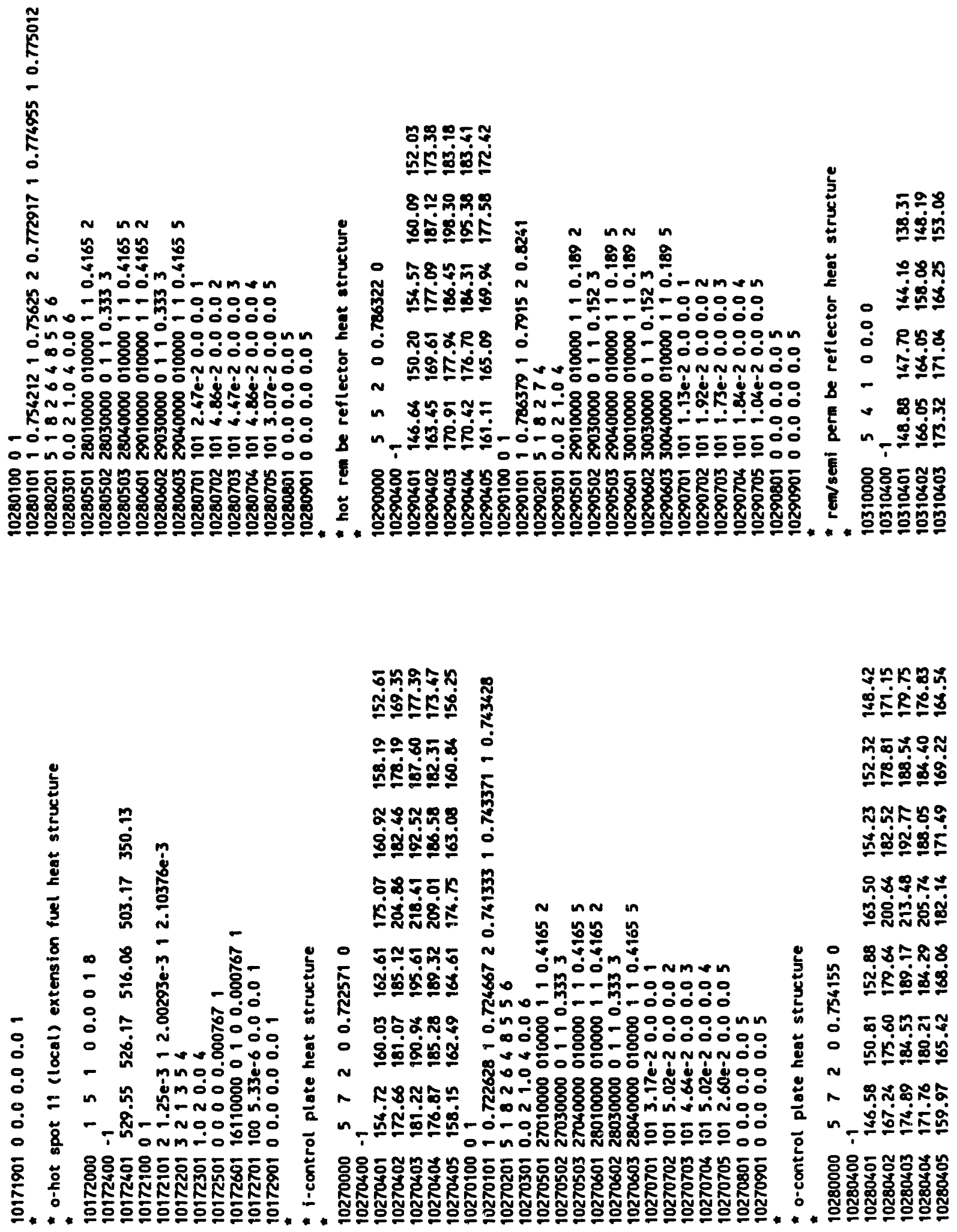

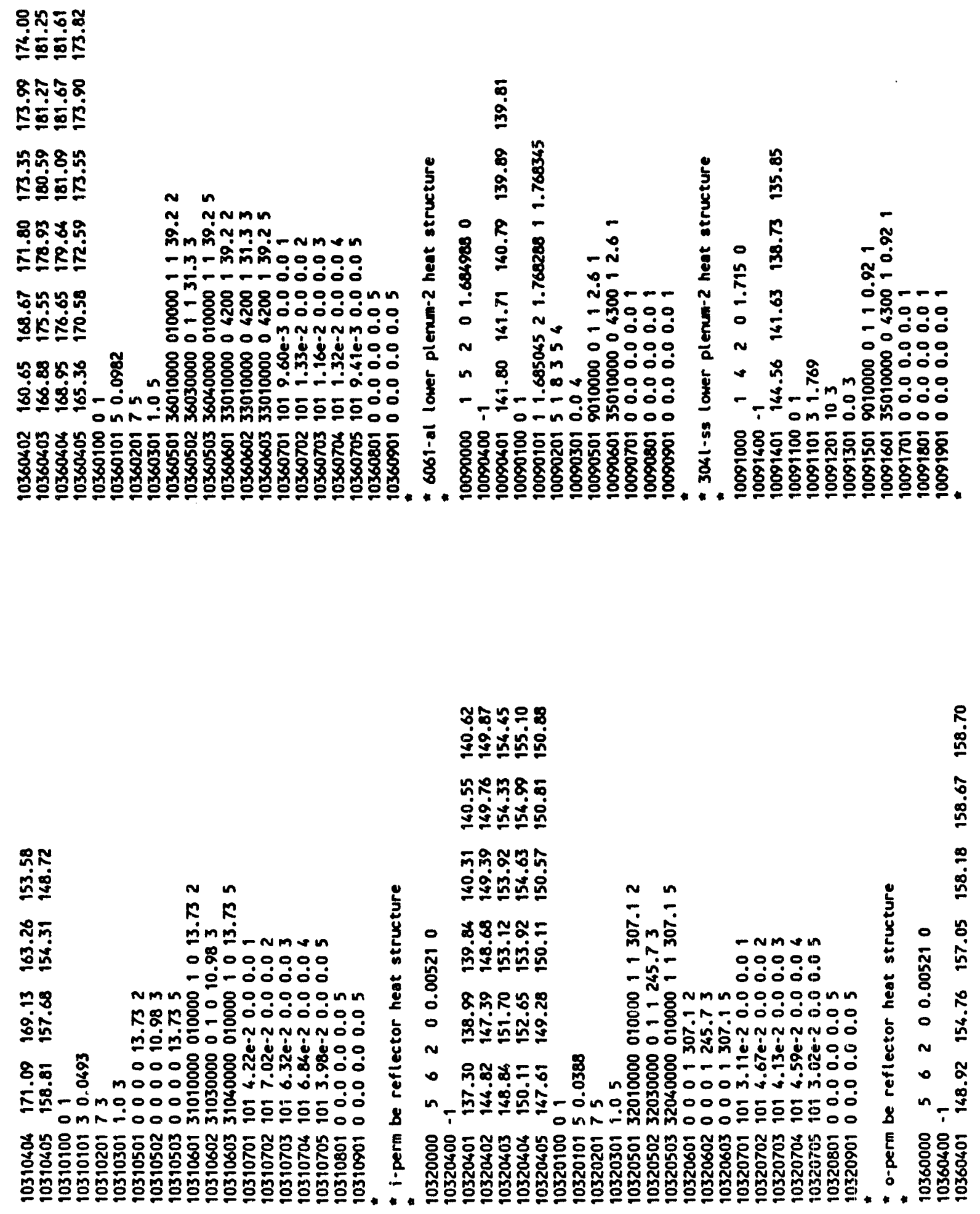

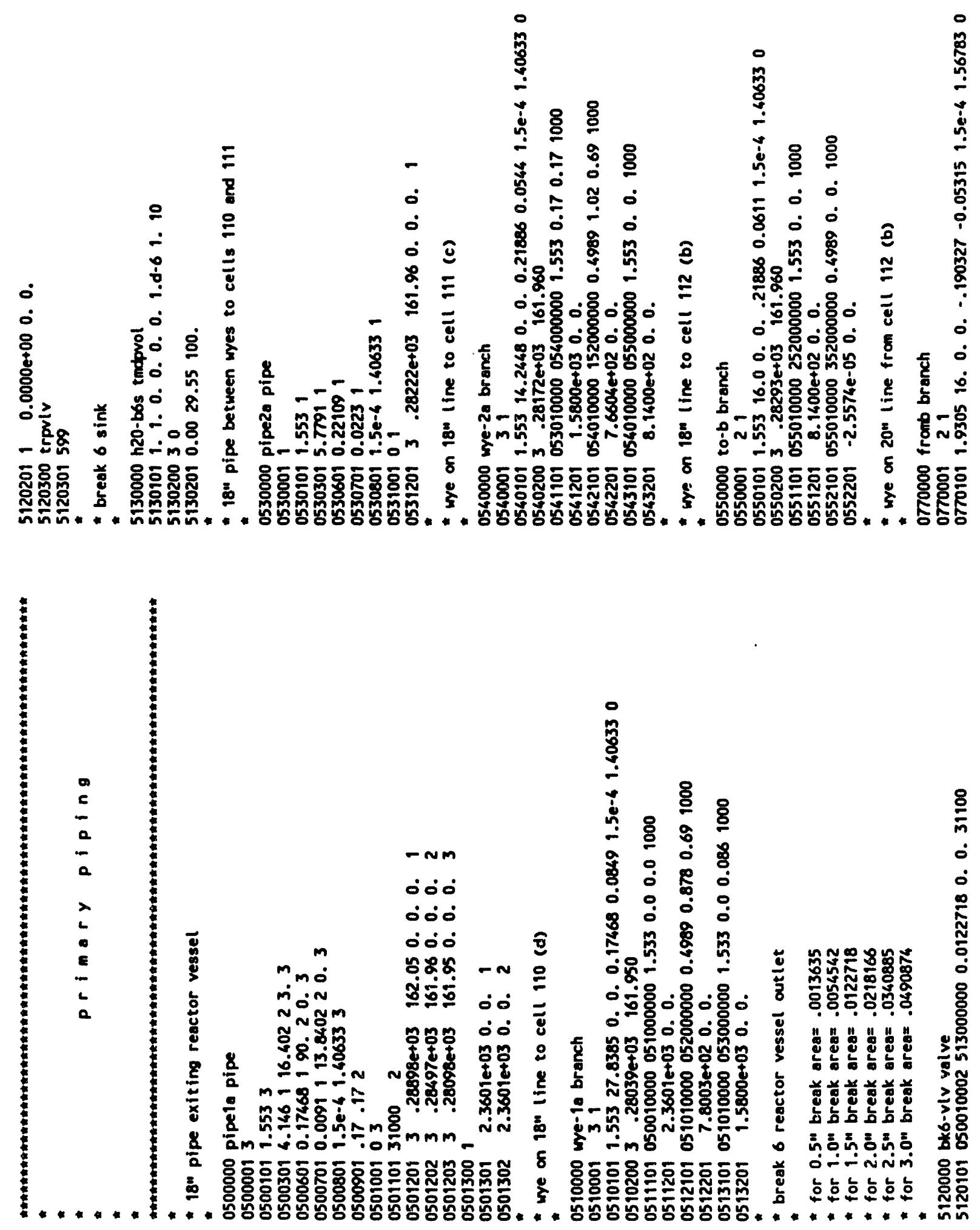

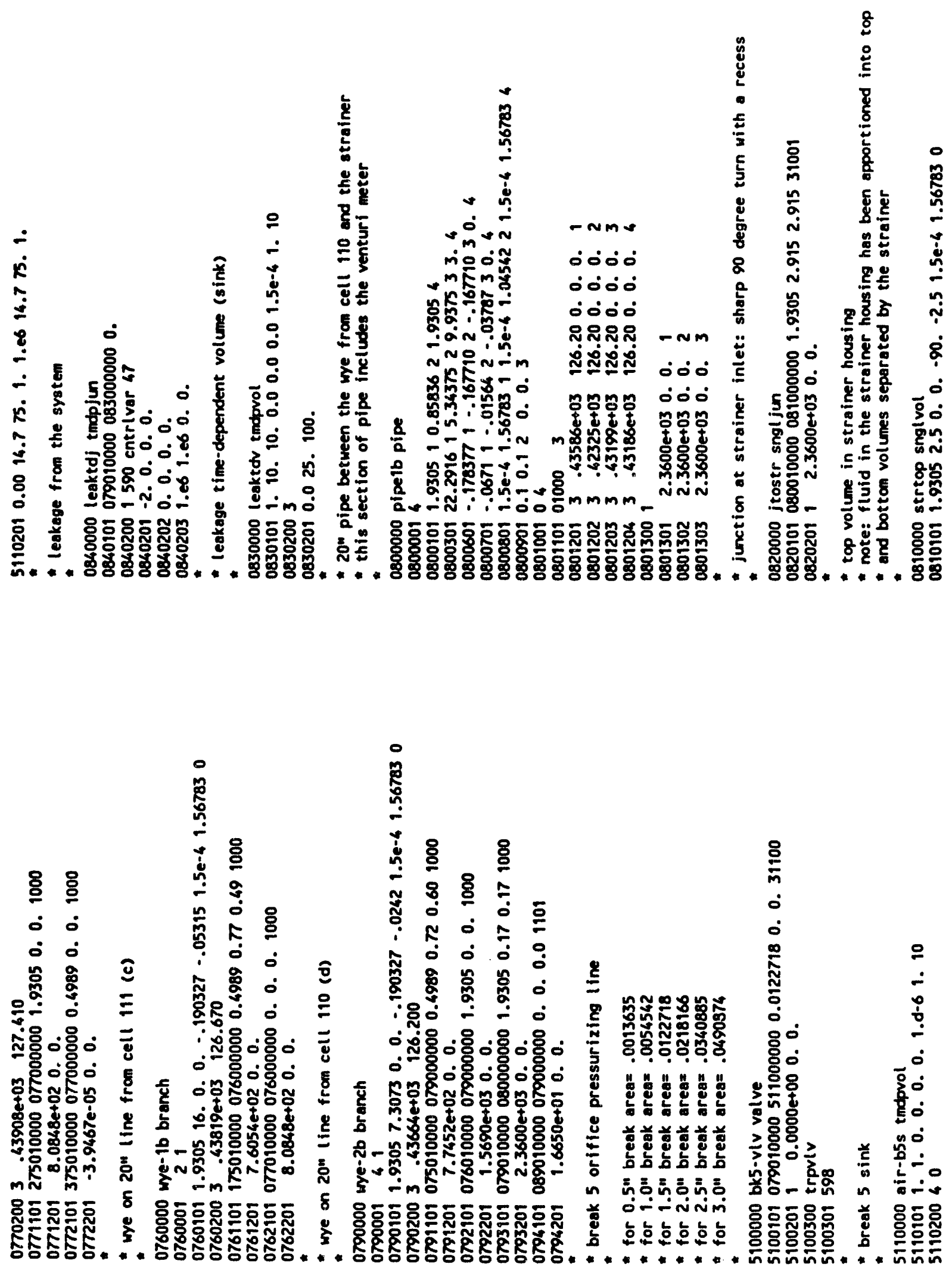

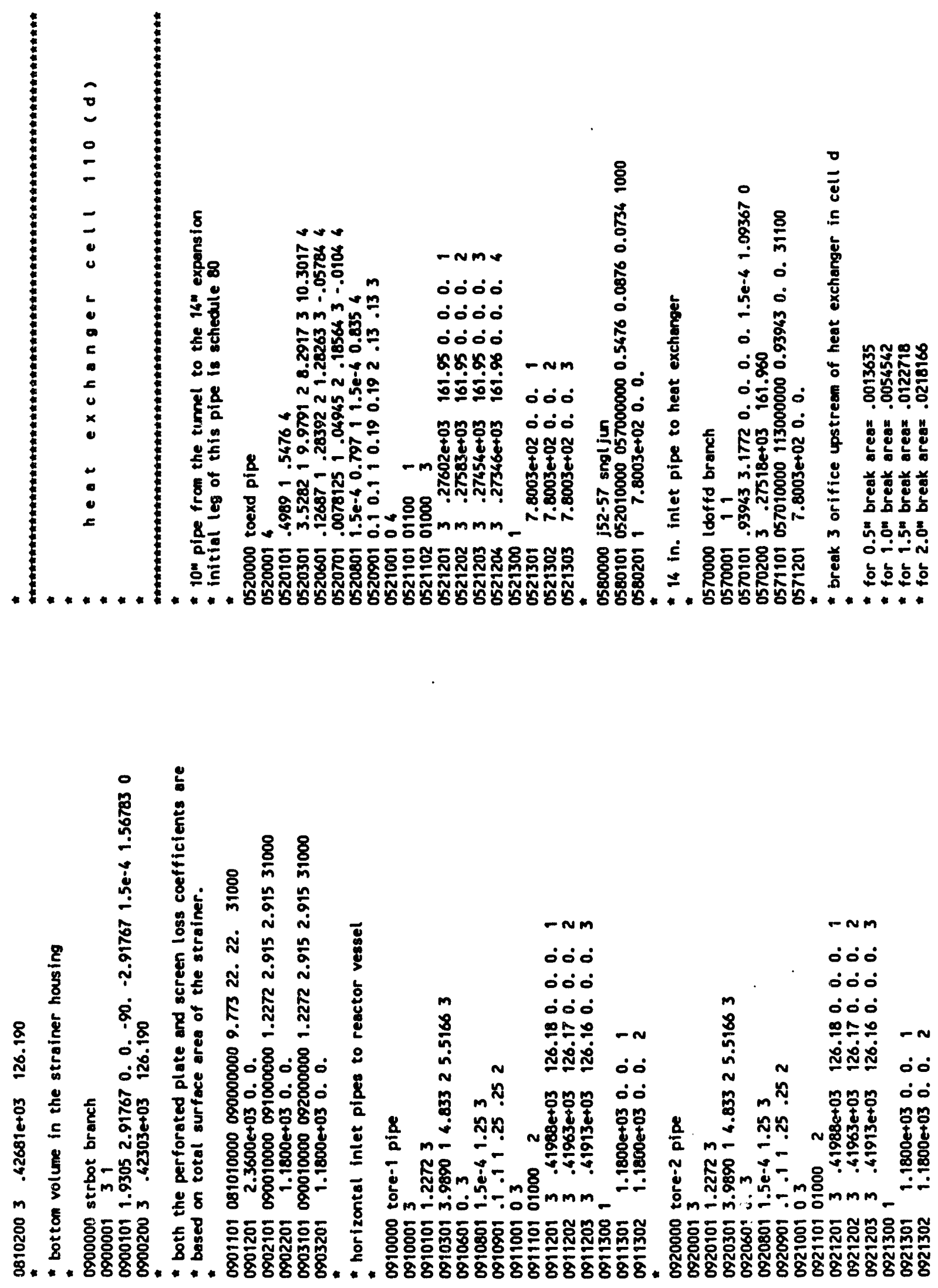

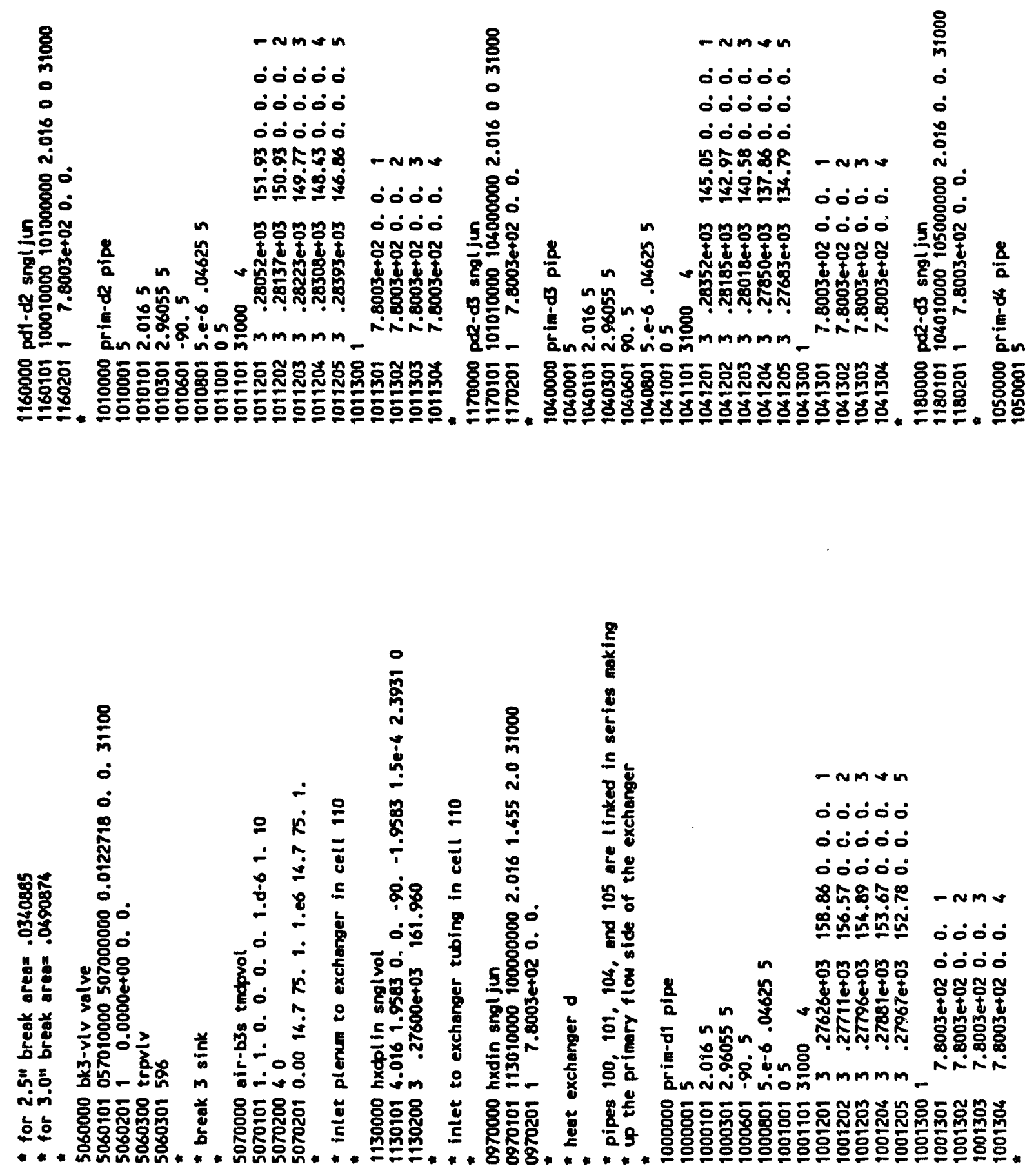

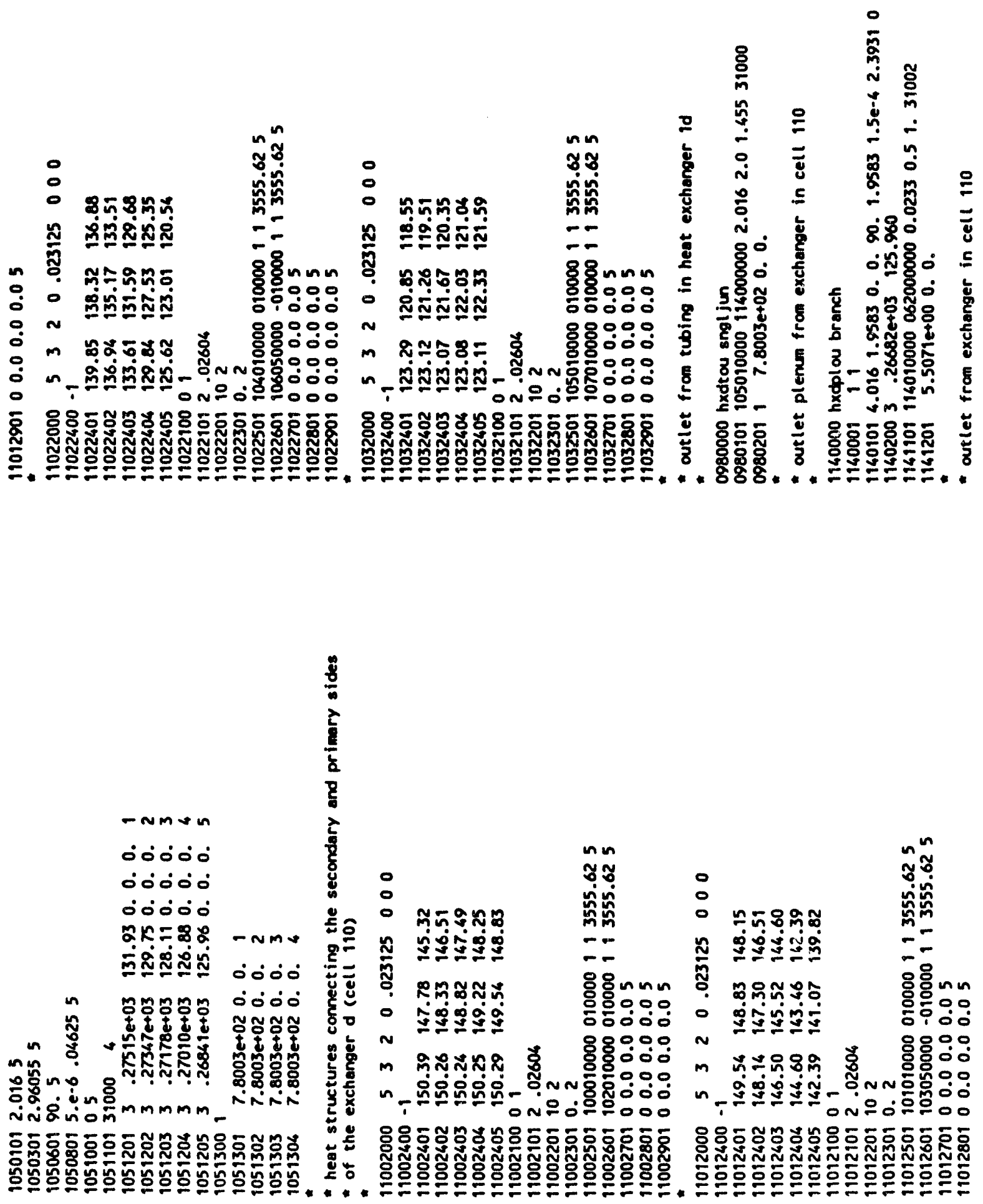

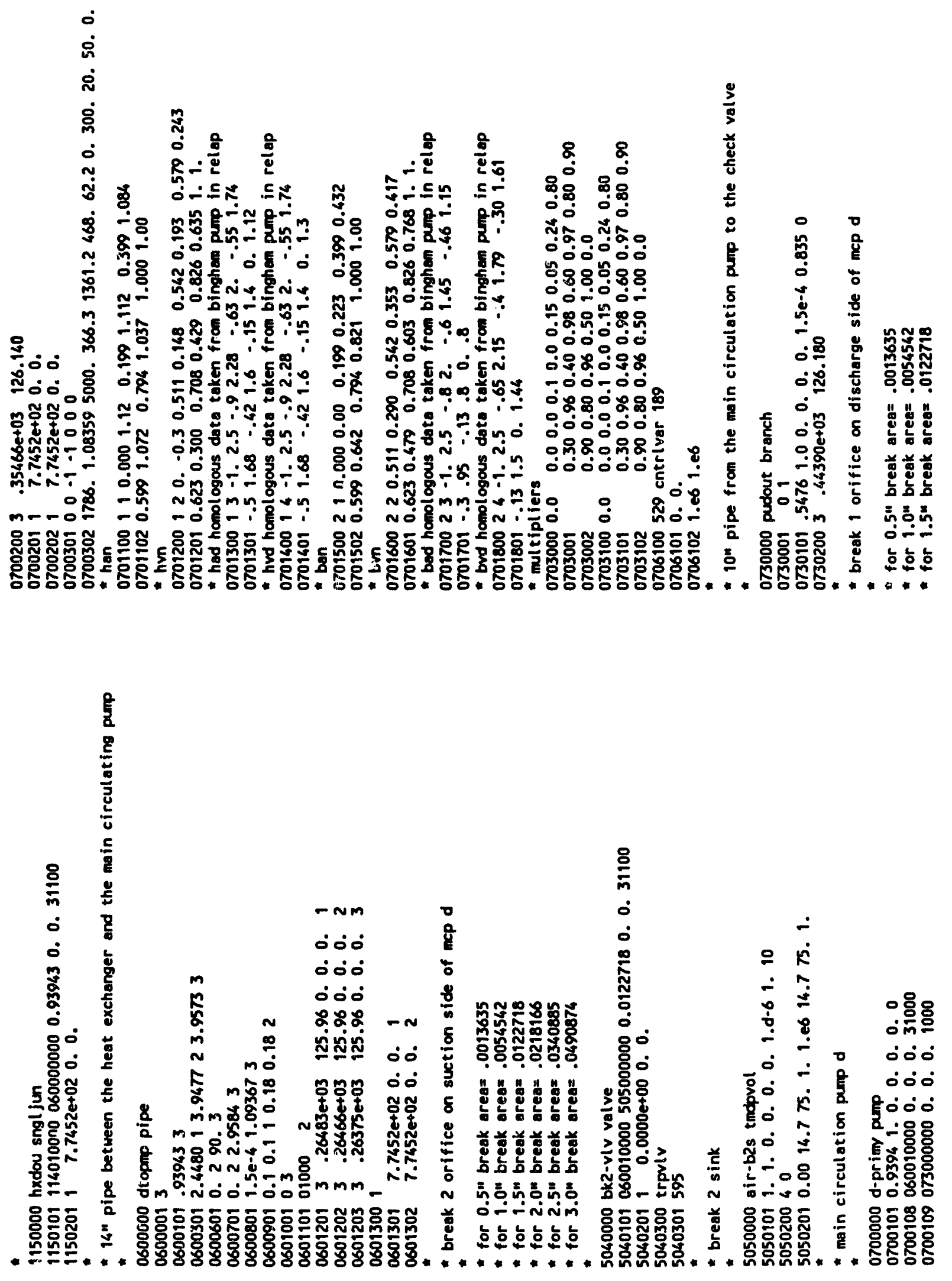

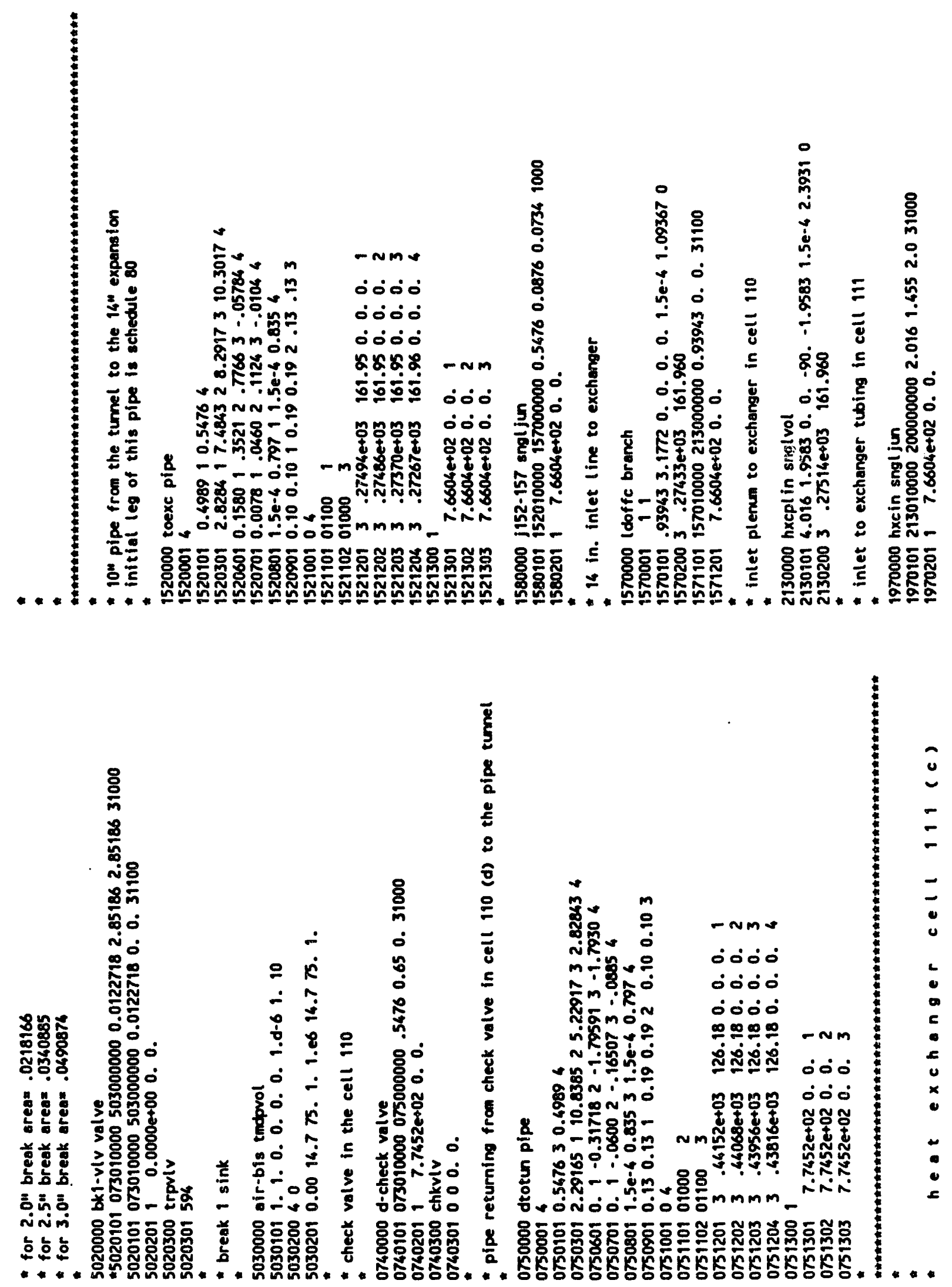

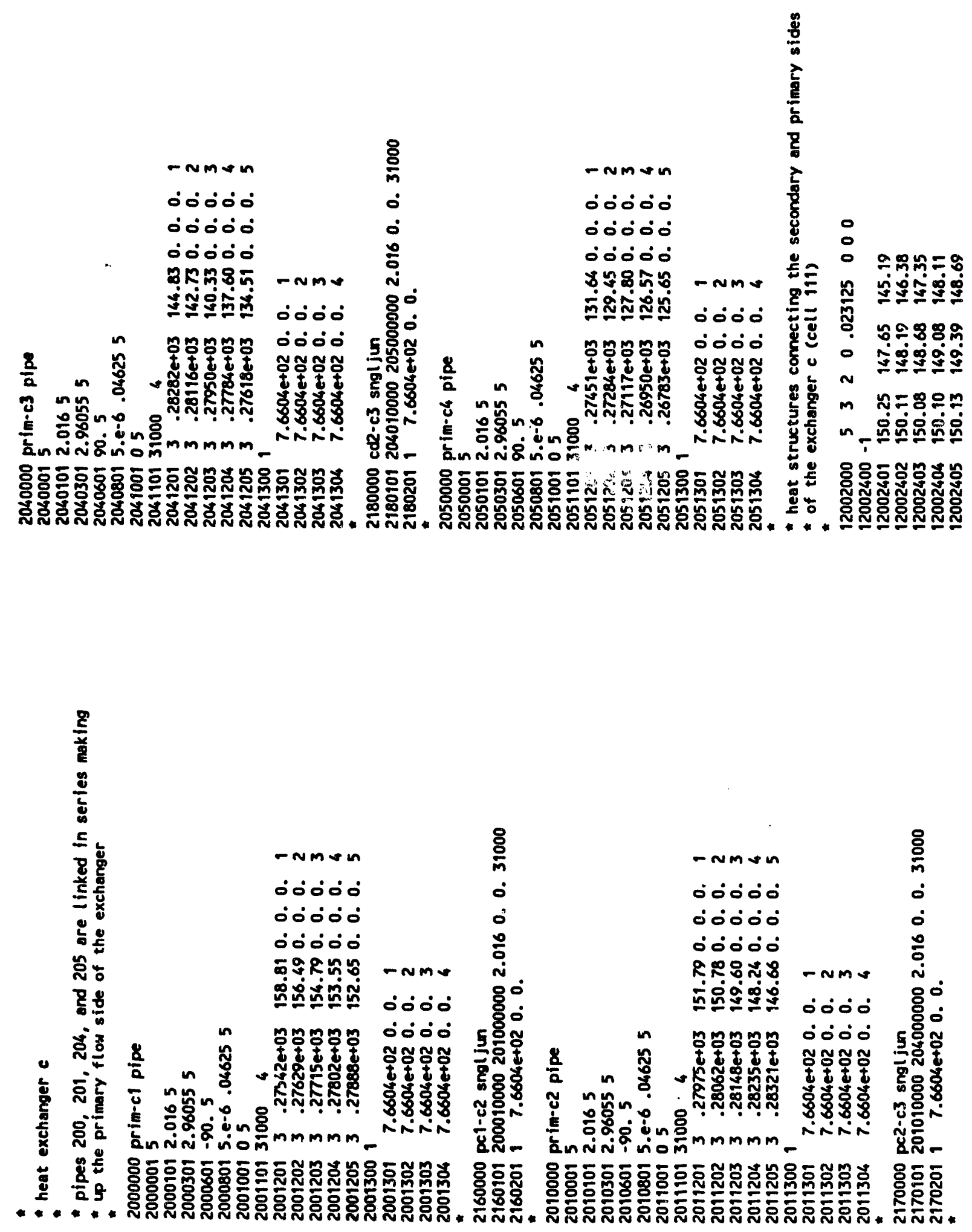

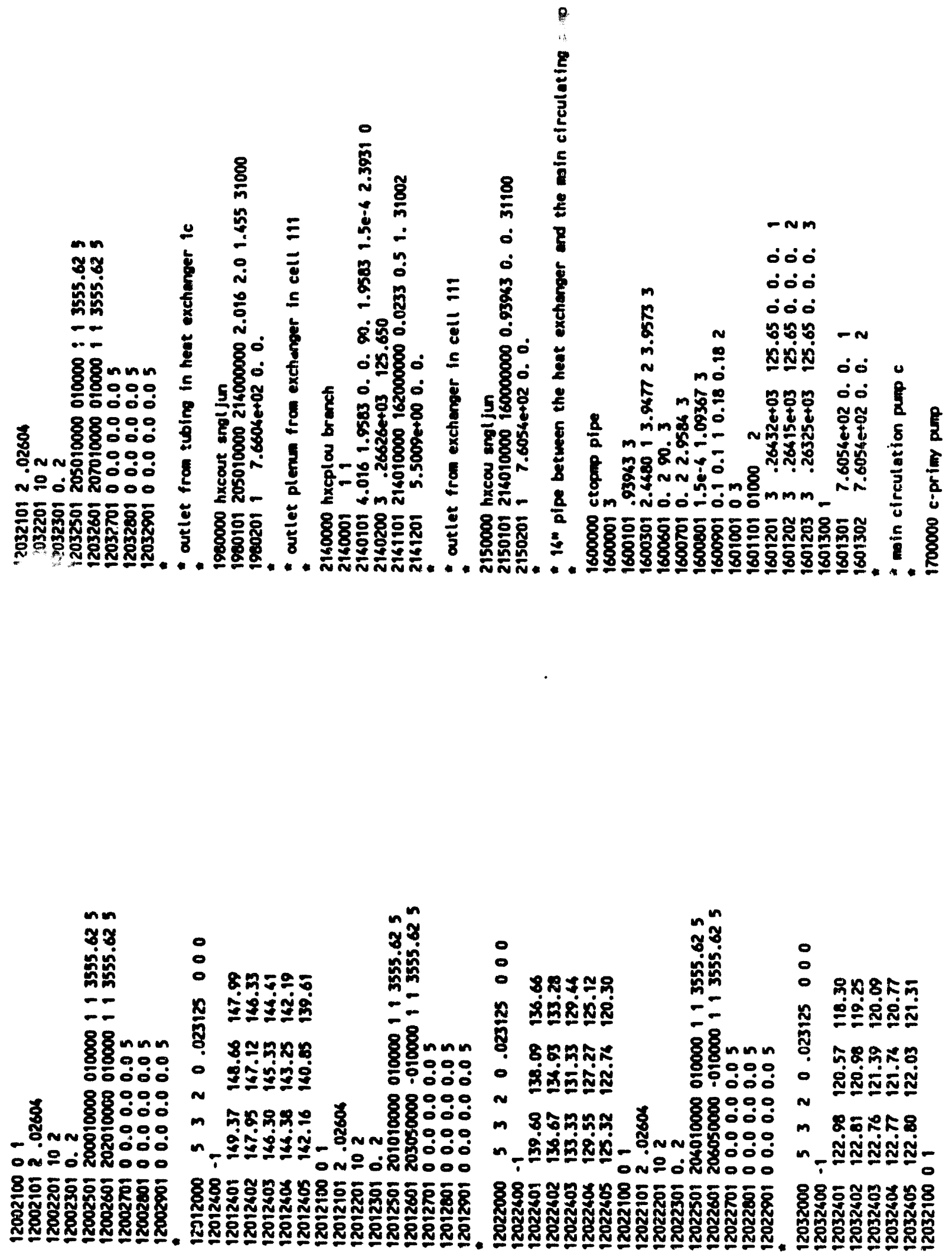

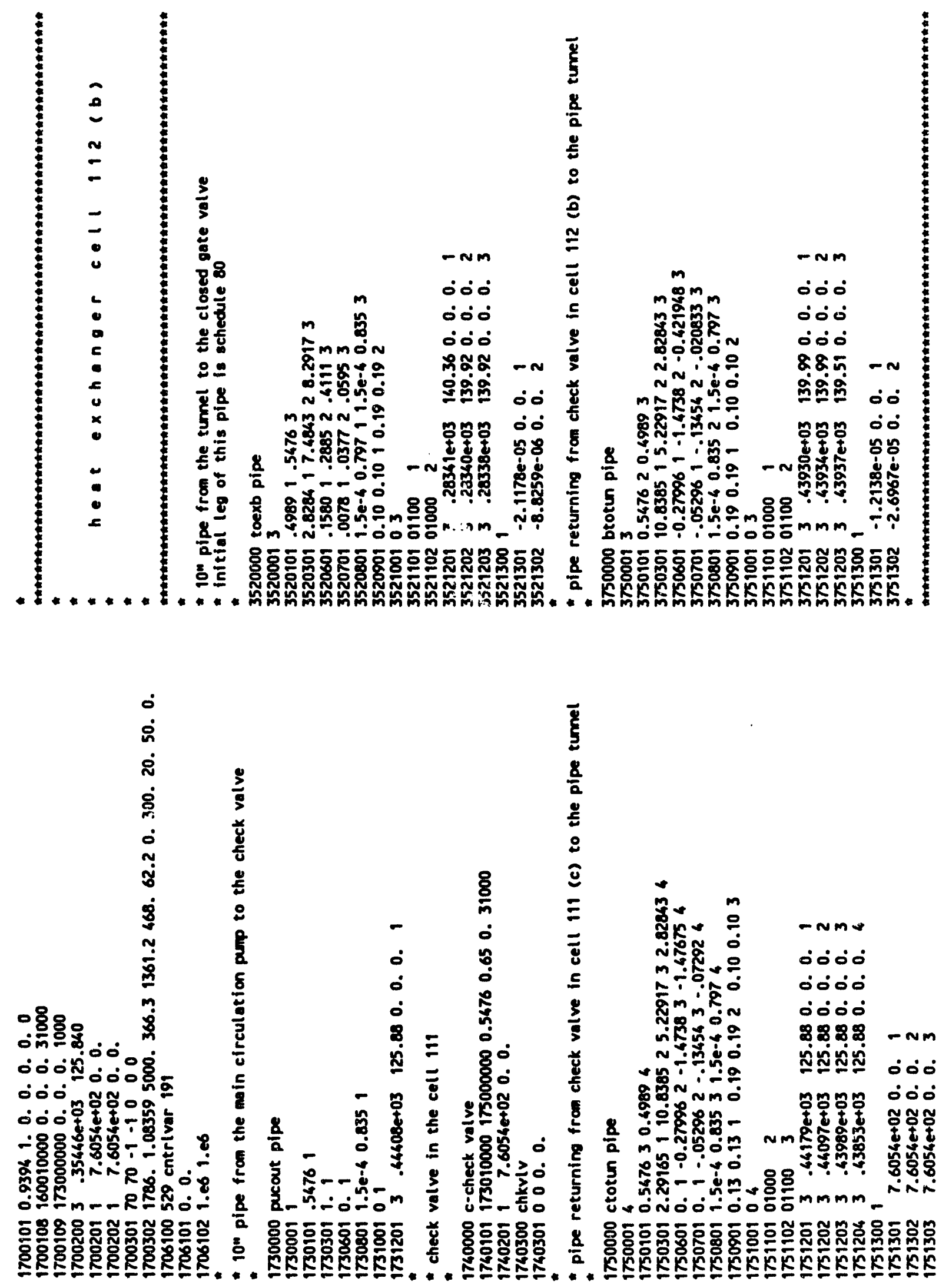

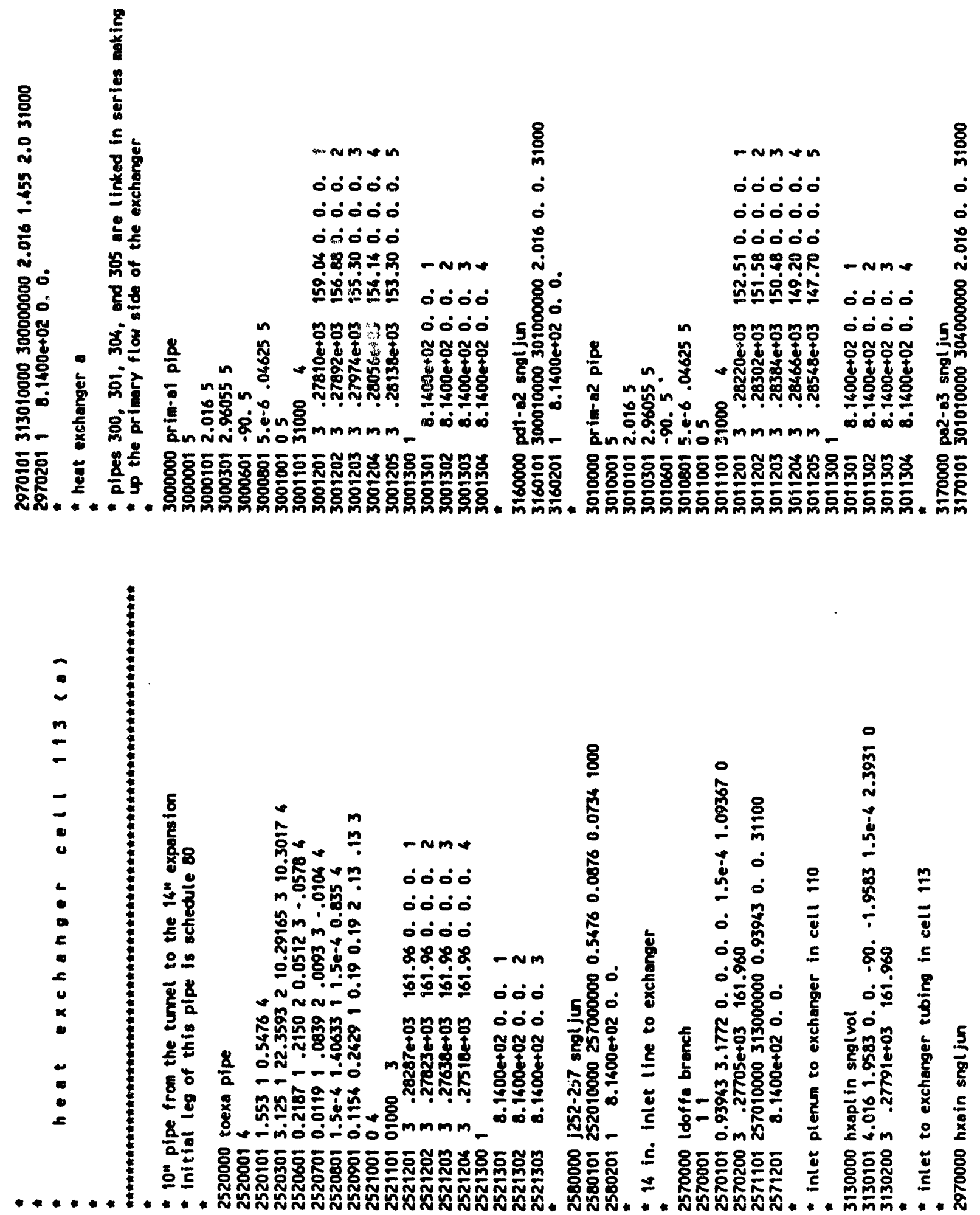

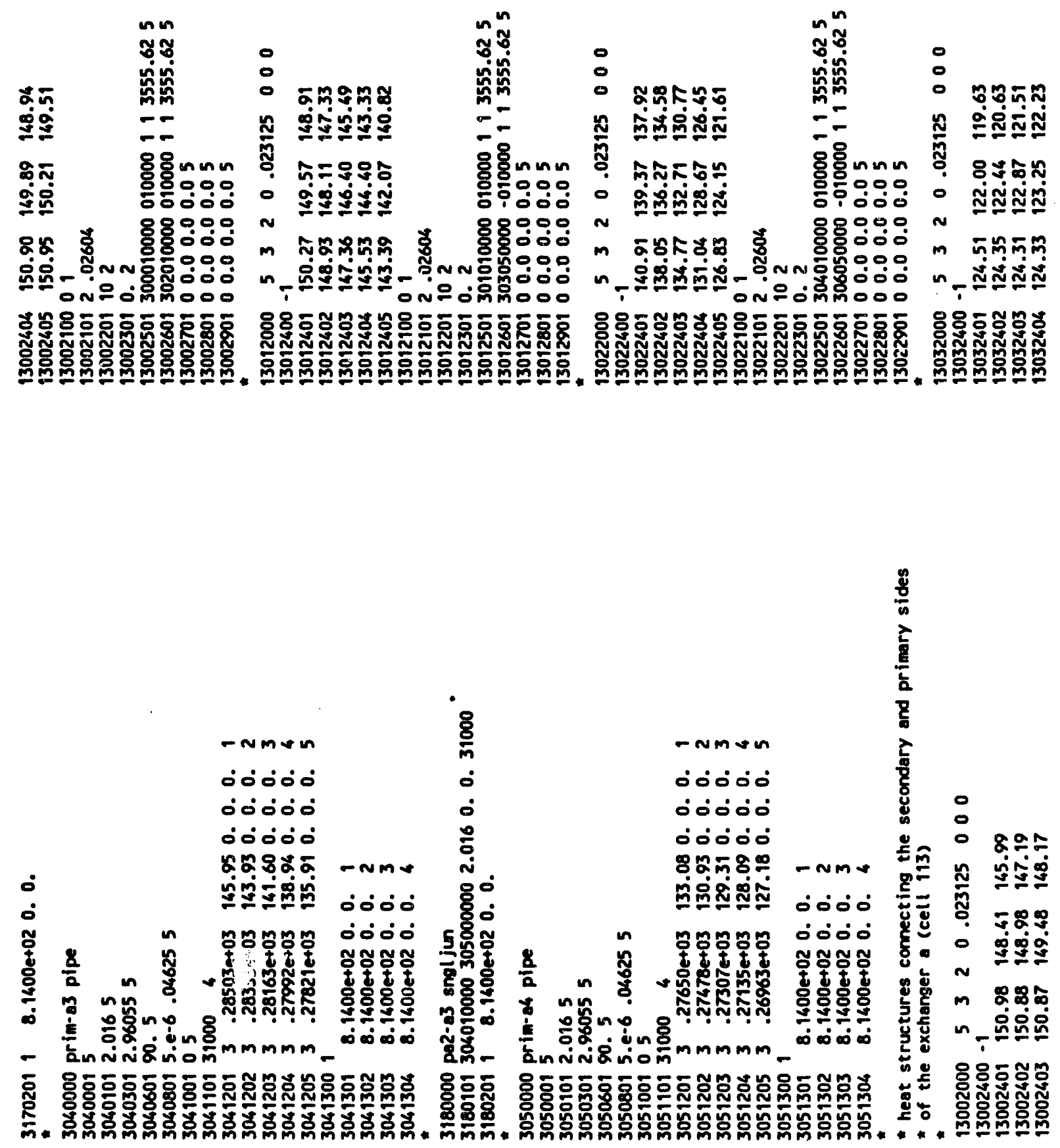

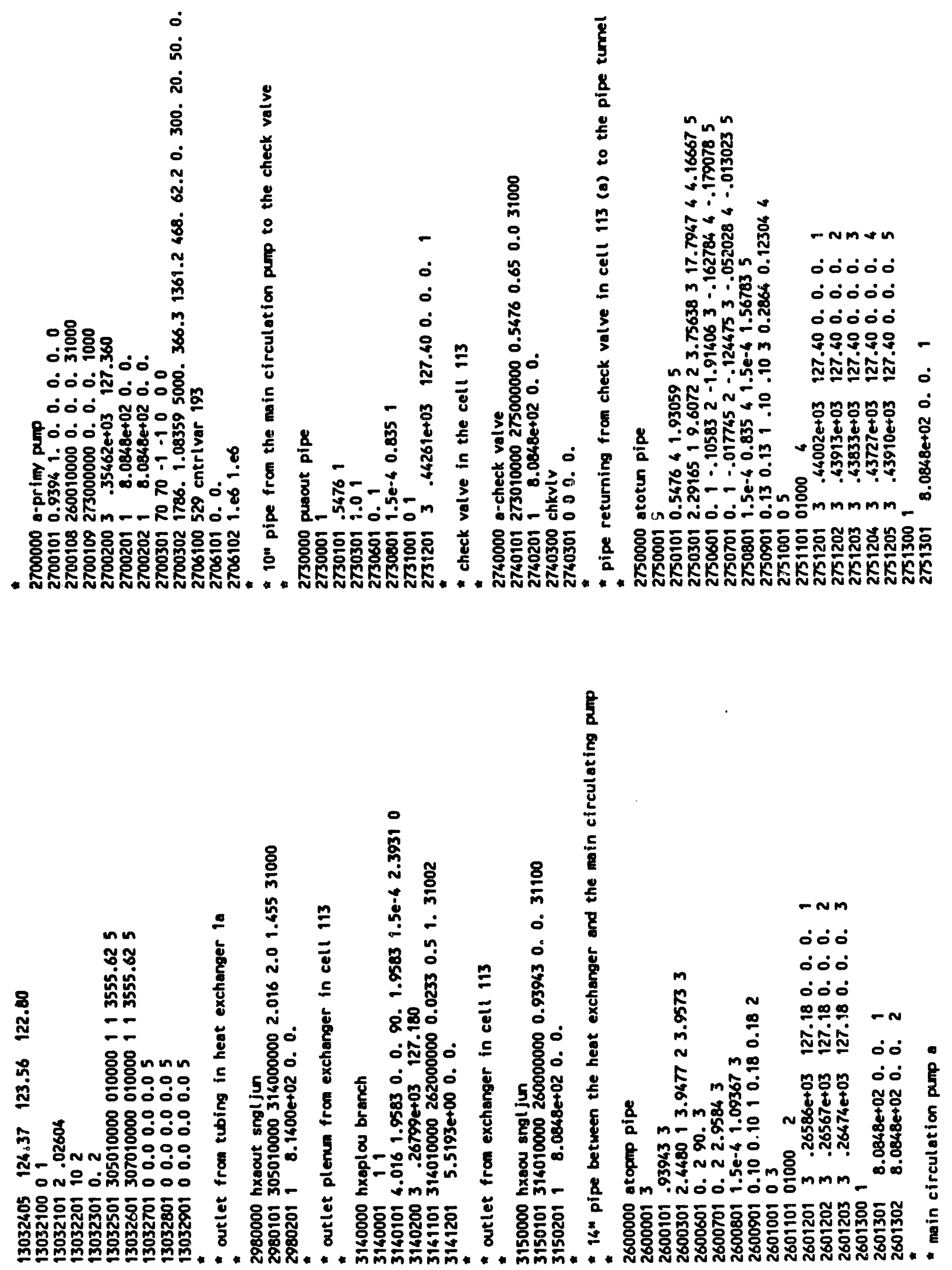

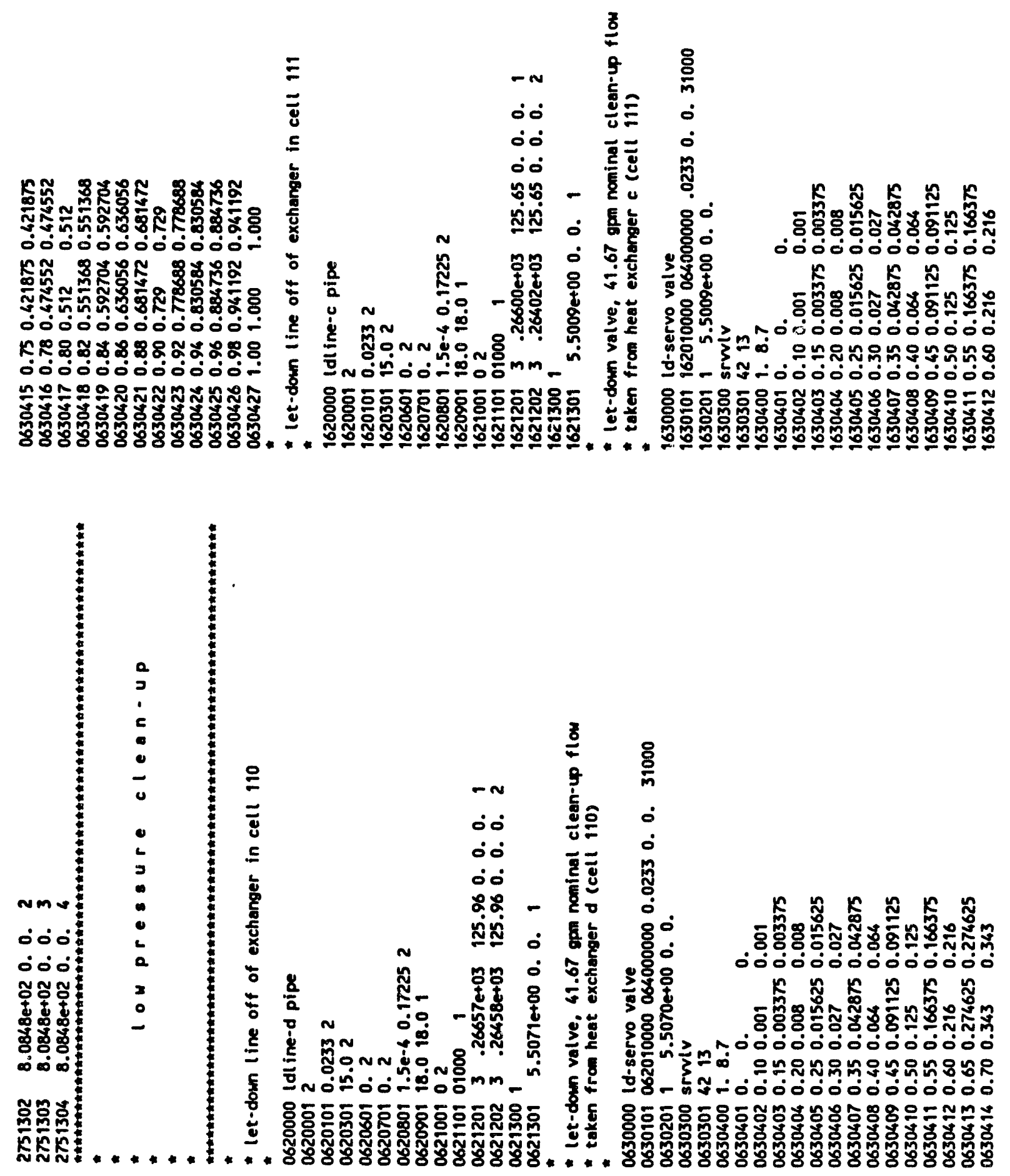


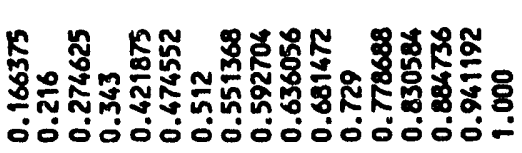

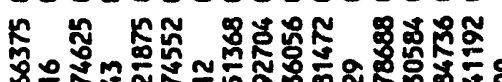

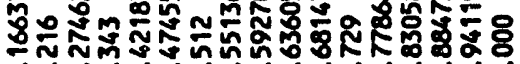

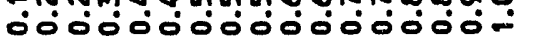

ش

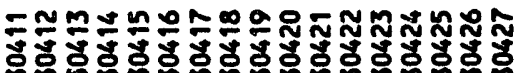

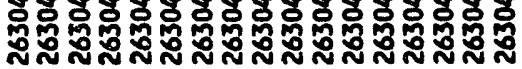
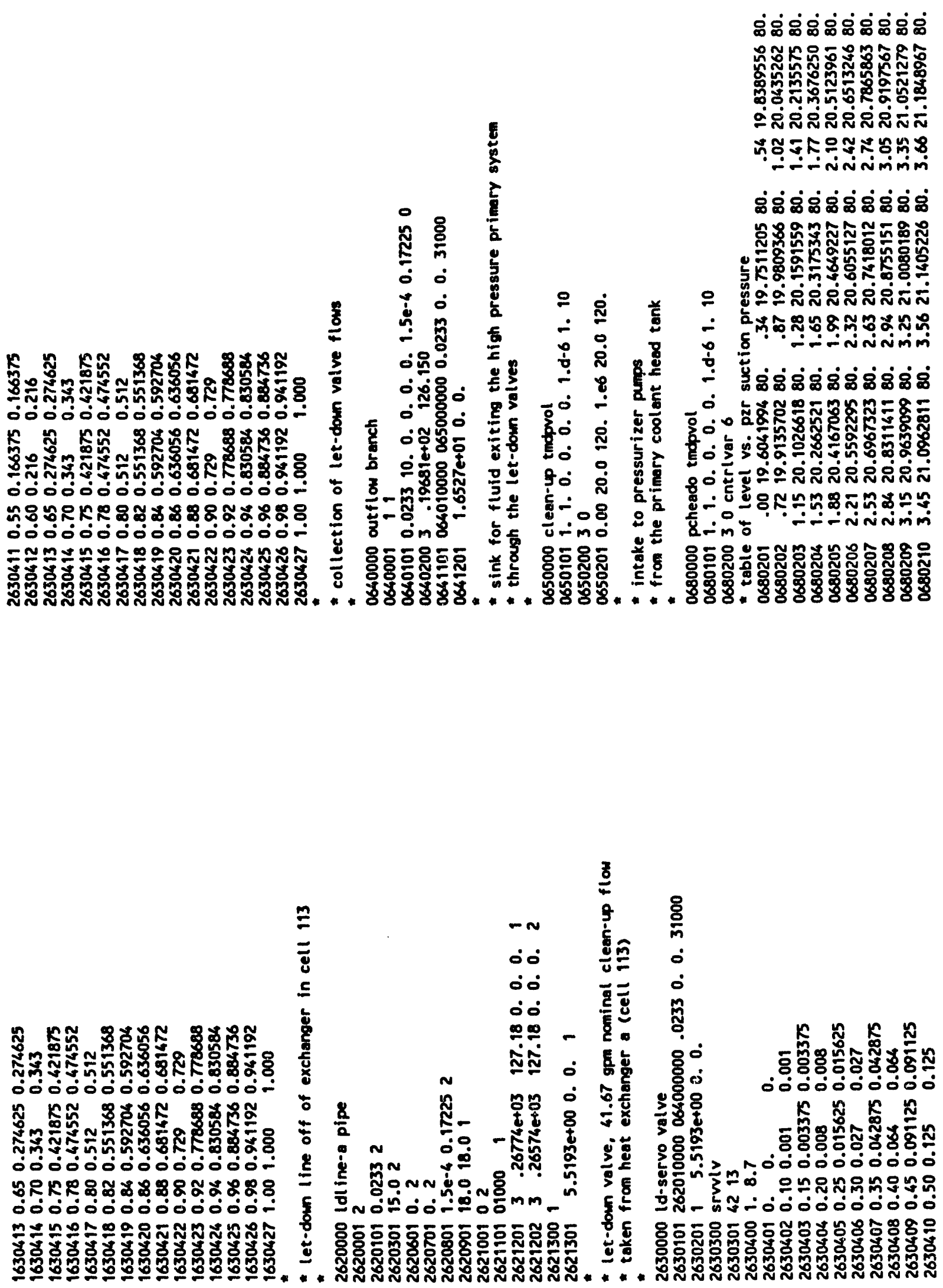

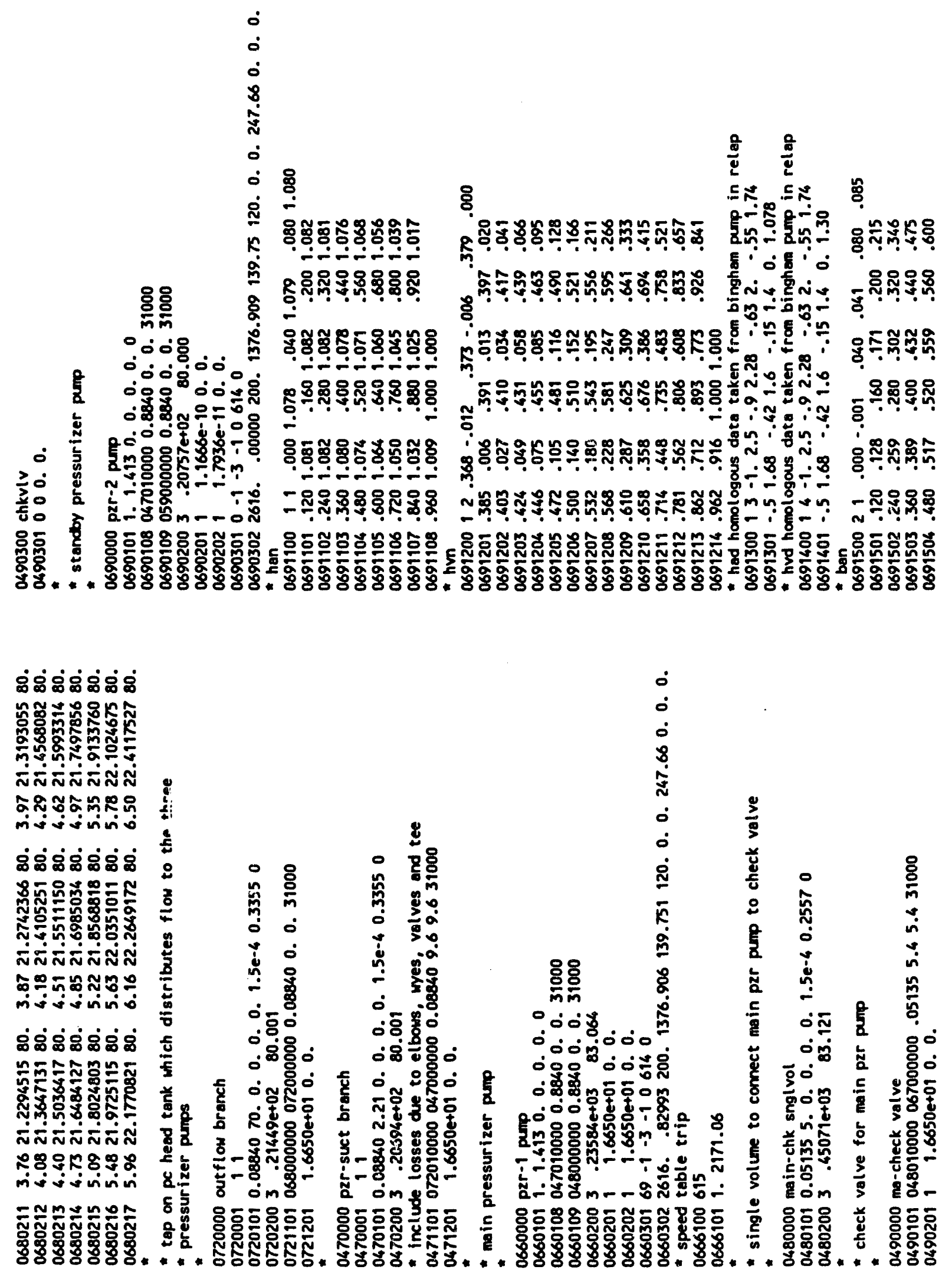

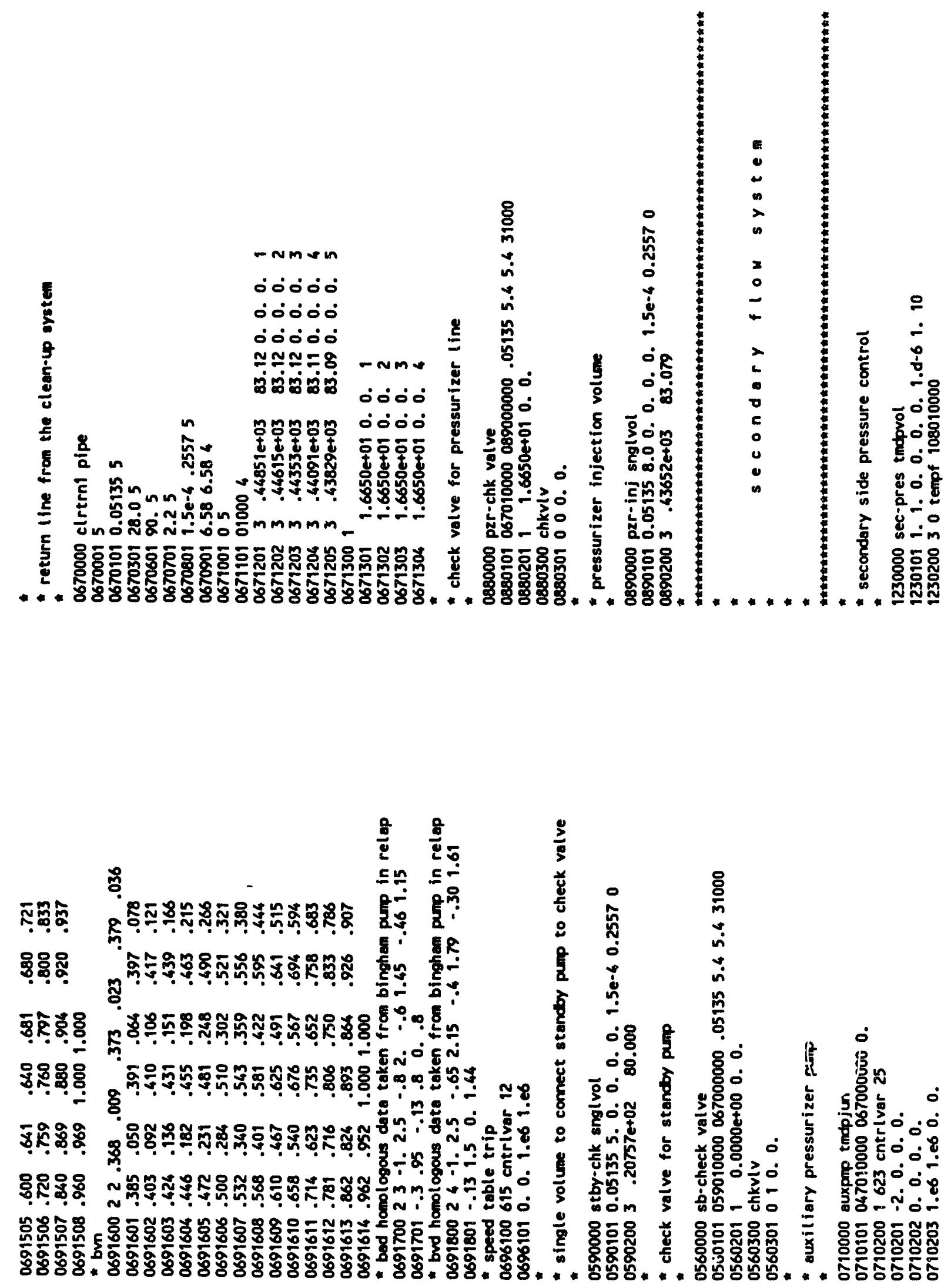

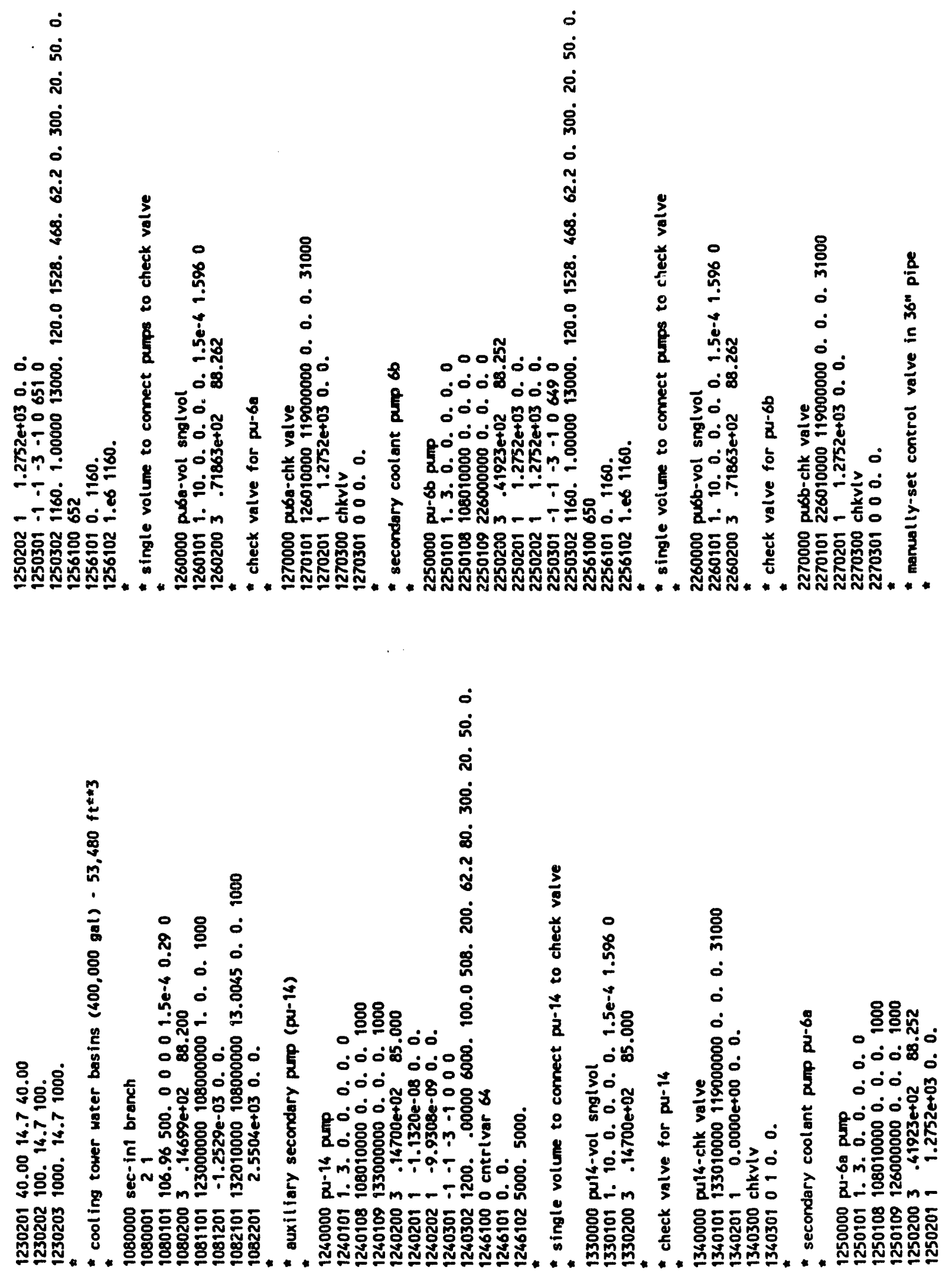

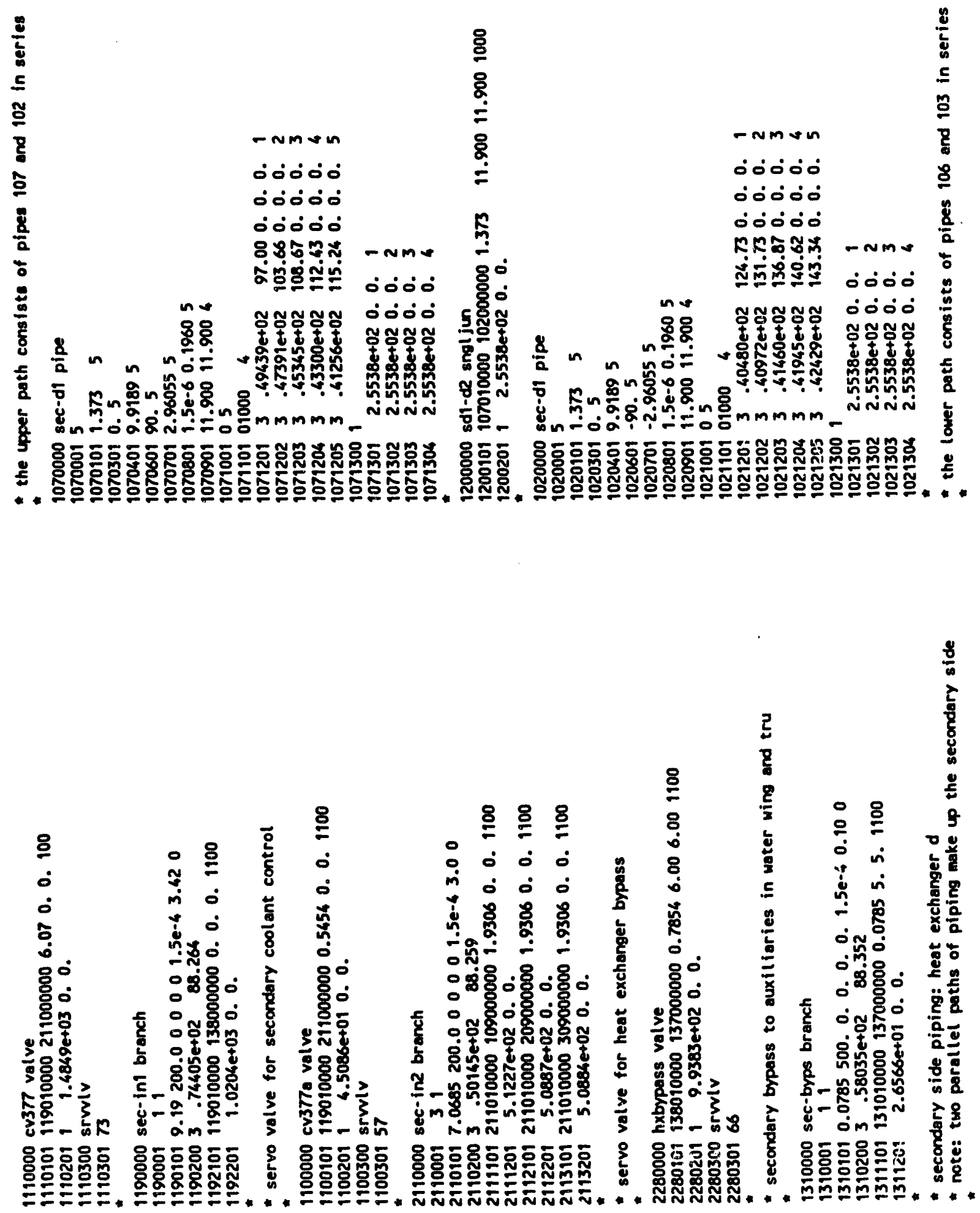

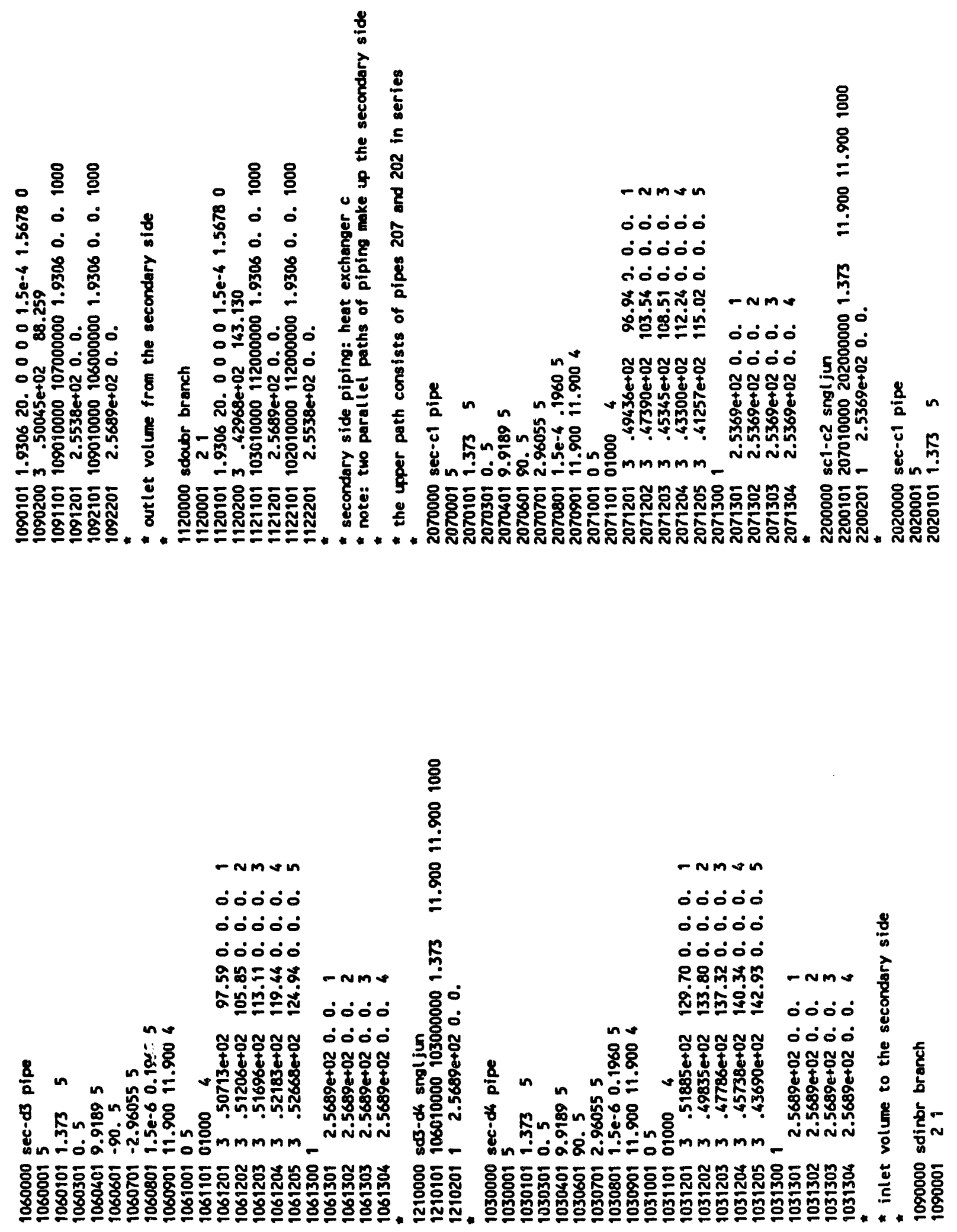

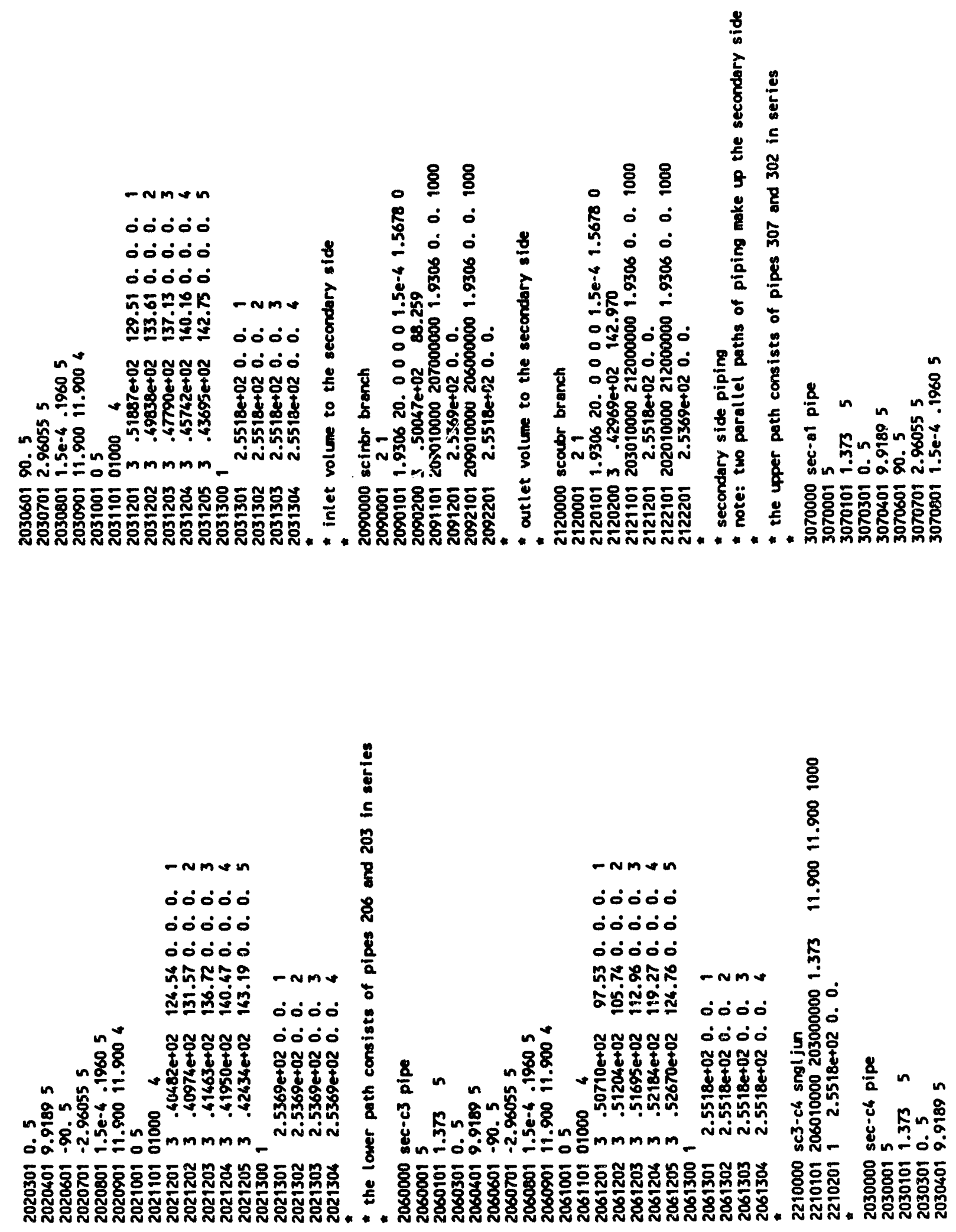

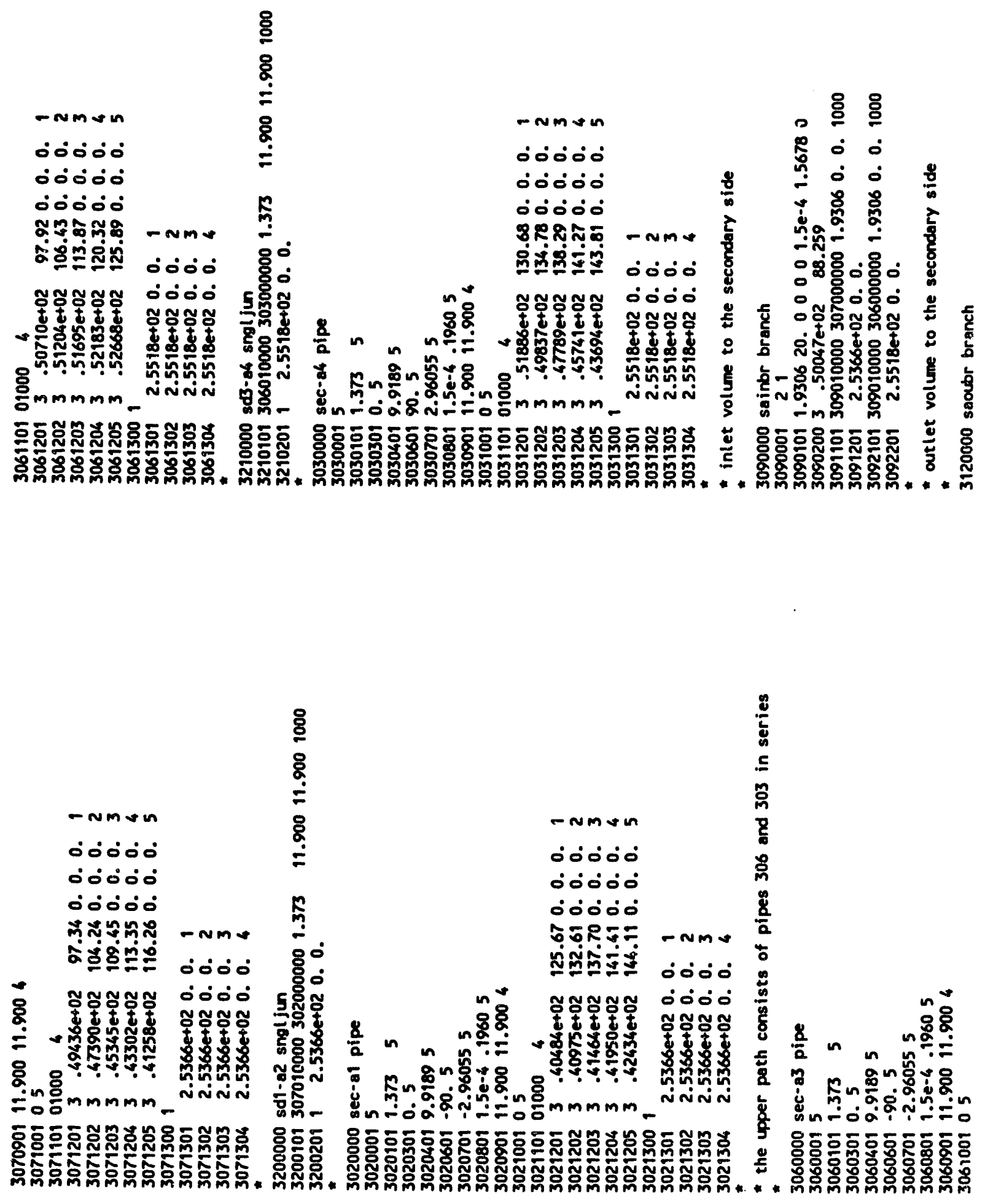

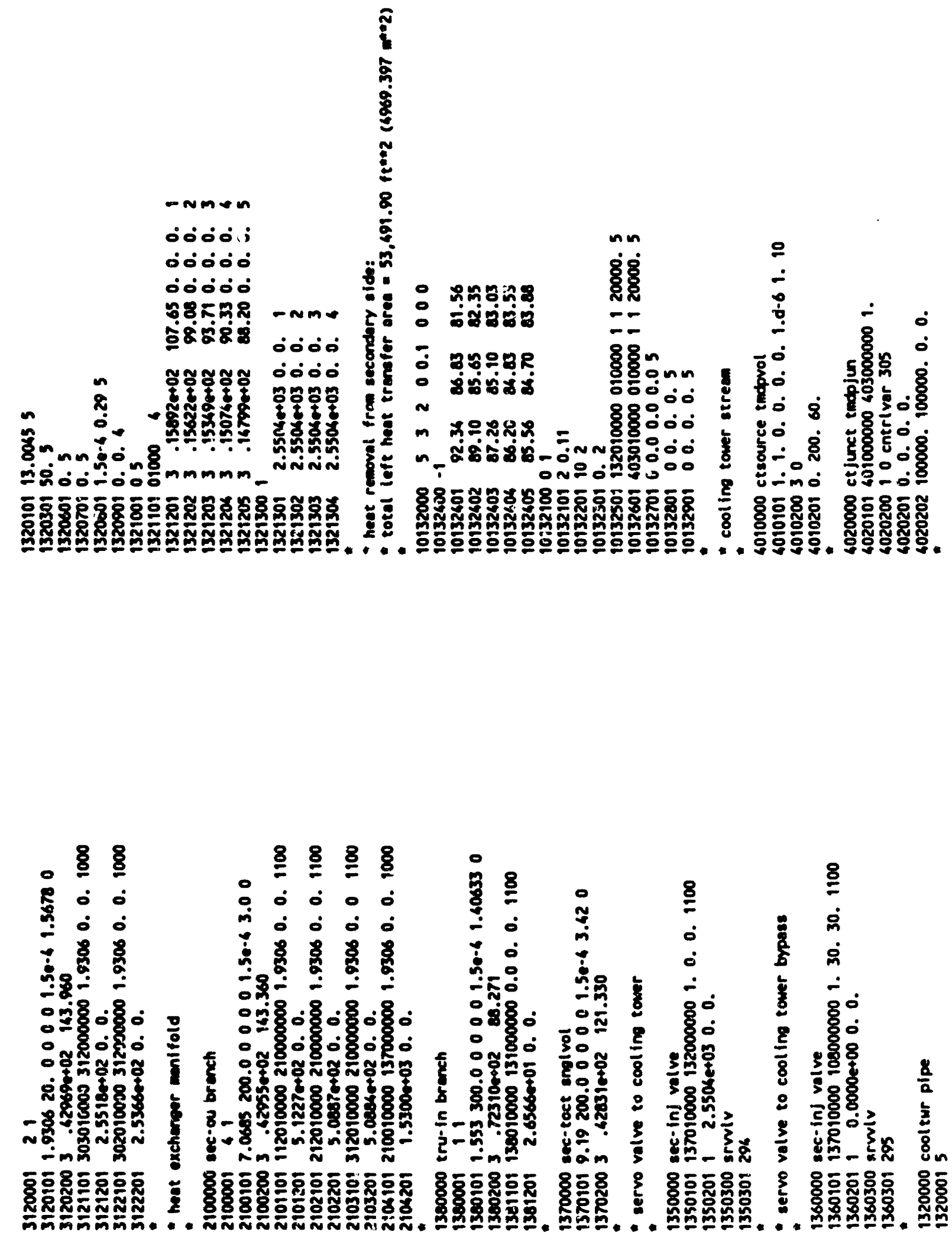

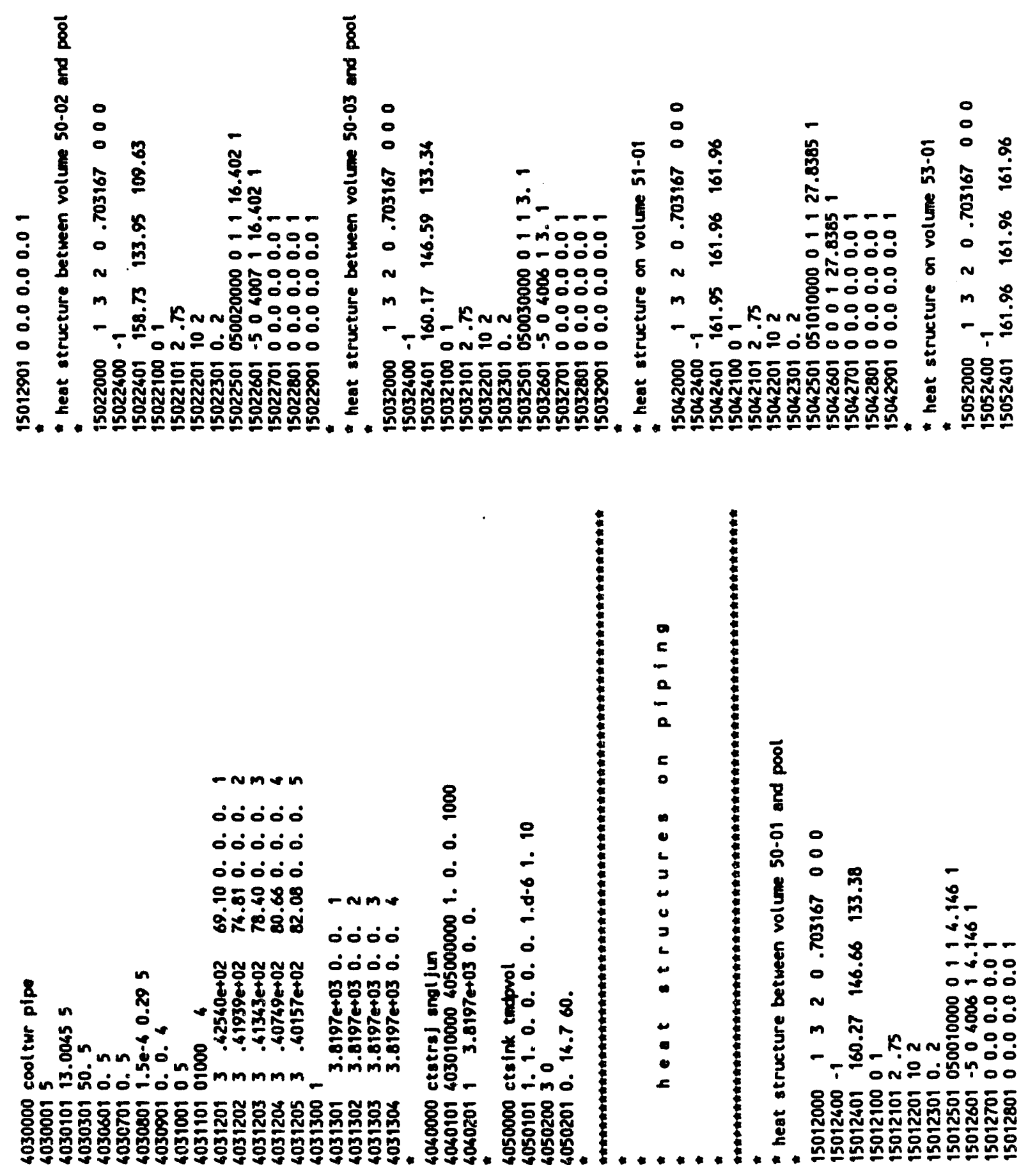

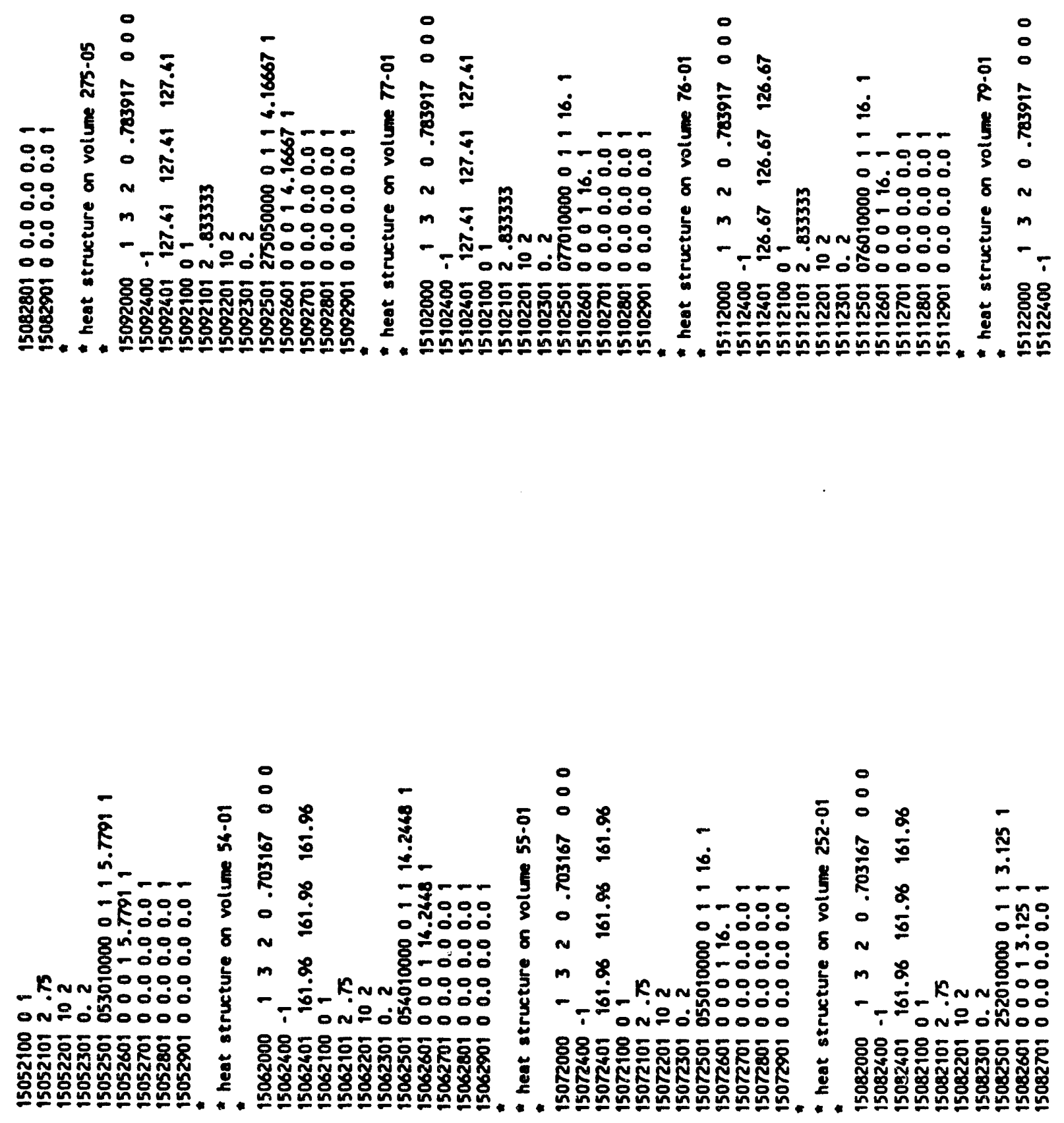

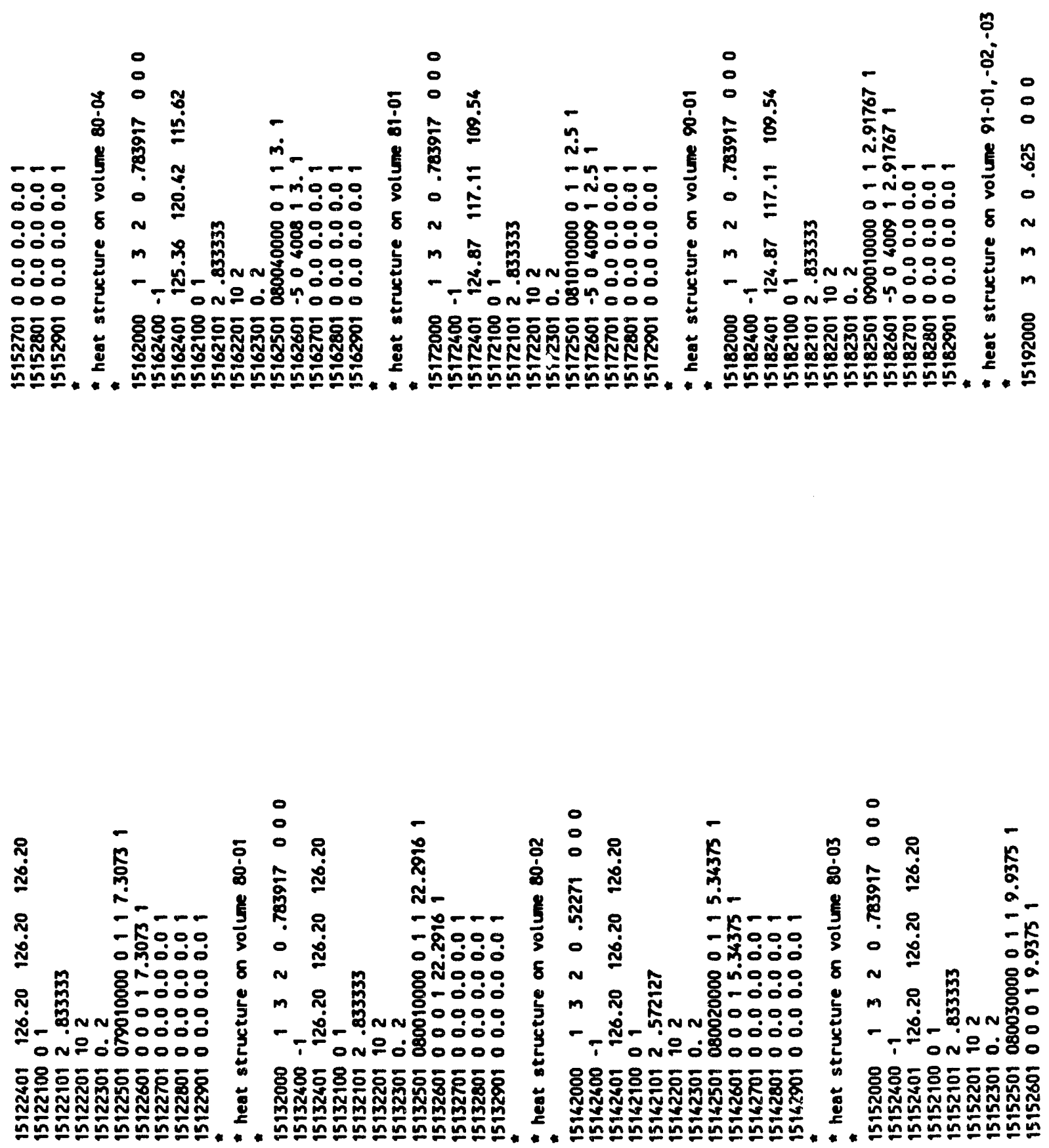

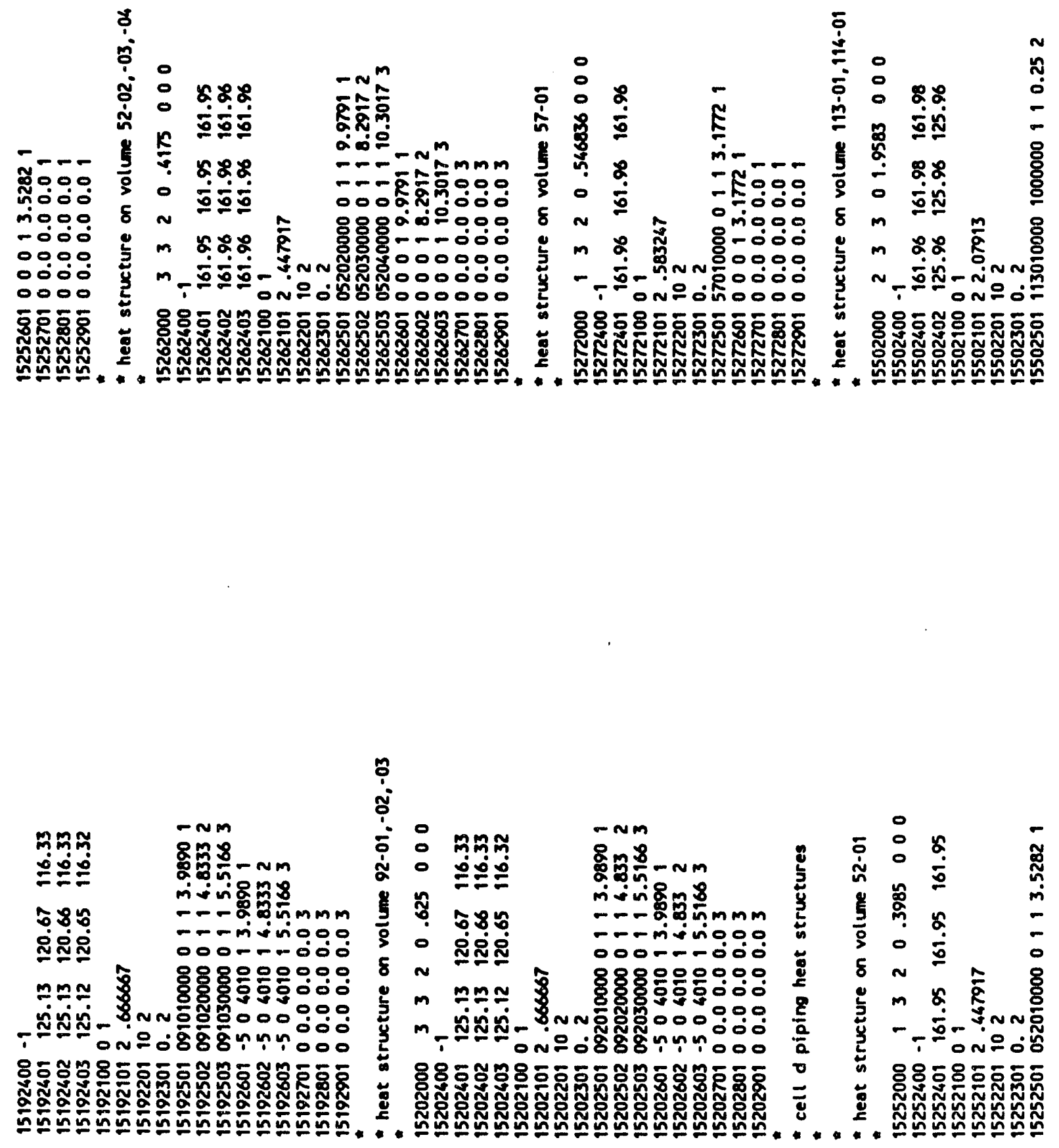

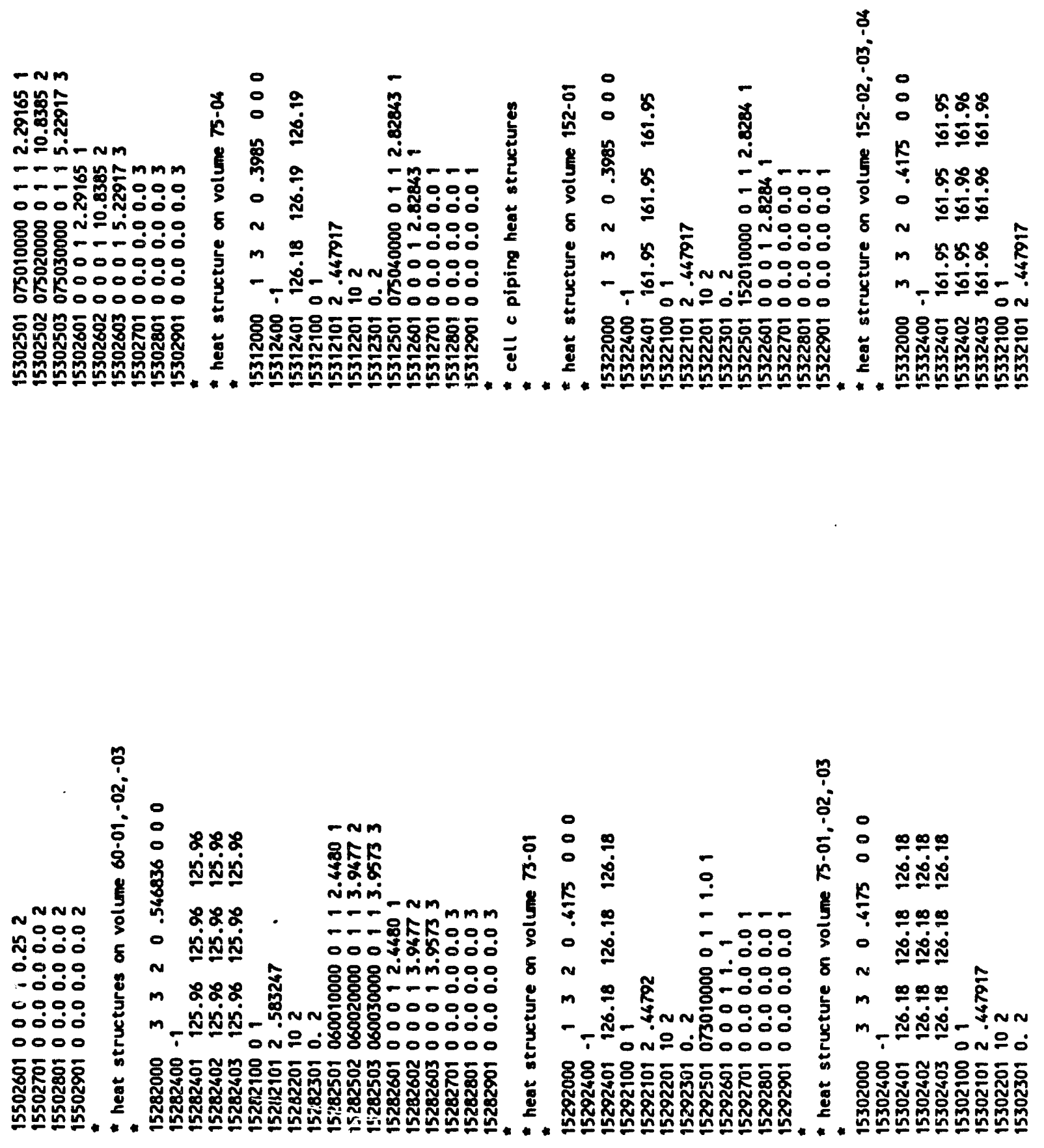

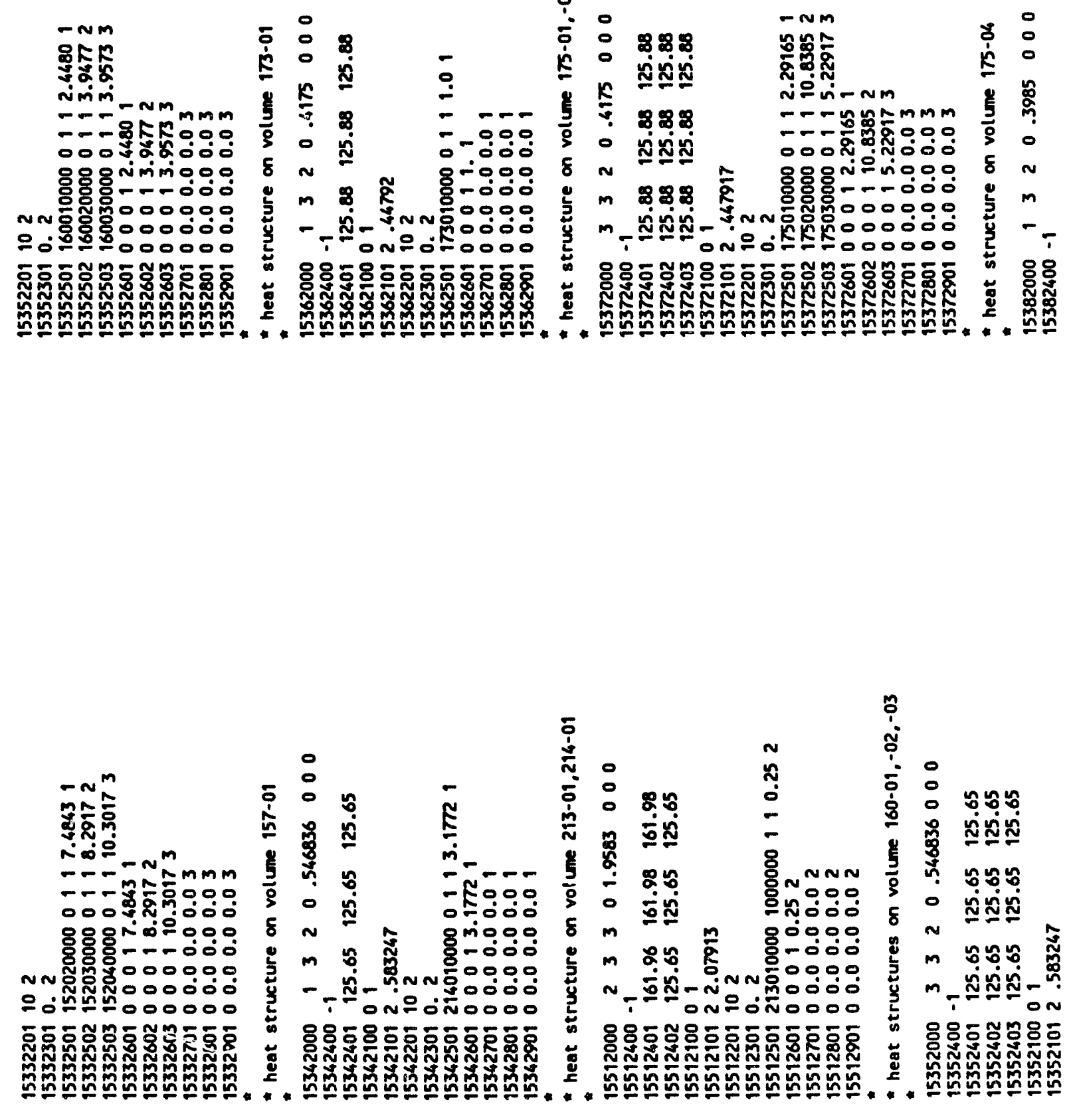

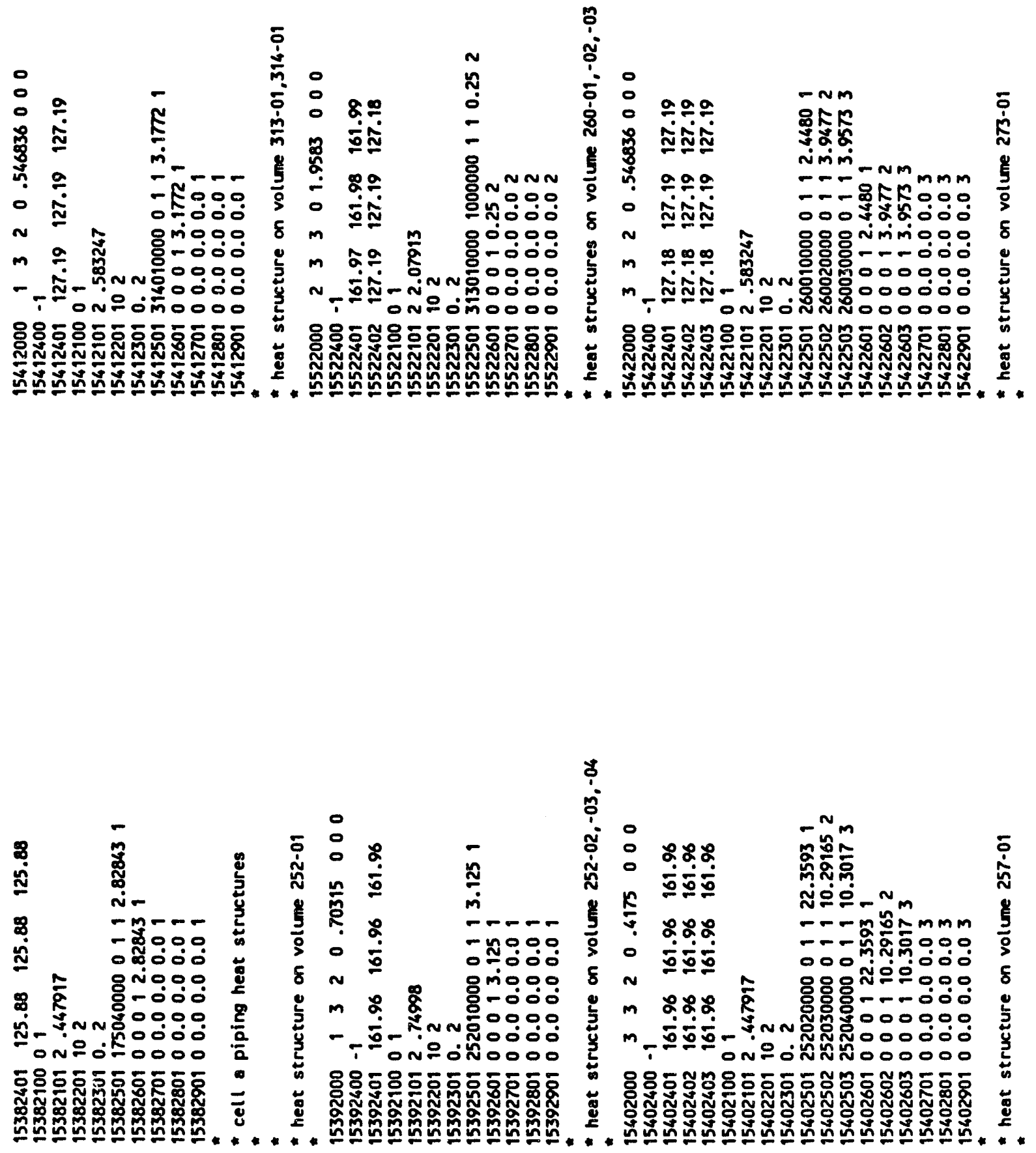

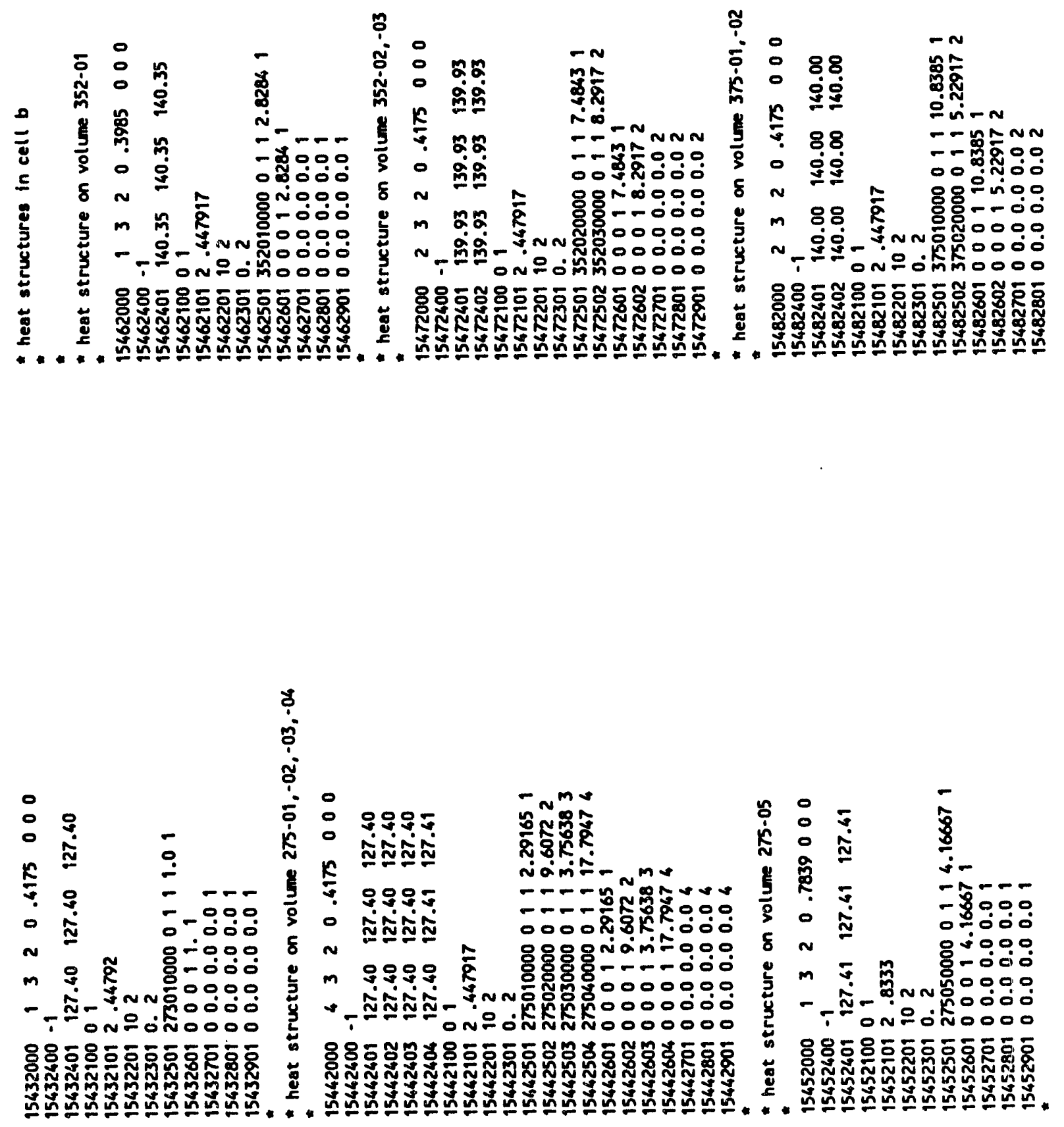

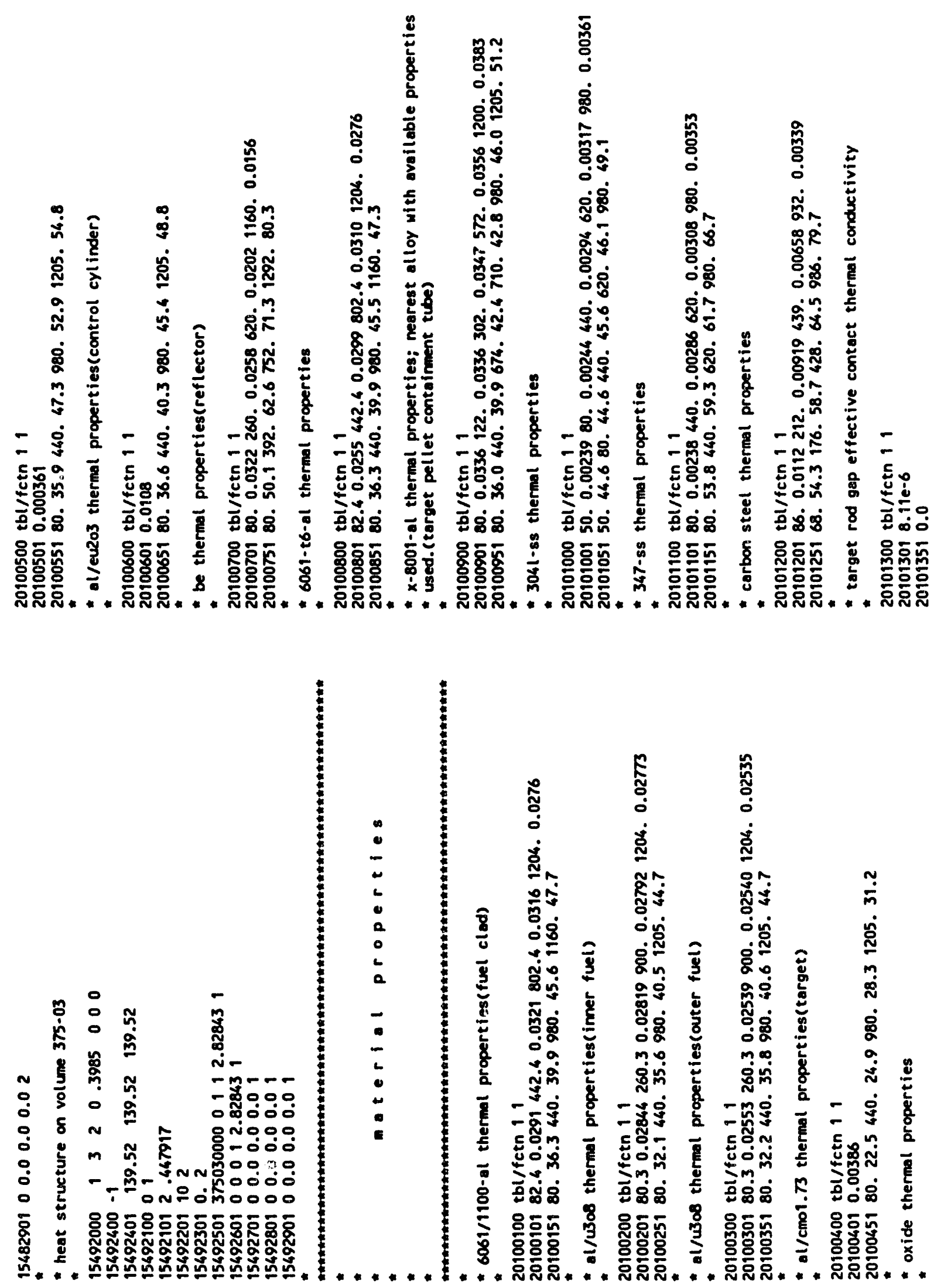

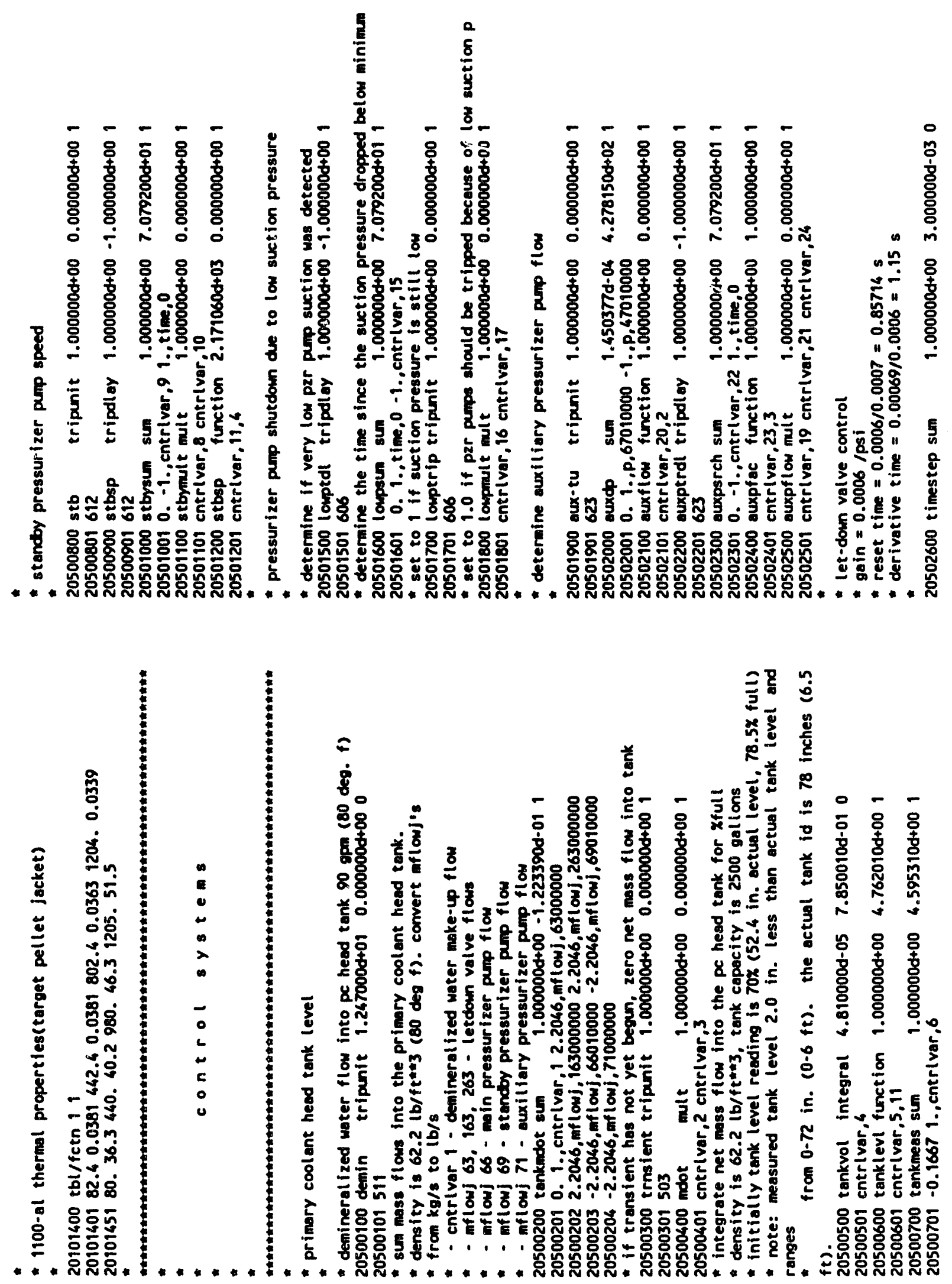


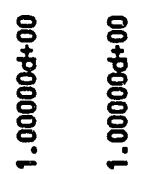

웅

웅

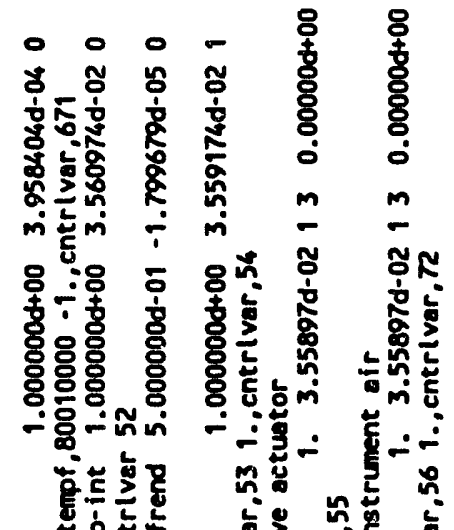

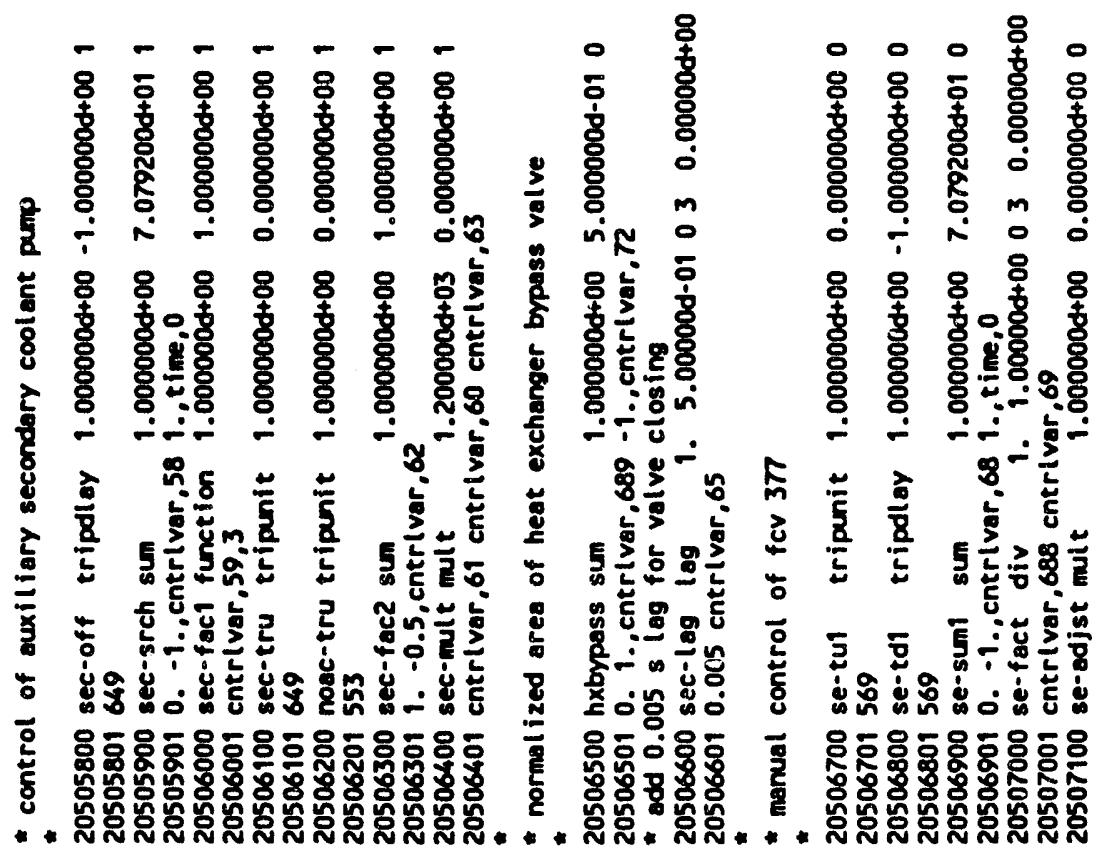

용

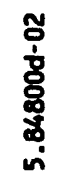

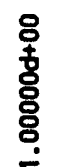

웅

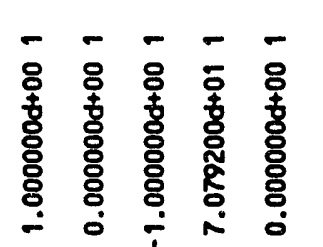

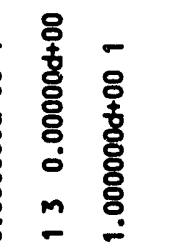

尊

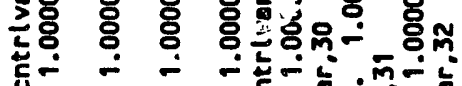

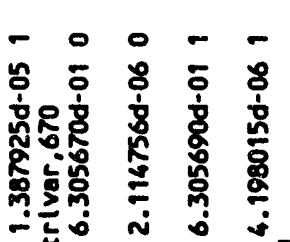

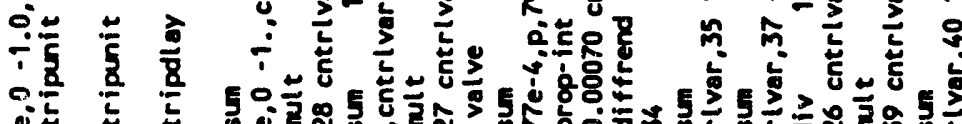

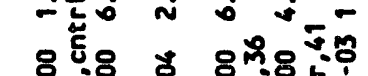

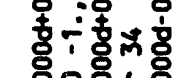

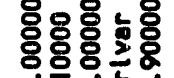

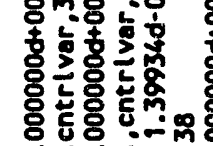

-

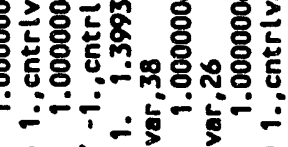

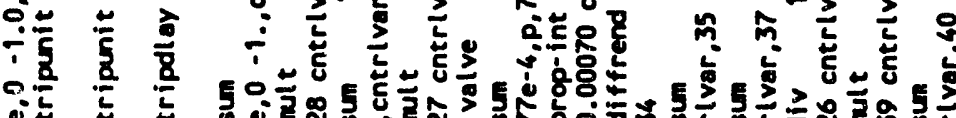

告

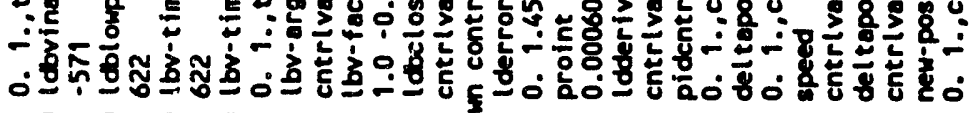

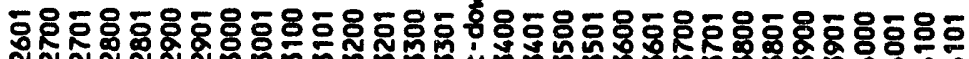

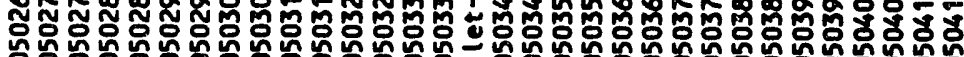

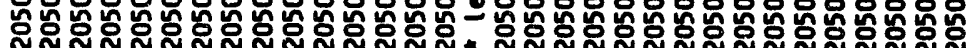



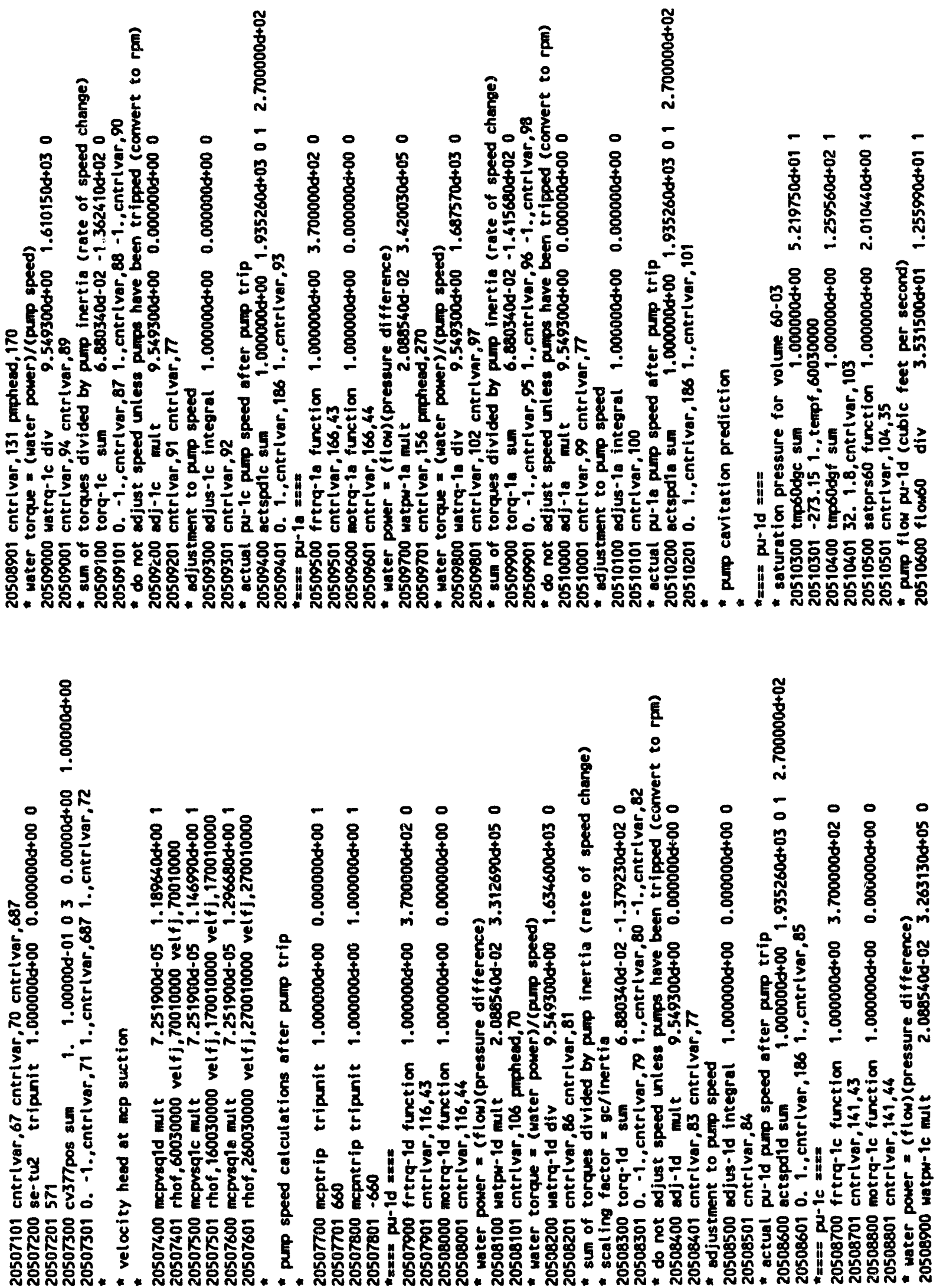

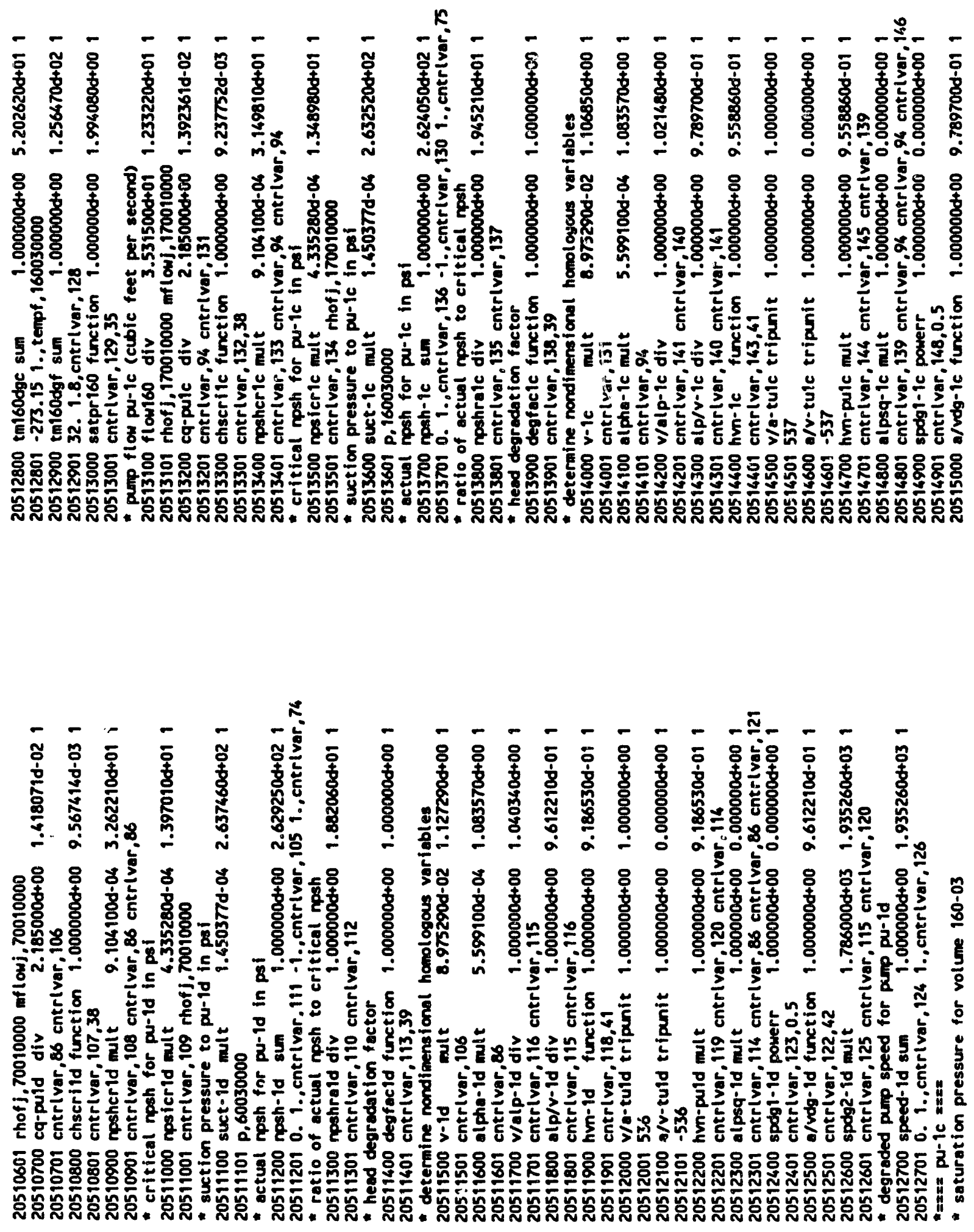

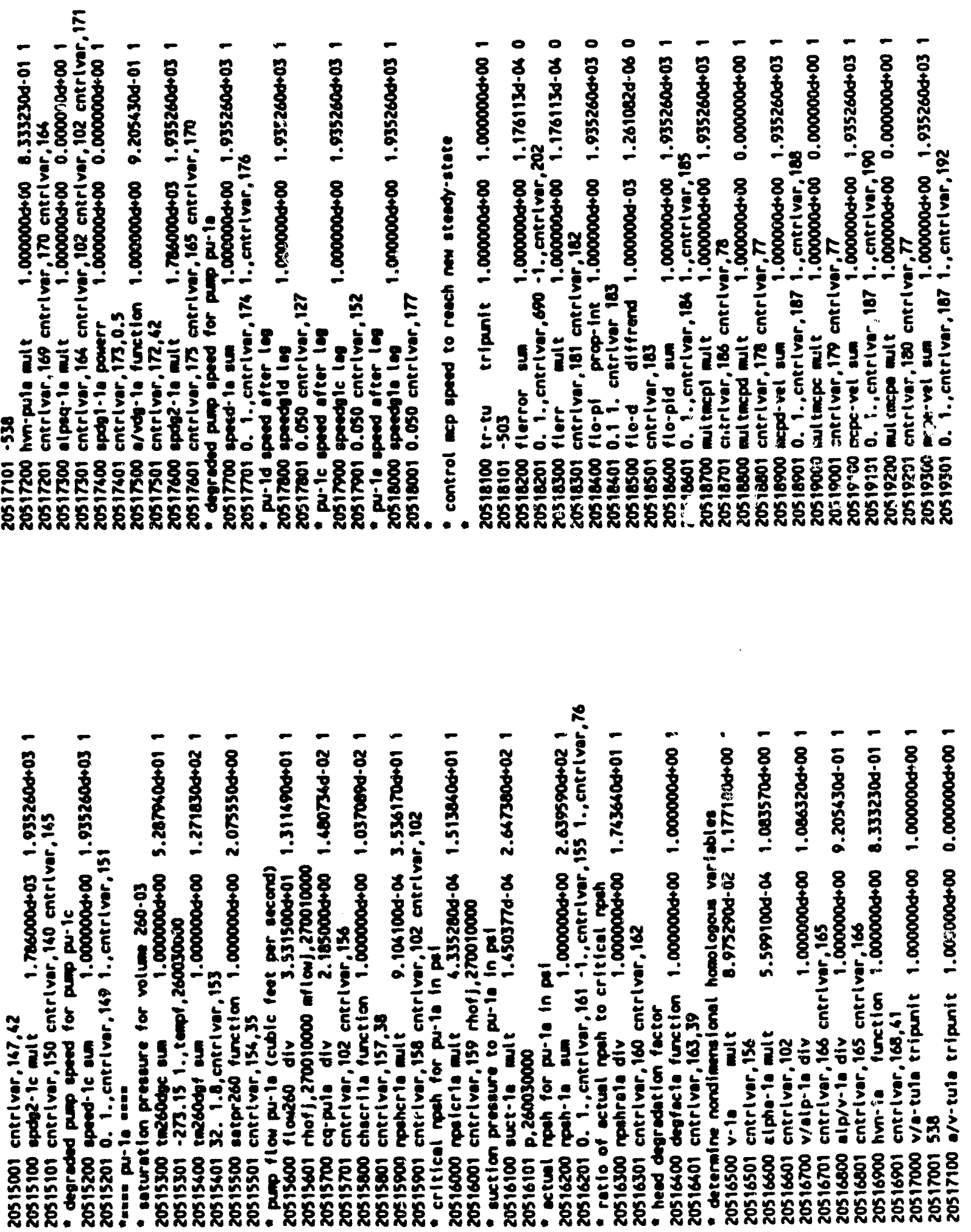

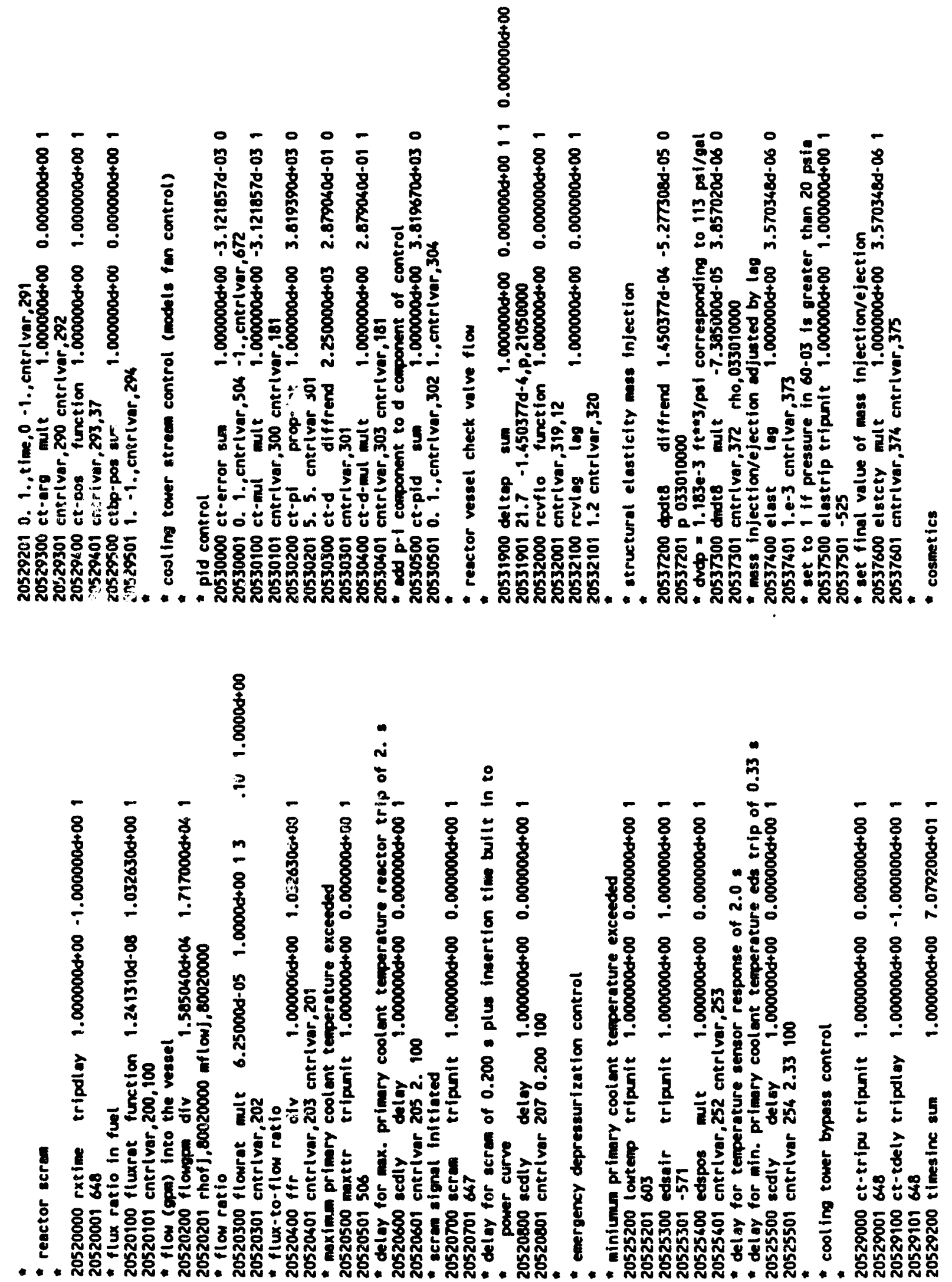

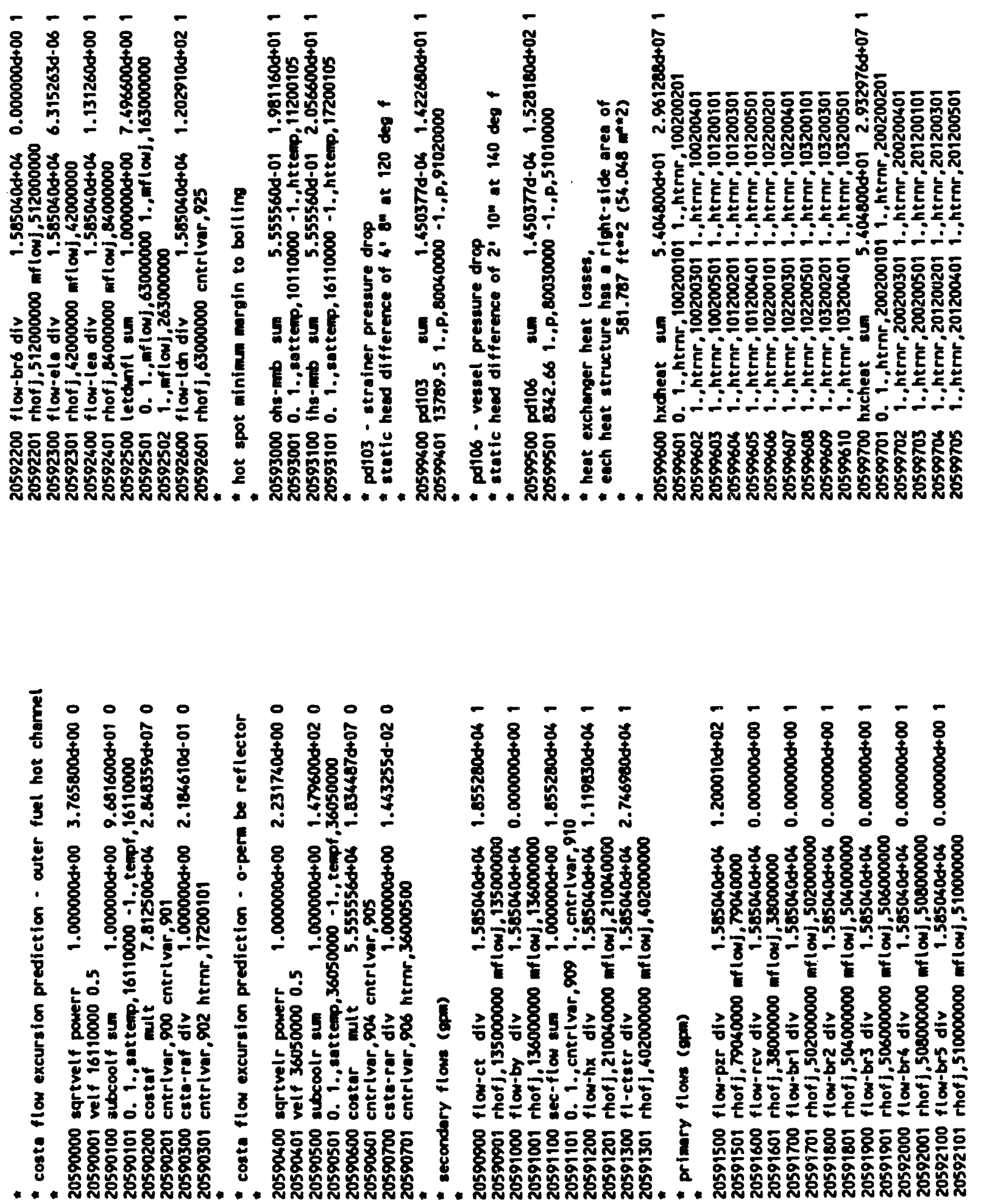


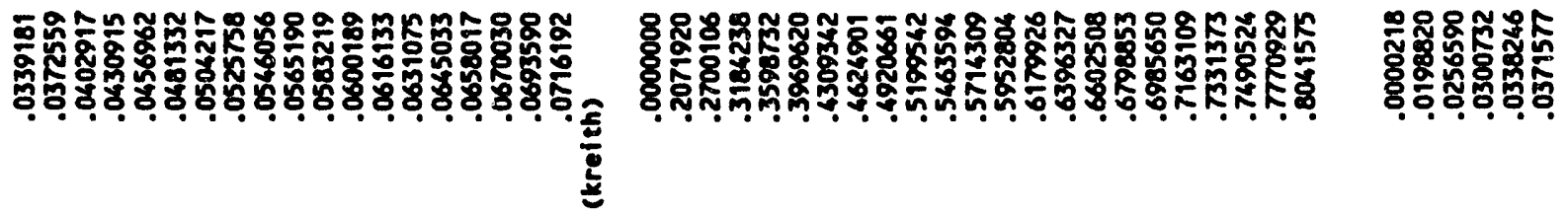

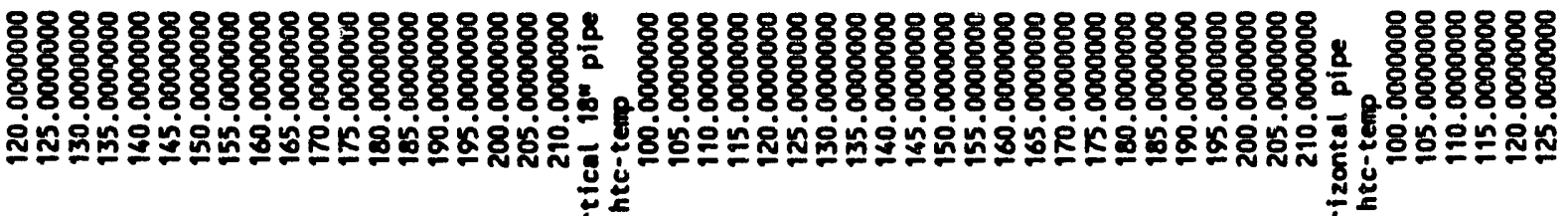

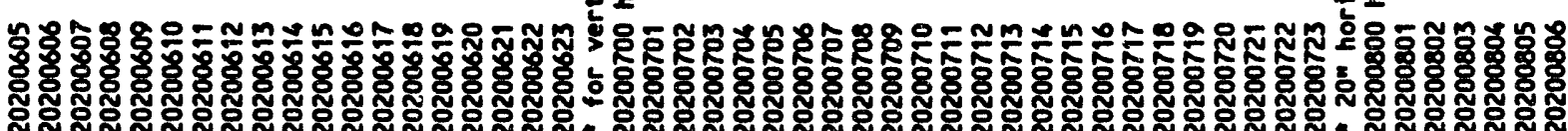

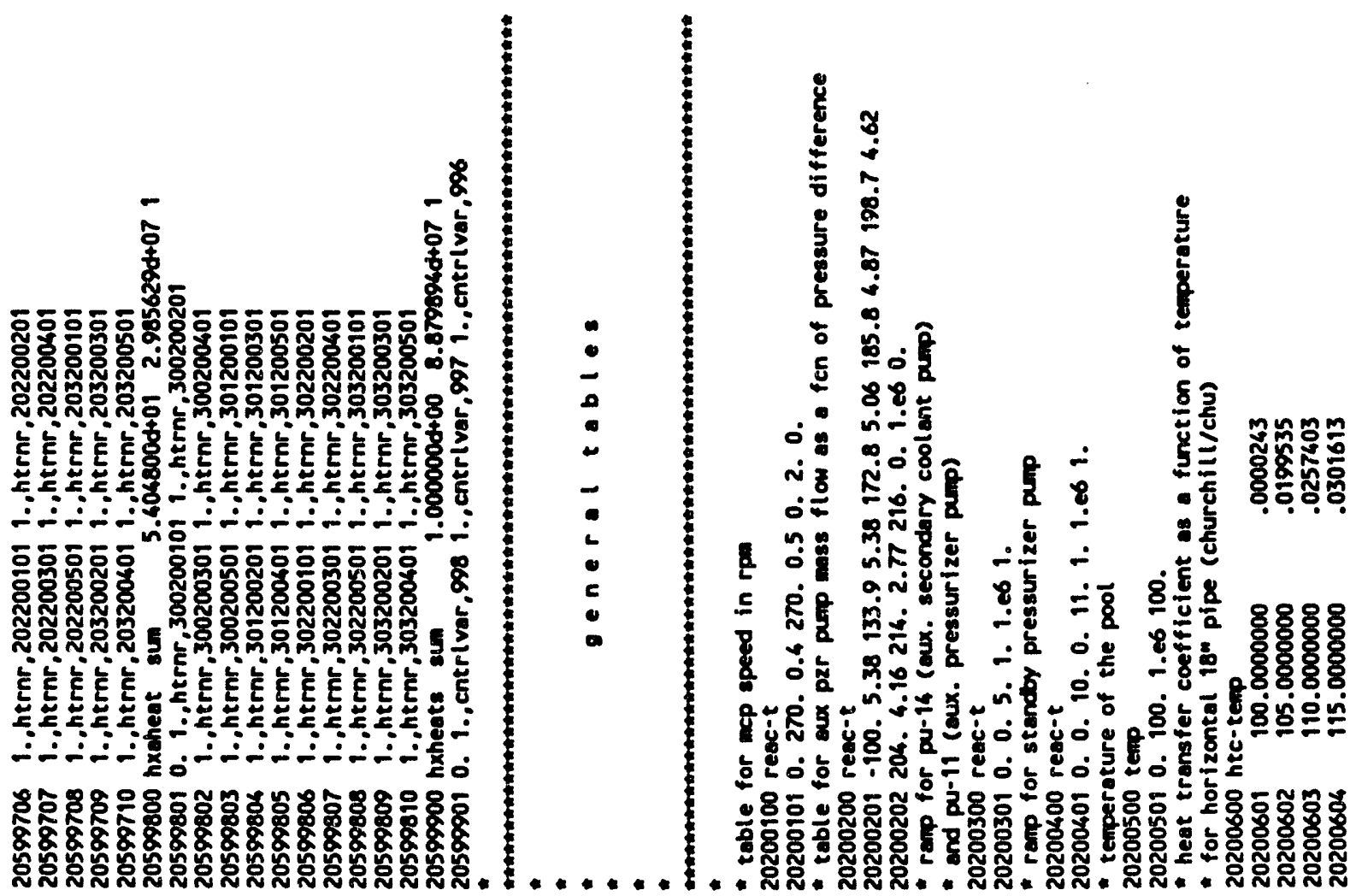




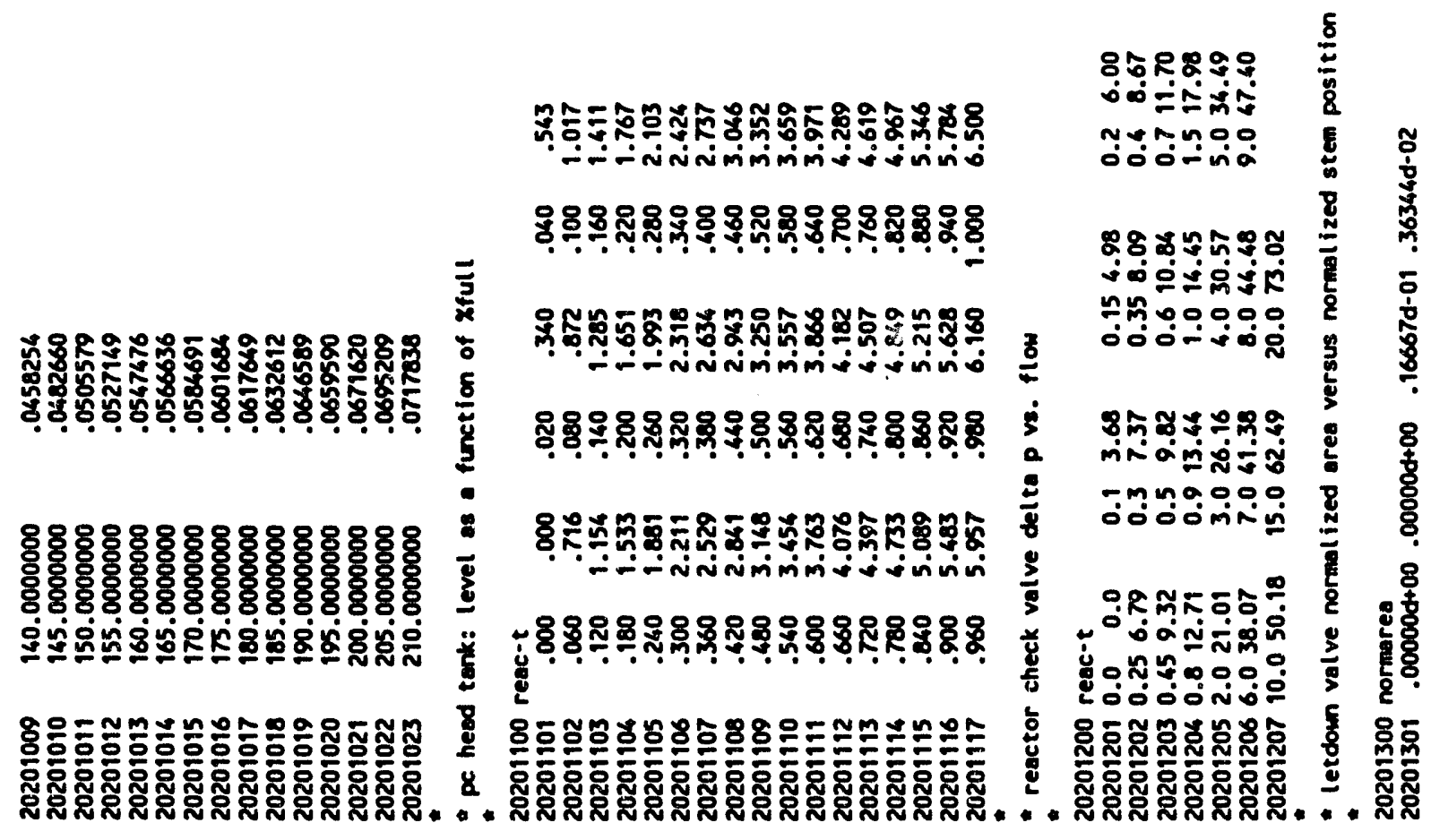

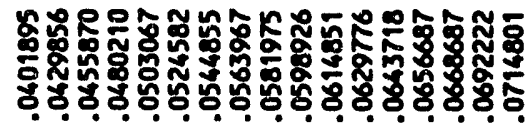

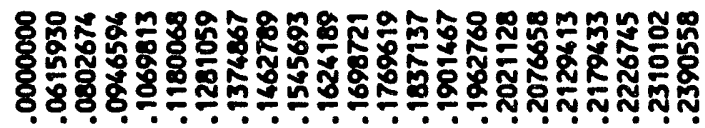

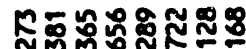

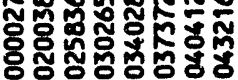
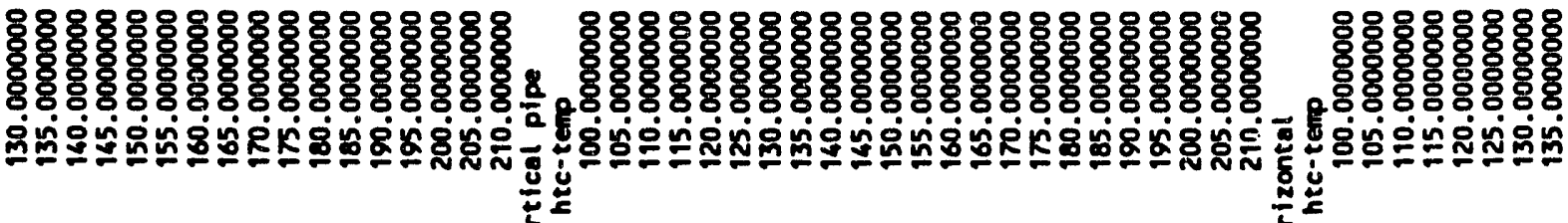
คื

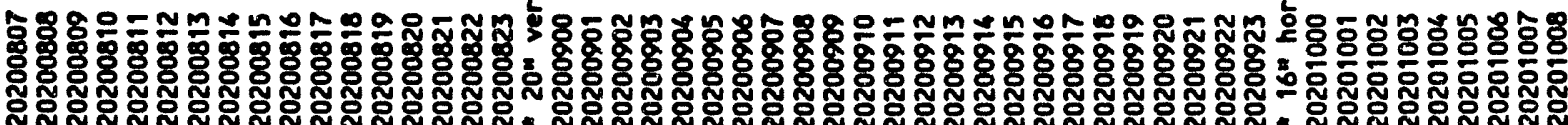




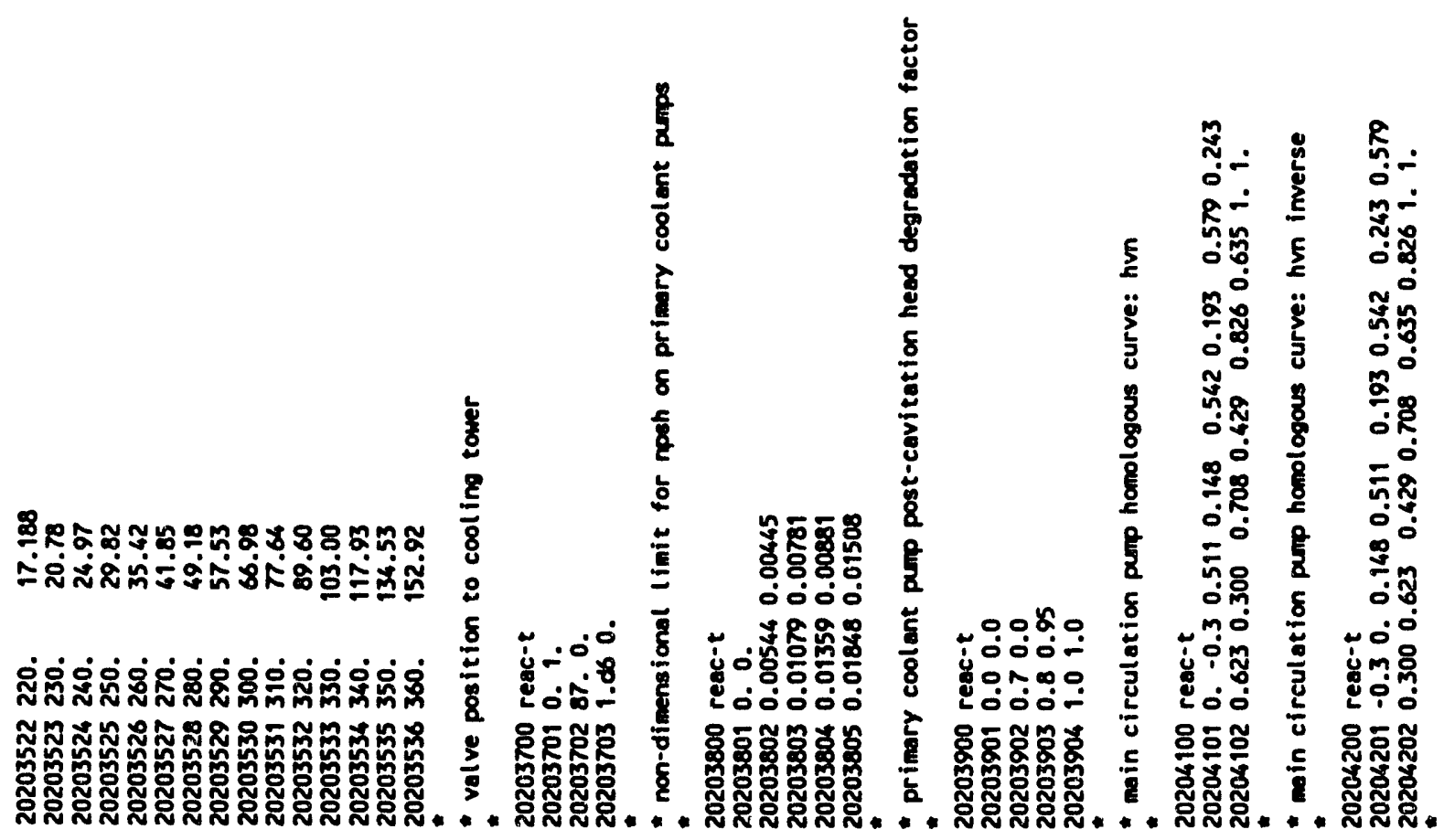

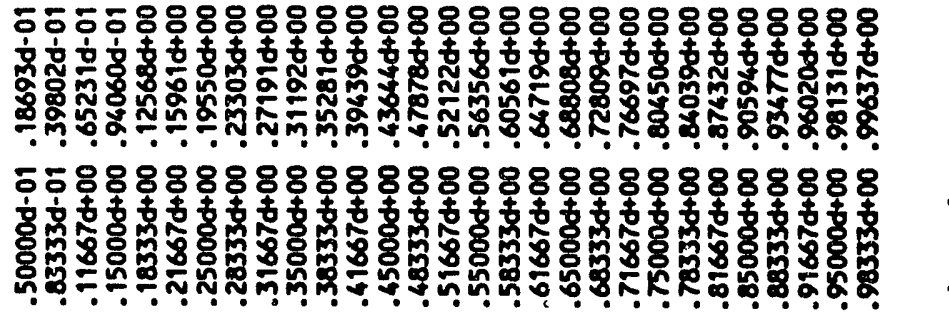

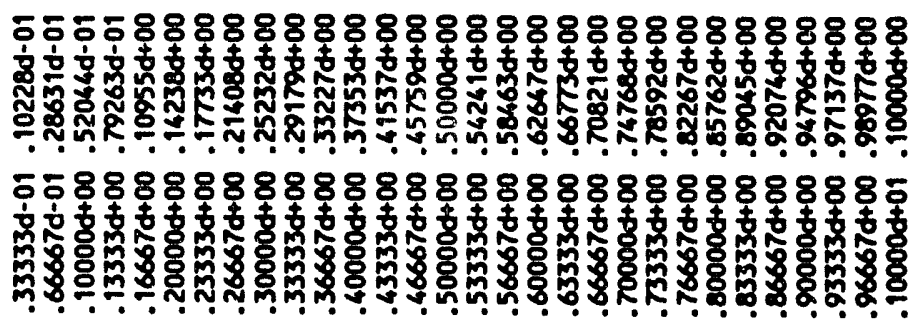

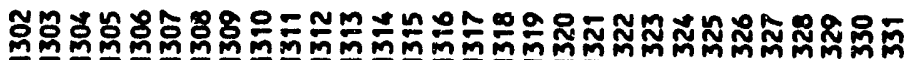

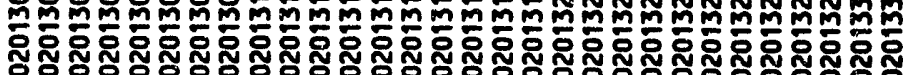

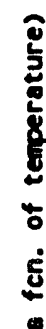

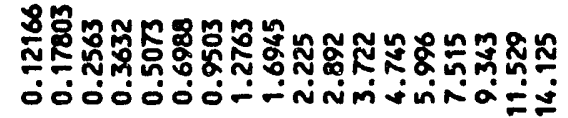

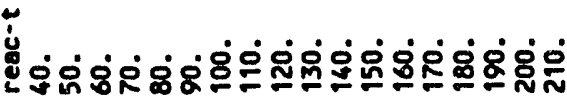

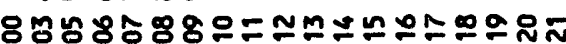

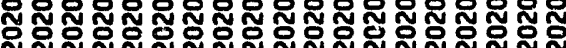




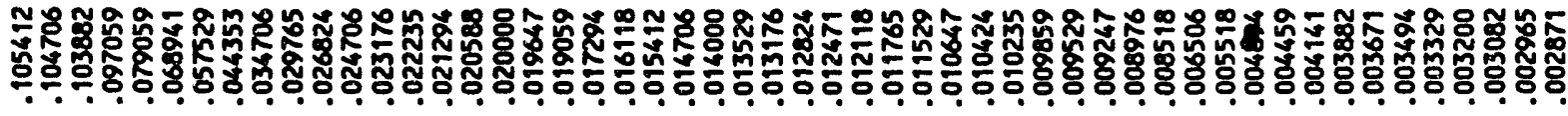

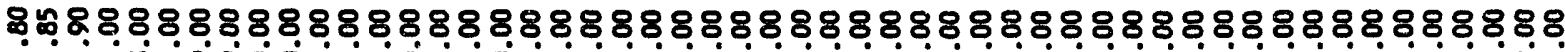

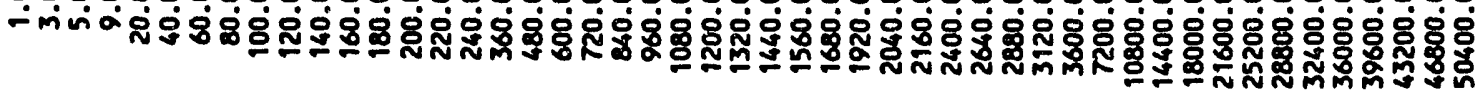

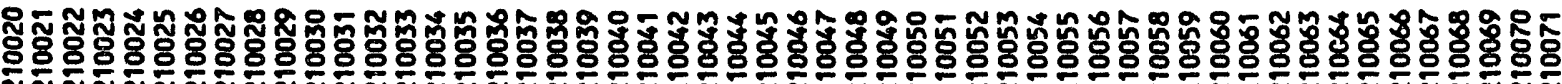

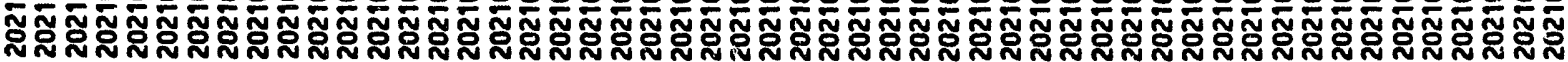

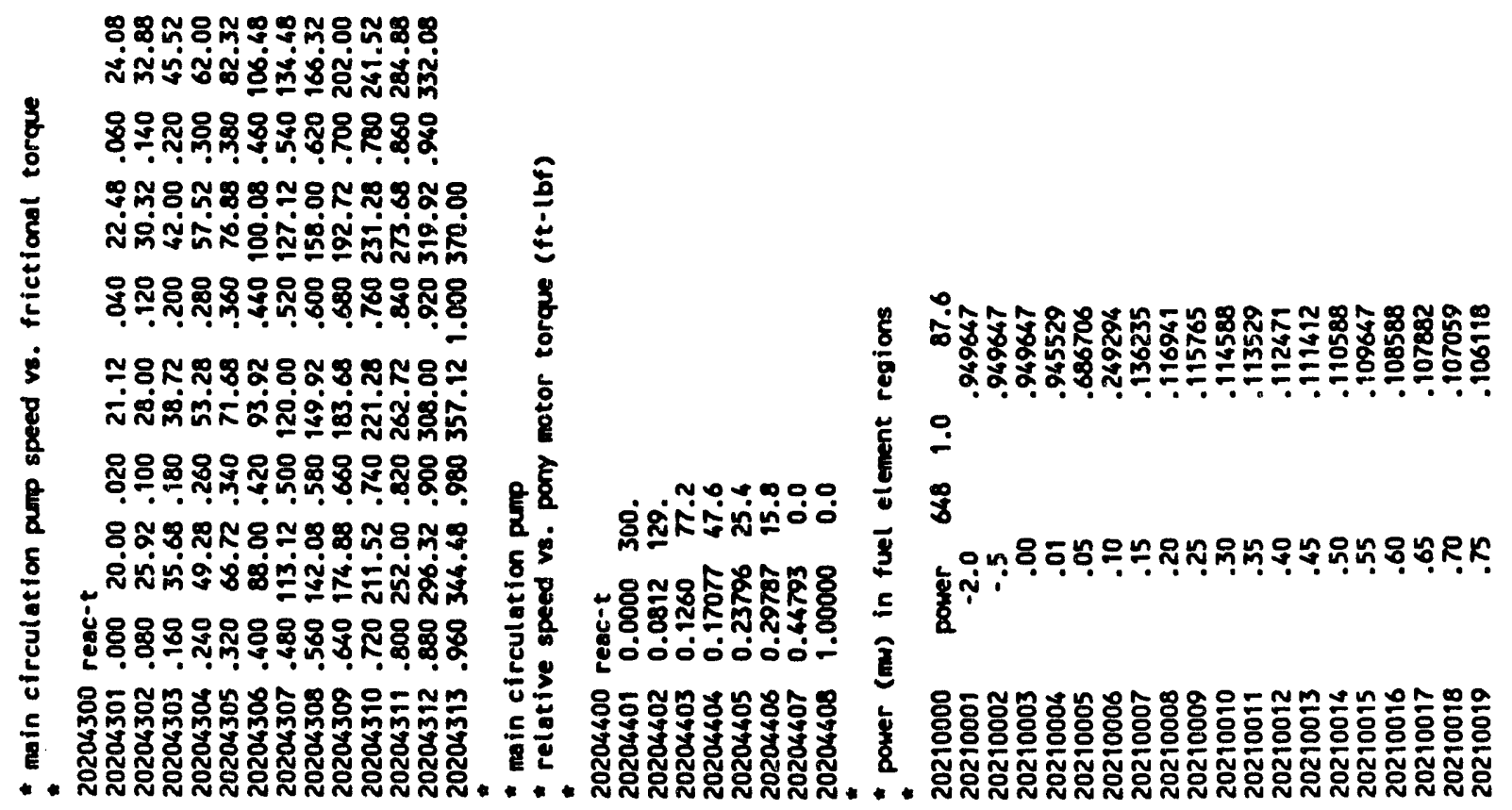



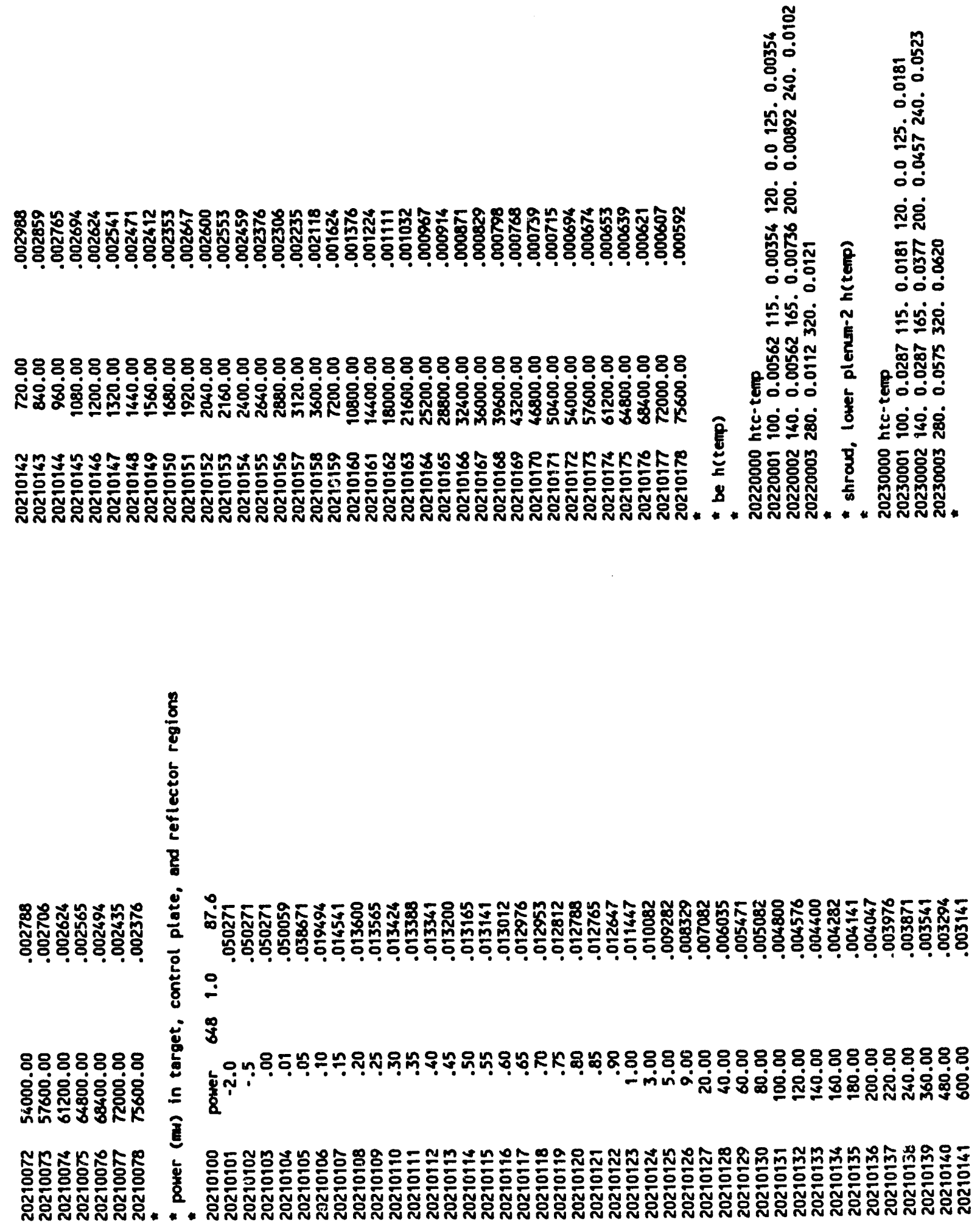


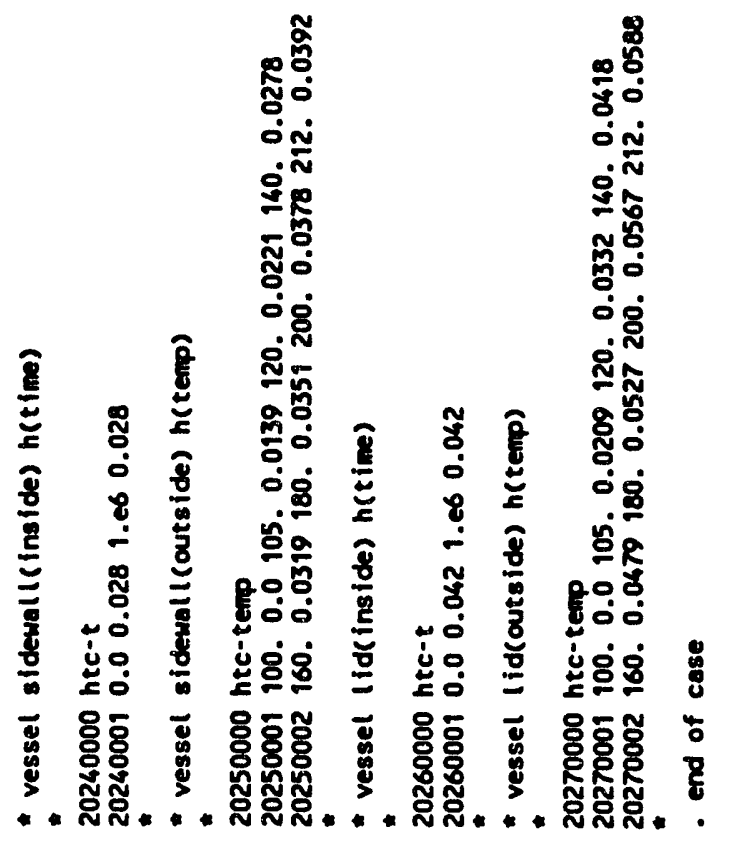




\section{Appendix B}

\section{MODELING CAVITATION OF THE HFIR PRIMARY COOLANT PUMPS}

\section{B.1 SUMMARY}

Because the HFIR primary coolant system is typically all liquid, when the pressure boundary is ruptured, the system will depressurize rapidly. For a 5.08-cm-diam (2.0-in.) pipe break, the system will depressurize in about $1 \mathrm{~s}$. Because of this rapid depressurization, the primary coolant pumps, which require about $10 \mathrm{~s}$ to completely coast down to pony motor speed, will cavitate as soon as the suction pressure falls below $\sim 0.103 \mathrm{MPa}$ (15 psia). As cavitation progresses, eventually the ability of the pump to deliver flow and head will be degraded. RELAP5/MOD2 does not contain a model for pump cavitation.

The objective of this effort was to represent the effects of pump cavitation within the context of the RELAP5 HFIR primary coolant system input model. Using the existing data available for the main circulating pumps, such a scheme was developed. The head degradation associated with pump cavitation was achieved in the model by modulating the pump speed value input to the RELAP5 pump model. The modulated pump speed is less than the noncavitation pump speed, thus producing the required head degradation.

The data used were taken during steady-state operation of the pumps; however, the pumps experience a harsh transient after a LOCA occurs. In particular, it is uncertain how long it takes for the developed pump head to respond to changes in the suction pressure once cavitation has occurred. The pump cannot respond instantaneously because a finite amount of time is required to (1) propagate pressure information through the pump and (2) condense, or "sweep away," bubbles that have formed near the tips of the impeller blades.

Because of this uncertainty, a time lag was applied to the modulated pump speed, and the time constant associated with that lag was varied from 0 (instantaneous response of pump head to suction pressure) to $50 \mathrm{~ms}$. It was found that the flow delivered to the core was nearly the same for all values of the time constant. It is concluded that the use of the steadystate data in the RELAP5 model gives accurate results.

\section{B.2 PUMP CAVITATION MODEL}

The RELAP5 pump model consists of two junctions and one thermal-hydraulic control volume having a momentum equation that includes pump head as a body force. The pump model can be controlled by specifying a pump speed (allowed to vary with time) or by specifying torques to be applied to the pump shaft. In the pump-cavitation calculations, the pump speed is always specified directly. RELAP5 does not have a pump cavitation model. Although it does have a method for degrading pump performance, should the pumped fluid be two phase, this cannot be applied for two reasons:

1. To use the two-phase head multipliers, the void fraction in the pump would have to be known. Because pump cavitation occurs before the pressure in any RELAP5 volume reaches its saturation pressure, this void fraction calculation would have to be done outside of RELAP5. 
2. Even if void fraction could be accurately and economically calculated, the behavior of a cavitating pump where bubbles are formed near the surface of the impeller is likely to be significantly different than the behavior of a pump that is working on a fluid that entered the pump saturated, even if the void fractions are identical.

Instead, a method similar to that used by C. B. Davis, ${ }^{1}$ of INEL, was employed. After cavitation occurs, if the degraded value for pump head is known, the pump speed can be artificially modulated to forc: the pump head to the degraded value. Because pump cavitation during a LOCA at the HFIR will generally occur after the pump has been tripped and is coasting down to pony motor speed, this method requires that the true pump speed be independently tracked using the control variables.

The available data for onset of cavitation and pump performance after cavitation are shown in Fig. B.1. These data were taken from Byron Jackson (the pump manufacturer) data sheets. ${ }^{2}$ From these constant flow curves, values for $N P S H_{\text {crit }}$ (that value of net positive suction head below which the pump performance begins to degrade) can be estimated. In addition, a plot was found in the HFIR files from Byron Jackson that appears to be a design curve of $N P S H_{\text {required }}$ for the pumps. $N P S H_{\text {required }}$ is the amount of NPSH required before the pump begins cavitating. Both sets of data were nondimensionalized according to White ${ }^{3}$ using the parameters $C_{H S}$ and $C_{Q}$, defined as

$$
C_{H S}=\frac{g(N P S H)}{n^{2} D^{2}}
$$

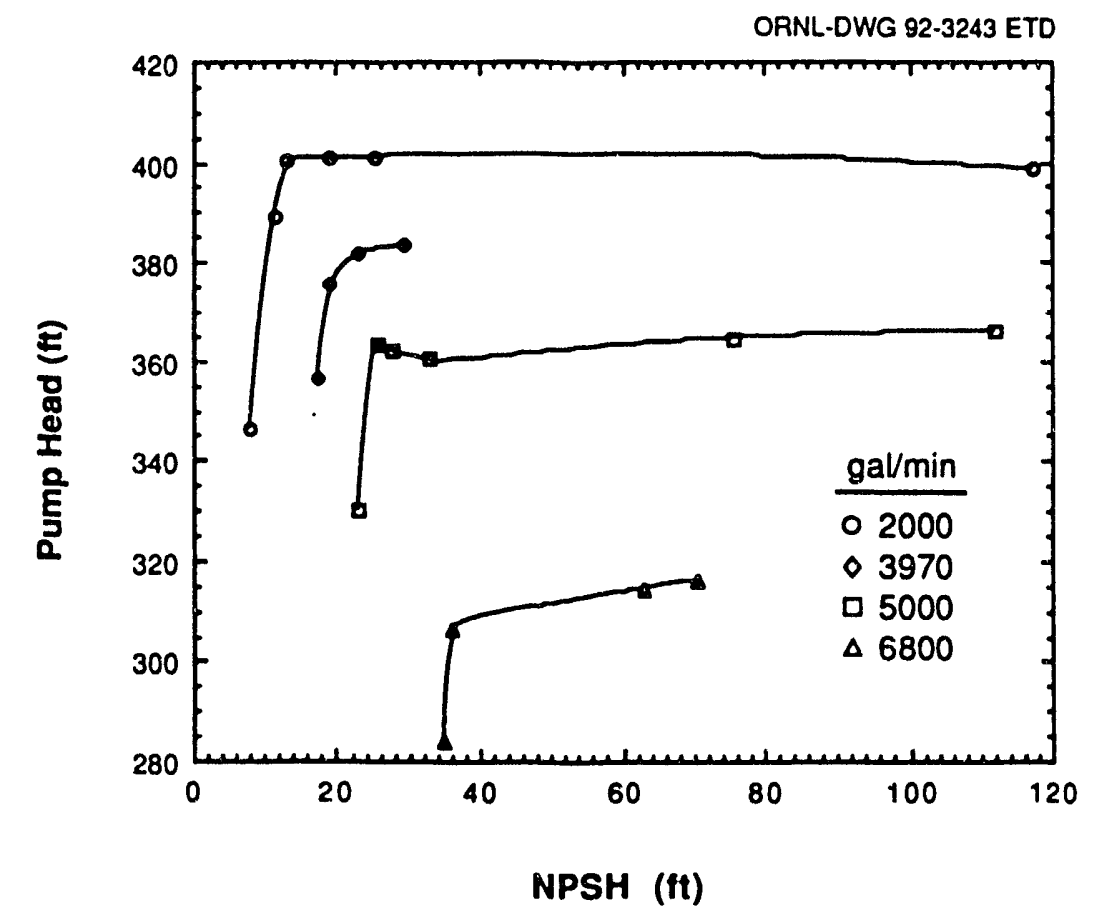

Fig. B.1. Manufacturer's data for required suction head for HFIR primary coolant pumps. 
and

$$
C_{Q}=\frac{Q}{n D^{3}}
$$

where

$$
\begin{aligned}
\boldsymbol{g} & =\text { acceleration of gravity }\left(32.2 \mathrm{ft} / \mathrm{s}^{2}\right), \\
N P S H & =\text { net positive suction head }(\mathrm{ft}), \\
n & =\text { pump speed }(\mathrm{rad} / \mathrm{s}), \\
D & =\text { diameter of pump impeller data sheets }{ }^{2}=1.635 \mathrm{ft} \\
Q & =\text { flow rate through pump in } \mathrm{ft}^{3} / \mathrm{s} .
\end{aligned}
$$

Although White uses pump speed in rpm, here we use rad/s for true nondimensionality. The resulting curves for $\left(C_{H S}\right)_{c r i t}$ and $\left(C_{H S}\right)_{\text {required }}$ as a function of $C_{Q}$ are plotted in Fig. B.2. As expected, $\left(C_{H S}\right)_{\text {crit }}$, which was estimated from the HFIR pump data and represents the onset of pump degradation, lies beneath the curve associated with onset of cavitation.

In the RELAP5 model, $\left(C_{H S}\right)_{c r i t}$ as shown in Fig. B.2 was used to indicate the point at which pump performance begins to degrade. If the suction head falls low enough that $C_{H S}$ is less than $\left(C_{H S}\right)_{c r i}$, then the pump head is degraded.

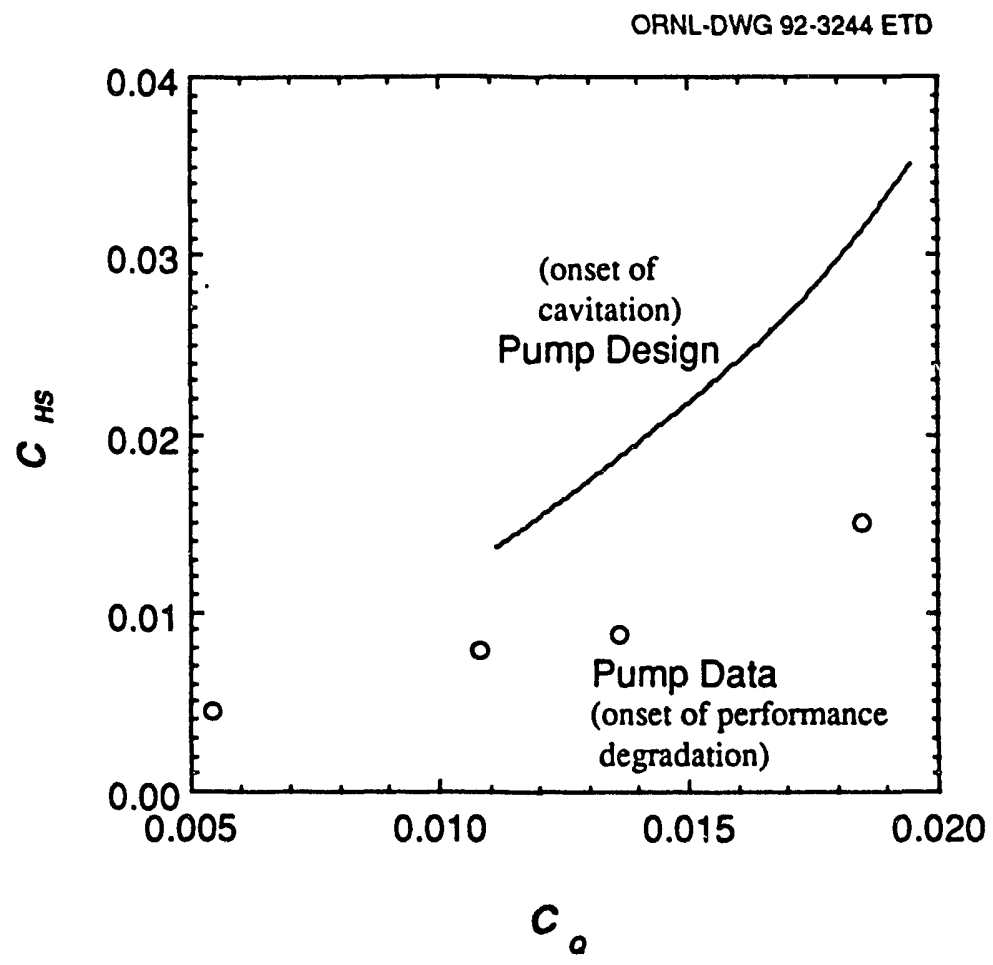

Fig. B.2. Nondimensionalized data for required suction head as function of pump flow. 
The HFIR pump data shown in Fig. B.1 are also used to determine how the pump behaves after the head begins to degrade. The data in Fig. B.3 show the Fig. B.1 data with the pump head normalized to the predegradation value and the NPSH normalized to the $N P S H_{\text {crit }}$ value. From this figure a relationship (FIT) was extracted for use in the model that dictated how the pump head degrades after $C_{H S}$ becomes less than $\left(C_{H S}\right)_{\text {crir }}$

Figure B.4 shows a flow chart that indicates how the pump speed is controlled. Because the pump data are $f: \mathrm{s}$ steady state, a time lag has been applied to the pump speed. During a transient, the pump head will not respond instantaneously to changes in the pump suction pressure because of pressure wave transit time and because of time required to sweep bubbles away from the pump impeller. However, no transient data are available for pump performance during pump cavitation. It was hoped that the time lag would not significantly affect the flow delivered to the core, which is the important result.

\section{B.3. CALCULATION RESULtS}

Results were obtained for a 5.08-cm (2-in.) break at the outlet of one of the main circulating pumps. In Fig. B.5, the flow delivered to the core is plotted for various time lags applied to the modulated pump speed. In Figs. B.6 and B.7, the mass flow through one of the pumps is shown for the same simulations. The IBM/RS6000 computational time to simulate the first $11 \mathrm{~s}$ of the transient is shown for each simulation in Table B.1.

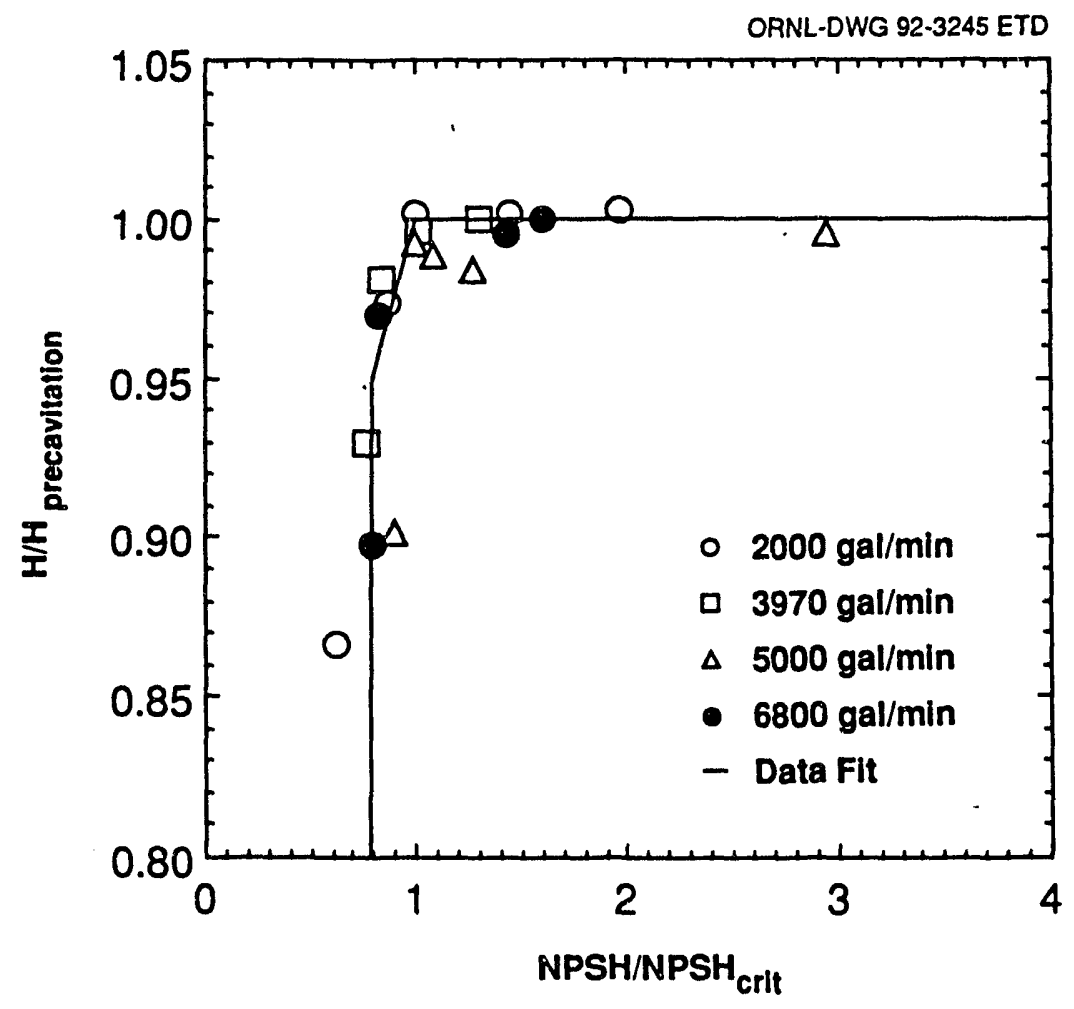

Fig. B.3. Normalized degraded pump head vs available suction head. 
ORNL-DWG 92-3246 ETD

\section{Actual Pump Speed Calcuiation}

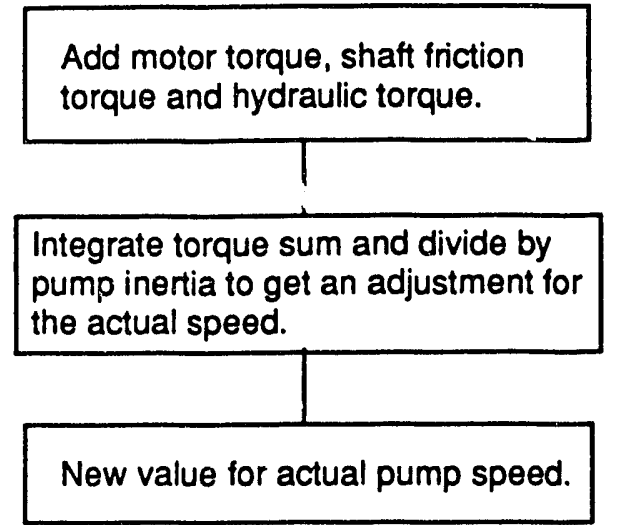

\section{Modulated Pump Speed Calculation}

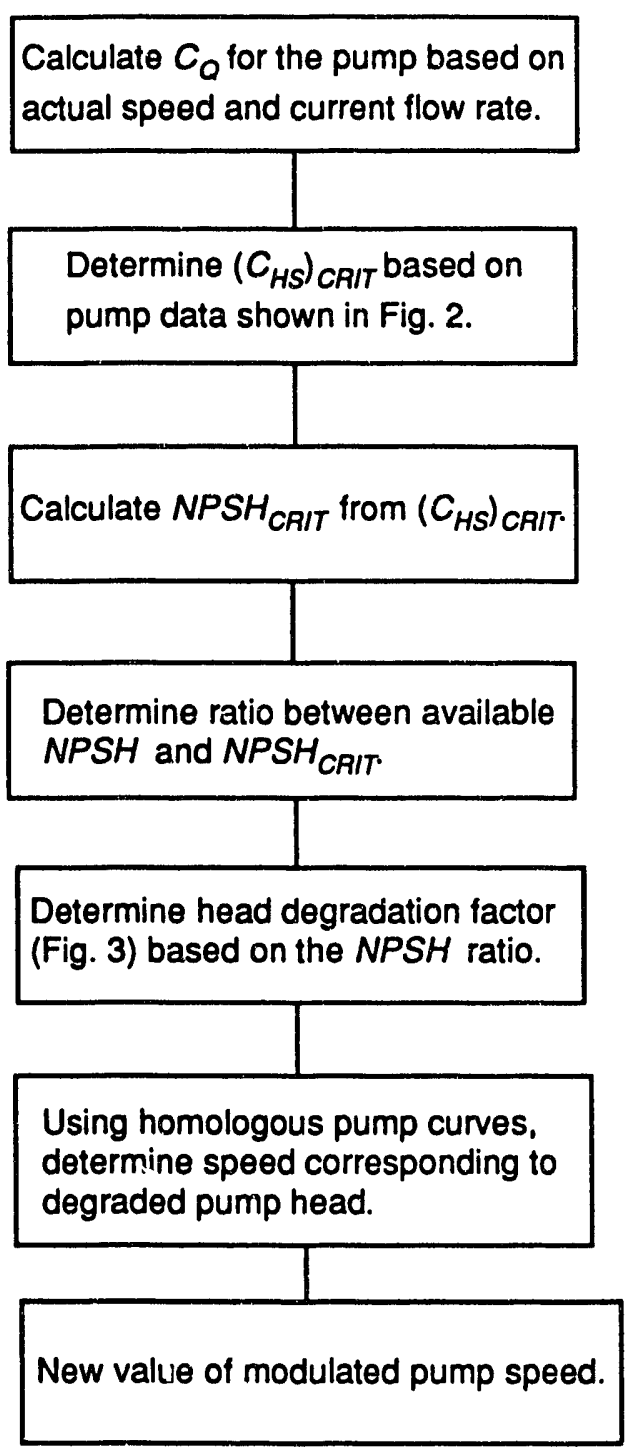

Fig. B.4. Control of HFIR primary coolant pump speed.

For longer time lags, fewer oscillations were calculated, and the calculation went smoother, requiring less CPU time.

The values for $C_{H S}$ for the simulation with a 50 -ms time lag are plotted in Fig. B.8.

\section{B.4. DAMAGE TO THE PUMP}

The main circulating pumps will cavitate for some of the LOCA transients that will be analyzed with the RELAP5 HFIR model. A model that is adequate for predicting pump 


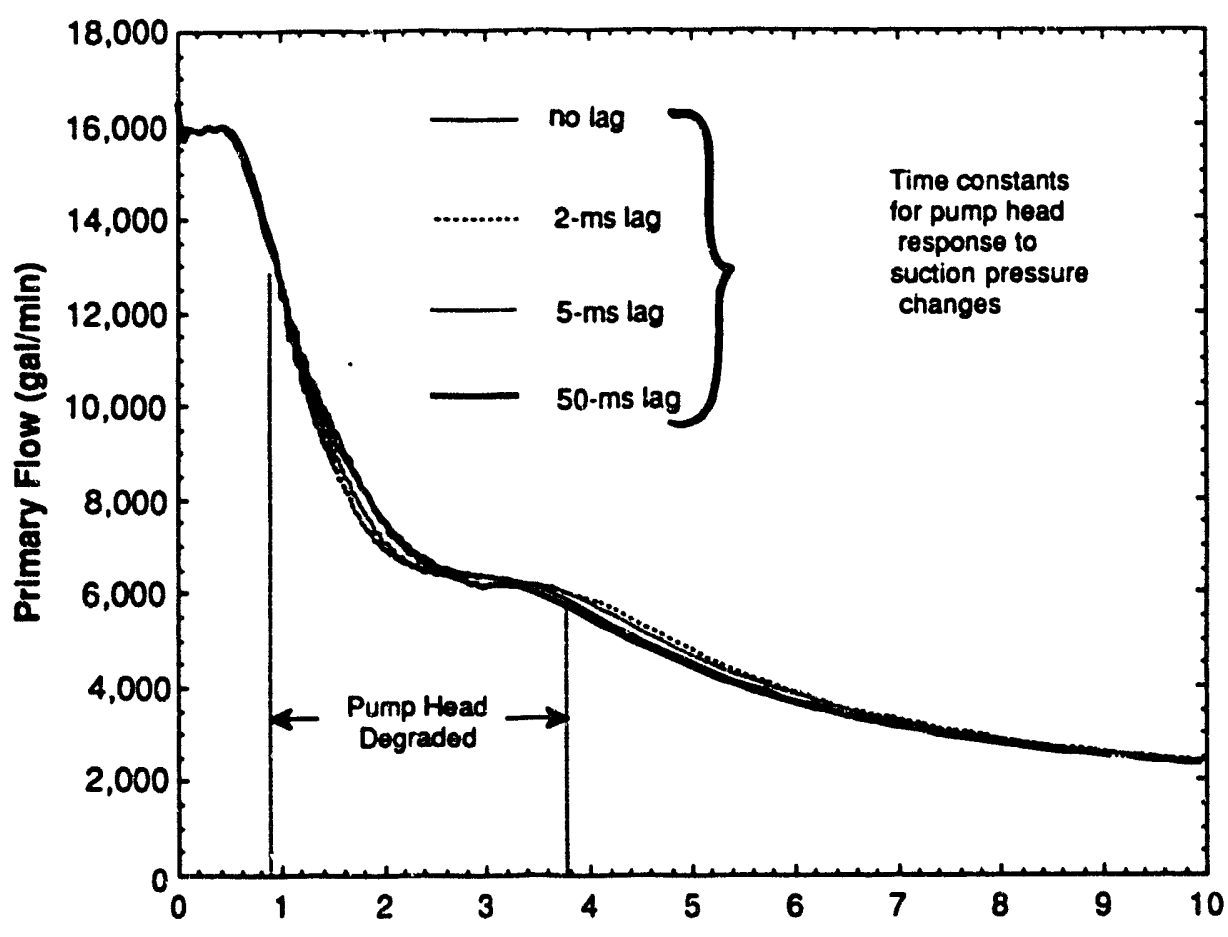

Time (s)

Fig. B.5. Flow delivered to reactor vessel during 2-in. break.

performance has been described in this appendix. The results should be realistic as long as the pump is not damaged enough to significantly affect pump performance. Two types of damage occur in pumps experiencing cavitation:

1. cavitation erosion at the impeller due to the implosion of collapsing voids on the impeller blades, and

2. metal-to-metal contact in the pump shaft journal bearing brought on by vibration and leading to pump lock-up (welding of the shaft to the bearing surface).

\section{B.4.1 Time of Exposure}

Pump cavitation will occur during a LOCA after the main circulating pumps have been tripped. The only power supplied to the pump shaft in such a scenario is from the pony motor. The pump shaft speed will decrease rapidly because of the resistance of the shaft friction torque and the hydraulic torque. The hydraulic torque during a period of cavitation is substantially less than what it is for fully liquid flow. If the hydraulic torque is completely neglected, then the rate of coastdown can be calculated as

$$
\frac{d(\alpha)}{d t}=\frac{T_{m}-T_{f}}{I},
$$




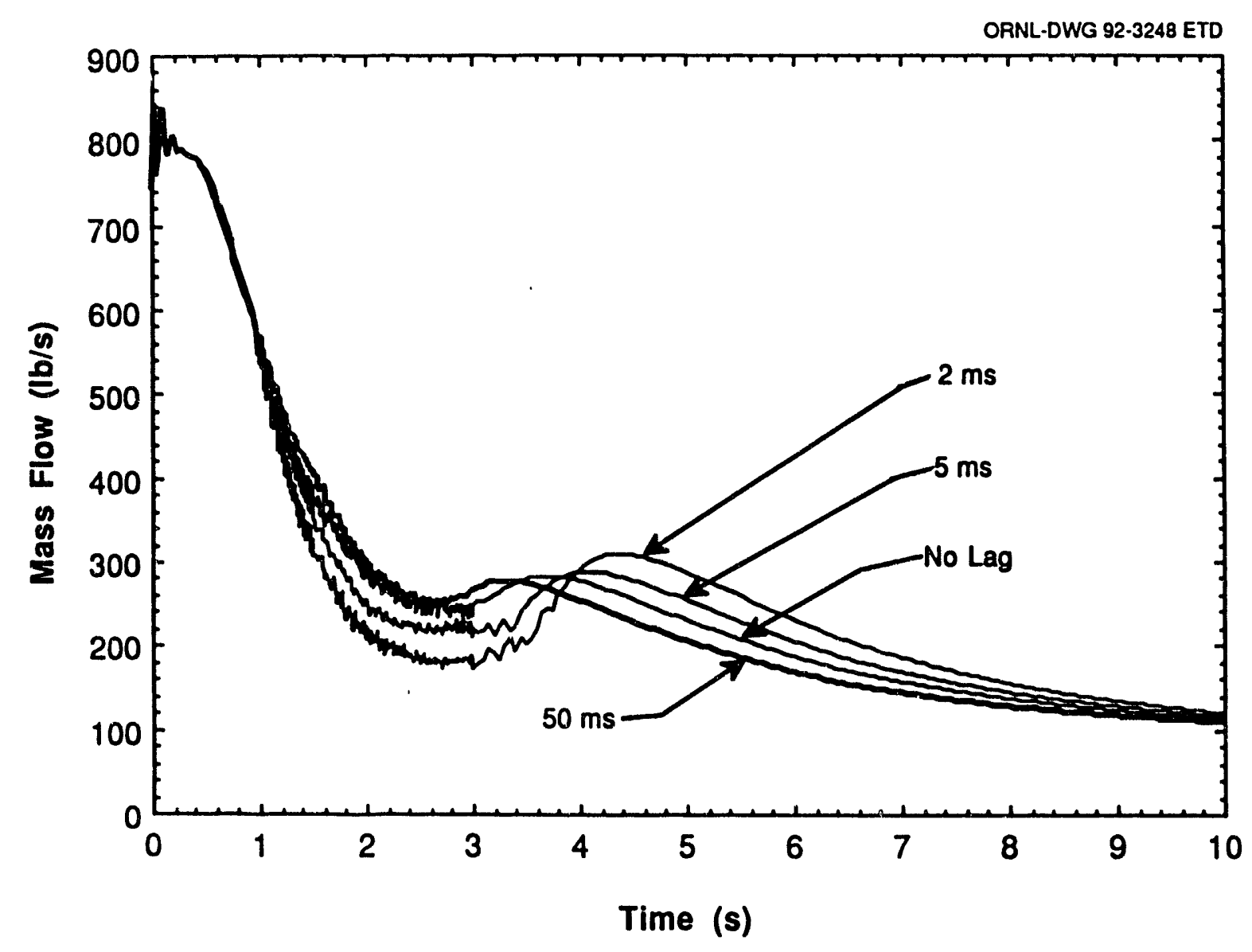

Fig. B.6. Mass flow through PU-1D during 2-in. break.

where $I$ is the moment of inertia for the pump $\left(19.7 \mathrm{~kg} / \mathrm{m}^{2}\right.$ or $\left.468 \mathrm{lb}_{\mathrm{m}}-\mathrm{ft}^{2}\right), \alpha$ is the pump speed ratio, $T_{f}$ is the torque due to shaft friction (see Sect. 3.3.3), and $T_{m}$ is the pony motor torque (Table 42). The above equation was solved numerically, and it was found that to coast down from full speed to pony motor speed $(36.7 \mathrm{rad} / \mathrm{s}$, or $350 \mathrm{rpm}$ for no hydraulic torque) required $40 \mathrm{~s}$. It is here demonstrated that once the pumps coast down to $36.7 \mathrm{rad} / \mathrm{s}$ $(350 \mathrm{rpm})$, they are no longer cavitating.

As the pumps coast down, the developed head and flow rates also decrease. At design conditions (188 rad/s or $1800 \mathrm{rpm})$, the pumps each supply $0.315 \mathrm{~m}^{3} / \mathrm{s}(5000 \mathrm{gal} / \mathrm{min})$ against a system head loss of $1.08 \mathrm{MPa}$ (157 psi). At pony motor speed $(28.3 \mathrm{rad} / \mathrm{s}$ or $270 \mathrm{rpm}$ ) the pumps each supply $0.0526 \mathrm{~m}^{3} / \mathrm{s}(833 \mathrm{gal} / \mathrm{min})$ against a system head loss of about $0.0276 \mathrm{MPa}$ (4 psi). Assuming that the system head loss varies with the square of the flow rate, a system loss coefficient can be calculated as

$$
K_{s}=\frac{\Delta P}{Q^{2}} .
$$

Because most of the pressure drop occurs across the reactor vessel, $Q$ is the combined flow rate of the three pumps. At design conditions, $K_{s}=1.21 \mathrm{MPa} /\left(\mathrm{m}^{3} / \mathrm{s}\right)^{2}\left[7.0 \times 10^{-7}\right.$ 


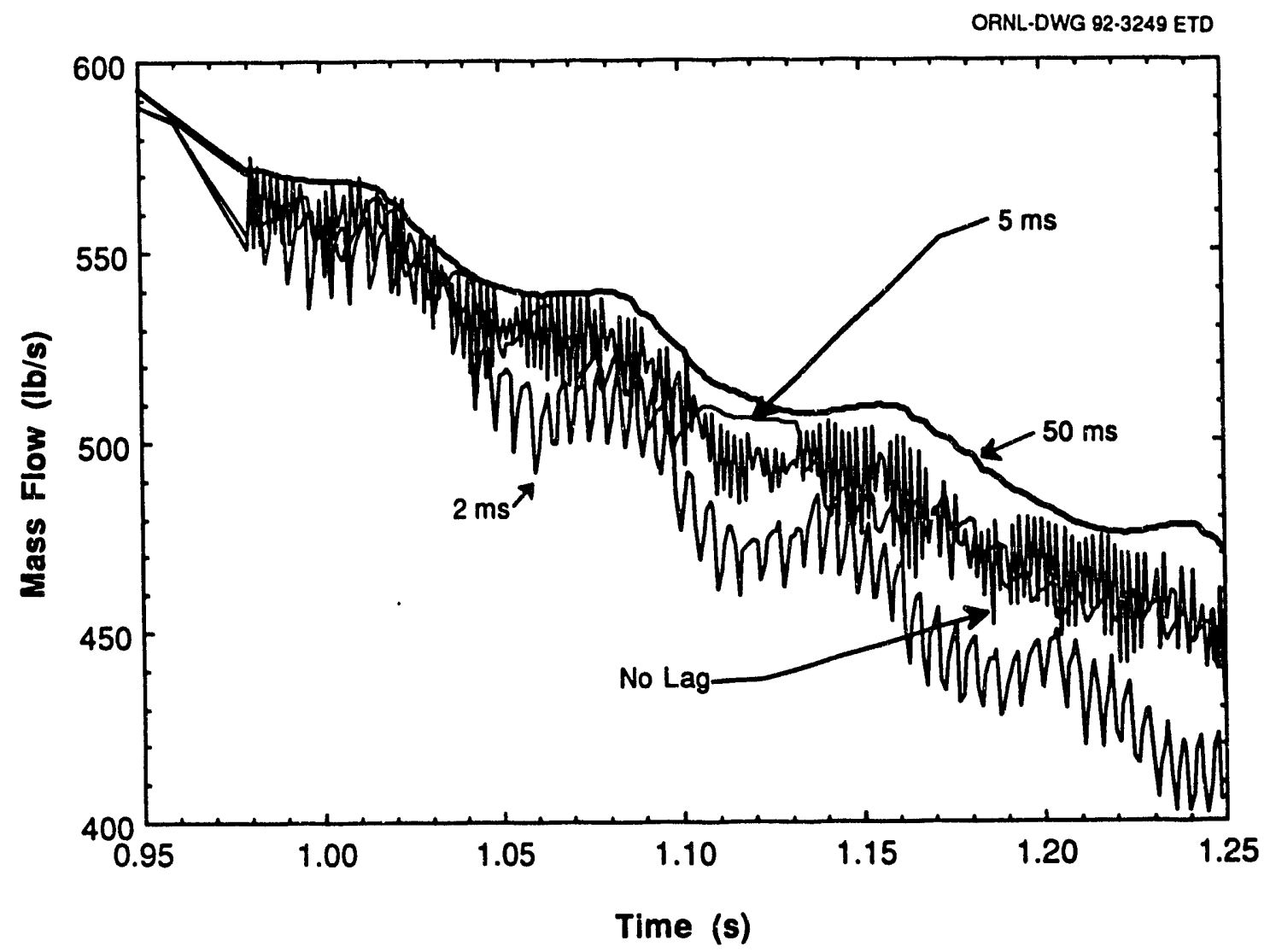

Fig. B.7. Closeup of mass flow through PU-1D during 2-in. break.

Table B.1. CPU times required for 5.08-cm (2-in.) break simulations

\begin{tabular}{cc}
\hline $\begin{array}{c}\text { Time lag } \\
(\mathrm{ms})\end{array}$ & $\begin{array}{c}\text { CPU time } \\
(\mathrm{s})\end{array}$ \\
\hline 0 & 13,217 \\
2 & 7,013 \\
5 & 3,552 \\
50 & 2,100 \\
\hline
\end{tabular}

$\left.\mathrm{psi} /(\mathrm{gal} / \mathrm{min})^{2}\right]$, and at pony motor speed $K_{s}=1.11 \mathrm{MPa} /\left(\mathrm{m}^{3} / \mathrm{s}\right)^{2}\left[6.4 \times 10^{-7} \mathrm{psi} /(\mathrm{gal} / \mathrm{min})^{2}\right]$. At $36.7 \mathrm{rad} / \mathrm{s}(350 \mathrm{rpm})$ the speed ratio is 0.194 , so the maximum total developed pump is about $0.0414 \mathrm{MPa}(6 \mathrm{psi})$. Using an average value of $K_{s}$, the above relation gives a flow rate of $0.0631 \mathrm{~m}^{3} / \mathrm{s}(1000 \mathrm{gal} / \mathrm{min})$ per pump. At $36.7 \mathrm{rad} / \mathrm{s}(350 \mathrm{rpm})$ and $0.0631 \mathrm{~m}^{3} / \mathrm{s}(1000 \mathrm{gal} / \mathrm{min})$, $C_{Q}$ is 0.014 (see Sect. B.2). From Fig. B.2 the required $C_{H S}$ is about 0.02 , and using the definition of $C_{H S}$ (Sect. B.2), the required NPSH for each pump is $0.00689 \mathrm{MPa}$ (1 psi). If 


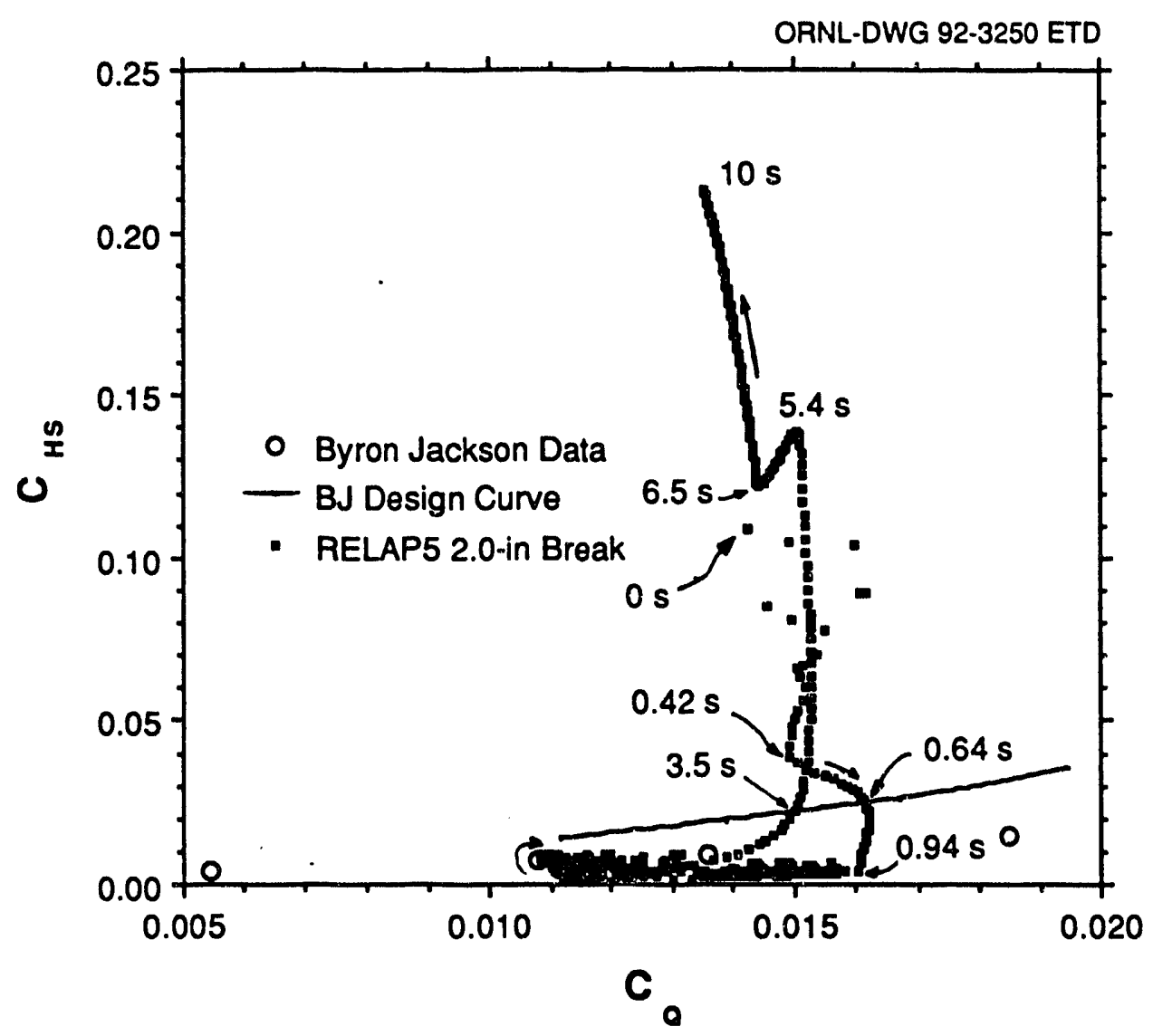
break.

Fig. B.8. Nondimensional suction head vs nondimensional flow rate during 2-in.

the break is at the outlet of the main circulating pumps (worst case) to the atmosphere, the suction pressure would be at least $0.0552 \mathrm{MPa}(8 \mathrm{psia})$. Because the saturation pressure at $48.9^{\circ} \mathrm{C}\left(120^{\circ} \mathrm{F}\right)$ is $<0.0138 \mathrm{MPa}$ (2 psia), the available suction head at $37.6 \mathrm{rad} / \mathrm{s}(350 \mathrm{rpm})$ is at least $0.0414 \mathrm{MPa}(6 \mathrm{psi})$, plenty to ensure that the pumps will recover from their cavitated state before they completely coast down.

Because the pumps will recover from their cavitated state by the time they slow to 37.6 $\mathrm{rad} / \mathrm{s}(350 \mathrm{rpm})$, the time during which cavitation damage may occur will be no longer than $40 \mathrm{~s}$, but probably much less. Results from preliminary calculations simulating a $5.08-\mathrm{cm}$ (2in.) break at the main circulating pump discharge, as shown in Figs. B.6-B.8, indicate cavitation lasts only $3 \mathrm{~s}$.

\section{B.4.2 Cavitation Erosion}

Data for the erosion of metals are given in Refs. 4-7. In all of these references, the data indicate that to significantly erode a steel surface, hours of exposure to bubble collapse are required. Although these data are not directly applicable to the case of cavitation in large centrifugal pumps, there is practically no such information available. ${ }^{8}$ However, the large amount of erosion data that do exist and the wide margin between those exposure times 
indicated by the data to cause significant mass loss and the exposure time typical for the HFIR main circulation pumps during a LOCA give a good basis for asserting that no significant erosion of the impeller will occur during a HFIR LOCA.

\section{B.4.3 Bearing Damage}

The more likely mechanism for cavitation-induced damage to the main circulating pumps is metal-to-metal contact in the water-lubricated shaft journal bearings. However, journal bearings are rugged in practice, ${ }^{9}$ and additional friction on the bearing would work to slow the pump down. Little information is available on failures of journal bearings because of their reliability. In the past, the HFIR primary coolant pumps have twice survived cavitation at full speed.

\section{B.4.4 Recommendation}

The only practical scenario where pump cavitation damage may lead to fuel damage is if all three pumps suddenly locked up, so that no flow could reach the core, because a single pony-motor-operated pump is enough to remove the core decay heat.

LOCA analysis using the input model will not include the effects of any cavitation damage that may occur. If the break is large enough to damage the fuel (cavitation damage not considered), based on preliminary calculations, it is expected that the fuel will be damaged before the pumps cavitate at all. However, for those breaks that are small enough that the reactor survives the initial depressurization, damage to the journal bearing may be a factor and will certainly lead to fuel damage should all three main circulating pump shafts lock up.

Because the pun:ps would be coasting down and in the past have survived cavitation at full speed, it is highly unlikely that all three would lock up during cavitation.

\section{B.5. CONCLUSIONS}

Because the flow delivered to the core was essentially the same for the range of time lags from 0 to $50 \mathrm{~ms}$, the use of the steady-state data should be legitimate. The pump cavitation model as implemiented in RELAP5 should provide realistic results, and the pump should not be significantly damaged during the transient.

\section{B.6 REFERENCES}

1. C. B. Davis, Pump Cavitation in L-Reactor During a LOCA Initiated by a Large Break in a Plenum Inlet Line, EGG-EAST-8148, Idaho National Engineering Laboatory, June 1988.

2. Report of Test From the Byron Jackson Hydraulic Test Facilities, Byron Jackson Order No. 371720 , January 1963.

3. F. M. White, Fluid Mechanics, McGraw-Hill, New York, 1979, pp. 646-648.

4. M. A. Rayan, "Experimental Study of the Cavitation Erosion in Centrifugal Pump Impeller," Cavitation and Multiphase Flow Forum, The Joint ASCE/ASME Mechanics Conference, Albuquerque, New Mexico, June 24-26, 1985. 
5. R. T. Knapp, J. W. Daily, and F. G. Hammitt, Cavitation, McGraw-Hill, New York, 1970, pp. $367,410,529,530$.

6. A. Thiruvengadam, "A Unified Theory of Cavitation Damage," J. Basic Engineering (Septemter 1963).

7. M. S. Plesset and R. E. Devine, "Effect of Exposure Time on Cavitation Damage," J. Basic Engineering (December 1966).

8. Ref. 4, p. 515.

9. D. M. Smith, Journal Bearings in Turbomachinery, Chapman and Hall, London, 1969, pp. 135-139. 


\section{Appendix C}

\section{PREPROCESSING PROGRAM}

The preprocessing program, which is useful for either (1) initializing a RELAP5/MOD2 or RELAP5/MOD3 input dataset at steady-state conditions or at uniform temperature and pressure, or (2) converting from a RELAP5/MOD2 dataset to a RELAP5/MOD3 dataset, is listed on the following pages. If the program is used for initializing a dataset at steady-state conditions, two files are read: a RELAP5 input file with all records correct except for initial conditions, and a file containing one major edit from the RELAP5 (MOD2 or MOD3) program.

The preprocessor will read the dependent variables (temperatures, pressures, flows, and control variables) from the file containing the major edit; it will read the model description from the RELAP5 input file; and finally, it will create a new input file containing the combined information that it has read. 


\section{RELAP5 Initialization Program}

c

c This program reads a RELAP5/MOOZ.5 generated MAJOR EDIT,

$c$ and initializes an inout file to contain the initial

c conditions read from the MAJOR EDIT.

c Also, a conversion to a MOO3 data set may be made.

C

c Written by M. W. Wendel (615-574-2825)

c

c $M 002.5$ onlylll

common / rinput/ strtmp, struct, $p, t$, flow, cntrl, d1, d2, pmpvel, acclev

common / $i$ input/ istr, $i 1, j 1$

common /ainput/ fin, fout

character 5 format

character 20 fin, fout, findat

character*10 blank

character 10 aread, al, cmplo

character ${ }^{8} \mathrm{cmp}$, type

character $\$ 80$ arec, arecc, line

character $\$ 132$ arec 1

character $\$ 3$ cnum

character*5 zeros, chsnum

logical long

real ic

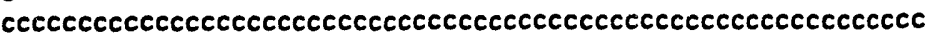

c Definition of arrays:

Pressures in ' $p$ '

Temperatures in ' $t$ '

Mass flow rates in 'flow'

Control variables in 'cntrl'

Heat structures: temperatures in 'struct'; istr( $i, j)$ contains the address in struct where the temperatures can be found for the $i$ th heat siructure and the $j$ th mesh point location

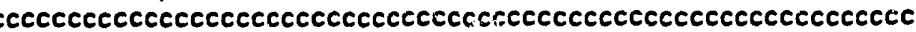

dimension $p(1000,20), t(1000,20)$, flow $(1000,20)$, entrl( 1000$)$,

8 strtmp (20), struct $(10000)$, istr $(10000,20)$

dimension $\mathrm{d} 1(10), \mathrm{d} 2(10), \mathrm{i} 1(10), \mathrm{a} 1(10), \mathrm{j} 1(10)$

dimension pmpvel $(1000)$, acclev $(1000)$

data format $/ 1(a) \%$

data zeros/ $10000 \%$ im $/ 0 /$

data 210.1 , iunif 121 , pinit/475.1, tinit 190.1

data ithree/3/, blank /" $1 /$

c

c Interact with user.

c

writec". '(" Do you wish to input (1) Uniform initial conditions"' $\&, \$)$ ')

Hrites ' $(/ / 1$

\&ion' 's)'

write $(*, 1 / 11$

\&om' ', $\$$ ') ')

writes $1,(1,1$

read(*,'(i1)') iflag

or (2) Previous output, no convers

or (3) Previous output, convert fr

MOO2.5 to MOO3: $(1, \$) ')$ 


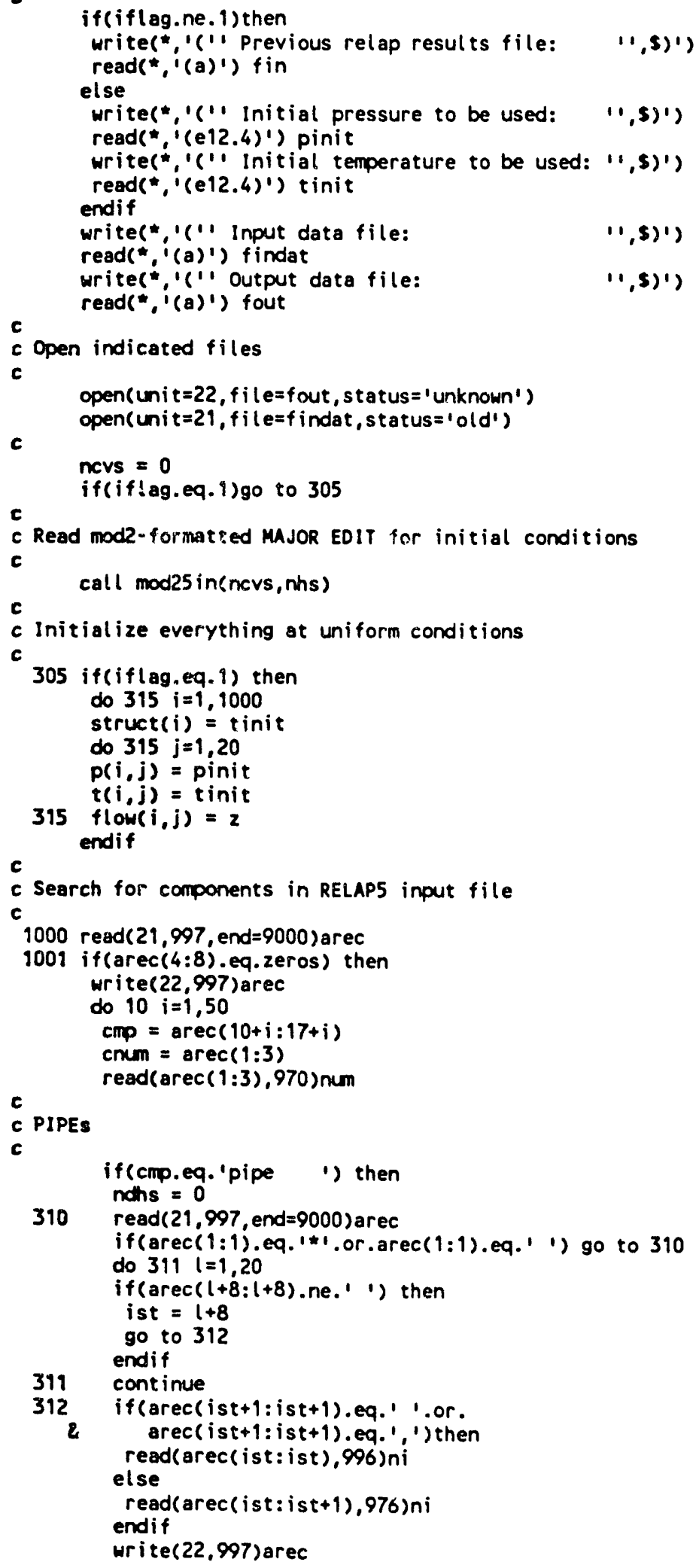




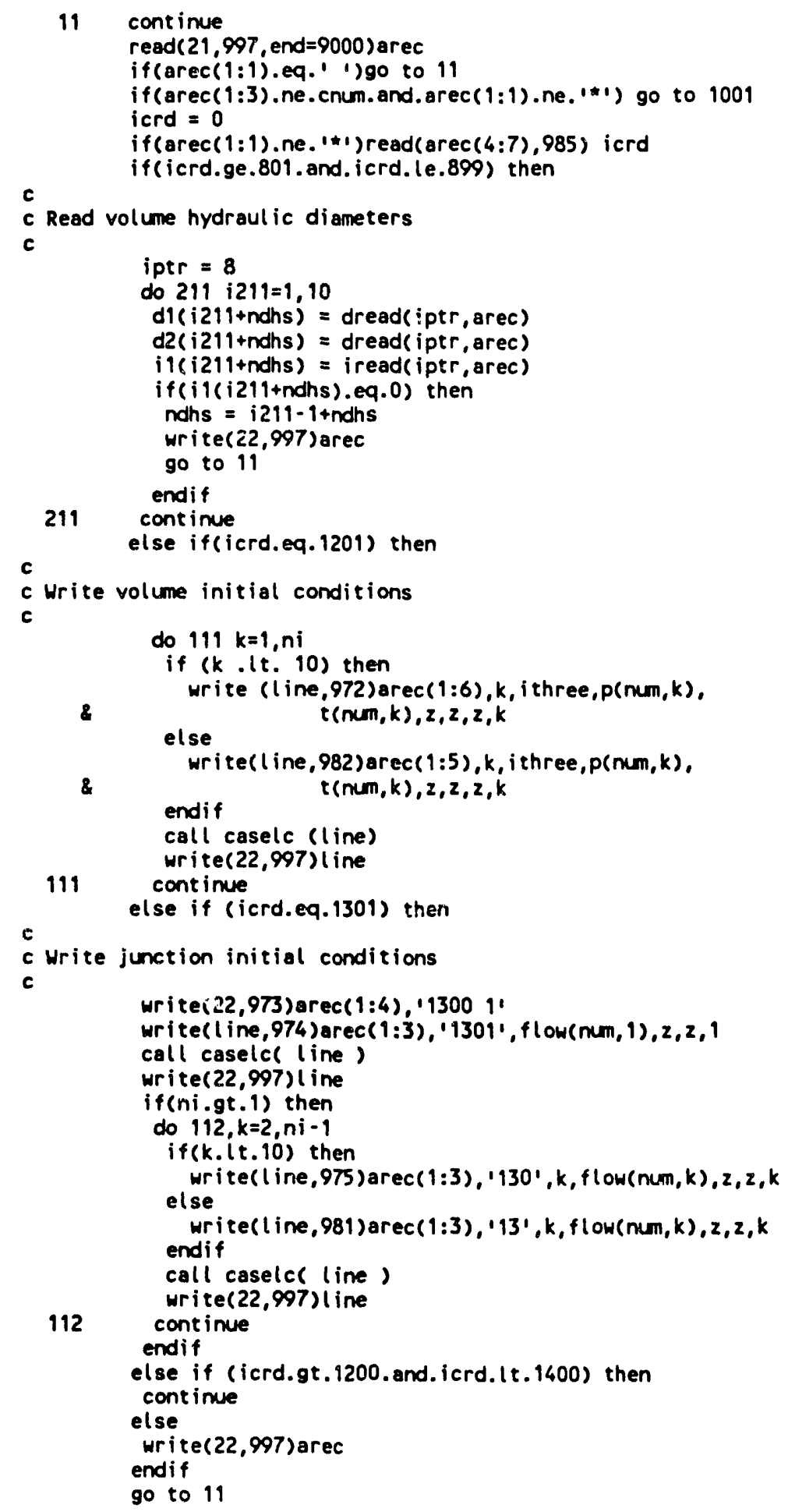


c

C BRANCH'S

$c$

else if (cmp.eq.'branch ") then

crum $=\operatorname{arec}(1: 3)$

read( $\operatorname{arec}(1: 3), 970) \mathrm{num}$

$12 \operatorname{read}(21,997$, end $=9000)$ arec

if(arec $(1: 1)$.eq. ' ') go to 12

if $(\operatorname{arec}(1: 3)$. ne.cnum. and.arec(1:1).ne.1*1) go to 1001

if $(\operatorname{arec}(4: 7)$.eq. 10200 ') then

write( line,993) arec(1:7), i three, $p(n u m, 1), t(n u m, 1)$

else if $(\operatorname{arec}(5: 7)$.eq. '201') then

read $(\operatorname{arec}(4: 4), 996) k$

write(line, 992 ) arec $(1: 8)$, flow(num, $k), 2, z$

else if $\operatorname{arec}(5: 7)$.eq. 1001 ') then

iptr $=8$

$n j=i \operatorname{read}(i p t r, a r e c)$

write(line, 91 ) arec( $1: 8), n j, 111$

else

write(line,997)arec

endif

call caselc( line)

write $(22,997)$ line

c

go to 12

c SINGLE VOLUMES

c

else if(cmp.eq.'snglvol ') then

cnum $=\operatorname{arec}(1: 3)$

13

read $(\operatorname{arec}(1: 3), 970)$ num

cont inue

read $(21,997$, end $=9000$ ) arec

if (arec (1:1).eq.' ') go to 13

if $(\operatorname{arec}(1: 3)$. ne.cnum. and.arec $(1: 1)$. ne.1*1) go to 1001

if $(\operatorname{arec}(4: 7)$.eq. 10200 ') then

write(line, 993 ) arec( $1: 7), i$ three, $p(n u m, 1), t(n u m, 1)$

call caselc( line)

write $(22,997)$ line

else

write $(22,997)$ arec

endif

go to 13

c

c ACCUMLLATORS

c

else if(cmp.eq.'accum ') then

crum $=\operatorname{arec}(1: 3)$

22 read(arec

$\operatorname{read}(21,997$, end $=9000)$ arec

if $(\operatorname{arec}(1: 1)$.eq. 1 ') go to 22

if $(\operatorname{arec}(1: 3)$. ne.crum. and.arec(1:1).ne.1*1) go to 1001

if $(\operatorname{arec}(4: 7), e q .10200$ ') then

write(line,980) arec(1:7), P(num, 1), t(num, 1)

call caselc( line)

write $(22,997)$ line

else if $\operatorname{arec}(4: 7)$.eq. '2200') then

iptr $=8$

$w 1=\operatorname{dread}(i p t r$, arec)

$w 2=\operatorname{dread}($ iptr, arec $)$

ip1 = iptr

W3 $=\operatorname{dread}(i p t r$, arec)

elev $=\operatorname{dread}($ ipt $r$, arec $)$

tnkelv = acclev(num)-elev

write(line, 971) arec(1:7), 2, tnkel $v$, arec(ipl:72)

call caselc( line)

write $(22,997)$ line

else

write $(22,997)$ arec

endif

go to 22 


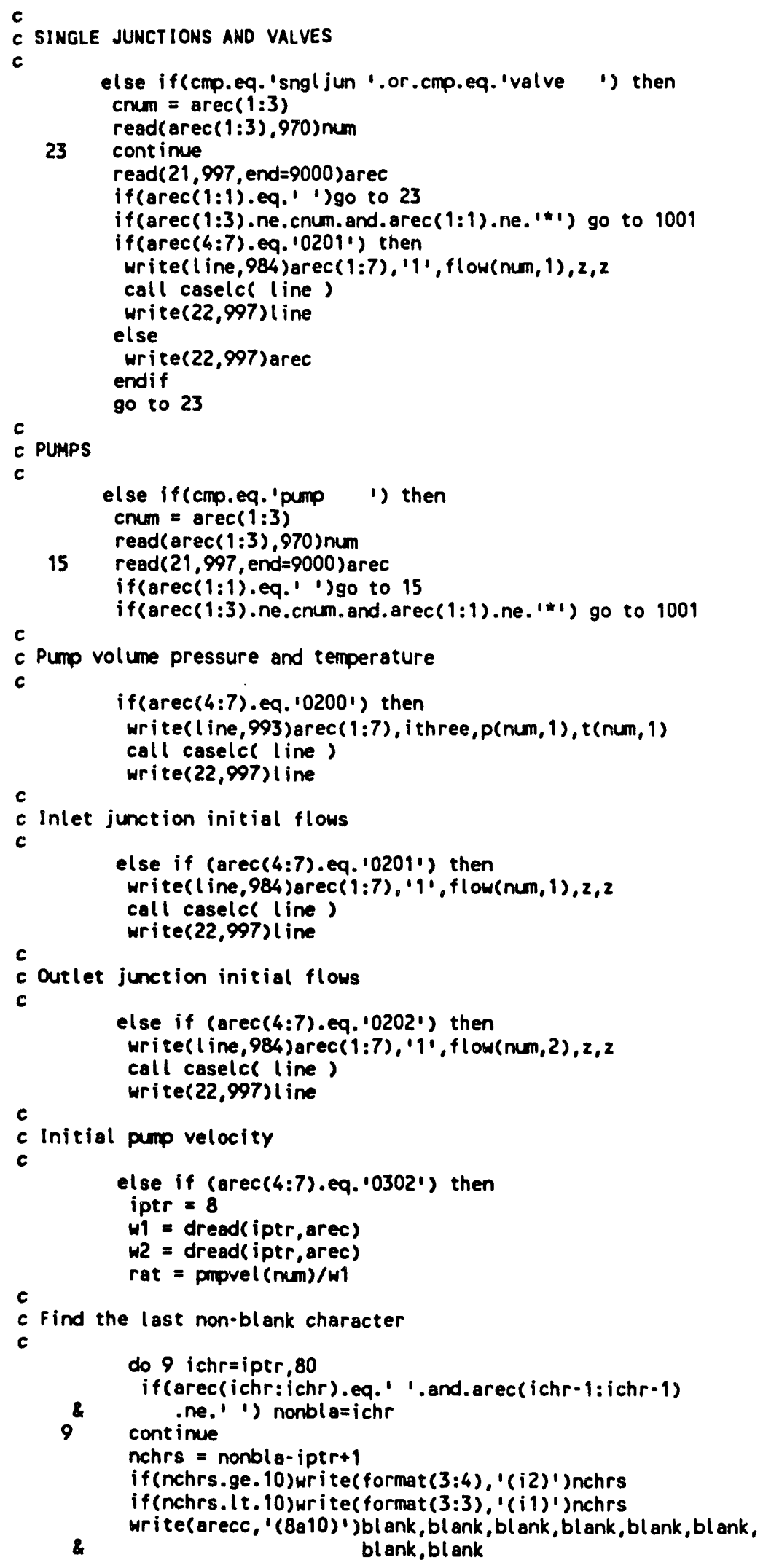

c Find the last non-blank character

do 9 ichr=iptr, 80

if (arec(ichr: ichr).eq.' ' and. arec(ichr-1:ichr-1)

8 ine.' ') nonblo=ichr

9 continue

nchrs = nonble-iptr+1

if (nchrs.ge.10)write(format (3:4), '(i2)')nchrs

if (nchrs.1t .10)write(format (3:3), ' (ii)') nchrs

write(arecc, '(8a10)') bl ank, blank, blank, blank, blank, blank, blank, blank 


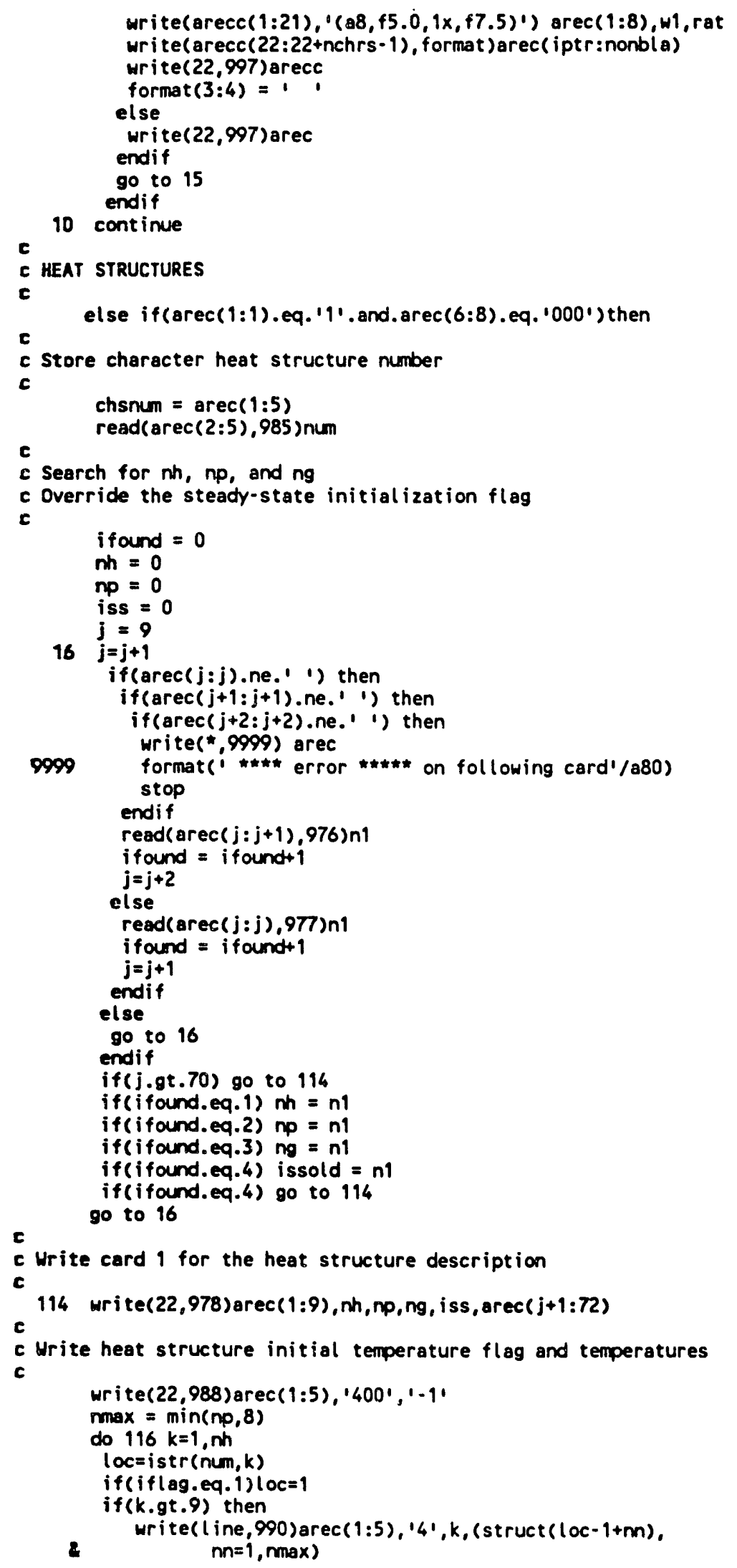




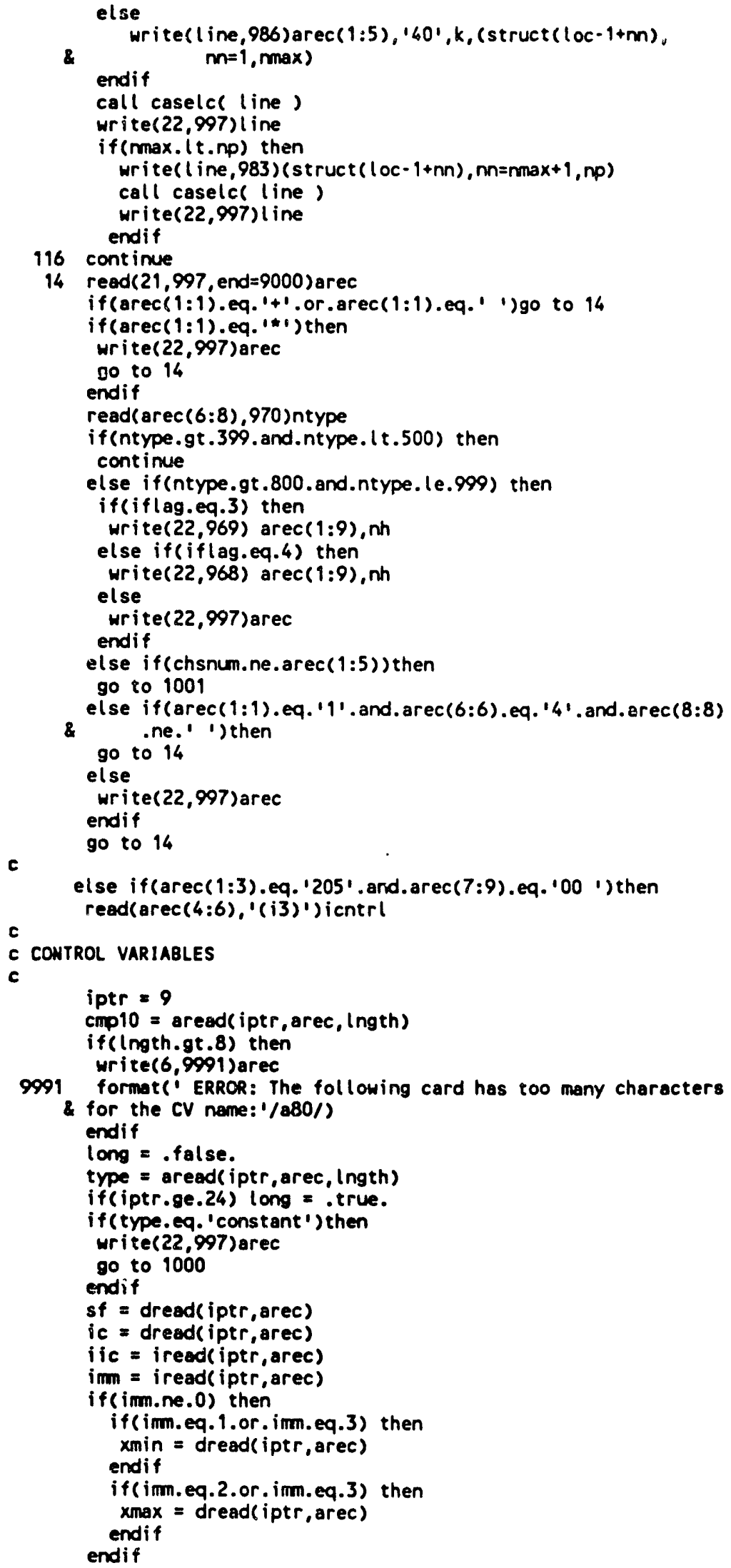




\section{c}

c write control variable cards

c

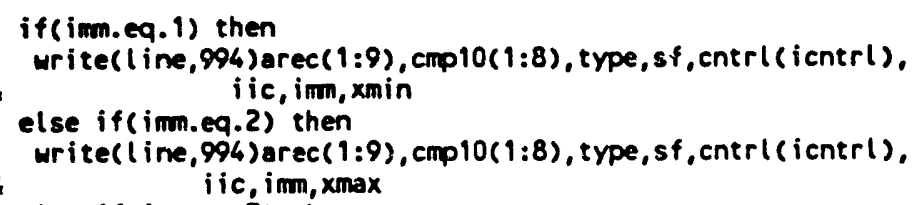




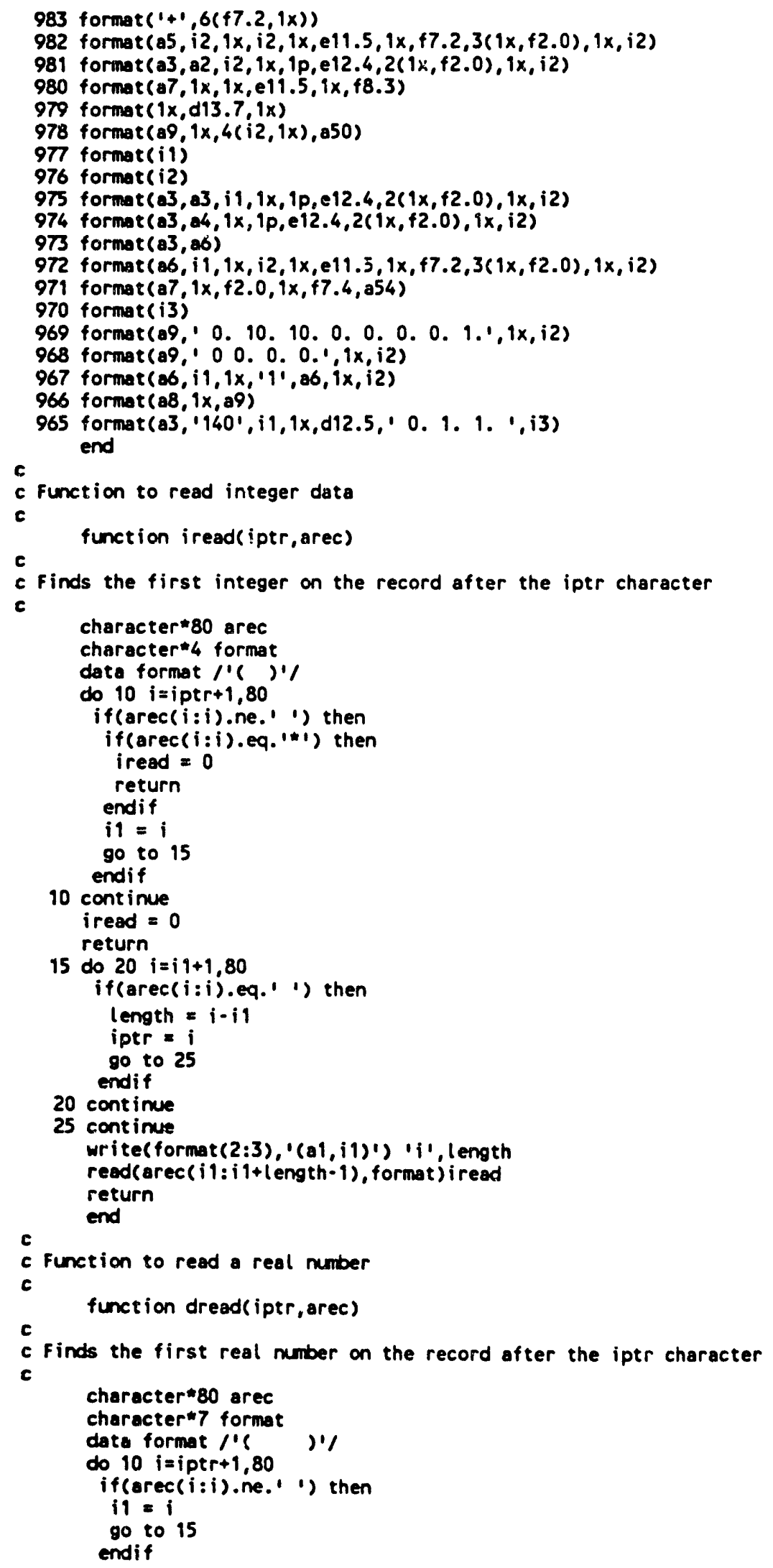




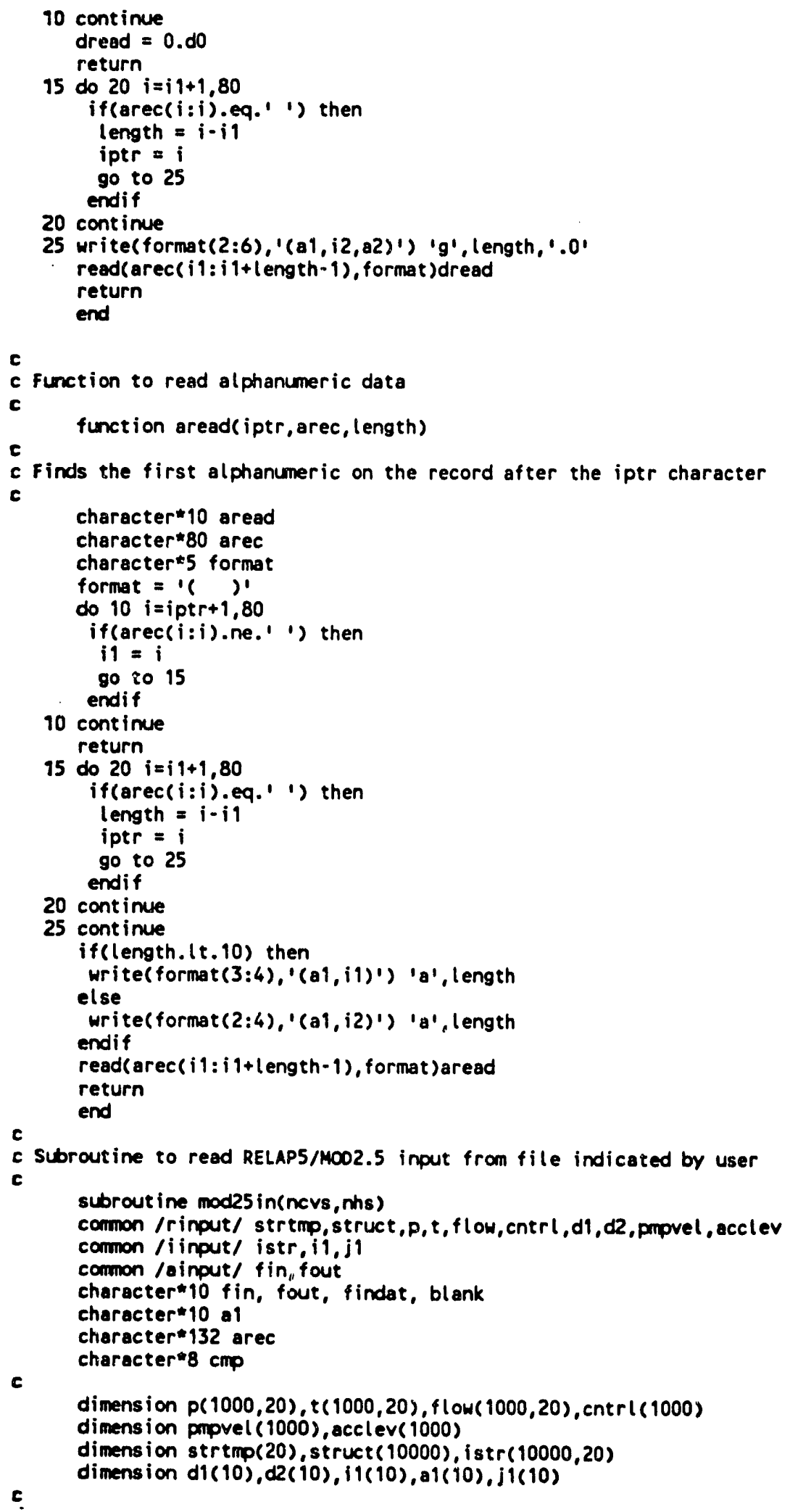


c Open file contoining the MAJOR EDIT

c open(unit $=23$, fil $=$ = in, status= ' unknown')

ii $=1$

pmov $=0$.

10 read $(23,997$, end $=200)$ arec

call caselc(arec)

c

c Read pressures and temperatures

C

if (arec(8:13).eq. 10000 1) then

$\operatorname{read}(\operatorname{arec}(1: 71), 999) i, j, p(i, j), t(i, j)$

if (pmpv.gt .0.d0)pmpvel (i) =pmpv

if (accl.gt.0.d0) acclev(i) =accl

pripv $=0$.

eccl $=0$.

if(i.eq.33) then

$t(i, j)=120$.

write(", '("' volume 33 is set to $120 \mathrm{f \prime \prime , \$ )')}$

endif

if(i.eq.35) then

t(i.j) $=120$.

write(", '(' volume 35 is set to $120+1$ ', 5$)$ ') endif

else if (arec( $4: 6)$.eq. 'rpm') then

read $\operatorname{arec}(9: 17), '(f 9.0) ')$ pmpv

else if(arec(2:12).eq. 'liq. volume') then

read(arec(74:82), '( 19.0$)$ ') accl

else if(arec(14:19).eq.' 'solute') then

go to 20

endif

90 to 10

20 read $(23,997$, end $=200$ ) arec

call coselc(arec)

if(arec( $2: 8)$.eq.' 'system ') go to 30

go to 20

$c$ Read mass flows

c

$30 \operatorname{read}(23,997$, end $=200$ ) arec

call caselc(arec)

if $\operatorname{arec}(8: 12)$.eq. $\left.\cdot 0000^{\prime \prime}\right)$ then

read(arec(1:74),971) $i, j, f(w$

if (j.eq. 0$) j=1$

$f($ ow $(i, j)=f(w$

else if(arec(14:19).eq. 'voidfj') then

go to 35

endif

go to 30

35 read $(23,997$, end $=200$ ) arec

call caselc(arec)

if( index(arec, 'mesh point temp').ne.0) goto 40 go to 35

c Read heat structure temperatures

C

$40 \operatorname{read}(23,997$, end $=200$ ) arce

call caselc(arec)

if(arec(22:42).eq. 'control variable adit') go to 50

if $\operatorname{arec}(6: 6) . e q .1-1)$ then

read (arec, 990 , end $=90) i, j,(\operatorname{strtmp}(k), k=1,10)$

$90 i \operatorname{str}(i, j)=i j$

do $45 k=1,19$

if (strtmp $(k) .9 t .1 . d-7)$ then

$\operatorname{struct}(i i)=\operatorname{strtmp}(k)$

$i i=i+1$

nhs $=n h s+1$

else 


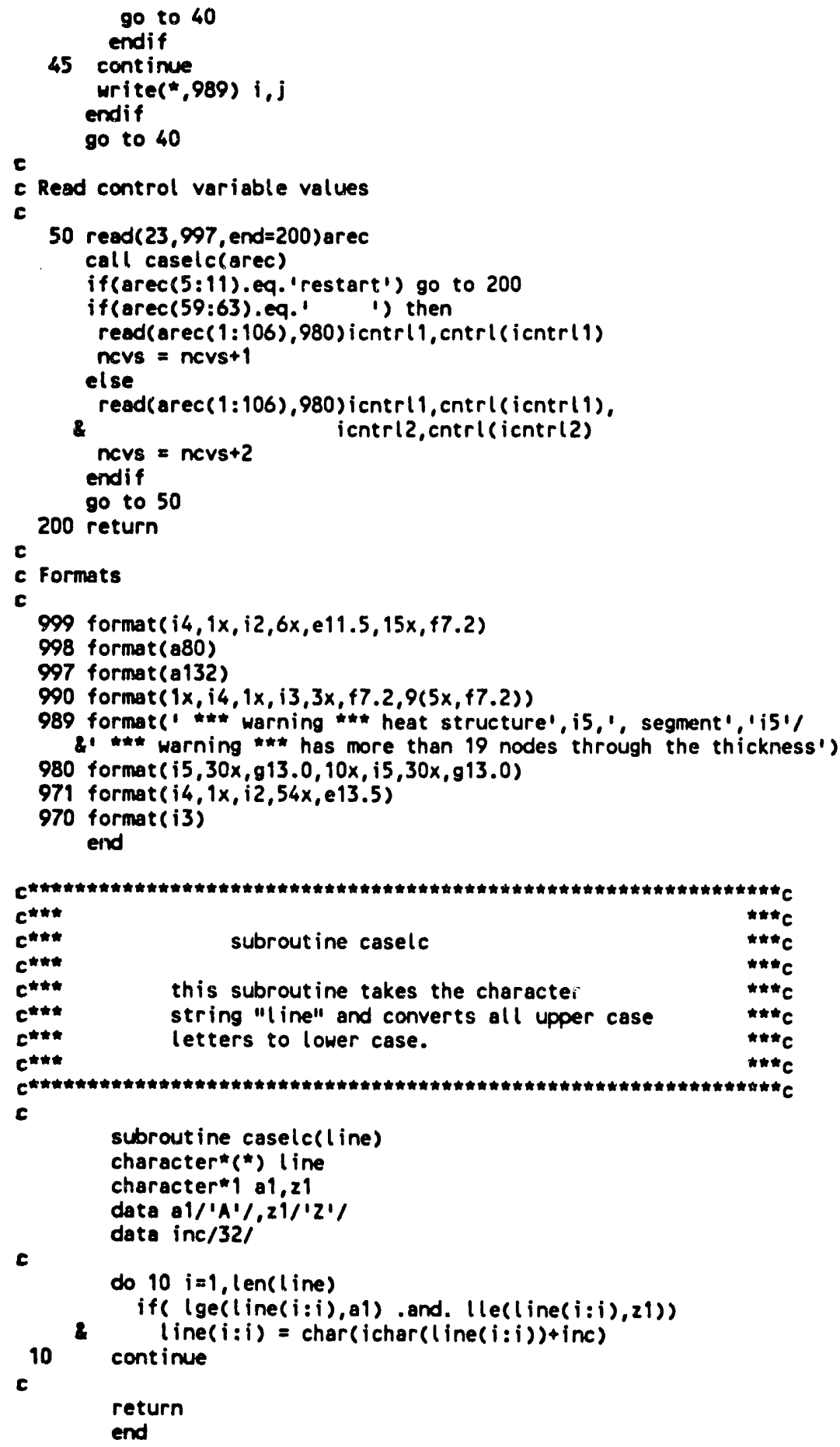




\section{Appendix D}

\section{POSTPROCESSING PROGRAM}

The postprocessing program is useful for plotting the dependent variables calculated by RELAP5 as a function of time with TECPLOT. This program, which reads a formatted "strip" file, displays a menu of the variables available on the strip file for plotting, and includes those selected variables in the TECPLOT data file, is given on the following pages. 
Postprocessing Program Used for Data Selection and Filtering

$\mathbf{c}$

c This program accomplishes the following:

C (1) Reads a RELAP5 generated strip file,

c (2) Gives the user a menu to select various dependent variables for plotting.

(3) Creates a TECPLOT-readable ASCIl data file containing the requested information.

c

c Uritten by M. H. Wendel $(615-574-2825)$

c

implicit double precision $(a-h, 0-z)$

dimension calc(200,10000), calci(200,10000)

character $\$ 8$ names (200), aduminy

character $\$ 5$ tecnam(200)

character 10 nums (200), fil nam

character $\$ 40$ title

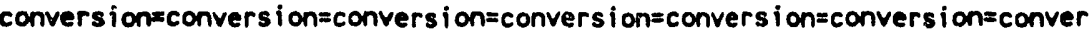

c

c Conversion factors from SI to British

c Pressure

data cpres $/ 1.0 /$

c Mass

data cmass /1.0/

c Internal energy data cu /1.0/

c Temperature data ctemp1, ctemp2 $/ 1.0,1.0 /$

c Heat flux data cht $f(x / 1.0 /$

c Pump velocity data cpmpv /1.0/

c Power data cpower /1.0/

c Density data coens /1.0/

c Velocity data crel /1.0/

c Interfacial area heat transfer coeff, density data chi $/ 1.0 /$

convers ion=convers $i$ on $=$ convers $i$ on $=$ conver ion $=$ convers $i$ on $=$ convers $i$ on $=$ conver

c

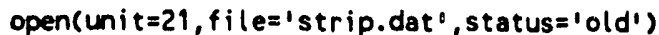

open(unit $=22$, file=' tecdat', status='new')

urite $(6,985)$

read $(6,979)$ title

zero $=0.0$

ithin $=1$

$m=0$

c Read list of variables from strip file

c

read $(21,990)$ aduminy

read $(21,990)$ adumm

read $(21,999) \mathrm{nt}$

$n t=n t-1$

$n t w=n t$

$n l=n t / 8$

last $=\min (n t, 7)$

$\operatorname{read}(21,998)$ (names ( $i), i=1$, (ast)

if $(\mathrm{nl} . \mathrm{gt} .0)$ then

do $10 \mathrm{j}=1, \mathrm{nl}$

last $=\min (n t, 7+j * 8)$

ifirst $=8 * j$

read $(21,988)$ (names ( $i), i=i f i r s t$, last)

10 continue

endif

$\operatorname{read}(21,991)($ nums $(i)(2: 10), i=1, n t)$ 
c

c Read time-dependent data for requested variables

C

do $20 i=1,10000$

$n 1=1$

$n 2=4$

$n 2=\min (n t, n 2)$

$\operatorname{read}(21,982$, end $=30)(\operatorname{calc}(j, i), j=n 1, n 2)$

$n 1=5$

do $25 i i=1,100$

if(n2.ge.nt) go to 21

$n 2=n 1+4$

$\operatorname{read}(21,986$, end $=30)(\operatorname{calc}(j, i), j=n 1, n 2)$

$n 1=n 1+5$

25 cont inue

21 if $(\bmod (i, 100)$.eq. 0$) w r i t e(6,984) i$

20 cont inue

$30 \mathrm{ilst}=\mathrm{i}-1$

c

write $(6,994)$ ilst

c Convert the units

c

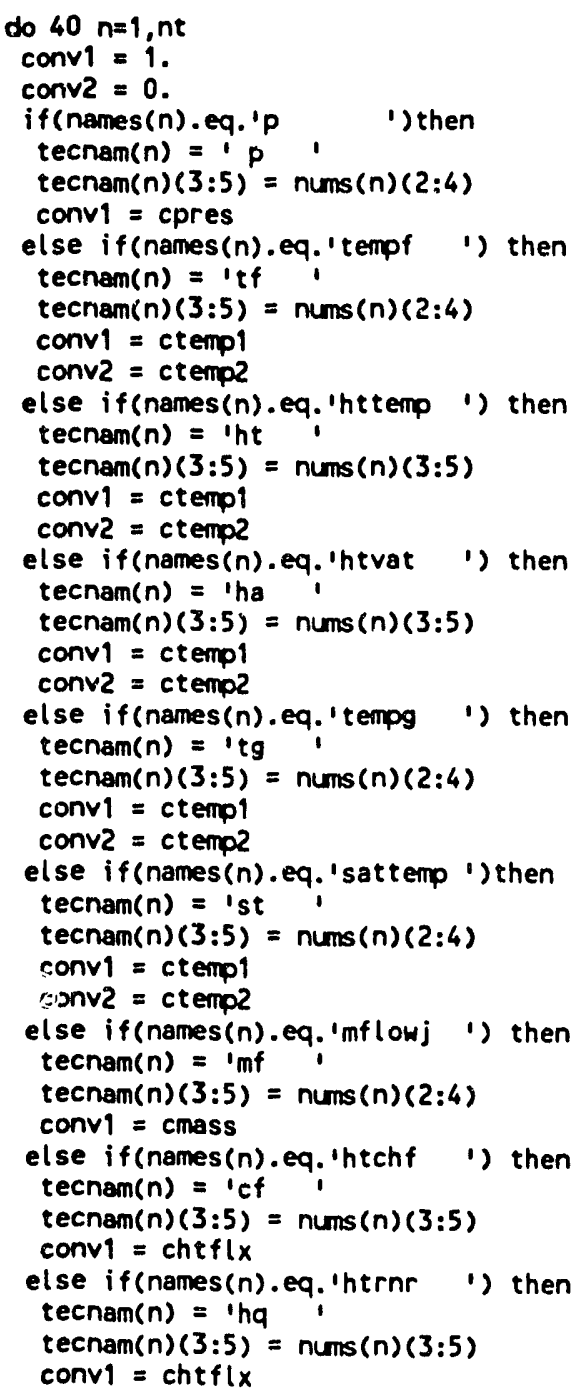




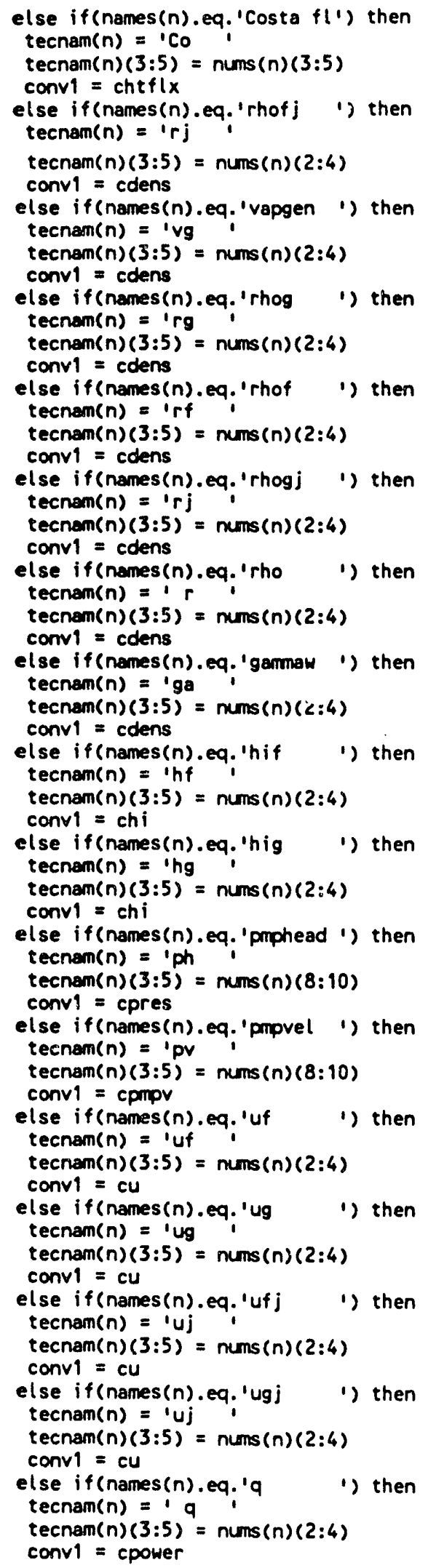




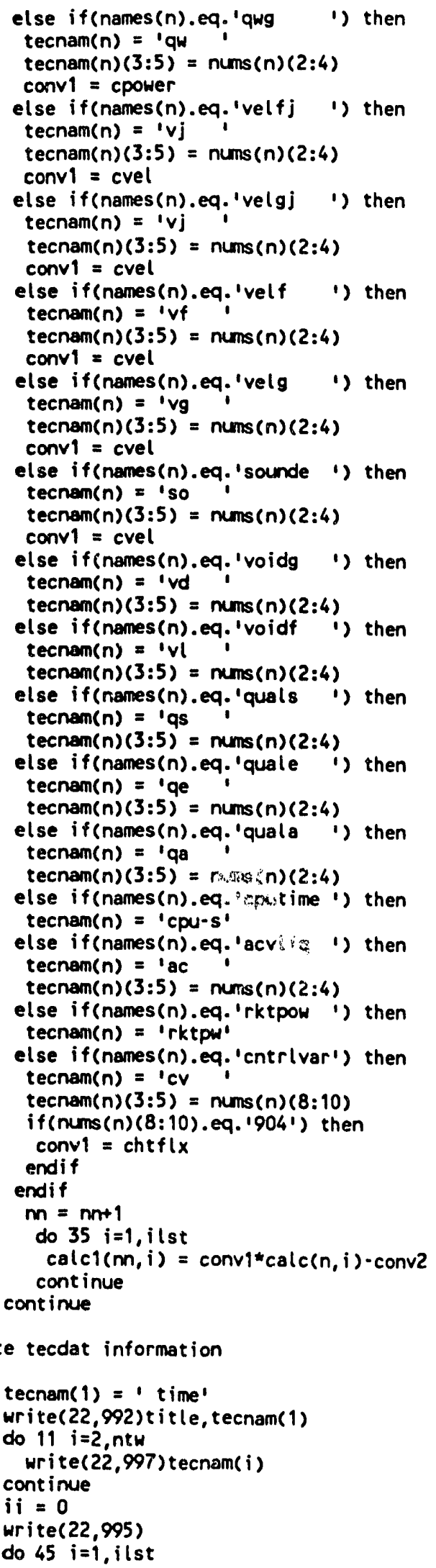




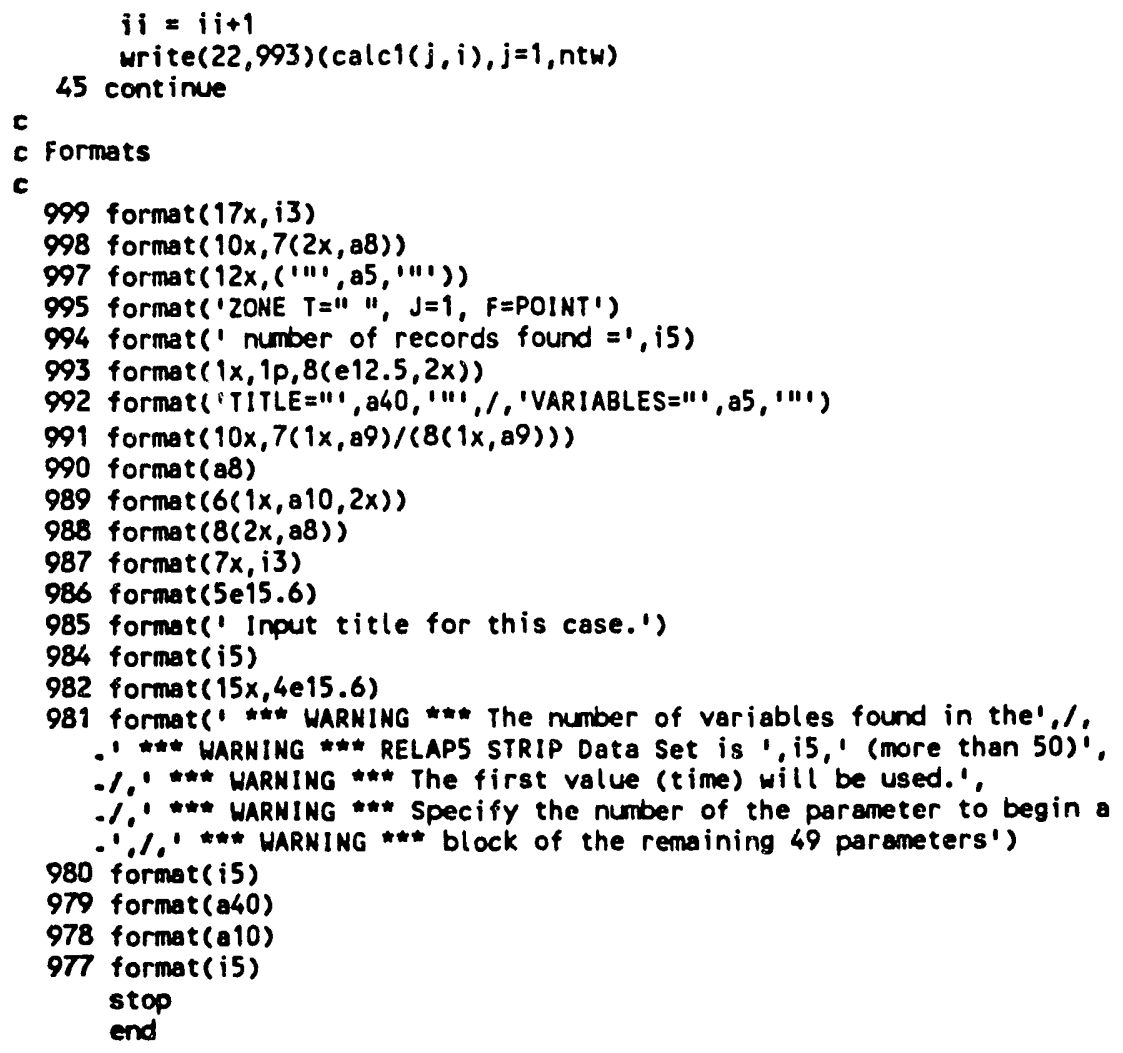




\section{Appendix E}

\section{ABBREVIATED MODEL FOR OPERATIONAL TRANSIENTS}

The model that has heretofore been discussed was developed primarily for simulating LOCAs, where detail (especially in the core region) is beneficial for resolving important flow and heat transfer characteristics. Usually for such transients the criteria for failure is either incipience of boiling or exceeding a critical heat flux limit (CHF) at the fuel/water interface. LOCAs, which result in complete depressurizaton because the pressurizer pump cannot respond quickly enough to recover system pressure, may involve two-phase flow in the reflector and control plate regions and in the piping between the reactor vessel and primary heat exchangers. Also, because the HFIR Final Safety Analysis Report will utilize a CHF (as opposed to incipient boiling) failure criteria, for some LOCAs, boiling will occur in the fuel regions. Much detail is necessary to accurately predict the system response for such transients.

Operational transients for which the system does not fully depressurize could be modeled with much less detail and, thus, less computational effort. For such transients an abbreviated version of the model has been assembled. Due to the coarse nodalization, it may not be clear from the results whether or not boiling (or voiding) would occur. However, the detailed model could be used to more accurately simulate the transient.

Another difference between the operational transient simulations and the LOCA simulations involves modeling reactor power fluctuation due to various feedback mechanisms. In a LOCA, the system immediately depressurizes so that the reactor is tripped very early in the transient, and the postshutdown heat curve is used to represent the decline in reactor power. However, the operational transient scenarios often involve longer simulation times before scram occurs, if it occurs at all. It is therefore necessary to represent changes in reactivity brought about by the changing temperatures of the structures and moderator in the core region. For this reason, the RELAP5 point (space-independent) kinetics model was invoked in the abbreviated model that will be used for simulating operational transients. Because RELAP5/MOD2.5 point kinetics capability has been found to be inadequate for the fast response of the HFIR system, a modification to the code has been made that requires changing the input model. ${ }^{1}$

This appendix describes the changes that have been made to the detailed model to produce the abbreviated model. Details of the changes that have been made are elaborated in calculational notes. ${ }^{2}$

\section{E.1. COARSENING OF NODALIZATION}

Two parameters directly affect the cost of a RELAP5 simulation: number of nodes and time-step size. ${ }^{3}$ The cost is proportional to the number of nodes and inversely proportional to the time-step size. The time-step size is limited by the minimum material Courant limit in the model. The limiting nodes in the detailed model are in the core region because the velocities are high and the control volumes (nodes) are short. In an operational transient simulation, two-phase flow is generally not expected, so the level of discretization in the core can be realized.

To reduce the cost of running the model, the discretization was coarsened throughout the primary system, as shown in Fig. E.1. The input model is listed in Appendix F. The most 


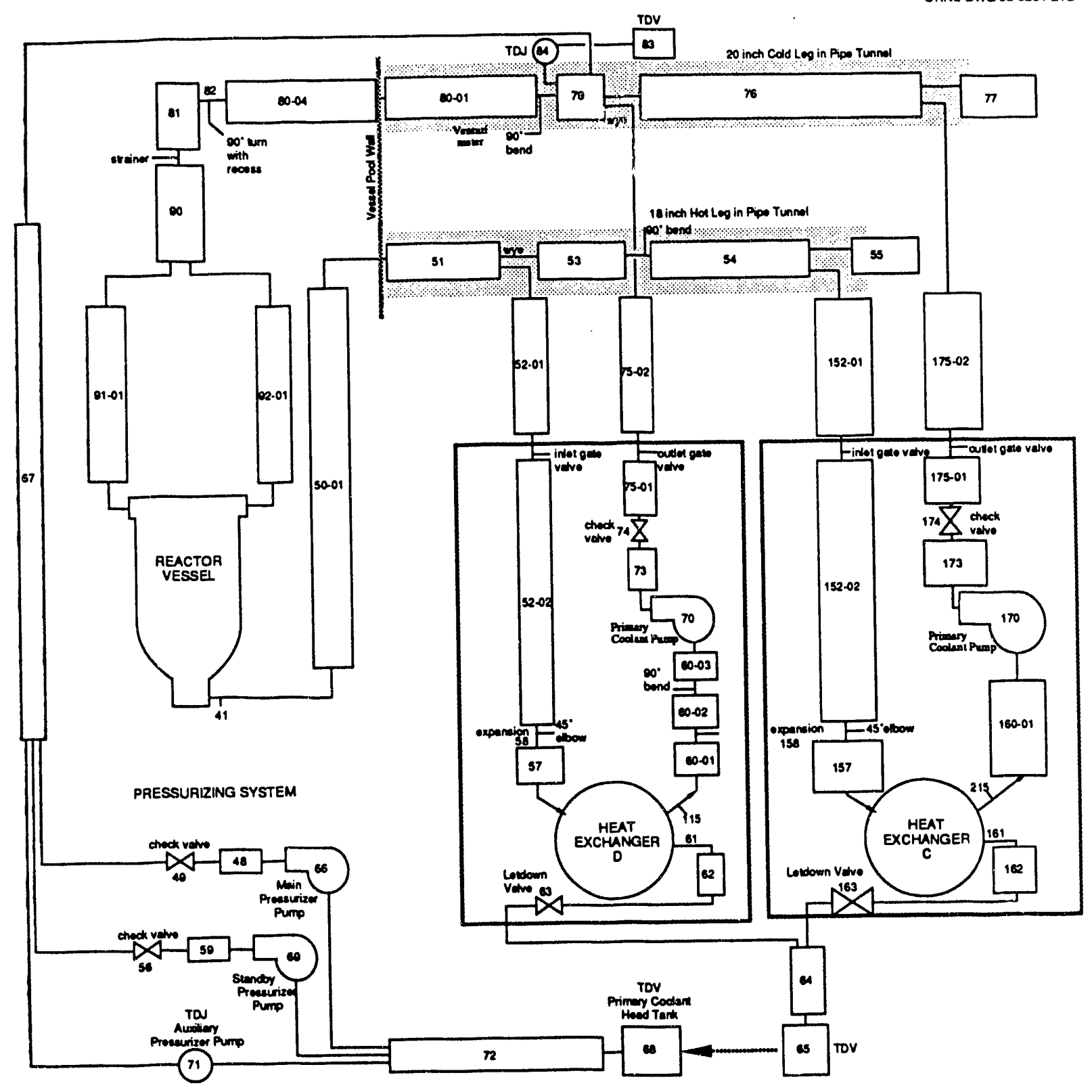

Fig. E.1. Abbreviated model primary system nodal diagram.

noticeable change is the combination of heat exchanger cells $\mathrm{A}$ and $\mathrm{C}$ into one loop. The flow areas, pump size, heat transfer areas, and volume in the combined loop were increased appropriately as indicated in the figure. The secondary side (except for the heat exchangers) and pressurizing system remained the same. In each heat exchanger, 8 nodes, instead of 20 , were used to represent primary coolant in the tubing, and 8 were also used for the shell (secondary) side. 
Within the core, the abbreviated discretization is shown in Fig. E.2. Here is where the greatest cost savings were made. Each channel and structure in the core/reflector were represented with only one axial node, whereas previously as many as 11 nodes were used. The heat source factors and heat structure areas used in the detailed model, which specify the power distribution in the core structures, were combined to get new factors for the singlenode structures. The same number of parallel channels was used in the abbreviated model as in the detailed model.

In reducing the level of discretization, as junctions were eliminated from the model, it was often necessary to combine loss coefficients. This means that some form losses are callculated by RELAP5 at a position more remote from where they actually occur, but for most operational transients, the overall flows and important pressure drops should be as accurate as if the detailed model was used.

\section{Q:? POINT KINETICS MODEL}

The point kinetics model available in RELAP5 was used to model changes in the HFIR fuel reactivity. The option of fission product decay calculations was invoked using the 1979 ANS Standard for Decay Heat Power in Light Water Reactors. ${ }^{4}$ A total of $85 \mathrm{MW}$ was specified as the nominal reactor power.

RELAP5 control variables (Table E.1) are used to calculate changes in reactivity of the HFIR fuel due to changes in (1) moderator temperature, (2) moderator density, (3) thermal expansion or contraction of the fuel plates, (4) position of control cylinders and safety rods, and (5) target region density. Insertion of the spring loaded safety rods (scram) is modeled with the control systems. R. B. Rothrock ${ }^{5}$ supplied the following reactivity constants that have been used in the RELAP5 HFIR point kinetics model:

1. effective total delayed neutron fraction, 0.0076 ;

2. prompt neutron lifetime, $35 \mu \mathrm{s}$ (BOL);

3. moderator temperature coefficients, Table E.2;

4. reactivity worth of the control cylinders and safety rods, Tables E.3 and E.4, and

5. uniform void coefficients: inner fuel element, $-0.11 \$$ per $1 \%$ void; outer fuel element, $-0.24 \$$ per $1 \%$ void.

Also, the target reactivity ${ }^{6}$ as a function of coolant void fraction is shown in Table E.5.

The four contributors to changes in reactivity are separated into sets of control variables. The value of the reactivity (in \$) of any one of the four contributors is unimportant except that the sum be zero at steady state. Rather, it is the change in the reactivity that is important, and modeling that change accurately was the goal of the RELAP5 HFIR reactivity control systems model.

\section{E21 Moderator Temperature Effects}

Increases in the water temperature within the target region lead to increases in the fuel reactivity; however, increases in the water temperature within the fuel region lead to decreases in the fuel reactivity. The RELAP5 control systems used to calculate these effects are diagrammed in Fig. E.3. The average moderator temperatures within the fuel and target regions are monitored, and the reactivity is adjusted as these average temperatures change. 


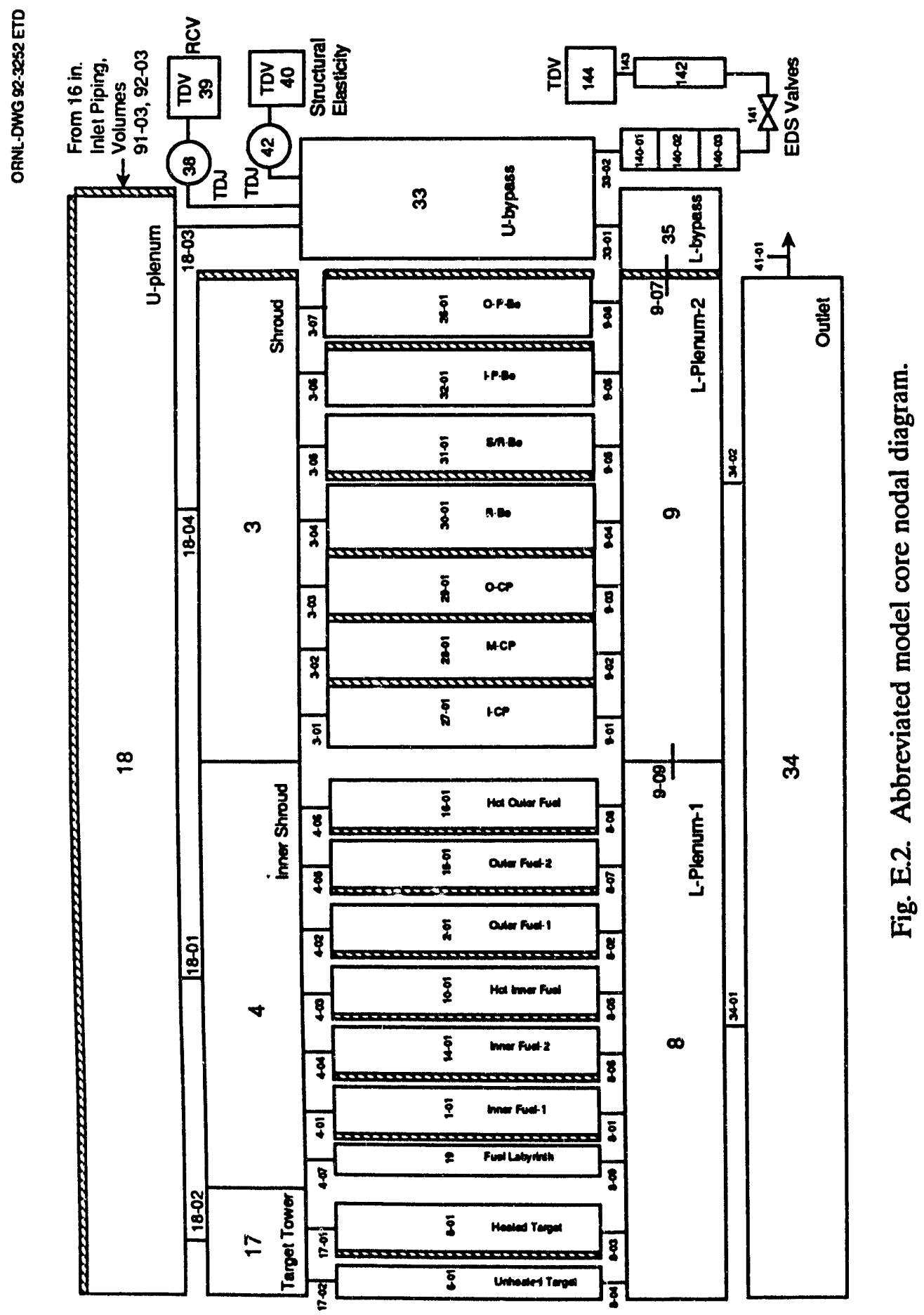


Table E.1. Control variables used for specifying changes in HFIR fuel reactivity

\begin{tabular}{|c|c|c|}
\hline Variable & Type & Description \\
\hline 776 & CONSTANT & Steady-state average density in control plate region \\
\hline 777 & SUM & Average coolant temperature in fuel channels \\
\hline 778 & SUM & $\begin{array}{l}\text { Moderator temperature coefficient for coolant in fuel } \\
\text { channels }\end{array}$ \\
\hline 779 & SUM & $\begin{array}{l}\text { Change in average coolant temperature during last time } \\
\text { step for fuel channels }\end{array}$ \\
\hline 780 & SUM & $\begin{array}{l}\text { Saved value of average coolant temperature in fuel } \\
\text { channels (CV 777) for later use }\end{array}$ \\
\hline 781 & MULT & $\begin{array}{l}\text { Adjustment of reactivity due to temperature change of } \\
\text { coolant in the fuel channels }\end{array}$ \\
\hline 782 & SUM & New value of fuel moderator worth \\
\hline 783 & SUM & Average coolant temperature in target channels \\
\hline 784 & FUNCTION & $\begin{array}{l}\text { Moderator temperature coefficient for coolant in target } \\
\text { channels }\end{array}$ \\
\hline 785 & SUM & $\begin{array}{l}\text { Change in average coolant temperature during last time } \\
\text { step for target channels }\end{array}$ \\
\hline 786 & SUM & $\begin{array}{l}\text { Saved value of the average coolant temperature in target } \\
\text { channels (CV 783) for later use }\end{array}$ \\
\hline 787 & MULT & $\begin{array}{l}\text { Adjustment of reactivity due to temperature change of } \\
\text { coolant in the target channels }\end{array}$ \\
\hline 788 & SUM & New value of target moderator worth \\
\hline 789 & SUM & Average inner fuel coolant temperature change \\
\hline 790 & SUM & Saved value of the average inner fuel coolant temperature \\
\hline 791 & SUM & Average inner fuel temperature change \\
\hline 792 & SUM & Saved value of the average inner fuel temperature \\
\hline 793 & SUM & $\begin{array}{l}\text { Difference between fuel temperature change and coolant } \\
\text { temperature change }\end{array}$ \\
\hline 794 & MULT & $\begin{array}{l}\text { Change in reactivity due to thermal expansion of the inner } \\
\text { fuel element (\$) }\end{array}$ \\
\hline 795 & SUM & $\begin{array}{l}\text { New reactivity contribution based on thermal expansion of } \\
\text { the inner fuel element }(\$)\end{array}$ \\
\hline 796 & SUM & Average outer fuel coolant temperature change \\
\hline 797 & SUM & Saved value of the average inner fuel coolant temperature \\
\hline
\end{tabular}


Table E.1 (continued)

\begin{tabular}{|c|c|c|}
\hline Variable & Type & Description \\
\hline 798 & SUM & Average outer fuel temperature change \\
\hline 799 & SUM & Saved value of the average outer fuel temperature \\
\hline 800 & SUM & $\begin{array}{l}\text { Difference between fuel temperature change and coolant } \\
\text { temperature change }\end{array}$ \\
\hline 801 & MULT & $\begin{array}{l}\text { Change in reactivity due to thermal expansion of the outer } \\
\text { fuel element (\$) }\end{array}$ \\
\hline 802 & SUM & $\begin{array}{l}\text { New reactivity contribution based on the thermal expansion } \\
\text { of the outer fuel element }(\$)\end{array}$ \\
\hline 803 & SUM & $\begin{array}{l}\text { Average change in density for coolant in control cylinder } \\
\text { and reflector regions }\end{array}$ \\
\hline 804 & SUM & Change in average density in control plate region \\
\hline 805 & DIV & $\begin{array}{l}\text { New worth contribution for density change of coolant in } \\
\text { control cylinder and reflector regions }(\$)\end{array}$ \\
\hline 806 & FUNCTION & Control plate worth $(\$)$ \\
\hline 808 & TRIPUNIT & Flag for initiating scram \\
\hline 809 & TRIPDLAY & Time that scram was initiated \\
\hline 810 & SUM & Time since scram was initiated \\
\hline 811 & FUNCTION & Safety rod insertion (in.) \\
\hline 812 & MULT & Safety rod insertion multiplied by initiating flag (CV 808) \\
\hline 813 & SUM & New position of safety rods (in.) \\
\hline 814 & FUNCTION & Safety rod worth $(\$)$ \\
\hline 815 & SUM & Average void fraction in target region \\
\hline 816 & FUNCTION & Average reactivity based on CV815 and general Table 14 \\
\hline 817 & SUM & Total reactivity $(\boldsymbol{\$})$ \\
\hline 819 & CONSTANT & Control cylinder position (in.) \\
\hline 850 & R - POW & Added input for modified version of RELAP5/MOD2.5 \\
\hline
\end{tabular}


Table E.2. Moderator temperature coefficients in fuel and fiux trap regions

\begin{tabular}{ccc}
$\begin{array}{c}\text { Temperature } \\
\left({ }^{\circ} \mathrm{F}\right)\end{array}$ & $\begin{array}{c}\text { Fuel region } \\
\left(\${ }^{\circ} \mathrm{F}\right)\end{array}$ & $\begin{array}{c}\text { Flux trap region } \\
\left(\$ /^{\circ} \mathrm{F}\right)\end{array}$ \\
\hline 80 & $-9.15 \times 10^{-3}$ & $7.46 \times 10^{-3}$ \\
90 & $-9.86 \times 10^{-3}$ & $7.75 \times 10^{-3}$ \\
100 & $-10.56 \times 10^{-3}$ & $8.03 \times 10^{-3}$ \\
110 & $-11.27 \times 10^{-3}$ & $8.31 \times 10^{-3}$ \\
120 & $-11.97 \times 10^{-3}$ & $8.59 \times 10^{-3}$ \\
130 & $-12.68 \times 10^{-3}$ & $9.01 \times 10^{-3}$ \\
140 & $-13.38 \times 10^{-3}$ & $9.58 \times 10^{-3}$ \\
150 & $-14.08 \times 10^{-3}$ & $10.0 \times 10^{-3}$ \\
160 & $-14.79 \times 10^{-3}$ & $10.56 \times 10^{-3}$ \\
\hline
\end{tabular}

Table E.3. HFIR control plate worth

\begin{tabular}{cc}
\hline $\begin{array}{c}\text { Insertion } \\
\text { (in.) }\end{array}$ & $\begin{array}{c}\text { Reactivity } \\
(\$)\end{array}$ \\
\hline 0.0 & 0.0 \\
0.543 & -0.1071 \\
1.086 & -0.2476 \\
1.629 & -0.4284 \\
2.172 & -0.6551 \\
2.715 & -0.9317 \\
3.258 & -1.2611 \\
3.801 & -1.6456 \\
4.344 & -2.0871 \\
4.887 & -2.5867 \\
5.43 & -3.1457 \\
5.973 & -3.7647 \\
6.516 & -4.4442 \\
7.059 & -5.1844 \\
7.602 & -5.9847 \\
8.145 & -6.8439 \\
8.688 & -7.7598 \\
9.231 & -8.7286 \\
9.774 & -9.74488 \\
10.317 & -10.8008 \\
10.860 & -11.8859 \\
19.86 & -16.63 \\
26.86 & -16.63 \\
& \\
\hline & \\
\hline &
\end{tabular}

Table E.4 Safety rod worth

\begin{tabular}{cc}
\hline $\begin{array}{c}\text { Insertion } \\
\text { (in.) }\end{array}$ & Reactivity \\
\hline 0.00 & 0.0000 \\
0.543 & -0.07833 \\
1.086 & -0.18291 \\
1.629 & -0.31909 \\
2.172 & -0.4911 \\
2.715 & -0.70237 \\
3.258 & -0.95569 \\
3.801 & -1.25346 \\
4.344 & -1.59773 \\
4.887 & -1.99024 \\
5.430 & -2.43236 \\
5.973 & -2.92495 \\
6.516 & -3.46822 \\
7.059 & -4.05143 \\
7.602 & -4.70255 \\
8.145 & -5.38790 \\
8.688 & -6.11166 \\
9.231 & -6.86532 \\
9.774 & -7.63706 \\
10.371 & -8.41110 \\
10.860 & -9.16695 \\
18.86 & -13.84 \\
26.86 & -13.84 \\
& \\
\hline &
\end{tabular}


Table E.5. HFIR target region reactivity as a function of coolant void fraction

\begin{tabular}{lll}
\hline Void & \multicolumn{1}{c}{$\Delta k$} & \multicolumn{1}{c}{$\$$} \\
\hline 0.0 & 0.0 & 0.0 \\
0.01 & $4.5 \times 10^{-4}$ & $6.34 \times 10^{-2}$ \\
0.10 & 0.006 & 0.8451 \\
0.20 & 0.010 & 1.408 \\
0.30 & 0.013 & 1.831 \\
0.40 & 0.0145 & 2.042 \\
0.42 & 0.015 & 2.113 \\
0.48 & 0.014 & 1.972 \\
\hline
\end{tabular}

In calculating the average temperature of the target region, both the heated and unheated channels (Fig. 7) were included. The temperatures in the inner and outer average fuel channels were combined into a single average that was used for the average moderator temperature in the fuel region.

\section{E22 Thermal Expansion Effects}

If the fuel plates heat up, they will also expand, the moderator volume contained within them is decreased, and the reactivity of the fuel increases by an amount proportional to the void coefficient. The RELAP5 control system diagrammed in Fig. E.4 shows how this effect for the inner fuel element is calculated in the model. The temperature change and, thus, thermal expansion/contraction of the fuel are assumed to occur uniformly. A similar control system is used to calculate the reactivity change due to thermal expansion/contraction of the outer fuel element. The coefficient of thermal expansion for the fuel plates was assumed to be that of Al6061 (Ref. 7) at $500 \mathrm{~K}: 27.5 \times 10^{-6} \mathrm{~K}^{-1}$.

\section{E23 Moderator Density Change in Control Region and Reflector}

Changes in reactivity due to moderator density changes in the control region and reflector are based on an assumed void coefficient of $0.028 \$ 1 \%$ void. ${ }^{8}$ The control plate and reflector region densities are area weighted, and a single void coefficient is applied to get the change in reactivity.

\section{E.2.4 Control Cylinder Worth}

The control cylinder position is specified in the input file, and the model determines control plate worth, using general Table 16.

\section{E.25 Safety Rod Worth}

The safety rod insertion at scram is calculated using a control system model (Fig. E.5). The rods are spring loaded, with the maximum acceleration of $4 \mathrm{~g}$ at the initial spring deflation of $0.5 \mathrm{ft}(0.152 \mathrm{~m})$. Once the spring is fully extended, the rods fall subject only to 


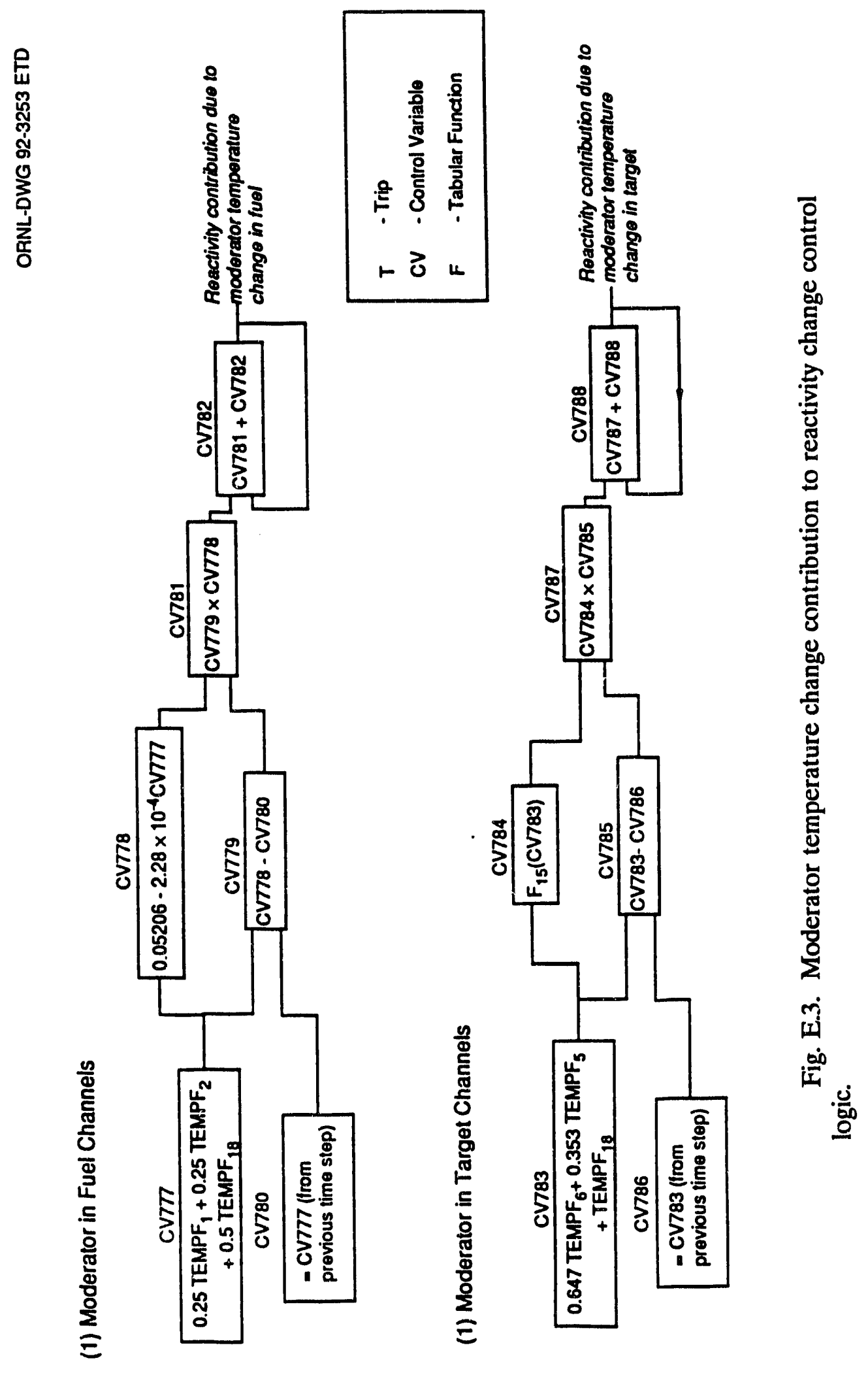


ORNL-DWG 92-3254 ETD

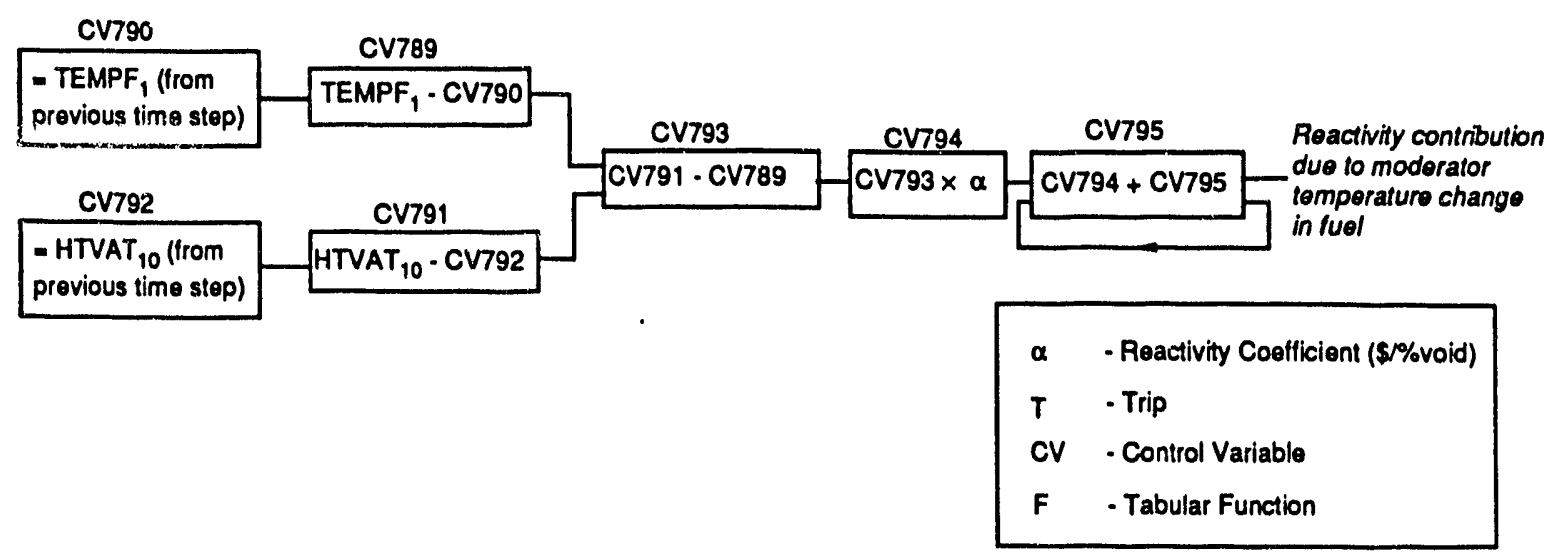

Fig. E.4. Inner fuel thermal expansion contribution to reactivity change control logic.

ORNL-DWG 92-3255 ETD

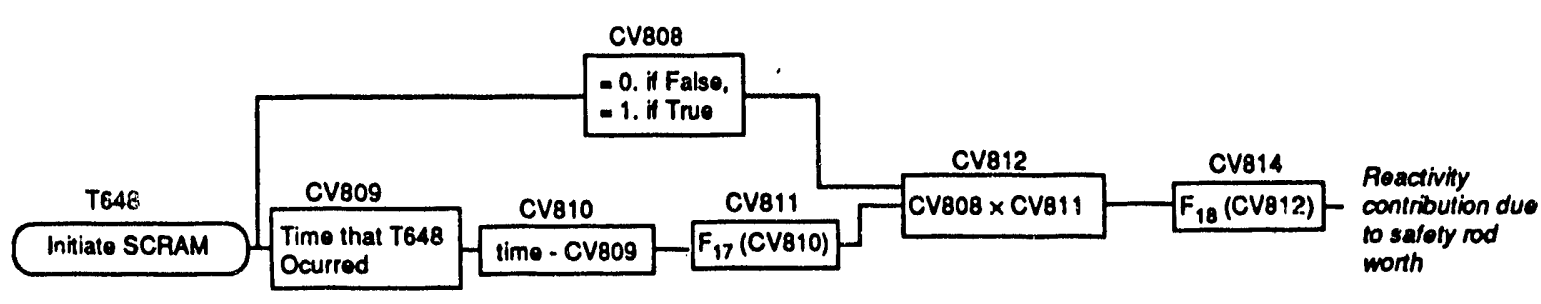

Fig. E.5. Control logic for safety rod insertion after scram is initiated.

the acceleration of gravity. A curve was generated for the safety rod position as a function of time after insertion, and the total insertion time was found to be $0.25 \mathrm{~s}$. Because the HFIR Technical Specifications allow an insertion time of $0.4 \mathrm{~s}$, the curve was steechest thut over $0.4 \mathrm{~s}$. (For operational transients, if a shorter insertion time is conswat then be assumed that the safety rods are instantaneously completely inserted.)

\section{E26 Target Region Void Feedback}

Based on the average vapor void fraction in the target region and general Table 14, the reactivity of the moderator in the target region is calculated. General Table 14 is the same as Table E.5. 


\section{E3 REFERENCES}

1. J. D. Freels, "Documentation of a Modification of the RELAP5/MOD2.5/v3t Code for Performing HFIR Safety Analyses of Events Involving Reactivity Changes," RRD Calculation ID: HFIR-RRD-91-JDF-15-02, Martin Marietta Energy Systems, Inc., Oak Ridge Natl. Lab., February 1992.

2. M. W. Wendel, "HFIR RELAP5 Abbreviated Model Notes," Research Reactors Division Calculation, C-HFIR-92-004, Martin Marietta Energy Systems, Inc., October 1988-December 1990, February 28, 1992.

3. V. H. Ransom et al., RELAP5 Code Manual, Vol. 1, p. 11, Idaho National Engineering Laboratory, December 1985.

4. American National Standard for Decay Heat Power in Light Water Reactors, ANSI/ANS-5.1, 1979.

5. R. B. Rothrock, Oak Ridge National Laboratory, letter to B. L. Lepard, Oak Ridge National Laboratory, October 1990.

6. R. D. Cheverton and T. M. Sims, HFIR Core Nuclear Design, ORNL-4621, p. 72, Union Carbide Corp. Nuclear Div., Oak Ridge Natl. Lab., July 1971.

7. Y. S. Touloukian et al., Thermophysical Properties of Matter, Vol. 12, p. 1028, IFI/Plenum, 1970.

8. R. D. Cheverton and T. M. Sims, HFIR Core Nuclear Design, ORNL-4621, Union Carbide Corp. Nuclear Div., Oak Ridge Natl. Lab., July 1971. 
Appendix F

INPUT LISTING FOR ABBREVIATED MODEL 

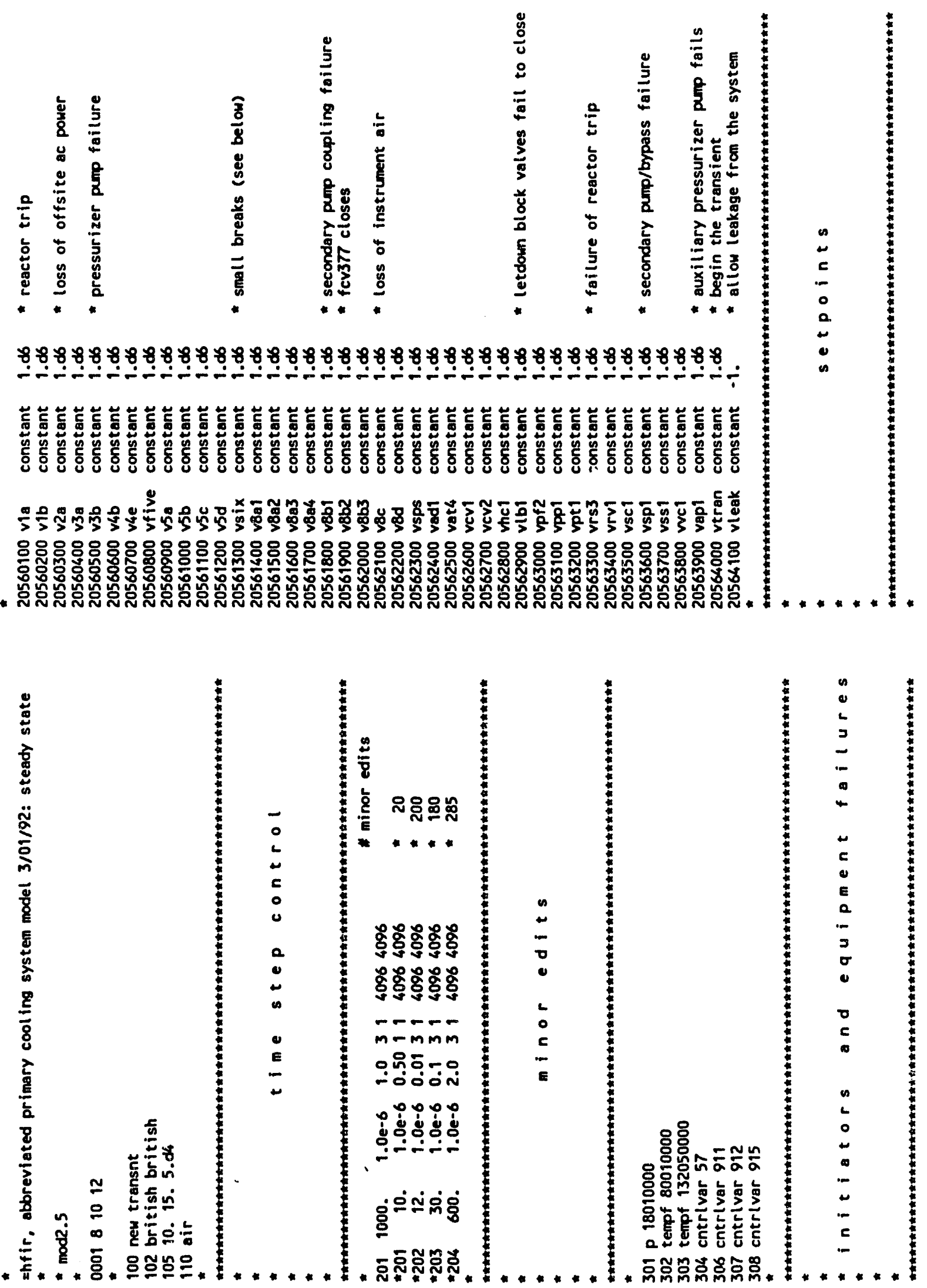


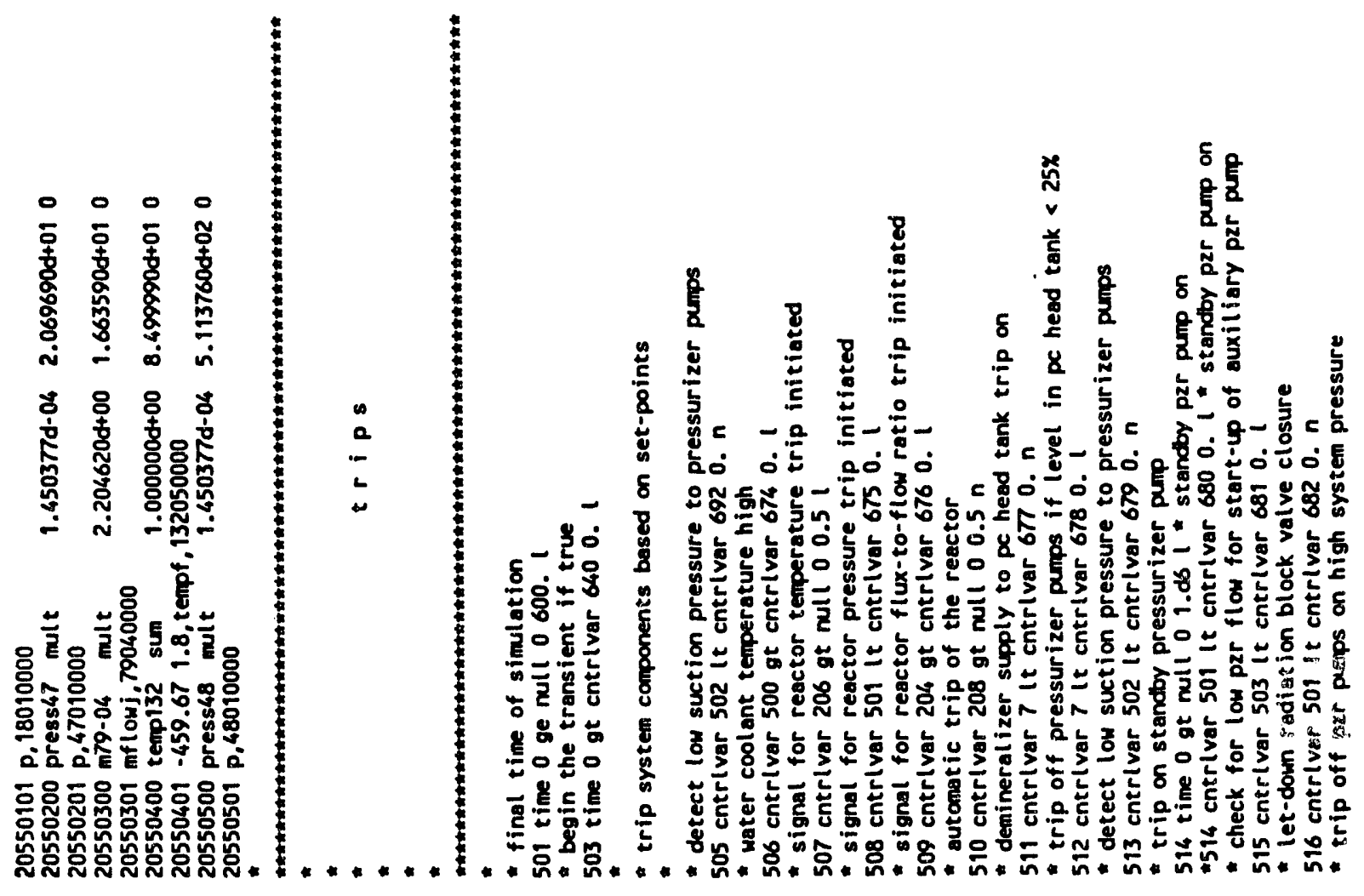

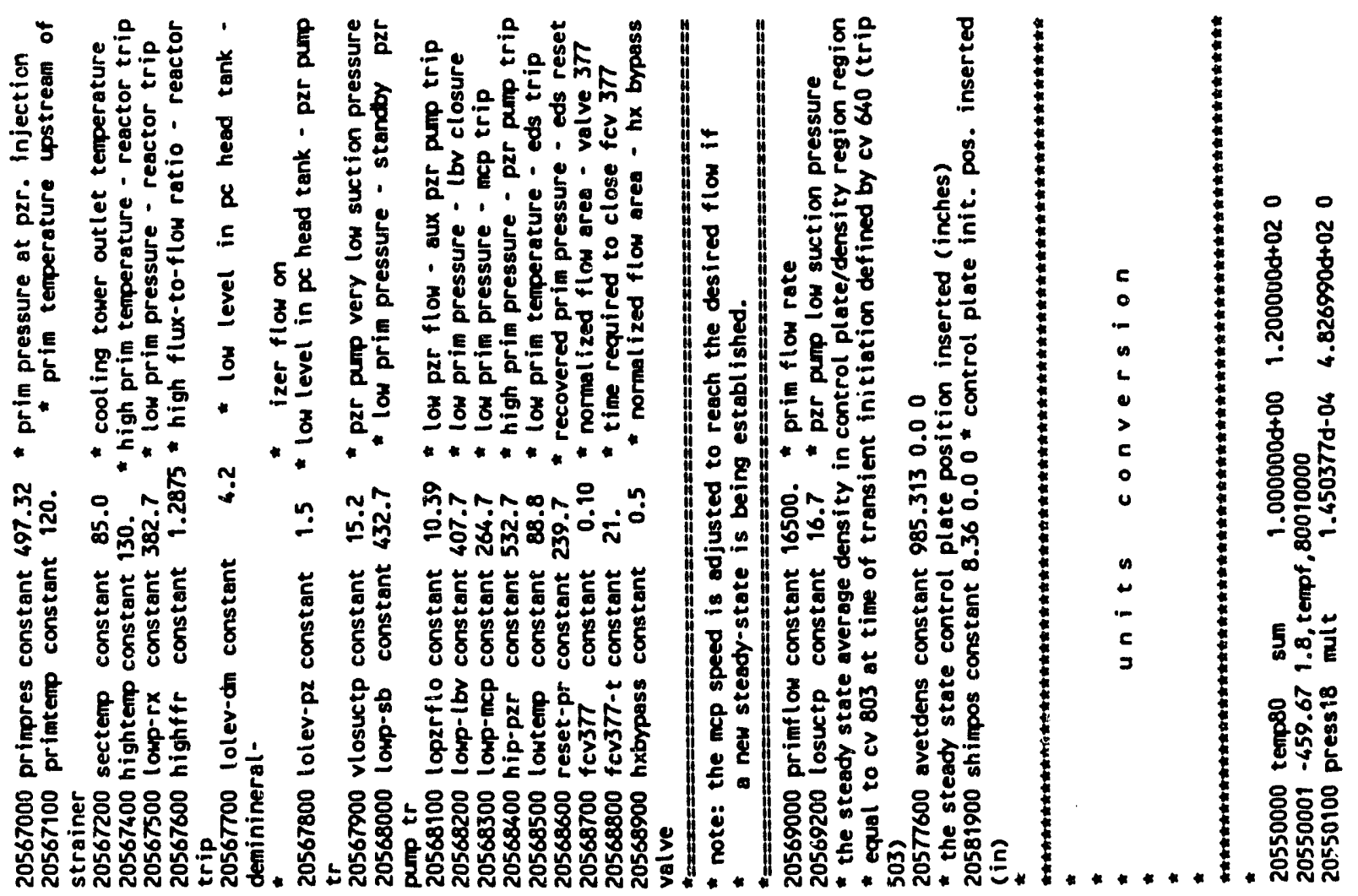



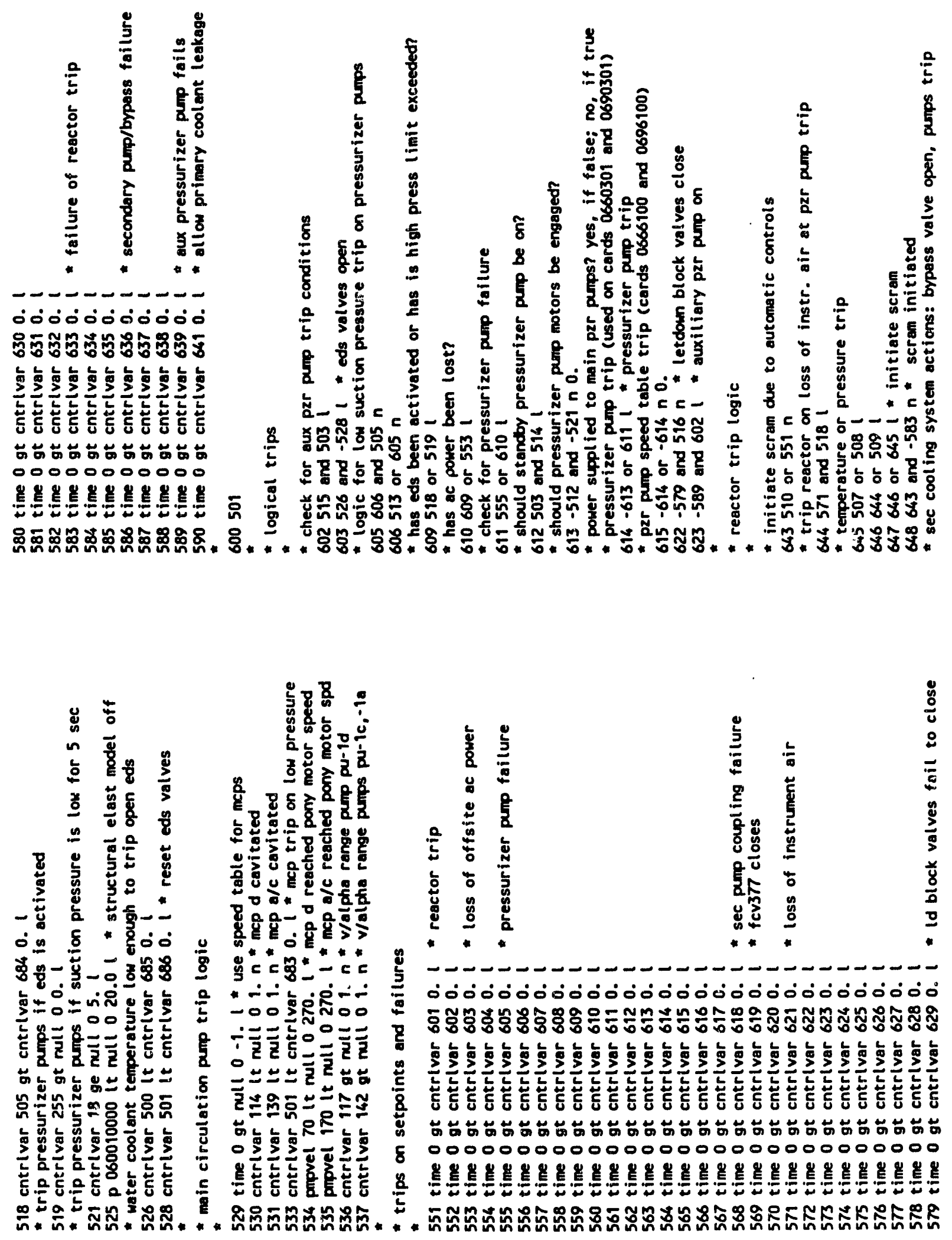

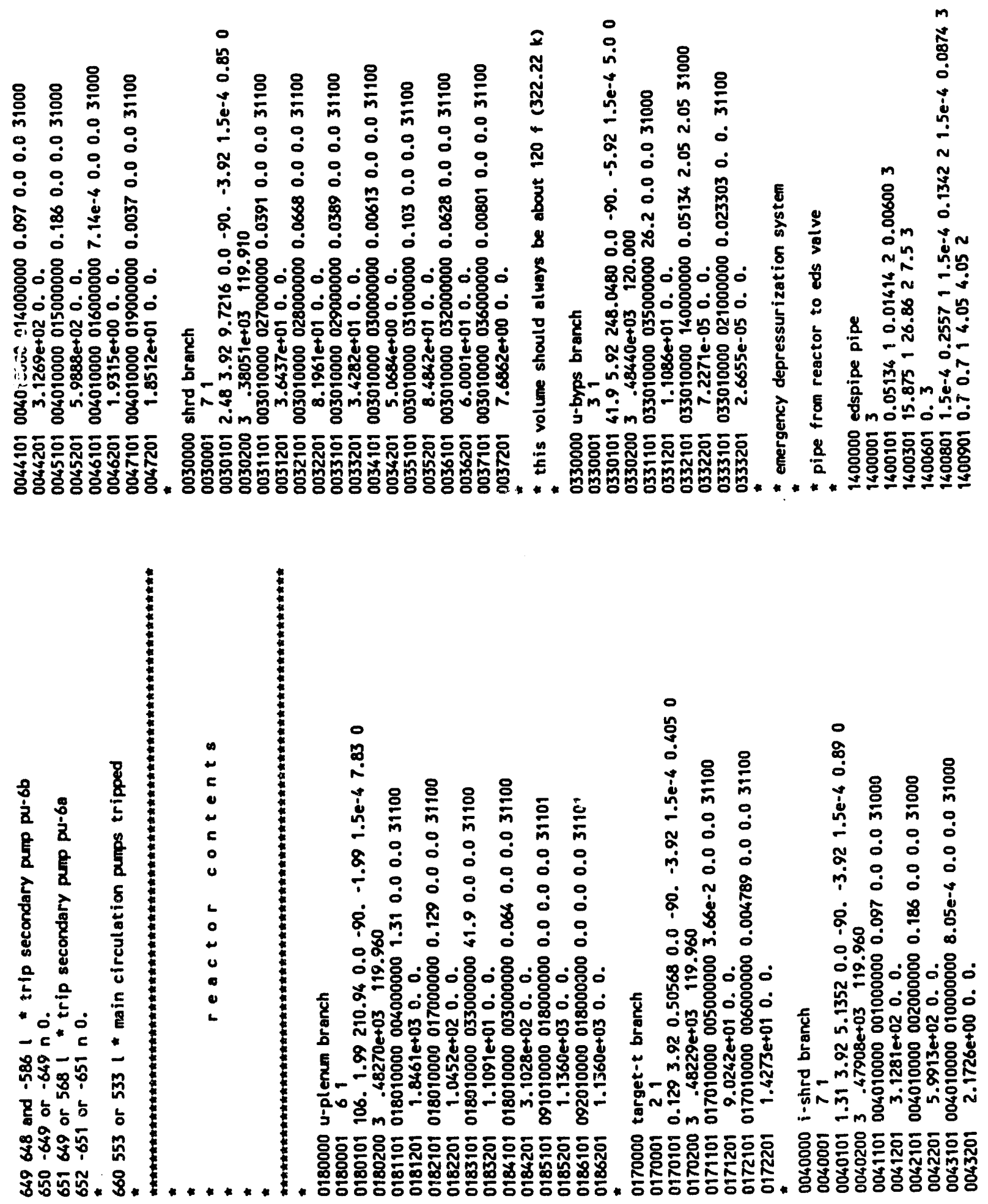

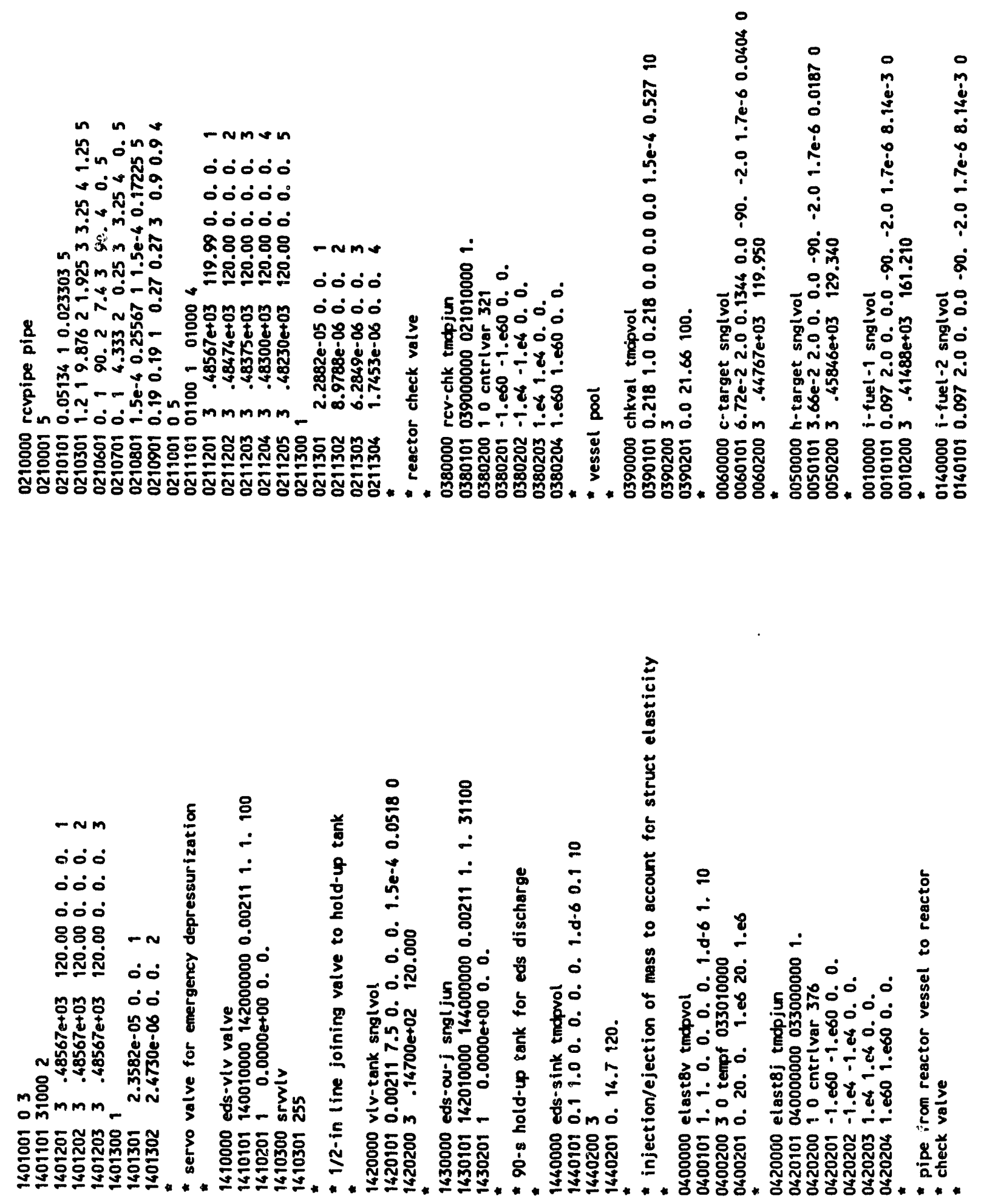

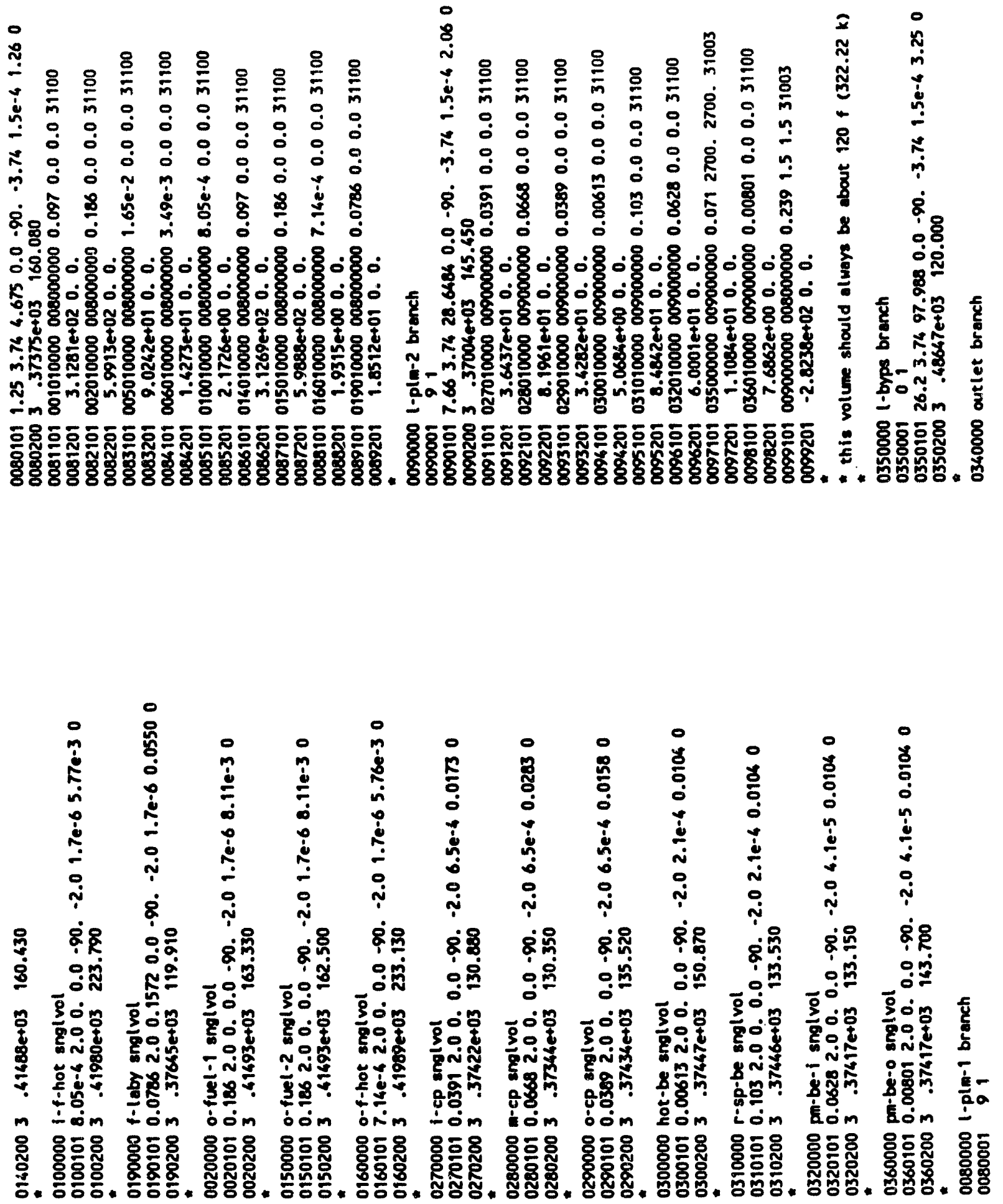

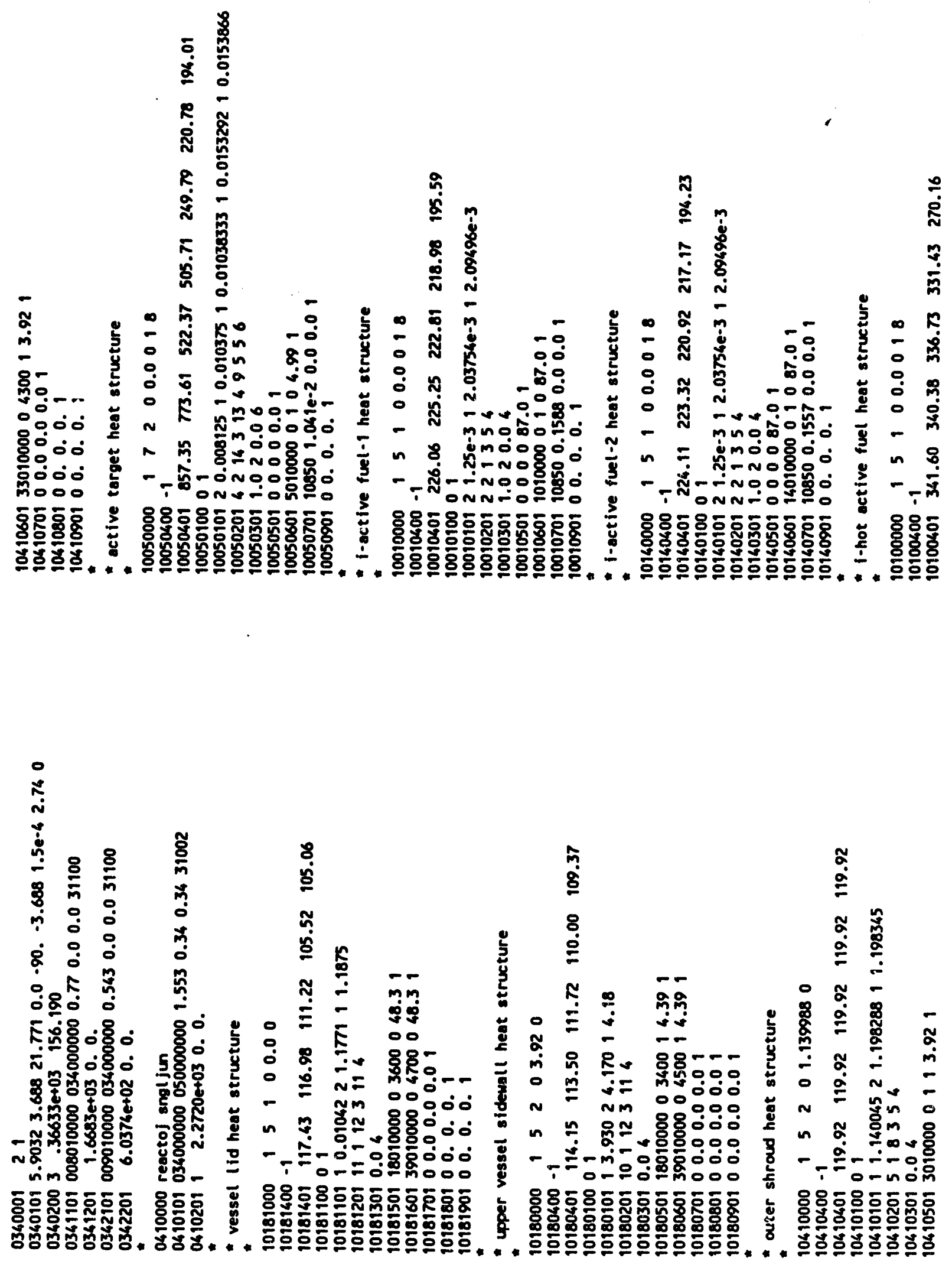

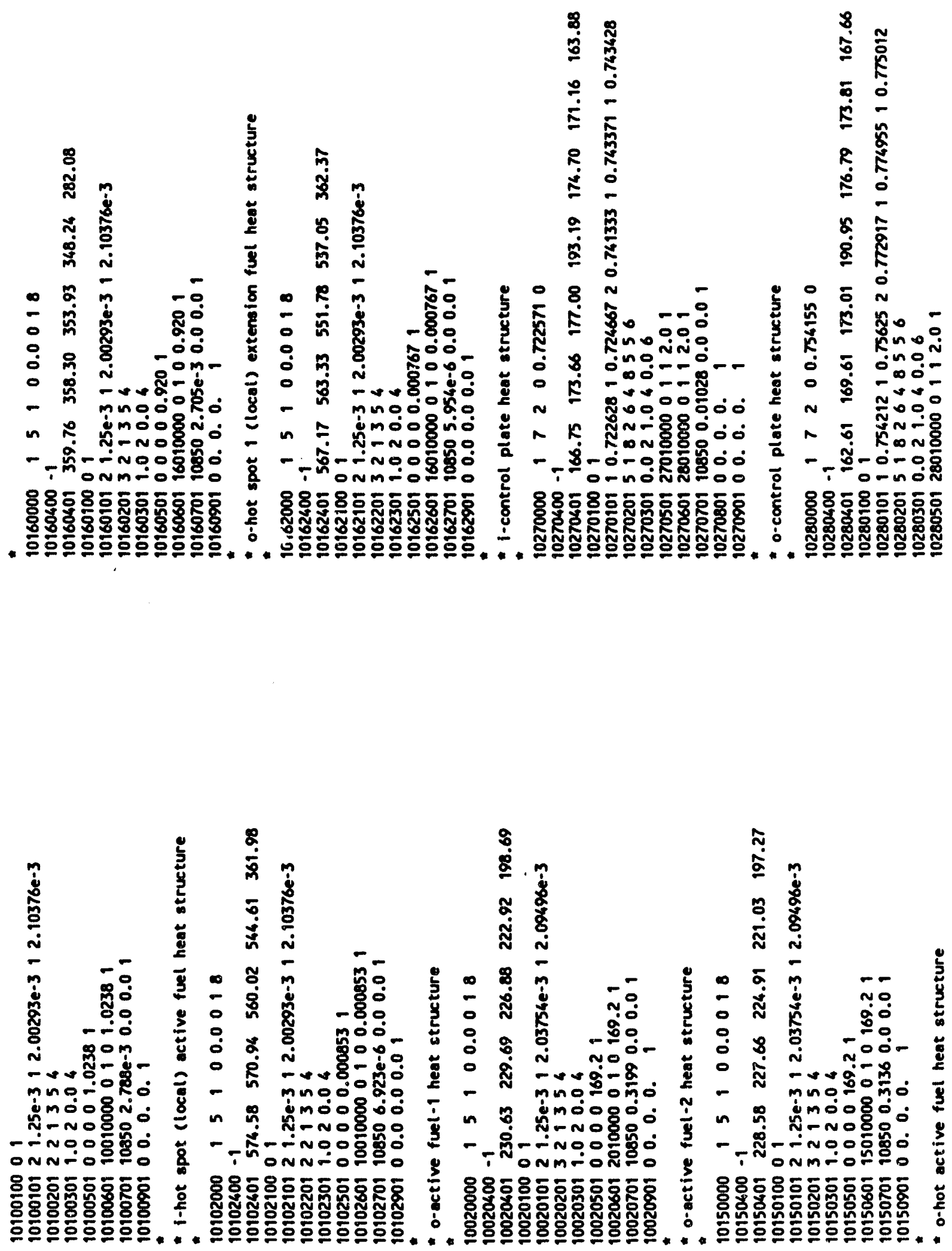


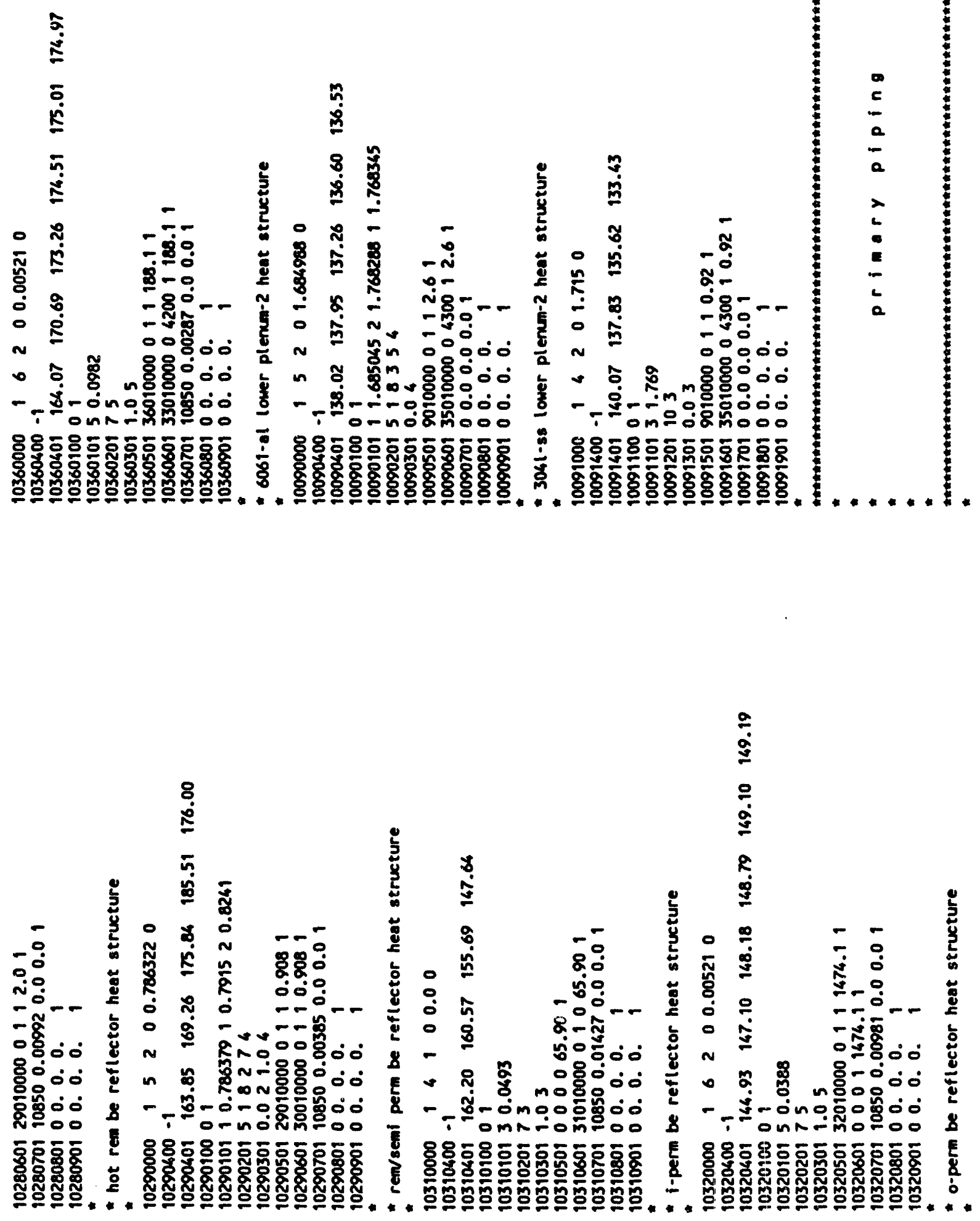



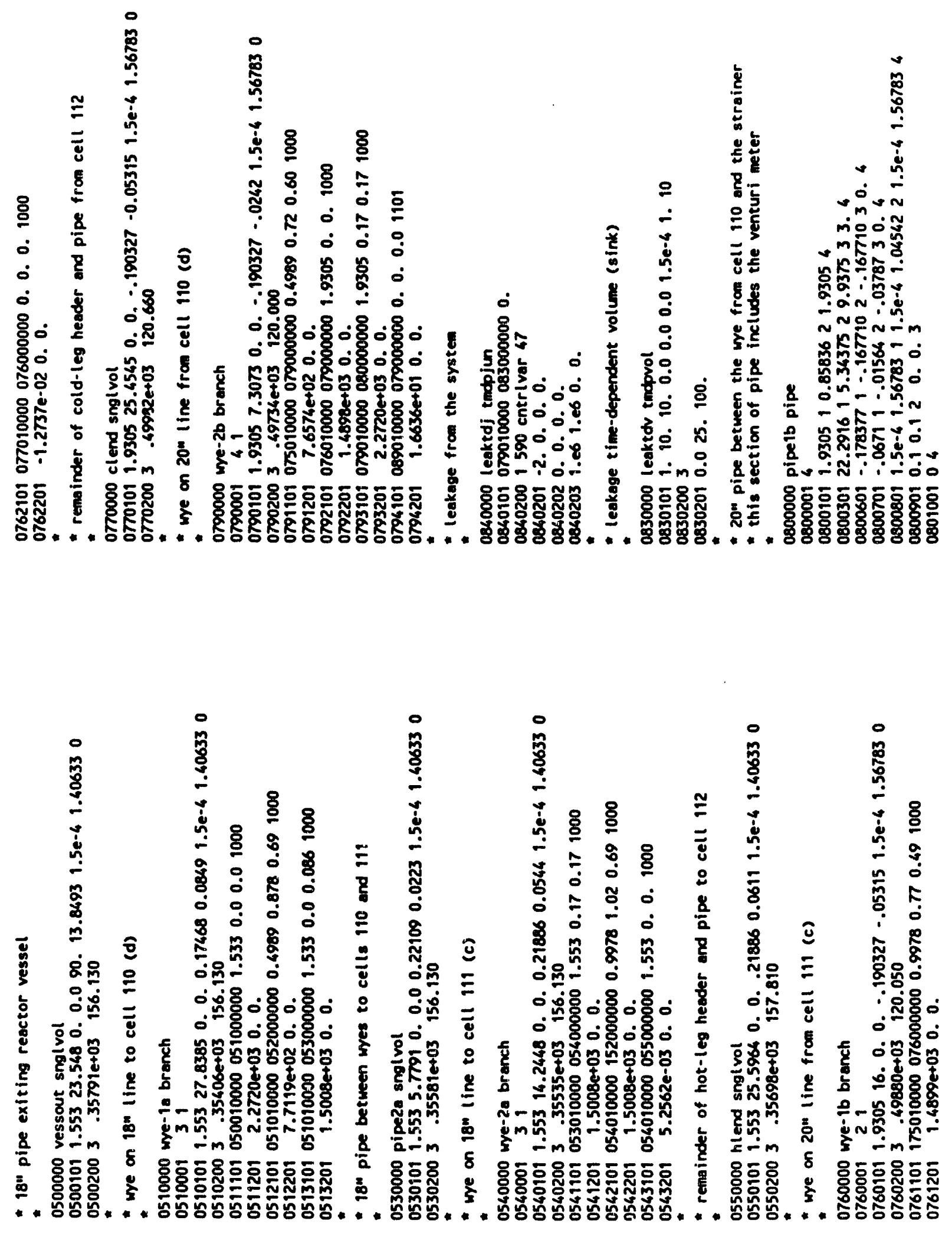

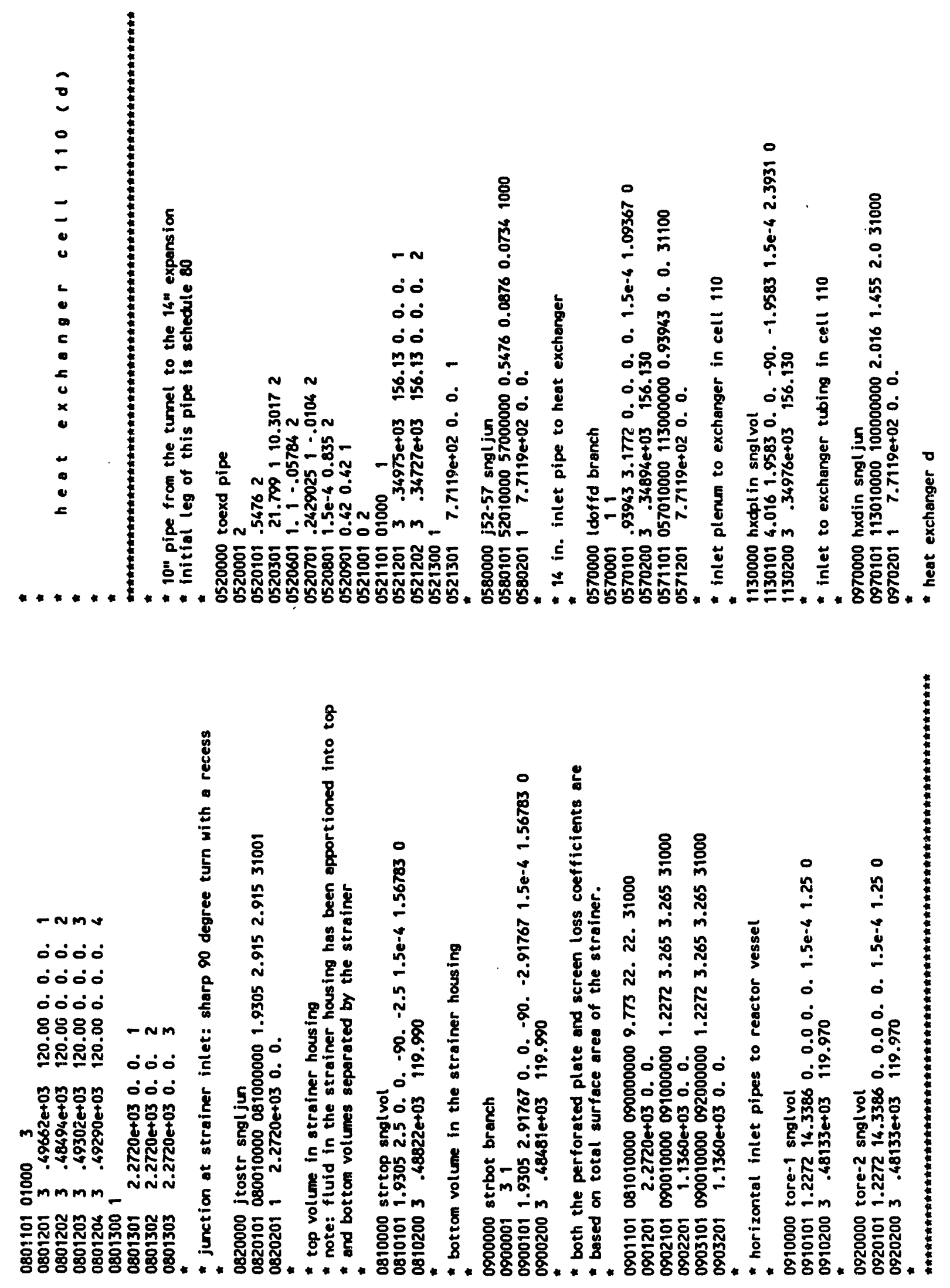

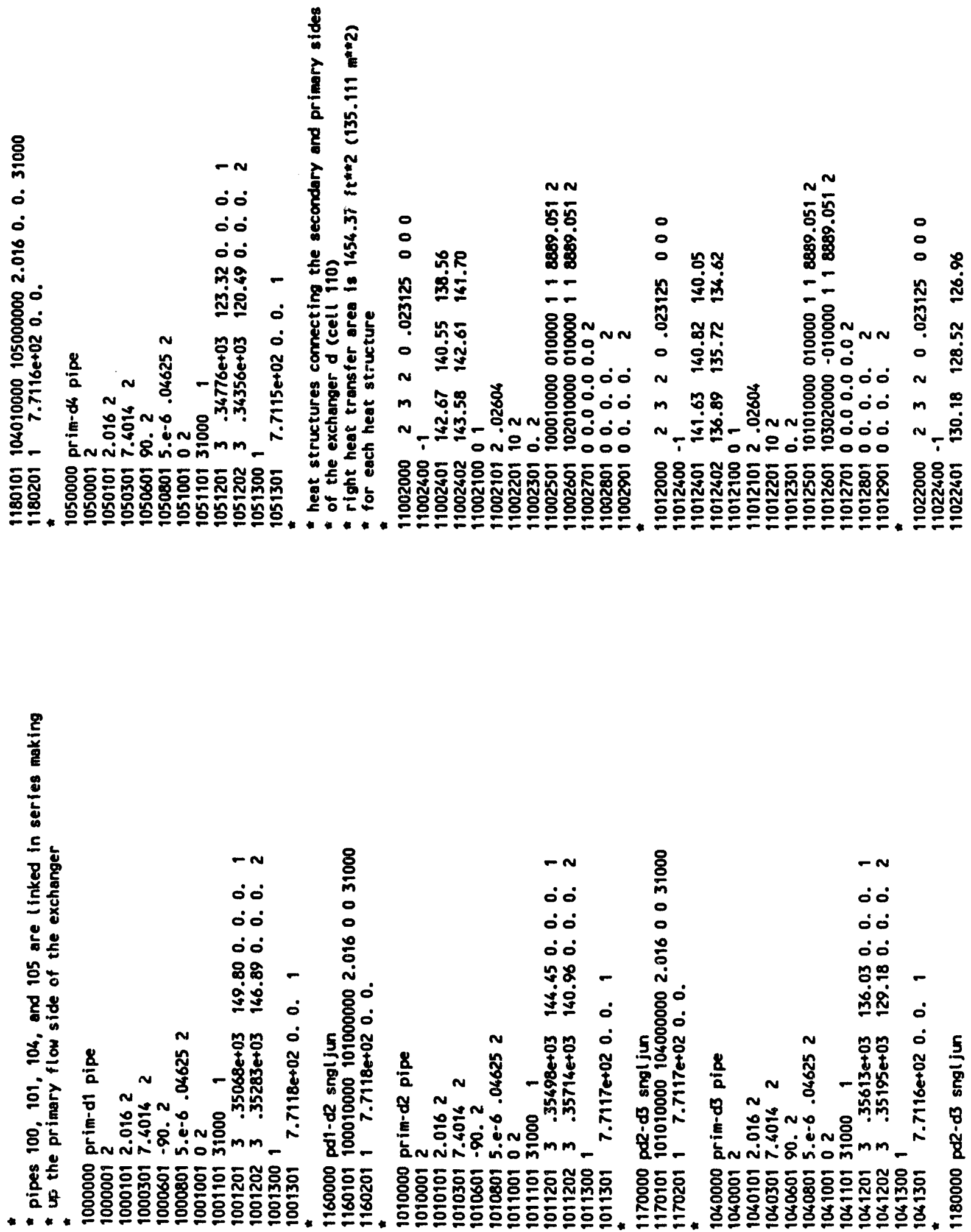

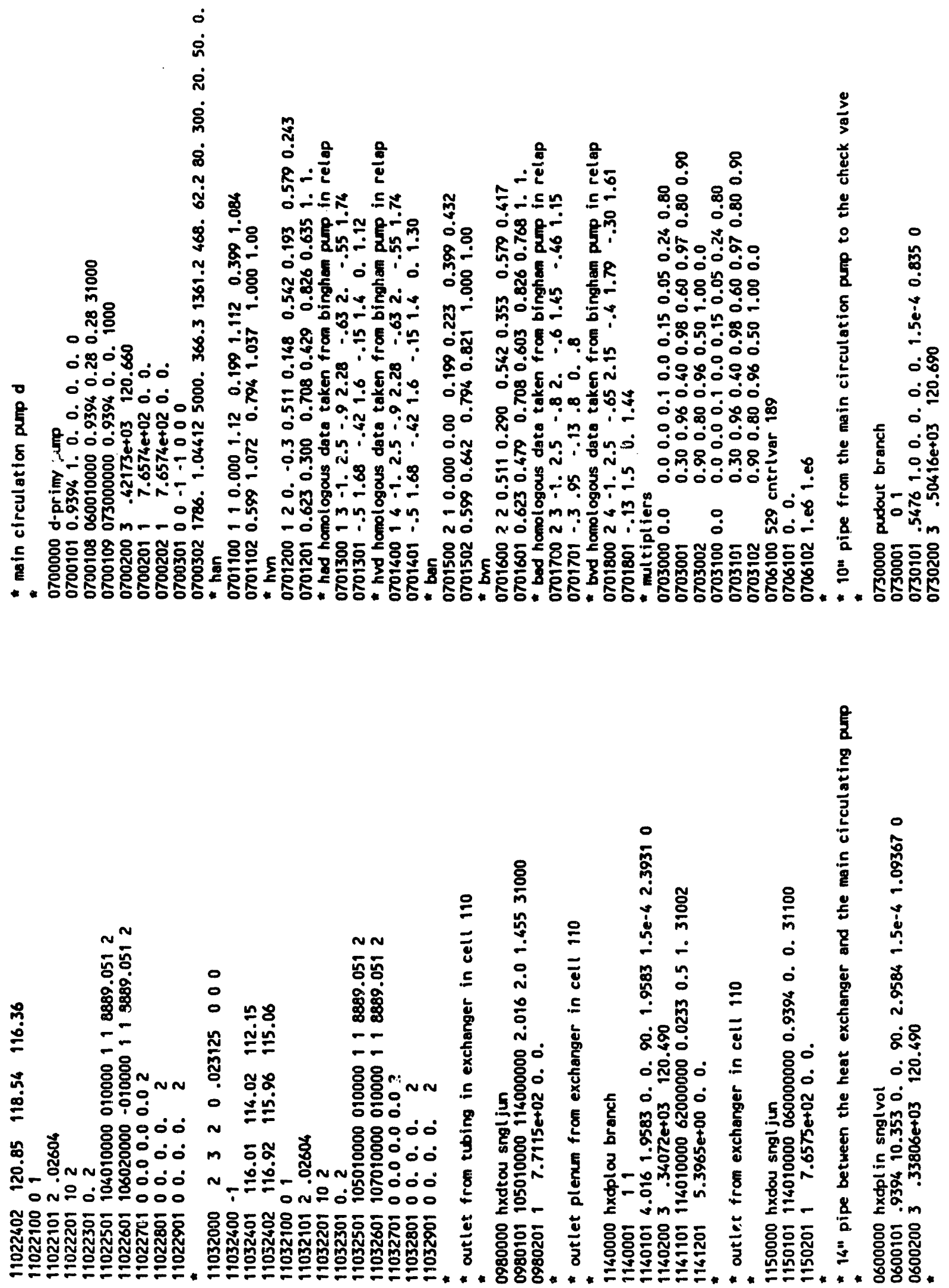

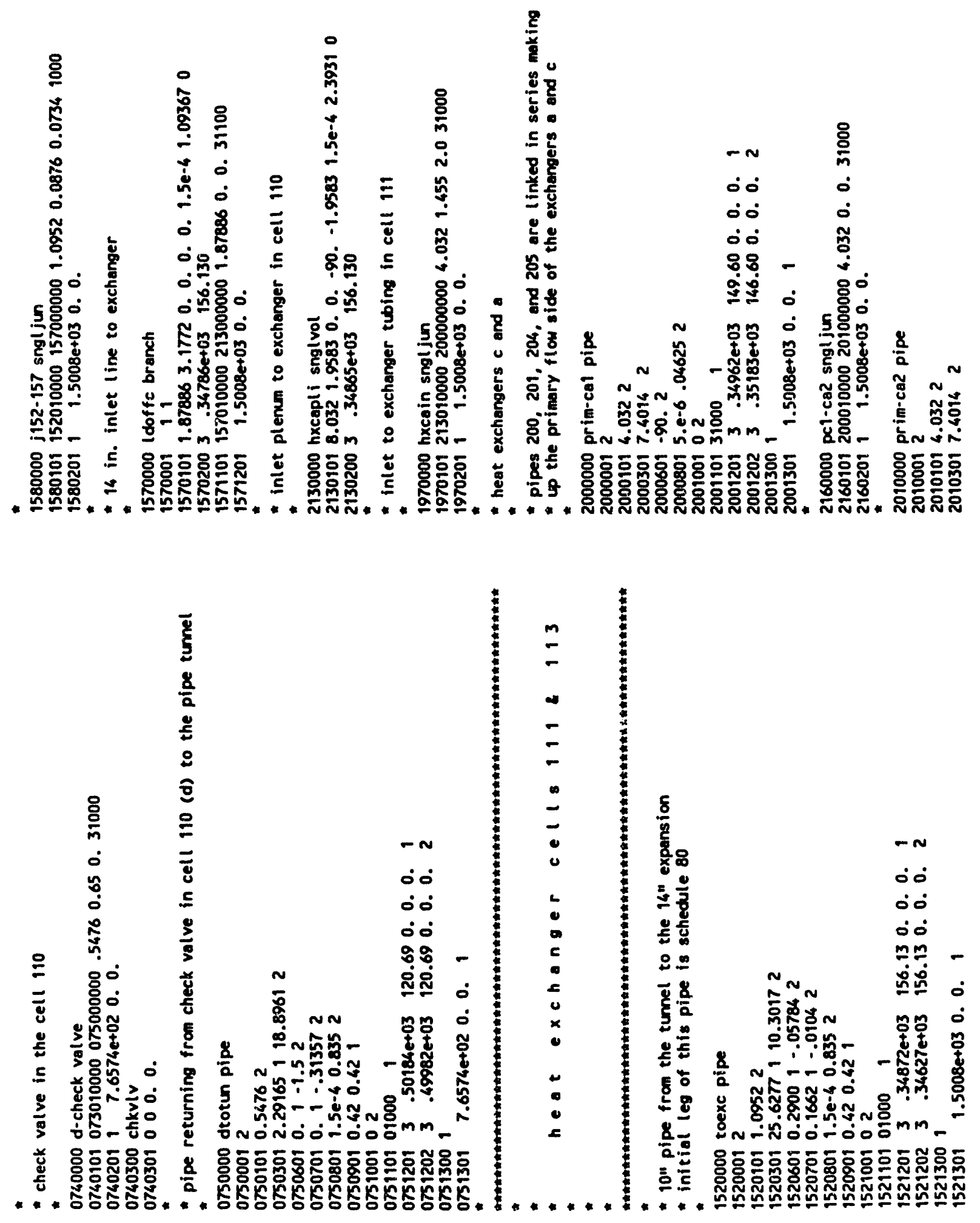

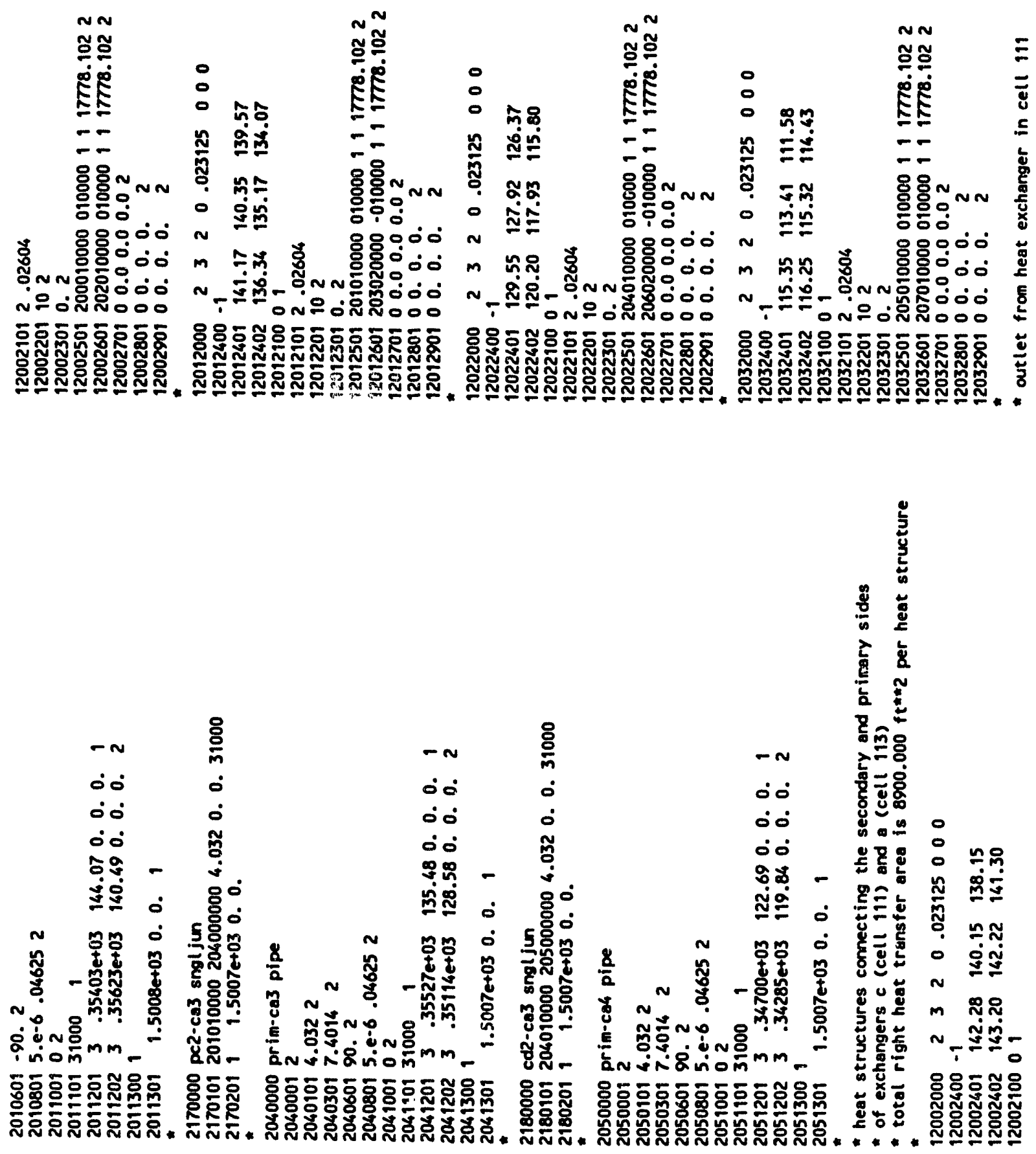

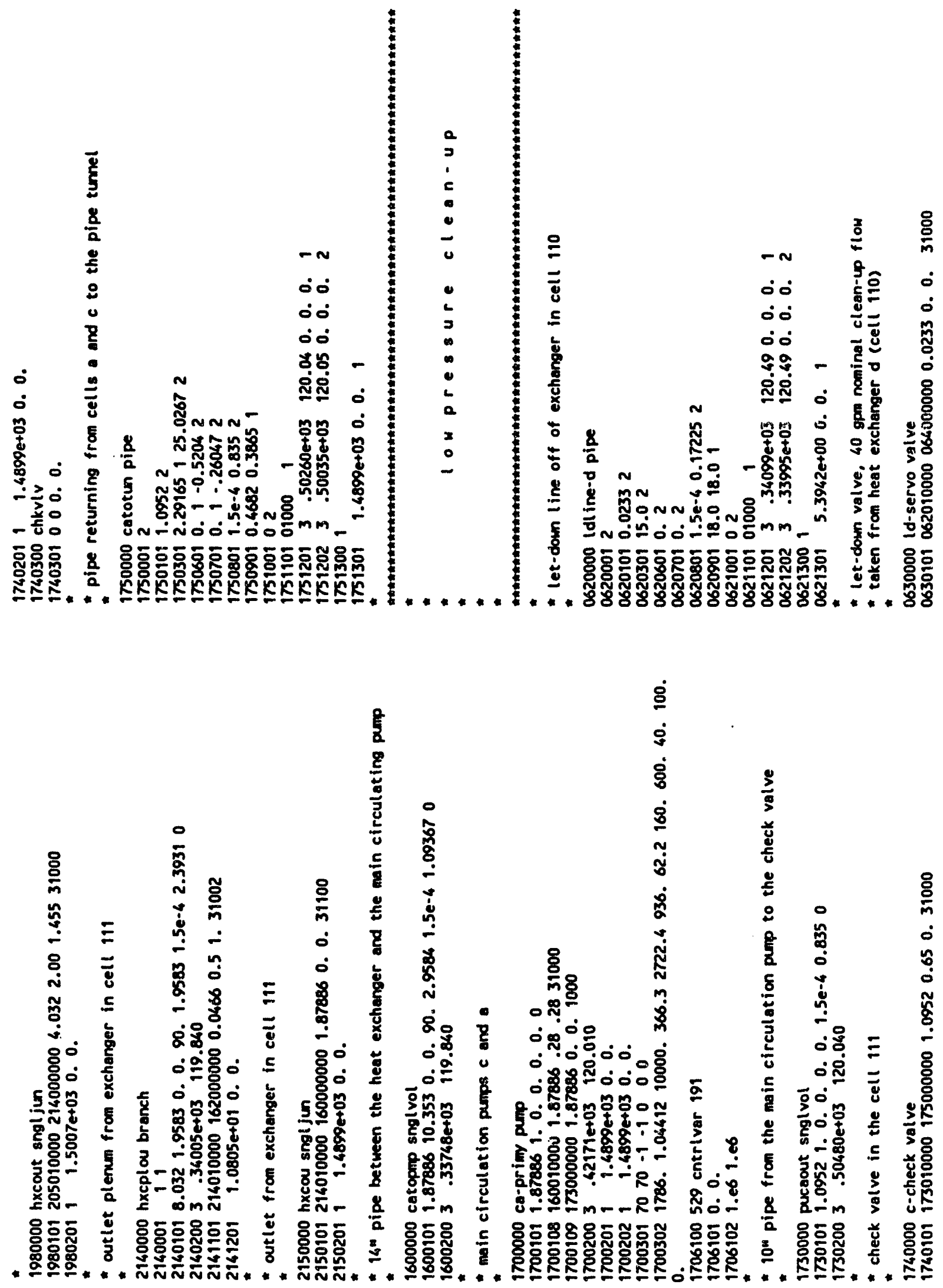

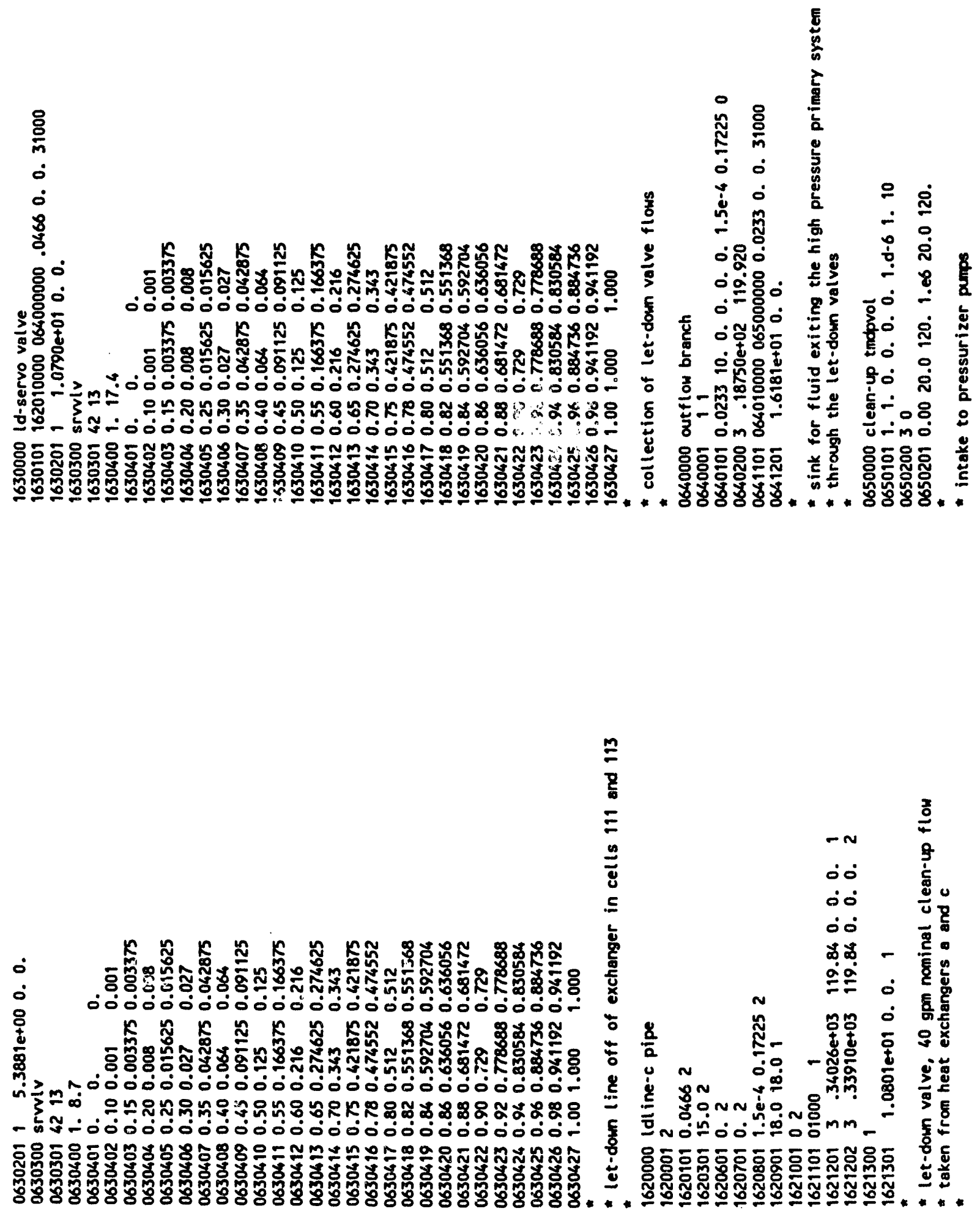

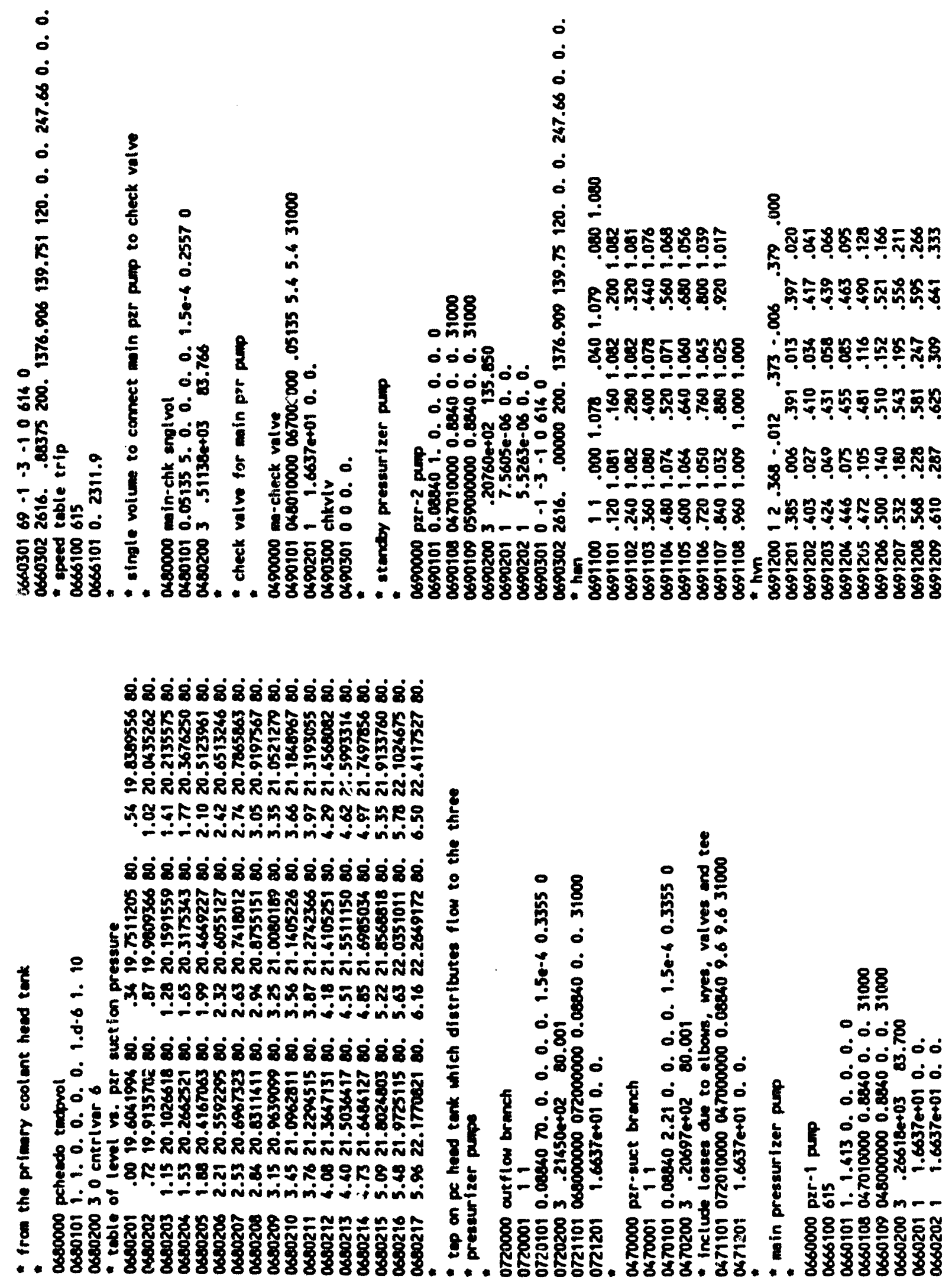

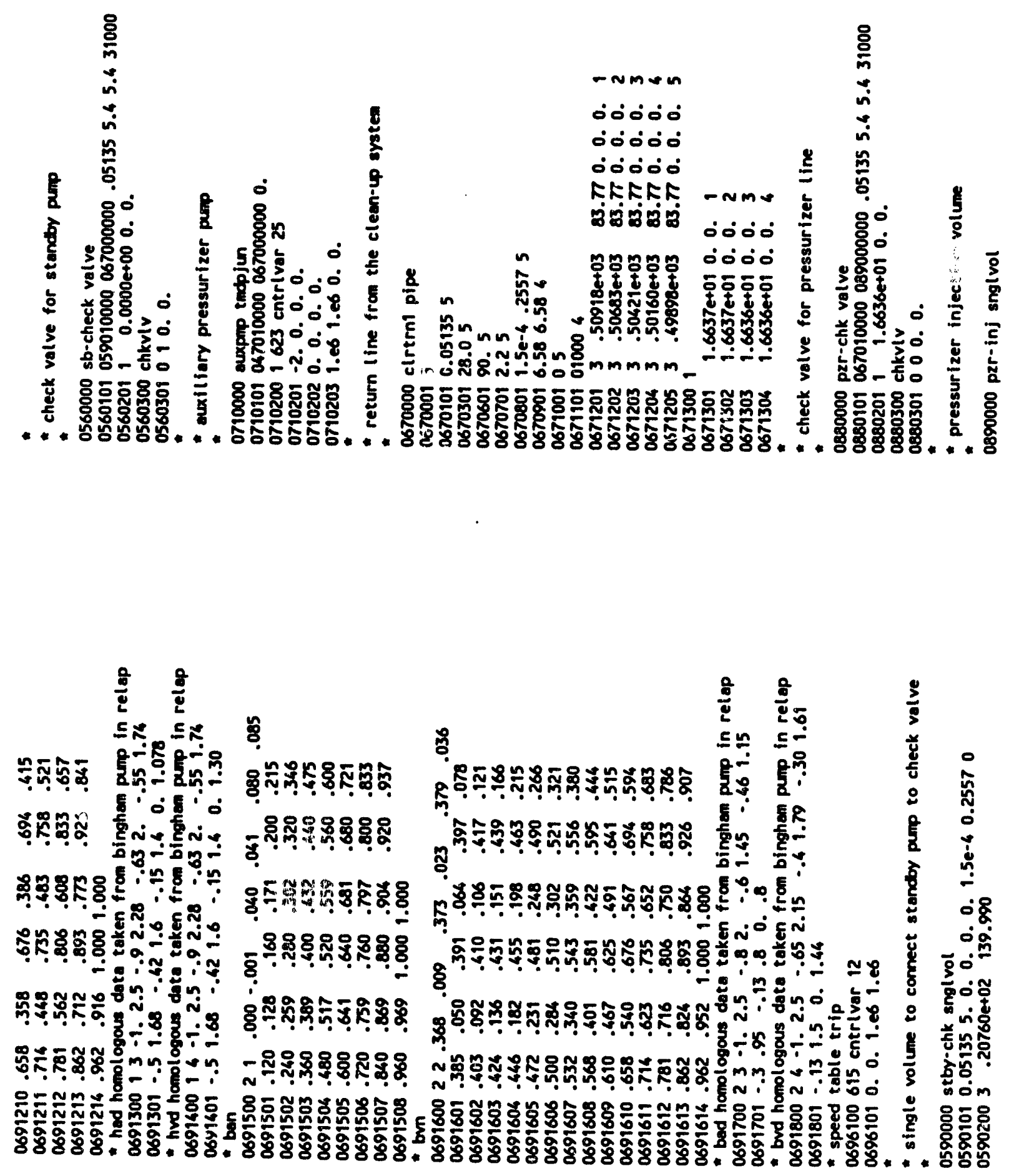

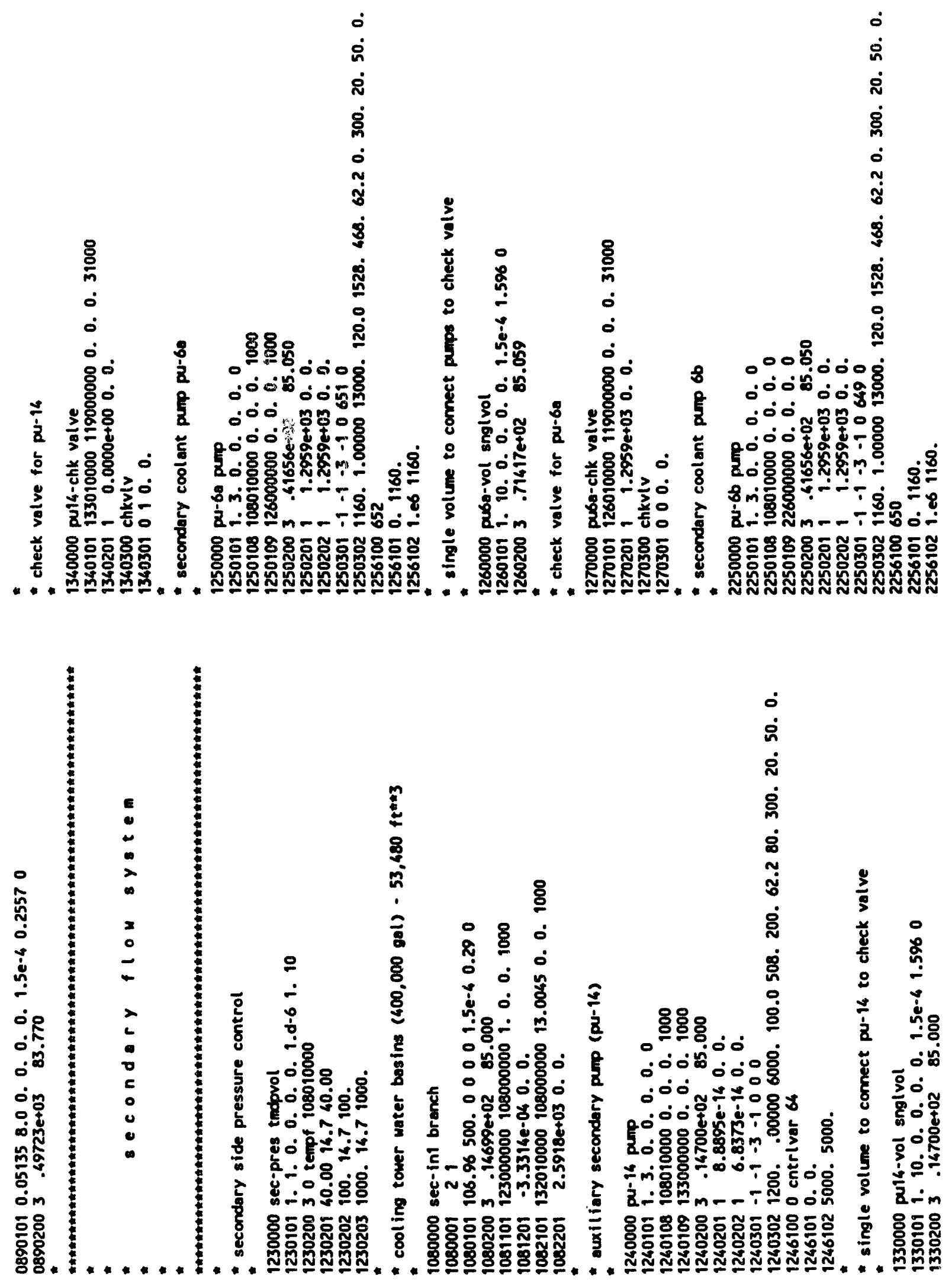

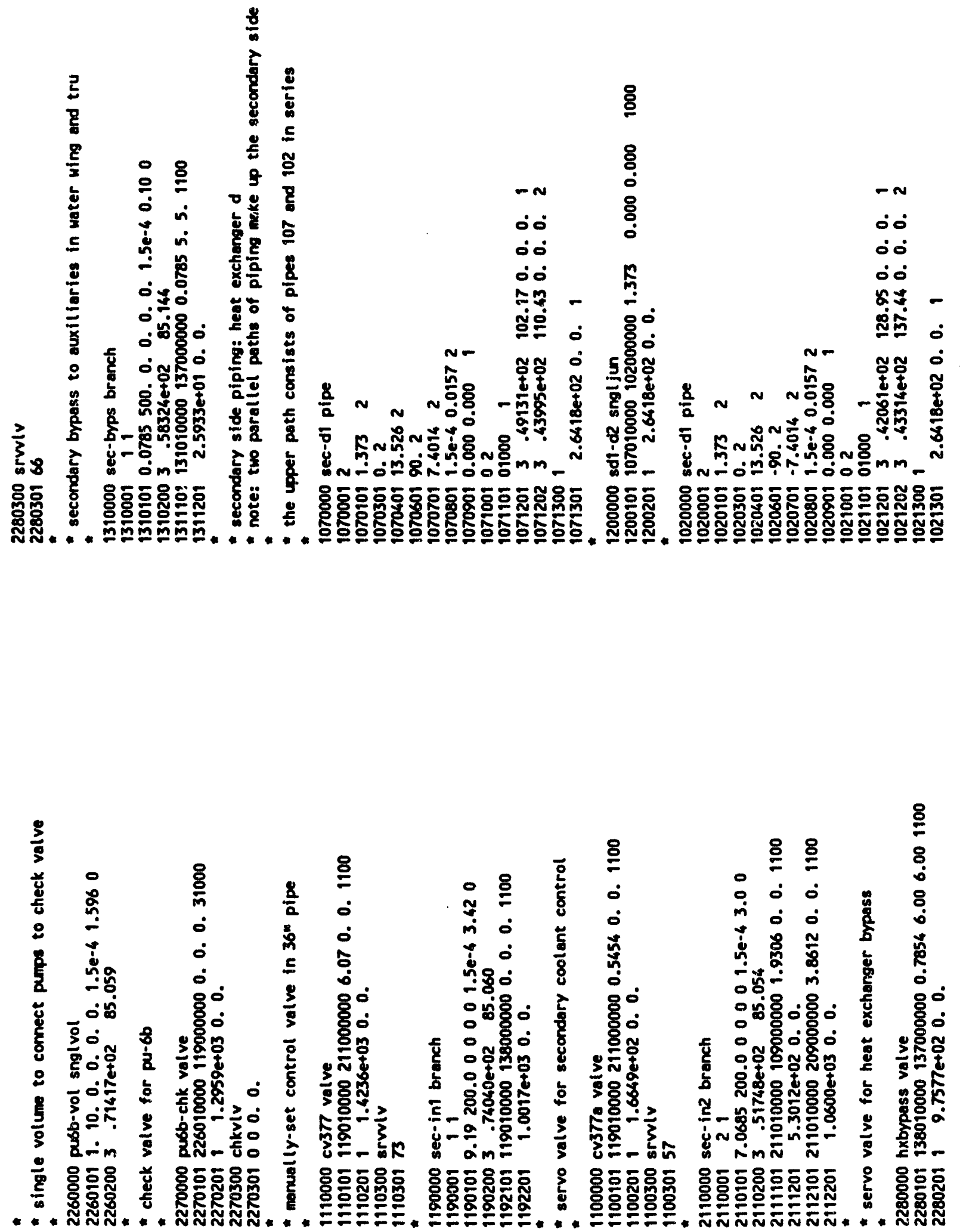

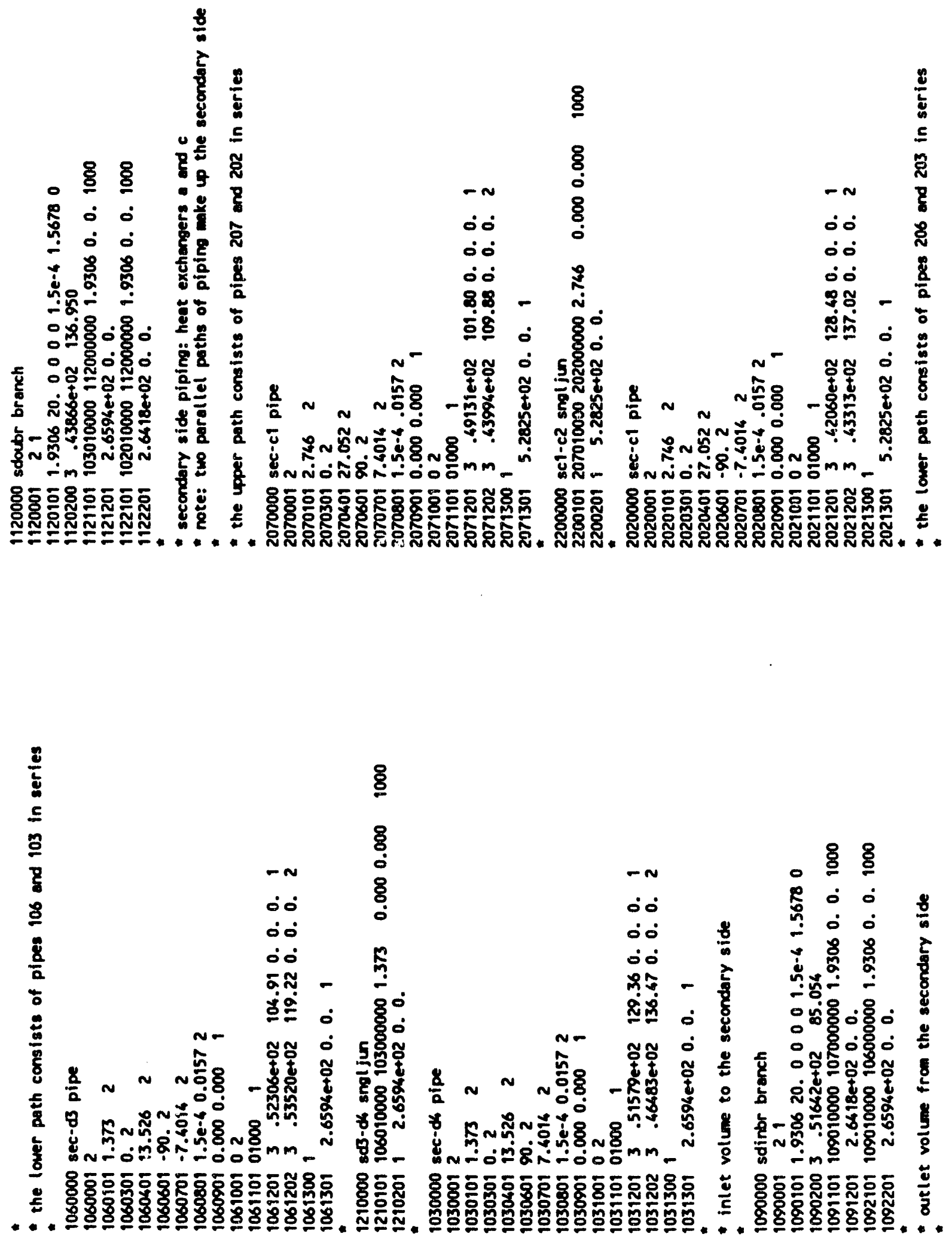

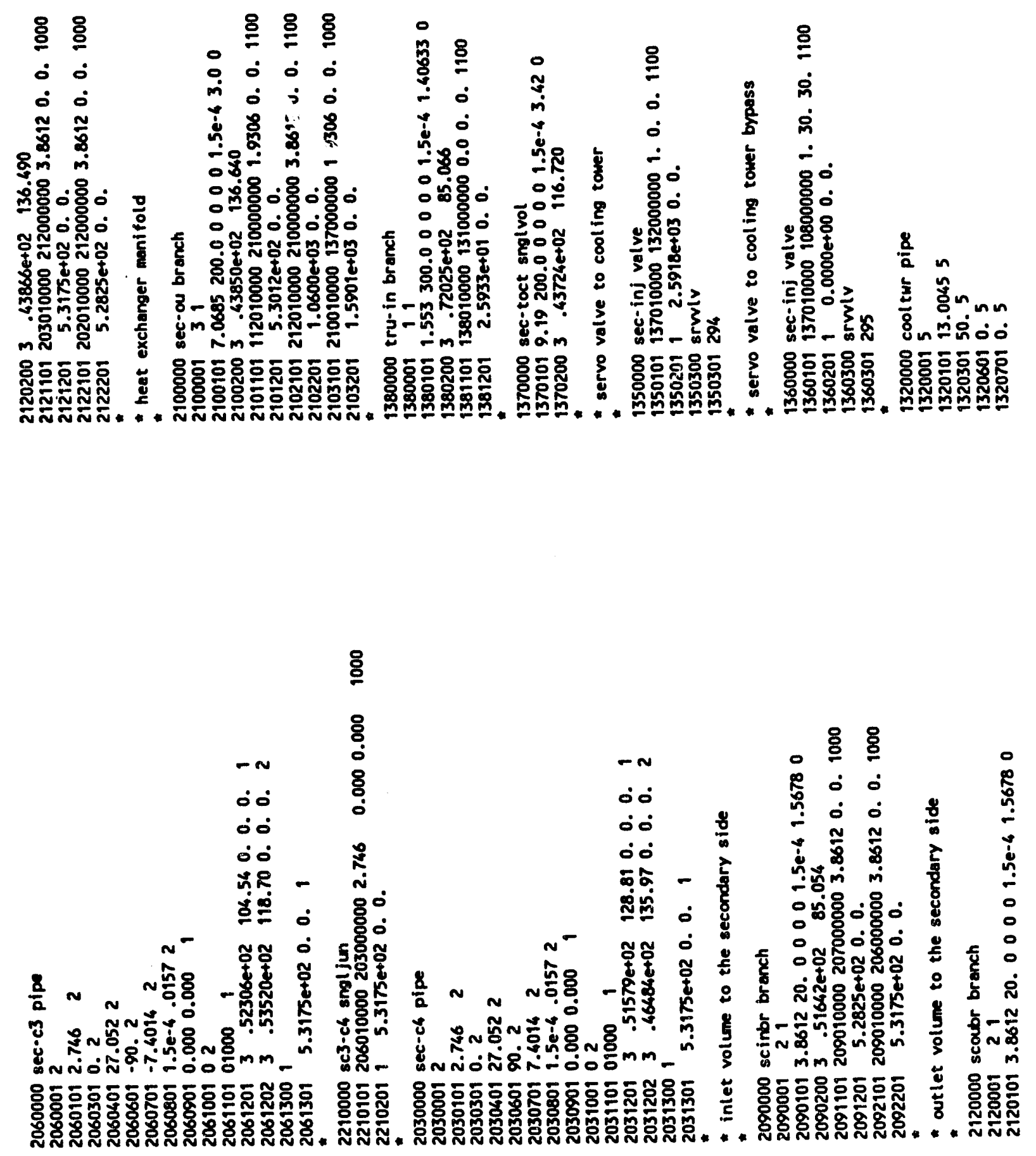

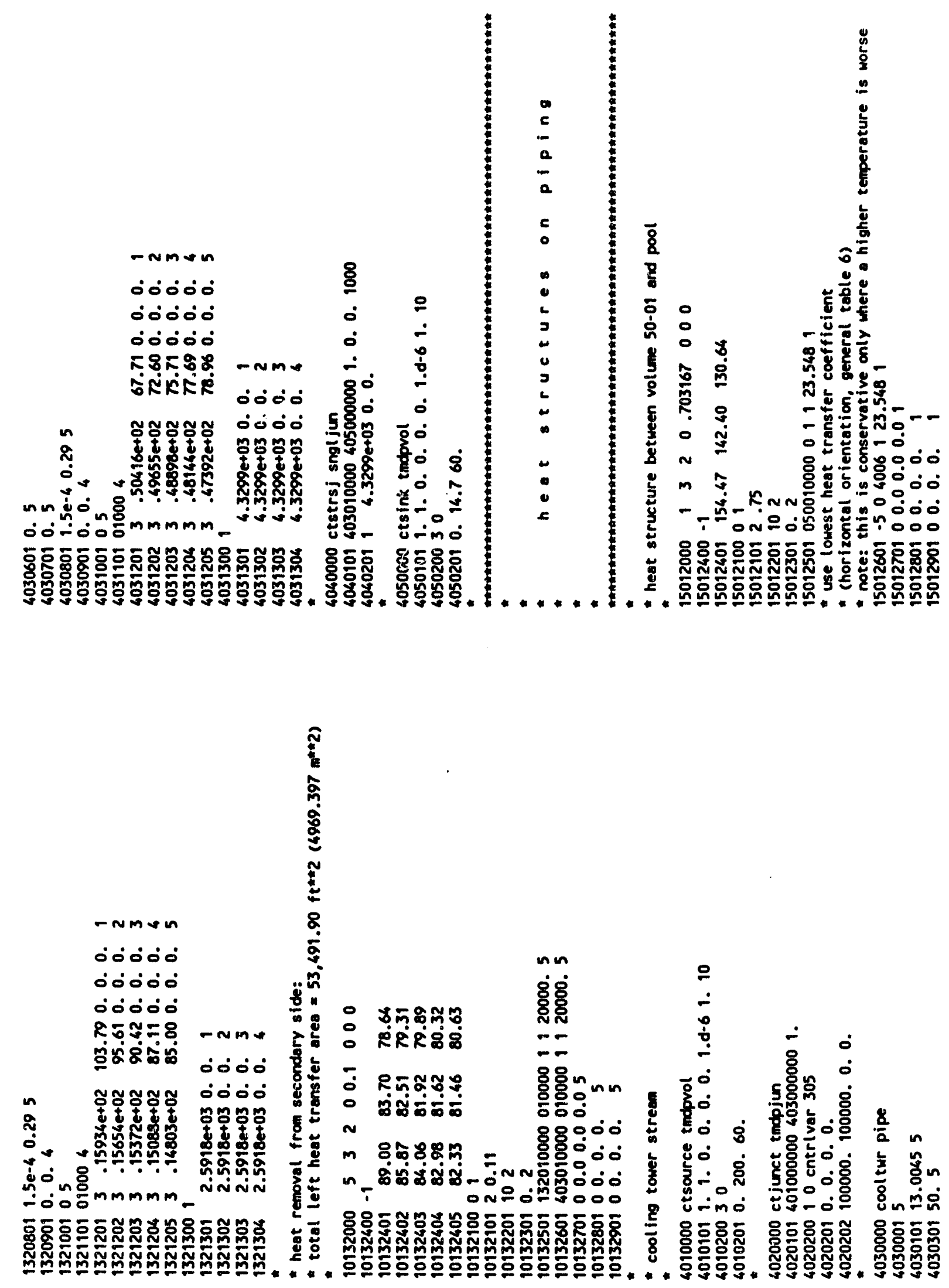

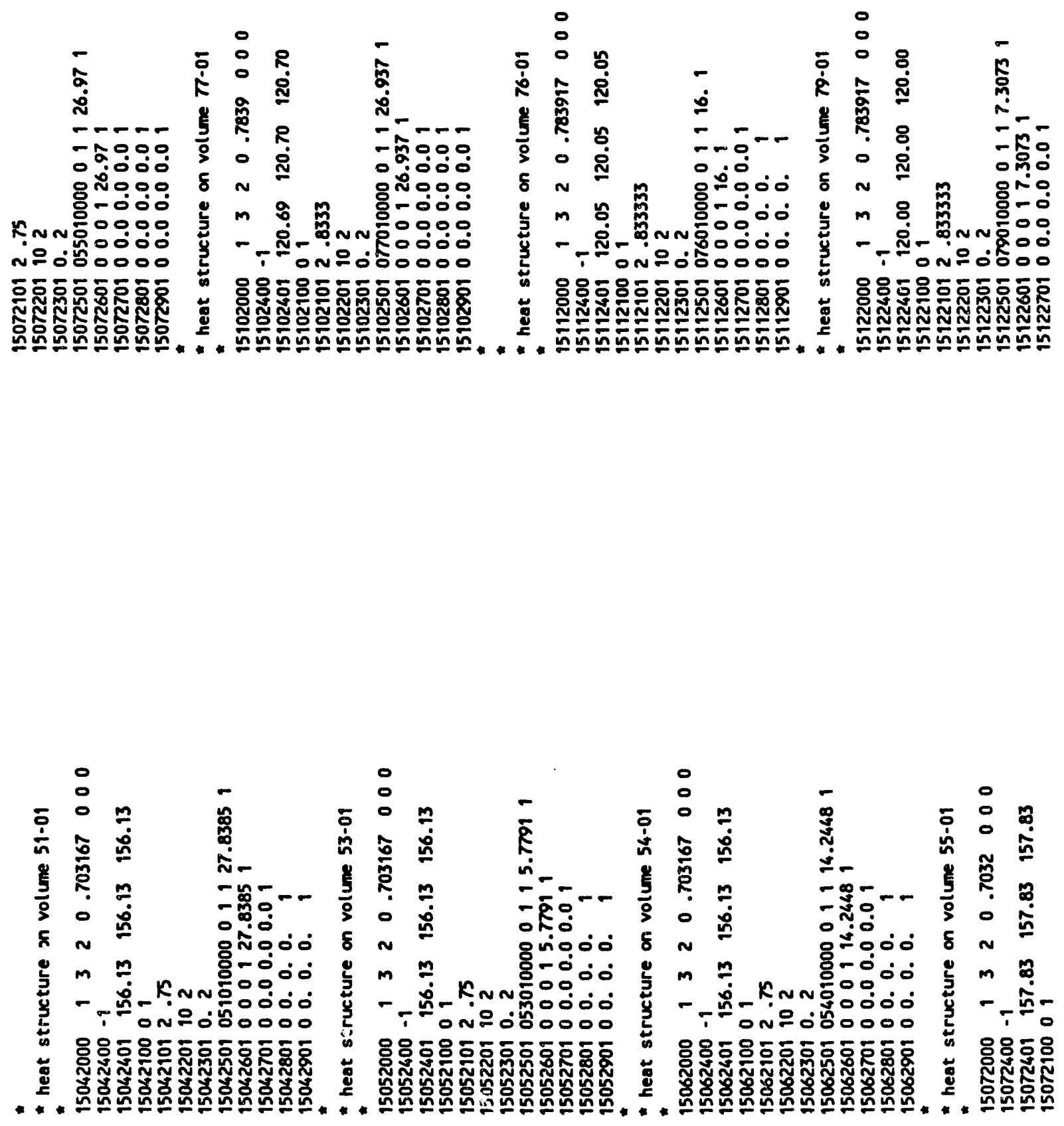

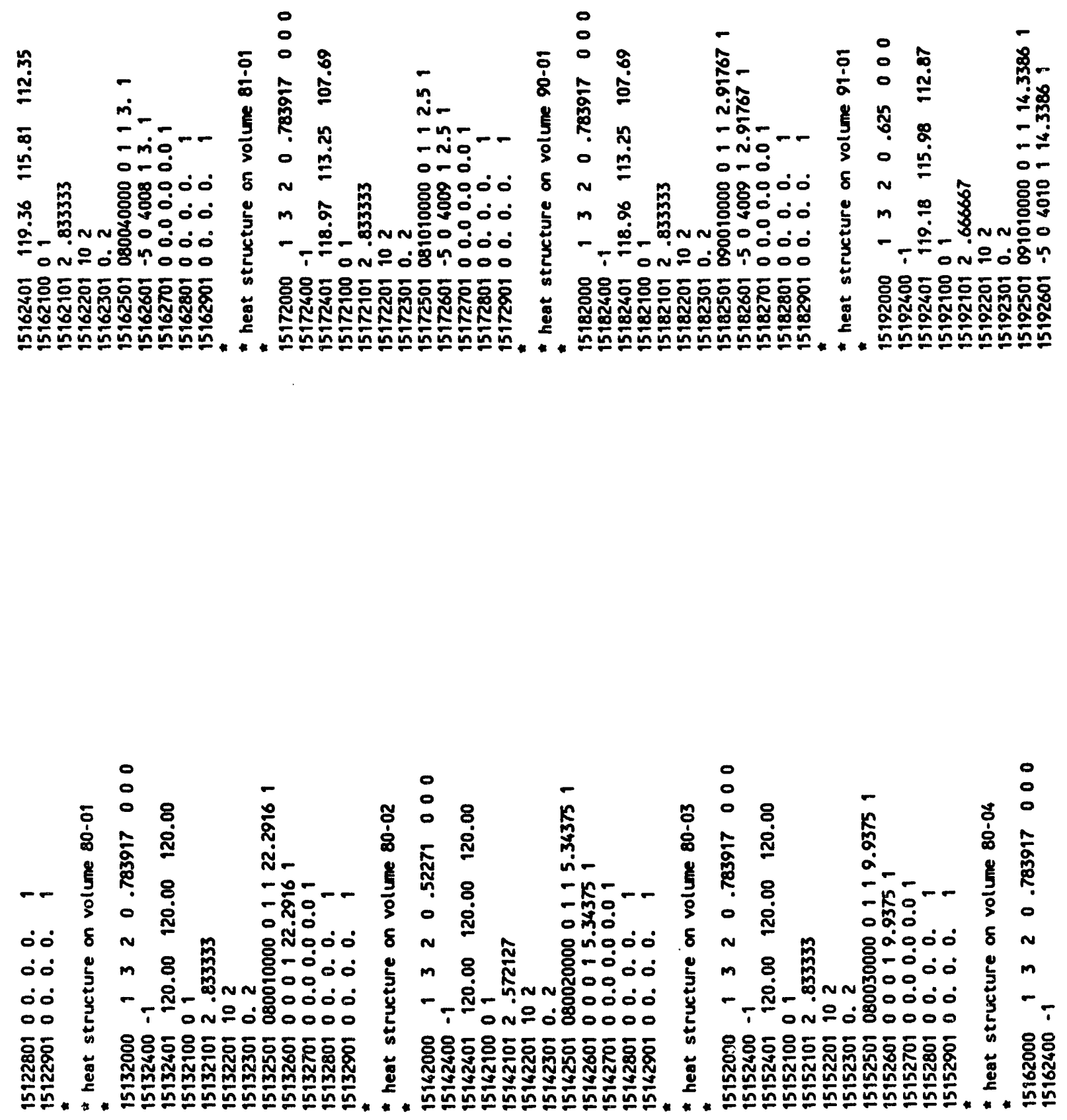

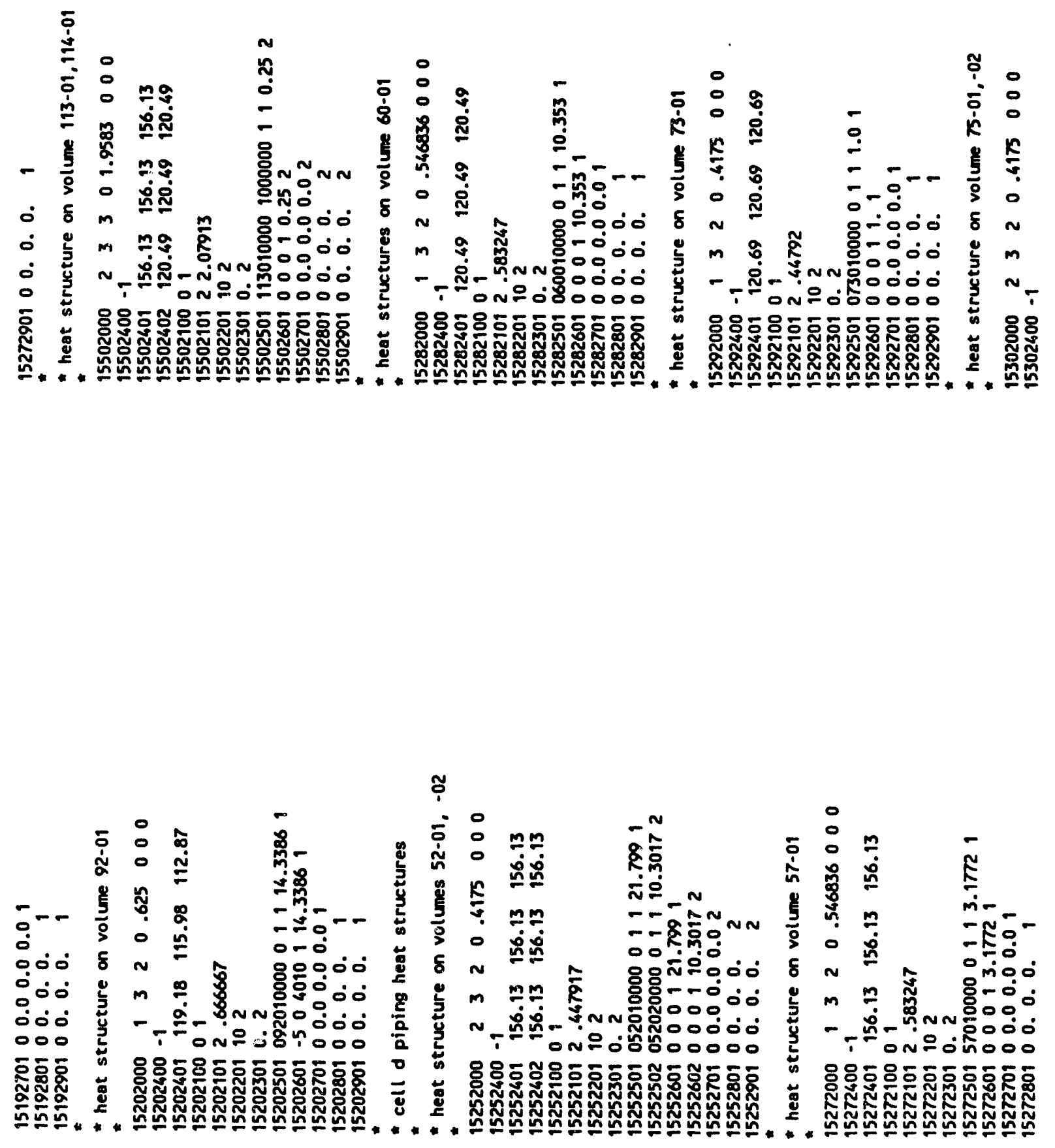

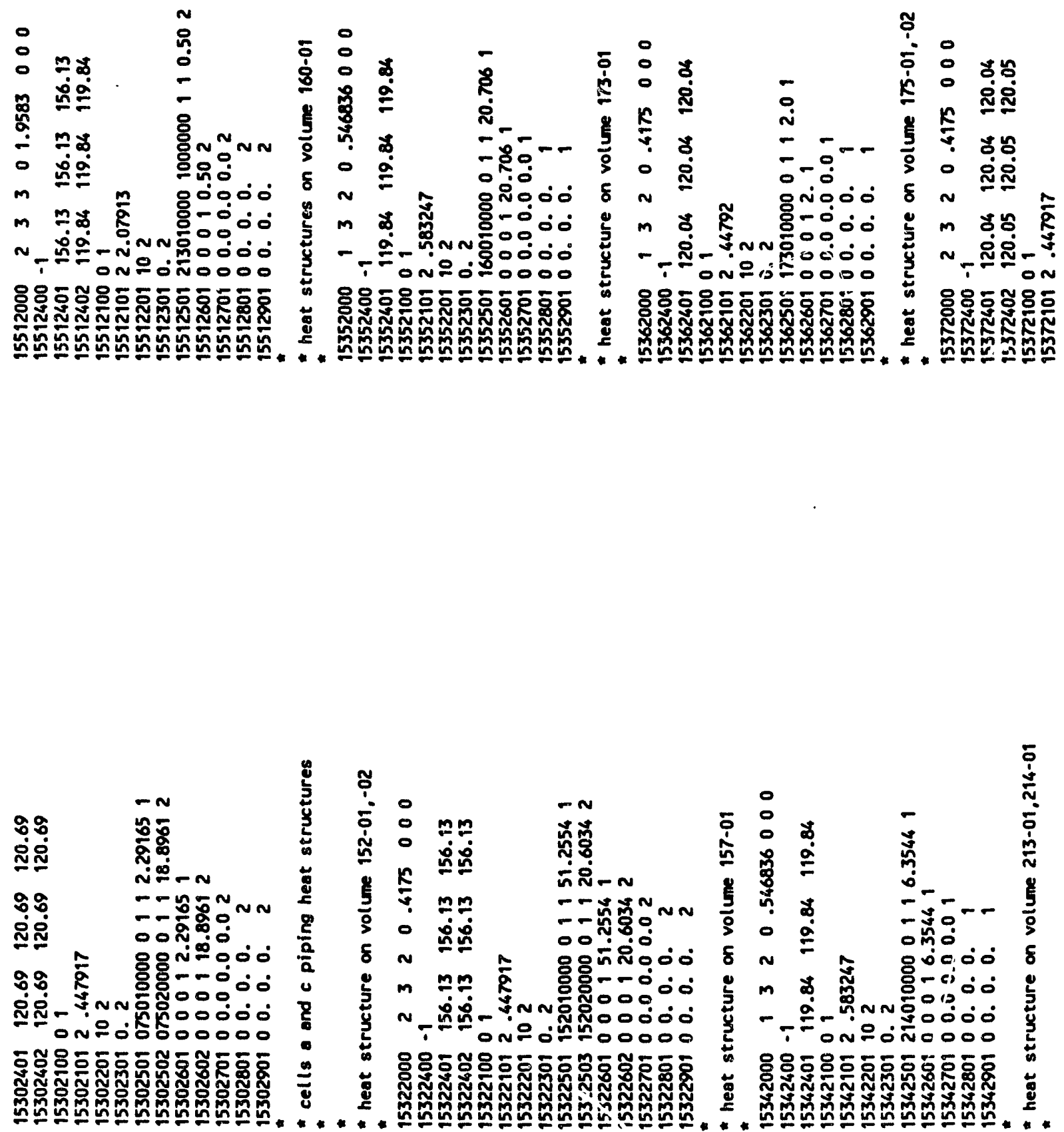

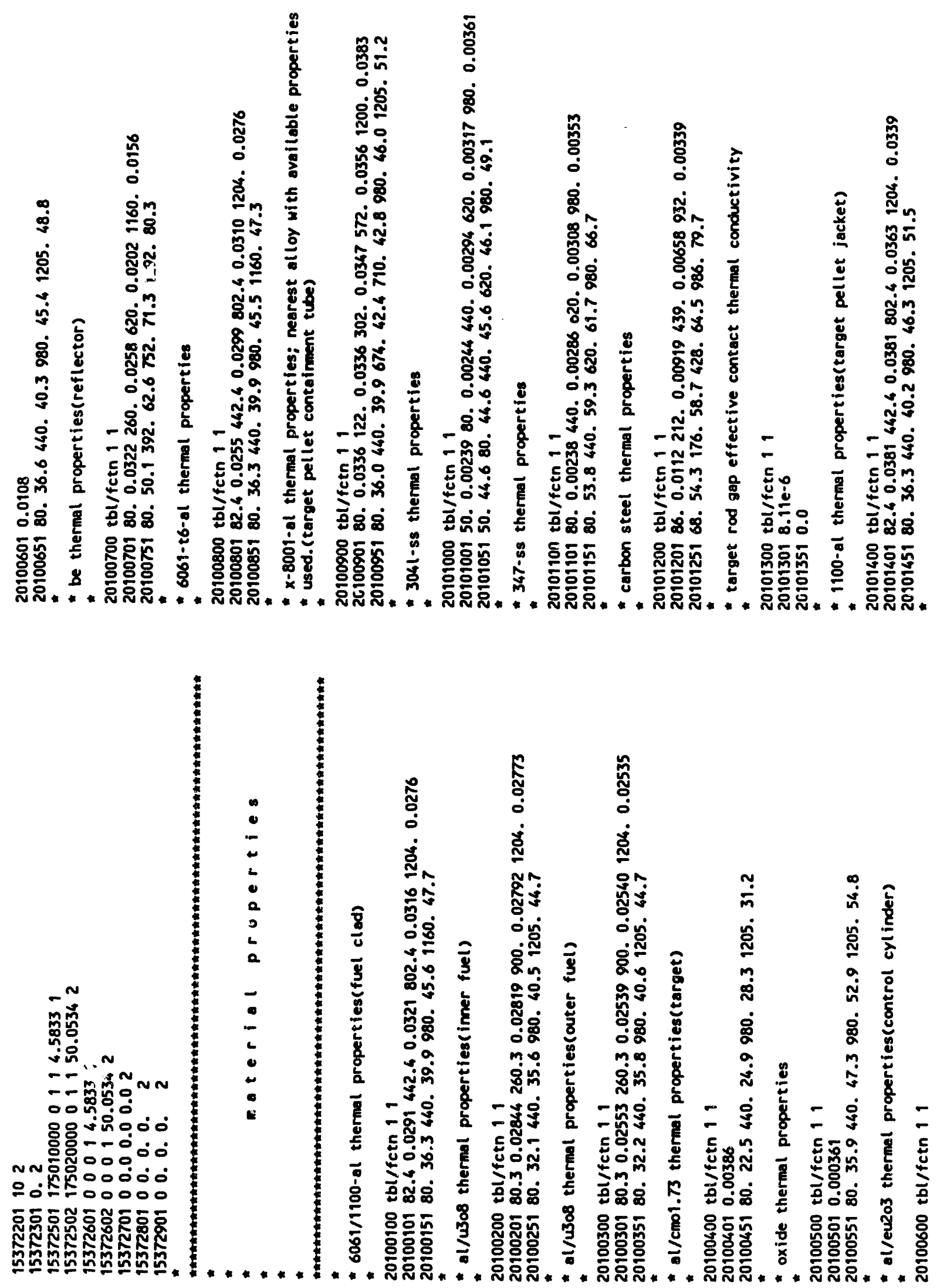

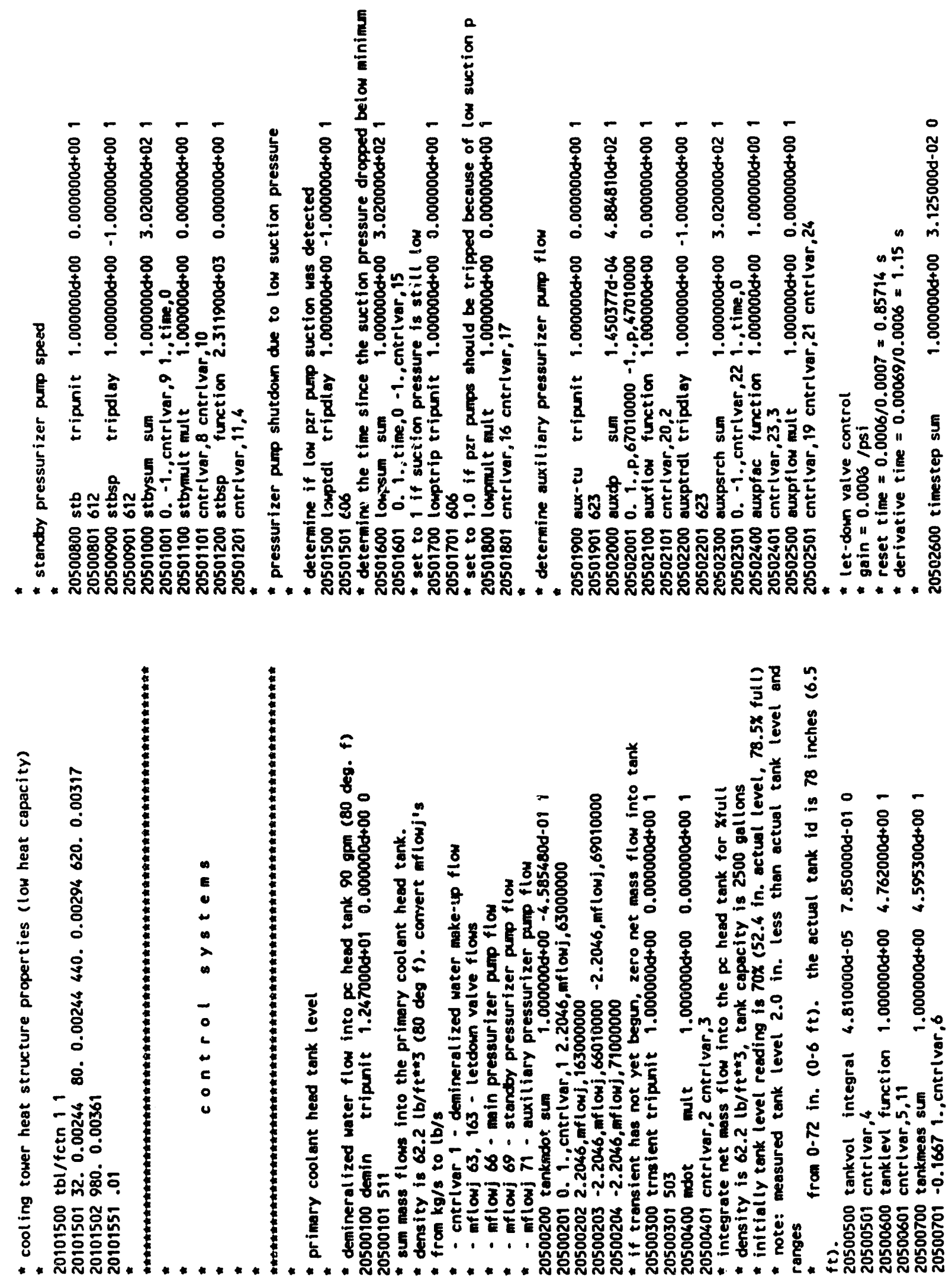


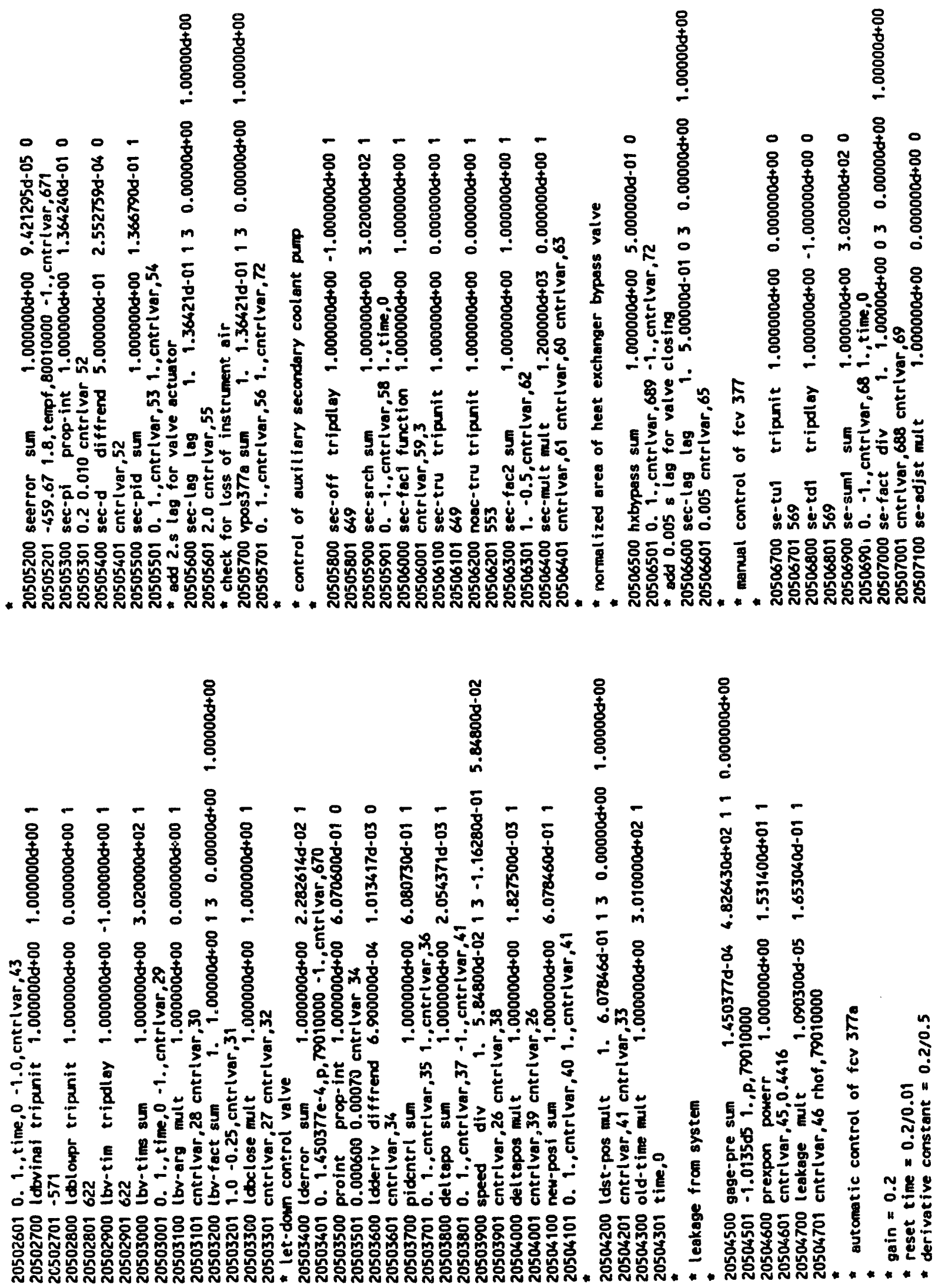



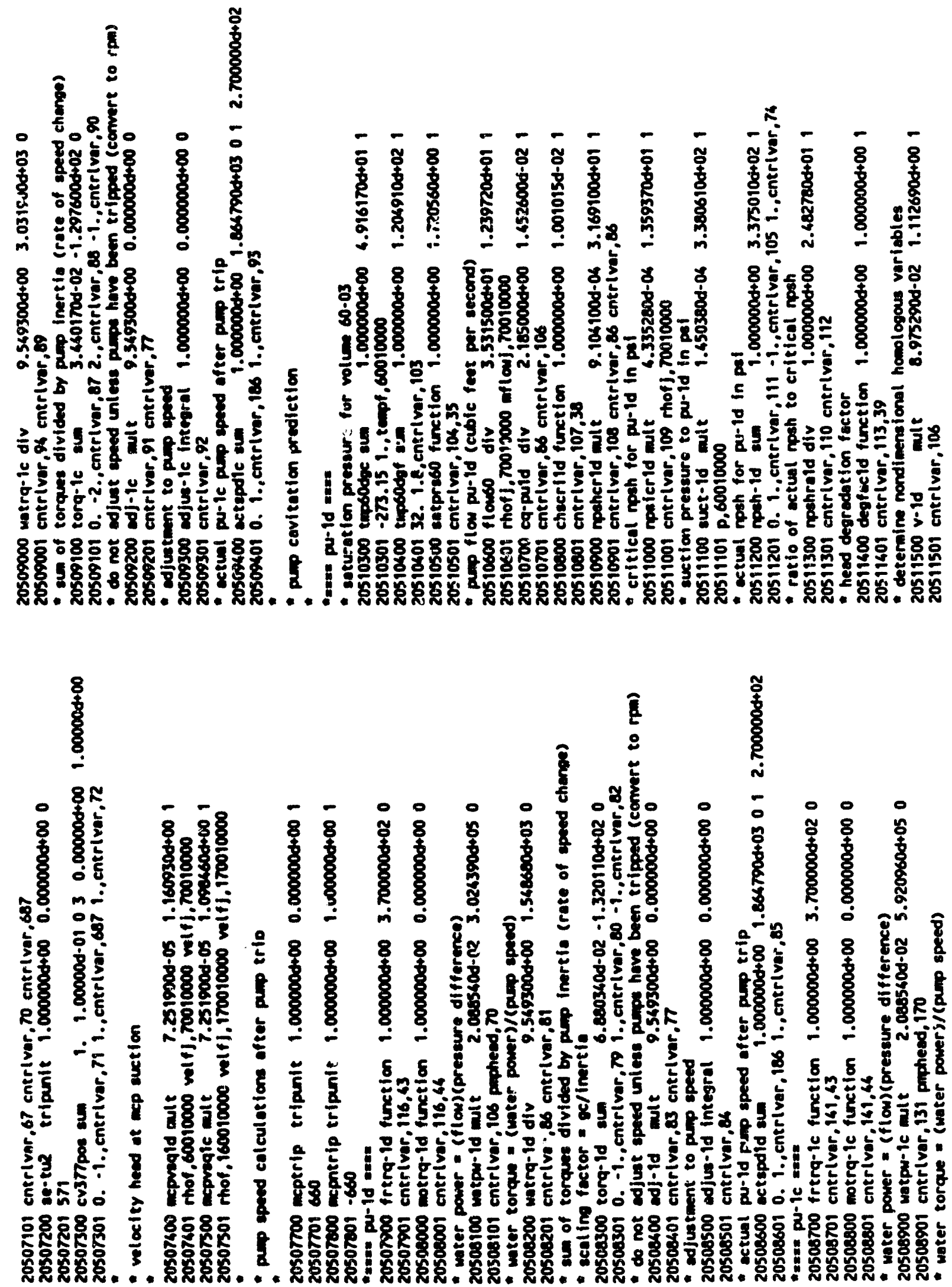

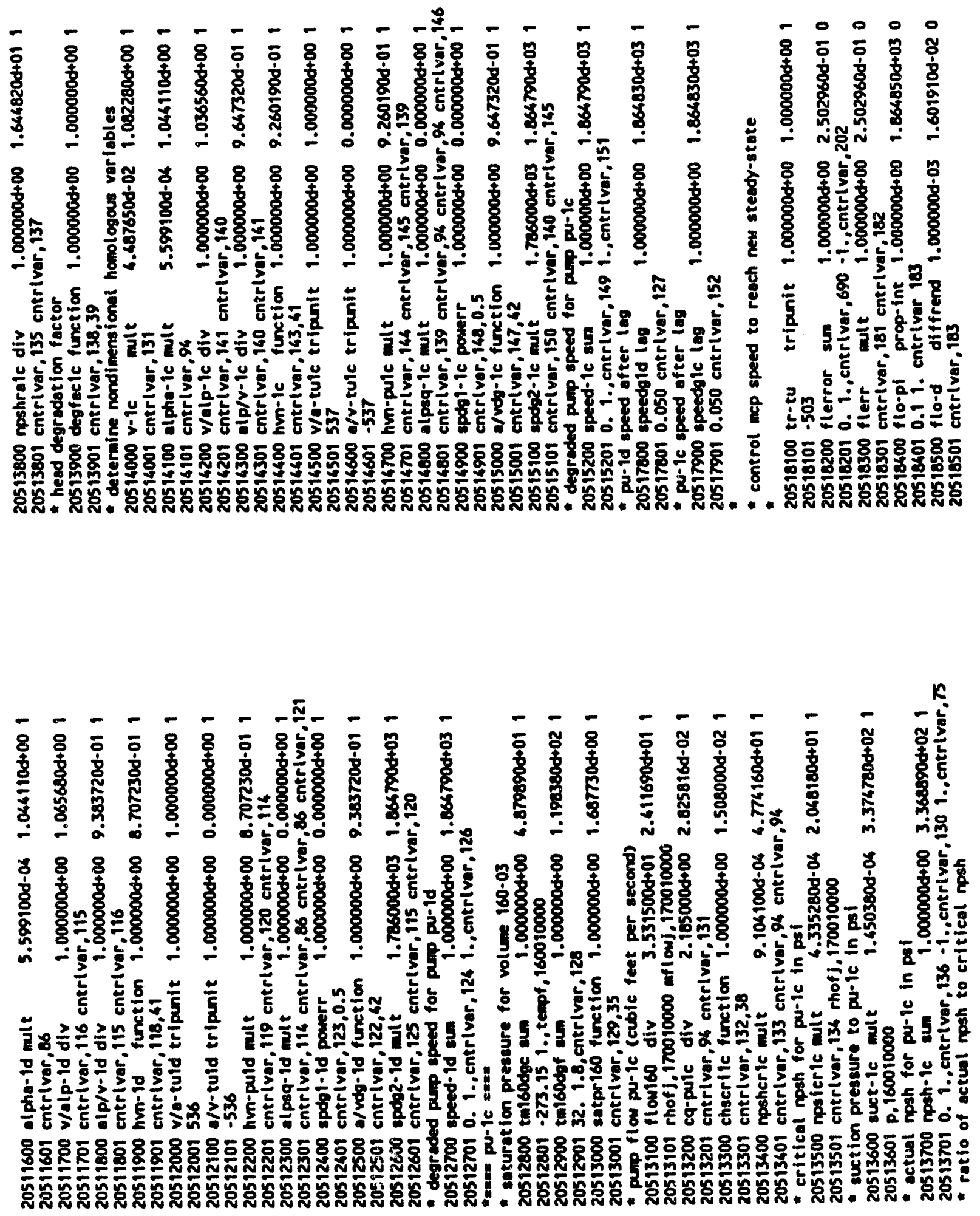

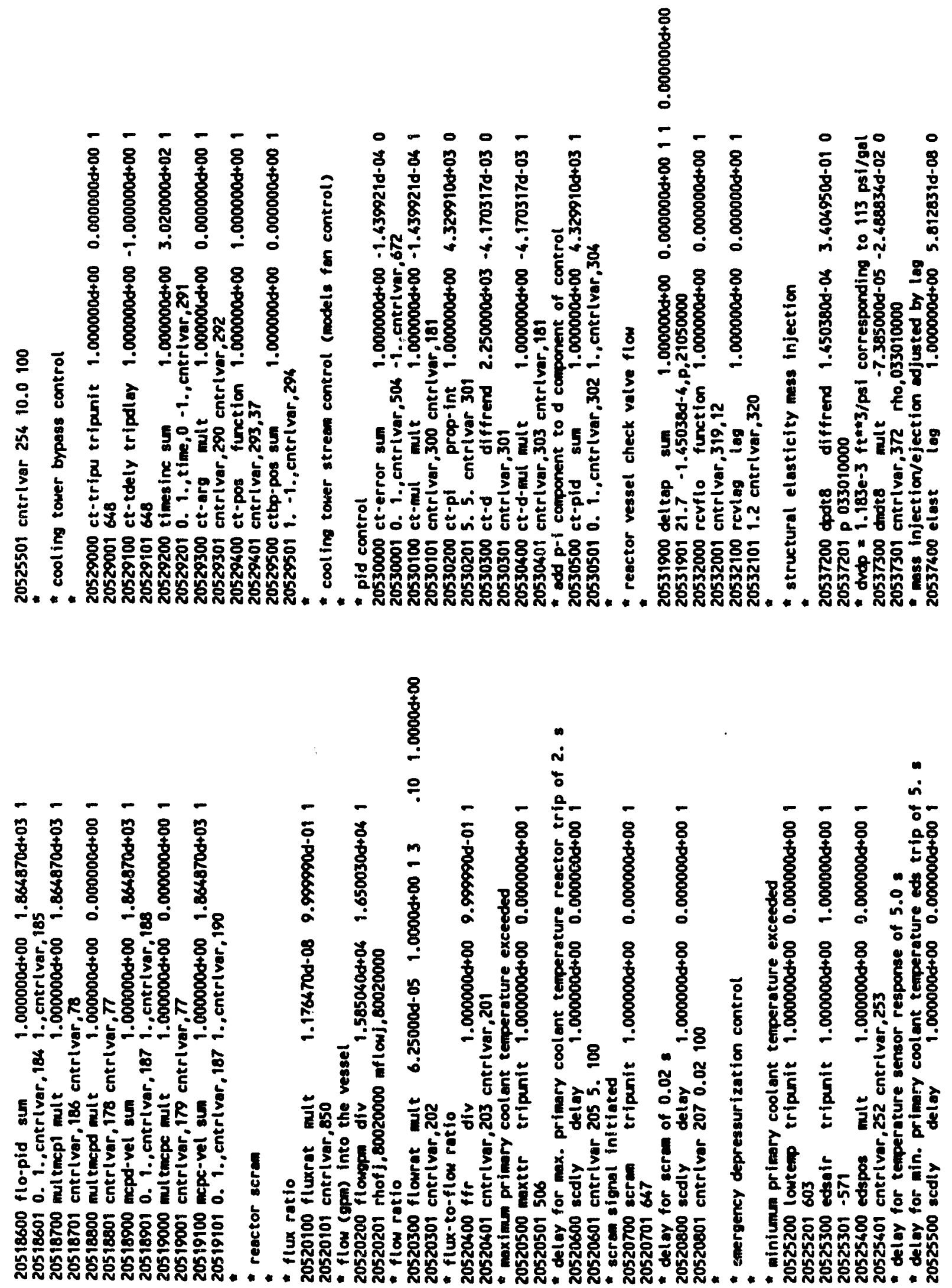

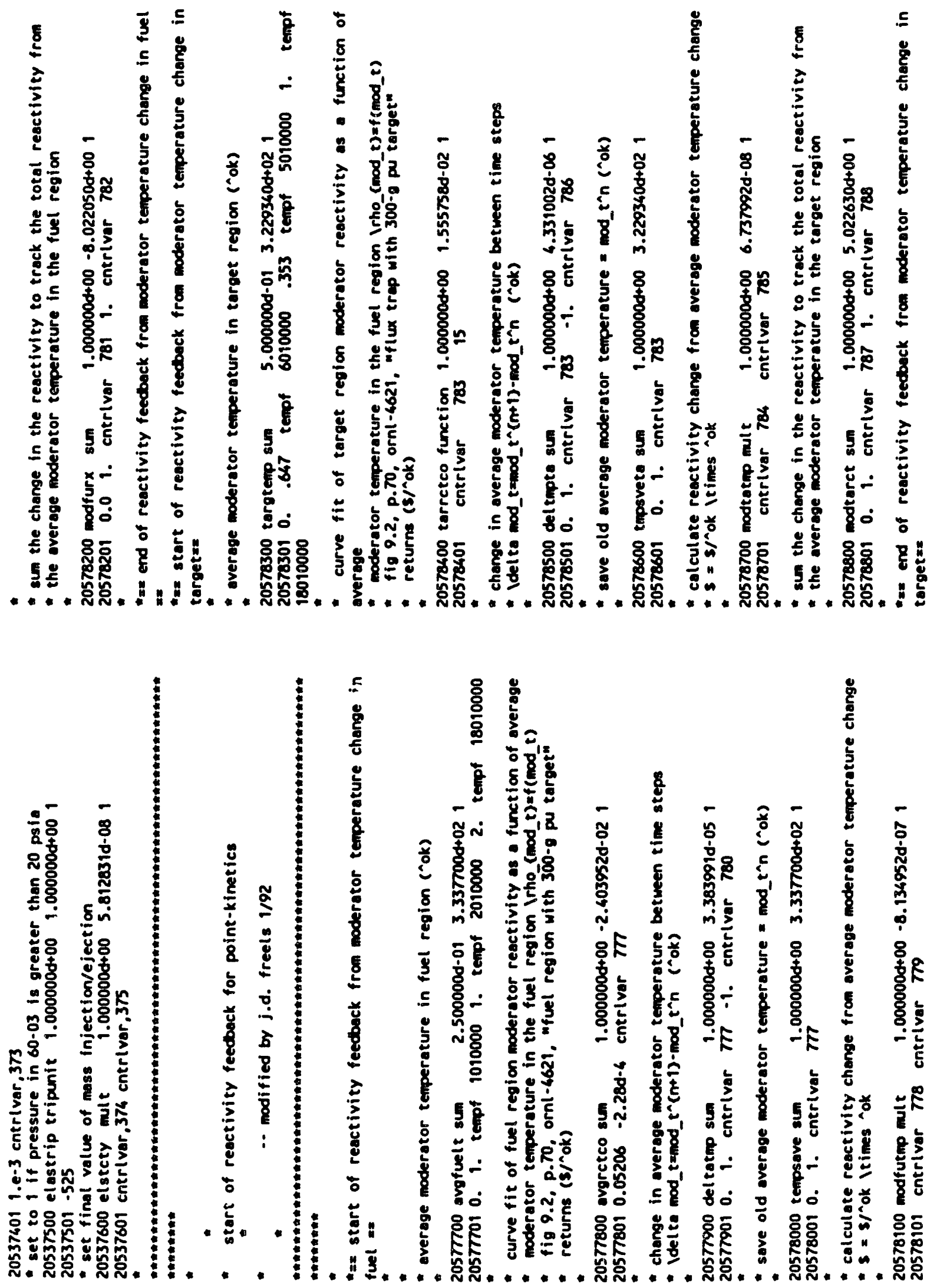

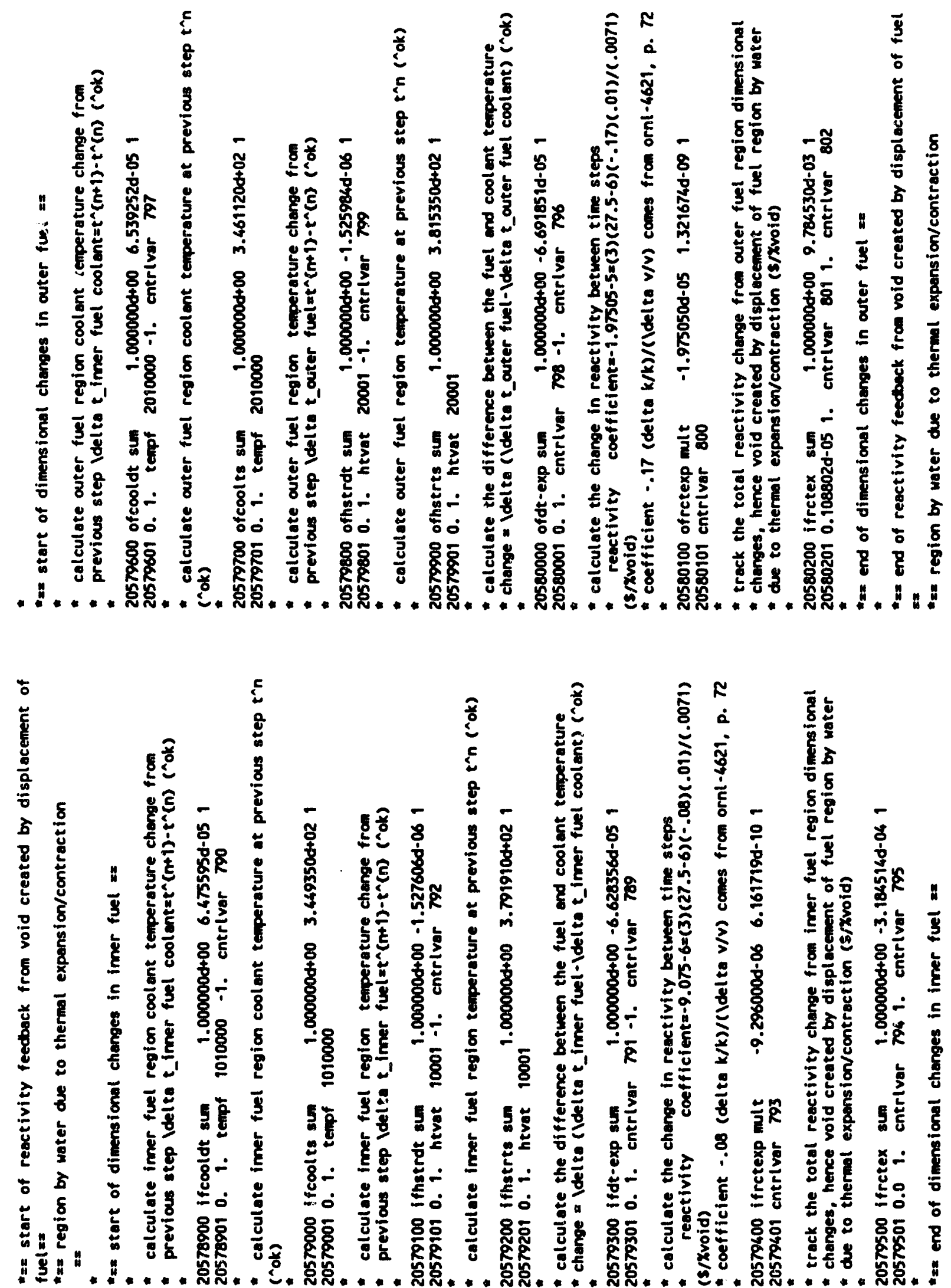

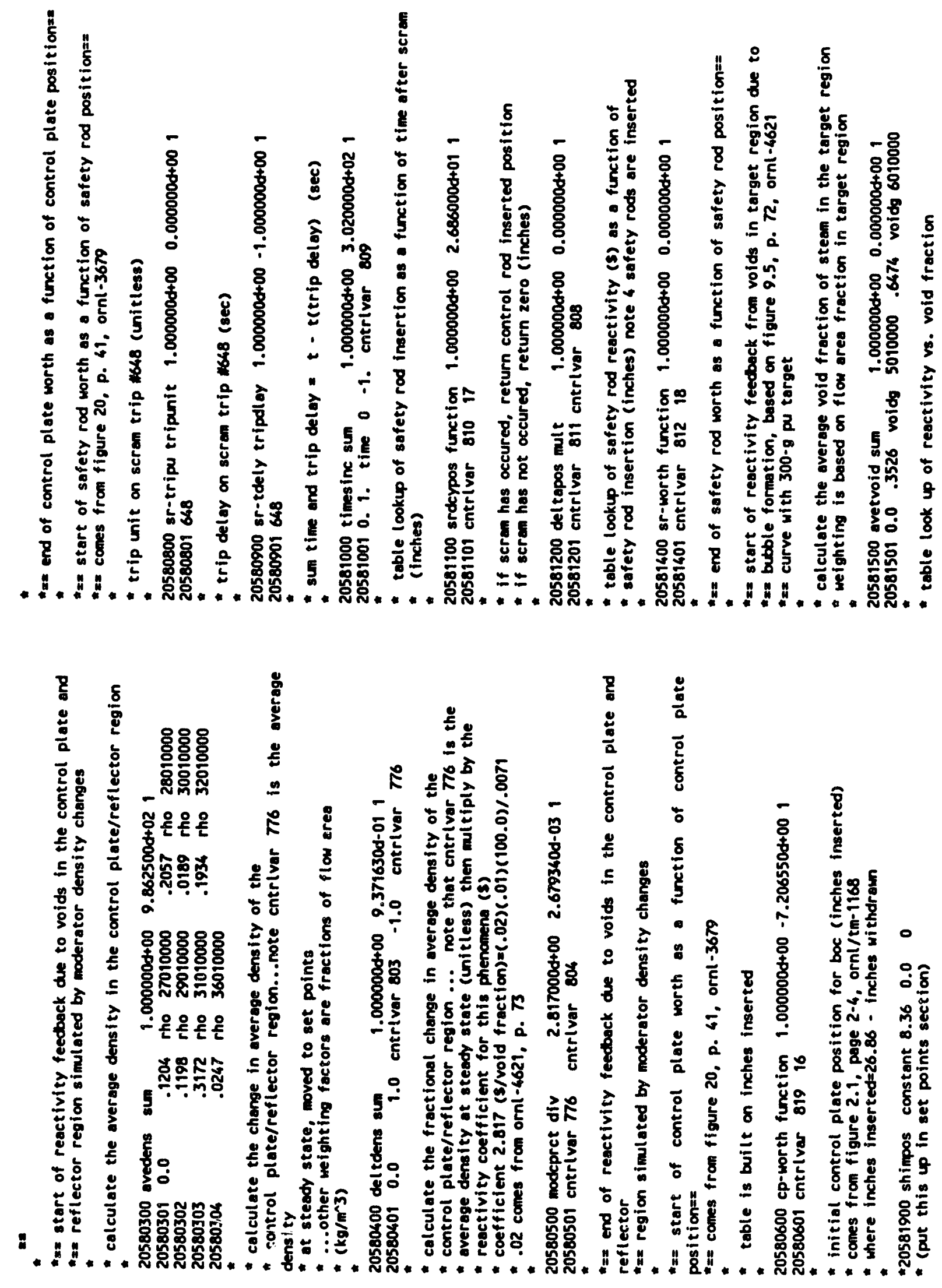

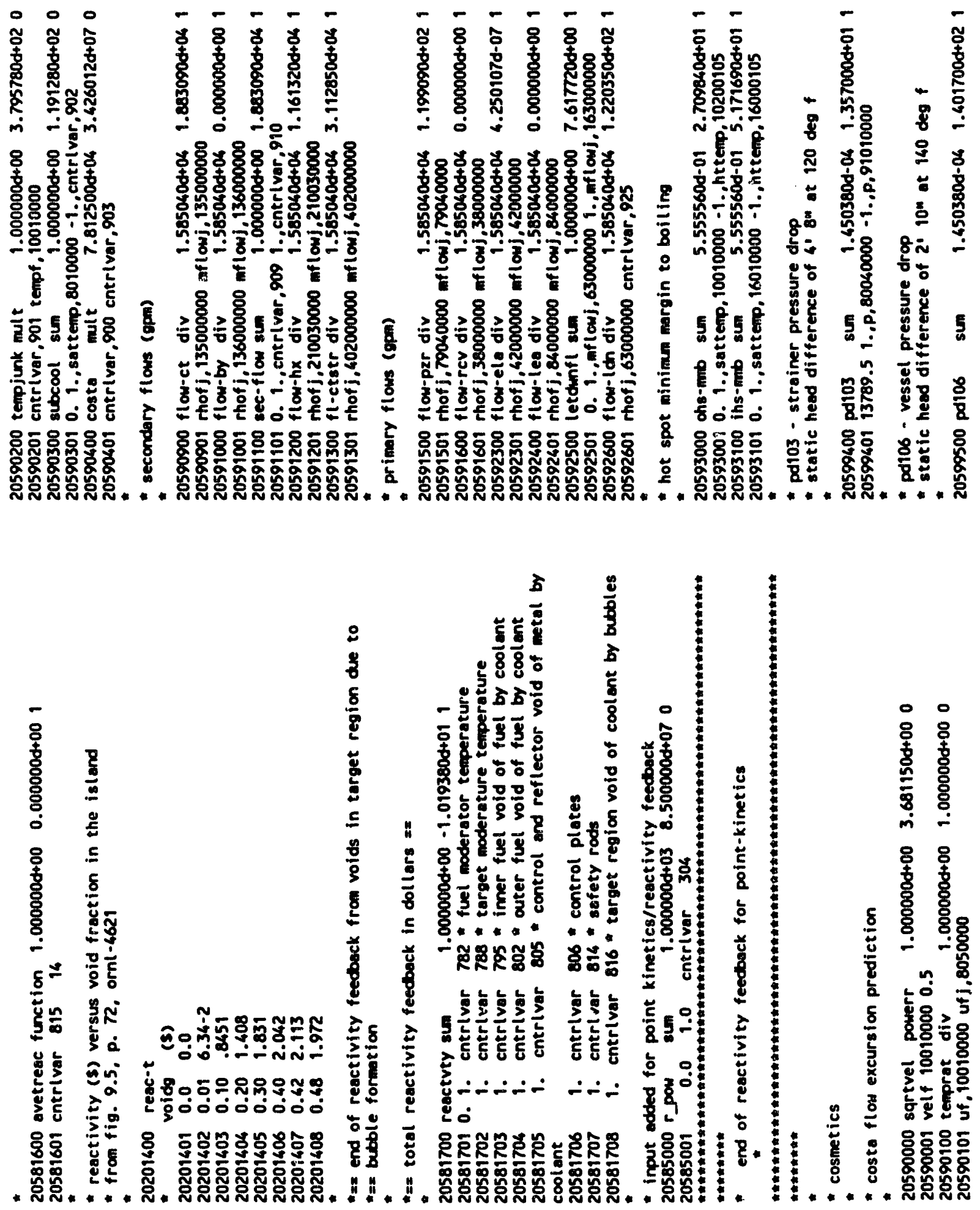


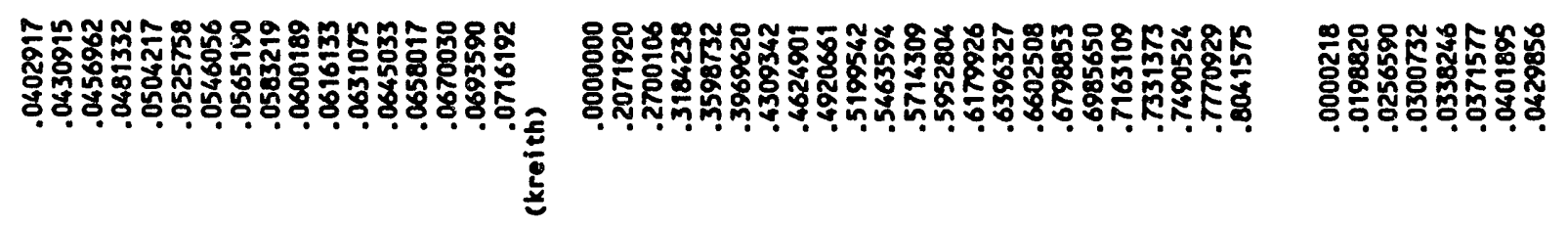

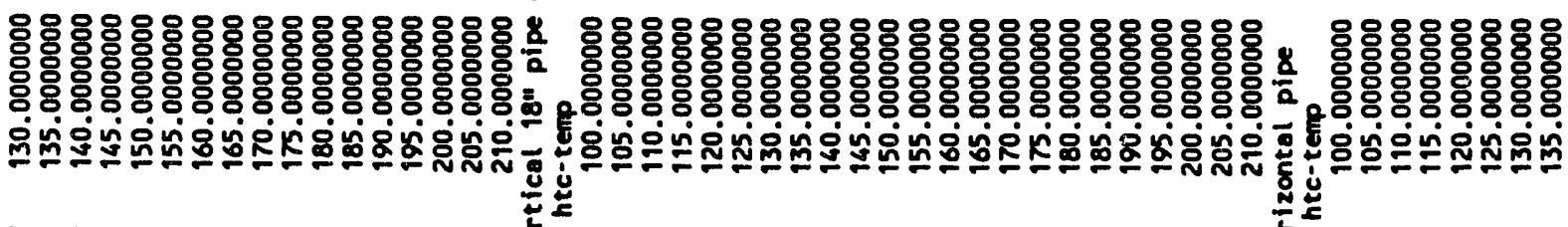

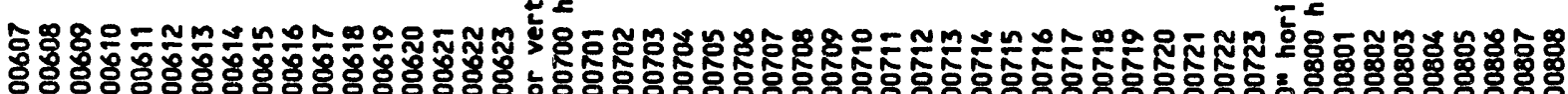

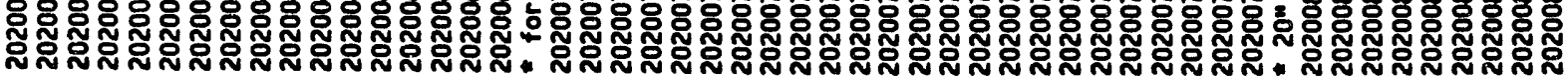

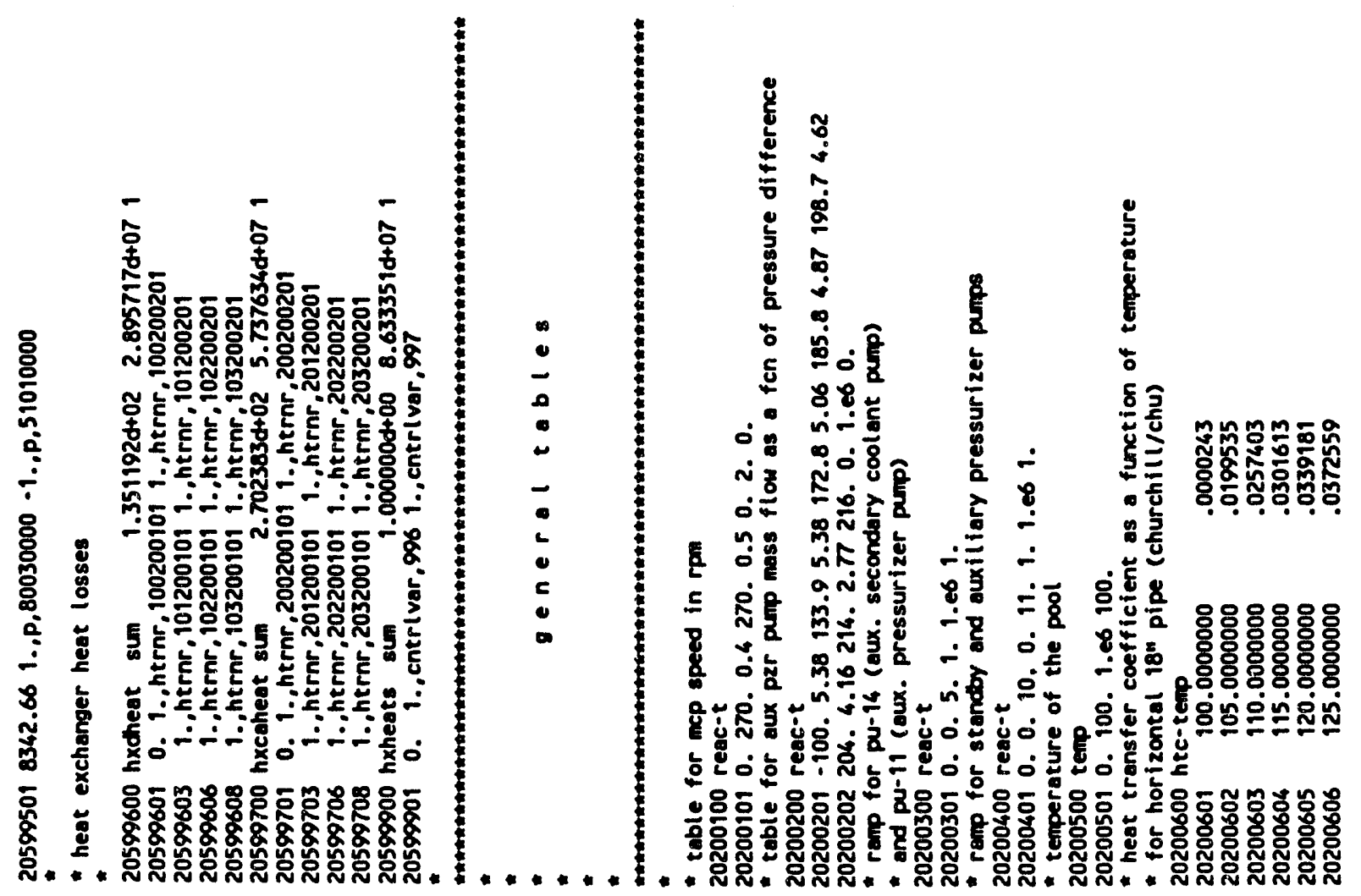




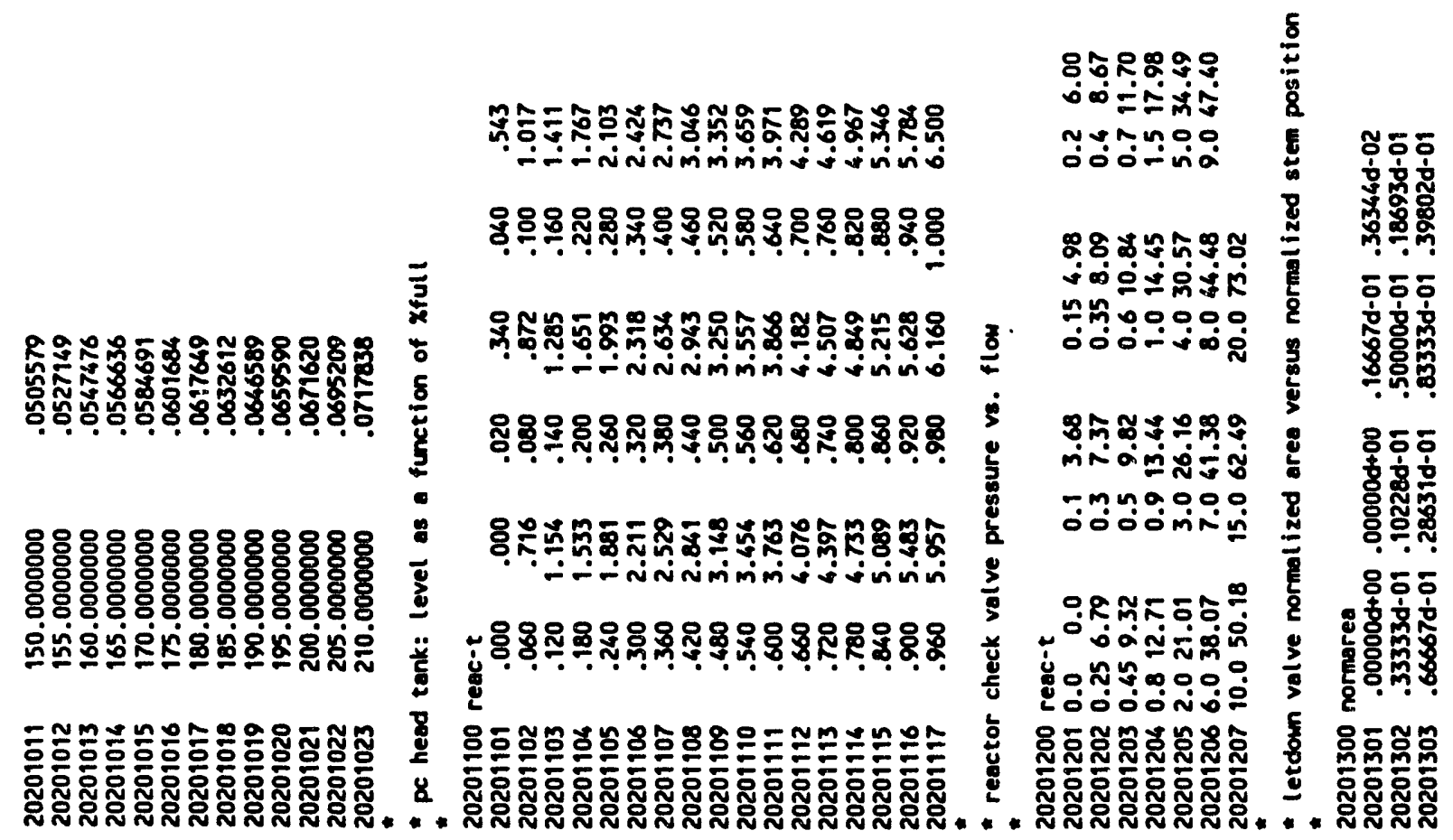

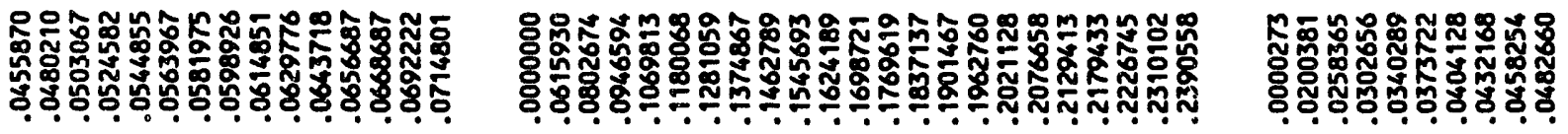

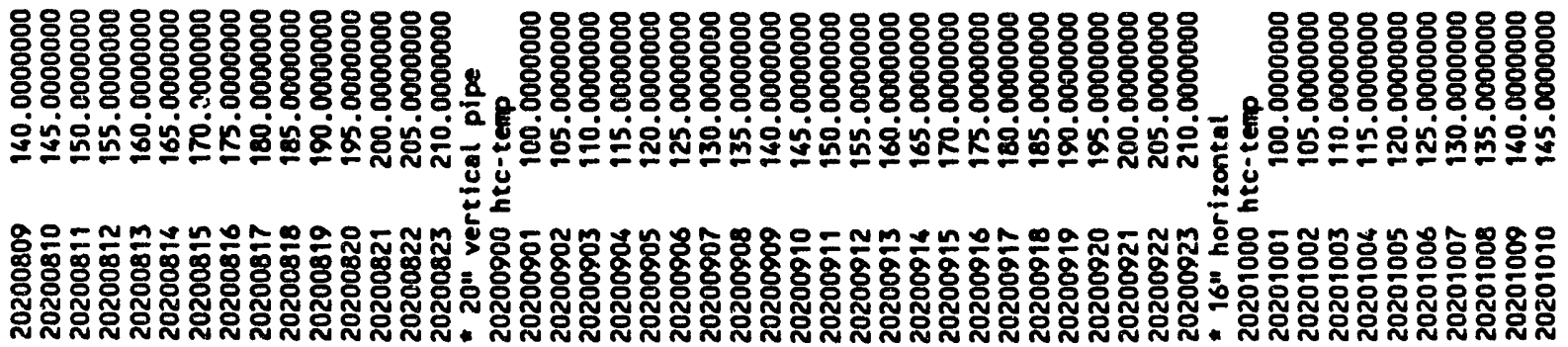




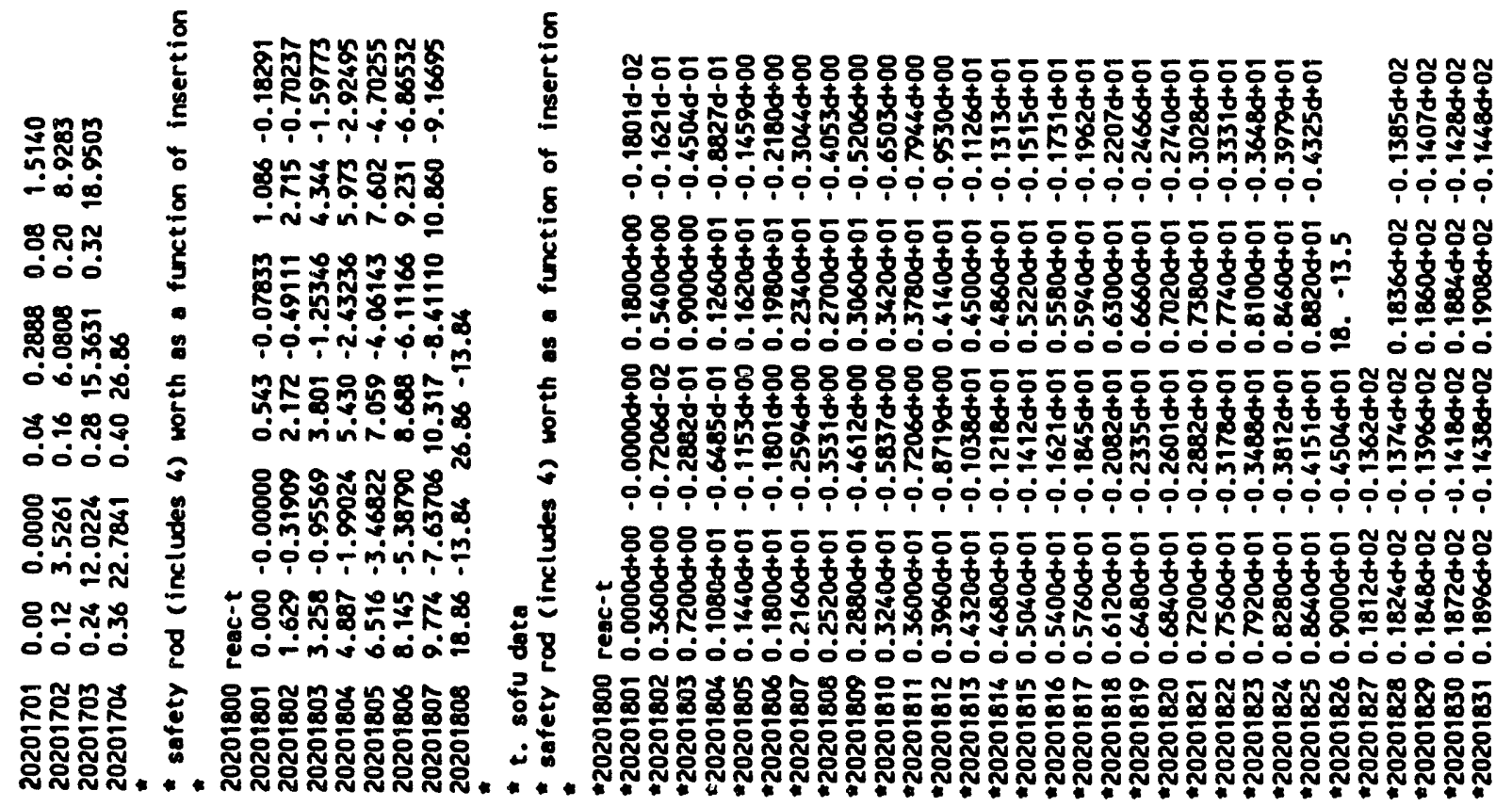

б5

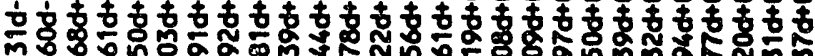

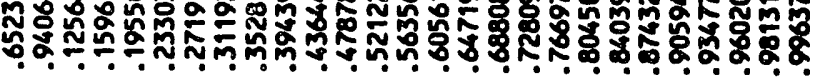

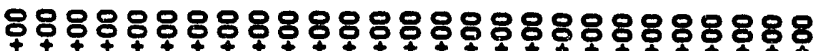

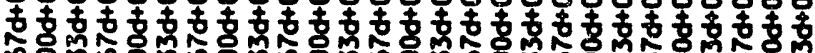

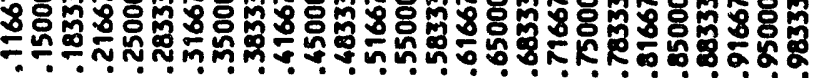

б588888888888888888888888888

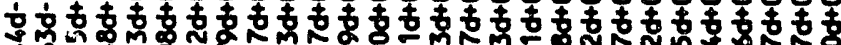

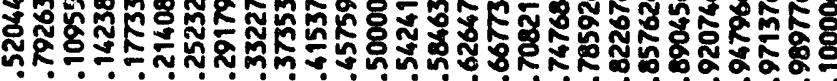

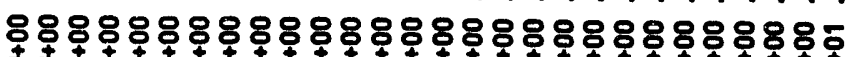

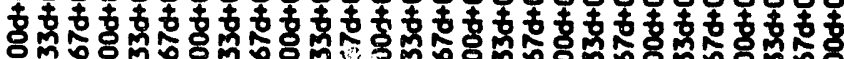

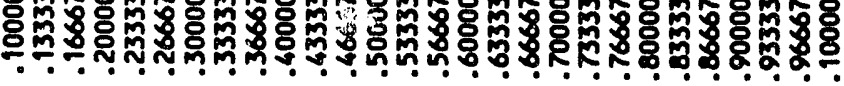

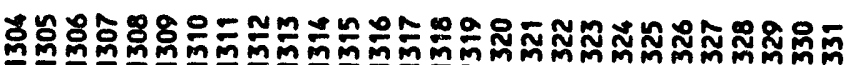

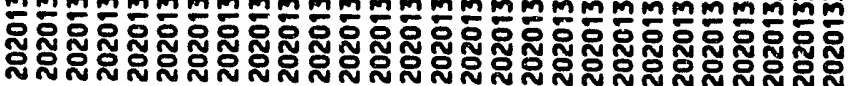

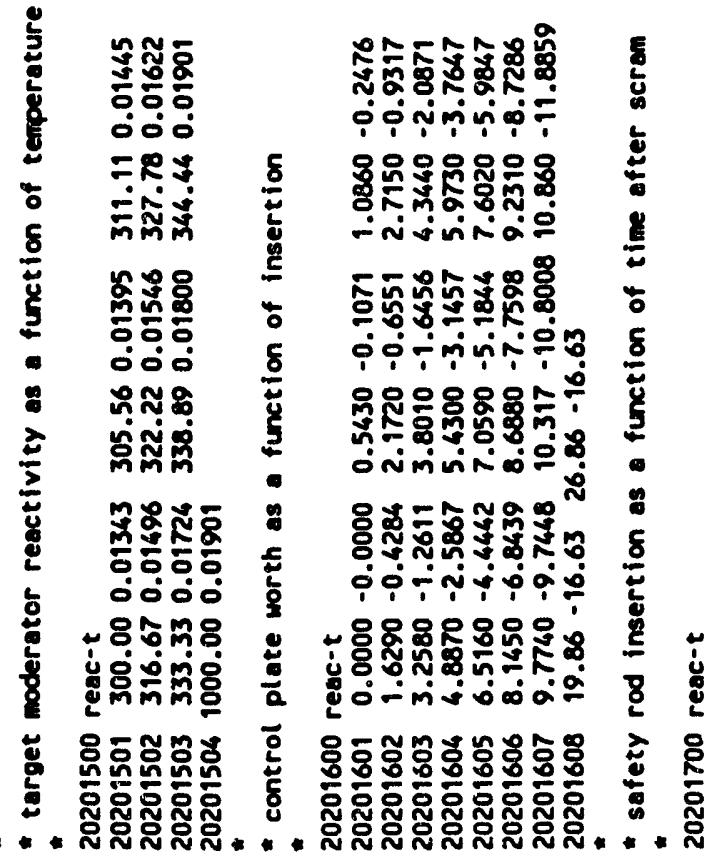




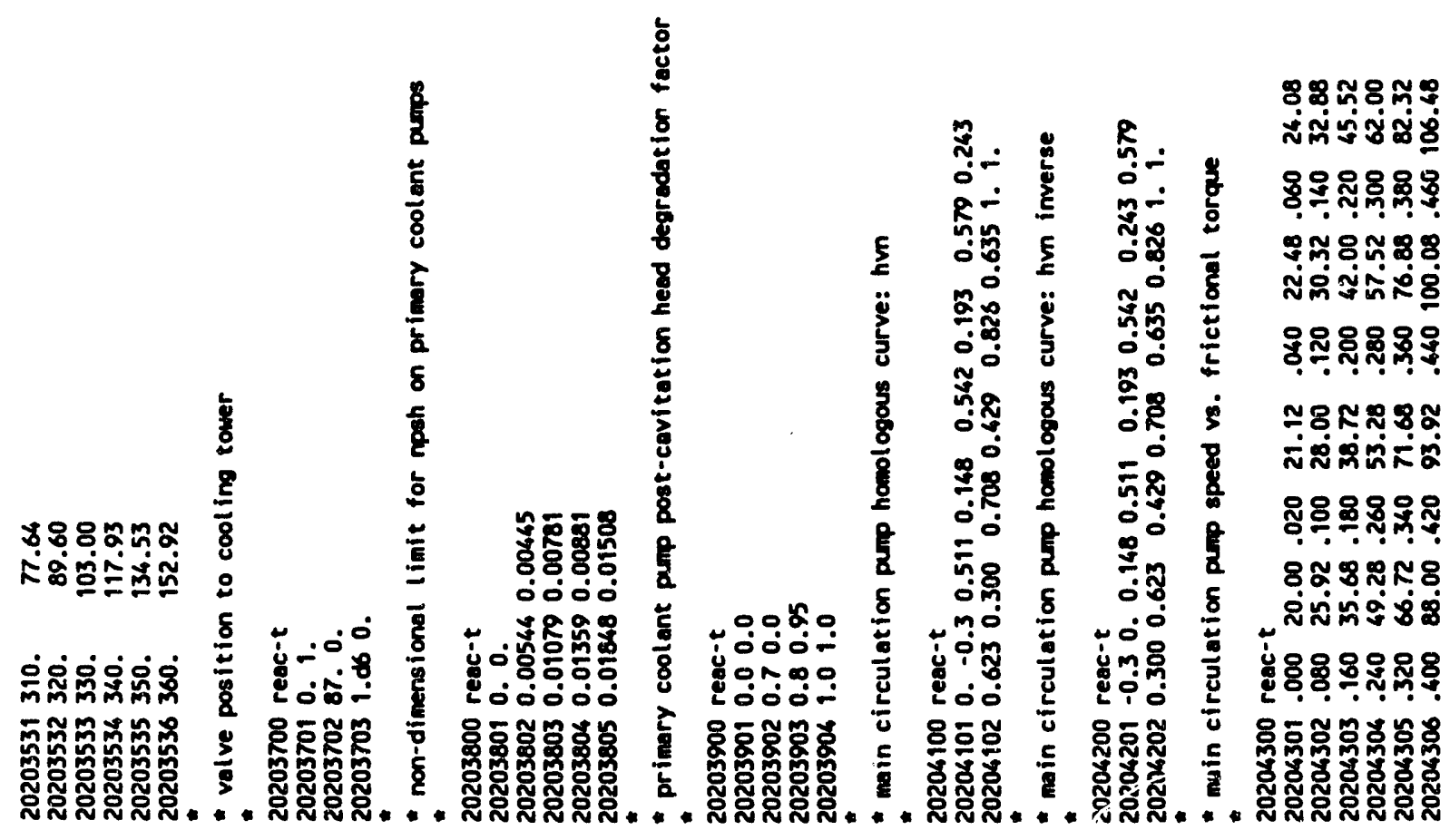

ก:

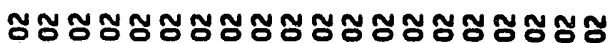

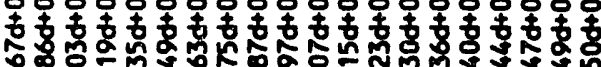

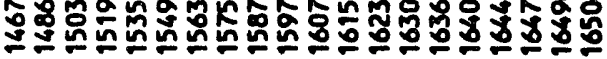

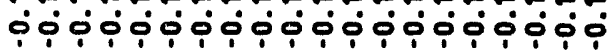

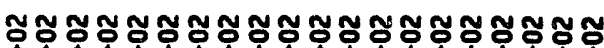

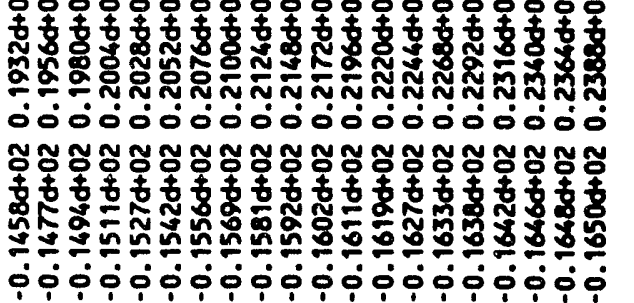

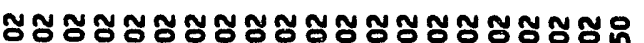

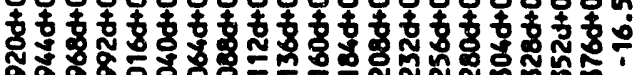

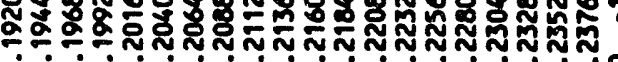

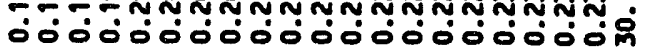

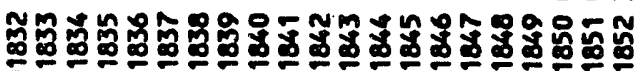

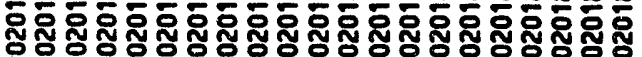

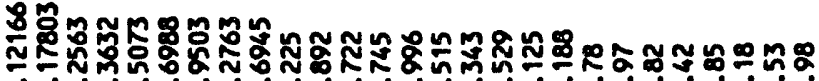

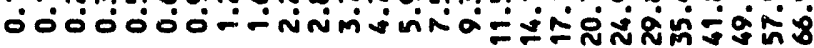

:

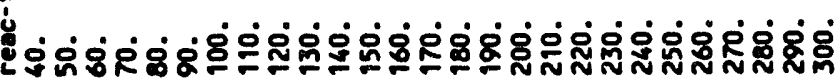

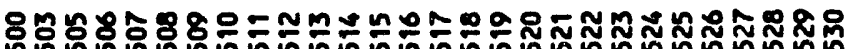

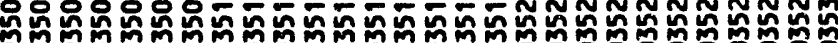




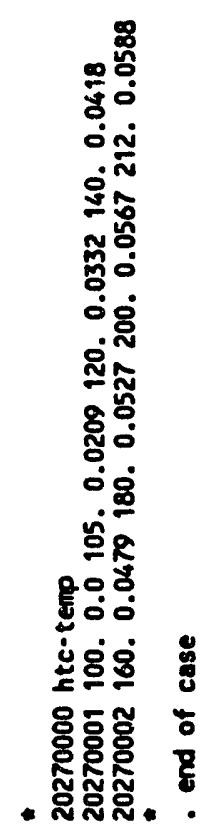

จำ 88

표

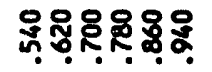

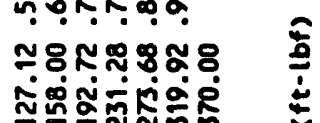

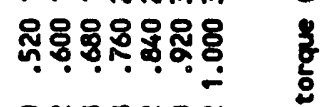

8ิะชำำ

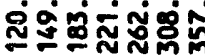

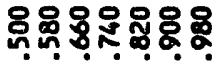

ㅇํำ

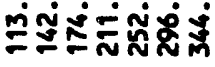

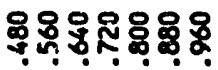

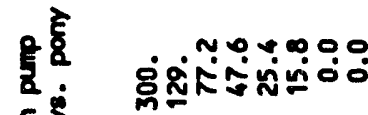

范

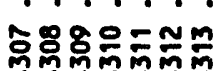

营

id

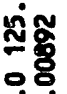

$\because 0$

จิ่ष्ल

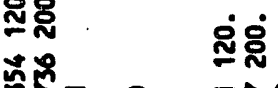

㐭合 i.ं.

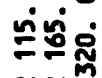

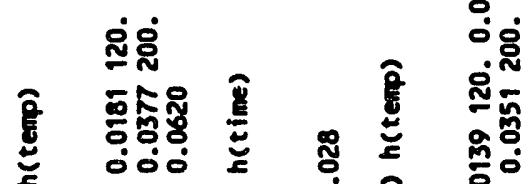

พับ

ธิด

G0.0

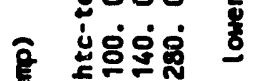

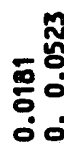

รูกั้ำ

กิ

政

잉

ผิต்ำ

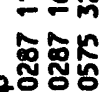

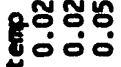

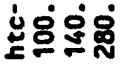

कू⿳亠口冋!.

○ं

을

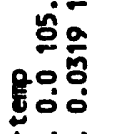

पे पें 
ORNL/TM-11647

\section{INTERNAL DISTRIBUTION}

1. N. C. J. Chen

2. K. W. Childs

3. D. H. Cook

4. W. G. Craddick

5. J. S. Crowell

6. R. D. Dabbs

7. G. F. Flanagan

8. J. D. Freels

9. R. E. Hale

10. R. M. Harrington

11. M. Ibn-Khayat

12. J. E. Jones Jr.

13. B. L. Lepard

14. J. A. March-Leuba

15. D. M. McGinty
16-21. D. G. Morris

22. A. E. Ruggles

23. M. Siman-Tov

24. C. C. Southmayd

25. A. Sozer

26-31. M. W. Wendel

32. C. D. West

33. P. T. Williams

34. G. L. Yoder

35. ORNL Patent Section

36. Central Research Library

37. Document Reference Section

38-39. Laboratory Records Department

40. Laboratory Records, RC

\section{EXTERNAL DISTRIBUTION}

41. C. D. Fletcher, Idaho National Engineering Laboratory, P.O. Box 1625, 2145 East 17th Street, Teton Village Complex, Idaho Falls, ID 83415-1575

42. Office of Assistant Manager for Energy Research and Development, DOE-Oak Ridge Field Office, P.O. Box 2001, Department of Energy, Oak Ridge, TN 37831-8600

43-52. Office of Scientific and Technical Information, P.O. Box 62, Oak Ridge, TN 37831 

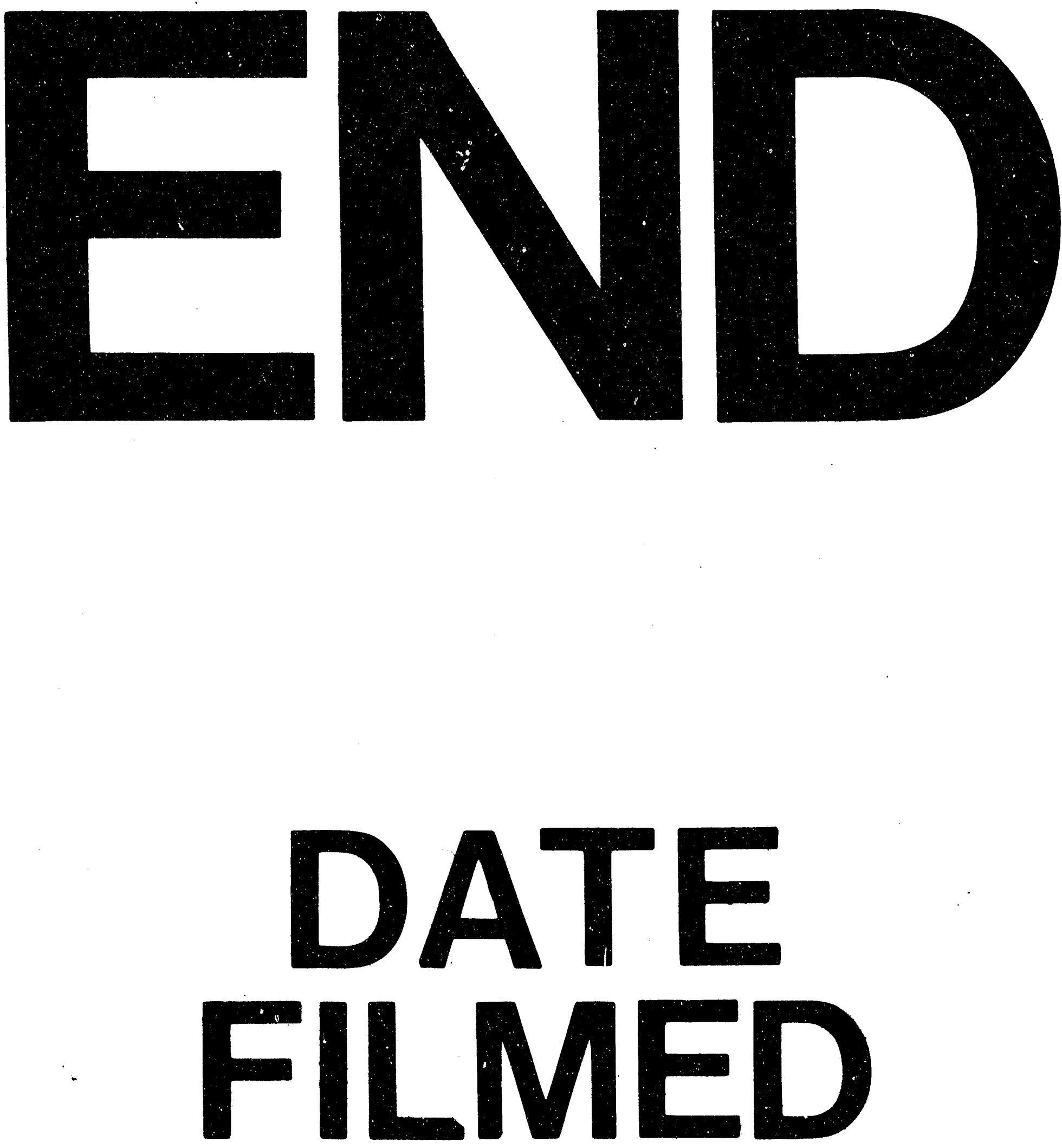

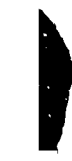

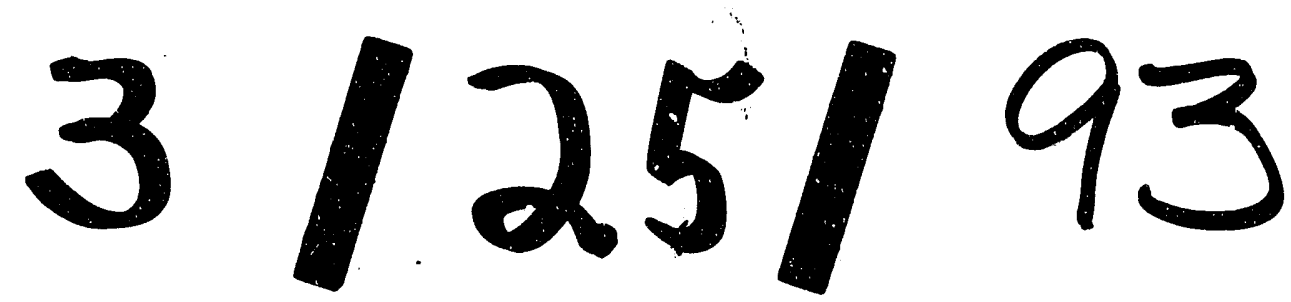

